
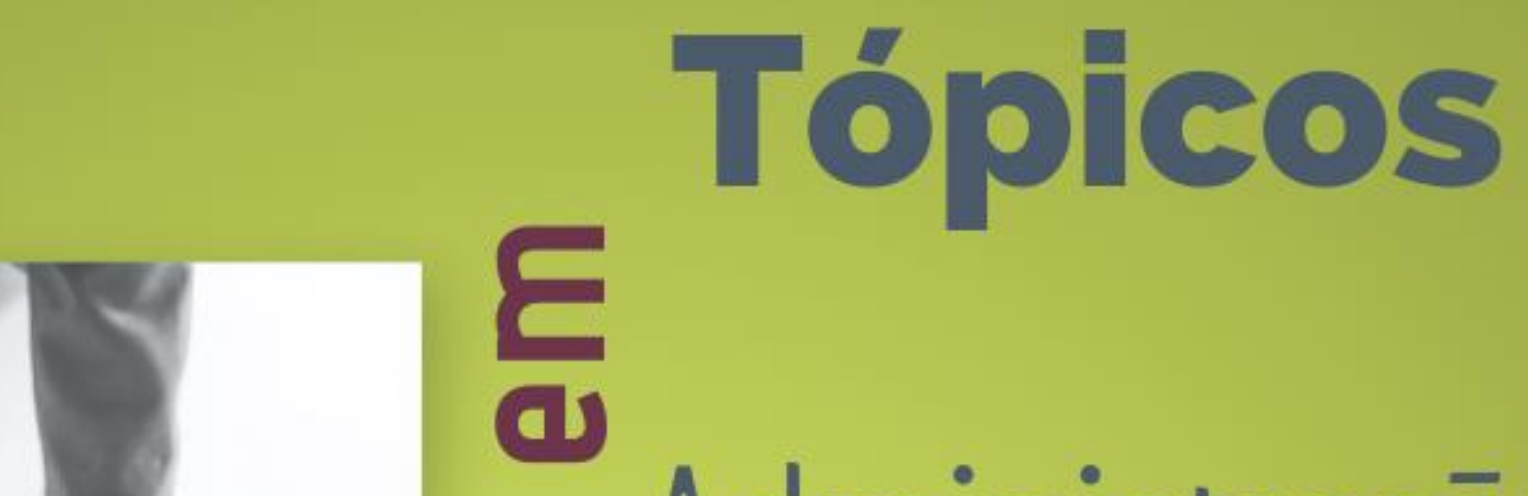
Ails

Administraçāo 
Editora Poisson

\title{
Tópicos em Administração Volume 18
}

\author{
1a Edição
}

Belo Horizonte

Poisson

2019 
Editor Chefe: Dr. Darly Fernando Andrade

\section{Conselho Editorial}

Dr. Antônio Artur de Souza - Universidade Federal de Minas Gerais

Ms. Davilson Eduardo Andrade

Msc. Fabiane dos Santos Toledo

Dr. José Eduardo Ferreira Lopes - Universidade Federal de Uberlândia

Dr. Otaviano Francisco Neves - Pontifícia Universidade Católica de Minas Gerais

Dr. Luiz Cláudio de Lima - Universidade FUMEC

Dr. Nelson Ferreira Filho - Faculdades Kennedy

Ms. Valdiney Alves de Oliveira - Universidade Federal de Uberlândia

Dados Internacionais de Catalogação na Publicação (CIP)
T674
Tópicos em Administração - Volume 18/
Organização Editora Poisson - Belo
Horizonte - MG: Poisson, 2019
222p
Formato: PDF
ISBN: 978-85-7042-057-2
DOI: 10.5935/978-85-7042-057-2
Modo de acesso: World Wide Web
Inclui bibliografia
1. Administração 2. Gestão. 3. Produção
I. Título

O conteúdo dos artigos e seus dados em sua forma, correção e confiabilidade são de responsabilidade exclusiva dos seus respectivos autores.

$\underline{\text { www.poisson.com.br }}$

contato@poisson.com.br 


\section{SUMÁRIO}

Capítulo 1: O papel dos planos na gestão estratégica de empresas nascentes inovadoras - Uma análise focada na dimensão social da ação empreendedora6 Jaime Beer Frenkel, Francisco Jose de Castro Moura Duarte, Nedson Antonio Campos, Hudson Lima Mendonça

Capítulo 2: Uma avaliação da estratégia operacional de bancos em processo de incorporação 20

Rogério da Silva Nunes

Capítulo 3: A influência dos 4P's nos índices de eficiência de DMUs (Decision Making Units)

Claudelino Martins Dias Junior, Rodrigo Speckhahn Soares da Silva, Ercules Costa, Letícia Cunico, Gueibi Peres Souza

Capítulo 4: Avaliação da relação entre o valor percebido e a retenção dos sócios de um clube social do segmento industrial de Natal-RN

Fernando José Machado Barbosa de Melo, Alexandre de Oliveira Siqueira, Humberto Caetano Cardoso da Silva, Marcus Augusto Vasconcelos Araújo, Patrícia Carneiro Lins de Novaes, Viviane Caú Amaral

Capítulo 5: Shopping da cidade em Teresina: Uma possibilidade para o setor informal no Brasil.

João Gabriel Moreno de Lacerda, Nívea Maria Pires Silva, Pedro Filipe da Conceição Pereira, Maíra dos Santos Liarth, Mateus Antônio Costa Andrade

Capítulo 6: Dependência do fornecedor, comprometimento calculativo e severidade da falha como antecedentes da retenção pós-falha de serviços em contextos business-to-business.

Humberto Caetano Cardoso da Silva, Alexandre de Oliveira Siqueira, Fernando José Machado Barbosa de Melo, Marcus Augusto Vasconcelos Araújo, Patrícia Carneiro Lins de Novaes, Viviane Caú Amaral

Capítulo 7: Avaliação do contrato dos serviços de limpeza e a gestão de terceirizados em uma universidade Federal

Joice Regina da Costa Santana da Lapa, Rogério da Silva Nunes

Capítulo 8: Capacitação na Gestão Pública: Bibliometria das Publicações das Bases SPELL e ANPAD entre 2000 E 2015. 


\section{SUMÁRIO}

Capítulo 9: A produção científica no Brasil sobre motivação de trabalho: Uma análise bibliométrica dos artigos publicados na base de dados ANPAD .......... 100 Fatinha Badjeta Mendonça, Marcus Brauer, Marcelo Motta Veiga, Rossando Ramos

Capítulo 10: Líder Coach: Coaching uma nova concepção de liderança 120 Priscila França Gonzaga Carneiro, Josiane Aparecida Cardoso de Souza

Capítulo 11: Cultura organizacional em contexto educacional: Dimensões culturais e a percepção dos atores de uma escola do programa de ensino integral do estado de São Paulo 128 Marcelo Oda Yamazato, Caio Marcelo Lourenço, Rita de Cássia Arruda Fajardo, Fernando César Almada Santos

Capítulo 12: Estudo do modelo de comportamentos éticos organizacionais 138 Eric David Cohen

Capítulo 13: Compliance - a transição moral no universo corporativo brasileiro 146 Célia de Lima Pizolato, Fleuri Cândido Queiroz, Michele Abib Pernice, Gicélia Lima Santos do Nascimento

Capítulo 14: A influência do treinamento na melhoria de produtividade: Um estudo de caso em uma empresa do segmento empírico de perfumaria 152

Maissa Rufino Theodoro, Thiago Bragança Nogueira, Maria de Lara Moutta Calado de Oliveira, Eduardo de Moraes Xavier de Abreu

Capítulo15: Protocolo de identificação do paciente: Uma proposta de implantação em uma maternidade pública

Hercules Guimarães Honorato, Maria Aparecida Campos de Azevedo

Capítulo 16: Análise e proposições para a humanização no Hospital Universitário Pedro Ernesto com base no Design Thinking.....

Andrea Santos Cabral, Diego Cesar Cavalcanti de Andrade, Ricardo Miyashita, Thais Spiegel

Capítulo 17: Condições de trabalho dos tatuadores: Uma análise ergonômica a

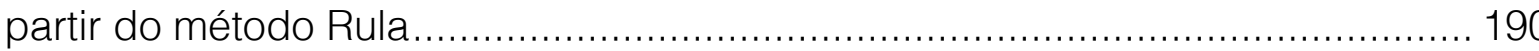

Anderson Vinicius Knoedler Farias, Humberto da Silva Gonçalves, Ettore de Lacerda Arpini, Fernando Gonçalves Amaral

Capítulo 18: Satisfação no trabalho: Uma análise dos servidores técnicos administrativos da faculdade de administração e finanças da UERJ 201

Milena Neves Gradim Ramos, Nátalie Gonçalves Silva, Marcus Brauer, Fábio Braun

Autores: 


\section{Capítulo 1}

\section{O PAPEL DOS PLANOS NA GESTÃO ESTRATÉGICA DE EMPRESAS NASCENTES INOVADORAS - UMA ANÁLISE FOCADA NA DIMENSÃO EMPREENDEDORA}

\section{Jaime Beer Frenkel \\ Francisco Jose de Castro Moura Duarte \\ Nedson Antonio Campos \\ Hudson Lima Mendonça}

Resumo: Embora os empreendedores sejam frequentemente recomendados a desenvolver planos de negócio, as numerosas pesquisas quantitativas já realizadas a respeito do tema não trazem resultados convergentes sobre os seus benefícios. O presente trabalho procura compreender como os empreendedores usam os planos para apoiar o desenvolvimento de novos negócios inovadores em ambientes de alta incerteza. Buscamos entender qual poderia ser a importância estratégica de uma atividade de planejamento em um contexto de alta incerteza, onde não se pode esperar que as previsões contidas nos planos de fato se concretizem. Para isso, um estudo de caso é realizado em uma empresa nascente que desenvolveu um modelo de negócio inovador. A análise do estudo de caso se estrutura sobre um referencial teórico que combina a Teoria do Crescimento da Firma, a lógica de efetuação e a Teoria Ator-Rede. A análise nos permite entender como empreendedores que seguem a lógica efetual podem efetivamente usar os planos de forma produtiva para desenvolver estrategicamente os seus negócios.

Palavras-chave: Estratégia, Planejamento, Empreendedorismo, Startup, Efetuação 


\section{INTRODUÇÃO}

O crescimento das novas firmas é um dos tópicos centrais da pesquisa a respeito do empreendedorismo (McKelvie e Wiklund 2010). Toda essa importância pode ser justificada pela relevância das novas firmas para a criação de empregos regionais, combinada com às barreiras ao crescimento enfrentadas pela maioria delas (Guilbert et. al 2006). Recentemente, essa questão passou a ser abordada sob a perspectiva da Gestão Estratégica Empreendedora, que visa fornecer um aparato conceitual e metodológico para auxiliar empreendedores a escolher a melhor abordagem para desenvolver os seus negócios (Duarte et. al 2015).

Entre as questões mais polêmicas relacionadas Gestão Estratégica Empreendedora está a contribuição do planejamento para o crescimento das empresas nascentes, assunto que recebeu grande destaque na última década (Delmar e Shane 2003; Liao e Gartner 2006; Gruber 2007; Denker et al. 2009; Brickmann et al. 2010; Burke et al. 2010; Duarte et. al 2015; Charlotta e Marko, 2016). Os pesquisadores que se debruçaram sobre ela, obtiveram resultados inconsistentes entre si. De acordo com Brickmann et al. (2010) essas inconsistências se deveram, em grande parte, à falta de atenção dada pelos estudos realizados às particularidades das organizações onde o planejamento acontece, ou seja, é necessário entender como os planos são usados pelo empreendedor para apoiar o desenvolvimento da nova firma. Nesse contexto, esse artigo visa responder à seguinte pergunta: "como os planos são usados pelos empreendedores para desenvolver novas firmas?". O artigo se inicia com a discussão atual da contribuição estratégica do planejamento para as novas firmas. A seguir discutimos a ação do empreendedor segundo a Teoria do crescimento da Firma (Penrose, 1959) e a comparamos com a visão da lógica de efetuação (Sarasvathy, 2009) mostrando a necessidade de darmos maior foco à dimensão social do seu trabalho. Na seção seguinte, mostramos como este foco pode ser dado ao modelarmos os novo negócio por meio da Teoria Ator-Rede (Law ,1992; Callon, 1999; Latour, 1996, 2005) e estudarmos os planos como objetos de fronteira (Star e Griesemer, 1989; Star e Bowker, 1999). Finalmente, é apresentado um estudo de caso de um firma nascente na cidade do Rio de Janeiro. O artigo termina com a discussão dos resultados desses estudos de casos e considerações finais sobre a sua contribuição e encaminhamentos futuros.

\section{FUNDAMENTAÇÃO TEÓRICA SOBRE A AÇÃO DO EMPREENDEDOR}

\subsection{DISCUSSÃO QUANTO A CONTRIBUIÇÃO DOS PLANOS PARA NOVAS FIRMAS}

A ideia de que o planejamento deve anteceder a execução da ação é um dos princípios básicos do que se entende por gestão de excelência (FNQ, 2009). Seguindo esse raciocínio, é muito comum que as novas empresas sejam instigadas por agências governamentais, instituições de ensino, consultores e investidores a desenvolver planos de negócio formais (Karlsson e Honig 2009; Burke et al. 2010; Brickman et al. 2010).

No entanto, a contribuição estratégica do planejamento ao contexto de novas firmas tem se mostrado um ponto importante de divergência acadêmica. Argumentos teóricos apontam que o planejamento na fase préoperacional gera aprendizado para a nova firma, aumenta a eficiência ao longo do seu desenvolvimento e the permite ganhar legitimidade (Castrogiovanni 1996). Outros autores argumentam que o planejamento é especialmente efetivo no contexto de novas firmas por gerar metas auto-impostas pelos empreendedores e um feedback rápido com relação ao alcance de resultados concretos elevando muito a sua capacidade motivacional (Delmar e Shane 2003). Piovezan (2008) apresenta e aplica com sucesso um método para formulação de estratégias cuja execução é suficientemente simples para não tomar muito tempo e esforço dos gestores de pequenas empresas.

Do outro lado estão os autores que defendem que a dinamicidade e incerteza inerentes ao contexto das novas firmas obrigam os empreendedores a perseguir oportunidades de curto prazo, mesmo sabendo que elas, provavelmente, não assegurem o futuro da empresa. Para contornar esse tipo de situação, a empresa nascente precisa ser capaz de desenvolver uma capacidade de resposta rápida para identificar e tirar proveito de novas oportunidades emergentes. Nesta perspectiva, planos de longo prazo tenderiam a retardar o tempo de resposta das novas empresas fazendo-as perder estas 
oportunidades (Behidé, 2000). Dessa forma, alguns autores argumentam que os empreendedores fariam melhor se simplesmente se guiassem pela sua intuição do que seguindo planos (Allinson et al., 2000). Finalmente, o desenvolvimento de planos de negócio toma um tempo precioso dos empreendedores que, se direcionado para atividades capazes de aumentar a visibilidade e concretude do novo negócio aos olhos dos seus Stakeholders, permitiriam um desenvolvimento mais rápido do negócio (Carter, 1996).

Muitas pesquisas quantitativas também foram realizadas ao redor do tema, porém com resultados divergentes. Enquanto alguns estudos identificaram relações positivas entre a execução de atividades de planejamento e o desenvolvimento de novas firmas (Delmar e Shane, 2003; Gruber, 2007; Burke et. al., 2010), outros encontraram efeitos opostos (Dencker et al., 2009; Tornikoski e Newbert, 2007). No entanto, em uma meta análise de 46 estudos quantitativos, Brinckmann et al. (2010) concluíram que o planejamento apresenta uma influência positiva sobre a performance das pequenas firmas estabelecidas.

É recorrente nas evidências empíricas da literatura a conclusão de que a forma como o planejamento acontece e a maneira como os planos são utilizados são cruciais para determinar a influência na performance da nova firma (Gruber, 2007; Loch, et al. 2008; Dencker et al. 2009; Brinckmann et al., 2010; Burke et al., 2010; Charlotta e Marko, 2016). Em especial, a utilização do planejamento como forma de gerar aprendizado estratégico tem recebido grande destaque tanto entre os autores que provém recomendações práticas (Blank e Dorf, 2014; Ries, 2014) quanto em trabalho empíricos (Charlotta e Marko, 2016).

\subsection{A ATUAÇÃO DO EMPREENDEDOR PELA TEORIA DO CRESCIMENTO DA FIRMA}

Mesmo tendo se passado mais de sessenta anos da publicação da Teoria do Crescimento da Firma (Penrose, 1959) ela ainda é considerada o principal referencial conceitual sobre o processo de crescimento da firma (McKelvie e Wiklund, 2010). Nela, a firma é entendida como um conjunto de recursos em sua maioria físicos ou humanos organizados de uma determinada maneira com o objetivo de realizar alguma forma de produção econômica. Esses recursos podem ainda ser produzidos internamente pela firma ou adquiridos no mercado externo.

Os recursos não são importantes per si, mas pelo serviço que prestam à firma. Esses serviços prestados dependem fundamentalmente da forma como o recurso é incorporado à firma e associado aos seus outros recursos. Tal associação, por sua vez, não acontece de forma autônoma, mas mediante a ação dos gestores cuja função é interagir com esses recursos e organizá-los. Os próprios gestores - ou os fundadores no caso de uma nova firma - são também considerados recursos que compõe a firma, sendo o trabalho de manipular os recursos o próprio serviço prestado por eles. Tais serviços podem ter duas naturezas: administrativos e empreendedores.

Os serviços administrativos são aqueles necessários para garantir o funcionamento da firma em um determinada configuração. Dessa maneira, os serviços administrativos podem atuar também como limitantes do crescimento. Por exemplo, não se pode abrir uma nova filial caso não se disponha de um gestor com capacidade de geri-la adequadamente.

Já os serviços empreendedores se referem à capacidade de reconhecer novas oportunidades de negócio e implementá-las. Essa implementação pode ser feita a partir da reorganização dos recursos existentes ou por meio da aquisição de novos recursos.

Uma conclusão importante derivada a partir daí é que a disponibilidade de tempo dos gestores da firma se torna um recurso importantíssimo, inclusive limitando a sua capacidade de crescimento. Em particular, os empreendedores responsáveis pelas novas empresas acabam acumulando diversas funções e precisam ser capazes de conciliar as atividades administrativas com as ações empreendedoras para garantir o crescimento do novo negócio.

Muito dificilmente a firma será capaz de organizar os seus recursos de forma a fazer uso de toda a sua disponibilidade, havendo sempre algum grau de subutilização. Essa sobra de recursos cria uma pressão para que o gestor busque novas formas de organização que the permitam utilizar os recursos sobressalentes para a geração de valor.

Um consequência importante da visão Penrosiana é destacada por Demil e Lecoca (2010): para que a firma possa tirar proveito 
de uma determinada oportunidade, é necessário que esse movimento ocorra primeiro na cognição dos seus gestores. A consequência disso é que a evolução da firma é restringida pelas ideias subjetivas dos gestores a respeito das oportunidades produtivas em potencial. Tais ideias subjetivas, por sua vez, dependem das experiências passadas e das características individuais do gestor (Demil e Lecocq 2010).

\subsection{EFETUAÇÃO - O PROCESSO DE RACIOCÍNIO DOS EMPREENDEDORES EXPERTS}

Sarasvathy (2009) estuda os elementos da expertise do empreendedor, trazendo contribuições interessantes para o entendimento de como se dá a atividade empreendedora, ou - para usar a terminologia de Penrose - do serviço empreendedor. De acordo com a autora, os empreendedores considerados experientes não raciocinam segundo a lógica causal tradicional, na qual se parte de um objetivo específico e seleciona-se os meios disponíveis mais adequados para atingi-lo. A lógica usada pelos empreendedores é a efetual. Ela baseia-se na premissa de que "na medida em que podemos controlar o futuro, nós não precisamos prevê-lo" (Sarasvathy, 2009, pp. 17). Ao agir segundo a lógica efetual, o empreendedor expert segue o processo visto na Figura 1.

Figura 1 - Processo de efetuação

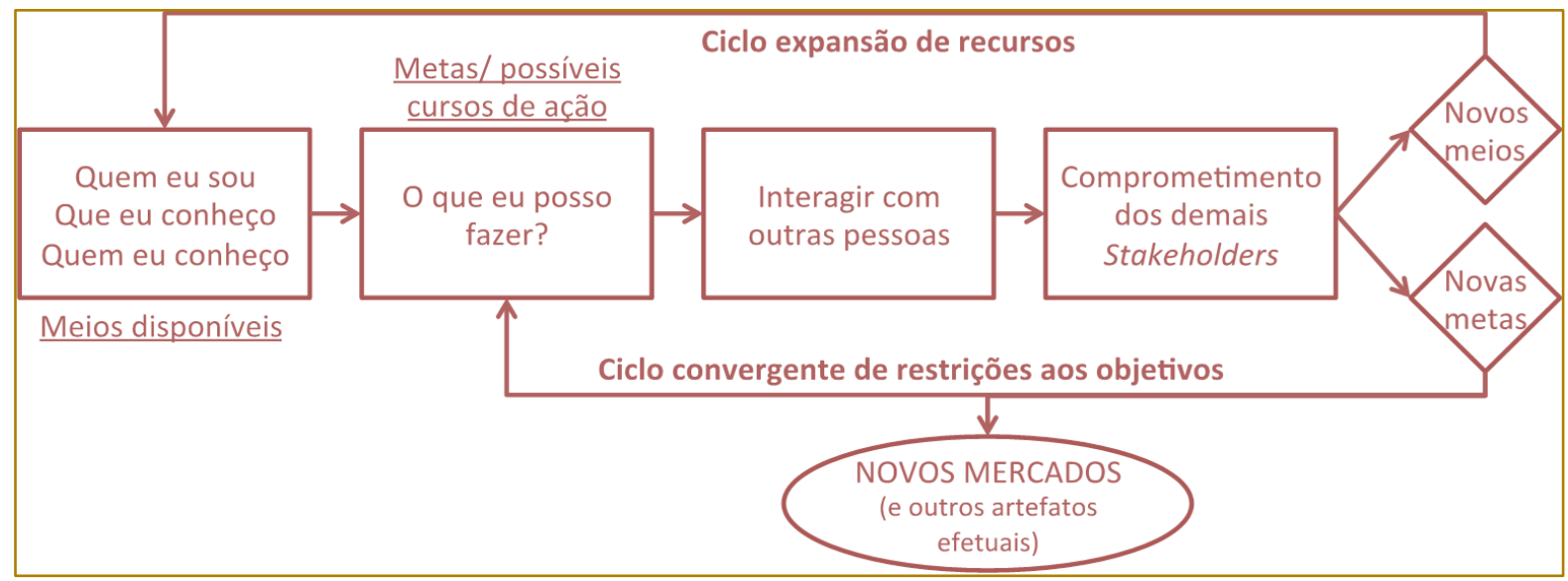

Fonte: Traduzido de Wiltbank et al. (2006)

O processo se inicia com o mapeamento, por parte do empreendedor, dos meios a sua disposição incluindo as suas próprias aptidões e vocações, o seu conhecimento e os indivíduos em sua rede de contatos com os quais pode cooperar. A partir daí ele se pergunta sobre quais efeitos ou resultados pode alcançar através dos meios mapeados para traçar metas amplas para o seu empreendimento. No entanto, os empreendedores experts, no lugar de perseguir suas metas sozinhos, apresentam suas ideias a todos aqueles que se mostrarem dispostos a cooperar com o novo empreendimento. A partir dessa interação, ele eventualmente consegue fazer com que outros Stakeholders decidam se comprometer com a empreitada. Esse comprometimento é uma via de mão dupla, os Stakeholders colocam alguns de seus meios à disposição do novo empreendimento, aumentando a disponibilidade de recursos e, por outro, restringem a amplidão das metas, já que as mesmas precisam agora estar alinhadas com os seus próprios interesses. Em outras palavras, quem aceita participar do novo empreendimento é que determina o seu direcionamento, e não o contrário. O resultado desse processo é a criação de uma rede efetual de empreendedores e de um novo mercado para a operação de novos negócios. Vale frisar que, ao realizar o processo de efetuação, o empreendedor não sabe e nem se preocupa em prever as especificidades sobre como os resultados das suas ações irão se desenrolar no longo prazo, se preocupando apenas em controlar o resultado de cada próximo passo antes de decidir o seguinte (Sarasvathy, 2009). 
Esse processo põe em evidência a dimensão social do trabalho do empreendedor - em grande parte negligenciada por grandes autores da literatura acadêmica sobre empreendedorismo como Penrose (1959) e Schumpeter (1942). Tais autores retratam o empreendedor como um visionário de novas oportunidades de negócio e executor dessas visões. Ao fazer isso, o foco é colocado nas dimensões individuais e econômicas do trabalho do empreendedor, uma representação incompleta da atividade empreendedora cuja dimensão social é colocada em evidência somente em trabalhos mais recentes (Campos, 2010).

\section{COMO ESTUDAR A DIMENSÃO SOCIAL DO EMPREENDEDORISMO E DO PLANEJAMENTO}

Nesta seção iremos introduzir conceitos oriundos da sociologia, especialmente da área da ciência, tecnologia e sociedade, com o objetivo de permitir o estudo da atividade do empreendedor e do uso dos planos sob o prisma social. Introduziremos primeiro a Teoria Ator-Rede para tratar da atividade de empreendedorismo como processo de formação de uma rede sócio-técnica e, a seguir, usaremos o conceito de objeto de fronteira para estudar a função dos planos na atividade empreendedora.

\subsection{A TEORIA ATOR-REDE E A DIMENSÃO SOCIAL DO TRABALHO DO EMPREENDEDOR}

A Teoria Ator-Rede (que trataremos por TAR daqui por diante) surgiu no âmbito dos estudos da sociologia da ciência e da tecnologia (Law, 1992). No entanto a aplicação do seu paradigma tem o potencial para, não só revolucionar todos os campos da sociologia, como é capaz de trazer impactos significativos sobre a política (Latour, 2005).

No paradigma tradicional da sociologia, o social é visto como uma estrutura global superior que conforma o comportamento dos atores locais. Em contraposição, no paradigma da TAR, essa estrutura social global, na qual os atores sociais estariam inseridos e à qual responderiam, é substituída por um mundo planificado onde atores sociais se relacionam entre si (Latour, 2005).

A forma de representação da TAR é o atorrede. Ambos os conceitos precisam ser combinados já que o seu foco de investigação é exatamente a forma como se dá a interação entre os seres sociais. Desta maneira, qualquer ser social, só é relevante na medida em que interage com os demais. Assim, o que o torna relevante são as suas ligações e as trocas que realiza por meio delas (Latour 2005).

É importante ressaltar que a TAR não faz qualquer distinção entre seres humanos e os objetos desprovidos de "vida própria" como projetores de imagem, telefones e computadores. Sendo ambos representados igualmente como atores-rede (Law 1992). Assim, o produto de uma descrição de um praticante da TAR é uma rede sócio-técnica formada tanto por entidades humanas quanto não humanas - na qual são detalhados os nós dessa rede, as suas ligações e o que circula por meio dessas ligações.

Um fenômeno central a ser descrito pelo praticante da TAR é o processo de tradução. Trata-se da forma pela qual os atores e organizações - representados como atoresrede - são mobilizados, formando determinados padrões de ordem social. Essa ordem social é dinâmica, precária e descentralizada, dependendo da contínua interação entre os atores-rede para sua manutenção. Portanto, para a TAR, mais importante do que o substantivo "ordem social", é o verbo "ordenação social" (Law 1992).

Nesse artigo estudaremos o processo de formação de uma nova firma como um processo de tradução. Nele, o papel dos fundadores de uma empresa, pode ser entendido como o de construir determinadas relações com outras entidades para formar uma rede por meio da qual sejam realizadas as trocas comerciais que materializam o novo negócio. Na prática, a construção dessas relações pode assumir diferentes formas, incluindo, por exemplo, realizar uma venda a um determinado cliente, recrutar um colaborador, firmar uma parceria, ou mesmo desenvolver um artefato "sem vida própria" como um produto, site ou material comercial que irá mediar a relação da nova firma com os seus Stakeholders.

\subsection{PLANOS COMO OBJETOS DE FRONTEIRA}

O conceito de objeto de fronteira foi proposto com o objetivo de permitir uma abordagem 
ecológica do processo de tradução (Star e Griesemer, 1989). Por uma abordagem mais ecológica, podemos entender uma mudança de foco que, na visão convencional da TAR está sobre a forma como uma entidade (o empreendedor, por exemplo) age sobre as demais fazendo-as alinhar-se à sua iniciativa. Nesse novo foco a preocupação está nos mecanismos de coordenação e alinhamento e com as cadeias descentralizadas de tradução (Trompette et al., 2009).

Para entender o significado de um objeto de fronteira, pode-se recorrer ao conceito de comunidade de prática. Por comunidade de prática entende-se um conjunto de relações existentes entre um grupo de pessoas que realizam coisas juntas. Ser membro dessas comunidades significa conhecer as suas crenças e práticas, o que se materializa na capacidade de interagir com determinados objetos de uma maneira específica. Esses objetos podem ser tanto materiais, como uma ferramenta, quanto imateriais, como uma terminologia específica (Star e Bowker, 1999).

Existem, no entanto, objetos capazes de habitar mais de uma comunidade de prática satisfazendo as necessidades de informação de cada uma delas e, ao mesmo tempo, mantendo um identidade única. Tais são os objetos de fronteira. Eles precisam ser plásticos o suficiente para satisfazer as necessidades de cada comunidade de prática que os usam e robustos o suficiente para manter uma identidade comum durante todo o tempo (Star e Bowker, 1999). No entanto, os objetos de fronteira não precisam ter o mesmo significado em todas as comunidades onde habitam, na verdade, quando usados por uma comunidade de prática específica os objetos de fronteira assumem significados mais complexos e estruturados do que quando usados para comunicação e coordenação entre comunidades (Star, 2009).

Ao discutir o planejamento estratégico, Mintzberg (1994, pp. 12) define o planejamento da seguinte forma: "Planejamento é um procedimento formal para produzir um resultado articulado, na forma de um sistema integrado de decisões". A partir dessa definição, podemos tratar os planos como objetos de fronteira desenvolvidos como resultado da execução desses procedimentos formais e usados pelos empreendedores para desenvolver a rede sócio-técnica que constitui o seu negócio. Tais objetos poderão trazer diferentes contribuições para o desenvolvimento dos novos negócios dependendo do contexto no qual são usados. Quando usados dentro do mundo do empreendedor, por exemplo entre os fundadores de uma empresa, o plano os ajudará a refletir, aprender e se preparar para tomar decisões quanto ao direcionamento do negócio. Já, quando usado para se conectar a atores de diferentes mundos sociais - como financiadores, clientes e parceiros - os planos deverão servir como mecanismo para coordenação, ganho de legitimidade e acesso a recursos.

\section{MÉTODO DE PESQUISA}

Dado que esse trabalho se propõe estudar como os empreendedores utilizam os seus planos para apoiar o desenvolvimento de novas firmas, decidiu-se utilizar a metodologia de estudo de caso (Yin 2003). Cientes de que a eficácia do planejamento depende em grande parte da sua adaptação ao contexto específico da organização que o realiza (Gruber, 2007; Burke et al., 2010), não pretendemos aqui obter resultados amplamente generalizáveis. Esse trabalho se propõe a ilustrar um fenômeno, ainda mau compreendido, dentro de um contexto específico. Dado que se pretende estudar o papel do planejamento no desenvolvimento de negócios inovadores, decidiu-se estudar uma empresa nascente carioca com uma proposta de valor diferenciada. Para ocultar a identidade desta empresa, chamaremos a mesma de Sonorus. A Sonorus é apoiada por uma aceleradora de negócios que chamaremos, neste artigo, de InovaTech.

A coleta de dados para a construção dos estudos de caso se iniciou com a busca de informações publicamente disponíveis a respeito da Sonorus. Com base nessas informações, um esquema representativo baseado no paradigma da TAR foi desenvolvido mostrando a rede sociotécnica que representa a empresa, apresentada na figura 2. É importante notar que essa rede não foi, nem poderia, ser representada na íntegra. Priorizaram-se as entidades cuja influência sobre as demais se mostrou essencial para o entendimento do funcionamento do negócio. Além disso, podem-se ver alguns nós sem conexão representada, estes são fornecedores de serviço para os sócios das empresas $e$ as suas conexões foram ocultadas do esquema para reduzir a poluição visual. 
De posse desse esquema (rede sociotécnica da empresa), foram realizadas e gravadas duas entrevistas semiestruturadas com duração entre 90 e 120 minutos junto aos sócios da empresa estudada. Nessas entrevistas foram feitas perguntas a respeito das atividades necessárias para desenvolver e manter cada uma das conexões representadas e, em particular, sobre a utilização de objetos que pudessem ser entendidos como planos. Uma vez que esses planos foram identificados pediu-se aos entrevistados uma cópia dos mesmos. Embora nem todos os planos estivessem disponíveis, os que estavam foram estudados para complementar as informações coletadas na entrevista. A análise das entrevistas e dos planos disponibilizados pelos empreendedores permitiu a compreensão da atividade da empresa e a descrição da forma como cada um dos planos foram usados para realizar o processo de tradução e formar a rede sociotécnica, o que será apresentado na figura 2.

Figura 2 - Rede de negócios da Sonorus no momento da entrevista

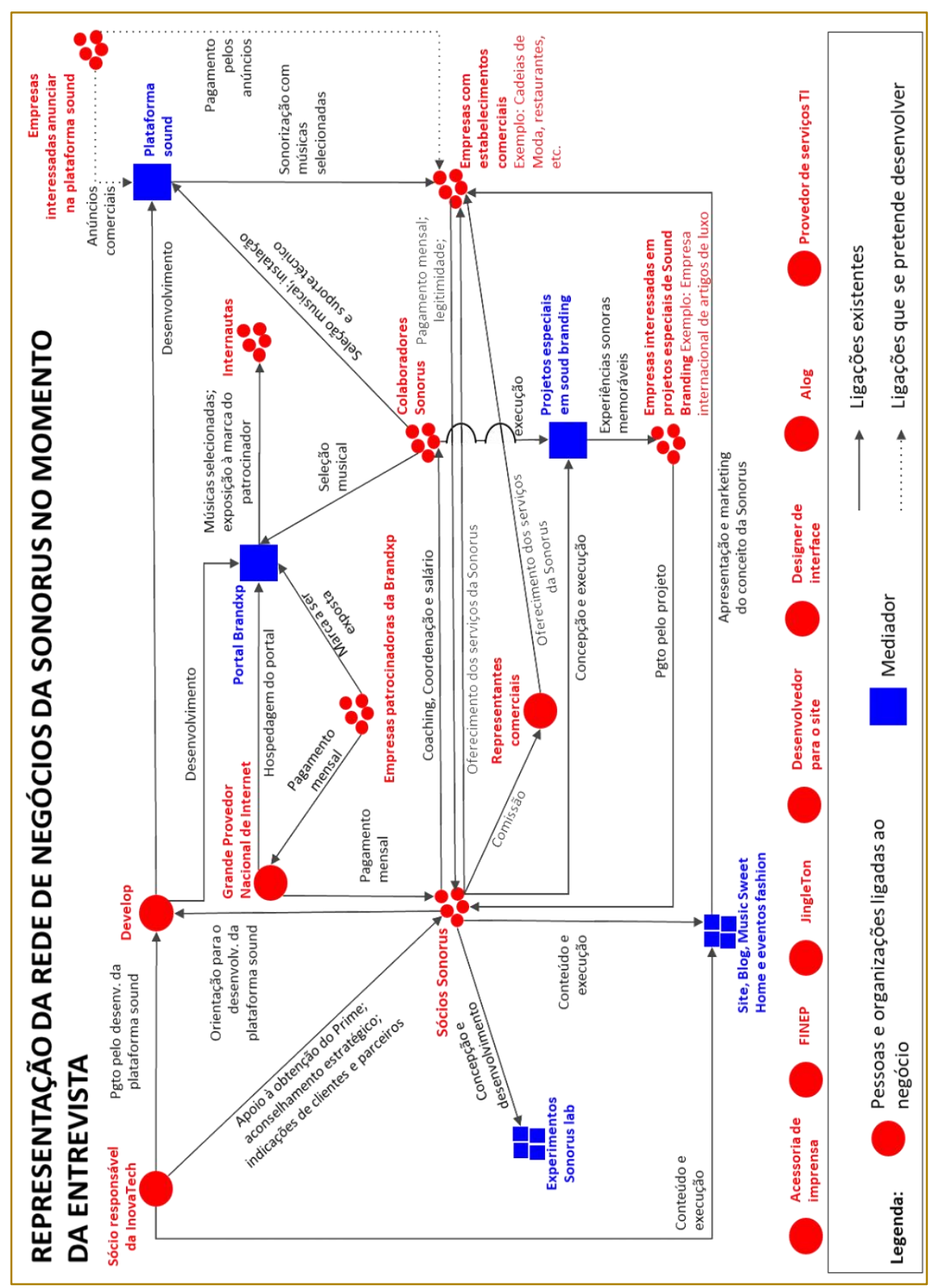




\section{RESULTADOS DO ESTUDO DE CASO}

\subsection{DESCRIÇÃO DA REDE DA SONORUS}

A rede de negócios da Sonorus, vista na Figura 2, é descrita a seguir.

Fundada por quatro sócios com diferentes experiências anteriores, a Sonorus opera desde janeiro de 2010. O grande diferencial da Sonorus está na sua expertise em Sound Branding. Este termo se refere à associação de uma marca a todo o tipo de experiências sonoras. Essa expertise é oriunda principalmente de dois de seus sócios, que há muito tempo, já trabalham com a produção de trilhas sonoras para comerciais, desfiles de moda, etc.

O seu principal negócio é a sonorização de estabelecimentos comerciais por meio da plataforma sound. Esta plataforma é um software que seleciona as músicas a serem tocadas em um estabelecimento a partir de uma lista pré-selecionada de acordo com a identidade da marca do cliente. Trata-se de um serviço de custo relativamente baixo: de $\mathrm{R} \$ 300$ a $\mathrm{R} \$ 1000$ mensais por estabelecimento. Para ser lucrativo, o negócio necessita de um grande volume em termos da quantidade de estabelecimentos comerciais. No futuro próximo, a Sonorus espera acelerar o crescimento do seu produto por meio da venda de Spots comerciais na programação dos estabelecimentos sonorizados gerando uma receita a ser dividida pelo estabelecimento e pela Sonorus.

A operação do serviço de sonorização conta com um grupo de colaboradores aficionados por música. Orientados e coordenados pelos sócios da Sonorus, eles exercem duas funções principais: (i) pesquisar continuamente novas músicas na internet $e$ cadastrá-las nas listas de músicas selecionadas para cada cliente; e (ii) realizar a instalação e manutenção da plataforma Sound nos clientes.

O desenvolvimento da plataforma Sound foi realizado por uma empresa de desenvolvimento de software que chamaremos aqui de Develop. A Develop, por sua vez, foi indicada por um dos sócios da InovaTech - a aceleradora de negócios que investe e apoia a Sonorus. Também foi a InovaTech quem pagou à Develop pelo desenvolvimento.

Além da Develop, os sócios da Sonorus contrataram um especialista em design de interfaces para garantir que a plataforma
Sound tivesse um design extremamente bonito. Esse design diferenciado seria muito importante para agregar valor ao estabelecimento contratante, permitindo que a plataforma fosse mostrada pelos atendentes do estabelecimento a qualquer cliente que se interesse pela música sendo tocada.

A venda do serviço é feita pelos próprios sócios da Sonorus ou por parceiros que atuam como representantes comerciais, recebendo uma comissão por cada negócio fechado. Muitos desses parceiros atuam em ramos complementares - por exemplo, o design de interior de estabelecimentos comerciais - e realizam a venda casada dos seus serviços junto aos serviços da Sonorus. Os esforços de vendas deram frutos de forma que, na época em que a entrevista foi realizada, a Sonorus já possuía cerca de duzentos estabelecimentos comerciais sonorizados, incluindo marcas de grande renome no mundo da moda e grandes redes de restaurantes no Rio de Janeiro. Estes clientes conferem grande legitimidade ao serviço da Sonorus.

A Sonorus utiliza um conjunto de canais para divulgar tanto a sua marca quanto o conceito de Sound Branding. Dentre esses canais, três estão na internet. $\mathrm{O}$ primeiro é o próprio site da Sonorus. Desenvolvido por uma empresa especializada, ele conta com uma identidade visual e musical muito particular e capaz de marcar profundamente a memória do visitante. O segundo é o Blog da Sonorus, constantemente atualizado com novidades que incluem desde projetos específicos desenvolvidos pela Sonorus, até curiosidades sobre o sound branding. O terceiro é o portal Music Sweet Home (nome descaracterizado) onde qualquer pessoa pode enviar uma foto sua, uma foto da sua casa e de uma música que ficam acessíveis aos visitantes do portal. O Music Sweet Home teve uma grande repercussão atraindo participantes de diversos países.

Além das páginas web, A Sonorus utilizou intensamente a assessoria de imprensa de uma empresa especializada e participou de eventos fashion como o Fashion Business. Como resultado, teve uma exposição significativa, aparecendo em mídias de destaque como o jornal Nacional, o jornal da Globo a revista Veja Rio e no jornal impresso O Globo.

O esforço de divulgação por meio desses quatro canais é de enorme importância pois a 
maior parte dos clientes não conhece a Sonorus e tem pouca consciência a respeito do conceito de Sound Branding e do seu potencial para melhorar os resultados do estabelecimento comercial. Os canais permitem que a Sonorus crie o interesse nos seus clientes antes de realizar uma abordagem direta, o que facilita muito o processo de venda.

Cientes de que o conceito de Sound Branding não se limita, nem deveria se limitar, à seleção de músicas para um estabelecimento comercial, os sócios da Sonorus se preocupam em experimentar outros mecanismos voltados à aplicação de experiências sonoras e a divulgação de uma marca. Esses experimentos são identificados com o conceito de Sonorus Lab. Tratam-se de várias ideias discutidas pelos sócios em reuniões chamadas de Lab Groups e desenvolvidas pelos sócios no seu tempo livre. O objetivo é criar um portfólio de serviços que possam ser oferecidos pela Sonorus além da plataforma Sound. Entre os exemplos de labs estão um sistema habilitado por RFID que permite que um provador toque uma música específica para cada peça de roupa que o cliente experimenta e o pod runner, trilha sonora digital, desenvolvidas para acompanhar corredores em seus treinos, nas quais spots comerciais podem ser inseridos. Embora, no momento da entrevista, os experimentos da Sonorus Lab ainda não tivessem sido implementados na forma de novos negócios, algumas negociações já haviam sido iniciadas com boas chances de serem concretizadas. Além disso, alguns dos experimentos foram apresentados em eventos de negócios de moda, dando grande destaque à Sonorus.

Outro tipo de negócio no qual a Sonorus atua é na realização de projetos especiais onde a Sonorus cria experiências sonoras memoráveis que estejam associadas à marca da contratante. Normalmente, tais projetos estão associados a um evento específico. Quando necessário, esses projetos podem incluir o desenvolvimento de trilhas sonoras originais, para os quais a Sonorus contrata a JingleTon (nome descaracterizado), empresa especializada no desenvolvimento de trilhas sonoras para marcas comerciais, cujos sócios são também sócios da Sonorus.

O último tipo de negócio realizado pela Sonorus é o portal brandxp. Trata-se de um projeto desenvolvido pela Develop para um grande provedor nacional de internet. Neste portal, hospedado pelo provedor nacional de internet, uma empresa pode patrocinar uma página na qual a sua marca é exposta junto a uma lista de músicas especialmente selecionadas pela Sonorus. A Develop esteve envolvida no desenvolvimento do portal brandxp e indicou a Sonorus para participar do negócio. No acordo, o pagamento mensal feito pelos patrocinadores é dividido entre o provedor de nacional de internet e a Sonorus. No momento da entrevista, o portal da brandxp já havia obtido o seu primeiro cliente: uma marca de bebidas alcólicas.

O sócio da InovaTech responsável pela relação com a Sonorus provê apoio de diversas maneiras. Em primeiro lugar, ele indicou a Develop e custeou, por meio da InovaTech, o desenvolvimento da plataforma Sound. Em segundo, ele mobilizou a equipe da InovaTech para apoiar a Sonorus na participação do Programa Prime da Finep, que resultou na obtenção de um apoio financeiro significativo na modalidade de subvenção econômica. Além disso, indicou a Sonorus para diversos clientes em potencial. Finalmente, ele atua como um conselheiro estratégico, participando de reuniões esporádicas com os sócios da Sonorus, nas quais ele muitas vezes assume o papel de sintetizar as diferente visões em um direcionamento capaz de obter a aprovação de todos os demais. No início da operação da Sonorus, no entanto, o sócio responsável da InovaTech tinha uma atuação ainda mais presente, participando inclusive de reuniões de vendas consideradas de maior importância.

\subsection{PLANOS USADOS PARA DESENVOLVER A REDE DE NEGÓCIO DA SONORUS}

Apresentamos a seguir os planos usados pelos sócios da Sonorus, destacando como eles contribuíram para o desenvolvimento da rede de negócio.

Plano de Negócios: Os sócios da Sonorus, antes de entrar em operação, elaboraram um plano de negócio como requisito do programa Prime para obtenção da subvenção econômica junto à Finep. O processo de elaboração desse plano de negócio incluiu uma série de reuniões com a participação do sócio da InovaTech, nas quais se discutiu aspectos importantes do negócio a ser estruturado. Pode-se dizer que a necessidade de escrever o plano de negócio catalisou as discussões que levaram à tomada de diversas 
decisões importantes. No entanto, o nível de detalhe exigido no plano de negócios foi considerado excessivo pelos sócios da Sonorus que simplesmente ignoraram boa parte do seu conteúdo a partir do momento em que o apoio do programa Prime foi garantido.

Resumos de reuniões de planejamento: Além da reunião para discussão do plano de negócio para o Prime, os sócios da Sonorus também se reuniram com o sócio responsável pela InovaTech em alguns momentos específicos para discutir outras decisões estratégicas como, a estrutura da equipe da Sonorus, ou a estratégia precificação e segmentação do mercado. Nessas reuniões, - sócio da InovaTech assumia um papel central, sintetizando as discussões e obtendo consenso com relação às principais decisões tomadas. Os produtos dessas reuniões, eram documentos simplificados, normalmente um texto de uma ou duas páginas ou um slide de PowerPoint. Tais documentos eram de uso interno apenas, não servindo para coordenação com atores externos.

Plano de trabalho Semanal (PTS): Os sócios da Sonorus realizam uma reunião semanal dividida em duas partes: na primeira são discutidos assuntos de caráter táticos e operacionais e, na segunda, são estabelecidos os principais afazeres ao longo da semana. As discussões registradas no PTS facilitam bastante a coordenação entre os sócios da Sonorus, tornando mais eficiente os seus esforços no sentido de desenvolver o novo negócio. Além disso, as conclusões do PTS levaram à melhoria de muitos dos processos internos da Sonorus.

Planilha de previsões e análises financeiras: A elaboração de uma planilha Excel foi de grande importância para equacionar diversas decisões quanto à operação e precificação dos serviços da Sonorus. Esse exercício permite aos sócios negociarem com Stakeholders como clientes, colaboradores e representantes comerciais de forma a alcançar um modelo de negócio sustentável. Além disso, essa planilha é mantida atualizada permitindo analisar a rentabilidade conseguida por meio de cada cliente, o que trouxe insights importantes sobre como a Sonorus deveria se posicionar e precificar o seu serviço, considerando os diferentes segmentos de clientes atendidos.

Documentos de suporte ao desenvolvimento da plataforma Sound: Ao longo do desenvolvimento da plataforma Sound, a Develop desenvolveu uma série de documentos que serviam de interface entre eles, a Sonorus e o designer contratado para desenvolver as telas do aplicativo. Esses documentos simples tinham o formato de histórias de usuário. Do ponto de vista da Sonorus e do designer, essas histórias representam a forma como o usuário final iria interagir com o software, já para a Develop ela significava funcionalidades a serem implementadas. Esses documentos funcionavam, portanto, como um instrumento simples e importante para a coordenação entre esses diferentes atores no desenvolvimento da plataforma que acabou sendo realizado em um prazo de apenas três meses. De acordo com um dos sócios entrevistados, este prazo foi extremamente rápido considerando a sofisticação da plataforma.

Documentos de suporte ao desenvolvimento do site institucional: Assim como ocorreu com a plataforma Sound, o planejamento e desenvolvimento do site institucional da Sonorus também foi apoiado por documentos simples. Embora o conteúdo destes documentos não estivesse formatado como histórias de usuário, ele também serviu para coordenar o trabalho entre o desenvolvedor do site, os sócios da Sonorus e o sócio da InovaTech. Para o primeiro, ele representava as características do site a ser desenvolvido, para os demais ele representava o conteúdo a ser construído, que incluía a produção de textos e vídeos. Os sócios da Sonorus e o sócio da InovaTech usaram esses documentos para distribuir responsabilidades quanto à elaboração desse conteúdo.

Materiais Institucionais: A Sonorus também desenvolveu materiais institucionais de diferentes tipos. Exemplos desses materiais são um folder digital descrevendo o modelo de negócio da Sonorus e um vídeo apresentando as principais características da plataforma Sound. O desenvolvimento desses materiais sempre envolve a discussão quanto ao posicionamento da empresa frente aos seus clientes, assim como detalhes operacionais a serem comunicados. Esses materiais foram extremamente importantes para divulgar a empresa para potenciais clientes. 


\section{DISCUSSÃO DOS RESULTADOS OBTIDOS}

Podemos classificar os planos desenvolvidos pela Sonorus em três categorias:

- Planos de concepção do negócio

- Planos voltados ao desenvolvimento de interfaces com Stakeholders

- Planos operacionais

Os planos de concepção do negócio são desenvolvidos para representar, de forma ampla, a estrutura que os empreendedores da Sonorus pretendiam dar ao novo negócio. Esse planos incluem os resumos das reuniões de planejamento, o próprio plano de negócio e a planilha de previsões e análises financeiras. A seguir, analisamos brevemente como cada um desses planos foram usados.

Os resumos das reuniões internas de planejamento eram registros de conclusões importantes alcançadas por meio das discussões envolvendo todos os sócios. Ter um documento sucinto consolidando essas conclusões foi importante para garantir que todos os sócios pudessem se guiar por um referencial comum sobre essas importantes decisões. No entanto, o único benefício desses planos estava no alinhamento das ações entre os sócios, não contribuindo diretamente para o desenvolvimento do negócio.

O plano de negócio da Sonorus foi elaborado com o objetivo de obter o apoio financeiro do programa PRIME da FINEP. No entanto, grande parte do conteúdo das decisões contidas no plano de negócio foi simplesmente abandonado. Pode-se dizer, por tanto, que o plano de negócio, apesar de ter alcançado os seus objetivos institucionais, não serviu como guias para o desenvolvimento futuro da empresa diferentemente do que a concepção tradicional de plano nos faria supor. Por outro lado, o exercício de desenvolvimento do plano de negócio obrigou os empreendedores da Sonorus a buscar novas informações sobre o mercado no qual pretendiam trabalhar e a refletir sobre os meios à sua disposição e as formas de utilizá-los. Pode-se dizer, por tanto, que o exercício de desenvolver o plano de negócios preparou os empreendedores da Sonorus a tomar melhores decisões.

Com relação ás planilhas financeiras, por mais que se soubesse que elas contivessem falhas, elas eram consideradas essenciais para balizar as estratégias de precificação e operações. O simples fato de ter desenvolvido a planilha financeira faz com que os empreendedores tenham uma boa noção do volume de vendas que precisariam almejar, da faixa de preço razoável para o produto ou serviço e dos custos operacionais com os quais podem arcar. Esse entendimento é muito importante para guiar os empreendedores a tomar decisões no dia-adia. Além disso, essas planilhas podem ter grande importância para legitimar as necessidades de capital da nova empresa como foi o caso quando a planilha da Sonorus foi utilizada pelo sócio da InovaTech para justificar internamente o investimento para o desenvolvimento da plataforma Sound.

A segunda categoria são os planos voltados ao desenvolvimento de interfaces com Stakeholders. Estes planos são documentos desenvolvidos com o objetivo de apoiar o processo de tradução, levando a uma mudança na rede sociotécnica onde se pretende formar o negócio. O plano do site, assim como o documento de suporte ao desenvolvimento da plataforma Sound especificam o funcionamento e coordenam o desenvolvimento de artefatos que intermediarão as trocas entre os Stakeholders que farão parte da rede de negócio. Já os materiais institucionais, trazem mensagens para estimular determinados Stakeholders a assumir comportamentos específicos - por exemplo, estimulam potenciais clientes a contratar os serviços da Sonorus.

Vale destacar que as decisões contidas nos planos voltados ao desenvolvimento de interfaces com Stakeholders afetam não apenas as trocas junto aos demais Stakeholders, como também a maneira como a empresa precisa se organizar para realizar estas trocas. Por exemplo, o plano para a plataforma Sound definiu, além da usabilidade da plataforma pelo cliente, a forma de trabalho segundo a qual as músicas teriam de ser cadastradas no computador.

Portanto, a elaboração dos planos para o desenvolvimento de interfaces se reflete de maneira muito mais direta sobre a trajetória estratégica tomada pelo negócio do que a elaboração dos planos de negócio ou as planilhas de análise financeira. Como diversos desses planos são desenvolvidos ao longo do tempo e assumem formas diferenciadas, pode-se dizer que a rede de negócios vai tomando forma de maneira não premeditada. 
A terceira categoria de planos são os planos operacionais. Entre eles, podemos destacar o PTS. Esse plano teve o papel de garantir a coordenação entre os sócios da Sonorus permitindo-Ihes trabalhar de forma mais coesa e eficiente no desenvolvimento do negócio.

Ao analisarmos cada uma dessas categorias de planos, é possível confrontar e identificar a correspondência existente entre o uso que os empreendedores fazem dos planos e a descrição de Sarasvathy (2009) da ação do empreendedor expert de acordo com a lógica de efetuação. Como vemos na Figura 1, o processo de efetuação começa com o empreendedor fazendo o exercício de mapear os meios que estão à sua disposição e, a partir daí, definir metas e objetivos a serem alcançados a partir desses meios. Podemos dizer que os exercícios que levaram à elaboração dos planos de concepção do negócio se encaixam muito bem nesta etapa. A elaboração desses planos leva o empreendedor a levantar um conjunto de informações sobre os recursos a sua disposição e propor uma possibilidade de ação para desenvolver o seu negócio a partir deles.

Continuando com a descrição do processo de efetuação, após ter definido os objetivos iniciais do empreendimento, o empreendedor interage com outros atores buscando levá-los a se comprometer com o desenvolvimento do novo negócio. Ao fazer isso, ele renegocia as metas e objetivos traçados anteriormente para acomodar o interesse dos novos parceiros. Tanto o plano de negócio quanto a planilha de análise financeira tiveram um papel importante nessa interação para obtenção de comprometimento de outros Stakeholders. O plano negócio da Sonorus foi utilizado para obtenção do apoio da FINEP, enquanto que a planilha foi importante para justificar o investimento da InovaTech na plataforma Sound.

Por outro lado, essa etapa de interação do processo de efetuação também traz uma explicação para o fato do plano de negócio ter sido abandonado Sonorus e de a planilha de previsões e análises financeiras ser atualizada constantemente. O plano de negócio foi abandonado pois, uma vez que o apoio do programa PRIME já estava garantido, o esforço para a atualização das suas muitas páginas simplesmente não seria justificado. Já a planilha pode ser atualizada pois o esforço se mostrava muito menor. Isto nos mostra a importância de que os instrumentos de planejamento para uma empresa nascente sejam de fácil atualização, para que possam se manter úteis no longo prazo.

Os planos voltados ao desenvolvimento de interface com Stakeholers se mostraram importantes a partir da etapa de "interagir com outras pessoas", vista na figura 1. Como discutido anteriormente, tais planos atuaram como objetos de fronteira ajudando os empreendedores da Sonorus a levar a rede sociotécnica a sua volta a se comportar de acordo com os padrões necessários ao funcionamento do negócio.

Uma conclusão interessante que se pode retirar daí é o fato de que não é o exercício de elaboração de um plano o que define a trajetória de uma empresa. A influência do plano nessa trajetória acontece ne medida em que ele é utilizado pelos empreendedores como objeto de fronteira em um esforço de moldar a organização dos atores na sua rede sócio-técnica. É por isso que, pelo menos no caso da Sonorus, os planos voltados ao desenvolvimento de interface com os Stakeholders se mostraram tão relevantes para a sua estratégia.

Finalmente, em relação aos planos operacionais (PTS), pode-se dizer que, por serem mantidos internos à Sonorus, eles não exerceram um papel relevante na conformação da sua trajetória estratégica. Da mesma forma que os resumos das reuniões de planejamento - que também não havia sido compartilhado externamente - o PTS serviu principalmente para garantir 0 alinhamento entre a equipe de empreendedores da Sonorus aumentando a sua eficiência.

\section{CONSIDERAÇÕES FINAIS}

No presente artigo tratamos de um assunto recorrente na literatura sobre a Gestão Estratégica Empreendedora: o papel do planejamento no crescimento das novas firmas. No entanto, usamos uma abordagem diferente dos numerosos estudos quantitativos que correspondem à maior parte dos trabalhos de pesquisa sobre o assunto (Brickman et al., 2010). Optamos pela realização de um estudo de caso qualitativo, usando como referencial teórico a teoria do crescimento da firma e a Teoria Ator-Rede. O estudo de caso realizado permitiu validar a metodologia utilizada e ilustrar como 
empreendedores utilizam seus planos. A aplicação dessa metodologia para outras empresas nascentes além de ampliar o número de casos estudados, permitirá aprofundar a compreensão da atividade empreendedora e o desenvolvimento de métodos de planejamento melhor adequados aos desafios das empresas nascentes.

Conforme destacado por Burke et al. (2010), pode -se dizer que os planos assumem formas diversas que vão além do plano de negócio tradicional. Além disso, estudar a utilização dos planos sob a ótica social da Teoria Ator-Rede, nos permite conciliá-la com a lógica efetual seguida pelos empreendedores experts e sistematizada por Sarasvathy (2009). Usando a lógica causal tradicional, seria de se esperar que os planos fossem vistos como a definição de um

\section{REFERENCIAS}

[1] Allinson, C. W., Chell, E., \& Hayes, J. (2000). Intuition and entrepreneurial behaviour. European Journal of Work and Organizational Psychology, 9(1), 31-43.

[2] Bhidé, A. V. (2003). The origin and evolution of new businesses. Oxford University Press. 8

[3] Blank, S., \& Dorf, B. (2014). Startup: manual do empreendedor. Alta Books Editora.

[4] Bowker, G. C., \& Star, S. L. (2000). Sorting Things Out: Classification and Its Consequences (Edição: Revised ed.). Cambridge, Massachusetts London, England: Mit Press.

[5] Brinckmann, J., Grichnik, D., \& Kapsa, D. (2010). Should entrepreneurs plan or just storm the castle? A meta-analysis on contextual factors impacting the business planning-performance relationship in small firms. Journal of Business Venturing, 25(1), 24-40.

[6] Burke, A., Fraser, S., \& Greene, F. J. (2010). The multiple effects of business planning on new venture performance. Journal of management studies, 47(3), 391-415.

[7] Callon, M. (1999). Actor-network theorythe market test. The Sociological Review, 47(1_suppl), 181-195.

[8] Campos, N. A. (2010). A transferência de tecnologia em incubadoras de empresa universitária: a influência da rede precedente dos empreendedores. Grenoble.

[9] Carter, N. M., Gartner, W. B., \& Reynolds, P. D. (1996). Exploring start-up event sequences. Journal of business venturing, 11(3), 151-166.

[10] Castrogiovanni, G. J. (1996). Pre-startup planning and the survival of new small businesses: conjunto de passos a serem realizados para chegar-se a um objetivo pré-definido, o que simplesmente não corresponde à realidade. Por outro lado, levando em conta a lógica de efetuação por trás das ações dos empreendedores, podemos distinguir contribuições de outras naturezas. Em primeiro lugar, 0 processo de desenvolvimento desses planos mostrou grande importância em ajudar os empreendedores a compreender os meios a sua disposição para o desenvolvimento da sua rede de negócio, primeira etapa do processo de efetuação visto na Figura 1. Em segundo lugar, se percebeu que os planos funcionam como objetos de fronteira atuando diretamente na construção de mudanças específicas na rede de negócios, quarta etapa do processo de efetuação.

Theoretical linkages. Journal of management, 22(6), 801-822.

[11] Delmar, F., \& Shane, S. (2003). Does business planning facilitate the development of new ventures? Strategic management journal, 24(12), 1165-1185.

[12] Demil, B., \& Lecocq, X. (2010). Business model evolution: in search of dynamic consistency. Long range planning, 43(2), 227-246.

[13] Dencker, J. C., Gruber, M., \& Shah, S. K. (2009). Pre-entry knowledge, learning, and the survival of new firms. Organization Science, 20(3), 516-537.

[14] Duarte, F., Gomes, L. A. de V., Frenkel, J. B., \& Clemente, R. G. (2015). Empreendedorismo e inovação em startups. In Gestão da Inovação e Competitividade no Brasil (1a edição). São Paulo, SP: Bookman.

[15] FNQ - Fundação Nacional da Qualidade. (2009). Critérios de Excelência 2010. Fundação Nacional da Qualidade.

[16] Gilbert, B. A., McDougall, P. P., \& Audretsch, D. B. (2006). New venture growth: A review and extension. Journal of management, 32(6), 926-950.

[17] Gruber, M. (2007). Uncovering the value of planning in new venture creation: A process and contingency perspective. Journal of Business Venturing, 22(6), 782-807.

[18] Guérin, F., Lavelle, F., Daniellou, J., Duraffourg, \& Kerguelen, A. (2001). Compreender o trabalho para transformá-lo: a prática da ergonomia. Edgard Blücher.

[19] Karlsson, T., \& Honig, B. (2009). Judging a business by its cover: An institutional perspective 
on new ventures and the business plan. Journal of Business Venturing, 24(1), 27-45.

[20] Latour, B. (1996). On actor-network theory: A few clarifications. Soziale welt, 369-381.

[21] Latour, B. (2005). Reassembling the social: An introduction to actor-network-theory. Oxford university press.

[22] Law, J. (1992). Notes on the theory of the actor-network: Ordering, strategy, and heterogeneity. Systemic practice and action research, 5(4), 379-393.

[23] Liao, J., \& Gartner, W. B. (2006). The effects of pre-venture plan timing and perceived environmental uncertainty on the persistence of emerging firms. Small Business Economics, 27(1), 23-40.

[24] Loch, C. H., Solt, M. E., \& Bailey, E. M. (2008). Diagnosing unforeseeable uncertainty in a new venture. Journal of product innovation management, 25(1), 28-46.

[25] McKelvie, A., \& Wiklund, J. (2010). Advancing firm growth research: A focus on growth mode instead of growth rate. Entrepreneurship theory and practice, 34(2), 261-288.

[26] Mintzberg, H. (1994). Rise and Fall of Strategic Planning. Simon and Schuster.

[27] Penrose, E. T. (1995). The Theory of the Growth of the Firm (3 edition). Oxford; New York: Oxford University Press.

[28] Piovezan, L. H., Laurindo, F. J. B., \& de Carvalho, M. M. (2008). Proposta de método para a formulação de estratégia em pequenas e médias empresas. Revista Produção Online, 8(2). Recuperado de http://producaoonline.org.br/rpo/article/view/117

[29] Ries, E. (2014). A startup enxuta. Leya.

[30] Sarasvathy, S. D. (2009). Effectuation: Elements of Entrepreneurial Expertise. Edward Elgar Publishing.

[31] Schumpeter, J. A. (1942). Capitalism, socialism and democracy (6o ed). Routledge.

[32] Sirén, C., \& Kohtamäki, M. (2016). Stretching strategic learning to the limit: The interaction between strategic planning and learning. Journal of Business Research, 69(2), 653663.

[33] Star, S. L., \& Griesemer, J. R. (1989). Institutional ecology,translations' and boundary objects: Amateurs and professionals in Berkeley's Museum of Vertebrate Zoology, 1907-39. Social studies of science, 19(3), 387-420.

[34] Tornikoski, E. T., \& Newbert, S. L. (2007). Exploring the determinants of organizational emergence: A legitimacy perspective. Journal of Business Venturing, 22(2), 311-335.

[35] Trompette, P., \& Vinck, D. (2009). Revisiting the notion of boundary object. Revue d'anthropologie des connaissances, 3(1), 3-25.

[36] Wiltbank, R., Dew, N., Read, S., \& Sarasvathy, S. D. (2006). What to do next? The case for non-predictive strategy. Strategic management journal, 27(10), 981-998.

[37] Yin, R. K. (2003). Case Study Research: Design and Methods. SAGE. 


\section{Capítulo 2}

\section{UMA AVALIAÇÃO DA ESTRATÉGIA OPERACIONAL DE BANCOS EM PROCESSO DE INCORPORAÇÃO}

\section{Rogério da Silva Nunes}

Resumo: Este artigo pretende verificar a existência de similaridade em processos de gestão operacional em bancos incorporados no mercado brasileiro e os fatores que podem ter sido de relevantes para a decisão final do incorporador. Neste sentido, pretende identificar os procedimentos operacionais utilizados pelas instituições financeiras incorporadas, os critérios de avaliação e análise das decisões de mercado nos bancos incorporados e o gerenciamento dos processos dos bancos envolvidos na incorporação. A pesquisa foi realizada em três bancos estrangeiros que foram incorporados por um banco de capital nacional, através de um protocolo de entrevistas junto a dois gestores de cada instituição. $O$ artigo permite identificar aspectos da estrutura organizacional, estratégia operacional e gestão bancária dos bancos incorporados e forma como são avaliados os serviços prestados pelos bancos.

Palavras-chave: gestão bancária, estratégia de operações, avaliação. 


\section{INTRODUÇÃO}

O mercado financeiro brasileiro passou por um significativo processo de transformação na transição do século XX para o XXI, com os bancos passando a definir melhor seu processo de atuação, dedicando maiores esforços a qualidade da prestação de serviços bancários, competitividade dos serviços, posicionamento de mercado e segmentação de clientes.

O processo de incorporação foi um caminho adotado para que o mercado financeiro brasileiro tivesse condições de adequar-se rapidamente ao cenário econômico estável, tornando possível uma integração com os agentes financeiros internacionais no sistema financeiro brasileiro.

A pesquisa visa verificar os critérios utilizados nas incorporações realizadas no mercado financeiro brasileiro nos últimos anos, em especial no tocante à similaridade de processos operacionais e programas de gestão operacional, com a intenção de verificar determinantes na definição do processo de incorporação e, principalmente, como ocorreu a escolha dos bancos incorporados. Para tanto, foi realizada em três bancos que atuavam no mercado brasileiro e que foram incorporados por um banco de capital nacional.

\section{BANCOS E AVALIAÇÃO DOS SERVIÇOS}

Um serviço é normalmente percebido pelo cliente conforme sua própria escala de valores, com impressões particulares, tais como confiança na empresa, a segurança que percebe em quem oferece um serviço e a experiência conquistada pela vivência no mercado.

Essa situação torna o serviço intangível, mas pode-se ressaltar que alguns incluem elementos altamente mensuráveis na hora da avaliação feita pelo cliente. Gronroos (1993) apresenta como exemplo que, em um restaurante, tanto são avaliados os atendimentos oferecidos como a comida servida.

A variabilidade é uma característica fundamental para avaliação da qualidade dos serviços. A qualidade nas empresas de serviços depende muito das habilidades interpessoais daqueles que atuam na linhade-frente. Para Kotler (1993; p.414) "A maneira como uma empresa lida com problemas resultantes da variabilidade pode afetar dramaticamente a percepção que o cliente tem da qualidade do serviço".

O serviço não se constitui em um ato isolado, e sim em uma série de atividades e processos que são produzidos e consumidos simultaneamente. Não é possível produzir um serviço de antemão, isso confere uma característica de inseparabilidade fazendo com que a interação entre fornecedor e cliente seja um aspecto fundamental para avaliação da proporção entre a demanda e a oferta.

Estabelecer uma distinção entre os diversos tipos de serviços pode ser útil. Para obter bons resultados devem-se levar em consideração aspectos dos serviços, tais como: processo utilizado, natureza do serviço e tipo de interface a ser utilizado com os clientes.

Kotler (1993), classifica os serviços em quatro tipos:

- Serviços baseados em pessoas versus baseado em equipamento;

- Serviços que requerem a presença do cliente ou não;

- Serviços que atendem necessidades pessoais ou de empresas;

- Serviços públicos versus privados, com fins lucrativos versus sem fins lucrativos.

Soares e Corrêa (1994), apresentam a seguinte classificação:

- Serviços puros - aqueles prestados exclusivamente por pessoas, sem a utilização de bens materiais;

- Serviços agregados - quando há a necessidade de agregar um bem ao serviço para que este aconteça;;

- Serviços diretos - quando o contato pessoa-pessoa se torna preponderante, sem a utilização de equipamentos;

- Serviços Indiretos - quando o contato com o atendente é substituído por um equipamento.

Fitzsimmons \& Fitzsimmons (2002), argumentam que uma classificação pode ajudar na discussão sobre administração de serviços e representar um papel importante no processo de quebra barreiras, auxiliando a troca de conhecimento entre diversos setores da organização. 
A tarefa de classificar e avaliar os serviços prestados pelos bancos pode se tornar muito complexa, em função de algumas características, principalmente, em função do mercado e do tipo de satisfação que se esteja procurando. Para Fitzsimmons \& Fitzsimmons (2002), as empresas de serviços são de tal forma diferentes, necessitando de abordagens gerenciais especiais, que vão além de simples adaptações das técnicas encontradas no setor de manufatura. Essas características diferenciadoras sugerem uma ampliação da visão do sistema, pois consideram o cliente como um participante no processo de serviço.

Investigar os critérios de avaliação dos processos de transformação pelos quais passaram os bancos no mercado brasileiro está intrinsecamente ligado ao processo de tomada de decisão gerencial e a necessidade de estarem adequados a um perfil de mercado.

\subsection{QUALIDADE DE SERVIÇOS}

A literatura tem analisado de forma significativa a importância da qualidade dos serviços e como as empresas devem atuar para alcançar a excelência nos serviços. Segundo Téboul (1999), o serviço propriamente dito é realizado na ribalta, os atos do prestador de serviços afetam diretamente o cliente.

Pelo fato da prestação de serviço dizer respeito antes de tudo ao cliente, ela é essencialmente "imaterial", mesmo que inclua elementos concretos, tais como bens manufaturados ou da informação.

Em função do tipo do serviço, o nível de contato pode ser bastante elevado. Em outros casos, pode ser breve e esporádico, padronizada em algumas transações bancárias. Outras vezes, o contato pode ser menos denso se for feito via telefone ou por intermédio de um computador. Em tal contexto, ocorre a importância das empresas focarem as operações internas, que faz emergir o conceito de serviços e clientes internos.

Parasuraman, Zeithaml e Berry (1994) atribuem à qualidade de serviços a discrepância que existe entre as expectativas e as percepções do cliente sobre um serviço experimentado. Para assegurar uma boa prestação de serviço, as percepções dos clientes devem exceder suas expectativas. Os autores afirmam que, embora esse raciocínio seja válido, não basta compreender a importância de fornecer serviços com excelência e qualidade; é preciso que haja um processo contínuo de monitoramento das percepções dos clientes sobre a qualidade do serviço, bem como uma identificação das causas das discrepâncias encontradas e seleção de alternativas adequadas para a melhoria contínua. Esses autores elaboraram um modelo que objetiva realizar análise e gerenciamento da qualidade de serviços que foi denominado "Modelo Conceitual para a Qualidade de Serviços" ou "Modelo de GAP", que propõe-se a responder:

- Como exatamente os consumidores avaliam a qualidade de um serviço?

- Os serviços são avaliados pelos consumidores de uma forma global ou parcial?

- Quais as múltiplas facetas das dimensões de um serviço?

- Estas dimensões diferem de acordo com o segmento do Serviço?

Parasuraman, Zeithaml, e Berry (1994) realizaram entrevistas com clientes de quatro setores de serviços: banco de varejo, cartão de crédito, seguros e serviços de manutenção. As questões abordadas nas entrevistas incluíam as razões para a satisfação e insatisfação dos consumidores com o serviço; descrição dos serviços ideais; significado da qualidade do serviço; fatores importantes na avaliação da qualidade do serviço.

Os pontos comuns observados determinaram que a chave da qualidade de um serviço é atender ou exceder a expectativa do cliente e, como decorrência, a qualidade de um serviço pode ser definida como o grau da discrepância entre as expectativas ou desejos dos clientes e suas percepções.

Parasuraman, Zeithaml e Berry (1994) identificaram os critérios para avaliar a qualidade dos serviços, chamados de dimensões da qualidade de serviço, envolvendo pontos tais como: aspectos tangíveis, confiabilidade, presteza, cortesia e segurança. Estes estudos mostram que a confiabilidade é a dimensão mais considerada pelos clientes quando estes avaliam a qualidade do serviço. Quando uma empresa presta um serviço de modo descuidado, e deixa de cumprir promessas feitas aos clientes, estremece a confiança e 
abala suas chances de obter reputação pela excelência do serviço.

Outro modelo de análise desenvolvido por Parasuraman, Zeithaml e Berry (1994) foi o chamado de escala SERVQUAL, "service Quality", que desenvolve um instrumento para medir a qualidade do serviço levando em conta às percepções dos clientes.

Quadro 1: Dimensões e afirmativas da escala SERVQUAL

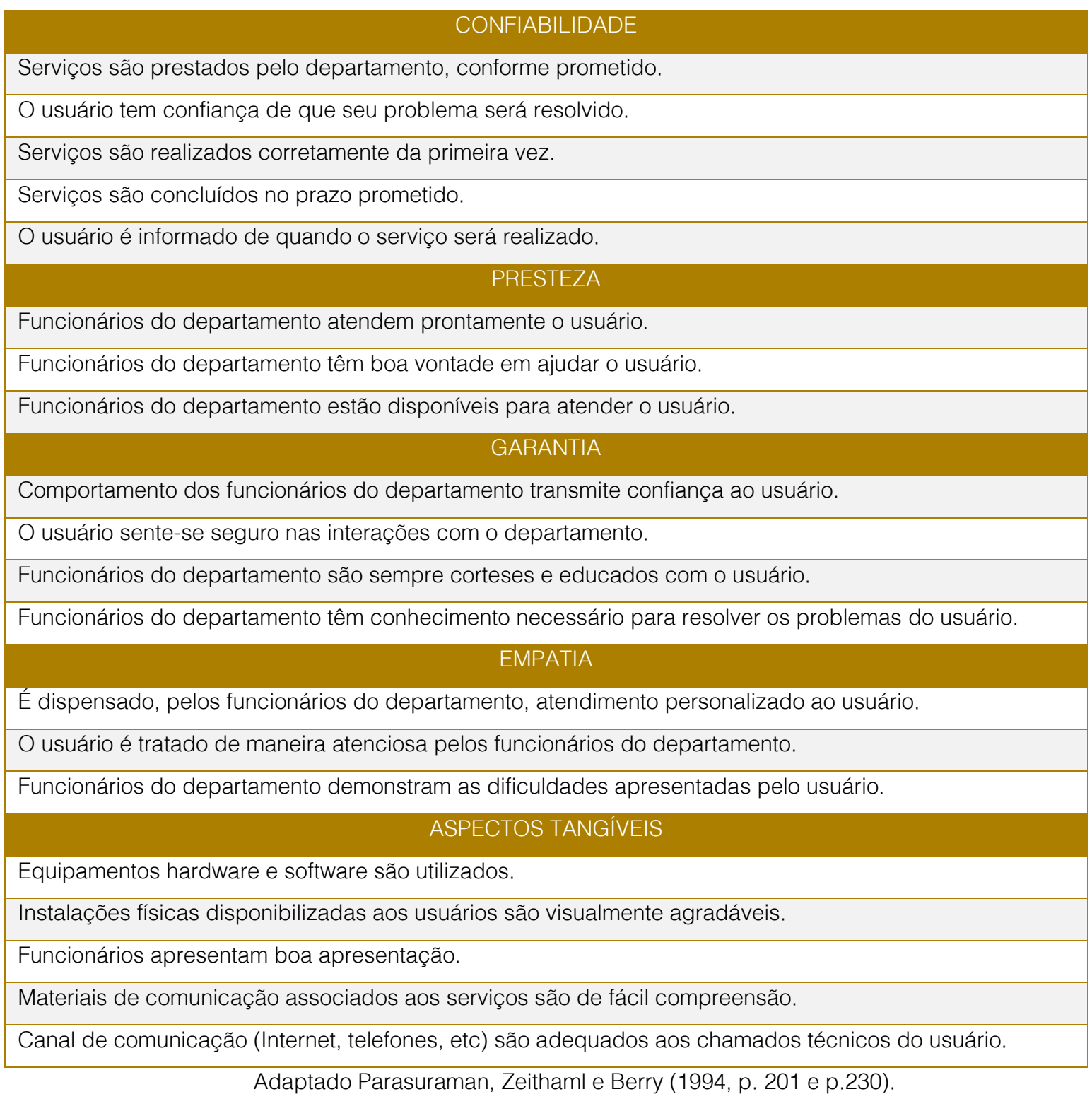

Os conceitos da escala SERVQUAL estão agrupados de acordo com cada dimensão da qualidade de serviço identificada, buscando pontos tais como:

- Aspectos tangíveis: aparência das instalações físicas, equipamentos, pessoal e materiais de comunicação;

- Confiabilidade: capacidade para realizar o serviço prometido de forma segura e correta;
- $\quad$ Presteza: disposição para ajudar os clientes e fornecer pronto atendimento;

- Garantia: conhecimento e cortesia dos funcionários e sua capacidade de inspirar confiança;

- $\quad$ Empatia: atenção personalizada que a empresa dispensa aos seus clientes.

A escala SERVQUAL tem como objetivo apresentar medidas de qualidade dos serviços, bem como mostrar a qualidade 
percebida pelos usuários e beneficiários de serviços, permitindo reportar às empresas os pontos críticos de seus processos.

\section{ESTRATÉGIA EM BANCOS}

Diversos significados já foram atribuídos para o termo estratégia, mas é possível identificar algumas palavras-chave relacionadas ao termo, entre elas: mudanças, competitividade, desempenho, posicionamento, missão, objetivos, resultados, integração, adequação organizacional. Tais palavras muitas vezes são empregadas como sinônimas delas próprias, confundindo a busca de um conceito mais preciso.

Para Mintzberg e Quinn (1991), estratégia é um modelo ou plano que integra os objetivos, as políticas e as ações seqüenciais de uma organização, em um todo coeso. Meireles e Gonçalves (2001) definem estratégia como a disciplina da administração que se ocupa da adequação da organização ao seu ambiente. Wright, Kroll e Parnell (2000) a definem como planos da alta administração para alcançar resultados consistentes com a missão e os objetivos gerais da organização. Para Meireles e Gonçalves (2001), a Administração Estratégica emergiu como parte do planejamento estratégico, que atualmente pode ser considerado um dos seus principais instrumentos. Surgiu assim, como uma das etapas do planejamento - a de seleção de caminhos a ser trilhado a partir da identificação dos pontos fortes e fracos de uma organização e das ameaças e oportunidades diagnosticadas em seu ambiente de atuação.

\subsection{NIIVEIS DE ESTRATÉGIA}

Na visão de Mintzberg e Quinn (1991), a estratégia existe em vários níveis de qualquer organização. Não deve restringir-se somente aos níveis gerenciais e diretivos, mas distribuir-se por toda a organização, levandose em conta os diferentes graus de importância de cada nível hierárquico para o alcance dos objetivos organizacionais. A alocação hierárquica da estratégia na estrutura organizacional pode ser:

- Corporativa - determina em qual setor a empresa deve operar;

- Unidade de negócios - determina como se deve competir no setor;
- Funcional - determina como uma área funcional deve trabalhar a partir da estratégia de negócio escolhida.

Porter (2001), define a estratégia corporativa como o plano geral para uma empresa diversificada que trata de duas questões diferentes: em que negócios a empresa deve competir e como a sede corporativa deve gerenciar o conjunto de unidades de negócios, é o elemento que faz com que o todo corporativo seja superior à soma das unidades de negócios. Zaccarelli (1995) defende a estratégia corporativa, como unidade de negócios partindo da concepção de que as estratégias existem para propiciar a obtenção de vantagens competitivas nas operações das empresas.

A estratégia de unidades de negócios diz respeito a como competir com êxito em determinado setor. Gupta (1999), também considera que um conjunto de estratégias genéricas pode ser muito útil para orientar as organizações, destacando cinco elementos considerados críticos, na gestão destas estratégias.

As estratégias funcionais podem ser consideradas como funções interrelacionadas assumindo formas, diversas conforme a função estratégica a ser adotada. Segundo Wright, Kroll e Parnell, (2000), estratégias funcionais podem ser desenvolvidas em conjunto com diversas áreas funcionais de uma organização como: finanças, produção e operações, compras e materiais, pesquisa e desenvolvimento, sistemas de informação, marketing e recursos humanos.

Para iniciar um processo de desenvolvimento de estratégias, é importante definir, com a maior clareza possível, quais as expectativas com relação aos objetivos organizacionais. $\mathrm{O}$ processo de fixação de objetivos tem, como desafio, enfrentar e superar o delineamento da ação estratégica.

Existem várias maneiras de formular os objetivos organizacionais: alvos financeiros, visões, intenções, missões, aspirações ou metas. Independentemente do conteúdo ou forma do objetivo, os gestores de estratégia devem procurar criar uma estrutura que facilite tais definições, considerando as restrições estratégicas. 


\subsection{DECISÕES ESTRATÉGICAS EM OPERAÇÕES DE SERVIÇOS}

Em termos de operações de serviços, a vantagem competitiva de longo prazo depende da qualidade do projeto do serviço e de seu processo de fornecimento. A estratégia de operações é uma ferramenta cujo objetivo principal é o aumento da competitividade da organização e, para tal, busca organizar os recursos da empresa conforme o padrão de decisões, para que possam prover um composto adequado de características de desempenho que possibilite à organização competir eficazmente no futuro.

O conteúdo de uma estratégia de operações constitui-se de objetivos e áreas de decisão. Os objetivos são definidos por critérios que permitam à organização competir no mercado: um determinado nicho que se esteja visando pode valorizar, por exemplo, a consistência na prestação de serviços; outro nicho pode valorizar mais a velocidade de atendimento. A partir daí, conclui-se que consistência e velocidade são exemplos de objetivos de uma estratégia de operações de serviços.

O processo estratégico das operações pode ser visto, então, como o processo implícito de ligação entre os objetivos e as áreas de decisão. Gianesi \& Correa (1994), sugerem que é possível identificar este processo por meio de uma adaptação, apresentada na Figura 2, onde são analisados os objetivos das operações, as áreas de decisão de um sistema de serviço e o processo de formulação das estratégias de operações.

Figura 2 - Modelo do processo de desenvolvimento da estratégia de operações de serviços.

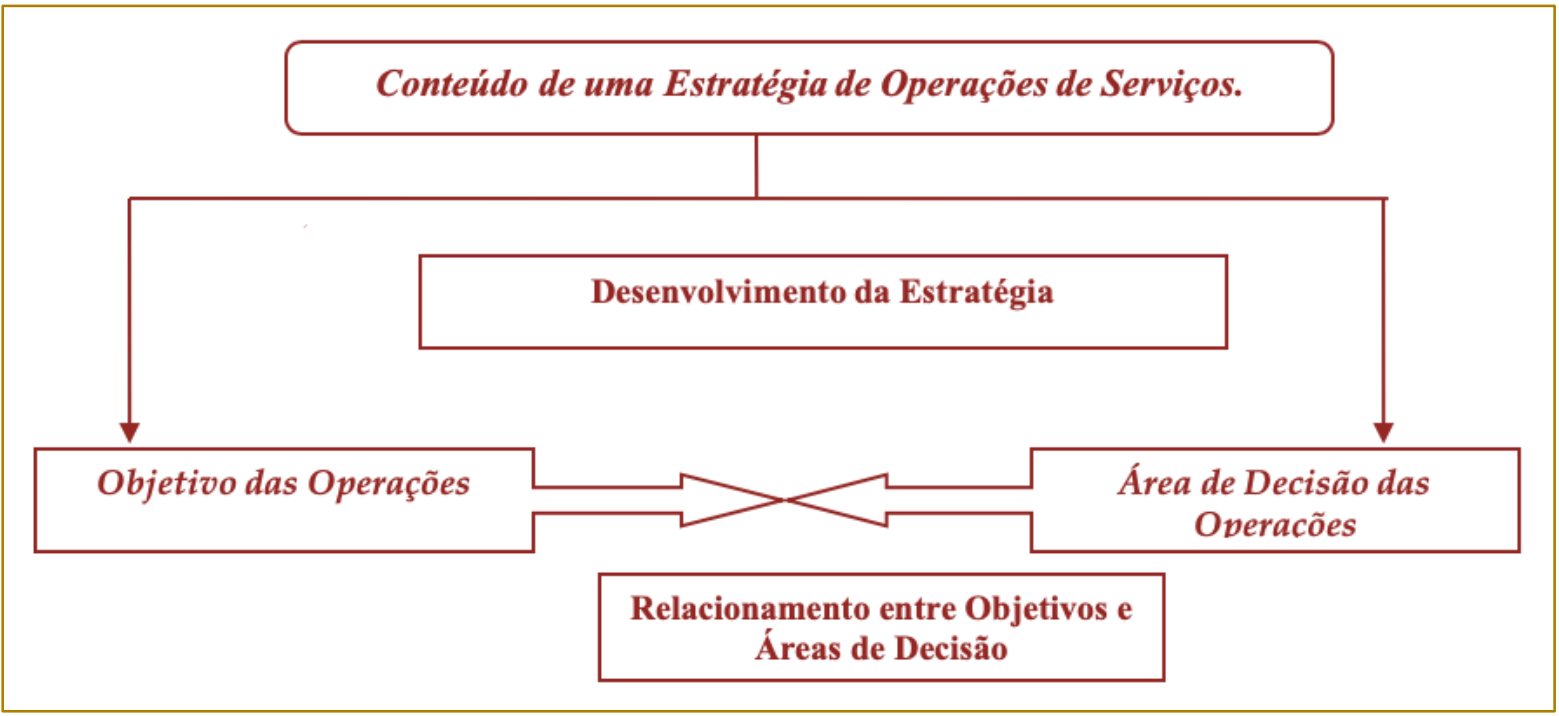

Adaptado de Gianesi e Correa (1994, p.102).

Embora se pretenda que este conjunto de critérios tenha caráter geral, não se quer dizer que todos os critérios competitivos tenham a mesma importância. Gianesi \& Correa (1994) argumentam que a importância relativa, dada a cada critério competitivo, deve variar de acordo com as prioridades colocadas pelos consumidores do segmento de mercado.

Os objetivos da estratégia de operações referem-se aos critérios competitivos. Estes podem ser estabelecidos e priorizados pelas necessidades e/ou expectativas do mercado, no qual o sistema de operações deve atingir excelência. Esses, devem refletir os fatores que determinam a satisfação do cliente, ou seja, qualidade do projeto e do fornecimento do serviço.

Um importante objetivo da determinação dos critérios competitivos, segundo Gianesi \& Correa (1994), é o de facilitar a comunicação entre as áreas de marketing e de operações, integrando estas funções de modo a permitir que os objetivos estratégicos de uma empresa sejam atingidos. A partir da definição dos critérios que priorizam a forma como a empresa conquista clientes em um determinado segmento de mercado, a área de operações pode estabelecer seus objetivos e detectar em que aspectos focalizar sua competência. Ao mesmo tempo, 
permite identificar como as competências, atuais e futuras, do sistema de operações, podem influenciar a estratégia, no sentido de explorá-las ao máximo, transformando-as em armas competitivas.

Gianesi \& Correa (1994), abordam que uma estratégia de operações pode ser caracterizada como um padrão coerente de decisões que afetam a habilidade da empresa para obter vantagem competitiva sustentada no longo prazo. Dada a complexidade da função de operações, é conveniente classificar estas decisões em áreas de decisão estratégicas. Estas áreas caracterizam famílias de problemas afins, com os quais os gerentes de operações têm de se preocupar, pois elas exercem influência na competência do sistema de operações, quanto aos critérios de desempenho que se deseja priorizar. Representam, portanto, uma lista de verificação para se analisar e tentar conformar este padrão coerente de decisões, que é, em termos práticos, a estratégia de operações em si mesma.

Cada uma das áreas de decisão apresentada deve ser considerada quando da formulação da estratégia de operações. Desse modo, pode-se facilitar o processo de difusão e desagregação da estratégia até o nível de cada função do sistema, analisando quais critérios de desempenho devem ser estabelecidos para cada uma delas. Sua contribuição para que seja possível atingir os objetivos do sistema como um todo estará garantida.

A formulação da estratégia necessita de um processo lógico, procedimental e prático, para que as tarefas possam se tornar sistemáticas, permitindo formulações que tenham condições de garantir o poder de competitividade. A definição da missão do serviço, na formulação estratégica, também depende de se eleger qual segmento de mercado pretende atuar, bem como a forma como a empresa deseja posicionar-se diante de seus concorrentes e consumidores. Portanto, a definição da missão ou conceito do serviço é subordinada à estratégia competitiva (PORTER, 1980).

A implementação da estratégia irá alterar o desempenho da empresa, que, juntamente com as mudanças no desempenho da concorrência, irá justificar a necessidade de reformulação da estratégia, com uma certa freqüência no tempo.

\subsection{GESTÃO BANCÁRIA}

O processo de Administrar dinheiro é uma atividade sensível, onde o funcionamento aceita muito pouco descontrole em seu gerenciamento. Uma instituição financeira vive de avaliar e assumir riscos, tendo forte responsabilidade perante a comunidade, governo e acionistas. Isto faz com que sejam estabelecidas técnicas e responsabilidades próprias para o desenvolvimento da atividade bancária. Como a atividade bancária trabalha diretamente com a avaliação de riscos, qualquer banco, para atuar no mercado financeiro brasileiro, deve manter um nível de recursos próprios, com relação ao volume de recursos de terceiros, tomando como base o patrimônio líquido e ativo total. Para isso, as autoridades monetárias passaram a seguir regras estabelecidas pelo acordo da Basiléia, comitê formado por representantes do chamado Grupo dos Dez Países (G-10), ou seja, Alemanha, Bélgica, Canadá, Estados Unidos, França, Holanda, Itália, Japão, Reino Unido e Suécia. Esse comitê desenvolveu na cidade de Basiléia (Suíça) um estudo visando assegurar a convergência das normas relativas aos Bancos, em todo o mercado financeiro internacional. Esses trabalhos tiveram dois objetivos fundamentais:

- Reforçar a solidez e estabilidade do sistema financeiro internacional;

- Definir uma estrutura com consistência quanto a sua aplicabilidade em bancos de diferentes países, visando diminuir a desigualdade competitiva.

Marshall (2002) cita as principais ferramentas que dão suporte a esses procedimentos:

Eficiência: tornar o mais eficiente possível o processo de entrega de serviços consistindo em marketing, vendas, processamento de transações, liquidação e contabilização;

Gestão de mudanças: gerenciar e facilitar mudanças flexíveis e eficazes em termos de custo para melhorar o processo de entrega de serviços;

Controle interno: agir com controle independente das ações dos iniciadores de serviços (a linha de frente) e de vários aspectos do processo operacional.

Esses objetivos são diretamente relacionados a impulsionadores de valor nos negócios tais como capital, margem operacional, coeficientes de custo-receita e capital de risco. 


\subsection{OPERAÇÕES EM BANCOS}

Os bancos que atuam no mercado brasileiro dispõem de muitas regulamentações que devem ser observados na contratação de operações e na prestação de serviços oferecidos aos clientes. Esses procedimentos são estabelecidos pelo Banco Central do Brasil e são divulgados por intermédio de Resoluções, Circulares e Cartas Circulares.

Para auxiliar o entendimento de alguns desses procedimentos, esta relacionada, uma síntese de conceitos contemplados na Resolução no 2.878 de 26 de Julho de 1991, que tem como objetivo regulamentar a contratação de operações e serviços no mercado brasileiro, assegurando os seguintes pontos:

- Usar de transparência nas relações contratuais, mediante prévio e integral conhecimento das cláusulas contratuais, evidenciando os dispositivos de responsabilidades e penalidades.

- Responder prontamente a dúvidas relativas aos serviços prestados e/ou oferecidos, bem como as operações contratadas, ou decorrentes de publicidade transmitida por meio de quaisquer veículos institucionais de divulgação;

- Efetivar prevenção e reparação de danos patrimoniais e morais causados a clientes e usuários;

- Obrigar as instituições financeiras a dar cumprimento a toda informação ou publicidade que veicularem, por qualquer forma ou meio de comunicação, referente a contatos, operações e serviços oferecidos ou prestados, que devem constar do contrato que vier a ser celebrado;

- Responsabilizar as instituições, sempre que necessário, pela comprovação da veracidade e da exatidão da informação divulgada ou da publicidade por elas patrocinada;

- Considerar a prestação de serviços por meios alternativos como prerrogativa das instituições financeiras, cabendo-lhes adotar as medidas que preservem a integridade, a confiabilidade, a segurança e o sigilo das transações, assim como a legitimidade dos serviços prestados.

Assim, é responsabilidade do Banco Central do Brasil, baixar normas e adotar medidas julgadas necessárias às situações decorrentes do relacionamento entre as instituições financeiras e clientes (pessoa física e jurídica).

Plano de ação operacional em bancos está relacionado à elaboração de um plano de negócios que compreenda o gerenciamento dos ativos e passivos, envolvendo, ainda, a criação ou geração de valores e políticas de gerenciamento de capital de uma instituição financeira. Segundo Handorf (2003), os planos de ação devem conter objetivos e formas de serem alcançados e para isso devem conter:

- Estabelecimento da missão - qual o propósito do banco e seu foco de atuação;

- Definição sobre o que se pretende alcançar - quais os produtos deverão ser atacados individualmente;

- Metas - resultados prioritários de curto, médio e longo prazo, de que forma serão eles atingidos e como assegurar o desenvolvimento da instituição;

- Objetivos - estabelecer resultados a serem obtidos conforme sejam alcançadas as metas;

- Medidas de desempenho adequadas para que se obtenha uma análise objetiva dos resultados.

Outro ponto abordado por Handorf (2003), é a grande dificuldade para se planejar estratégia no mercado financeiro brasileiro que se deve ao fato da taxa de juros ser volátil. Isto afeta, diretamente, o plano de desenvolvimento de infra-estrutura e confiança na concessão de linhas de crédito.

\section{METODOLOGIA}

Para definição das etapas da pesquisa foram utilizadas as medidas sugeridas por Yin (2003), dentre elas é possível destacar os conceitos para a elaboração de entrevistas, material para a formatação do protocolo e definição de tópicos para que seja possível estruturar fontes de apoio durante 0 desenvolvimento e condução das pesquisas realizadas.

Após a definição do protocolo de entrevistas o desenvolvimento da pesquisa foi estruturado com a identificação e delimitação das 
instituições financeiras de acordo com os seguintes critérios:

- Bancos privados e múltiplos classificados como de médio porte;

- $\quad$ Atuação em todo o mercado bancário brasileiro, não havendo objeção quanto à possibilidade de atuação em outros mercados ou número mínimo de agências;

- Foco de atuação no segmento de Mercado de pessoa jurídica;

- Os bancos, mesmo os que possuem participação estrangeira, deveriam ter seu corpo diretivo ou centralização dos processos de decisão na região sudeste do Brasil ;

- Ter como um de seus objetivos a melhoria de desempenho na conquista do mercado alvo e;

- Ter passado por processo de incorporação ou aquisição sem que tivesse apresentado prejuízo contábil nos resultados de exercícios anteriores.

Os profissionais entrevistados preenchem às seguintes características:

- Currículo profissional com comprovada experiência na gestão de departamentos ou unidades de operações ou negócios em instituições financeiras do mercado brasileiro;

- Participação nos processos de tomada de decisão operacional ou estratégica em Bancos Múltiplos;

- Mínimo de dez anos de experiência no mercado financeiro brasileiro;

- Trabalharam em bancos que passaram por processos de fusão ou aquisição dentro do período pesquisado;

- Conhecimento da estrutura organizacional das instituições em que trabalhavam, com noção da contextualização histórica da instituição financeira pesquisada; e

- Estar exercendo atualmente alguma função no mercado financeiro brasileiro, não sendo obrigatório estar trabalhando em algum banco ou na instituição foco da pesquisa.

As entrevistas tiveram como objetivo fazer com que os entrevistados passassem informações relevantes a respeito da estrutura organizacional e os conceitos relativos à administração dos procedimentos operacionais bancários.
A pesquisa foi realizada em duas etapas. A primeira levou a um levantamento de dados, que envolveu um trabalho de classificação dos bancos, identificação das legislações do Banco Central do Brasil sobre o tema proposto e definição dos critérios de segmentação bancária, onde procurou-se identificar a existência de algum tipo de similaridade entre os processos de prestação de serviços adotados pelas instituições pesquisadas.

$\mathrm{Na}$ segunda, foi desenvolvido um protocolo para entrevista, com o objetivo de conseguir dados e informações necessárias, para comprovar as similaridades entre as instituições financeiras pesquisadas. $\mathrm{O}$ protocolo foi elaborado tendo em vista:

- O processo e estrutura organizacional e encontrar fatores;

- As formas e critérios de gerenciamento dos fluxos de processos operacionais;

- Os eventuais pontos de similaridade ou diferenças entre os processos;

O protocolo de entrevistas também teve como objetivo estabelecer um instrumento, que pudesse conter procedimentos e regras gerais para serem seguidas. Segundo YIN (2003), considera-se isto uma ferramenta de extrema importância para o desenvolvimento de um projeto de casos múltiplos. A preocupação com a elaboração de um protocolo adequado aos propósitos da pesquisa é considerada uma das principais táticas para que se possa aumentar a confiabilidade do estudo de caso e tem um papel muito importante na orientação do pesquisador na condução das entrevistas com o público alvo.

Após a entrevista, foi realizado um fichamento das informações coletadas com o propósito de comparar dados e depoimentos e identificar pontos de similaridade com objetivo do trabalho desenvolvido. Durante o desenvolvimento das entrevistas foi utilizado um roteiro de perguntas semi-estruturadas, para que houvesse possibilidade de realizar complementações das perguntas.

Todas informações foram armazenadas e compiladas por similaridade de objetivos, gerenciamento de processos, critérios de decisão operacional e Gestão Bancária. Após a apuração dos dados foi feita uma análise comparativa com as informações conseguidas na primeira etapa da pesquisa, 
com o objetivo de identificar pontos de similaridade entre as instituições que pudessem contribuir para identificação de resultados e considerações finais.

Foram identificadas cinco instituições financeiras privadas que passaram por processo de incorporação. Todas foram contatadas, mas três se disponibilizaram a participar do estudo.

\section{ANÁLISE DE RESULTADOS}

Foram pesquisadas instituições financeiras, aqui tratadas como Banco Gama, Beta e Ômega. Durante a apuração dos dados foram identificados três grandes blocos: Serviços e Processos, Estratégia Operacional e Critérios estratégicos, Gestão Bancária que permitiram a realização das considerações finais.

\subsection{SERVIÇOS E PROCESSOS}

Este tópico tem como meta relatar as informações registradas sobre Serviços e Processos cujo foco estava em obter, dos entrevistados, informações sobre a estrutura organizacional, processos de implantação dos serviços e ferramenta possível de avaliar a qualidade dos serviços prestados pelas instituições pesquisadas.

O Entrevistado SEIS, com o cargo de Gerente Regional, responsável pelo planejamento operacional e assessoria da diretoria executiva do Banco Gama, informou que a instituição apresentava uma estrutura organizacional que facilitava os processos e sistemas operacionais do Banco. O Entrevistado CINCO, com o cargo de Gerente Administrativo e Operacional da Área Internacional do mesmo banco, informou que a instituição apresentava agilidade em seu processo de tomada de decisão confirmando as informações do Entrevistado SEIS. Ambos os entrevistados do Banco Gama confirmaram a existência de uma estrutura familiar e respeito à hierarquia, apesar de existir efetiva participação da diretoria executiva no processo de decisão. Com relação ao processo de implantação de serviços, ambos informaram que a instituição apresentava uma preocupação com a eficiência e capacitação dos funcionários aos processos de atendimento. Informaram que o Banco Gama buscava apresentar ferramentas adequadas para atendimento aos clientes e prestação de serviços.
Os protocolos de entrevista também identificaram a preocupação em estabelecer ligação com segmentos específicos, principalmente no atendimento de pessoas jurídicas, considerando, em ambos os casos, que o serviço prestado pelo banco era de boa qualidade. Os entrevistados informaram que o Banco Gama tinha como procedimento desenvolver ferramentas e sistemas de informação para diminuir os trabalhos burocráticos, melhorando assim as condições de prestação de serviços que pudessem atender necessidades específicas de cada segmento.

Por intermédio dos protocolos de entrevista, também foi possível observar que o sistema desenvolvido pelo Banco Gama permitia medir parâmetros de qualidade da prestação de serviços, com possibilidade de atender às necessidades dos clientes. Os entrevistados apresentaram esta ferramenta como um diferencial em relação ao mercado, sendo adequadamente utilizada em serviços para o banco incorporador.

Com relação às informações do Entrevistado QUATRO, com o cargo de Gerente de Produtos e Expansão de negócios no Banco Ômega, também foi possível observar que a estrutura da instituição era simplificada, permitindo que os processos de decisão fossem considerados eficientes, apesar de considerá-la um pouco burocrática (o conceito burocrático, conforme opinião do entrevistado, significa que a filial brasileira tinha de seguir determinados processos de uniformização estabelecidos pela matriz que não agregavam valor aos resultados). Já o Entrevistado UM, com o cargo de Superintendente de Produtos Estruturados da mesma instituição, informa que a estrutura seguia um modelo de gestão global que respeitava muito a hierarquia, apesar de não existir um centralizador de decisões. Considerava o modelo, na teoria, muito bom, mas, na prática, necessitava de adequações. Ambos confirmaram a existência de um modelo de gestão, implantado para atender às necessidades e demandas do mercado bancário brasileiro. O Entrevistado UM informou que houve demora em implantar o modelo de gestão, por esse motivo houve alguns problemas de assimilação e, automaticamente, a necessidade de promover pequenos ajustes para adaptá-lo ao mercado. O entrevistado QUATRO, não forneceu detalhes sobre este ponto. 
Houve um consenso entre os entrevistados, quanto ao modelo de gestão utilizado pelo Banco Ômega, pois identificou-se que a instituição buscava uma melhora de qualidade na prestação de serviços, bem como, um diferencial em relação aos serviços da concorrência que pudesse facilmente ser identificado pelos clientes. Os

entrevistados informaram que o Banco Omega procurava estabelecer suporte tecnológico e equipamentos adequados para que os serviços pudessem ser evidenciados. Segundo os entrevistados, o banco tinha preocupação efetiva com a formação e capacitação dos funcionários, principalmente para adequá-los ao modelo de gestão proposto. Os entrevistados também informaram que foram desenvolvidas plataformas de atendimento, focadas nas necessidades de pessoa jurídica, o que exigiu o preparo de equipes, visando a este nicho de mercado. Em ambos, as plataformas de atendimento foram consideradas um diferencial na prestação de serviços.

O Entrevistado TRÊS, com o cargo de Diretor Adjunto da Região Sudeste do Banco Beta, esclareceu-se que a instituição apresentava uma estrutura organizacional centralizada e obedecia a uma hierarquia muito rígida. Não obstante, os processos de decisão não eram demorados, segundo o entrevistado. Esta cultura acompanhou o banco desde sua fundação até sua venda. Sendo considerado, segundo o entrevistado, durante toda sua existência, uma empresa de 'dono'. O Entrevistado DOIS, com o cargo de Gerente Regional do setor de desenvolvimento de negócios do Banco Beta, não defende a mesma opinião. Informou que a estrutura muito centralizada dificultava o processo de tomada de decisão e o fluxo operacional. Apesar da divergência com relação ao processo de tomada de decisão, ambos concordaram que os serviços prestados pelo banco eram considerados de boa qualidade pelos clientes.

Questionados, sobre a existência de uma ferramenta capaz de ajudar na avaliação da prestação dos serviços ou processos utilizados pela instituição, ambos informaram que o Banco não possuía esse tipo de instrumento. Quando questionados sobre como conseguiam identificar o nível de satisfação dos clientes em relação aos serviços prestados, informaram que o banco tinha como procedimento manter contato freqüente com os clientes, feito pelos próprios funcionários, que identificavam como o serviço poderia ser melhorado. O Banco Beta, por intermédio dos protocolos realizados, informou que havia uma aposta muito grande na tradição e eficiência em determinados serviços e produtos, como também, na competência para praticar preços competitivos em relação aos concorrentes diretos no mercado.

Com relação à implantação de processos para realização dos serviços, também não houve consenso entre os entrevistados. O Entrevistado TRÊS informou que o banco procurava direcionar seus esforços para determinados nichos de mercado. Já o Entrevistado DOIS informou que não existia segmentação implantada, mas o projeto estava em andamento.

Outro ponto passível de ser identificado durante as entrevistas, foi que a instituição, apesar de não apresentar uma estrutura de segmentação, trabalhava realmente com seus esforços direcionados para determinados nichos de mercado, alterando-os de acordo com os movimentos do mercado. Os entrevistados manifestaram a mesma opinião quando foram questionados a respeito dos sistemas e tecnologia utilizada pela instituição. Ambos informaram que o Banco Beta não desenvolvia seus próprios sistemas. Quando necessário, buscava no mercado produtos já desenvolvidos que pudessem atender suas demandas e necessidades. O Entrevistado DOIS informou que as aquisições eram realizadas não por uma questão de preço e sim por falta de um corpo funcional qualificado, para desenvolver determinados sistemas.

Ambos informaram que o banco possuía um sistema de informação consolidado, apesar de apresentar dificuldades com relação à agilidade e adequação de linguagem dos sistemas. Com relação ao diferencial de mercado, os entrevistados informaram que a instituição era caracterizada pelo serviço especializado e competitividade em preço.

\subsubsection{ANÁLISE COMPARATIVA DE SERVIÇOS E PROCESSOS}

Procurando identificar pontos em comum para consolidar as informações recebidas sobre serviços e processos utilizados nas instituições pesquisadas, foi possível identificar que as instituições Omega e Gama desenvolviam objetivos similares em relação 
ao processo de capacitação tecnológica, e formação profissional.

Ambas instituições apresentaram uma preocupação com a adequação dos sistemas do banco com as necessidades de seu público alvo, procurando adaptar ou desenvolver sistemas de acordo com as demandas de mercado, demonstrando também uma preocupação com a avaliação da qualidade dos serviços prestados. Enquanto que o Banco Beta apresentou uma preocupação maior com resultados e uma concentração de esforços em produtos específicos que possibilitassem à instituição um determinado reconhecimento no mercado.

Os depoimentos registrados confirmam a contribuição teórica de Zeithami, Parasuraman e Berry (1990) que defende a necessidade de compreender a importância do fornecimento dos serviços, desenvolvendo um processo contínuo de monitoramento das percepções dos clientes sobre a qualidade, identificando as causas das discrepâncias e adotando alternativas adequadas para realização dos processos de melhoria contínua.

Foi possível observar que todas as instituições pesquisadas direcionavam seus esforços para segmentos específicos do mercado. As instituições Omega e Gama já estavam estruturadas para este tipo de atendimento, já a instituição Beta, não apresentava uma estrutura claramente definida, mas sua forma de atuar caracterizava uma evidente preocupação com determinados nichos de mercado. Estes pontos vão de encontro às considerações de Soares e Correa (1994) que observam a necessidade de estabelecer classificação para os serviços, para que seja possível obter de forma adequada resultados esperados.

Com relação à estrutura organizacional, todas as instituições pesquisadas independentemente da composição acionária, apresentaram um mesmo ponto em comum, ou seja, uma evidente preocupação com o respeito hierárquico organizacional.

\subsection{ESTRATÉGIA OPERACIONAL E CRITÉRIOS ESTRATÉGICOS}

Este tópico procura relatar as informações registradas sobre Estratégias Operacionais e Critérios Estratégicos, cujo foco está em obter dos entrevistados, informações sobre conceitos e política de aplicação de estratégias voltadas para atuação de produtos e serviços ou algum segmento de mercado específico, objeto de estratégia operacional.

As informações do Banco Gama, representadas no Entrevistado SEIS, informam que as bases das estratégias estavam direcionadas para a segmentação de mercado com foco principal nas chamadas plataformas de "Middle Market". Segundo o entrevistado, o banco considerava que o desenvolvimento de produtos focados em um segmento específico de mercado poderia melhorar consideravelmente a atuação do Banco em relação à concorrência.

Durante os depoimentos foi possível observar que o Banco Gama utilizava também um modelo de gestão como base para aplicação dos processos, amparando-se em manuais de procedimentos e definição de responsabilidades. O Entrevistado CINCO chegou a mencionar a utilização de uma empresa de consultoria externa para ajudar na definição dos objetivos e colaborar com a implantação, de forma adequada, de um segmento, considerado pela instituição, de grande potencial de exploração.

Os dois protocolos do Banco Gama demonstraram que a instituição realizava vários procedimentos para a execução das estratégias, apresentando uma preocupação com a identificação e o envolvimento do corpo funcional com o processo de implantação das atividades. Sendo mencionado durante $\mathrm{o}$ depoimento do Entrevistado CINCO, a existência de uma equipe de trabalho responsável pelo acompanhamento das atividades e execução das estratégias.

O Banco Ômega apresentou estratégia operacional fortemente amparada em um modelo de gestão global. Os depoimentos mostraram que as estratégias tinham como objetivo estabelecer um trabalho específico para o segmento chamado 'Empresas'. Para o Entrevistado QUATRO, as estratégias procuravam estabelecer critérios rígidos de análise, sendo definido por intermédio de um plano estratégico anual com avaliações trimestrais e semestrais. Em sua opinião, este tipo de procedimento permitia um melhor acompanhamento das metas, e quando necessário, possibilitava intervenções rápidas e eficientes para evitar distorções nos objetivos. 
Os entrevistados confirmam a utilização de consultoria especializada para auxiliar a formalização das estratégias definidas pela instituição. No caso do Banco Ômega, foi identificada uma preocupação para adequar o modelo de gestão previamente estabelecido, às condições do mercado financeiro brasileiro. O Entrevistado UM procurou evidenciar que o Banco Ômega apresentava suas estratégias para todos os funcionários, de forma clara e bem definida. Em sua opinião o banco também demonstrava uma preocupação com o desempenho e capacitação funcional de toda sua equipe de trabalho. Os meios utilizados para divulgação de procedimentos utilizados pelo Banco Ômega foram considerados como eficientes, pelos entrevistados, embora burocráticos. Em alguns casos, não apresentavam muita clareza, causando certa confusão de entendimento junto à rede de agências.

A análise realizada nos protocolos do Banco Beta, não permitiu identificar a existência de um modelo de gestão para realização de estratégias, aplicado a um segmento específico de mercado. Foi possível observar é que as estratégias eram estabelecidas pela alta direção do banco, conforme as oportunidades de mercado, podendo ser modificadas de acordo com os índices de produtividade e avaliação dos serviços. Os dois entrevistados informaram que o Banco Beta não apresentava uma segmentação de mercado explícita, mas concordaram que o banco procurava trabalhar direcionado para determinados produtos ou oportunidades pontuais de mercado.

Durante os depoimentos, foi possível observar que a execução das estratégias era realizada de forma segmentada. O Banco Omega buscava identificar em quais dos produtos por ele oferecidos, pudesse colher melhores resultados. Para isto, desenvolveu uma área chamada de riscos, com o objetivo de fornecer parâmetros e suporte operacional para que a alta direção tivesse ferramentas capazes de ajudar na definição e estabelecimento de estratégias, de acordo com a necessidade de cada área da instituição.

Os protocolos do Banco Beta, não apresentaram um consenso com relação à divulgação dos procedimentos de estratégias. Isto porque, durante o depoimento do Entrevistado TRÊS foi observada a existência de um sistema capaz de divulgar material e suporte para execução das estratégias, bem como, acompanhamento e evolução das metas e objetivos. No depoimento do Entrevistado DOIS, foi recebida a informação de não haver nenhum instrumento formal para divulgação das estratégias. As diretrizes eram passadas de maneira informal pela diretoria, o que possibilitava uma freqüente alteração na forma de execução das estratégias. Não foi possível identificar qual dos dois depoimentos estava realmente mais consistente.

\subsubsection{ANÁLISE COMPARATIVA DE ESTRATÉGIA OPERACIONAL E CRITÉRIOS ESTRATÉGICOS}

Para identificar pontos em comum visando consolidar as informações recebidas sobre estratégias operacionais e critérios estratégicos aplicados nas instituições pesquisadas, foi possível identificar claramente que as instituições Gama e Omega apresentavam uma preocupação com a implantação de um modelo de gestão, capaz de estabelecer diretrizes e adequar o posicionamento destes bancos conforme a tendência do mercado e expectativa de exploração de potencialidade por eles identificados.

Não foi possível observar com os entrevistados do Banco Beta um modelo de gestão específico, mas podia ser caracterizado por sua eficiência em determinados produtos e oportunidades pontuais de mercado, mostrando com isso uma capacidade muito grande para atuar de forma direcionada e focada em determinados objetivos. Esses conceitos abordados pelos entrevistados contribuem com os estudos de Gonçalves Jr e Leitão (1996), que abordam a importância da modelagem dos sistemas de informação e sua contribuição para o apoio das decisões de natureza estratégica.

Com relação à avaliação das oportunidades de mercado, os protocolos dos bancos entrevistados mostraram a existência de departamentos específicos dentro das instituições, responsáveis por realizar pesquisas de mercado e identificar oportunidades que pudessem ser exploradas de forma eficiente. Os entrevistados informaram que estas áreas eram muito eficazes em suas atividades apresentando trabalhos de qualidade. Gianesi \& Correa (1994), também abordam que identificar as oportunidades de mercado colabora com os critérios competitivos. Lembram que a importância desses critérios pode variar de 
acordo com as prioridades identificadas em consumidores de um segmento de mercado.

Os entrevistados dos Bancos Gama e Omega apresentaram muita similaridade nos meios de divulgação e procedimento das estratégias. Foi possível observar que o modelo de gestão utilizado por estas instituições sugeria uma preocupação com a eficiência dos processos e comprometimento do corpo funcional com a execução das estratégias. Estes pontos também estão subordinados a conceitos de Estratégia Competitiva abordados por Porter (1980).

\subsection{GESTÃO BANCÁRIA}

Este tópico apresenta as informações relativas à Gestão Bancária, cujo foco estava em obter informações sobre conceitos de Gestão Bancária, política de controle sobre os riscos e prevenção contra fraudes e o grau de comprometimento dos funcionários com a instituição.

As informações do Banco Ômega sobre gestão bancária, através entrevistados UM e QUATRO, registram uma preocupação muito grande do Banco em estabelecer um controle de sistema de segurança de informação. Os entrevistados informaram a existência de uma área específica para responder pelos controles de risco e gerenciamento de processos, tendo a responsabilidade de acompanhar a consolidação e veracidade das informações registradas na instituição. Os controles foram classificados como adequados e os entrevistados entendiam que a instituição tinha uma preocupação com a diminuição de dispersão dos processos.

No tocante à competitividade, os entrevistados afirmaram que o Banco Omega acreditava muito na credibilidade e estabilidade que apresentava para o mercado financeiro. O banco acreditava em um modelo de gestão com padrão internacional, com plenas condições de ser implantado e assimilado pelo mercado brasileiro. Os protocolos também registraram que a instituição conseguia manter uma política de comprometimento e dedicação efetiva dos funcionários em relação aos objetivos da organização.

As informações sobre gestão bancária conseguidas sobre o Banco Gama, por meio do depoimento dos Entrevistados CINCO e SEIS, deixam claro que o Banco possuía um sistema de plataforma que possibilitava uma consolidação de dados, sendo possível gerenciar riscos e estabelecer controles de prevenção. O banco desenvolveu um sistema de classificação de risco de crédito para seus clientes, muito similar ao utilizado pelo próprio Banco Central, e segundo o Entrevistado SEIS, chegou a ser elogiado pelo próprio órgão fiscalizador.

Para os sistemas de informação do Banco Gama, os protocolos informaram que o banco apresentava uma preocupação com o fluxo das informações procurando facilitar os processos por intermédio de sistemas eletrônicos. Com relação à competitividade o Entrevistado CINCO não foi muito objetivo, apesar de confirmar a existência de comprometimento do corpo funcional com a organização, enquanto que entrevistado SEIS destacou a eficiência do Banco nas atividades operacionais e administrativas, principalmente em relação ao segmento-foco da pesquisa, e a existência de um alto índice de comprometimento das equipes de trabalho com a instituição.

As informações sobre gestão bancária do Banco Beta registraram a existência de uma área específica, responsável pelos controles de risco e gerenciamento de processos. Os protocolos também informaram que houve muito investimento, com o objetivo de fiscalizar as informações registradas na instituição, bem como, estabelecer prevenção contra riscos de lavagem de dinheiro. Os entrevistados informaram que os sistemas foram adquiridos junto a grandes bancos principalmente os que foram sugeridos pelo Banco Central.

Para o sistema de informação e gerenciamento de processos do Banco Beta, o Entrevistado DOIS não respondeu, alegando falta de informações suficientes, e o entrevistado TRÊS informou que não havia preocupação em estabelecer processos sofisticados, sendo realizado de forma burocrática e eficiente.

Com relação à competitividade, os protocolos do Banco Beta registraram informações como a busca na centralização de serviços; foco no atendimento personalizado de determinados serviços e produtos; política de pouca exposição ao risco, o que representava solidez para o mercado, segundo o entendimento do entrevistado. Com relação ao comprometimento do quadro funcional não foi efetivamente declarado, mas foi possível observar que o Banco contava com um alto 
índice de comprometimento de seu quadro de funcionários. Esta afirmação pode ser evidenciada, após o entrevistado declarar, que o percentual médio de tempo de serviço do quadro funcional da instituição era superior a dez anos, mostrando com isso pouca rotatividade e baixo índice de demissão em toda a instituição.

Foi possível identificar que os bancos pesquisados, disponibilizavam boa parte de seu orçamento anual, em torno de $40 \%$, para serem aplicados em sistemas de segurança e consolidação de informações. Principalmente no que se refere à exposição ao risco de crédito, mostraram muita preocupação com as políticas de crédito e risco estabelecidas pelo Banco Central e procuravam trabalhar em conformidade com as exigências do órgão regulador.

Com relação aos gerenciamentos de processos, os protocolos não apresentaram nenhum destaque em especial, até mesmo porque os entrevistados não mostraram a preocupação de mencionar detalhes específicos sobre as questões. Com relação à competitividade, o comprometimento do quadro funcional com os objetivos do banco foi um ponto importante.

\section{CONSIDERAÇÕES FINAIS}

Esta pesquisa teve como objetivo investigar os processos e critérios de avaliação utilizados, para tomada de decisão gerencial, em Bancos Comerciais Privados, que passaram por um processo de incorporação, devido à mudança de perfil do mercado financeiro brasileiro.

A pesquisa mostrou a preocupação com a conquista de nichos de mercado específicos, como identificado nos processos de segmentação ou estratégias de posicionamento, para exploração de determinados produtos ou serviços do mercado financeiro.

Os bancos demonstraram preocupação com o desenvolvimento de processos capazes de destacar, com eficiência, produtos e serviços prestados para seus clientes. Objetivavam a conquista de nichos específicos de mercado denominados de segmento Empresas, classificado como pessoa jurídica de médio porte.

Após a análise das entrevistas, foi possível mensurar que o processo de segmentação utilizado pelas instituições foi uma das principais estratégias utilizadas para que seu público alvo obtivesse uma melhor qualidade na prestação de serviços, e um diferencial de oferta de produtos oferecidos pelo mercado financeiro brasileiro. Esse processo, também possibilitou que os Bancos passassem a estabelecer fluxos operacionais específicos de atendimento, de acordo com a necessidade ou perfil de seus clientes.

Sendo assim, estes bancos estabeleceram dentro de seus objetivos a necessidade de desenvolver sistemas próprios que atendessem demandas específicas de seus clientes; procuraram investir na capacitação e formação profissional das equipes de trabalho; e buscaram um equilíbrio entre recursos disponibilizados e as habilidades e competências do corpo funcional em relação às necessidades do público alvo.

A conquista deste público específico e o atendimento diferenciado foram aspectos em comum identificados nos objetivos das instituições. Quanto aos processos e critérios de estratégia operacional, observou-se divergência em sua concepção. Os Bancos Gama e Ômega buscavam a implantação de um modelo de gestão, já o Banco Beta preocupou-se em explorar produtos específicos e determinadas oportunidades de negócios dentro do mercado bancário.

Essa diferença de estratégias é possível de ser explicada devido à estrutura organizacional das instituições. O corpo diretivo, tanto do Banco Gama quanto do Banco Ômega, apresentavam uma preocupação estratégica com a conquista de mercado e uma preocupação em estabelecer posicionamento de mercado conforme a tendência de seus clientes explorando potencialidades previamente identificadas.

Apesar de existir diferença entre as formas de implantação das estratégias, a análise de resultados evidenciou uma preocupação das instituições com a avaliação das oportunidades de mercado, eficiência dos processos e equipe de trabalho, com a qualidade na prestação dos serviços e reconhecimento do público alvo.

Conforme informações colhidas sobre gestão bancária, uma preocupação comum referia-se à política de controle de riscos e prevenção contra fraudes dentro das instituições. Os Bancos buscavam desenvolver, em seus sistemas, formas para obter segurança na consolidação das informações, 
principalmente em pontos referentes à exposição de risco de crédito e regras

\section{REFERÊNCIAS}

[1] ANSOFF, Igor $\mathrm{H}$, MCDONELL, Edward J. Implantando a Administração Estratégica. São Paulo: Atlas, 1993.

[2] FITZSIMMONS, James A., FITZSIMMONS, Mona J., Administração de Serviços. Porto Alegre: Bookman, 2002.

[3] GIANESI, L. G. N. e CORRÊA, H. L., Administração estratégica de serviços: operações para a satisfação do cliente, São Paulo: Atlas, 1994.

[4] GRONROOS, Christian, Marketing Gerenciamento e Serviços - A competição por Serviços na Hora da Verdade. Rio de Janeiro: Campus, 1993

[5] GUPTA, A K. Estratégia das Unidades de Negócios: Gerenciando um Único Negócio. In: FAHEY, L., RANDALL, R. M. Curso prático; estratégia. Rio de Janeiro: Campus, 1999. p.100125. estabelecidas pelo órgão regulador do sistema financeiro, o Banco Central do Brasil.

[6] HANDORF, William C. Business Plans and Bank Asset/liability Management Seminary. São Paulo: Bradesco, Novembro 2003.

[7] JOHNSTON, Robert; GRAHAM Clark. Administração de Operações e Serviços. São Paulo: Atlas, 2002.

[8] KOTLER, Philip, Princípios de Marketing, São Paulo: Santuário, 1993.

[9] PORTER, Michael. Estratégia Competitiva. Rio de Janeiro: Campus. 1980.

[10] PORTER, Michael E. Competição: Estratégicas Competitivas Essenciais. Rio de Janeiro: Campus, 2001.

[11] REED, Edward W. GILL, Edward k. Bancos Comerciais e Múltiplos. São Paulo: Makron Books, 1995.

[12] WRIGHT, P.; KROLL, M.; PARNELL, L. Administração Estratégica: Conceitos. São Paulo: Atlas,

2000. 


\section{Capítulo 3}

\section{A INFLUENNCIA DOS 4P'S NOS ÍNDICES DE EFICIENNCIA DE DMUS (DECISION MAKING UNITS)}

\section{Claudelino Martins Dias Junior}

Rodrigo Speckhahn Soares da Silva

\section{Ercules Costa}

\section{Letícia Cunico}

Gueibi Peres Souza

Resumo: Composto mercadológico ou 4P's (preço, praça, promoção e produto) é a forma pela qual as estratégias empresariais são operacionalizadas. Sendo os 4P's elementos de interferência no desempenho organizacional, tem-se em conta que esses elementos condicionam de UTD's/DMUs. Para tanto, o objetivo deste estudo é verificar o quanto as eficiências de empresas simuladas, tidas como DMUs guardam relação com suas decisões de investimentos nos elementos formadores do composto mercadológico. A DEA (Data Envelopment Analysis) é a metodologia utilizada para mensurar a eficiência de cada DMU, através de uma modelagem orientada a saídas (BCC - Banker, Charnes e Cooper), sendo estabelecidas como variáveis de entrada os 4P's e como variável de saída o Patrimônio Líquido de 5 (cinco) DMUs (empresas simuladas). Os resultados obtidos sugerem que existe um forte grau de correlação entre a evolução do patrimônio líquido e os investimentos nos 4P's, no entanto, maiores níveis eficiência não sugerem melhores desempenhos econômicos para as DMUs da amostra estudada.

Palavras chave: 4P's, eficiência, DEA, DMUs. 


\section{INTRODUÇÃO}

Tem-se por composto mercadológico ou 4P's (Preço, Praça, Promoção e Produto) a base dos estudos de Marketing (VAN WATERSCHOOT; VAN DEN BULTE, 1992). Mix de marketing é uma outra forma encontrada para denominá-los, sendo a partir desses elementos do composto que as estratégias organizacionais são operacionalizadas (OLIVEIRA; TOALDO, 2015).

O conceito de composto mercadológico tem origem nos estudos de Neil Borden da Universidade de Harvard nos anos 1940 e com as pesquisas de Jerome McCarthy da Universidade do Estado de Michigan nos anos 1950 quando se adotou a denominação 4 P's, os quais foram popularizados por Philip Kotler da Universidade de Northwestern nas últimas décadas (SCHULTZ; DEV, 2012).

Os 4P's ainda têm um impacto direto no processo de compra do consumidor e tendem a possibilitar que este vivencie a experiência que 0 produto pode the oferecer, considerando sua disponibilidade em canal de venda a um preço compatível e no período de entrega de acordo com a necessidade do consumidor afim de que uma compra se efetive (OLIVEIRA; TOALDO, 2015).

Cabe assim dizer que as decisões tomadas em relação ao composto mercadológico exercem influência no desempenho organizacional. Como exemplo, toma-se um cenário de atendimento a um consumidor formado por regiões geograficamente dispersas que obriga o desenvolvimento de diferentes canais de distribuição de produto. Para tanto, decisões assertivas relacionadas ao 4P's podem representar uma vantagem competitiva se bem gerenciadas, por outro lado, falhas na estratégia ou mesmo na composição dos elementos do composto mercadológico ocasionam prejuízos (KETCHEN; HULT, 2007).

A combinação estratégica dos 4P's junto ao entendimento do que é valor para o consumidor resultam boas decisões. Observa-se que o foco da SCM (Suply Chain Management - Gerenciamento da Cadeia de Suprimentos) está na eficiência e na questão da efetividade de entrega da oferta, enquanto que as estratégias de marketing se encarregam de prover a demanda pelos produtos. Dessa forma, as decisões integradas entre as estratégias de marketing e as decisões de gerenciamento dos suprimentos determinam a rentabilidade e o posicionamento competitivo da empresa (MADHANI, 2010).

Esse amplo processo de decisões é replicado por com o apoio da realidade virtual, através de um modelo de simulação atrelado à representação de uma realidade organizacional com a perspectiva de aproximação do comportamento de um sistema (mercado) (FORRESTER, 1968).

Tal sistema é capaz de revelar conexões entre as causas e os efeitos de determinada decisão organizacional e também possibilita entender processos e operações dentro e fora da organização, verificar gargalos, otimizar atividades, obter maior controle de estoque, armazenamento, programação da produção e avaliação dos resultados gerenciais (GOMES; KLIEMANN NETO, 2015).

Nesse sentido, partindo-se de um exercício simulado, onde o conjunto de decisões sobre os elementos do composto mercadológico condicionam a execução das estratégias de um dado grupo de empresas, tem a seguinte pergunta de pesquisa: qual o grau de relacionamento entre os índices de eficiência de UTDs/DMUs analisadas com a gestão de seus compostos mercadológicos (4Ps)?

Consoante a pergunta de pesquisa, estabelecem-se alguns objetivos, quais sejam: estabelecer variáveis de entradas (insumos - inputs) e variáveis de saídas (resultados - outputs) entre diferentes UTDs/DMUs (empresas concorrentes); determinar o grau de relacionamento entre índices de eficiência e decisões de investimentos em marketing.

\section{REFERENCIAL TEÓRICO}

\subsection{COMPOSTO MERCADOLÓGICO}

O composto mercadológico influencia diretamente o comportamento de compra do consumidor. Não é a toa que os investimentos destinados a conquistar a atenção de clientes e consumidores representam um montante considerável no planejamento financeiro das organizações (ESTEVEZ; SUÁREZ, 2016). Algumas das variáveis do composto mercadológico merecem destaque, segundo a lista de E. J. Carthy são os 4P's do marketing.

Em destaque, o produto é a expressão da organização diante da demanda percebida no mercado, a concretização de um serviço, de 
uma experiência de compra. Ele é formado por determinados componentes, dentre eles os funcionais (composição, forma etc), corporativos (nome, preço e marca), componentes de imagem (o significado do produto na mente do consumidor) e os componentes de comunicação (informações enviadas ao consumidor) (C. G. NIT Ă apud GHERASIM, 2011).

O consumidor adquire o produto em função da sua utilidade. É ela responsável por gerar a satisfação após o consumo, toma-se como exemplo: a aquisição de um veículo que cumpre a utilidade de transporte com conforto. Pode-se destacar essas funções como: funções básicas, com correspondência direta ao atendimento da necessidade do consumidor e funções auxiliares que dizem respeito a um ou mais requisito(s) extra ofertado(s), como um melhor conforto, design diferenciado ou mais velocidade (GHERASIM, 2011).

O preço é o elemento do composto mercadológico que gera receita à organização. Tem como característica mais importante a sua flexibilidade, quando comparado a outros elementos como as características presentes no produto e seu processo de distribuição (KOTLER, 2000). Ainda para Kotler (2000) vários fatores são considerados na formação do preço como: análise de custo; demanda do produto; qualidade; concorrência e posicionamento da sua oferta no mercado. Pode estar relacionado inclusive com a percepção de valor do cliente, onde a empresa pode utilizarse da propaganda e da força de vendas na tentativa de elevar o valor percebido.

A distribuição ou praça relaciona-se a acessibilidade do consumo, ou seja, o canal que o cliente encontrará o produto influencia sua performance no mercado. Une-se a esse a importância de se construir uma comunicação eficaz, através da propaganda ou da promoção (KOTLER, 2000).

\subsection{DESEMPENHO ORGANIZACIONAL}

A sobrevivência e o sucesso da organizacional estão diretamente ligados à competitividade da cadeia de suprimento (SINGH; SHARMA, 2015). Para acompanhar a demanda de um mercado consumidor com características dinâmicas e com elevado grau de exigência, as organizações industriais precisam se adaptar à Agile Manugacturing
(AM) ou Manufatura Ágil (VINODH et al., 2013).

Para entender o resultado das operações realizadas por uma empresa, utiliza-se uma medida de performance, capaz de avaliar a eficiência e/ou eficácia de uma dada ação. Neste caso, a eficácia está relacionada à medida com que as metas são cumpridas e eficiência a medida de quão bem os recursos são gastos ou investidos. Quando se trata da perspectiva do negócio e do marketing, eficácia está relacionada a atender as necessidades e demandas do consumidor, enquanto eficiência é a medida de como, economicamente, a empresa está investindo seus recursos para prover esse nível de satisfação a seu cliente (OKONGWU et al., 2016).

Ademais, para que uma empresa de natureza industrial apresente êxito em seu desempenho é necessário traçar estratégias de diferenciação com o passar do tempo, que possibilitem a construção de vantagens competitivas relevantes e perceptíveis ao consumidor. Uma empresa diferencia-se da concorrência se puder ser singular em algo valioso, considerando que exista um ponto conhecido até o qual essa e os demais concorrentes consigam diferenciar-se (MONTGOMERY; PORTER, 1998).

Montgomery e Porter (1998) observam ainda que existem várias possibilidades para a diferenciação e essas podem ter origem em qualquer parte da cadeia de suprimento onde a empresa se encaixe. É necessário que ações de diferentes partes sejam trabalhadas em harmonia de forma a resultar um diferencial perceptível ao cliente (MONTGOMERY; PORTER, 1998).

A seguir apresentam-se os procedimentos metodológicos a fim de se estabelecer um ferramental capaz de mensurar o grau de relacionamento entre os elementos do composto mercadológico e os índices de eficiência relativa das UTDs/DMUs analisadas.

\section{PROCEDIMENTOS METODOLÓGICOS}

Quanto ao método, essa pesquisa orienta-se por um método dedutivo, qual seja o de testar a existência de uma relação entre as variáveis selecionadas em um dado ambiente (SAUNDERS; LEWIS; THORNHILL, 2009). A pesquisa dedutiva se desenvolve a partir de testes, levantando-se a hipótese baseada em 
uma teoria, ao passo que se expressa tal hipótese em termos mensuráveis, e a partir disso os resultados são examinados. Após a obtenção e a análise dos resultados reafirmase o postulado teórico ou o altera, sugerindose um retorno à etapa inicial do processo.

Decidiu-se por uma abordagem qualiquantitativa. Quanto à parte qualitativa, esta prende-se à interpretação dos resultados à luz do referencial teórico utilizado. A parte quantitativa refere-se à análise estatística efetivada por meio da utilização da Análise Envoltória de Dados (DEA), que consiste uma técnica de mensuração da eficiência relativa entre unidades tomadoras de decisão (DMUs), de acordo com Giacomello e Oliveira (2014). Como estratégia de pesquisa é utilizado um estudo de caso (exercício simulado de gestão), tomando-se como objeto de análise 5 (cinco) empresas simuladas do tipo industrial. Os dados foram obtidos a partir de decisões individuais de cada unidade fabril/comercializadora de produtos, correspondendo a 12 (doze) períodos trimestrais de atividades ou 3 (três) anos de gestão.

Considerando-se que os dados foram obtidos do resultado de um exercício de simulação, a modelagem utilizada foi a DEA orientada a saídas ou BCC (Banker, Charnes e Cooper). A escolha pelo método BCC dá-se pelo fato de que, tanto quanto para as empresas industriais como empresas simuladas utilizadas no estudo, em algum momento, optam por se diferenciar, por meio de um conjunto de decisões que representem sua estratégia. Dessa forma não se mantêm com as dimensões inicialmente idênticas, considerando-se os dados simulados. Neste caso, a quantidade de inputs e outputs igualmente se diferenciam, conquanto que a opção por um determinado conjunto de decisões, criando oportunidades e restrições muito próprias, sugerindo desempenhos diferenciados pela capacidade de maximizarem suas saídas.

\subsection{A DEA}

A DEA é definida como uma nova forma de organização e análise de dados. Ela se utiliza do método de otimização de programação matemática, que permite avaliar comparativamente o desempenho produtivo de unidades semelhantes. É utilizada para estimar a eficiência do funcionamento de unidades produtivas homogêneas que utilizam um mesmo conjunto de recursos com o objetivo de produzir um mesmo conjunto de resultados. A DEA leva em consideração planos de operação tendo em conta entrada(s) e saída(s), permitindo criar um espaço onde possibilidades produtivas estarão delimitadas por uma fronteira de eficiência entre as unidades em estudo, de acordo com BELLONI (2000), CHARNES; COOPER; RHODES (1978), COOPER; SEIFORD; TONE (2007), KASSAI (2002).

Dyson et al. (2001) sugerem uma série cuidados que devem ser tomados nas aplicações práticas e na condução da análise dos resultados obtidos com a DEA. Dentre eles citam: homogeneidade, que afirma que as DMUs devem produzir produtos e serviços comparáveis entre si e possuam recursos similares à sua disposição; que as variáveis de input e output devem cobrir todos os recursos utilizados e atingir todos os níveis de atividades e medidas de desempenho; as variáveis devem ser comuns a todas as DMUs e, se necessário, incluir variáveis ambientais, e; a quantidade de variáveis de entrada e saída no modelo deve ser limitada, pois acarretam um nível de discriminação baixo.

\subsection{DEFINIÇÃO DAS VARIÁVEIS DE ENTRADA E SAÍDA}

O desempenho das empresas simuladas está sob a influência de alguns indicadores macroeconômicos e ações de cada uma das empresas concorrentes. Não obstante, são avaliadas positivamente as empresas com indicadores de resultado que demonstrem evolução de seu Patrimônio Líquido, aumento da Margem de Lucro Líquida, da Rentabilidade de Ativo e da Participação de Mercado (market share). De forma a se optar por variáveis de saída (outputs) que guardem relação com as variáveis de entrada (inputs), definidos como Preço, Praça, Produto e Promoção, opta-se, inicialmente, pelas saídas: Participação de Mercado; Dividendos distribuídos e Lucro Líquido obtidos em cada um dos trimestres, bem como a evolução patrimonial das empresas (Patrimônio Líquido) transcritos em $\quad 1$. 
Quadro 1 - Resumo das variáveis de entrada (inputs) e saída (outputs).

\begin{tabular}{|l|c|l|}
\multicolumn{2}{|c|}{ Variáveis de Entrada e Saída } & Classificação \\
\hline Preço de venda $(\mathrm{R} \$)$ & Input & Preço de venda total em Reais (\$) por período. \\
\hline Praça $(\mathrm{R} \$)$ & Input & $\begin{array}{l}\text { Valor total em reais gasto em distribuição (custos } \\
\text { logísticos) trimestrais. }\end{array}$ \\
\hline Produto (estrelas) & Input & $\begin{array}{l}\text { Qualidade dos produtos em quantidade de estrelas } \\
\text { obtidas. }\end{array}$ \\
\hline Promoção (unidades) & Input & Número de campanhas contratadas por cada DMU. \\
\hline Participação de Mercado (\%) & Output & Participação percentual de mercado. \\
\hline Dividendos (R\$) & Output & Remuneração dos acionistas. \\
\hline Lucro Líquido (R\$) & Output & Lucro auferidos em todos os períodos simulados. \\
\hline Patrimônio Líquido (R\$) & Output & Evolução patrimonial dos ativos. \\
\hline
\end{tabular}

De forma a se ter em conta a modelagem proposta DEA-BCC é necessário que as DMUs inputs e outputs sejam correspondentes. No entanto, observa-se que a partir do sétimo trimestre do exercício simulado as DMUs 02, 05 e 07 (empresas NewFace, High5 e ABMT) apresentaram dados nulos para o input "Praça", optou-se por retirar essas DMUs da análise. Paralelamente, para que a modelagem pudesse demonstrar as DMUs mais eficientes foi necessário se optar por output(s) mais representativos. Neste caso, considerando que 5 (cinco) apresentaram resultados nulos, em algum momento, em termos de distribuição de "Dividendos", retirou-se essa variável de saída da análise.

\section{DISCUSSÃO E ANÁLISE DOS RESULTADOS}

Para uma análise quantitativa dos dados obtidos das decisões das empresas simuladas, é necessário determinar qual é a força entre as variáveis dependentes e independentes. Desta forma, procede-se a análise de correlação entre inputs (variáveis de entrada) e outputs (variáveis de saída), cujos resultados encontram-se em Tabela 1.

Tabela 1 - Correlação das variáveis de entrada e saída.

\begin{tabular}{|c|c|c|c|c|c|c|c|}
\hline & $\begin{array}{l}\text { Preço } \\
\text { de } \\
\text { Venda }\end{array}$ & Praça & $\begin{array}{l}\text { Produto } \\
\text { Estrela }\end{array}$ & Promoção & $\begin{array}{l}\text { Lucro } \\
\text { Líqui } \\
\text { do }\end{array}$ & $\begin{array}{l}\text { Patrimônio } \\
\text { Líquido }\end{array}$ & $\begin{array}{l}\text { Participaç } \\
\text { ão de } \\
\text { Mercado }\end{array}$ \\
\hline Preço de Venda & 1,00 & & & & & & \\
\hline Praça & 0,92 & 1,00 & & & & & \\
\hline Produto Estrela & 0,93 & 0,93 & 1,00 & & & & \\
\hline Promoção & 0,92 & 0,93 & 0,97 & 1,00 & & & \\
\hline Lucro Líquido & 0,89 & 0,94 & 0,80 & 0,81 & 1,00 & & \\
\hline Patrimônio Líquido & 0,97 & 0,97 & 0,98 & 0,97 & 0,89 & 1,00 & \\
\hline Participação de Mercado & 0,91 & 0,83 & 0,95 & 0,93 & 0,69 & 0,91 & 1,00 \\
\hline
\end{tabular}

Fonte: Elaborado pelos autores.

Por conveniência, elegeu-se o output Patrimônio Líquido o único output a ser considerado na análise (ver APÊNDICE 2), por se tratar da variável de saída com os maiores coeficientes de correlação com as demais variáveis de entrada (ver Tabela 1).
As DMUs mais eficientes demonstradas pelo resultado DEA-BCC são aquelas que, com os inputs, apresentaram melhor resultado $(=1)$ em comparação às outras DMUs (ver Quadro 2). 
Quadro 2 - Eficiência Performance das DMUs.

\begin{tabular}{|c|c|c|c|c|c|}
\hline \multicolumn{7}{c|}{ Resultado DEA-BCC } \\
Período & 1 & 2 & 3 & 4 & 5 \\
\hline 1 & 1,000 & 1,000 & 1,000 & 1,000 & 1,000 \\
\hline 2 & 1,000 & 0,992 & 1,000 & 1,000 & 1,000 \\
\hline 3 & 1,000 & 0,958 & 1,000 & 1,000 & 0,994 \\
\hline 4 & 1,000 & 0,996 & 1,000 & 1,000 & 1,000 \\
\hline 5 & 1,000 & 1,000 & 1,000 & 0,949 & 1,000 \\
\hline 6 & 1,000 & 1,000 & 1,000 & 0,992 & 1,000 \\
\hline 7 & 1,000 & 1,000 & 1,000 & 1,000 & 0,990 \\
\hline 8 & 1,000 & 1,000 & 1,000 & 1,000 & 1,000 \\
\hline 9 & 1,000 & 1,000 & 1,000 & 1,000 & 1,000 \\
\hline 10 & 1,000 & 1,000 & 1,000 & 1,000 & 1,000 \\
\hline 11 & 1,000 & 0,855 & 1,000 & 1,000 & 1,000 \\
\hline 12 & 1,000 & 0,899 & 1,000 & 1,000 & 1,000 \\
\hline \multicolumn{7}{|c|}{ Fonte: Elaborado pelos autores. } \\
\hline
\end{tabular}

A DMU 1 (Becoratti) e a DMU 3 (Shenlong) apresentaram-se como eficientes em todos os períodos, o que não aconteceu com as com as DMUs 4 (CloudLinus), 5 (NewDo) e 2 (Alfafly), esta última com os menores níveis de eficiência relativa encontrados em $41 \%$ do período estudado. A técnica DEA-BCC não permite que se faça comparação entre períodos, portanto, não permite avaliar se os problemas enfrentados pelas DMU menos eficientes foram os mesmos. Por se tratar da comparação estática (período a período), o nível de eficiência apresentado por uma DMU em um período, por mais que seja inferior ao anterior, ou seja, nem sempre demonstra que sua situação piorou. Como uma análise nãoparamétrica onde as empresas não se mantém iguais em suas dimensões iniciais e existe uma variação constante entre inputs e outputs, o cenário para algumas delas pode melhorar em função de uma melhor gestão dos recursos, no entanto, em comparação a outras DMUs pode permanecer ineficiente.

Outra análise a ser realizada na relação das DMUs menos eficientes e seus benchmarks é demonstrada em Quadro 3 (período a período), evidenciando quais DMUs servem de referência para as demais.

Quadro 3 - Benchmarks das DMUs.

\begin{tabular}{|c|c|c|c|c|c|c|}
\hline \multicolumn{7}{|c|}{ Benchmarks (DMUs) } \\
\hline Períodos & DMU menos eficiente & 1 & 2 & 3 & 4 & 5 \\
\hline 1 & 0 & & & & & \\
\hline 2 & 2 & & & 1,000 & & \\
\hline \multirow{2}{*}{3} & 2 & 0,319 & & 0,681 & & \\
\hline & 5 & 0,635 & & & 0,365 & \\
\hline 4 & 2 & 0,488 & & 0,124 & 0,388 & \\
\hline 5 & 4 & 0,423 & & & & 0,577 \\
\hline 6 & 4 & 0,463 & 0,537 & & & \\
\hline 7 & 5 & & & & 1,000 & \\
\hline 8 & 0 & & & & & \\
\hline 9 & 0 & & & & & \\
\hline 10 & 0 & & & & & \\
\hline 11 & 2 & & & & 1,000 & \\
\hline 12 & 2 & 0,444 & & & 0,556 & \\
\hline
\end{tabular}

Fonte: Elaborado pelos autores.

Ao visualizar o Quadro 3, nota-se que a DMU4 (CloudLinus) foi a empresa que mais vezes se tornou benchmark (períodos 7 e 11). No entanto, percebe-se que a mesma DMU4 foi a empresa com menor eficiência em dois outros períodos, sendo esses o período 5 e 6 . A DMU2 (Alfafly), como anteriormente relatado, foi a empresa com os menores índices de 
eficiência observados, sendo a menos eficiente nos períodos 2, 3, 4, 11, 12. A DMU5 (NewDo) também aparece no rol das DMUs com menor eficiência (períodos 3 e 7) e a DMU1 foi a única empresa que não aparece como menos eficiente em todos os períodos analisados. Se faz importante ressaltar, uma vez mais, que a DEA não permite a análise dinâmica, só estática, neste caso, por período.

As DMUs 6 e 8 passaram a ser designadas na análise como DMUs 4 e 5. Paralelamente, a DMU2 (Alfafly), passou a ser designada como DMU3 em APÊNDICES 1 e 2 , aparecendo como a menos eficiente entre todas as demais. Com isto, percebe-se que não existe uma relação direta de dependência entre os índices de eficiência operacional observados e os elementos do composto mercadológico (4P's).

Não obstante, há que se considerar que o desempenho econômico das empresas não pode ser explicado somente tendo em conta os índices de eficiência, quiçá em função de não se ter em conta todas as variáveis de saída (outputs) inicialmente pretendidas, neste caso, o Lucro Líquido, os Dividendos e a Participação de Mercado. A demonstração de tal fato se dá pelos os índices de eficiência das DMUs 1 e 3 , sendo esses os melhores em relação as demais DMUs (ver Quadro 4) em todos os períodos e, em nenhum momento, as DMUs 1 e 3 tiveram seus conjuntos de decisões tidas como as menos ineficientes (ver Quadro 5) segundo a modelagem proposta. No entanto, a DMU1 (Becoratti) foi referência de indicador econômico dentro do exercício de simulação e a DMU3 (Shenlong) obteve somente $05^{\circ}$ desempenho nesse quesito.

\section{CONSIDERAÇÕES FINAIS E CONCLUSÕES}

Mesmo que se tenha em consideração os devidos cuidados sugeridos para a aplicação da metodologia DEA-BCC, deve se observar que a falta de homogeneidade do conjunto de dados a analisar exigem ajustes procedimentais severos em sua modelagem, de forma a se manter a integridade dos princípios metodológicos citados por Dyson et al. (2001). Desta forma, da opção metodológica pela DEA, encontrou-se dificuldade em se ter a disposição a integralidade dos dados necessários à modelagem preliminarmente concebida, o que não perseguição dos objetivos inicialmente propostos.

A partir da leitura do conceito de eficiência proposto por Okongwu et al. (2016) tem se que a eficiência operacional pode ser representada por uma medida de performance relacionada a melhor utilização possível dos recursos utilizados. Com a DEA foi possível estabelecer uma medida de eficiência para a DMUs (empresas), determinada pelo relacionamento (correlação) entre o conjunto de decisões de investimentos no composto mercadológico e a evolução patrimonial das empresas. No entanto, não se pode garantir que, maiores índices de eficiência repercutam melhor desempenho econômico dentro da amostra estudada, talvez pela representatividade de somente uma variável de saída "Patrimônio Líquido", dada a necessidade de adequação da modelagem aos dados disponíveis.

Dado que o enfoque do estudo é quantitativo, não se pode aferir o "como" cada DMU empregou seus recursos para potencializar o resultado econômico obtido na criação de valor para o cliente, essa análise seria eminentemente qualitativa, estando relacionada ao conceito de eficiência sob a perspectiva do negócio defendida por OKONGWU (2016). Para tanto, sugere-se uma análise de gestão de ativos em cada uma das DMUs e em cada período, de forma a trazer explicações mais precisas.

O objetivo de relacionar as variáveis de entrada e a variáveis de saída das DMUs estudadas foi alcançado com a aplicação da modelagem DEA-BCC, onde se estabelecem como inputs (Preço, Praça, Promoção e Produto) e como output a evolução patrimonial de cada uma das empresas.

Com o cálculo dos índices de eficiência com as decisões de investimentos nos 4P's foi dado em Tabela 1. Neste sentido, o objetivo de averiguar se os índices de eficiência das DMUs condicionam seus desempenhos econômicos foi alcançado, na medida em não é possível inferir que, das cinco DMUs tomadas na análise, os com maiores índices de eficiência remontem melhores desempenhos econômicos, bem como os menores índices de eficiência estejam atrelados a desempenhos econômicos inferiores.

As limitações do estudo giram em torno da adequação metodológica dada preliminarmente por uma abordagem 
quantitativa, onde estatisticamente não podem ser levados em consideração conjuntos de decisões das DMUs que contivessem dados nulos, ou seja, sem representatividade. Não obstante, mesmo que retirados de um conjunto de decisões tidas por seus gestores, os dados utilizados para análise, neste caso, as decisões de investimentos nos 4P's "inputs" e a evolução econômica do patrimônio líquido "outputs" se ajustaram a perspectiva metodológica e ao alcance dos objetivos inicialmente propostos.

\section{REFERÊNCIAS}

[1] BELLONI, J. A. Uma Metodologia de Avaliação da Eficiência Produtiva de Universidades Federais Brasileiras. [s.l.]. Universidade Federal de Santa Catarina, 2000.

[2] CHARNES, A.; COOPER, W. W.; RHODES, E. Measuring the efficiency of decision making units. European Journal of Operational Research, v. 2, n. 6, p. 429-444, nov. 1978.

[3] COOPER, W. W.; SEIFORD, L. M.; TONE, K. DATA ENVELOPMENT ANALYSIS A Comprehensive Text with Models, Applications, References and DEA-Solver Software. 2nd. ed. New York: Springer, 2007.

[4] DYSON, R. G. et al. Pitfalls and protocols in DEA. European Journal of Operational Research, v. 132, n. 2, p. 245-259, jul. 2001.

[5] ESTEVEZ, M.; SUÁREZ, M. M. Cálculo del ROI de marketing en modelos de marketing mix, del ROMI, al valor creado del marketing para los accionistas EVAM. Universia Business Review, $\mathrm{n}$. 51, p. 34-51, 2016.

[6] FÄRE, R. et al. Productivity developments in Swedish hospitals: a Malmquist output index approach. In: CHANERS, A. et al. Data envelopment analysis: theory, methodology, and applications. New York: Springer Netherlands, 1994. p. 253-272.

[7] FORRESTER, J. W. Industrial Dynamics After the First Decade. Management Science, v. 14, n. 7, p. 398-415, 1968.

[8] GHERASIM, T. An Approach of the Product View through the Perspective of the Marketing - Mix. Economy Transdisciplinarity Cognition, v. 14, n. 1, p. 402-409, 2011.

[9] GIACOMELLO, C. P.; DE OLIVEIRA, R. L. Análise Envoltória de Dados (DEA): uma proposta para avaliação de desempenho de unidades acadêmicas de uma universidade. Revista Gestão Universitária na América Latina - GUAL, v. 7, n. 2, p. 130, 28 maio 2014.
Sugere-se que, para a realização de novos estudos, possam se estabelecer formas de cálculo para índices de eficiência mercadológica de cada uma das DMUs consideradas. Mesmo que não tenham sido objeto desse estudo, poder-se-ia investigar a influência de cada elemento do composto mercadológico (4Ps) na criação de demanda, valendo-se para tanto da DEA e do proposto por FARË et al. (1994).

[10] GOMES, L. D. C.; KLIEMANN NETO, F. J. Métodos Colaborativos na Gestão de Cadeias de Suprimentos: Desafios De Implementação. Revista de Administração de Empresas, v. 55, n. 5, p. 563577,2015

[11] KASSAI, S. Utilização da análise por envoltória de dados (DEA) na análise de demonstrações contábeis. São Paulo: Universidade de São Paulo, 3 out. 2002.

[12] KETCHEN, D. J.; HULT, G. T. M. Bridging organization theory and supply chain management: The case of best value supply chains. Journal of Operations Management, v. 25, n. 2, p. 573-580, mar. 2007.

[13] KOTLER, P. Administração de Marketing: a edição do novo milênio. 10 ed ed. São Paulo: Prentice Hall, 2000.

[14] MADHANI, P. M. SCM and Marketing Management: Mutual Integration. SCMS Journal of Indian Management, p. 16-25, 2010.

[15] MONTGOMERY, C. A.; PORTER, M. E. Estratégia: a busca da vantagem competitiva. Rio de Janeiro: Campus, 1998.

[16] OKONGWU, $U$. et al. Impact of the integration of tactical supply chain planning determinants on performance. Journal of Manufacturing Systems, v. 38, p. 181-194, 2016.

[17] OLIVEIRA, M. G.; TOALDO, A. M. M. New times, new strategies: proposal for an additional dimension to the 4 P'S for E-commerce dot-com. Journal of Information Systems and Technology Management, v. 12, n. 1, p. 107-124, 2015.

[18] SAUNDERS, M.; LEWIS, P.; THORNHILL, A. Research Methods for Business Students. 5. ed. Harlow: Pearson Education, 2009.

[19] SCHULTZ, D. E.; DEV, C. Revisiting the Marketing Mix. Marketing Management, v. 21, n. 2, p. 45-47, 2012.

[20] SINGH, R. K.; SHARMA M. K. Selecting competitive supply chain using fuzzy AHP and 
extent analysis, Journal of Industrial and Production Engineering, 2015, vol. 31, №. 8, 524-538,

[21] SElLitTO, M. A. et al. A SCOR-based model for supply chain performance measurement: application in the footwear industry. International Journal of Production Research, v. 53, n. 16, p. 4917-4926, 2015.

[22] VAN WATERSCHOOT, W.; VAN DEN BULTE, C. The Classification of the Revisited
Marketing Mix. Journal of Marketing, v. 56, n. 4, p. 83-93, 1992.

[23] VINODH, S. et al. Design of agile supply chain assessment model and its case study in an Indian automotive components manufacturing organization. Journal of Manufacturing Systems, v. 32, n. 4, p. 620-631, 2013. 
APÊNDICE 1 - DESCRIÇÃO DAS VARIÁVEIS DE ENTRADA (INPUTS).

\begin{tabular}{|c|c|c|c|c|c|c|c|c|c|c|c|c|c|}
\hline Variável & EMPRESA & TRIM01 & TRIM02 & TRilM03 & TRIM04 & TRilM05 & TRIM06 & TRIM07 & TRIM08 & TFilM09 & TFilM10 & TRIM11 & TRIM12 \\
\hline \multirow{8}{*}{ 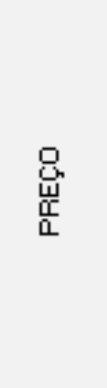 } & DMU01 & 461 & 454.1 & 481.8 & 484.9 & 499.9 & 523.9 & 557.2 & 549.2 & 581 & 578 & 587.8 & 591.9 \\
\hline & DMU02 & 461 & 450.4 & 464.2 & 476 & 481.7 & 486.4 & 516.2 & 457 & 440.9 & 431 & 462 & 426.8 \\
\hline & DMU03 & 461 & 469.7 & 470.5 & 485.2 & 488.2 & 487.2 & 500.9 & 523.7 & 543.2 & 553.1 & 562.6 & 583.3 \\
\hline & DMU04 & 461 & 461.3 & 465.2 & 475.1 & 480.9 & 502.2 & 481.8 & 476.7 & 467.9 & 485 & 504.6 & 525.8 \\
\hline & DMU05 & 461 & 454.2 & 476.4 & 483.2 & 488.2 & 473.7 & 469.1 & 504.6 & 466.9 & 467.5 & 457.5 & 464.3 \\
\hline & DMU06 & 461 & 459 & 485.9 & 449 & 493.4 & 501.1 & 493.2 & 488.4 & 479.7 & 477.9 & 478.5 & 468.1 \\
\hline & DMU07 & 461 & 453.4 & 472.5 & 488.8 & 511.8 & 504.2 & 522.4 & 530.5 & 530.1 & 526.2 & 529 & 528.2 \\
\hline & DMU08 & 461 & 458.8 & 481.7 & 500.1 & 498 & 495 & 526.6 & 536.6 & 554.1 & 562.2 & 565.1 & 576.1 \\
\hline \multirow{8}{*}{ 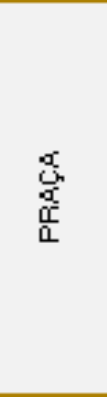 } & DMU01 & 480700 & 532454 & 511821 & 770790 & 625040 & 703603 & 836280 & 1096597 & 909104 & 1129650 & 1134932 & 1551647 \\
\hline & DMU02 & 480700 & 486810 & 448230 & 713136 & 583284 & 475348 & 0 & 0 & 0 & 0 & 0 & 0 \\
\hline & DMU03 & 480700 & 478797 & 483354 & 671714 & 688652 & 624023 & 859228 & 944682 & 985148 & 1058880 & 1336055 & 1721718 \\
\hline & DMU04 & 480700 & 460928 & 468941 & 561360 & 722892 & 495577 & 730311 & 889865 & 1075422 & 824590 & 1380664 & 1940256 \\
\hline & DMU05 & 480700 & 542003 & 150246 & 568712 & 454162 & 537270 & 712737 & 450112 & 0 & 0 & 0 & 0 \\
\hline & DMU06 & 480700 & 507366 & 506701 & 720752 & 661956 & 368086 & 395804 & 801145 & 0 & 0 & 0 & 0 \\
\hline & DMU07 & 480700 & 467021 & 424858 & 582388 & 561135 & 666994 & 659878 & 1051770 & 1050036 & 1030530 & 1270222 & 1509772 \\
\hline & DMU08 & 480700 & 449946 & 480102 & 647314 & 514296 & 592192 & 751059 & 735177 & 653976 & 846180 & 843160 & 1208226 \\
\hline \multirow{8}{*}{$\begin{array}{l}\text { 号 } \\
\text { 号 } \\
\text { 茄 }\end{array}$} & DMU01 & 1 & 1 & 1 & 1 & 1 & 2 & 3 & 3 & 4 & 5 & 5 & 5 \\
\hline & DMU02 & 1 & 1 & 1 & 1 & 1 & 1 & 1 & 1 & 1 & 1 & 1 & 1 \\
\hline & DMU03 & 1 & 1 & 1 & 1 & 1 & 1 & 2 & 3 & 4 & 5 & 5 & 5 \\
\hline & DMU04 & 1 & 1 & 1 & 1 & 1 & 1 & 1 & 1 & 1 & 2 & 3 & 3 \\
\hline & DMU05 & 1 & 1 & 1 & 1 & 1 & 1 & 1 & 1 & 1 & 1 & 1 & 1 \\
\hline & DMU06 & 1 & 1 & 1 & 1 & 1 & 1 & 1 & 1 & 1 & 1 & 1 & 1 \\
\hline & DMU07 & 1 & 1 & 1 & 1 & 1 & 2 & 2 & 2 & 3 & 3 & 3 & 4 \\
\hline & DMU08 & 1 & 1 & 1 & 1 & 1 & 1 & 2 & 2 & 3 & 4 & 4 & 5 \\
\hline \multirow{8}{*}{ 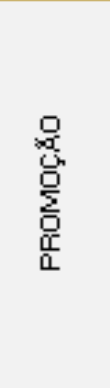 } & DMU01 & 3 & 3.2 & 2.4 & 3.3 & 4.3 & 3.7 & 4.2 & 5.6 & 4.7 & 7 & 6.6 & 7 \\
\hline & DMU02 & 3 & 2.8 & 3.2 & 0.4 & 1.1 & 3.3 & 2.2 & 1.3 & 0.8 & 0 & 0.2 & 0.7 \\
\hline & DMU03 & 3 & 3 & 3.2 & 3 & 3.2 & 3.2 & 3.9 & 3 & 3.9 & 3.9 & 6 & 6 \\
\hline & DMU04 & 3 & 2.8 & 3.4 & 3.8 & 3.2 & 3.3 & 3.4 & 2.9 & 6.1 & 6.2 & 6.2 & 7.3 \\
\hline & DMU05 & 3 & 3.2 & 1.3 & 2.1 & 3.2 & 3.1 & 3.2 & 3 & 3.3 & 3.3 & 3.3 & 3 \\
\hline & DMU06 & 3 & 3 & 2.9 & 3 & 2.9 & 3 & 3 & 4 & 4 & 4 & 4 & 5 \\
\hline & DMU07 & 3 & 1.9 & 2.8 & 1.9 & 4.2 & 4 & 1.8 & 3.8 & 5.1 & 4.6 & 6 & 5.2 \\
\hline & DMU08 & 3 & 2.7 & 3.1 & 3.3 & 2.8 & 4 & 4 & 4.4 & 4.8 & 5.8 & 7.1 & 7.1 \\
\hline
\end{tabular}


APÊNDICE 2 - DESCRIÇÃO DA VARIÁVEL DE SAÍDA (OUTPUT).

\begin{tabular}{|c|c|c|c|c|c|c|c|c|c|c|c|c|c|}
\hline Variável & EMPRESA & TRIM01 & TRilM02 & TRIM03 & TFilM04 & TFiM05 & TFilM06 & TRiM07 & TFIM08 & TFilM09 & TRIM10 & TRilM11 & TFilM12 \\
\hline \multirow{8}{*}{ 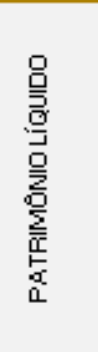 } & DMU01 & $5 \mathrm{E}+06$ & 5230196 & 5536284 & 6414997 & 7037010 & 7766953 & 9187821 & $1,1 \mathrm{E}+07$ & $1,3 \mathrm{E}+07$ & $1,4 E+07$ & $1,5 \mathrm{E}+07$ & $1,7 \mathrm{E}+07$ \\
\hline & DMU02 & $5 \mathrm{E}+06$ & 5229686 & 5082721 & 5441868 & 5808114 & 5887178 & 5265282 & 4332074 & 2383413 & 36594 & $-3 \mathrm{E}+06$ & $-7 \mathrm{E}+06$ \\
\hline & DMU03 & $5 E+06$ & 5321611 & 5254088 & 6103179 & 6823677 & 7142210 & 7780172 & 8730058 & 9751862 & $1,1 \mathrm{E}+07$ & $1,2 \mathrm{E}+07$ & $1,5 \mathrm{E}+07$ \\
\hline & DMU04 & $5 \mathrm{E}+06$ & 5361876 & 5463641 & 5633840 & 6292751 & 6527914 & 6723405 & 8140857 & 8148182 & 8007454 & 8306451 & 9479746 \\
\hline & DMU05 & $5 \mathrm{E}+06$ & 5192123 & 3563742 & 4139875 & 4429175 & 4629028 & 4339000 & 4620425 & 4617697 & 3329543 & 737127 & $-1 E+06$ \\
\hline & DMU06 & $5 \mathrm{E}+06$ & 5182336 & 5418735 & 5780134 & 6444654 & 6585324 & 6364842 & 6494715 & 5990001 & 5130492 & 3572885 & 1338297 \\
\hline & DMU07 & $5 \mathrm{E}+06$ & 5197831 & 5394465 & 5929048 & 6556057 & 7372775 & 8026765 & $1,1 \mathrm{E}+07$ & $1,2 \mathrm{E}+07$ & $1,3 E+07$ & $1,4 E+07$ & $1,5 \mathrm{E}+07$ \\
\hline & DMU08 & $5 E+06$ & 5315452 & 5453236 & 6262718 & 6811043 & 7115732 & 7943261 & 8636992 & 8913014 & 9551979 & $1 E+07$ & $1,1 E+07$ \\
\hline
\end{tabular}




\section{Capítulo 4}

\section{AVALIACÃO DA RELACÃO ENTRE O VALOR PERCEBIDO E A RETENCÃO DOS SÓCIOS DE UM CLUBE SOCIAL DO SEGMENTO INDUSTRIAL DE NATAL-RN}

\section{Fernando José Machado Barbosa de Melo}

Alexandre de Oliveira Siqueira

Humberto Caetano Cardoso da Silva

Marcus Augusto Vasconcelos Araújo

Patrícia Carneiro Lins de Novaes

Viviane Caú Amaral

Resumo: O propósito central deste artigo é estudar o valor percebido dos associados de um clube social do segmento industrial, bem como o impacto desse, na retenção dos associados, tendo a retenção como consequente do valor percebido. A partir de uma revisão da literatura o modelo foi desenvolvido, tendo sido hipotetizado que a retenção é antecedida pelo valor percebido e, concomitantemente, pela qualidade de serviço, benefícios (emoção, dimensão social) e sacrifício (preço). A construção deste modelo resultou em 4 (quatro) hipóteses, que foram submetidas a teste, tomando como contexto empírico um clube social do segmento industrial da cidade de Natal - RN. Uma amostra de 167 respondentes foi pesquisada, com coleta de dados por meio de questionado estruturado. Os construtos foram avaliados em separado, por meio de estatísticas descritivas, e a análise preliminar das hipóteses foi feita com o apoio da técnica estatística de regressão logística. Os resultados encontrados mostraram uma forte correlação entre o valor percebido e a retenção, bem como revelaram sutilezas na correlação entre qualidade de serviços, benefício e sacrifício com a retenção. O objetivo foi satisfatoriamente atendido, indicando, a partir de dados empíricos, reforços de gestão em operações de serviços, com ênfase no relacionamento com o consumidor. 


\section{INTRODUÇÃO}

Uma forma de se delinear estratégias voltadas para a retenção do cliente é o estudo do valor percebido a partir de construtos que, relacionados, evidenciam quanto e como certas variáveis determinam o valor percebido e são determinadas por ele. Estudos do valor percebido nas relações unidimensionais de troca entre cliente e fornecedor (ZEITHALM, 1988), e nas suas sutilezas multidimensionais, observável nessas relações (HOLBROOK, 1999), vem sendo desenvolvidos, confirmando a importância do valor percebido para conquistar clientes e garantir sua permanência na empresa (DE OLIVEIRA SANTINI; et al., 2015). Com isso, identificar valores e adotar práticas de gestão voltadas para o fortalecimento do valor percebido, criam vínculos mais fortes com os consumidores e faz com que os clientes se sintam envolvidos com a empresa.

São antecedentes relevantes do valor percebido, já confirmados em estudos anteriores, a qualidade, o preço, a emoção e a dimensão social (SWEENEY; SOUTAR, 2001; DE OLIVEIRA SANTINI et al., 2015). Esses antecedentes, unidimensionais e multidimensionais, foram parametrizados em um instrumento de pesquisa intitulado PERVAL, que considera tanto a abordagem de Zeithaml (1988), como a tipologia de valor de Holbrook (1999) como insumo para o seu desenvolvimento (SWEENEY; SOUTAR, 2001). Sendo a retenção de clientes o meio para o sucesso no mercado do novo milênio (VAVRA; PRUDEN, 1995) a sua relação com o valor percebido também será analisada.

Um dos mercados que pouco tem se beneficiado com 0 marketing de relacionamento é o mercado dos clubes sociais do segmento industrial. Um dos aspectos de gestão identificados como relevante para suportar crises, nesse ambiente de mercado, é o reconhecimento dos associados (RIEDE, 2002), e este ainda tem muito a se desenvolver. O contexto analisado será um clube social desse segmento que tem personalidade jurídica de direito privado situado na cidade de Natal $\mathrm{RN}$.

Este artigo traz a seguinte questão de pesquisa: qual a relação entre 0 valor percebido e a retenção dos sócios do clube de uma empresa do segmento industrial situado na cidade de Natal - RN? Tem como objetivo verificar a relação entre 0 valor percebido e a retenção dos sócios do clube. Além disso, pretende verificar qual a relação entre a qualidade de serviços, benefícios (emoção e dimensão social) e sacrifício (preço) com a retenção, bem como identificar, a partir dos construtos qualidade de serviços, benefícios e sacrifícios, enquanto valor percebido, quais os fatores mais fortemente associados à retenção do clube, pelos seus sócios.

Esta pesquisa adotou a análise das variáveis PERVAL com a retenção dos sócios do clube, mediante a estrutura hierárquica do valor percebido do consumidor, como abstração de segunda ordem, trazida por De Oliveira Santini et al., (2015). A proposta do trabalho é de natureza quantitativa, descritiva, com a utilização de um levantamento (survey), de corte transversal único e foi aplicada neste trabalho a regressão logística (HAIR JR. et al., 2009, p.154). Com o objetivo de validar o instrumento de mensuração das variáveis pesquisadas, testando quão bem as variáveis medidas representam os construtos, foi utilizada a Análise Fatorial Confirmatória, a partir de técnicas de modelagem de equações estruturais (HAIR JR., et al., 2009).

Para a avaliação do modelo foi utilizado o teste ajuste do modelo Estatística HosmerLemeshow. Este, com o objetivo de verificar se o modelo gera valores não significativos de $x$ 2. Os valores desta estatística para um modelo logístico devem ser superiores a 0,05 (HOSMER; LEMESHOW; STURDIVANT, 2013).

Este trabalho é relevante para a área do Marketing de Relacionamento no setor de serviços. Especialmente por se propor a trazer contribuições de gestão para o ambiente do terceiro setor (RIEDE, 2002), a partir do conceito unidimensional de valor percebido de Zeithalm (1988), complementado pela tipologia do valor de Holbrook (1999). Essa relevância se estende aos conceitos sobre retenção de De Oliveira Santini et al. (2015), num modelo que investiga, no âmbito do comportamento do consumidor, a relação entre o valor percebido e a retenção.

\section{REFERENCIAL TEÓRICO}

A percepção é uma determinante importante do comportamento do comprador. Compradores usam sinais "cues" como características do produto, imagem da loja, marcas e preços para diferenciar produtos e 
formar impressões da qualidade do produto. É importante entender não somente como os compradores usam tais sinais, mas também quais sinais eles realmente percebem (MONROE; KRISHNAN, 1985). Enquanto a qualidade percebida é considerada uma avaliação global que, em alguns casos, lembra atitude, a qualidade objetiva é o termo utilizado na literatura para descrever a superioridade técnica ou excelência efetiva dos produtos (ZEITHAML, 1988).

De acordo com Holbrook (1999) as dimensões da qualidade vão desde algo perceptível implicitamente e explicitamente, passando pela objetividade mecanicista e pela subjetividade humanística até definições conceituais de qualidade e definições de natureza mais operacionais. A qualidade total percebida segundo Grönroos (1995) tem a dimensão técnica que guarda relação com o que o cliente recebe em suas interações com a empresa, e a qualidade funcional que diz respeito à maneira como o cliente recebe 0 serviço e como ele vivencia o processo de produção do serviço. No contexto de serviço, a palavra qualidade pode ser empregada a partir de várias perspectivas: eficiência operacional, maximização do valor, percepção de excelência pelo cliente e transcendência - como algo inato (LOVELOCK; WIRTZ; HEMZO, 2011).

Para avaliar a expectativa e a percepção dos consumidores a respeito da qualidade do serviço, Parasuraman, Berry e Zeithaml (1985) apresentaram um instrumento de pesquisa, denominado SERVQUAL, composto de vinte e duas perguntas, constando as dimensões tangíveis, confiabilidade, sensibilidade, segurança e empatia. A SERVQUAL adaptada, contém apenas a seção performance do serviço e é identificada como SERVPERF (CRONIN; TAYLOR, 1992), modificada, correlaciona fatores intangíveis e tangíveis, constituindo a SERVICESCAPE (REIMER; KUEHN, 2005). A escala SERVQUAL tem sido largamente utilizada em estudos sobre qualidade existentes (CRONIN; BRADY; HULT, 2000).

Segundo Padilla, Milton e Johnson (2015) a qualidade é uma variável que compõe o valor percebido do produto ou serviço. A partir do exposto, a qualidade compõe o objeto de pesquisa a partir de uma avaliação geral, constante na escala PERVAL (SWEENEY; SOUTAR, 2001) enquanto constituinte do valor percebido. Como uma variável antecedente em correlação com a retenção, a qualidade é complementada por De Oliveira Santini et al. (2015).

Valor são todos os fatores, qualitativo e quantitativo, subjetivo e objetivo, que fazem a completa experiência de comprar (SCHECHTER, 1984). Consta como tradição no ambiente acadêmico o reconhecimento de que o valor percebido de um cliente é um fenômeno que decorre de uma troca de benefícios e sacrifícios, sendo a qualidade intrínseca o benefício primário e o preço o sacrifício primário (KUMAR; GRISAFFE, 2004). $O$ entendimento universal é de que as percepções do consumidor sobre preço, qualidade e valor são considerados decisivos no comportamento de compra e escolha do produto (BISHOP, 1984; JACOBY; OLSON, 1985).

Para Zeithaml (1988), o que constitui valor, mesmo em uma única categoria de produto, parece ser totalmente pessoal e idiossincrático. Em seu estudo, afirma que valor percebido é a avaliação geral do consumidor sobre a utilidade de um produto baseada nas percepções do que é recebido e o que é dado. Dessa forma, o valor representa um equilíbrio importante dos componentes de doação e ganho, onde o valor percebido significa o que deriva de um trade-off entre o valor do que é recebido e o valor do que é dado.

Além dos trabalhos que consideram o valor percebido como um trade-off entre o que é dado e recebido, defendendo uma perspectiva vivencial, incluindo aspectos simbólicos, hedônicos e estéticos do processo de consumo, Holbrook (1999) sugeriram, no tocante ao valor percebido, perspectivas de processamento de informações implícitas aos produtos, em grande parte julgados por critérios utilitaristas, com base em quão bem um produto ou serviço atende a sua finalidade. Nesse contexto, pesquisas do consumidor evoluíram de um foco sobre os aspectos cognitivos da tomada de decisão para incluir aspectos intrínsecos, de modo que um objeto ou experiência podem ser vistos para serem valorizados por seu próprio bem. Numa perspectiva experiencial os produtos ou serviços são vistos através de critérios hedônicos, com base na apreciação do bem ou serviço para seu próprio bem (SWEENEY; SOUTAR, 2001), entendimento fundamentado, inclusive, a partir de achados de Batra e Ahtola (1990) que confirmaram a presença de componentes utilitários e hedônicos distintos, 
referidos nas dimensões do pensamento e do sentimento.

Estudos de Holbrook (1999) consideram valor um benefício como uma experiência de preferência relativista interativa que se refere à avaliação de algum objeto por um sujeito, entendendo experiência como o fato de que o valor não está presente no produto comprado, na marca escolhida ou no objeto possuído, mas sim na experiência de consumo derivada dele, sejam quantas experiências forem. Tomando como referência os estudos observados, pode-se apreender que o valor percebido do consumidor revela, a partir do movimento de projeção ou retração do consumidor para o objeto de consumo, uma unidimensionalidade e uma multidimensionalidade que compõem a natureza do valor de consumo como parte de um todo do valor percebido, trazendo o fenômeno ${ }^{1}$ como elemento aferidor das dimensões que compõem o valor percebido (PADILLA; MILTON; JOHNSON, 2015). Sendo, então, a geração e a autogeração determinantes do conhecimento, é importante buscar nas referências cognitivas e na ação o liame que nos confere o entendimento do significado atual do valor percebido.

São antecedentes relevantes do valor percebido: a qualidade, o preço, a emoção e a dimensão social (DE OLIVEIRA SANTINI et al., 2015). Esses antecedentes foram parametrizados em um instrumento de pesquisa intitulado PERVAL, que considera tanto a abordagem de Zeithaml (1988), como a tipologia de valor de Holbrook (1999) como insumo para $O$ seu desenvolvimento (SWEENEY; SOUTAR, 2001). Esse instrumento será utilizado neste estudo com as devidas parametrizações, por unir em suas dimensões antecedentes do valor percebido, aderentes ao objeto de pesquisa e por possibilitar uma aferição mútua, unidimensional e multidimensional do valor percebido, essas, inclusive, com exceção da qualidade, como elementos que compõem benefícios e sacrifícios antecedentes do valor percebido.

A retenção de clientes é a capacidade de receber os clientes atuais, motivando-os para utilizarem os serviços mais intensivamente e para comprarem serviços adicionais, tendo

\footnotetext{
1 Segundo Hegel o fenômeno passa por uma espiral em movimento que trata do absoluto e do momento particular da realidade, exigindo necessariamente a totalidade das partes sem nenhuma exclusão. (REALE; ANTISERI, 1991).
}

como objetivo principal aprofundar e ampliar os relacionamentos com os clientes atuais a fim de melhorar o desempenho financeiro e aumentar o valor do cliente através da manutenção do mesmo ao longo do tempo (AURIER; N'GOALA, 2010). O objetivo principal da retenção de clientes é aprofundar e ampliar as relações dos serviços existentes, de modo que seus clientes se sintam progressivamente bloqueados por trocar de parceiros de negócio (KAMAKURA et al., 2003). Para tanto, Palmatier et al. (2006) salientam que, o desenvolvimento de tais vínculos estruturais permite que as empresas de serviços alcancem uma diferenciação nos mercados onde estão inseridas, permitindo que obtenham vantagem competitiva sustentável e melhorem seus desempenhos.

Segundo Johnson e Selnes (2004) há benefícios econômico-financeiros provenientes da retenção de clientes. O aumento de $5 \%$ na retenção de clientes poderia gerar um aumento na lucratividade de uma empresa entre $25 \%$ e $85 \%$ (REICCHELD, 1996) e um aumento de $1 \%$ sobre a taxa de retenção de clientes poderia repercutir em um acréscimo de $5 \%$ no valor patrimonial das empresas (GUPTA; LEHMANN; STUART, 2004). Como as empresas investem recursos a fim de atrair clientes para, então, cultivá-los, a retenção de clientes pode diminuir custos (ANDERSON; MITTAL, 2000).

A retenção é o ponto crítico para o equilíbrio financeiro de uma empresa e também um dos relevantes problemas enfrentados pelos gestores e pode estar associada à falta de opções ou a comodidade (DE FRANÇA ARCOVERDE, 2015). Segundo Jones, Mothersbaugh e Beatty (2000) os benefícios sociais, para além das características do serviço, são uma estratégia de diferenciação, uma forma de conseguir vantagem sobre as concorrentes. Nesse diapasão, De Oliveira Santini et al. (2015) avalia a retenção como uma variável dependente do valor percebido e incrementa a escala PERVAL (SWEENEY; SOUTAR, 2001) com esse construto, possibilitando a utilização da sua escala como referência para este estudo.

Considerando o exposto é possível enunciar as seguintes hipóteses: 
Quadro 1 - Hipóteses.

H1: A Qualidade de Serviços se relaciona direta e positivamente com a retenção de um clube social do segmento industrial em Natal-RN.

H2: Os Benefícios Percebidos (emoção e dimensão social) se relacionam direta e positivamente com a retenção de um clube social do segmento industrial em Natal-RN.

H3: O Sacrifício Percebido (preço) se relaciona direta e positivamente com a retenção de um clube social do segmento industrial em Natal-RN.

H4: O Valor Percebido se relaciona direta e positivamente com a retenção de um clube social do segmento industrial em Natal-RN.

Fonte: Elaborado pelo autor (2017)

\section{PROCEDIMENTO METODOLÓGICO}

A pesquisa foi aplicada através da utilização de um questionário estruturado, no clube social de uma empresa do segmento industrial, situado na cidade de Natal - RN. Fundado em 22 de abril de 1981, o clube tem em sua constituição 3.163 sócios e seu objetivo é prestar um serviço de qualidade, oferecendo lazer, entretenimento, prática esportiva e cultural para os seus associados.

A escala adotada fora a de múltiplo item utilizada por De Oliveira Santini et al. (2015), que possui medidas já conhecidas e amplamente testadas em trabalhos realizados na área da administração de empresas e marketing, e que tem como escala seminal de referencia a denominada PERVAL (SWEENEY; SOUTAR, 2001. Como o papel do preço no valor percebido duplo, representando um sacrifício monetário e, ao mesmo tempo, influenciando a percepção de sacrifício e benefício nas avaliações mais subjetivas dos consumidores (MONROE; KRISHNAN, 1985), para este estudo, utilizou-se apenas a única questão cujo preço significa sacrifício. Como técnica de amostragem optou-se pelo método não probabilístico por conveniência (MALHOTRA, 2006).

O pré-teste foi realizado em duas etapas. $\mathrm{Na}$ primeira, em 28 de janeiro de 2017, os sócios frequentadores do clube responderam ao questionário apontando suas principais dúvidas, críticas e sugestões. Na segunda, um especialista em marketing foi convidado a criticar $O$ instrumento, não havendo necessidade de adequações no instrumento.

A análise foi efetuada utilizando software Statistical Package for the Social Sciences (SPSS) versão 22 e a Análise de Regressão Logística foi a técnica estatística utilizada neste estudo. Foi utilizada a Análise Fatorial Confirmatória para a validação do instrumento de mensuração das variáveis pesquisadas, a partir de técnicas de modelagem de equações estruturais (HAIR Jr. et al., 2009). Para a avaliação do modelo foi utilizado o teste ajuste do modelo Estatística HosmerLemeshow, com o objetivo de verificar se o modelo gera valores não significativos de $x 2$, devendo os valores desta estatística para um modelo logístico serem superiores a 0,05 (HOSMER; LEMESHOW; STURDIVANT, 2013).

\section{ANÁLISE DOS DADOS E DISCUSSÃO DOS RESULTADOS}

O questionário estruturado foi aplicado junto aos sócios do clube nos meses de fevereiro e março de 2017. Ao todo, foram encaminhadas 2953 comunicações, convidando os sócios a responder o questionário, com um total de 167 questionários respondidos, todos válidos. Cada sócio foi orientado a responder ao questionário uma única vez.

A distribuição dos participantes por categoria de sócio apresentou predominância nas respostas do sócio contribuinte, 64,8\%. No que se refere ao tipo de sócio, prevaleceu como participante o sócio titular, com 90,4\%. No tocante ao sexo, o masculino prevaleceu como respondente com $82,6 \%$.

A frequência relativa das faixas etárias, extraídas dos dados da data de nascimento dos respondentes, demonstrou um perfil bem distribuído entre as faixas etárias pesquisadas, com predominância de sócios da faixa etária entre 39 e 48 anos, com 20,4\%. Em relação ao nível de escolaridade, a predominância é de sócios com formação em nível superior, $46,1 \%$. A renda familiar dos respondentes variou sua frequência relativa tendo nos respondentes com renda entre $\mathrm{R} \$ 5.000,01$ a $\mathrm{R} \$ 10.000,00,40.70 \%$ de participação e no tocante ao estado civil, observa-se a predominância do status de casado, $84,4 \%$.

A mediana de cada variável segue apresentada e é útil para a análise do 
comportamento do efeito agregado das experiências aleatórias independentes e semelhantes, na circunstância de pesquisa dada, quando o número de experiências é considerado válido para uma análise não probabilística (HAIR Jr. et al., 2009). Em uma escala de cinco pontos que varia de discordo totalmente (1) a concordo totalmente (5) apresentaram mediana das respostas igual a 4,00 as dimensões Qualidade de Serviço e Emoção. As dimensões Social, Preço e Retenção apresentaram mediana das respostas igual a 3,00.

A confiabilidade do instrumento foi estimada mediante a aplicação do alfa de Cronbach. Alfas acima 0,6 são considerados satisfatórios e acima de 0,7 demonstram boa consistência interna da escala (HAIR Jr. et al., 2009). Todas as variáveis apresentaram valores acima do limite de 0,70.

A escala utilizada no estudo foi obtida mediante a utilização de instrumentos de pesquisa já utilizados em estudos anteriores (SWEENEY; SOUTAR, 2001; DE OLIVEIRA SANTINI et al., 2015). O total de respondentes, 167 casos, supera o valor informado por Hair Jr. et al. (2009), que é de no mínimo 5, sendo recomendado a utilização de 10 respondentes por item do questionário. Os valores das cargas fatoriais para todas as dimensões foram acima de 0,60, sendo que a primeira variável da dimensão emoção foi removida por não apresentar carga fatorial na dimensão correta.

O valor do teste estatístico de $\mathrm{KMO}$ foi de 0,897, o teste de esfericidade de Barlett foi significativo $(p<0,001)$ e a variância explicada no modelo foi de $85,763 \%$. Para a retenção, o valor do teste estatístico de $\mathrm{KMO}$ foi de 0,818, o teste de esfericidade de Barlett foi significativo $(p<0,001)$ e a variância explicada no modelo para variável de fator único foi de $78,72 \%$. Os valores da Análise Fatorial Confirmatória das variáveis do questionário que compõem o valor percebido cargas fatoriais dentro dos parâmetros estatísticos esperados.

A variável Retenção teve relação teorizada com a Qualidade, Benefício, Sacrifício e o Valor Percebido, este último, obtido através da média das variáveis Qualidade, Benefício e Sacrifício, sendo componente do Benefício, a Emoção e a Dimensão Social e, do Sacrifício, o Preço (ZEITHAML, 1988; HOLBROOK, 1999; SWEENEY; SOUTAR, 2001; DE OLIVEIRA SANTINI et al., 2014; PADILLA; MILTON;
JOHNSON, 2014). Mesmo seguindo Sweeny e Soutar (2001) e De Oliveira Santini et al. (2014), ao admitirmos a cocriação de Padilla, Milton e Johnson (2014), o Valor Percebido foi medido de forma unidimensional, entendendo que, em se tratando do Valor Percebido enquanto um fenômeno (REALE; ANTISERI, 1991) inerente ao comportamento do consumidor, o que compõe o Valor Percebido, na unidimensionalidade de Zeithaml (1988), é, também, a multidimensionalidade de Holbrook (1999), e vice e versa. Outros estudos também corroboram com esse entendimento, porém de forma fragmentada, quanto ao estabelecimento das relações dos antecedentes com o Valor Percebido (SNOJ; KORDA; MUMEL, 2004).

Quando as variáveis Qualidade, Benefício e Sacrifício são tratadas de maneira conjunta, o modelo apresentou Odds Ratio de 11,761 para a variável Benefício, indicando que quando há uma relação de benefício percebido, as chances de se afirmar que há Retenção na relação aumentam 11,761 vezes. As relações das variáveis Qualidade e Sacrifício (Preço) com a Retenção não obtiveram suporte estatístico, não confirmando as Hipóteses H1 e H3. Já a relação Benefício com a Retenção, foi suportada estatisticamente, o que confirma a Hipótese H2.

Finalmente, a relação significativa para a variável Retenção, que possui relacionamento teorizado com a variável Valor Percebido (DE OLIVEIRA SANTINI et al., 2014), se apresentou para a variável Valor Percebido. Essa sustentação estatística confirma a relação positiva entre a Retenção e o Valor Percebido, ratificando estudos que já previam essa relação (ZEITHAML, 1988; SWEENEY; SOUTAR, 2001). Destaque para o Odds Ratio de 8,375, indicando que quando há uma relação de dependência percebida, as chances de se firmar que há Retenção na relação aumentam 8,375 vezes. Com isso, a relação entre o Valor Percebido e a Retenção, encontrada por De Oliveira Santini et al., (2014), foi suportada estatisticamente, confirmando a Hipótese H4.

Para a estatística de Hosmer e Lemeshow, Hair Jr. et al. (2009) indicam a utilização de valores acima de 0,05. Na regressão logística da Qualidade, Benefício e Sacrifício, e Retenção, o valor de 0,000 não supera o limite considerado mínimo, sendo o valor preditivo do modelo de $77,2 \%$. Na regressão logística do Valor Percebido e Retenção, o valor de 
0,000 obtido no estudo é inferior ao considerado mínimo, mesmo sendo o valor preditivo do modelo de $74,3 \%$.

Inserindo os dados demográficos nas análises de regressão logística, os mesmos não foram significativos ao ponto de alterar a leitura dos dados supracitados. Credita-se o resultado ao fato do grupo pesquisado apresentar um nível de homogeneidade muito elevado, fazendo com que as variáveis demográficas não causem efeito nas relações. Da forma como se apresentaram os 167 respondentes, apenas 20 são do sexo feminino, número que de acordo com Hair et al., (2009) não favorece qualquer tipo de análise probabilística, a partir da regressão logística.

Dada a não obtenção do suporte estatístico da variável qualidade de serviços na sua relação com a Retenção, através da regressão logística, buscou-se a identificação da causa e duas possíveis explicações se apresentam para 0 entendimento do fenômeno: (I) uma possível assimetria da distribuição do item qualidade, uma vez que, por mais que se use a mediana para gerar a dicotomização, a representação da distribuição total nunca é plena. (II) a força das outras variáveis na equação influenciando no resultado, pois quando a relação da qualidade de serviço com a retenção é analisada de forma isolada ela apresenta significância.

O mesmo ocorreu para a não obtenção do suporte estatístico da variável Sacrifício (Preço) na sua relação com a Retenção, através da regressão logística. Como os consumidores, de maneira geral, tornam-se muito menos sensíveis ao preço quando têm poucas escolhas ou opções para atender suas necessidades e desejos (FERRELL; HARTLINE, 2005) e sendo os preços das mensalidades historicamente subsidiados pela indústria é possível que o preço dos produtos complementares não tenha tanta relevância para o sócio do clube ao ponto de torna-lo significante para a Retenção. Há, inclusive, influências situacionais peculiares ao segmento clube, como o senso de pertencimento para cada categoria de sócio, por exemplo, que podem influenciar nessa percepção (RIEDE, 2002).

Sendo assim, buscou-se no teste KruskalWallis (MATTAR, 2006) a estatística necessária ratificar ou não a não confirmação das Hipóteses H1 e H3. Comparando as medianas dos construtos Qualidade, Benefício e Sacrifício (Preço) com a Retenção - X2 (Qui-Quadrado) para a variável Qualidade foi de 38,069, bem superior ao quiquadrado tabelado, fazendo com que a Hipótese Nula HO para esta relação seja rejeitada em favor da Hipótese $\mathrm{H} 1$. Efetuando a mesma comparação o X 2 (Qui-Quadrado) para a variável Sacrifício (Preço) foi de 0,114, fazendo com que a Hipótese Nula HO para esta relação prevaleça em detrimento a Hipótese H3.

\section{CONCLUSÃO}

A utilização das variáveis como Qualidade de Serviços, Benefício, Sacrifício e Valor Percebido enquanto antecedentes de Retenção, possibilitou não só ratificar que a Qualidade de Serviços, determina o Valor Percebido, juntamente com Benefício e Sacrifício, como também requereu a confirmação estatística para identificação da sua relação com a Retenção dos sócios do clube, o que confirma o que Zeithaml (1988) propôs ao preconizar em seu ensaio, o protagonismo do Beneficio e Sacrifício na determinação do Valor Percebido. O estudo possibilitou ainda confirmar que os Benefícios e Sacrifícios compõem fortemente o Valor Percebido e determinam uma forte interação deste, com a Retenção dos sócios do clube. Outro achado relevante é que do trade-off que compõe o valor percebido, entre benefício e sacrifício, apenas Benefícios, ambos isoladamente, ou seja, desvinculados do Valor Percebido, determinam a Retenção dos sócios do clube.

\section{REFERÊNCIAS}

[1] ANDERSON, E. W.; MITTAL, V. Strengthening the satisfaction-profit chain. Journal of Service Research. n. 2, v. 3, p. 107-120, 2000.

[2] AURIER, P.; N'GOALA, G. The differing and mediating roles of trusdt and relationship commitment in service relationship maintenance and development. Journal of the Academic Marketing Science, v. 38, p. 303-325, 2010.

[3] BATRA, R.; AHTOLA, O. T. Measuring the hedonic and utilitarian sources of consumer 
attitudes. Marketing letters. n. 2, v. 2, p. 159-170, 1990.

[4] BISHOP JR, W. R. Competitive intelligence, progressive grocer. p. 19-20, march, 1984.

[5] DE FRANÇA ARCOVERDE, D. Preditores da retenção e lealdade de clientes em academia de ginástica. 2015. 76p. Dissertação (Mestrado em Gestão Empresarial), Faculdade Boa Viagem/Devry, Pernambuco, 2015.

[6] DE OLIVEIRA SANTINI, F.; LADEIRA JR., W.; ARAÚJO, C. F.; DA ROSA FINKLER, E. N. A relação entre percepção de valor e retenção: uma análise comparativa entre faculdade e universidade particulares. REGE Revista de Gestão. n. 3, v. 22, p. 417-433, 2015.

[7] FERRELL, O. C.; HARTLINE, M. D. Estratégia de Marketing. 3. ed. São Paulo: Pioneira Thomson Learning, 2005.

[8] GRÖNROOS, C. Marketing, gerenciamento e serviços: a competição por serviços na hora da verdade. Rio de Janeiro: Campus, 1995.

[9] GUPTA, S.; LEHMANN, D. R.; STUART, J. A. Valuing customers. Journal of Marketing Research. n. 1, v. 41, p. 7-18, 2004.

[10] HAIR JR., J. F.; BLACK, W. C.; BABIN, B. J.; ANDERSON, R. E.; TATHAM, R. L. Análise multivariada de dados. 6. ed. Porto Alegre: Bookman, 2009.

[11] HOLBROOK, M. B. Consumer value:a framework for analysis and research. London: Routledge, 1999.

[12] HOSMER JR, D. W.; LEMESHOW, S.; STURDIVANT, R. X. Applied logistic regression. John Wiley \& Sons, 2013.

[13] JACOBY, J. R. W.; OLSON, J. C. Perceived quality. Lexington. MA: Lexington Books, 1985.

[14] JOHNSON, M. D.; SELNES F. Customer portfolio management: toward a dynamic theory of exchange relationships. Journal of Marketing. n. 2, v. 68, p. $1-17,2004$.

[15] JONES, M. A.; MOTHERSBAUGH, D. L.; BEATTY, S. E. Switching barriers and repurchase intentions in services. Journal of Retailing. n. 2, v. 76, p. 259-274, 2000.

[16] KAMAKURA, W. A. et al. Cross-selling through database marketing: a mixed factor analyzer for data augmentation and prediction. International Journal of Research in Marketing. $v$. 20, p. 45-65, 2003.

[17] KUMAR, A.; GRISAFFE, D. B. Effects of extrinsic attributes on perceived quality, customer value, and behavioral intentions in B2B settings: a comparison across goods and service industries. Journal of Business-to-Business. n.4, v. 11, p. 4374, 2004.

[18] MALHOTRA, N. K. Pesquisa de marketing: uma orientação aplicada. 4. ed. Porto Alegre: Bookman, 2006.

[19] MATTAR, F. N. Pesquisas de marketing. Editora Atlas,v. 1 e 2, São Paulo, 2006.

[20] MONROE, K. MITTAL, B.; KRISHNAN, R. The effect of price on subjective product evaluations. In: Perceived quality - how consumers view stores and merchandise. Lexington: Lexington Books, p. 209-232, 1985.

[21] PADILLA, R. S.; MILTON, S. K.; JOHNSON, L. W. Components of service value in business-to-business cloud computing. Journal of Cloud Computing. n. 1, v. 4, p. 1, 2015.

[22] PALMATIER, R. W.; DANT, R. P.; GREWAL, D.; EVAN, K. R. Factors influencing the effectiveness of relationship marketing: a metaanalysis. Journal of Marketing. n. 4, v. 70, p. 136153, 2006

[23] PARASURAMAN, A.; BERRY, L. L.; ZEITHAML, V. A. Problems and strategies in services marketing. Journal of Marketing. v. 49, Spring, p. 33-46, 1985.

[24] REALE, G., ANTISERI, D. História da Filosofia: Do Romantismo até os nossos dias. Coleção filosofia. São Paulo: Paulus, 1991.

[25] REIMER, A.; KUEHN, R. The impact of servicescape on quality perception. European Journal of Marketing. n. $7 / 8$, v. 39, p. 785-808, 2005

[26] RIEDE, A. S. Fatores críticos de sucesso na gestão das AABBs - Associações Atléticas Banco do Brasil. Brasília, 2002.

[27] SCHECHTER, L. A Normative conception of value, progressive grocer. Executive Report, $\mathrm{p}$. 12-14, 1984.

[28] SNOJ, B.; KORDA, A. P.; MUMEL, D. The relationships among perceived quality, perceived risk and perceived product value. Journal of Product \& Brand Management. n. 3, v. 13, 2004

[29] SWEENEY, J. C.; SOUTAR, G. N. Consumer perceived value: The development of a multiple item scale. Journal of retailing. n. 2, v. 77 , p. 203-220, 2001.

[30] VAVRA, T. G. PRUDEN, D. R. Using aftermarketing to maintain a customer base. Discount Merchandiser. n. 5, v. 35, p. 86-88, May, 1995.

[31] ZEITHAML, V. A. Consumer perceptions of price, quality, and value: a means-end model and synthesis of evidence. Journal of Marketing. v. 52, p. 2-22. 1988. 


\section{Capítulo 5}

\section{SHOPPING DA CIDADE EM TERESINA: POSSIBILIDADE PARA O SETOR INFORMAL NO BRASIL \\ João Gabriel Moreno de Lacerda \\ Nívea Maria Pires Silva \\ Pedro Filipe da Conceição Pereira \\ Maíra dos Santos Liarth \\ Mateus Antônio Costa Andrade}

Resumo: O trabalho informal é um problema de ordem econômica e social que atingiu diversas localidades do Brasil, inclusive na capital do Piauí, Teresina. O presente artigo aborda os principais desafios e possibilidades gerados por uma economia informal crescente, objetivando mostrar como a construção Shopping da Cidade em Teresina melhorou diversos aspectos na vida dos trabalhadores por conta própria na capital. Para isso, foi-se utilizado o método da entrevista com base em um questionário semi-estruturado para a Secretaria Municipal de Planejamento da cidade e para os comodatários do espaço popular, além de estudos bibliográficos acerca do tema da informalidade como norte da pesquisa. Nos resultados, foi identificado por meio de dados qualitativos-quantitativos que 0 shopping popular trouxe contribuições positivas para o espaço e para os comodatários, uma vez que se pode concluir que o mesmo promoveu a inclusão de diretos no campo da Segurança do Trabalho, assim como possibilitou uma melhor qualidade de vida para eles e para o meio que os rodeia.

Palavras-chave: Trabalho informal, segurança do trabalho, Qualidade de vida 


\section{INTRODUÇÃO}

Segundo a Organização Internacional do Trabalho 2006 (OIT), na maioria dos países ocidentais, especialmente na América do Sul, o crescimento do trabalho informal ganhou significativa notoriedade pelas autoridades e pela sociedade, pois é percebido como um problema econômico e social (SASAKI, 2012).

Para a OIT essa realidade está associada à pobreza, à baixa escolaridade e à falta de proteção social, haja vista que o trabalhador informal está em condições de desvantagens no mercado de trabalho. Segundo Sasaki (2012), isto se deve ao progresso técnico, à instabilidade empregatícia, ao excesso de regulamentação do mercado e escassez de empregos que deixaram os trabalhadores à margem da economia formal e dos direitos laborais. No Brasil, por exemplo, uma pesquisa realizada pelo IBGE em 2017, mostrou que os trabalhadores por conta própria somam 22,8 milhões de pessoas, crescimento de 2,1\% em relação ao ano anterior, e a população com carteira assinada se manteve estável com 33,4 milhões, evidenciando, assim, os níveis preocupantes de informalidade no país (CARTACAPITAL, 2017).

A Consolidação das Leis Trabalhistas (CLT), sancionada em 1943 pelo então presidente Getúlio Vargas, unificou toda legislação trabalhista existente no Brasil e se tornou o principal instrumento para regulamentar as relações de trabalho, assim como proteger os trabalhadores (MTE, 2018). Porém, as legislações da CLT e dos seguros sociais oferecidos pela Previdência Social por meio do INSS, abrange somente o setor formal da economia, ou seja, o trabalhador que contém carteira assinada.

Nesse contexto, com a mão de obra excedente dos centros urbanos, o trabalhador encontrou no meio informal uma forma de sobrevivência, uma vez que a realidade do mercado deslocou essas pessoas da economia formal, dos seus direitos trabalhistas e dos benefícios oferecidos por leis. Logo, esses trabalhadores vivem em desvantagem em relação ao empregado de carteira assinada.

Segundo Iriart (2006) estudos epidemiológicos acerca da saúde e bemestar dos trabalhadores mostraram situações diferentes, pois enquanto em países industrializados trabalhadores informais apresentam maiores incidências de acidentes de trabalho e doenças ocupacionais, no Brasil, essas informações não são encontradas, o que é atribuído a pouca efetividade das políticas de proteção. Com isso, observa-se que a metodologia de controle da incidência de acidentes nos países desenvolvidos é realizada por meio de dados, o que mostra a preocupação que os órgãos de proteção ao trabalhador possuem. Já no Brasil não há essa atenção, uma vez que é feito pouco investimento na melhoria da qualidade de vida dos trabalhadores.

Nesse contexto, criou-se um ambiente para que esses trabalhadores informais pudessem se integrar e realizar suas atividades como forma de diminuir os riscos sofridos por eles, bem como proporcionar uma melhor qualidade de vida: o Shopping da Cidade em Teresina.

Esse artigo tem como objetivo principal mostrar como o planejamento e a construção do Shopping da Cidade em Teresina, um espaço comercial que abriga vendedores ambulantes, melhoraram diversos aspectos da vida do trabalhador informal regional, evidenciando a inclusão de direitos no campo da Segurança do Trabalho. O trabalho foi executado especificamente por meio de pesquisas bibliográficas acerca do assunto, bem como entrevistas feitas em forma de questionário para trabalhadores da área $e$ para a secretaria de planejamento da cidade de Teresina.

O trabalho realizado sob a justificativa de contribuir para a melhoria da qualidade de vida e das condições de trabalho do subemprego nacional, deixará contribuições sociais a partir do momento que informará e sensibilizará as autoridades públicas sobre as condições dos trabalhadores informais.

\section{REFERENCIAL BIBLIOGRÁFICO \\ 2.1 SEGURANÇA DO TRABALHO}

Segundo Barsano (2012) a Segurança do Trabalho é um conjunto de ciências e tecnologias que promovem a proteção do trabalhador visando à redução de acidentes de trabalho e doenças ocupacionais. Conforme o mesmo autor, um ambiente laboral com segurança atinge sua finalidade quando consegue proporcionar ao empregado e empregador um ambiente de trabalho saudável e seguro garantindo as condições que vão produzir num ambiente agradável. 
Com o objetivo de padronizar, fiscalizar e oferecer orientações sobre procedimentos obrigatórios relacionados à segurança e a saúde no trabalho, o Ministério do Trabalho aprovou, em 1978, as Normas Regulamentadoras (NRs), as quais hoje somam 36, que visam a prevenção de doenças e acidentes provocados pelo serviço, bem como auxiliar nas ações dos empregadores e funcionários, de forma a tornar o ambiente laboral um espaço saudável e decente (MTE, 2018).

Segundo a NR-9, Programa de Prevenção de Riscos de Acidentes Ambientais, a segurança do trabalho está também relacionada com o ambiente de trabalho, pois o ambiente laboral forma um conjunto de fatores interdependentes que atuam direta ou indiretamente na qualidade de vida das pessoas e nos resultados dos seus trabalhos (MTE, 2018). Portanto, no ambiente de trabalho é necessário encontrar condições capazes de proporcionar proteção e ao mesmo tempo satisfação, pois quando existe essa combinação, resultam num aumento significativo da produtividade, da qualidade dos serviços, redução de doenças ocupacionais e acidentes de trabalho.

Em contrapartida, diante da crise atual, muitos trabalhadores foram empurrados para informalidade, os quais não possuem os direitos trabalhistas assegurados aos empregados pela CLT. Porém, as normas de segurança no trabalho devem ser aplicadas ao trabalhador informal, uma vez que segundo o artigo $2^{\circ}$ da lei 8.080/1990 da Constituição da República Federativa do Brasil, "a saúde é um direito fundamental do ser humano, devendo o Estado promover as condições indispensáveis ao seu pleno exercício" (TRT/MG, 2017).

\subsection{TRABALHO INFORMAL}

A existência de trabalhadores que estão à margem dos programas e ações da saúde e segurança do trabalho no setor informal da economia, o qual o termo foi criado pela Organização Internacional do Trabalho (OIT) e pode ser definido como pequenas atividades urbanas, geradoras de renda, que ocorrem fora do sistema normativo e oficial segundo o Programa Regional de Emprego para a América Latina e Caribe (PREALC), cresce paulatinamente e agrava $\mathrm{O}$ cenário nacional (MENDES, 2004).
O trabalho é a base da economia de um país e no Brasil a situação do trabalhador informal tem suscitado muita atenção por estar relacionada a problemas de ordem econômica e social, uma vez que é um fenômeno que está presente no mundo capitalista (SANTOS, 2008). Com isso, estudos e debates acerca do tema da informalidade no mercado de trabalho apresentaram distintos motivos para o crescente número de pessoas nesse âmbito, como por exemplo o aumento da regulamentação da economia e o desemprego (LOPES et.AL, 2013).

No Brasil, cerca de $50 \%$ da população economicamente ativa exerce atividades informais segundo pesquisa realizada pelo IBGE em 2007. Esse índice, segundo Sasaki (2012), é resultado de vários fatores como, por exemplo, o excesso de regulamentação do mercado de trabalho, haja vista que é limitada a capacidade de pequenas empresas e trabalhadores informais de cumprirem as regras trabalhistas e previdenciárias.

Por outro lado, conforme o mesmo autor, as mudanças econômicas e sociais produzidas pela globalização geraram altas taxas de desemprego e aumentou o número de trabalhos a margem do aparato legal. Com isso, houve o excedente de mão de obra, e o desempregado encontrou no emprego informal, não uma forma de obter lucro, mas de sobrevivência.

Segundo pesquisa realizada pelo IBGE em 2017, houve um aumento na população economicamente ativa, pois o desempregado entrou no mercado informal para se manter (GLOBO, 2018). Porém, é notório que apesar dos trabalhadores estarem adentrando o setor informal, seja por necessidade ou escolha, possuem desvantagens em relação ao setor formal da economia, uma vez que não possuem carteira assinada, renda fixa, possuem baixa remuneração e principalmente a falta de segurança e proteção, já que com a vulnerabilidade trabalhista, ficam totalmente desprotegidos das vantagens oferecidas como seguro-desemprego, INSS e FGTS (ALVES, 2015).

Conforme Ribeiro (2000), além do trabalhador, o Estado também sai prejudicado, pois não arrecada dinheiro suficiente com os impostos para investir na criação de novos empregos para o país e assim, diminuir o número de trabalhadores informais. Dessa forma, 
segundo o mesmo autor, a economia informal torna-se um desafio, pois uma economia informal ativa e crescente gera uma redução na receita do Estado, resultando em uma diminuição da quantidade de serviços e bens públicos postos à disposição da sociedade, 0 que leva a um aumento das taxas tributaria e consequentemente o incentivo a participação dos agentes na economia informal.

Em outro contexto, segundo Bouças (2012) a forma como as atividades se desenvolve num determinado local, refletem a sociedade a qual estão implantadas, pois o espaço é um produto social e econômico. Isso evidencia que com o crescimento de trabalhadores informais nas ruas, houve uma modificação no espaço físico, haja vista que se 'organizam' da forma que thes convier para vender suas mercadorias, colocando os produtos em calçadas ou em carrinhos no meio das ruas, o que, consequentemente atrapalha a mobilidade urbana da região.

A rua é um espaço público, mas também é um ambiente de trabalho, e os trabalhadores que vivem neste meio estão sujeitos a riscos como violência, roubos, atropelamentos, além do perigo de contrair doenças, já que realizam seus trabalhos em meio à poluição das ruas e condições climáticas adversas como sol e chuva, podendo, além disso, perder suas mercadorias e comprometer sua renda (SOUZA, 2011).

Conforme o Ministério do Trabalho (2018), a norma Regulamentadora número 21, ao se referir ao trabalho a céu aberto, aponta a obrigatoriedade da existência de abrigos para proteger os trabalhadores de intempéries, como calor, frio, insolação, umidade e ventos inconvenientes. Além desta, de acordo com o mesmo órgão, a norma regulamentadora número 15 , assegura o trabalhador contra condições insalubres como agentes químicos, biológicos e poeiras por exemplo. Com isso, é notório que a condição em que se encontra o trabalhador informal, se distancia dessas políticas sociais.

\subsection{REALIDADE NO ESTADO}

O estado do Piauí apresenta pouca participação na economia nacional, pois sua economia está voltada para o setor de serviços, predominantemente nas atividades comerciais. Sua população tem nível de renda extremamente baixo e essa realidade é intensificada pelo desemprego crescente e pela fragilidade da classe trabalhadora na luta pelos seus direitos, os quais devem ser garantidos pela Justiça do Trabalho, Ministério Público do Trabalho e pela Auditoria do Ministério do Trabalho (COSTA et. AL, 2011).

$\mathrm{Na}$ capital Teresina, é comum se notar trabalhadores por conta própria, seja nos semáforos se utilizando da arte para garantir o alimento de cada dia, ou como vendedores ambulantes nas ruas como forma de se obter alguma renda. Essas formas de trabalho, vistas em primeiro plano como uma 'válvula de escape' para a própria sobrevivência, esconde sérias consequências para os trabalhadores e para a cidade.

Segundo ITIKAWA (2006), a vulnerabilidade em que se encontra o trabalhador informal nas cidades está associada à exposição a riscos que fugiram do controle e interferem na integridade física de uma pessoa ou grupo.

É fácil perceber que a condição em que se encontra o trabalhador por conta própria é bastante precária, pois além de não possuírem garantias da legislação trabalhista, como estabilidade e FGTS, por exemplo, estão sujeitos á riscos que interferem diretamente na sua qualidade de vida e que poderiam ser evitados com uma política de assistencialismo feita pelas autoridades públicas.

Além da vertente de adentrar o setor informal por necessidade, como forma de garantir a sobrevivência, o trabalho pela informalidade, por outro lado, pode ser visto como uma oportunidade de impulsionar o empreendedorismo a partir de ideias de novos modelos e negócios, uma vez que grande parte da economia informal é constituída de micro ou pequenos empreendedores (POTRICH, 2013).

Portanto, além de propiciar o sustento de muitas famílias, o trabalho informal é capaz de sustentar grande parte da população brasileira, além de contribuir significativamente para o Produto Interno Bruto (PIB) de um país (ALVES, 2015). Nesse sentido, foi diante dessa realidade que o estudo e análise dos efeitos e vantagens da construção do shopping da cidade de Teresina para os trabalhadores e para a cidade evidenciaram a importância da pesquisa presente, uma vez que o mesmo veio como forma de organizar o espaço, assim como propiciar uma melhor qualidade de vida para eles. 


\section{METODOLOGIA}

A metodologia é de natureza básica, pois não apresenta finalidades imediatas, tem objetivo descritivo, uma vez que descreve os fatos observados sem interferir neles, e estudo de caso com procedimento, haja vista que o presente estudo consistiu em coletar e organizar informações sobre determinado grupo, a fim de estudar aspectos variados que sejam objeto da pesquisa (POTRICH, 2013).

O artigo pretende compreender a satisfação do trabalhador informal do Shopping da Cidade em Teresina - Pl e o objetivo da Prefeitura com o feito. Para obter essas informações a pesquisa foi dividida em duas etapas, a primeira com uma entrevista realizada com a coordenação da Secretaria Municipal do Planejamento (SEMPLAN) da cidade e a segunda etapa um questionário respondido por uma amostra de trabalhadores.

A princípio, uma entrevista foi realizada a coordenação da SEMPLAN, levantando questões de caráter social, de ordem pública e do funcionamento do Shopping. Posteriormente, foi feita uma visita ao espaço físico do Shopping da Cidade, selecionado aleatoriamente uma amostra não probabilística baseada na conveniência de 50 trabalhadores escolhidos de forma aleatória que interromperam suas atividades e com posse de um questionário inspirado no modelo utilizado na pesquisa de campo da monografia "Setor informal urbano (Estudo do comercio ambulante)" do autor André Ilson Vicente Conceição feita em 2010, os pesquisadores fizeram um estudo qualitativo a respeito da qualidade de vida dessas pessoas.

Os dados obtidos no questionário respondido pelos trabalhadores geraram gráficos que ajudaram a representar melhor o índice de satisfação com o empreendimento teresinense. Para isso, utilizou-se como procedimento estudo de caso e levantamentos bibliográficos.

\section{RESULTADOS}

Durante o estudo realizado na SEMPLAN, por meio de um questionário semiestruturado, foi analisado os impactos da construção do espaço popular para a região e para os trabalhadores. Segundo a coordenação do órgão público o shopping da cidade é resultado de um longo processo de discussão sobre os problemas no centro da cidade, pois desde que o centro começou a ter essa ocupação informal e a vivenciar os problemas naturais do crescimento da cidade como a mobilidade urbana, a prefeitura sempre colocou o centro como pauta principal na questão do planejamento do centro da cidade.

O Shopping da Cidade de Teresina, localizado na Avenida Maranhão, possui 1956 boxes distribuídos em três pavimentos, praça de alimentação, terminais de autoatendimento bancário, loteria e abriga mais de 1600 comodatários que antes trabalhavam pelas ruas do centro em barracas improvisadas, uma vez que é resultado do processo de revitalização do centro da capital piauiense (GLOBO, 2013).

Com o crescente número de trabalhadores ambulantes no centro da capital, o shopping popular veio como forma de organizar o espaço, bem como oferecer melhores condições aos trabalhadores que antes eram vulneráveis a situações de risco intensificadas pelo trabalho no meio das ruas, pois conforme representante da SEMPLAN

\begin{abstract}
"o shopping veio com a intenção de organizar o comércio informal e a organização desse comércio teve dois objetivos principais: primeiro, desocupar o espaço público, as praças e devolver esses espaços pra população, para que ela pudesse transitar de uma maneira segura e confortável, e segundo, dar condições dignas para os ambulantes, pois a prefeitura procurou ver a questão social já que são famílias que dependem desse comércio para sobreviver."
\end{abstract}

É importante considerar também, quem os trabalhadores que estão na informalidade não possuem os direitos assegurados pela CLT para trabalhadores formais. Porém, conforme análise da pesquisa na SEMPLAN, a construção do shopping popular também pretendeu oferecer benefícios para os trabalhadores nesse âmbito, pois segundo a entrevistada

\footnotetext{
"um dos compromissos com a construção do shopping foi tornar o nosso camelô um microempreendedor através do MEl que significa Microempreendedor Individual, e oferece um grande benefício para eles, pois apesar de ter uma despesa, ela se torna mínima frente aos benefícios que vão ter em termos de aposentadoria, auxílio doença,
} 
como já tivemos comodatários que já se beneficiaram disso."

Nesse sentido, pode-se inferir que a construção do Shopping da Cidade foi uma forma encontrada pela Prefeitura de Teresina de oferecer uma melhor qualidade de vida aos trabalhadores, uma vez que pretendeu amenizar as dificuldades dos mesmos nas condições de trabalho as quais eram submetidos no meio das ruas e proporcionar direitos trabalhistas e previdenciários.
A maioria dos trabalhadores que estão na informalidade enfrentam dois desafios principais: o de sobrevivência e as consequências do trabalho sem legalidade (PEREIRA et. AL, 2012). Dessa maneira, um estudo realizado com uma amostra de 50 trabalhadores do Shopping da Cidade, mostrou as mudanças ocorridas na vida desses diligentes depois da construção do espaço popular. A gráfico 1 apresenta a análise das respostas dos trabalhadores informais do Shopping da Cidade.

Gráfico 1 - Análise das respostas dos trabalhadores informais do Shopping da Cidade

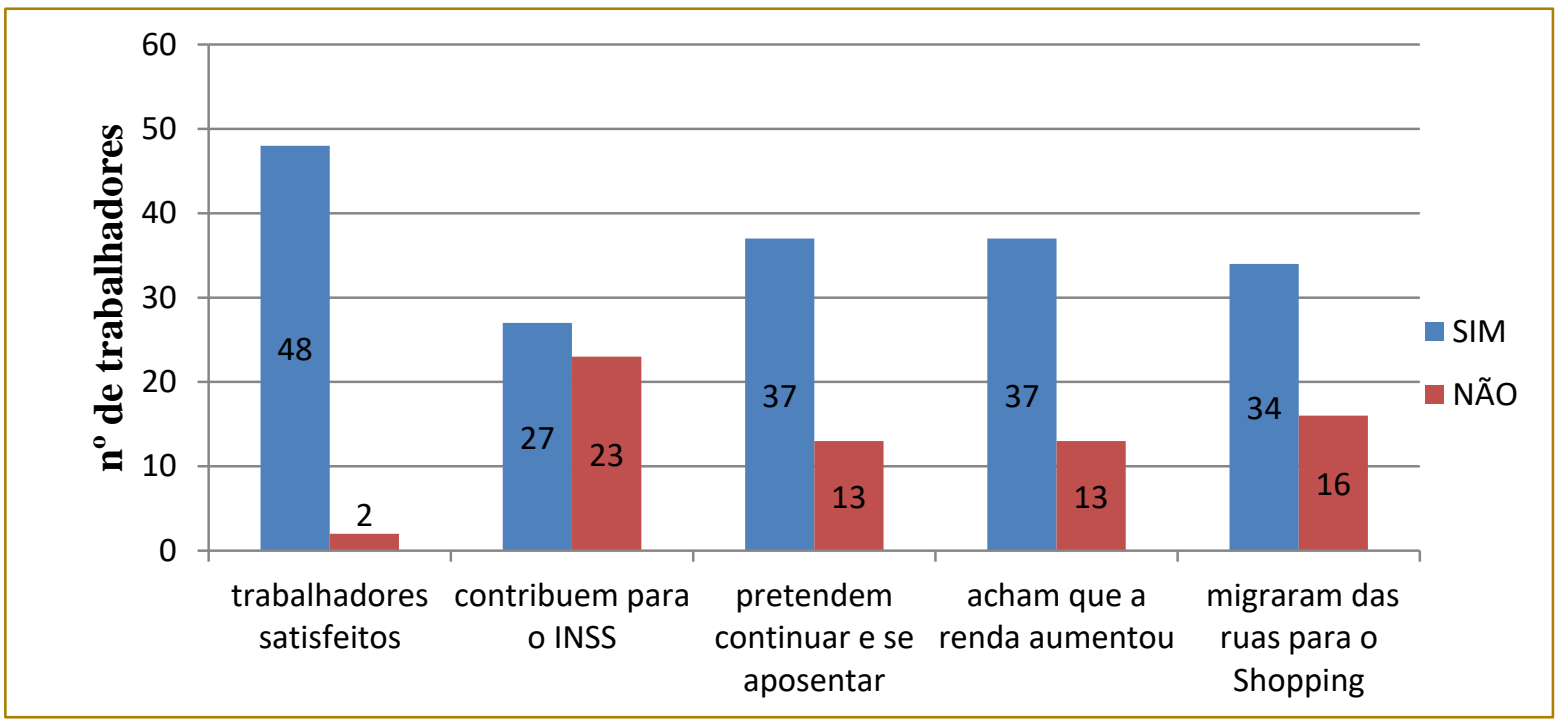

Fonte: Elaboração própria (2018)

Os resultados da pesquisa apontam que 48 dos 50 entrevistados se apresentam satisfeitos com o seu trabalho no Shopping da Cidade e que 37 dos interrogados pretendem continuar trabalhando no local até sua aposentadoria, a qual 27 afirmam que contribuem para o INSS. Além disso, o gráfico mostra que depois que migraram das ruas para o espaço popular, a renda de mais da metade dos questionados aumentou, uma vez que afirmam que por ser um shopping comercial, possui maior visibilidade e fluxo de pessoas.

A condição em que se encontrava os trabalhadores informais no meio das ruas eram sub-humanas se comparadas as que vivem hoje trabalhando no espaço popular, pois de acordo com as respostas dos entrevistados os fatores que mais os incomodavam fora do shopping eram as intempéries, como sol e chuva, além da violência. Os entrevistados afirmaram
"Nas ruas a gente sofria risco de sofrer mercadoria por causa da chuva e o sol também era muito ruim. Aqui a gente tem uma qualidade de vida melhor porque não tem mais esse risco e tem mais segurança pra gente né?!"

"Na rua eu tinha prejuízo, porque perdia minhas mercadorias pra chuva e para ladrão, e aqui já é mais seguro, tem mais conforto para a gente"

Nessa perspectiva, de acordo com as Normas Regulamentadoras do Ministério do Trabalho e Emprego (2018) número 21, a qual afirma que os trabalhos a céu aberto é obrigatório a existência de abrigos que sejam capazes de proteger os trabalhadores contra intempéries, e a número 15, que determina as atividades e condições insalubres como ruído, umidade e calor, nos permite inferir que o shopping trouxe contribuições positivas para os trabalhadores informais em termos de Segurança do Trabalho, uma vez que 
ofereceu abrigo e proteção a eles, além de ter melhorado as condições de trabalho desses comodatários, oferecendo um maior conforto.

Outrossim, é importante considerar que a similaridade das respostas dos entrevistados foi de suma importância para a obtenção dos resultados e obtenção da conclusão, uma vez que a situação do trabalhador informal é um problema de cunho social e econômico para o país.

\section{CONSIDERAÇÕES FINAIS}

O objetivo de estudo foi demonstrar a realidade do trabalhador informal, bem como mostrar as melhorias da qualidade de vida dos mesmo a partir da construção do

\section{REFERÊNCIAS}

[1] ALVES, Tatiany. REGIME GERAL DA PREVIDÊNCIA: implicações para o acesso a Previdência Social dos trabalhadores informais do Shopping da Cidade em Teresina. 59 f. Monografia (Bacharelado em Serviço Social) - Universidade Federal do Piauí, 2015.

[2] BARSANO, Paulo; BARBOSA, Rildo. Segurança do Trabalho: guia prático e didático. São Paulo: Érica, 2013.

[3] BOUÇAS, Rose Laila de Jesus. Trabalhadores de rua: uso do solo urbano e apropriação do espaço público. Trabalho de Conclusão de Curso (Graduação) - Universidade do Estado da Bahia. Departamento de Ciências Exatas e da Terra. Colegiado de Urbanismo. Campus I. 2012.

[4] BRASIL. Ministério do Trabalho e Emprego. NR 01 - Disposições Gerais. Brasília: Ministério do Trabalho e Emprego, 1978. Disponível em:<

http://trabalho.gov.br/images/Documentos/SST/NR/ NR1.pdf>. Acesso em: 17 mai. 2018.

[5] BRASIL. Ministério do Trabalho e Emprego. NR 09 - Programa de Prevenção de Riscos Ambientais - PPRA. Brasília: Ministério do Trabalho e Emprego, 1978. Disponível em:< http://trabalho.gov.br/images/Documentos/SST/NR/ NR-09.pdf>. Acesso em: 17 mai. 2018.

[6] CARTA-CAPITAL. IBGE: trabalho informal cresce e desemprego cai para $12,6 \%$ em agosto. Disponível em:

https://www.cartacapital.com.br/economia/ibgetrabalho-informal-cresce-e-desemprego-cai-para12-6-em-agosto> Acessado em: 15 de Mai. 2018.

[7] CONCEIÇÃO, André: Setor Informal Urbano( estudo do comércio ambulante). 34 f. pós-
Shopping da Cidade. Os estudos indicam que depois da obra, esses trabalhadores estão satisfeitos com suas condições de trabalho atuais

Podemos inferir também a partir do sucesso da obra, que as ações públicas de sucesso repercutem também em outros campos da sociedade, como foi em Teresina quando o ato da prefeitura em resgatar os ambulantes das ruas colocando-os dentro de um aparato legal resguardado da segurança do trabalho, melhorou na mobilidade urbana do centro da capital quando realocou os trabalhadores e tudo isso resultou na criação de um centro comercial que devido a organização gerou retorno financeiro ao trabalhador e ofereceu mais uma alternativa de mercado a população teresinense.

graduação(lato sensu) - Universidade Candido Mendes, 2010.

[8] COSTA, Samuel et al. Piauí, emprego, direito trabalhista e desenvolvimento da crise do capital. São Luís: 2011.

[9] GLOBO G1. Desemprego fica em 12,2\% em janeiro de 2018 e atinge 12,7 milhões de pessoas:

https://g1.globo.com/economia/concursos-eemprego/noticia/desemprego-fica-em-122-emjaneiro-de-2018.ghtml. Acesso em: 17 mai. 2018.

[10] GLOBO G1. O espaço comercial mais popular de Teresina: http://g1.globo.com/pi/piaui/noticia/2013/08/shoppi ng-da-cidade-o-espaco-comercial-mais-popularde-teresina.html. Acesso em: 14 fev. 2018.

[11] ITIKAWA, Luciana Fukimoto. "Trabalho informal nos espaços públicos no centro de São Paulo: pensando parâmetros para políticas públicas". São Paulo: FAUUSP, 2006. Tese de Doutorado.

[12] IRIART, J. A. B. et al. Representações do trabalho informal e dos riscos à saúde entre trabalhadoras domésticas e trabalhadores da construção civil. Ciência \& Saúde Coletiva, v. 13, n. 1, p. 165-174, 2008

[13] LOPES, Amanda et al. Perfil sócio econômico dos trabalhadores informais do Shopping popular da região central de Cuiabá em 2013. Revista de Estudos Sociais, Cuiabá, N. 30, V.15 p. $175,2013$.

[14] MENDES, R.; CAMPOS, A. C. C. Saúde e segurança no trabalho informal: Desafios e oportunidades para a indústria brasileira. Revista 
Brasileira de Medicina do Trabalho, v. 2, n. 3, p. 209-223, 2004

[15] PEREIRA, Rodrigues et al. O sofrimento dos trabalhadores informais, vítimas de acidentes de trabalho. Revista Eletrônica de Enfermagem do Centro de Estudos de Enfermagem e Nutrição, Goiás, 2012.

[16] POTRICH, A. C. G.; RUPPENTHAL, J. E. Empreendedorismo na informalidade: um estudo de caso no Shopping Independência de Santa Maria-RS. GEPROS. Gestão da Produção, Operações e Sistemas, Bauru, Ano 8, no 3, jul.set/2013, p. 145-158.

[17] PRODANOV, Cleber; FREITAS, Ernani. Metodologia do Trabalho Científico: Métodos e Técnicas da Pesquisa e do Trabalho Acadêmico. Novo Hamburgo: Feevale, 2009.

[18] RIBEIRO, Gustavo Faria. Causas, Efeitos e Comportamentos da Economia Informal no Brasil. Tese de Mestrado da Universidade de Brasília Mestrado em Economia do Setor Público, 2000. Disponivel em: http://www.receita.fazenda.gov.br/Publico/estudotri
butarios/TrabAcademicos/Textos/RobertoCausasEf eitoseComportamentodaEconomialnformalnoBrasil. pdf. Acessado em: 15 de Mai. 2018.

[19] SANTOS, G. P. G. dos "Desemprego, informalidade e precariedade: a situação do mercado de trabalho no Brasil pós 1990". Proposições, vol. 19, n. 2, Campinas, 2008.

[20] SASAKI, M. A.; MENEZES, I. V. Trabalhador informal e Previdência Social: o caso dos trabalhadores por conta própria de Brasília-DF. Política \& Sociedade, v. 11, p. 173-198, 2012.

[21] SOUZA, L. J. R.; FREITAS, M. DO C. S. O agente comunitário de saúde: violência e sofrimento no trabalho a céu aberto. Revista Baiana de Saúde Pública, v. 35, n. 1, p. 96-109, 2011.

[22] Tribunal Regional do Trabalho/MG. Disponível em:

https://portal.trt3.jus.br/internet/imprensa/noticiasjuridicas/importadas-2017/nj-especial-otrabalhador-informal-e-as-regras-que-garantemsaude-e-seguranca-no-trabalho-24-01-2017 acesso em: $15 /$ 04/2018. 


\section{ANEXO A - ENTREVISTA (SEMPLAN)}

Qual o objetivo da obra do Shopping da Cidade?(motivo da construção)

Quais os critérios e obrigações para trabalhar no Shopping da Cidade? Existem taxas?

Quais os benefícios do Shopping para os trabalhadores? No âmbito fiscal, de auxílios doença e acidente, aposentadoria.

Quais os benefícios que o Shopping trouxe para a cidade e população?

Existe algum tipo de retorno ou lucro para a prefeitura? Quais?

Sobre o arranjo físico do Shopping, no que foi pensado e por que seu arranjo físico é daquela maneira? 
Você gosta de trabalhar aqui? Por quê?

Você faz contribuições para o INSS?

Pretende se aposentar trabalhando no Shopping?

Sua renda melhorou quando veio trabalhar no Shopping?

É difícil conseguir vaga ou manter vaga no shopping? Pôr quê?

Teria alguma reclamação? Qual?

Você acha justa a taxa que você paga para trabalhar aqui?

Já trabalhou no setor formal?

Já trabalhou no meio da rua?

Quais os riscos que você sofria quando trabalhava nas ruas? 


\section{Capítulo 6}

\section{DEPENDENCIA \\ DO \\ FORNECEDOR, COMPROMETIMENTO \\ CALCULATIVO E SEVERIDADE DA FALHA COMO ANTECEDENTES DA RETENÇÃO PÓS- FALHA DE SERVIÇOS EM CONTEXTOS BUSINESS-TO- BUSINESS}

\section{Humberto Caetano Cardoso da Silva \\ Alexandre de Oliveira Siqueira \\ Fernando José Machado Barbosa de Melo \\ Marcus Augusto Vasconcelos Araújo \\ Patrícia Carneiro Lins de Novaes \\ Viviane Caú Amaral}

Resumo: O ideal seria que as falhas de serviço não existissem, mas estas são inerentes ao processo de prestação de serviços. A severidade da falha, em um ambiente de grande competitividade como o business-to-business (B2B), pode levar ao fim do relacionamento cliente-fornecedor. Entretanto, a qualidade da recuperação, e os resultados que geram, pode criar índices de comprometimento entre cliente e o fornecedor que irão reforçar os laços comerciais, gerando relacionamentos duradouros. A dependência do cliente pode ser um dos motivos pelos quais estes se mantêm em relações, mesmo em situações de insatisfação com a prestação do serviço. O propósito deste trabalho foi o de estudar a relação entre a retenção e o comprometimento obtido após uma recuperação de falha de serviços, juntamente com a severidade percebida da falha de serviços e a dependência do cliente em relação ao fornecedor, em ambientes B2B. O estudo foi realizado com profissionais de tecnologia da informação que ocupam cargo de chefia. A análise dos dados foi realizada a partir da utilização de regressão logística. Como resultado final da regressão, relações significativas foram identificadas entre dependência do fornecedor, comprometimento e severidade da falha, e comprometimento calculativo com a retenção. 


\section{INTRODUÇÃO}

Sendo a prestação de serviços suscetível a falhas, possuir mecanismos que garantam o tratamento e recuperação pode representar a diferença entre perder ou manter o cliente. A boa recuperação de serviços pode gerar maiores níveis de comprometimento e, consequente, retenção do cliente (TAX et al., 1998; WHITE; YANAMANDRAM, 2007; CHANG et al., 2012; WANG; CHANG, 2013).

$\mathrm{Na}$ literatura, poucos são os estudos que tratam, de forma conjunta, os construtos comprometimento calculativo, dependência e severidade da falha, como antecedentes da retenção de clientes. Quando o contexto estudado é o de relações Business-toBusiness (B2B), este número torna-se ainda menor. Assim, autores como White e Yanamandram (2007), Oliveira e Roth (2012) e Johns (2014), solicitam maiores esforços no entendimento dessas relações.

Adicionalmente, manter clientes atuais satisfeitos e desenvolver mecanismos que permitam relações de longo prazo é um fator imperativo para o sucesso das empresas. Uma falha de serviços, de modo geral, produz um impacto negativo na percepção do cliente em relação à empresa fornecedora (MCCOLLOUGH, 2009). Assim, identificar o resultante de um momento de falha e como a falha deste fornecedor impactou nas operações do cliente, representam a diferença entre manter ou perder o cliente.

Assim, considerando o ambiente de relacionamentos Business-to-Business, a necessidade de retenção de clientes, e as falhas que possam ocorrer na prestação de serviços, o presente estudo busca avaliar as relações entre a retenção de clientes severidade da falha, comprometimento calculativo e dependência do fornecedor após a ocorrência de falhas de serviços de TI em contextos B2B.

\section{O AMBIENTE B2B, O SERVIÇO DE TI E AS FALHAS DE SERVIÇOS}

No mercado B2B a aquisição de produtos e serviços é realizada a partir de dois critérios, sendo o primeiro relacionado ao tipo de compra a ser realizada, com aspecto mais tangível, como matérias primas ou equipamentos para produção, ou mais intangível, como serviços de limpeza, legais ou de tecnologia. Já o segundo critério verifica se este produto ou serviço está ligado ao consumo interno, à venda direta ao consumidor, ou ainda à transformação do mesmo (PARASURAMAN, 1998; OLIVEIRA; ROTH, 2012).

A partir dos critérios apresentados, uma maior complexidade pode se apresentar na prestação de serviços em ambientes B2B, pois estes exigem maior conhecimento técnico que em serviços direcionados à consumidores finais, e podem incluir manutenções, reparos, consultorias e serviços especializados (JACKSON et al., 1995). A capacidade técnica exigida na prestação de serviços no contexto B2B pode ser percebido na prestação de serviços de TI. Os serviços de TI apresentam alto índice de intangibilidade, trazendo vários desafios para que altos níveis de satisfação do cliente sejam alcançados (BEATSON et al., 2007).

Neste contexto, o paradigma da desconfirmação de expectativas pode ser percebido no momento em que o cliente utiliza o serviço e assume-se satisfeito ou insatisfeito (OLIVER, 1980; SILVA; ARAÚJO, 2015). A performance ou resultado observados durante o encontro de serviços é comparada com a expectativa anterior. Caso a comparação seja positiva o cliente percebe um encontro de serviços satisfatório, caso contrário, a performance ou o resultado observado durante o encontro de serviços foi inferior à expectativa e encontro de serviços foi insatisfatório, gerando a falha de serviços (BITNER, 1990; SILVA; ARAÚJO, 2015).

Assim, a recuperação de serviço é toda a atividade associada à intenção ou esforço que a empresa realiza no sentido de identificar e corrigir as eventuais falhas de serviço (TAX et al., 1998; WANG; CHANG, 2013). A impossibilidade de evitar a ocorrência das falhas torna necessário que sejam criados procedimentos e controles que possibilitem a identificação de sua frequência, bem como de quais os resultados obtidos após a sua recuperação (WANG et al., 2011).

\section{ANTECEDENTES DA RETENÇÃO}

Henning-Thurau e Klee (1997) definem retenção de clientes como o comportamento de compra de forma repetida. É importante salientar que a inclinação do cliente em relação à marca não está associada à recompra, mas sim a simples ação de realizar ou não a compra (HENNIG-THURAU; KLEE, 1997). Adicionalmente, a retenção pode ser, 
também, definida como a inclinação do cliente em continuar com o provedor de serviços atual (RANAWEERA; PRABHU, 2003).

Entretanto, ambientes de relações B2B tem características específicas e eventos únicos podem desencadear 0 fim da relação (HOLLMANN et al., 2015). Adicionalmente, incidentes críticos negativos influenciam a natureza e a magnitude da relação entre satisfação e participação no mercado em ambientes B2B (VAN DOORN; VERHOEF, 2008).

Tax et al. (1998) propõem que a confiança e o comprometimento são consequentes de um processo de recuperação de falhas. Adicionalmente a confiança e o comprometimento estão relacionados à retenção de clientes (RANAWEERA; PRABHU, 2003) e, ainda, alguns estudos confirmam esta relação em situações pós falha de serviços (WHITE; YANAMANDRAM, 2007; WANG; CHANG, 2013).

\subsection{COMPROMETIMENTO CALCULATIVO}

O Comprometimento pode ser definido como uma relação contínua tão importante que o "parceiro de troca", ou a "outra parte na relação", esforce-se para justificar a manutenção dessa relação. As partes do compromisso acreditam que o relacionamento vale a pena ser mantido e se asseguram que esta relação dure o máximo de tempo possível. Adicionalmente, no marketing de relacionamento, o comprometimento assume papel central, juntamente com a confiança (MORGAN; HUNT, 1994).

Tax et al. (1998) estudaram os consequentes da recuperação de serviços e um deles é o comprometimento. Pode ser verificado que bons níveis resolução de falhas de serviço poderiam levar a maiores níveis de comprometimento. Essa relação de satisfação com a resolução de falhas de serviço e comprometimento foi verificada em estudos empíricos posteriores como os de Wang e Chang (2013).

O comprometimento calculativo pode ser compreendido como uma avaliação cognitiva do valor da continuação de um relacionamento. $\mathrm{O}$ comprometimento calculativo é, portanto, um estado de ligação à um fornecedor, pois o final dessa relação implicaria sacrifícios e perdas conquistadas ao longo do tempo. Um aspecto importante do comprometimento calculativo é o reconhecimento de altos custos de mudança associados ao fim do relacionamento (SIQUEIRA, 2001; WETZELS et al., 1998).

Dessa forma, em situações de falha e recuperação de serviços, a qualidade percebida na recuperação da falha pode levar a níveis mais altos de comprometimento (TAX et al., 1998). White e Yanamandram (2007), em seu estudo sobre clientes insatisfeitos em ambientes B2B, identificaram uma alta correlação entre o comprometimento calculativo e a retenção de clientes. Com base no apresentado, é formulada a hipótese de estudo 1.

H1: A retenção de clientes é positivamente relacionada ao comprometimento calculativo percebido após a recuperação de falhas de serviço.

\subsection{DEPENDÊNCIA DO FORNECEDOR}

Para Gao et al. (2005), a dependência pode ser definida como a falta de melhores alternativas ou, pelo menos, a falta de alternativas que se apresentem no mesmo nível do fornecedor atual. Ademais, um dos antecedentes do comprometimento em uma relação é a dependência (VENETIS; GHAURI, 2004). Outra situação, comum, é a interdependência, quando as partes dependem, em certo nível, uma da outra. Entretanto, é possível que essa relação seja assimétrica, ou uma das partes percebe a dependência mais que a outra. Assim, a exploração potencial da parte com mais força na relação tem sido a razão principal para a antecipação de efeitos negativos da dependência no comprometimento. (GEYSKENS et al., 1996; JAMBULINGAM et al., 2011).

A partir do apresentado, e tomando como base o fato de que a dependência do cliente em relação à um fornecedor é um construto que se faz presente em vários trabalhos relacionado ao marketing de serviços (GEYSKENS et al., 1996; YANAMANDRAM; WHITE, 2010, 2012; CHANG et al., 2012), e que a dependência do cliente está ligada diretamente à sua retenção (YANAMANDRAM; WHITE, 2010, 2012), é possível apresenta-se as hipóteses de pesquisa $\mathrm{H} 2 \mathrm{a}$ e H2b:

H2a: A retenção do cliente é positivamente relacionada à dependência do cliente em relação ao fornecedor. 
H2b: O comprometimento calculativo do cliente em relação ao fornecedor é positivamente relacionado à dependência do cliente em relação ao fornecedor.

\subsection{O PAPEL DA SEVERIDADE DA FALHA}

Devido à natureza variável do serviço as falhas são inevitáveis. A falha de serviço pode ocorrer quando o serviço não atende às expectativas do cliente. Vários estudos argumentam que a severidade da falha deve ser levada em consideração quando está sendo analisada a falha e recuperação de serviço. A severidade da falha pode ser definida como a severidade percebida pelo cliente do problema, quanto mais intensa a severidade de um problema, maior será a perda percebida pelo cliente (WANG et al., 2011).

Weun et al. (2004) argumentam que, apesar de vários estudos tratarem de falha $e$ recuperação de serviços, estes não incluem a severidade da falha nos seus modelos, apesar de autores identificarem que a severidade da falha é importante fator a ser considerado no processo de recuperação de serviços. A severidade da falha terá influência na avaliação de um provedor de serviços após a falha ter sido recuperada. Mesmo após uma recuperação de serviços eficiente, uma falha com alto grau de severidade produziria uma perda irreparável para o cliente (WEUN et al., 2004).

Em situações de falha de serviço, que são ubíquas e inevitáveis na prestação de serviços, os clientes tendem a fazer uma avaliação do quão grave é a falha e se esta está contida em uma chamada zona de tolerância. Esta zona de tolerância é uma área na qual o cliente absorve a falha e avalia qual o grau de severidade a falha teve. Caso essa falha tenha um alto grau de severidade, o cliente escolhe pela troca de fornecedor, caso a falha seja de um grau de severidade baixo ou dentro da sua zona de tolerância, a decisão do cliente estará vinculada aos esforços para recuperação desta falha (GRÖNROOS, 2001; WANG; CHANG, 2013).

Weun et al. (2004) argumentam que a severidade da falha tem um impacto negativo na confiança, no comprometimento e no boca-a-boca positivo. Concomitantemente, Wang e Chang (2013) afirmam que a severidade da falha percebida pelo cliente é um fator crítico da qualidade do relacionamento. Dessa forma, apresentam-se as hipóteses de pesquisa $\mathrm{H} 3 \mathrm{a}$ e H3b:

H3a: A severidade da falha de serviços é negativamente relacionada à retenção do cliente.

H3b: A severidade da falha de serviços é negativamente relacionada ao comprometimento calculativo do cliente no fornecedor.

\subsection{MODELO TEÓRICO PROPOSTO}

Após a análise de estudos e a proposição das relações entre os construtos é possivel apresentarmos o modelo teórico proposto no estudo, demonstrado na figura 1. Este foi desenvolvido de forma que possibilitasse uma melhor compreensão das relações entre os construtos propostos na pesquisa. O modelo foi desenvolvido a partir dos modelos teóricos propostos por Tax et al. (1998), Weun et al. (2004), Yanamandram e White (2007), Henning-Thurau e Klee (1997), Morgan e Hunt (1994) e Wang et al. (2011).

\section{FIGURA 1 - Modelo Teórico Proposto}

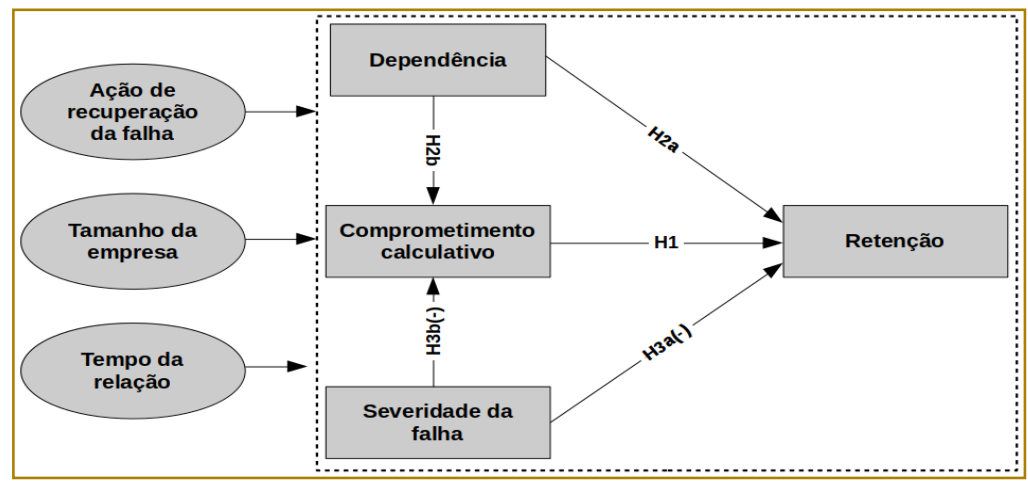




\section{PROCEDIMENTOS METODOLÓGICOS}

De maneira a operacionalizar a presente pesquisa, foram utilizados os pressupostos para estudos de natureza quantitativa propostos por Hair Jr. et al. (2009). Esta caracteriza-se com sendo uma pesquisa como descritiva, com a utilização de um levantamento (survey), com corte transversal único. Quatro construtos foram abordados e testados. Na tabela 1 estão apresentadas as variáveis pesquisadas através da survey.

Considerando a técnica de informanteschave, os participantes do estudo foram gestores de Tecnologia da Informação. Este cargo foi escolhido, pois são estes que recebem o serviço de suporte, que contratam as empresas terceirizadas, e que têm que reportar à alta administração os sucessos e as falhas do serviço (KUMAR; STERN; ANDERSON, 1993).

Após a elaboração e estruturação do instrumento de coleta de dados da pesquisa, este passou por um procedimento de validação conhecido como validade de face ou validade nominal (MALHOTRA; BIRKS; WILLS, 2012). Posteriormente a validação de face, foram realizados três testes, a dimensionalidade, a análise de confiabilidade e a validade convergente. De forma a identificar possíveis problemas com o questionário foi realizada a etapa de pré-teste (HAIR JR. et al., 2009). A realização do préteste obteve um total de 22 questionários. De maneira geral os participantes não tiveram dificuldades na compreensão das questões, não sendo necessários ajustes no questionário.

TABELA 1 - Escalas utilizadas no estudo

\begin{tabular}{|l|c|c|l|}
\multicolumn{1}{c|}{ Construtos } & Itens de Escala & Item & \multicolumn{1}{c|}{ Escalas Utilizadas } \\
\hline Retenção & RETE_1 & 1 & Escala binária (Continuar ou trocar) \\
\hline $\begin{array}{l}\text { Severidade da Falha } \\
\text { Dependência do } \\
\text { Fornecedor }\end{array}$ & SEVE_1 a 3 & $1 ; 2$ e 3 & Weun et al. (2004); Tang (2014) \\
\hline Comp. Calculativo & DEPE_1 a 3 & $4 ; 5$ e 6 & $\begin{array}{l}\text { Ganesan (1994); Yanamandram e White } \\
\text { (2010); Chang et al. (2012) }\end{array}$ \\
\hline
\end{tabular}

Para que fossem coletados os dados foram utilizadas duas estratégias, sendo a primeira a partir da entrega do questionário diretamente pelo próprio pesquisador em empresas nas quais o mesmo tem acesso à equipe decisora em questões relacionadas a TI, e a segunda a através da utilização de alunos de graduação em cursos de Sistemas de Informação, Ciência da Computação e Redes de Computadores, que atuaram como pesquisadores junto aos gestores das empresas às quais estão trabalhando.

Antes da análise dos dados que foram coletados na pesquisa, foi necessário filtrar as informações de forma que foi possível localizar erros de digitação, dados omissos ou não respostas (missings) e observações atípicas (outliers).

\section{ANÁLISE DOS DADOS E DISCUSSÃO DOS RESULTADOS}

A pesquisa foi operacionalizada através da utilização de um questionário estruturado, aplicado entre os meses de abril e junho de 2018, junto à gestores de Tecnologia da Informação. Ao todo 190 questionários foram respondidos.

\subsection{CARACTERIZAÇÃO DA AMOSTRA}

Em relação ao tamanho das empresas, obteve-se uma grande variação. Os valores vão desde empresas com apenas 5 funcionários, até grandes empresas com mais de 22.000 funcionários. De maneira a utilizar um critério considerado internacional, definido pela Organização para a Cooperação e Desenvolvimento Económico (OECD), para o presente estudo, uma empresa será classificada como empresa de micro, pequeno e médio porte (MPME) caso o número de funcionários se situe na faixa abaixo de 250 (OECD, 2005). A tabela 2 apresenta a distribuição de empresas do estudo. 
TABELA 2: Tamanho da empresa a partir do número de funcionários da amostra pesquisada

\begin{tabular}{|c|c|}
\hline Tamanho & Frequência Relativa \\
\hline MPME & $67,40 \%$ \\
\hline Grande & $32,60 \%$ \\
\hline Total & $100,00 \%$ \\
\hline
\end{tabular}

Fonte: Coleta de dados (2018)

Entre as empresas que participaram do estudo, o maior percentual, de 50,50\%, foi das empresas do setor de serviços, em seguida as empresas do setor de comércio com 30,00\%. A distribuição das empresas por setor está apresentada na tabela 3.

TABELA 3: Setor de atuação da amostra pesquisada

\begin{tabular}{|c|c|}
\hline Setor & Frequência Relativa \\
\hline Serviço & $50,50 \%$ \\
\hline Comércio & $30,00 \%$ \\
\hline Governamental & $11,60 \%$ \\
\hline Indústria & $7,90 \%$ \\
\hline Total & $100,00 \%$ \\
\hline
\end{tabular}

Fonte: Coleta de dados (2018)

\subsection{CONFIABILIDADE DO INSTRUMENTO DE PESQUISA}

Hair Jr. et al. (2009) afirmam que valores de alfa de Cronbach acima de 0,6 são considerados satisfatórios. Adicionalmente, Hair Jr. et al. (2009) sugerem que alfas acima de 0,7 demonstram boa consistência interna da escala. Para o bloco que mediu a variável Severidade da Falha, obteve-se um alfa de Cronbach de 0,857. Já a variável Dependência do Fornecedor, teve o valor calculado do alfa de Cronbach 0,829. Para o comprometimento calculativo, o valor do alfa de Cronbach foi de 0,711.

\subsection{REGRESSÃO LOGÍSTICA}

Para que as variáveis, originalmente obtidas a partir da utilização de escala Likert de 5 pontos, pudessem ser aplicadas à regressão logística, foi utilizado o procedimento proposto por Silva, Araújo e Lucian (2016). Assim, após a verificação das medias de cada escala, o valor de 0 foi atribuído para as escalas que foram iguais ou menores que a mediana, caso contrário o valor de 1 foi atribuído.

Os modelos de Regressão Logística foram gerados a partir do método Stepwise
Backward LR. Adicionalmente, também foram analisadas as relações com as variáveis tamanho da empresa, tempo como cliente e ação de recuperação da falha. As variáveis foram dicotomizadas para que pudessem ser analisadas no contexto de Regressão Logística.

\subsubsection{VARIÁVEL COMPROMETIMENTO CALCULATIVO}

Para o modelo final, com todas as relações hipotetizadas no estudo, as variáveis que formaram a equação logística final foram a dependência e a ação de recuperação. A relação entre dependência e comprometimento calculativo corrobora com os achados de Gounaris (2005), Yanamandram e White (2010) e Chang et al., (2012), suportando a Hipótese H2b.

Já a relação entre severidade da falha percebida pelo cliente e comprometimento calculativo, proposta e, também, suportada por Weun et al. (2004), foi mensurada a partir de uma visão do unidimensional do construto Comprometimento. $\bigcirc$ presente estudo analisou o construto a partir de uma perspectiva multidimensional, analisando a dimensão comprometimento calculativo, o 
que pode ter levado a não confirmação da relação, refutando a Hipótese H3b.

O Odds Ratio obtido para a variável dependência de 3,210, indica que quando existe uma percepção de dependência do cliente em relação ao fornecedor as chances de ser percebido o comprometimento calculativo na relação aumentam 3,210 vezes. Uma variável do contexto, ação de recuperação também apresentou relações significativas.
O Odds Ratio para a ação de recuperação foi de 2,806 indicando que quando percebe o engajamento do fornecedor na resolução da falha as chances de perceber 0 comprometimento calculativo aumentam em 2,806 vezes. O modelo final teve um valor preditivo de $67,9 \%$. Os valores do modelo da regressão logística do comprometimento calculativo estão disponíveis na tabela 4.

TABELA 4: Coeficientes do modelo de regressão do comprometimento calculativo

\begin{tabular}{|l|c|c|c|c|c|c|}
\multicolumn{1}{|c|}{ Variáveis } & B & S.E. & Wald & GL & Sig. & Exp(B) \\
\hline Dependência & 1,032 & 0,358 & 8,286 & 1 & 0,004 & 3,210 \\
\hline Ação de recuperação & 1,166 & 0,335 & 12,105 & 1 & 0,001 & 2,806 \\
\hline Constante & $-1,237$ & 0,381 & 10,526 & 1 & 0,001 & 0,290 \\
\hline
\end{tabular}

\subsubsection{VARIÁVEL RETENÇÃO}

Para o modelo final, com todas as relações hipotetizadas no estudo, as variáveis que formaram a equação logística final foram comprometimento calculativo, corroborando com os achados de Morgan e Hunt (1994), Wang e Chang (2013), Gounaris (2005) e Venetis e Ghauri (2004), e suportando a Hipótese $\mathrm{H} 1$, e severidade da falha, também corroborando com os achados de Wang et al. (2011) e McQuilken e Robertson (2011), e suportando a Hipótese H3a.

Adicionalmente, a ação de recuperação de serviço e o tempo de relacionamento entre cliente e fornecedor, mostraram-se significativas na equação logística final. A ação de recuperação da falha também suporta o Paradoxo da Recuperação proposto por Tax et al. (1998) e o tempo de relacionamento indica que relações de longo prazo tendem a reforçar os laços entre os parceiros.

A relação da retenção com a variável dependência não pode ser suportada estatisticamente, apesar dessa relação ter tido suporte nos estudos de Wang et al. (2011) e McQuilken e Robertson (2011), refutando a Hipótese H2a. Yanamandram e White (2012) argumentam que a dependência se apresenta a partir das alternativas disponíveis no mercado e do investimento acumulado na relação com o fornecedor. A alta competitividade do mercado de TI pode explicar o porquê do não suporte à essa relação.

O Odds Ratio obtido para a variável comprometimento calculativo foi de 3,378, indicando que quando existe a percepção de comprometimento calculativo na relação, as chances de o cliente permanecer retido na relação aumentam 3,378 vezes. Já em relação à severidade percebida da falha, o Odds Ratio foi de 0,359 , indicando que quando o cliente percebe falhas de maior impacto nas suas operações, as chances de este permanecer na relação diminuem $64,1 \%$.

A variável tempo de relacionamento também se apresentou na relação final, indicando que relacionamentos com menos de 3 anos tem $50,2 \%$ de chances de serem encerrados no caso de ocorrerem falhas de serviço. Finalmente, caso a empresa fornecedora tenha agido para resolver a falha de serviços, as chances de o cliente permanecer na relação aumentam 17,770 vezes. O modelo final teve um valor preditivo de $75,8 \%$. Os valores da Regressão Logística da Retenção estão disponíveis na Tabela 5. 
TABELA 5: Coeficientes do modelo de regressão da retenção

\begin{tabular}{|l|c|c|c|c|c|c|}
\hline \multicolumn{1}{|c}{ Variáveis } & B & S.E. & Wald & GL & Sig. & Exp(B) \\
\hline Comprometimento calculativo & 1,217 & 0,372 & 10,726 & 1 & 0,001 & 3,378 \\
\hline Severidade & $-1,025$ & 0,410 & 6,245 & 1 & 0,012 & 0,359 \\
\hline Ação de Recuperação & 2,877 & 0,507 & 32,166 & 1 & 0,000 & 17,770 \\
\hline Tempo de relação inferior a 3 anos & $-0,696$ & 0,411 & 2,864 & 1 & 0,091 & 0,498 \\
\hline Constante & $-1,765$ & 0,541 & 10,632 & 1 & 0,001 & 0,171 \\
\hline
\end{tabular}

Fonte: Calculado pelos autores

\subsection{MODELO DAS HIPÓTESES SUPORTADAS NO ESTUDO}

Após a avaliação das hipóteses proposta pelo presente estudo, e para que seja possível melhor entendimento daquelas que apresentaram suporte estatístico nas relações entre as variáveis propostas, foi elaborada a figura 2, nela estão presentes as relações existentes nas equações de regressão finais.

FIGURA 2 - Modelo das Hipóteses Suportadas no Estudo

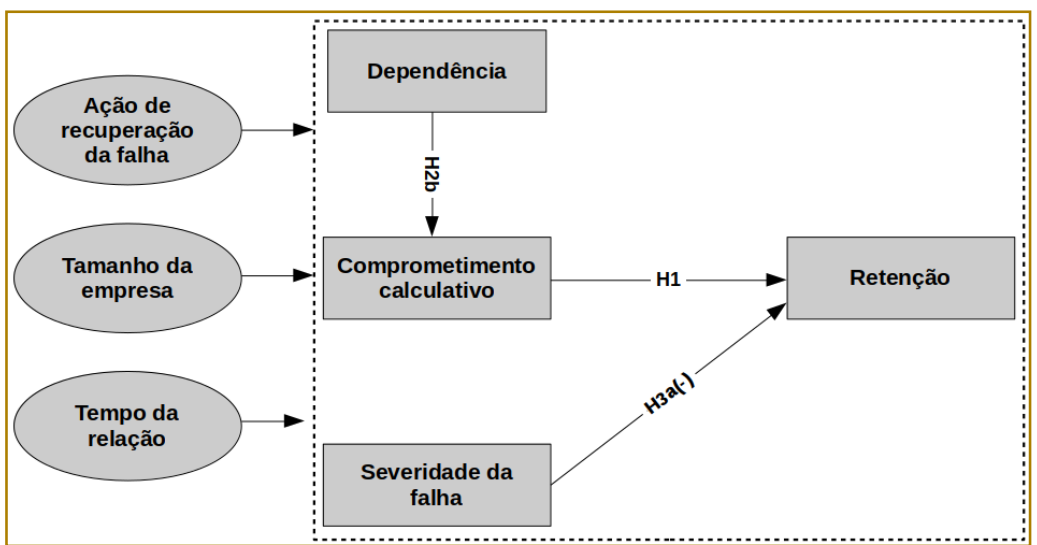

\section{CONCLUSÃO}

A proposta deste estudo foi a de analisar as relações existentes entre vários dos antecedentes de retenção de clientes de serviços de Tecnologia da Informação em ambientes B2B após um evento de falha e recuperação de serviços. Para isso foram avaliados os construtos severidade da falha, dependência do fornecedor e comprometimento calculativo.

A TI é um setor no qual grande parte das operações é realizada a partir de provedores de serviços externo, e que a confiança entre as partes é um requerimento para que ocorra a efetiva operação. O comprometimento é um dos consequentes de uma recuperação de falhas realizada com sucesso (TAX et al. 1998), sendo as falhas, no contexto da prestação de serviço, inevitáveis. Em ambientes B2B, a complexidade na prestação de serviços exige maiores conhecimentos técnicos e uma boa gestão de reclamações e recuperação de serviços pode resultar em altos índices de satisfação do cliente (HOMBURG; RUDOLPH, 2001).

Uma contribuição importante do presente estudo é a análise do impacto da severidade em contextos B2B. Nas relações entre a severidade da falha e a retenção, a variável ação de recuperação esteve presente, indicando que a ação de recuperação promove maiores índices de confiança, comprometimento e de retenção. O fato das duas variáveis surgirem conjuntamente nas relações pode indicar a ação contrária que a recuperação do serviço tem na percepção da severidade da falha.

Mais uma informação complementa o papel do comprometimento de clientes em contextos B2B é fornecida por Doney et al. 
(2007). Os autores argumentam que em ambientes de serviços B2B, onde as complexidades de se examinar muitos aspectos de intangibilidade dos serviços oferecidos, juntamente com a incerteza dos resultados obtidos pelos serviços prestados, fazem com que o cliente passe a utilizar

\section{REFERÊNCIAS}

[1] BEATSON, A; LEE, N; COOTE, LV. SelfService Technology and the Service Encounter. Service Industries Journal. 27, 1, 75-89, Jan. 2007. ISSN: 02642069

[2] BITNER, M.J.; BOOMS, B.H.; TETREAULT, M.S. The service encounter: Diagnosing Favorable and Unfavorable Incidents. Journal of Marketing. 54, 1, 71-84, Jan. 1990. ISSN: 00222429.

[3] CHANG, S. H.; WANG, K. Y.; CHIH, W. H.; TSAI, W. H. Building customer commitment in business-to-business markets. Industrial marketing management, v. 41, n. 6, p. 940-950, 2012.

[4] DONEY, P.M.; BARRY, J.M.; ABRATT, R. Trust determinants and outcomes in global B2B services, Vol. 41 Iss: 9/10, pp.1096 - 1116, 2007.

[5] GANESAN, S. Determinants of long-term orientation in buyer-seller relationships. the Journal of Marketing, p. 1-19, 1994.

[6] GAO, T.; SIRGY, M. J.; BIRD, M. M. Reducing buyer decision-making uncertainty in organizational purchasing: can supplier trust, commitment, and dependence help?. Journal of Business Research, v. 58, n. 4, p. 397-405, 2005.

[7] GEYSKENS, I.; STEENKAMP, J.B.E.; SCHEER, L.K.; KUMAR, N. The effects of trust and interdependence on relationship commitment: A trans-Atlantic study. International Journal of research in marketing, v. 13, n. 4, p. 303-317, 1996.

[8] GOUNARIS, S.P. Trust and commitment influences on customer retention: insights from business-to-business services. Journal of Business research, v. 58, n. 2, p. 126-140, 2005.

[9] GRÖNROOS, C. Value co-creation in service logic: A critical analysis. Marketing Theory. 11, 3, 279-301, Sept. 2011. ISSN: 14705931.

[10] GUSTAFSSON, A.; JOHNSON, M. D.; ROOS, I. The effects of customer satisfaction, relationship commitment dimensions, and triggers on customer retention. Journal of marketing, v. 69, n. 4, p. 210-218, 2005.

[11] HAIR JR, Joseph $F$. et al. Análise Multivariada de dados. Traduçao: Adonai Schlup Sant 'Anna e Anselmo Chaves Neto. 2009.

[12] HENNIG-THURAU, T.; KLEE; A. The impact of customer satisfaction and relationship quality on customer retention: a critical aspectos relacionais que sugerem que o fornecedor está alinhado com os objetivos e necessidades futuros do cliente. Dessa forma - valor da transação pode ser suplantado pela sensação de que o fornecedor está comprometivo.

reassessment and model development. Psychology \& Marketing, v. 14, n. 8, p. 737-764, 1997.

[13] HOLLMANN, T; JARVIS, C; BITNER, M. Reaching the breaking point: a dynamic process theory of business-to-business customer defection. Journal of the Academy of Marketing Science. 43, 2, 257-278, Mar. 2015. ISSN: 00920703.

[14] HOMBURG, C.; RUDOLPH, B. Customer satisfaction in industrial markets: dimensional and multiple role issues. Journal of Business Research, v. 52, n. 1, p. 15-33, 2001

[15] JACKSON, R.W.; NEIDELL, L.A.; LUNSFORD, D.A. An empirical investigation of the Differences in Goods and Services as Perceived by Organizational Buyers, Industrial Marketing Management, 24:2, 99-108, 1995.

[16] JAMBULINGAM, Thani; KATHURIA, Ravi; NEVIN, John R. Fairness-trust-loyalty relationship under varying conditions of supplier-buyer interdependence. Journal of Marketing Theory and Practice, v. 19, n. 1, p. 39-56, 2011.

[17] JOHNS, Raechel. Do self-service technologies affect interfirm relationships? A B2B perspective. Australasian Journal of Information Systems, v. 18, n. 3, 2014.

[18] KUMAR, N.; STERN, L. W.; ANDERSON, J. C. Conducting interorganizational research using key informants. Academy of management journal, v. 36, n. 6, p. 1633-1651, 1993.

[19] MALHOTRA, Naresh K.; BIRKS, David F.; WILLS, Peter. Essentials of marketing research. Pearson, 2013

[20] MCCOLLOUGH, Michael A. The recovery paradox: The effect of recovery performance and service failure severity on post-recovery customer satisfaction. Academy of Marketing Studies Journal, v. 13 , n. 1, p. 89, 2009.

[21] MCQUILKEN, Lisa; ROBERTSON, Nichola. The influence of guarantees, active requests to voice and failure severity on customer complaint behavior. International Journal of Hospitality Management, v. 30, n. 4, p. 953-962, 2011.

[22] MORGAN, R.M.; HUNT, S.D. The commitment-trust theory of relationship marketing. Journal of Marketing, v. 58, n. 3, p. 20-38, 1994. 
[23] OECD. ORGANISATION FOR ECONOMIC CO-OPERATION AND DEVELOPMENT. OECD SME and entrepreneurship outlook. OECD, 2005.

[24] OLIVEIRA, Pedro; ROTH, Aleda V. Service orientation: the derivation of underlying constructs and measures. International Journal of Operations \& Production Management, v. 32, n. 2, p. 156-190, 2012.

[25] OLIVER, R.L. A Cognitive Model of the Antecedents and Consequences of Satisfaction Decisions. Journal of Marketing Research (JMR). 17, 4, 460-469, Nov. 1980. ISSN: 00222437.

[26] PARASURAMAN, A. Customer service in business-to-business markets: An agenda for research. Journal of Business \& Industrial Marketing. 13, 4/5, 309, Apr. 1998.

[27] RANAWEERA, C.; PRABHU, J. The influence of satisfaction, trust and switching barriers on customer retention in a continuous purchasing setting. International Journal of Service Industry Management, v. 14, n. 4, p. 374-395, 2003.

[28] SILVA, H. C. C.; ARAUJO, M. A. V. Determinantes de satisfação e insatisfação em serviços de suporte à tecnologia da informação em ambientes B2B. Anais - SIMPEP, 2015.

[29] SILVA, H. C. C.; ARAÚJO, M. A. V.; LUCIAN, R. COMPROMETIMENTO AFETIVO, CUSTOS DE MUDANÇA E DEPENDÊNCIA COMO ANTECEDENTES DE RETENÇÃO DE CLIENTES EM CONTEXTOS B2B. XIX SEMEAD. 2016.

[30] SIQUEIRA, M.M.M. Comprometimento organizacional afetivo, calculativo e normativo: evidências acerca da validade discriminante de três medidas brasileiras. Encontro Anual da ANPAD, v. 25, p. 23-40, 2001.

[31] TANG, Andrew C. Justice-Based Normative Recovery Expectations in Enterprise Information Technology Services: The Effect of Failure Severity and Criticality on Disconfirmation and Satisfaction. 2014.

[32] TAX, S.S.; BROWN, S.W.; CHANDRASHEKARAN, M. Customer Evaluations of Service Complaint Experiences: Implications for
Relationship Marketing. Journal of Marketing. 62, 2, 60-76, Apr. 1998. ISSN: 00222429.

[33] VAN DOORN, J.; VERHOEF, P.C. "Critical incidents and the impact of satisfaction on customer share". Journal of Marketing, 72(3), 12442. 2008.

[34] VENETIS, K.A.; GHAURI, P.N. Service quality and customer retention: building long-term relationships. European Journal of marketing, v. 38, n. 11/12, p. 1577-1598, 2004.

[35] WANG, E. S.; CHANG, S. Creating Positive Word-of-Mouth Promotion Through Service Recovery Strategies. Services Marketing Quarterly, v. 34, n. 2, p. 103-114, 2013.

[36] WANG, Y.; WU, S.C.; LIN, H.H.; WANG, Y.Y. The relationship of service failure severity, service recovery justice and perceived switching costs with customer loyalty in the context of $e$ tailing. International Journal of Information Management, v. 31, n. 4, p. 350-359, 2011.

[37] WETZELS, M.; DE RUYTER, K.; VAN BIRGELEN, M. Marketing service relationships: the role of commitment. Journal of business \& industrial marketing, v. 13, n. 4/5, p. 406-423, 1998.

[38] WEUN, S.; BEATTY, S. E.; JONES, M.A. The impact of service failure severity on service recovery evaluations and post-recovery relationships. Journal of Services Marketing, v. 18, n. 2, p. 133-146, 2004.

[39] WHITE, L.; YANAMANDRAM, V. A model of customer retention of dissatisfied business services customers. Managing Service Quality: An International Journal, v. 17, n. 3, p. 298-316, 2007.

[40] YANAMANDRAM, V.; WHITE, L. An empirical analysis of the retention of dissatisfied business services customers using structural equation modelling. Australasian Marketing Journal (AMJ), v. 18, n. 4, p. 222-232, 2010

[41] YANAMANDRAM, V.; WHITE, L. Why do some business relationships persist despite dissatisfaction? A social exchange review. Asia Pacific Management Review, v. 17, n. 3, p. 301320,

2012. 


\section{Papítulo 7}

\section{AVALIACÃO DO CONTRATO DOS SERVICOS DE LIMPEZA E A GESTÃO DE TERCEIRIZADOS EM UMA UNIVERSIDADE FEDERAL}

\section{Joice Regina da Costa Santana da Lapa}

Rogério da Silva Nunes

Resumo: O trabalho trata da avaliação da gestão de contratos de terceirização em universidades públicas, analisando a gestão do contrato de terceirização do serviço de limpeza, firmado entre uma universidade pública e uma empresa privada. A metodologia utilizada na pesquisa é a de um estudo de caso descritivo, com coleta de dados documentais e entrevistas junto aos fiscais do contrato, representante da contratada, gestor do contrato e o Pró-Reitor em que ocorre tal gestão. Os resultados foram agrupados em cinco blocos de análise e revelaram problemas com relação a rotatividade e capacitação do pessoal da contratada e, por parte da contratante, destacam-se desconhecimento de atribuições e parâmetros de avaliação da qualidade do serviço prestado.

Palavras-chave: Terceirização; Administração Universitária; Avaliação; Gestão de Contratos. 


\section{INTRODUÇÃO}

Com a necessidade globalizada de modernização da gestão de bens e serviços, para a adequação das novas demandas do mercado, as organizações passaram a delegar a terceiros as atividades secundárias, focando-se mais nas suas atividades principais. As atividades que não sejam consideradas fundamentais, que não representam o seu principal objetivo, podem ser terceirizados a empresas externas especializadas, permitindo que a organização valorize sua própria competência, concentrando seus esforços nas atividades de maior valor agregado, refreando custos e adquirindo serviços e produtos indispensáveis ao seu desenvolvimento. Tal processo de transferência tem sido chamado de terceirização. (BASSO, 2008).

Assim. "a terceirização é o processo de gestão pelo qual se repassa alguma atividade para terceiros - com os quais se estabelece uma relação de parceria - ficando a empresa concentrada apenas em tarefas essencialmente ligadas ao negócio que atua". (GIOSA, 1997, p.14).

Quando uma organização do setor público decide optar pela terceirização de bens e serviços é preciso que tenha a participação efetiva do seu público interno e externo como força propulsora, capaz de impulsionar esse processo de forma exitosa. Ou seja, essa decisão precisa ser resultado de uma estratégia previamente concebida, pois a gestão de contratos de terceirização abrange muitas etapas, da preparação da minuta contratual, com seus respectivos anexos, até o término do prazo de vigência do mesmo. (GONÇALVES, 2006).

Sendo assim, a implantação da terceirização exige mudanças radicais nessa organização, uma vez que o gestor de contratos precisa possuir conhecimento sobre a terceirização e ter uma visão geral sobre ela e todas as suas implicações no setor público. (GONÇALVES, 2006, p. 24)

A Lei no 8.666, de 21 de junho de 1993, constitui normas gerais para licitações e contratos administrativos de serviços terceirizados no âmbito da União, dos Estados, do Distrito Federal e Municípios. Conforme prevê a Lei, o processo de terceirização requer a elaboração de um termo de referência para elaboração do edital de licitação. A empresa que apresenta a proposta mais vantajosa é a vencedora da disputa e celebra contrato administrativo com a contratante do objeto licitado. A definição de critérios pré-estabelecidos no preparo do projeto básico ou termo de referência poderá evitar o insucesso do referido processo e o consequente desperdício dos recursos públicos. O art. 6ำ da Lei no 8.666/93 define Projeto Básico como:

Conjunto de elementos necessários e suficientes, com nível de precisão adequado, para caracterizar a obra ou serviço, ou complexo de obras ou serviços objeto da licitação, elaborado com base nas indicações dos estudos técnicos preliminares, que assegurem a viabilidade técnica e o adequado tratamento do impacto ambiental do empreendimento, e que possibilite a avaliação do custo da obra e a definição dos métodos e do prazo de execução. (BRASIL, 1993).

A Instituição Federal de Ensino Superior (IFES), vinculada ao Ministério as Educação, está envolvida com a terceirização e é responsável direta pela contratação de empresas terceirizadas para prestação dos serviços secundários, como é o caso da limpeza. Assim, o trabalho procura avaliar como é gerenciado pela IFES o contrato de serviço terceirizado de limpeza firmado com uma empresa privada. Para atingir tal propósito, foram traçados os seguintes objetivos específicos:

a) Apresentar os dispositivos legais que normatizam os contratos na Administração Pública;

b) Descrever a gestão do contrato de serviços terceirizados de limpeza na IFES; e,

c) Identificar a ocorrência de divergências entre o previsto na legislação pertinente e os procedimentos de gestão de contrato de serviços terceirizados na IFES.

Sendo a IFES uma autarquia de regime especial, criada e vinculada ao Ministério da Educação, em conformidade com a Lei $\mathrm{n} . \stackrel{\circ}{ }$

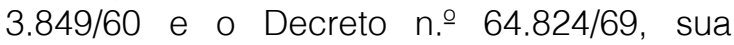
administração deve estar pautada nos princípios da legalidade, impessoalidade, moralidade, publicidade e eficiência. Consequentemente, a pesquisa se justifica pelo fato de que a gestão dos contratos de serviços terceirizados deve obrigatoriamente estar ajustada aos princípios que regem a administração pública, de modo que sua execução ocorra com qualidade e respeito à legislação vigente. 


\section{ASPECTOS METODOLÓGICOS}

Com a finalidade de abordar aspectos da gestão do contrato de serviços terceirizados de limpeza na IFES, o trabalho utilizou-se de uma abordagem de natureza qualitativa. Godoy (1995b, p.62) justifica o exposto ao dizer que essa modalidade "tem como preocupação fundamental o estudo e a análise do mundo empírico em seu ambiente natural". A abordagem qualitativa, conforme Godoy (1995a), está dividida em três diferentes estratégias de pesquisa: a documental, o estudo de caso e a etnografia. Nessa pesquisa a estratégia utilizada pode ser considerada como estudo de caso, por investigar um fenômeno contemporâneo dentro de seu contexto real, no qual as fronteiras entre o fenômeno e o contexto não são claramente evidentes, por isso, múltiplas fontes de evidências são utilizadas (YIN, 2008).

Em relação ao método, trata-se de pesquisa descritiva, pois, segundo Gil (2002, p.46): "as pesquisas descritivas têm como objetivo primordial a descrição das características de determinada população ou fenômeno ou, então, o estabelecimento de relações entre as variáveis".

No tocante à técnica, a pesquisa é bibliográfica e documental, complementada por dados empíricos fornecidos por atores sociais ligados diretamente ao tema. A pesquisa bibliográfica é desenvolvida com base em material já elaborado, constituído de livros e artigos científicos, e a documental por elementos que ainda não receberam um tratamento analítico (GIL, 2002). Os dados empíricos foram obtidos através de aplicação de um instrumento semiestruturado junto a diferentes atores envolvidos. Responderam ao instrumento doze gestores de contrato, lotados em diferentes setores da IFES, envolvidos diretamente com a gestão, além de serem passíveis de responsabilização por possíveis falhas na prestação do serviço.

As informações foram obtidas nos registros formais de documentos constantes nos arquivos da IFES, tais como cópias de contrato e respectivos termos aditivos, portarias, memorandos, fichas de acompanhamento dos serviços prestados, carta de apresentação dos serventes da contratada, relatório mensal de ocorrências, formulário de avaliação, fichas de controle de frequência, formulários de registros de reclamações enviados para a Ouvidoria da IFES e relatórios de pesquisa de qualidade.

\section{PRESTAÇÃO DE SERVIÇOS EM ÓRGÃOS PÚBLICOS}

A Lei no 8.666, de 21 de junho de 1993, conceitua contrato como "todo e qualquer ajuste entre órgãos ou entidades da Administração Pública e particulares, em que haja um acordo de vontade para a formação de vínculo e a estipulação de obrigações recíprocas, seja qual for a denominação utilizada". (BRASIL, 1993).

A gestão de contratos é uma atividade exercida pela Administração Pública e deve primar pelo controle, o acompanhamento e a fiscalização do pleno cumprimento das obrigações assumidas pelas partes. Cabe à Administração Pública a designação formal de um representante legal, que deverá registrar as ocorrências referentes ao contrato, adotando medidas visando à regularização das eventuais falhas ou danos identificados, em atendimento ao que preceitua o artigo 67, da Lei n. 8.666/93.

Além da Lei n. 8.666/93, os critérios para as contratações de serviços continuados na Administração Pública estão também determinados pelo Decreto no 2.271/97, pela Instrução Normativa (IN) no 18/1997, Instrução Normativa (IN) no 02/2008 e Instrução Normativa n. 06/2013. Esta última, publicada em 23 de dezembro 2013, altera a IN no 02/2008 e seus Anexos I, III, IV, V e VII e inclui o Anexo VIII.

Vale registrar que a IN no 02 , de 30 de abril de 2008, já havia sido alterada pela IN n.o 03/2009, pela IN n.우 04/2009 e pela IN n.응 05/2009. Da mesma maneira, a IN n. 06/2013 teve retificações textuais dadas pela IN no 3 , de 24 de junho de 2014. O Quadro 01 elenca a legislação básica que regulamenta as contratações de serviços terceirizados na Administração Pública: 
Quadro 01 - Legislação sobre a contratação de serviços na Administração Pública

\begin{tabular}{|c|c|c|}
\hline Dispositivo legal & Data & Assunto \\
\hline Decreto-Lei № 200/67 & 25/02/1967 & $\begin{array}{l}\text { Dispõe sobre a descentralização da Administração Federal } \\
\text { e diretrizes para a Reforma Administrativa. }\end{array}$ \\
\hline $\begin{array}{l}\text { Constituição } \\
\text { Federal/1988 }\end{array}$ & 05/10/1988 & $\begin{array}{l}\text { O Artigo 37, inciso XXI, estabelece que as obras, serviços, } \\
\text { compras e alienações serão contratados mediante licitação } \\
\text { pública. }\end{array}$ \\
\hline Lei № 8.666/1993 & 21/06/1993 & $\begin{array}{l}\text { Institui normas para Licitações e Contratos na } \\
\text { Administração Pública. }\end{array}$ \\
\hline Decreto № $2.271 / 1997$ & 07/07/1997 & $\begin{array}{l}\text { Dispõe sobre a contratação de serviços pela Administração } \\
\text { Pública Federal direta, autárquica e fundacional. }\end{array}$ \\
\hline $\begin{array}{l}\text { Instrução Normativa } \\
\text { /SLTI/MP no 18/1997 }\end{array}$ & 22/12/1997 & $\begin{array}{l}\text { Disciplina a contratação de serviços executados de forma } \\
\text { indireta e contínua, celebrados por órgãos ou entidades } \\
\text { integrantes do Sistema de Serviços Gerais (SISG) }\end{array}$ \\
\hline Lei № 9.632/1998 & 07/05/1998 & $\begin{array}{l}\text { Dispõe sobre a extinção de cargos no âmbito da } \\
\text { Administração Pública Federal direta, autárquica e } \\
\text { fundacional. }\end{array}$ \\
\hline Decreto n으 3.555/2000 & 08/08/2000 & $\begin{array}{l}\text { Aprova o Regulamento para a modalidade de licitação } \\
\text { denominada pregão, para a aquisição de bens e serviços } \\
\text { comuns. }\end{array}$ \\
\hline Decreto n $3.722 / 2001$ & 09/01/2001 & $\begin{array}{l}\text { Regulamenta o art. } 34 \text { da Lei no } 8.666 / 1993 \text { e dispõe sobre } \\
\text { o Sistema de Cadastramento Unificado de Fornecedores - } \\
\text { SICAF. }\end{array}$ \\
\hline Lei no 10.520/2002 & $17 / 07 / 2002$ & $\begin{array}{l}\text { Institui, no âmbito da União, Estados, Distrito Federal e } \\
\text { Municípios, a modalidade de licitação denominada pregão, } \\
\text { para a aquisição de bens e serviços comuns. }\end{array}$ \\
\hline Decreto $\mathrm{n}^{\circ} 4.485 / 2002$ & $25 / 11 / 2002$ & $\begin{array}{l}\text { Dá nova redação a dispositivos do Decreto n 3.722/2001, } \\
\text { que regulamenta o art. } 34 \text { da Lei no } 8.666 / 93 \text {, dispõe sobre } \\
\text { o Sistema de Cadastramento Unificado de Fornecedores. }\end{array}$ \\
\hline Decreto $n^{\circ}$ 5.450/2005 & $31 / 05 / 2005$ & $\begin{array}{l}\text { Regulamenta o pregão, na forma eletrônica, para aquisição } \\
\text { de bens e serviços comum. }\end{array}$ \\
\hline Decreto n으 6.204/2007 & 05/09/2007 & $\begin{array}{l}\text { Regulamenta o tratamento favorecido, diferenciado e } \\
\text { simplificado para as microempresas e empresas de } \\
\text { pequeno porte nas contratações públicas de bens, serviços } \\
\text { e obras, no âmbito da administração pública federal. }\end{array}$ \\
\hline $\begin{array}{l}\text { Instrução Normativa } \\
\text { /SLTI/MP no 2/2008 }\end{array}$ & $30 / 04 / 2008$ & $\begin{array}{l}\text { Dispõe sobre regras e diretrizes para a contratação de } \\
\text { serviços, continuados ou não. }\end{array}$ \\
\hline $\begin{array}{l}\text { Instrução Normativa } \\
\text { /SLTI/MP no 03/2009 }\end{array}$ & $15 / 10 / 2009$ & Altera a Instrução Normativa no 02, de 30 de abril de 2008. \\
\hline $\begin{array}{l}\text { Instrução Normativa } \\
\text { /SLTI/MP no 04/2009 }\end{array}$ & $11 / 11 / 2009$ & Altera a Instrução Normativa no 02, de 30 de abril de 2008. \\
\hline $\begin{array}{l}\text { Instrução Normativa } \\
\text { /SLTI/MP nº 05/2009 }\end{array}$ & 18/12/2009 & Altera a Instrução Normativa no 02, de 30 de abril de 2008. \\
\hline $\begin{array}{l}\text { Instrução Normativa } \\
\text { /SLTI/MP no 06/2013 }\end{array}$ & 23/12/2013 & $\begin{array}{l}\text { Altera a Instrução Normativa no 02/2008 e seus Anexos I, III, } \\
\text { IV, V e VII e inclui o Anexo VIII. }\end{array}$ \\
\hline $\begin{array}{l}\text { Instrução Normativa } \\
\text { /SLTI/MP no 03/2014 }\end{array}$ & 24/06/2014 & $\begin{array}{l}\text { Altera a Instrução Normativa no 02/2008, e seus Anexos VII } \\
\text { e VIII e inclui o Anexo IX. }\end{array}$ \\
\hline
\end{tabular}

Nas licitações para contratação de bens e serviços é obrigatória a modalidade Pregão, sendo preferencial a utilização da sua forma eletrônica. Esta modalidade poderá deixar de ser aplicada somente nos casos de inviabilidade comprovada, devidamente justificada pela autoridade competente, (BRASIL, 2005).

O Pregão foi instituído pela Lei N.⒑520/2002, no âmbito da União, Estados, Distrito Federal e Municípios, nos termos do art. 37, inciso XXI, da Constituição Federal de 
1988, para aquisição de bens e serviços comuns. (BRASIL, 2002).

Para Gasparini (2008), Pregão Eletrônico é a modalidade de pregão a qual a disputa pelo fornecimento de bens ou pela prestação de serviços comuns para a Administração Pública é realizada em sessão pública, à distância, por intermédio de propostas de melhor preço, apresentadas pela internet.

Segundo a Lei nº 10.520/2002, "são considerados bens e serviços comuns aqueles cujo padrão de desempenho e qualidade possam ser objetivamente definidos pelo edital por meio de especificações usuais no mercado". (BRASIL, 2002).

Com base no Art. 7. da Lei 8.666/93, para a execução de obras e prestação de serviços, as licitações deverão ser precedidas de Projeto Básico ou Termo de Referência, devidamente aprovado pela autoridade competente. O descumprimento do disposto neste artigo "implica a nulidade dos atos ou contratos realizados e a responsabilidade de quem Ihes tenha dado causa". (BRASIL, 1993). Da mesma forma, se o Projeto Básico de uma licitação de obras e serviços "for falho ou incompleto, a licitação estará viciada e a contratação não atenderá aos objetivos da Administração". (TCU, 2006, p. 62).

Na fase preparatória da forma eletrônica do Pregão é necessário observar alguns procedimentos. O Quadro 02 relaciona esses procedimentos, em conformidade com o que dispõe o art. 9. do Decreto N. 5.450/2005:

\section{Quadro 02 - Procedimentos a serem observados na preparação do Pregão}

\begin{tabular}{|c|c|}
\hline Item & Observação \\
\hline I & $\begin{array}{l}\text { Elaboração de termo de referência pelo órgão requisitante, com indicação do objeto de forma } \\
\text { precisa, suficiente e clara, vedadas especificações que, por excessivas, irrelevantes ou } \\
\text { desnecessárias, limitem ou frustrem a competição ou sua realização; }\end{array}$ \\
\hline II & Aprovação do termo de referência pela autoridade competente; \\
\hline III & Apresentação de justificativa da necessidade da contratação; \\
\hline IV & Elaboração do edital, estabelecendo critérios de aceitação das propostas; \\
\hline V & $\begin{array}{l}\text { Definição das exigências de habilitação, das sanções aplicáveis, inclusive no que se refere aos } \\
\text { prazos e às condições que, pelas suas particularidades, sejam consideradas relevantes para a } \\
\text { celebração e execução do contrato e o atendimento das necessidades da administração; }\end{array}$ \\
\hline V & Designação do pregoeiro e de sua equipe de apoio. \\
\hline
\end{tabular}

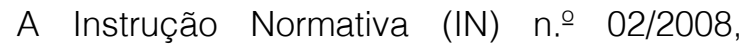
editada em 30 de abril de 2008, dispõe sobre regras e diretrizes para a contratação de serviços, continuados ou não, no âmbito do
Governo Federal. A IN n. 02/2008 é composta por 57 artigos e acompanhadas de 6 anexos. O Quadro 03 demonstra de forma sumária essa estrutura e os temas abordados: 
Quadro 03 - Sumário da IN n.ำ 02/2008

\begin{tabular}{|c|c|}
\hline TEMAS & DISPOSITIVOS LEGAIS \\
\hline Disposições Gerais & Artigos $1^{\circ}$ a $5^{\circ}$ \\
\hline Da Terceirização & Artigos $6 \div$ a 13 \\
\hline Do Projeto Básico ou Termo de Referência & Artigos 14 a 17 \\
\hline Do Instrumento Convocatório & Artigos 18 a 20 \\
\hline Das Propostas & Artigos 21 a 24 \\
\hline Do Julgamento das Propostas & Artigos 25 a 29 \\
\hline Da Vigência dos Contratos & Artigo 30 \\
\hline $\begin{array}{l}\text { Do Acompanhamento e Fiscalização da } \\
\text { Execução dos Contratos }\end{array}$ & Artigos 31 a 35 \\
\hline Do Pagamento & Artigo 36 \\
\hline Da Repactuação & Artigos 37 a 41 \\
\hline Dos Serviços de Limpeza e Conservação & Artigos 42 a 48 \\
\hline Dos Serviços de Vigilância & Artigos 49 a 51 \\
\hline Das Disposições Finais & Artigos 52 a 57 \\
\hline Anexol & Glossário \\
\hline Anexo II & Modelo do Acordo de Níveis de Serviços (ANS) \\
\hline Anexo III & Planilha de custos e formação de preços \\
\hline Anexo III A & Mão-de-obra \\
\hline Anexo III B & Demais custos \\
\hline Anexo III C & $\begin{array}{l}\text { Quadro com detalhamento de encargos sociais e } \\
\text { trabalhistas }\end{array}$ \\
\hline Anexo IV & Guia de fiscalização dos contratos de terceirização \\
\hline Anexo V & $\begin{array}{l}\text { Metodologia de referência dos serviços de limpeza e } \\
\text { conservação }\end{array}$ \\
\hline Anexo VI & Metodologia de referência dos serviços de vigilância \\
\hline
\end{tabular}

Fonte: Santana (2008, p. 19).

A chamada IN 02/2008 trouxe para o atual contexto muitas determinações já afiançadas pela lei, doutrina e jurisprudência, tratando essencialmente da terceirização de serviços na Administração Pública, tema complicado e desafiador. (SANTANA, 2008).

A IN 02 tem conteúdo apropriado aos tempos atuais, que reclamam a adoção de uma nova postura da Administração Pública diante do objeto de que cuida. Por certo que o trilhar por novos caminhos demandará a adoção de práticas que implicarão numa natural refração cultural. Está colocado o grande desafio que se descortina no presente momento. (SANTANA, 2008, p. 25).

No tocante à vigência dos contratos de terceirização de serviços continuados, o artigo 30 da IN mostra algo que não costuma ganhar muita atenção por parte dos gestores públicos. A prorrogação, prevista na Lei $n .$. 8.666/93, necessita de comprovada vantagem para a Administração, por meio da elaboração de estudos e relatórios que justifiquem essa prorrogação, sempre em favor do interesse público.

Em publicação, trazendo orientações básicas sobre licitações e contratos, o Tribunal de
Contas da União (TCU) define serviços continuados como "aqueles serviços auxiliares, necessários à administração para o desempenho de suas atribuições, cuja interrupção possa comprometer a continuidade de suas atividades e cuja contratação deva estender-se por mais de um exercício financeiro". (TCU, 2006, p. 397).

Mais adiante, 0 art. $6 . .9$ da IN 02/2008 acrescentou:

Os serviços continuados que podem ser contratados de terceiros pela Administração são aqueles que apoiam a realização das atividades essenciais ao cumprimento da missão institucional do órgão ou entidade, conforme dispõe o Decreto $n^{\circ}$ - 2.271/97. Parágrafo único. A prestação de serviços de que trata esta Instrução Normativa não gera vínculo empregatício entre os empregados da contratada e a Administração, vedando-se qualquer relação entre estes que caracterize pessoalidade e subordinação direta. (BRASIL, 2008).

Cabe ressaltar que a Instrução Normativa $\mathrm{N}$. . 02/2008, por meio da Instrução Normativa N ‥ 06, editada em 23 de dezembro de 2013, sofreu alterações. Foram alterados os arts. 3, 
19, 19-A, 29-A, 30-A, 31, 32, 34, 34-A, 35 e 36 e seus anexos I, III, IV, V e VII, além de incluído o Anexo VIII.

Ainda sobre vigência dos contratos de serviços terceirizados, o artigo 30, da Instrução Normativa n.․ 02/2008, com as modificações dadas pela Instrução Normativa N.․ 06/2013, de 23 de dezembro de 2013, traz: "A duração dos contratos ficará adstrita à vigência dos respectivos créditos orçamentários, podendo, quando for o caso, ser prorrogada até o limite previsto no ato convocatório, observado o disposto no art. 57 da Lei 8.666/93". (BRASIL, 2008).

Ressalte-se que, por força de lei, quando a organização pública celebra contrato administrativo, é imperioso que a execução do objeto contratual seja acompanhada e fiscalizada pela sua Administração.

\section{GESTÃO DE CONTRATOS NA ADMINISTRAÇÃO PÚBLICA}

A Instrução Normativa no 02/2008, em seu artigo 31, com redação alterada e acrescida pela IN 06/2013, dispõe que:

O acompanhamento e a fiscalização da execução do contrato consistem na verificação da conformidade da prestação dos serviços e da alocação dos recursos necessários, de forma a assegurar o perfeito cumprimento do contrato, devendo ser exercido pelo gestor do contrato, que poderá ser auxiliado pelo fiscal técnico e fiscal administrativo do contrato. (BRASIL, 2013).

O texto do artigo 31, da IN 02/2008, antes com um único parágrafo, em virtude das alterações dadas pela a IN 06/2013, segue agora com três parágrafos. O primeiro parágrafo impõe que a fiscalização dos contratos dos serviços contínuos obedeça ao disposto no Anexo IV desta IN. O segundo parágrafo considera:

- Gestor do Contrato - Servidor designado para coordenar e comandar o processo da fiscalização da execução contratual;

- Fiscal técnico do contrato - Servidor designado para auxiliar o gestor do contrato quanto à fiscalização do objeto do contrato;

- Fiscal administrativo do contrato Servidor designado para auxiliar o gestor do contrato quanto à fiscalização dos aspectos administrativos do contrato.

○ acompanhamento e fiscalização do contrato é instrumento poderoso que o gestor dispõe para a defesa do interesse público. É dever da Administração acompanhar e fiscalizar o contrato para verificar 0 cumprimento das disposições contratuais, técnicas e administrativas, em todos os seus aspectos. (TCU, 2006, p. 346).

A fiscalização adequada do contrato é fundamental para evitar danos ao erário, ocasionado pelo pagamento de obrigações trabalhistas decorrentes do inadimplemento por parte da contratada, uma vez que, pelo Enunciado ํㅡ 331/1993, a Administração responde, subsidiariamente, por esse tipo de encargo. (SILVA, 2008, p. 55).

Dessa forma, a gestão de contratos precisa ser regida por princípios de eficiência e eficácia, com uma atuação administrativa pautada na legalidade, assegurando o cumprimento das disposições contratuais. O descumprimento total ou parcial das cláusulas do contrato poderá gerar prejuízo à Administração, a aplicação de penalidades para a empresa contratada e a apuração de responsabilidade. Em última instância poderá culminar com a rescisão contratual. Conforme preconiza o art. 66 da Lei no 8.666/93, o contrato deverá ser executado fielmente pelas partes, de acordo com as cláusulas estabelecidas e as normas constantes da citada lei, respondendo cada qual pelas consequências de sua inexecução total ou parcial.

A Lei no 8.666/93 também estabelece em seus artigos algumas obrigações da contratada durante a execução contratual:

Art. 68. O contratado deverá manter preposto, aceito pela administração, no local da obra ou serviço, para representá-lo na execução do contrato. Art. 69. O contratado é obrigado a reparar, corrigir, remover, reconstruir ou substituir, às suas expensas, no total ou em parte, o objeto do contrato em que se verificarem vícios, defeitos ou incorreções resultantes da execução ou de materiais empregados. Art. 70. O contratado é responsável pelos danos causados diretamente à Administração ou a terceiros, decorrentes de sua culpa ou dolo na execução do contrato, não excluindo ou reduzindo essa responsabilidade a fiscalização ou o acompanhamento pelo órgão interessado. (BRASIL, 1993). 
Em relação às atribuições do gestor e dos fiscais - técnico e administrativo - a bibliografa estudada elenca algumas delas:

- Acompanhar a execução dos serviços, verificando a correta utilização dos materiais e equipamentos em quantidades suficientes à manutenção da qualidade dos mesmos;

- Solicitar, quando for o caso, ou pedir a substituição dos serviços por inadequação ou vícios que apresentem; efetuar glosas de medição por serviços mal executados ou não executados;

- Sugerir a aplicação de penalidades ao contratado diante do inadimplemento das obrigações;

- Controlar o prazo de vigência do instrumento contratual sob sua responsabilidade;

- Verificar se a entrega de materiais, execução de obras ou a prestação de serviços será cumprida integral ou parceladamente;

- Anotar em formulário próprio as ocorrências relacionadas à execução do contrato, determinando o que for necessário à regularização das faltas ou defeitos observados, conforme modelo sugerido no banco de formulários;

- Atestar as notas fiscais e encaminhálas à unidade competente para pagamento, se estas não precisarem de nenhum saneamento;

- Comunicar à unidade competente, formalmente, irregularidades cometidas passíveis de penalidade, após os contatos prévios com a contratada;

- Recomendar, se for o caso, quando do término da vigência do contrato, a liberação da garantia contratual em favor da contratada formalmente;

- Receber, provisória e definitivamente, as aquisições, obras ou serviços sob sua responsabilidade, mediante termo circunstanciado, quando não for designada Comissão de Recebimento ou outro servidor;

- Comunicar à unidade competente eventuais atrasos nos prazos de entrega e/ou execução do objeto, bem como os pedidos de prorrogação, se for o caso;
- Zelar pela fiel execução da obra, sobretudo no que concerne à qualidade dos materiais utilizados e dos serviços prestados;

- Acompanhar o cumprimento, pela contratada, do cronograma físico-financeiro;

- Receber as etapas de obra mediante medições precisas e de acordo com as regras contratuais;

- Apresentar, mensalmente ou quando solicitado, relatório circunstanciado de acompanhamento de execução do serviço;

- Manter, no local do serviço, livro-diário e registrar todas as ocorrências relevantes;

- Encaminhar pedido de alteração em projeto, serviço ou de acréscimos (quantitativos e qualitativos) ao contrato, acompanhadas das devidas justificativas e observadas as disposições do artigo 65 da Lei no. 8.666/1993;

- $\quad$ Estabelecer prazo para correção de eventuais pendências na execução do contrato e informar à autoridade competente ocorrências que possam gerar dificuldades à conclusão da obra ou em relação a terceiros;

- Encaminhar à autoridade competente, eventuais pedidos de modificações no cronograma físico-financeiro, substituições de materiais e equipamentos, formulados pela contratada;

- Cientificar à autoridade competente, com antecedência mínima de sessenta dias, da possibilidade de não conclusão do objeto na data aprazada, com as devidas justificativas;

- Realizar, juntamente com a contratada, as medições dos serviços nas datas estabelecidas, antes de atestar as respectivas notas fiscais.

É imprescindível que gestor e os fiscais de contratos terceirizados conheçam minuciosamente o contrato e suas respectivas cláusulas, dirimindo suas dúvidas com os setores responsáveis da Administração. Estes precisam estar cientes das suas responsabilidades, certificando-se de como deverão efetivamente cumprir as suas atribuições. Isso também é relevante em função da Lei de Licitações e Contratos Públicos atribuir ao gestor/fiscal o benefício de poder solicitar auxílio técnico, caso necessitar. Somente a partir daí é que o gestor/fiscal poderá: 
- Assegurar-se da efetiva e eficaz execução dos serviços dentro do estabelecido no contrato (especificações técnicas, normas), solicitando de imediato a correção dos vícios/imperfeições/ deficiências/omissões, porventura encontradas;

- Avaliar a qualidade dos serviços executados;

- Emitir atestados de avaliação dos serviços prestados (certidões ou atestados);

- Emitir atestado de realização do serviço (parcial ou total);

- Registrar as ocorrências durante o período de prestação de serviços e cumprimento de obrigações;

- Controlar a medição dos serviços executados, aprovando a medição dos serviços efetivamente realizados;

- Atestar a fatura.

Assim:

A ação do fiscal não se esgota no acompanhamento das situações previstas na proposta de preços, no projeto básico, no plano de trabalho ou no contrato em si. Cabe a ele, na qualidade de agente especialmente designado, fazer o acompanhamento rotineiro, recolhendo as queixas ou reclamações dos funcionários, por exemplo, anotando-as e levando as para uma solução junto ao preposto da empresa contratada. Nunca demais será lembrar a grande responsabilidade que pesa sobre os ombros dos fiscal/gestor, que deverá sempre estar de olhos bem abertos, ou seja, atendo a todas as situações decorrentes da execução de um contrato firmado com a Administração Pública. A Lei de Responsabilidade Fiscal, Lei Complementar nำ101, de 4 de maio de 2000 trouxe novo elenco de atribuições para o fiscal/gestor. Logo no seu artigo 1으, deixa claro que é uma lei de responsabilidade do gestor na gerência fiscal. (BRASIL, 2005).

Magalhães et al. (2010) mostra que os principais desafios dos gestores de contratos de serviços terceirizados são a (i) qualificação e capacitação dos envolvidos, (ii) qualidade e padronização dos serviços e (iii) o comprometimento dos terceirizados.

O instrumento de controle mais efetivo, no domínio da administração pública, é a ação preventiva. A promoção de cursos de capacitação e treinamento aos gestores e fiscais de contratos poderá contribuir sobremaneira para que não haja equívocos na condução dos objetivos contratuais da instituição. Ainda que existam leis e normas disciplinando os gastos com terceiros no setor público, muitas vezes estas não são claras ou de simples interpretação, gerando dúvidas e incertezas na gestão pública.

\section{A GESTÃO DO CONTRATO DE TERCEIRIZAÇÃO DE LIMPEZA}

A IFES é uma autarquia de regime especial, vinculada ao Ministério da Educação, Instituição de Ensino Superior, com autonomia administrativa, didático-científica, gestão financeira e disciplinar.

A IFES, em seu campus sede, é composta por onze centros de ensino. A estrutura física dos Centros de Ensino abriga departamentos, coordenadorias de cursos de graduação e de pós-graduação, salas de aula, salas de eventos, salas de professores, salas meio de informática, laboratórios, auditórios, sanitários, vestiários.

A partir da década de 1990, a IFES passou a terceirizar algumas de suas atividades, limpeza foi uma delas, em conformidade com os critérios estabelecidos pela Lei de Licitações e Contratos (Lei n.o 8666/93). É por intermédio do Departamento de Contratos e Convênios, vinculado à Pró-Reitoria de Administração, que a IFES realiza a contratação dos serviços terceirizados de limpeza, cuja execução deve ocorrer nos Centros de Ensino.

O contrato de prestação de serviços terceirizados de limpeza em vigência é resultado do processo licitação instaurado por meio da Comissão Permanente de Licitação, que tornou público o Pregão Eletrônico, tipo menor preço, nos termos da Lei no 10.520/2002, do Decreto $n^{\circ}$ 3.555/2000. do Decreto ํㅡ 5.540/2005 e da Lei oㅡ 8.666/1993.

Desde janeiro do ano de 2008, a IFES mantém o contrato de serviços de limpeza inicial em vigência, embora o prazo máximo de 60 meses tenha expirado em dezembro de 2012. Conforme preceitua a Lei $\mathrm{n}^{\circ}$ 8.666/93 (com redação alterada pela Lei n. 9648/98) e a cláusula sexta do Termo de Contrato de Prestação de Serviços de Limpeza e Conservação, o contrato poderá ser prorrogado por períodos subsequentes de doze meses, até o limite máximo de sessenta meses (UFSC, 2007). 
Art. 57. II - a prestação de serviços a serem executados de forma contínua, que poderão ter a sua duração prorrogada por iguais e sucessivos períodos com vistas à obtenção de preços e condições mais vantajosas para a administração, limitada a sessenta meses. [...]. § 40 - Em caráter excepcional, devidamente justificado e mediante autorização da autoridade superior, o prazo de que trata o inciso II do caput deste artigo poderá ser prorrogado em até doze meses. (BRASIL, 1993).

A Administração da IFES não conseguiu viabilizar em tempo hábil o processo licitatório indispensável para uma nova contratação dos serviços de limpeza. Amparou-se legalmente

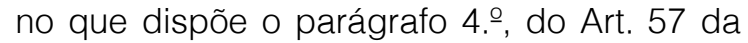
Lei n. $=8666 / 93$, para prorrogar por cento e oitenta dias, em caráter excepcional, o mencionado contrato. Esse prazo de prorrogação excepcional também expirou e foram feitos novos adiamentos extraordinários. Conforme informações do Departamento de Contratos e Convênios, a última licitação realizada com o objetivo de contratar serviços terceirizados de limpeza, está sub judice, em virtude de recurso impetrado por uma das empresas participantes no certame.

Diante do exposto, enquanto não for solucionada a demanda judicial, a Administração da IFES não poderá realizar nova licitação para esse serviço e o contrato inicial, que deveria ter duração máxima de sessenta meses, já perdura por mais de oitenta e sete meses.

O acompanhamento e o controle da execução dos serviços de limpeza são realizados por agentes públicos investidos na função de gestor, de fiscal administrativo e de fiscais técnicos das unidades previstas para a execução dos serviços. A designação formal desses agentes é feita pela Pró-Reitoria de Administração, através de portarias.

Compete ao gestor e fiscais verificar se as cláusulas contratuais estão sendo cumpridas e se os serviços estão sendo realizados em conformidade com as normas de limpeza e higiene estipuladas. Assim, para cada área descentralizada precisa ter um fiscal técnico acompanhando a execução do serviço de cada empregado terceirizado, procedendo a sua avaliação com conceitos pré-definidos em ótimo, bom, regular e fraco. Esse procedimento possibilita a verificação de faltas sem reposição ou com reposição, permitindo a aplicação das penalidades contratualmente previstas. Os fiscais devem apresentar ao gestor do contrato relatórios mensais da regularidade e da qualidade dos serviços prestados no mês.

A omissão do funcionário encarregado para o ofício - ou o incorreto cumprimento da tarefa pode gerar dano ao erário. NesTe caso, além da responsabilidade no plano disciplinar, por exemplo, ele sofrerá as consequências civis, atraindo para si o dever de reparar o prejuízo (ALVES, 2005, p. 60-69).

O Departamento de Contratos e Convênios, vinculado à Pró-Reitoria de Administração, é o setor da IFES responsável pelo planejamento, organização e coordenação dos contratos de bens e serviços, bem como pela gestão e fiscalização da execução e do acompanhamento execução desses contratos, inclusive o de prestação de serviços de limpeza terceirizados, em vigência desde 2008.

As informações através de documentos e depoimentos dos atores diretamente ligados à matéria apontam para a existência de fragilidades na gestão e fiscalização do Contrato, que afetam sobremaneira 0 acompanhamento e o controle da execução dos serviços de limpeza contratados, tanto por parte da contratada quanto da contratante. Em relação à contratante, podese citar:

- Grande parte dos fiscais técnicos acumulam outras funções, cujas atividades demandam muito tempo da carga de trabalho diária deles;

- Nem o gestor e nem os fiscais do Contrato receberam, inicialmente, orientação, treinamento ou capacitação formal específica para o exercício da função à qual foram designados;

- Muitos dos fiscais sequer receberam cópia do contrato e desconhecem as especificações com a descrição dos indicadores para avaliação dos serviços a serem fiscalizados;

- Muitos fiscais desconhecem suas atribuições e as atribuições da empresa contratada em relação ao contrato; do contrato;

Os fiscais não sabem quem é o gestor - Há ausência absoluta de comunicação e de interação entre os atores envolvidos diretamente nesse Contrato; 
- Não há uma padronização dos procedimentos de acompanhamento e controle da execução dos serviços contratados:

- Poucos são os fiscais técnicos que enviam relatórios mensais com os registros de ocorrências, da frequência e da avaliação dos prestadores do serviço e não há tal cobrança por parte do gestor e nem do fiscal administrativo;

É inviável, no cotidiano, o controle efetivo das irregularidades constatadas pelos fiscais técnicos, que se queixam que o formulário para a avaliação e frequência mensal adotado pela contratante é ineficaz, não evidencia fielmente os fatos ocorridos e induz a prática do 'faz de conta'. Além disso, o registro da frequência do pessoal contratado é uma ficha que os serventes de limpeza podem assinar a qualquer hora.

No tocante à empresa contratada, foram identificados as seguintes fragilidades:

- A contratada não emprega pessoas treinadas ou capacitadas para a execução dos serviços de limpeza contratados;

- Há alta rotatividade do pessoal contratado, tanto dos encarregados pela fiscalização, quanto dos atendentes que realizam a limpeza;

- O serviço de limpeza prestado pela contratada é alvo de constantes reclamações por parte dos usuários;

- A reposição dos faltosos demora a ocorrer, comprometendo a execução diária dos serviços de limpeza;

- A empresa contratada não adota o ponto eletrônico para o controle do pessoal que executa a limpeza, sendo que a fichaponto utilizada é falha como controle de assiduidade;

- A fiscalização feita pelo encarregado da contratada é precária, os fiscais não podem permanecer muito tempo na área fiscalizada, pois têm, no mínimo, três unidades da IFES para fiscalizar diariamente;

- A obrigação da contratada de manter seu pessoal devidamente identificado e uniformizado frequentemente é descumprida;

- O preposto ou representante da contratada não possui cópia do Contrato e não tem conhecimento do termo de referência com a descrição detalhada dos serviços a serem executados;
- A empresa contratada não define critérios para a divisão de atividades aos executores do serviço de limpeza, ocasionando, frequentemente, uma má distribuição de atendentes por área a ser limpa;

Não há por parte da empresa contratada uma planificação adequada para a execução e supervisão dos serviços de limpeza nas áreas descentralizadas ou centros de ensino da contratante.

Da mesma forma, conforme já mencionado, a empresa contratada para execução dos serviços terceirizados de limpeza na IFES continua em vigência por meio de sucessivas prorrogações, contrastando com o que a Lei N. 8.666/93 estabelece sobre essa matéria. Como implicação, a empresa tem sido beneficiada pelos intermináveis adiamentos contratuais, computando, até o presente momento, vinte e sete meses além do tempo máximo permitido de sessenta meses. Nesse sentido, salvo melhor juízo, há o choque com o princípio constitucional da legalidade, desviando-se do que estipula a lei.

A legalidade, como princípio da administração, esta em toda a sua atividade funcional, sujeita aos mandamentos da lei, e às exigências do bem-comum, e deles não se pode afastar, desviar, sob pena de praticar ato inválido e expor-se à responsabilidade disciplinar, civil e criminal, conforme o caso. (MEIRELLES, 1991, p. 78).

Chama ainda a atenção que os fiscais não tenham recebido cópia do contrato, cuja execução deve ser fiscalizada, tornando insustentável a atividade. O contrato também não especifica como deve ser feita a mensuração da qualidade dos serviços de limpeza, tornando, assim, subjetivos os critérios de avaliação do serviço de limpeza.

A situação apontada pelos entrevistados como a causadora dos maiores transtornos na rotina de acompanhamento do cumprimento do contrato é o reiterado descumprimento, por parte da contratada, do item que prevê a "imediata substituição dos empregados, no caso de falta ou descumprimento na execução dos serviços"

A elaboração de um manual de gestão e fiscalização de contratos, especificamente para os de serviços terceirizados de limpeza, foi sugestão apontada por um dos entrevistados e, se adotada, propiciará aos 
agentes públicos, investidos na função de gestor e fiscal, o conhecimento imprescindível ao acompanhamento e ao controle da execução desses serviços.

\section{CONSIDERAÇÕES FINAIS}

O contrato administrativo pode vir a ser um importante instrumento em prol do interesse público, se bem gerenciado e acompanhado, podendo proporcionar maior qualidade na utilização de recursos públicos. No entanto, a complexidade e a insuficiência de mecanismos de gestão e fiscalização, bem como o perfil e capacitação de quem deveria acompanhar a execução dos parâmetros e atributos constantes no contrato, sinaliza para um processo que tem se mostrado negligenciado e ineficiente.

A impressão é que aos agentes administrativos parece que a assinatura do contrato exaure suas atividades, como se não fosse necessário mais nada, como se o interesse público fosse cumprido com a assinatura dele. Essa percepção é equivocada, sobretudo porque apreende o processo de licitação pública e de contrato administrativo isoladamente, sem atentar que um e outro não passam de meios para a consecução do interesse público, finalidade maior que norteia todas as atividades administrativas. É fundamental que se perceba a licitação pública como meio para escolher a melhor proposta, o que é pressuposto para a celebração de contrato administrativo. Outrossim, o contrato administrativo também não passa de um meio para o fim consubstanciado no excelente e efetivo cumprimento do interesse público. (NIEBUHR, 2008, p. 471)

A contratação de serviços de limpeza e conservação deve proporcionar ambientes agradáveis para todos os indivíduos que utilizam o espaço da IFES no desenvolvimento de suas atividades. É necessário manter

\section{REFERÊNCIAS}

[1] ALVES, Léo da Silva. Prática de gestão e fiscalização de contratos públicos. Ed. Brasília Jurídica, 2005.

[2] BASSO, Guilherme Mastrichi. Terceirização e Mundo Globalizado: O Encadeamento produtivo e a complementaridade de serviços como potencializadores da limpos, conservados e higienizados ambientes como: salas de aula, laboratórios, oficinas, secretarias administrativas de departamentos e de coordenadorias de cursos, sanitários, copas e afins, incluindo pisos, vidraças, mesas e equipamentos, varrição e lavagem de pisos externos.

O sucesso da gestão/fiscalização de contratos está diretamente relacionado ao comprometimento e a seriedade dos seus atores, que devem exercer suas atividades de maneira consciente, sistêmica e precisa, para que não haja desperdício de tempo e do dinheiro público, gasto com pagamentos feitos por serviços não prestados ou prestados de forma precária pelas empresas contratadas.

Ainda que não exista um modelo ideal de operacionalização, controle e avaliação do processo de terceirização dos serviços de limpeza e conservação na IFES, a criação de um manual com a orientação aos servidores poderá trazer elementos essenciais ao planejamento e ao cumprimento das etapas inerentes ao processo como um todo.

Vale mencionar que a IFES identificou falta de conhecimento específico e de treinamento do gestor e dos fiscais de contratos no final de 2014 e tomou a iniciativa de oferecer cursos de capacitação de gestão e fiscalização de contratos terceirizados, para três turmas. Foram vinte quatro horas de curso para cada turma e está prevista, ainda, para o primeiro semestre de 2015, a oferta de novas turmas do curso a todos os agentes públicos da IFES.

Portanto, a direção da IFES está ciente de que - acúmulo de funções compromete a qualidade dos trabalhos a serem realizados pelos agentes públicos, dificultando o controle diário efetivo da execução de contratos, e está trabalhando na implantação de uma Central de Fiscalização de Contratos e na elaboração de um Manual de Fiscalização próprio da Instituição.

formalização de Contratos.TST, Brasília, 2008. vol. 74, n 4, out/dez 2008.

[3] BRASIL. Constituição (1988). Constituição da República Federativa do Brasil. Disponível em http://www.planalto.gov.br/ccivil_03/constituicao/co nstituiçao.htm>. Acesso feito em 20 Jan 2014. 
[4] BRASIL. Lei no 8.666, de 21 de junho de 1993. Disponível em: <http://www.planalto.gov.br/ccivil_03/leis//8666HYP ERLINK

"http://www.planalto.gov.br/ccivil_03/leis//8666cons. htm"cons.htm>. Acesso feito em: 12 jun. 2014.

[5] BRASIL. Decreto 2.271, de 07 de julho de $1997 . \quad$ Disponível em <http://www.planalto.gov.br/ccivil_03/decreto/d227 1.htm>. Acesso em 20 maio 2013

[6] BRASIL. Ministério de Estado da Administração Federal e Reforma do Estado. Instrução Normativa 18, de 22 de dezembro de 1997. Disponível em < http://www010.dataprev.gov.br/sislex/paginas/38/M ARE/1997/18.htm>. Acesso em 26 agosto 2014.

[7] BRASIL. Lei no 9.632, de 7 de maio de 1998. Disponível em: < http://www.planalto.gov.br/ccivil_03/Leis/L9632.htm >. Acesso feito em: 12 jun 2013.

[8] BRASIL. Decreto $n \div$ 3.555, de 8 de agosto de 2000. Disponível em: < http://www.planalto.gov.br/ccivil_03/decreto/d3555. htm>. Acesso feito em: 12 jun 2013.

[9] BRASIL. Decreto $n$ ㅇ 3.722, de 9 de janeiro de 2001. Disponível em: < http://www.planalto.gov.br/ccivil_03/decreto/2001/d 3722.htm>. Acesso feito em: 12 jun 2014.

[10] BRASIL. Lei no 10.520, de 17 de julho de 2002. Disponível em: < http://www.planalto.gov.br/ccivil_03/leis/2002//1052 0.htm>. Acesso feito em: 12 jun. 2014

[11] BRASIL. Decreto no 4.485, de 25 de novembro de 2002. Disponível em: < http://www.jusbrasil.com.br/busca?q=Decreto +448 5\%2F02>. Acesso feito em: 12 jun 2014.

[12] BRASIL. Decreto-lei 5.450, de 31 de maio de 2005. Disponível em http://www.planalto.gov.br/ccivil_03/_Ato20042006/2005/Decreto/D5450.htm. Acesso em 20 maio 2013.

[13] BRASIL. Decreto-lei 6.204, de 05 de setembro de 2007. Disponível em http://www.normaslegais.com.br/legislacao/decreto 6204_2007.htm. Acesso em 20 maio 2013.

[14] BRASIL. Ministério do Planejamento, Orçamento e Gestão. Secretaria de Logística e Tecnologia da Informação. Instrução Normativa 02, de 30 de abril de 2008. Disponível em <http://www010.dataprev.gov.br/sislex/paginas/38/ MPOG/2008/2.htm>. Acesso em 20 maio 2014.

[15] BRASIL. Ministério do Planejamento, Orçamento e Gestão. Secretaria de Logística e Tecnologia da Informação. Instrução Normativa 03, de 15 de outubro de 2009. Disponível em <http://www010.dataprev.gov.br/sislex/paginas/38/ MPOG/2009/3.htm>. Acesso em 20 maio 2014.
[16] BRASIL. Ministério do Planejamento, Orçamento e Gestão. Secretaria de Logística e Tecnologia da Informação. Instrução Normativa 04, de 11 de novembro de 2009. Disponível em < http://www010.dataprev.gov.br/sislex/paginas/38/M POG/2009/4.htm>. Acesso em 20 maio 2014.

[17] BRASIL. Ministério do Planejamento, Orçamento e Gestão. Secretaria de Logística e Tecnologia da Informação. Instrução Normativa 05, de 18 de dezembro de 2009. Disponível em http://www010.dataprev.gov.br/sislex/paginas/38/M POG/2009/5.htm>. Acesso em 20 maio 2014.

[18] BRASIL. Ministério do Planejamento, Orçamento e Gestão. Secretaria de Logística e Tecnologia da Informação. Instrução Normativa no 06, de 23 de dezembro de 2013. Disponível em http://www.auditoria.mpu.mp.br/audin/IN-SLTI2013-06-TERCEIRIZACAO-DE-MAO-DE-OBRAALTERA-A-IN-SLTI-02-2008.pdf . Acesso em: 20 out. 2014.

[19] BRASIL. Ministério do Planejamento, Orçamento e Gestão. Secretaria de Logística e Tecnologia da Informação. Instrução Normativa no 03, de 24 de junho de 2014. Disponível em http://ifc.edu.br/wp-content/uploads/2014/05/IN-

SLTI-MPOG-3-2014-altera-a-2-2008-contavinculada-e-minuta-de-Termo-deCoopera\%C3\%A7\%C3\%A3o-T\%C3\%A9cnica.pdf. Acesso em: 20 out. 2014

[20] BRASIL. Presidência da República. Casa Civil. Decreto-lei No. 200, de 25 de fevereiro de 1967. Dispõe sobre a organização da Administração Federal, estabelece diretrizes para a Reforma Administrativa e dá outras providências. Disponível <https://www.planalto.gov.br/ccivil_03/decretolei/Del0200.htm>. Acesso feito em 24 jun. 2013.

[21] BRASIL. Tribunal Superior do Trabalho. Súmulas do Tribunal Superior do Trabalho. Súmula 331 - Contrato de prestação de serviços. Legalidade (Revisão da Súmula no 256 - Res. 23/1993, DJ 21.12.1993. Inciso IV alterado pela Res. 96/2000, DJ 18.09.2000). Disponível em: <http://www.trt02.gov.br/geral/tribunal2/tst/Sumulas .htm> Acesso em: 24 jun. 2014

[22] BRASIL. Ministério da saúde. Manual de Orientação para gestão de Contratos de Prestação de Serviços na Fiocruz. Brasília, 2005. Disponível em:

<http://www.dirad.fiocruz.br/files/manuaHYPERLIN $\mathrm{K}$

"http://www.dirad.fiocruz.br/files/manual_gestao_co ntratos.pdf"I_gestao_contratos.pdf>. Acesso feito em: 10 maio 2014

[23] BRASIL. Lei № 3.849, de 18 de Dezembro de 1960. Disponível em: < http://dpgi.proplan.ufsc.br/files/2014/09/Credencia mento-Lei-n\%C2\%BA-3.849-de-18-de-dezembrode-19601.pdf>. Acesso feito em: 18 jun. 2014. 
[24] BRASIL. Decreto no 64.824, de 15 de julho de 20001969. Disponível em: < http://www2.camara.leg.br/legin/fed/decret/19601969/decreto-64824-15-julho-1969-406147-normape.html>. Acesso feito em: 12 jun 2014.

[25] DEIMLING, Moacir Francisco; GEHNO, Jamile. Avaliação das práticas de terceirização em empresas industriais na cidade de Chapecó/SC. 2007. Artigo para o Simpósio de Excelência em Gestão e Tecnologia Universidade Comunitária Regional de Chapecó - Unochapecó. Disponível em:

<http://www.aedb.br/seget/artigos07/881_Artigo\%2 OTercerizacao\%20SEGET.pdf>. Acesso feito em 12 Fev 2014

[26] GASPARINI, Diógenes. Pregão presencial e eletrônico. Belo Horizonte: Fórum, 2008.

[27] GIL, Antonio Carlos. Como elaborar projetos de pesquisa. 3. ed. São Paulo: Atlas, 1991.

[28] GIL. Antonio Carlos. Como elaborar projetos de pesquisa. 4. ed. São Paulo: Atlas, 2002.

[29] GIOSA, Lívio Antonio. Terceirização: uma abordagem estratégica. 5. ed. São Paulo: Pioneira, 1997, p. 14.

[30] GODOY, Arilda Schmidt. Pesquisa qualitativa: tipos fundamentais. In: Revista de administração de empresas. N. 3, v. 35. P. 20-29. São Paulo: mai/jun, 1995a.

[31] GODOY, Arilda Schmidt. Introdução à pesquisa qualitativa e suas possibilidades. In: Revista de administração de empresas. $\mathrm{N} . \stackrel{\circ}{2}$, v. 35. P. 57-63. São Paulo: mar/abr, 1995b.

[32] GONÇALVES, Laura Atalanta Escobar Bello. Sistema de controle de terceirização na Universidade Federal do Rio Grande do Sul. Dissertação (Mestrado Profissional em Economia com ênfase em Controladoria) - Universidade Federal do Rio Grande do Sul, 2006.
[33] MAGALHÃES, Y. T. de; CARVALHO NETO, A. M. de; GONÇALVES, P. P. B. Os Múltiplos Desafios da Gestão de Terceirizados: a experiência dos gestores de contratos. Revista de Ciências da Administração. Belo Horizonte, 2010, p. 116-143. Disponível em: http://www.pucminas.br/imagedb/documento/DOC _DSC_NOME_ARQUI20130503111027.pdf. Acesso feito em 26 mar 2014

[34] MEIRELLES, Hely Lopes, Direito Administrativo Brasileiro. 16. ed. São Paulo: Ed. Revista dos Tribunais, 1991, p. 78.

[35] NIEBUHR, Joel de Menezes. Licitação Pública e Contrato Administrativo. Curitiba: Zênite, 2008.

[36] SANTANA, Jair Eduardo. Licitação e Contratação de Serviços Continuados ou Não. A Instrução Normativa 02/2008 - SLTI/MPOG. 2008. Disponível em: http://transparencia.pi.gov.br/phocadownload/Legi slacao_Controle_Interno/Instrucoes_Normativas/in0 2_np.pdf . Acesso feito em 15 out.2014

[37] SILVA, Edna Aparecida. Terceirização na Administração Pública: Conflitos na legislação, orçamentação e escrituração da despesa. 2008. Brasília. Monografia TCU.

[38] TCU. Tribunal de Contas da União. Licitações e contratos: orientações básicas /Tribunal de Contas da União. - 3. ed, rev. atual. e ampl. Brasília: TCU, Secretaria de Controle Interno, 2006. 409 p. Disponível em: http://portal2.tcu.gov.br/portal/page/portal/TCU/co munidades/licitacoes_contratos/LICITACOES_CON TRATOS_3AED.pdf . Acesso feito em: 13 out. 2014.

[39] YIN, Robert. Estudo de caso. Disponível em: <http://www.focca.com.br/cac/textocac/Estudo_Ca so.html>. Acesso feito em: 22 jul. 2008. 


\section{Capítulo 8}

\section{CAPACITAC̄̃̃ NA GESTÃO PÚBLICA: BIBLIOMETRIA DAS PUBLICAÇÕES DAS BASES SPELL E ANPAD ENTRE 2000 E 2015}

\section{Leonardo Ribeiro de Almeida}

\section{Marcus Brauer*}

\section{Luiz Pereira Pinheiro Júnior}

Resumo: Sintetizar resultados de pesquisas anteriores é uma das mais importantes tarefas para avançar o conhecimento científico. Este estudo buscou mapear a pesquisa sobre Capacitação na Administração Pública, nas bases SPELL e ANPAD, no período 2000- 2015. Por meio de análise bibliométrica de 42 artigos, os resultados apontaram os principais autores e que a pesquisa nacional sobre o tema é concentrada em poucas instituições, utilizando-se de pouca variedade de referências e métodos de pesquisa.

Palavras-chave: Capacitação; Gestão Pública; Revisão da Literatura. 


\section{INTRODUÇÃO}

As discussões sobre capacitação, não só em termos gerais, mas também contemplando diferentes subdivisões e especificidades, são recorrentes nas mais diversas organizações contemporâneas e vêm ganhando força, em especial a partir dos anos 1990, (FLEURY, 1990; BRESSER-PEREIRA, 1998) com a maior profissionalização das organizações de diferentes naturezas (SHIROMA, 2004; ABRÚCIO, 2007; LACOMBE e CHU, 2008; FREITAS E BARTH, 2011).

Tal fato se deve à percepção de que, no cenário atual, delimitado por um alto nível de competitividade (KING, FOWLER e ZEITHAML, 2002), este é um fator que diferencia as organizações, ou seja, aquelas mais capacitadas têm mais facilidade em ocupar as melhores posições no mercado, tendo assim um acesso mais fácil a um maior número de negócios e clientes, o que tem por consequência seu fortalecimento e, em muitos casos, a possibilidade de assumir a liderança em seu setor de atuação (MOURÃO, ABBAD e ZERBINI, 2014).

Ressalta-se ainda que este maior foco no processo de capacitação organizacional termina por influenciar os indivíduos, na medida em que aqueles que buscam se capacitar de forma constante, normalmente conseguem melhores resultados profissionais com reflexos diretos na sua carreira, assim como maior nível de reconhecimento institucional (CAMPOS, ABBAD, MACEDO e SILVA, 2015).

Ancorado em tais concepções, este trabalho tem como objetivo explorar quais são as características da produção científica brasileira sobre capacitação na administração pública, nas bases SPELL e ANPAD, no período 2000-2015. Para isso foi estruturado uma revisão sistemática da literatura nas bases de dados respectivas e mapeado 0 campo de estudo.

Este estudo parte ainda do pressuposto de que a polissemia do conceito capacitação é forte no contexto da produção brasileira, havendo ainda a hegemonia da ideia tradicional de que estes processos podem ser vistos como sinônimos de modelos de treinamento tradicionais. Sendo assim justifica-se a realização do trabalho com base na concepção da relevância de se refletir e analisar sobre o que foi publicado sobre Capacitação na Gestão Pública entre os anos de 2000 e 2015, uma vez que se considera o tema relevante para o cenário administrativo contemporâneo.

A relevância e o ineditismo do estudo é ainda maior por conta do fato de ser o primeiro a analisar publicações acerca desta temática específica, além de sintetizar os resultados de pesquisas anteriores, uma das mais importantes tarefas para avançar na produção de conhecimento de uma específica linha de pesquisa (ZUPIC e ČATER, 2015). Ressaltase ainda, que a opção pela análise dos artigos publicados nas bases SPELL e ANPAD deveu-se à relevância e representatividade das mesmas no cenário da produção acadêmica brasileira, por contemplar trabalhos vistos como de qualidade em relação a diferentes fenômenos organizacionais.

Este artigo possui intuído de contribuir para os gestores públicos na elaboração de capacitações mais eficazes, visto que os recursos públicos estão cada vez mais escassos (ABRÚCIO, 1997; WANG, 2008; BARROSO, 2009; SILVA NETO e RIBEIRO, 2012) e que a falta de competência/qualificação/treinamento/capacit ação adequada é considerada um problema que afeta historicamente o setor público brasileiro (BRESSER-PEREIRA, 2004; SCHWARTZMAN e CASTRO 2013) além de avançar na discussão acadêmica dos respectivos estudos citados.

Assim o artigo está estruturado numa breve revisão da literatura no tópico 2 apresentando os principais conceitos sobre capacitação, treinamento, desenvolvimento de pessoas e competências especificamente no setor público. No tópico 3 é descrito a metodologia operacionalizada na pesquisa e no tópico 4 uma sintetização dos achados e uma análise dos dados minuciosa acerca do tema. Por fim, no tópico 5 apresentam-se as considerações finais da pesquisa, limitações e sugestões futuras.

\section{CAPACITAÇÃO E TREINAMENTO}

O conceito de capacitação é bastante amplo e vale destacar que o mesmo possui uma série de sentidos, vistos por vezes como sinônimos. Isso faz com que possa ser caracterizado como um conceito polissêmico. Neste cenário contemporâneo segundo Pantoja, Camões e Bergue (2010), o foco principal de todo e qualquer esforço de capacitação pode ser sintetizado como o 
desejo que as organizações de distintas naturezas possuem para desenvolver seu corpo funcional, visando atender suas necessidades e objetivos, ao tempo em que buscam para além de um bom desempenho, também alcançar os resultados e metas organizacionais traçados no seu planejamento estratégico.

Teixeira Filho e Almeida (2014) corroboram tal visão, ao constatar que até os anos de 1990, apesar dos avanços na gestão de pessoas, persistia a falta de políticas de formação/capacitação permanente e incentivo para o exercício da função pública em geral. Destacam estes autores, contudo que este cenário começa a se modificar a partir de 1995 com a publicação do Plano Diretor de Reforma do Aparelho do Estado (PDRAE). Com este plano, conforme os últimos autores e Gaetani (1999), a área de Gestão de Pessoas da Administração Pública Federal passa a realizar ações voltadas à profissionalização dos servidores públicos, buscando a valorização e motivação dos mesmos, demarcando assim o início da transição da Administração Pública Burocrática para a Gerencial.

Ainda no que se refere à operacionalização de um processo de capacitação das organizações públicas em geral, destaca-se que este necessita de estreita relação com um mapeamento prévio das competências organizacionais, frente às suas demandas reais em termos de pessoal. A partir desta visão, constata-se que um processo de capacitação deve partir da identificação explícita do gap existente entre as competências existentes e aquelas necessárias para a organização em tela (PANTOJA, CAMÕES e BERGUE, 2010).

Pacheco, Scofano, Beckert e Souza (2005) apontam que o processo de treinamento organizacional inicialmente visava atender exclusivamente à competitividade do mercado e à necessidade de profissionalização interna, sendo relativamente limitado e atendendo apenas parcialmente às demandas organizacionais mais amplas. Com tais características, também segundo estas autoras, tornaram-se ineficientes e obsoletos com o tempo, ainda que agregassem algum valor aos processos para os quais os indivíduos eram treinados.

Visando superar esta visão estreita de treinamento enquanto um modelo limitado à simples requalificação dos funcionários de uma organização, seja ela pública ou privada, em relação às suas atividades cotidianas e por vezes extremamente repetitivas, como pontuado por Pantoja, Camões e Bergue (2010), surge a necessidade da adoção de um conceito mais amplo, representado pela capacitação enquanto instrumento diretamente relacionado às demandas estratégicas da organização.

Pacheco et al. (2005) afirmam que o simples ato de treinar passa a ser insuficiente nas organizações modernas e complexas, surgindo a necessidade de aprendizagem e maior assimilação de conceitos necessários à realização de determinadas atividades, fatores estes que guardam forte relação com o processo de capacitação. Assim, as carências do treinamento podem ser supridas através de maior cobrança acerca do aprendizado de conhecimentos e técnicas, o que ocasiona uma consequente atualização dos indivíduos, refletindo-se na incorporação de novas competências e na adoção de comportamentos diversos dos anteriormente existentes.

Em relação à Administração Pública, ENAP (2012) destaca a importância do mapeamento dos programas de capacitação ofertados, pois através do mesmo é possível acompanhá-los, analisá-los e implementar melhorias nos mesmos, sempre que necessário, tornando possível sua constante melhoria, algo já implementado no Brasil através do Sistema Mapa da Oferta de Capacitações nas Escolas do Governo.

\subsection{DESENVOLVIMENTO DE PESSOAS E DE COMPETÊNCIAS}

O desenvolvimento de pessoas é algo complexo, pois lida diretamente com indivíduos, o que envolve questões e interesses próprios de cada um, ou seja, interesses de natureza pessoal que devem ser associados aos interesses da organização na qual estes indivíduos atuam. Com isso, a organização deve procurar auxiliar o funcionário a alcançar motivação para que, dessa forma, ao sentir que suas necessidades estão sendo atingidas, contribua da melhor maneira possível para o pleno funcionamento organizacional (DUTRA, HIPÓLITO e SILVA, 2000).

Sob a mesma ótica, Fleury e Fleury (2001) destacam que a noção de competência certamente agrega valor econômico à 
organização, mas que, para além desta dimensão, também deve permitir a agregação de valor social aos indivíduos enquanto parte fundamental da organização. Isto se torna necessário, uma vez que o desenvolvimento de competências essenciais pelos funcionários contribui de forma sensível para o sucesso organizacional, ao mesmo tempo em que funciona como um processo de investimento pessoal para atuação em diferentes esferas da organização, constituindo-se assim em um ciclo virtuoso envolvendo indivíduos e organização.

Conforme os últimos autores, em total consonância com Pantoja, Camões e Bergue (2010), o modelo de Gestão por Competências tem ganhando espaço constante e crescente nas organizações, graças à sua verificação através de fatos, consistindo numa análise dos principais pontos fortes dos funcionários e da utilização dessas competências para o aumento da produtividade, seja no nível individual, seja no nível organizacional.

Ao se falar de Gestão por Competências, deve-se ter em mente a sua estreita relação com o processo de capacitação. A Gestão por Competências objetiva planejar, executar e desenvolver o acompanhamento e a avaliação das diferentes habilidades dos componentes da organização, no intuito de desenvolver as mesmas para atingir o bem comum, atuando enquanto um instrumento para mudança da cultura organizacional e possibilitando maior flexibilidade às organizações, além de fortalecer o sentimento de espírito corporativo nas mesmas (MELLO e AMÂNCIO FILHO, 2010).

De acordo com Brandão (2012), trata-se de um modelo de Gestão de Pessoas que emerge no cenário mundial no começo dos anos de 2000, momento em que são postas em curso experiências organizacionais na esfera privada, com o objetivo de implantar esta nova concepção.

No caso do setor público brasileiro, o foco na Gestão por Competências apenas passa a existir quando do Decreto 5707/2006, que instituiu a Política Nacional de Desenvolvimento de Pessoal (PNDP), fixando ainda o prazo de dez anos para que todo o serviço público brasileiro em todos os níveis federal, estadual e municipal - adotasse este novo modelo, adequando as competências exigidas dos servidores aos objetivos institucionais vigentes. Tal política, de acordo com Pantoja, Iglesias, Benevenuto e Paula (2012), é fundamental para o desenvolvimento de novos perfis de capacitação profissional, no que se refere à Administração Pública Federal (APF), os quais são peças-chave no processo transitório entre a gestão por normas e procedimentos e a gestão por resultados.

\section{PROCEDIMENTOS METODOLÓGICOS}

Esta pesquisa está utilizou a técnica de revisão sistemática da literatura por meio de Bibliometria (ZUPIC e ČATER, 2015) com o intuito de prover uma possível discussão sobre o tema ranqueando principais autores, locais de publicações além de discutir possíveis agendas de pesquisa.

Para isso estruturou-se um protocolo de pesquisa no intuito de analisar a produção acerca do tema sob uma ótica longitudinal, optando pela análise dos artigos científicos publicados nas bases SPELL (2017) e ANPAD (2017), no período compreendido entre os anos de 2000 e 2015. A escolha destas duas bases de dados enquanto fonte de pesquisa é justificada por se entender que as mesmas reúnem os trabalhos mais relevantes da produção acadêmica nacional no campo da Administração, tanto no que se refere à Administração Pública, quanto à Administração de Empresas.

A pesquisa foi operacionalizada no $1^{\circ}$ semestre de 2016 utilizando as palavraschave: "capacitação", "treinamento", "desenvolvimento" relacionados aos termos "administração pública", "área pública" e seus respectivos plurais, buscando-se ao longo do texto, no título, no resumo ou nas palavraschave nas bases de dados citadas. Tais escolhas decorreram da concepção de que, em muitos casos na produção acadêmica brasileira, como observado em Teixeira e Barbosa (2006), estas palavras- chave são usadas como sinônimos ou termos equivalentes.

Ao final deste trabalho inicial, encontrou-se um total de 42 artigos, sendo 15 deles da base SPELL e 27 da base ANPAD. Estes artigos foram considerados pelo autor deste estudo como de fato pertinentes ao tema aqui analisado. Para se chegar a este número de artigos, verificou-se por meio da leitura dos títulos e dos resumos dos mesmos à sua real aderência ao tema. 
Ressalta-se que, quando não era possível encontrar no resumo dos mesmos as expressões anteriormente explicitadas, o autor realizava a leitura do referencial teórico do artigo em análise, a fim de sanar qualquer tipo de dúvida em relação à inclusão ou ao descarte do trabalho analisado. A adoção destes procedimentos viabilizou a seleção e descarte de trabalhos de forma consistente com o objetivo do estudo bibliométrico aqui apresentado, sem que houvesse qualquer tipo de prejuízo à pesquisa realizada.

Destaca-se que foram pesquisados estudos bibliométricos na área da Administração a fim de que fosse possível ao autor deste trabalho tecer comparações entre os resultados aqui apresentados e estes, em que pese abordarem temáticas distintas, pois debruçam-se sobre diferentes fenômenos organizacionais igualmente importantes. Assim, foram lidos e analisados os artigos de Caldas, Tonelli e Lacombe (2002), Loiola e Bastos (2003), Camargos, Coutinho, e Amaral (2005), Silva e Fadul (2008) e Ribeiro (2009) no intuito de utilizar as mesmas técnicas para garantir a validade e confiabilidade da pesquisa proposta.

\section{ANÁLISE DOS DADOS}

Dando início a este processo, identificou-se o número de trabalhos nos diferentes congressos ANPAD e na base SPELL, nos quais se encontraram artigos sobre a temática aqui discutida. A Figura 1 demonstra a distribuição quantitativa de artigos entre estas duas bases de dados, ao longo do período estudado.

Figura 1: Publicações anuais por bases de dados.

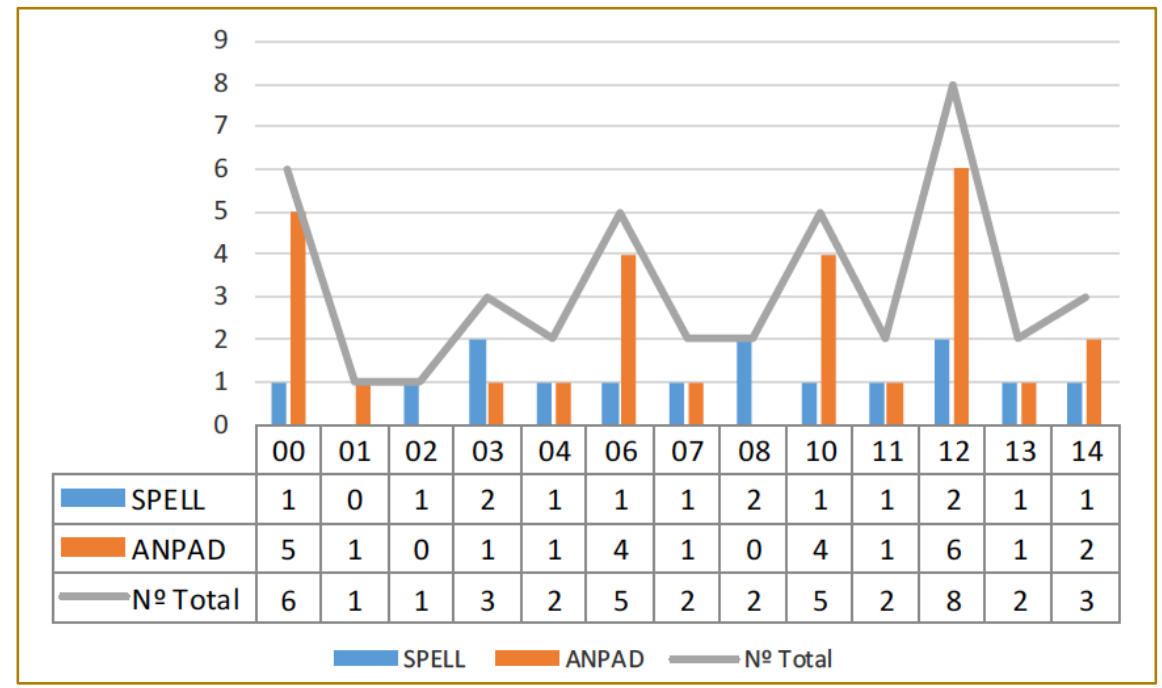

FONTE: Elaboração própria, 2016.

Dos dados apresentados, percebe-se a maior participação de trabalhos publicados nos anais dos diferentes congressos promovidos pela ANPAD quando comparados aos da base SPELL, representando $64,3 \%$ do total dos artigos. Esta concentração de publicações pode ter como explicação o sinalizado por Loiola e Bastos (2003) e Ribeiro (2009) autores que afirmam ser tal situação justificativa pelo fato da base ANPAD reunir, além do maior congresso nacional em Administração com edicões anuais, diferentes congressos temáticos da área com edições a cada dois anos. Sobre esta característica das publicações, ressalta-se ainda, a maior concentração de estudos versando sobre o tema nos anos de 2000, 2006, 2010 e 2012, assim como a ausência de publicações nas duas bases de dados nos anos de 2005, 2009 e 2015.

Na Figura 2 é possível evidenciar informações mais detalhadas acerca da avaliação dos periódicos nos quais foram encontradas publicações sobre a temática aqui analisada utilizando o indicador denominado de Qualis CAPES Periódicos.

Figura 2: Publicações base SPELL por Qualis CAPES 


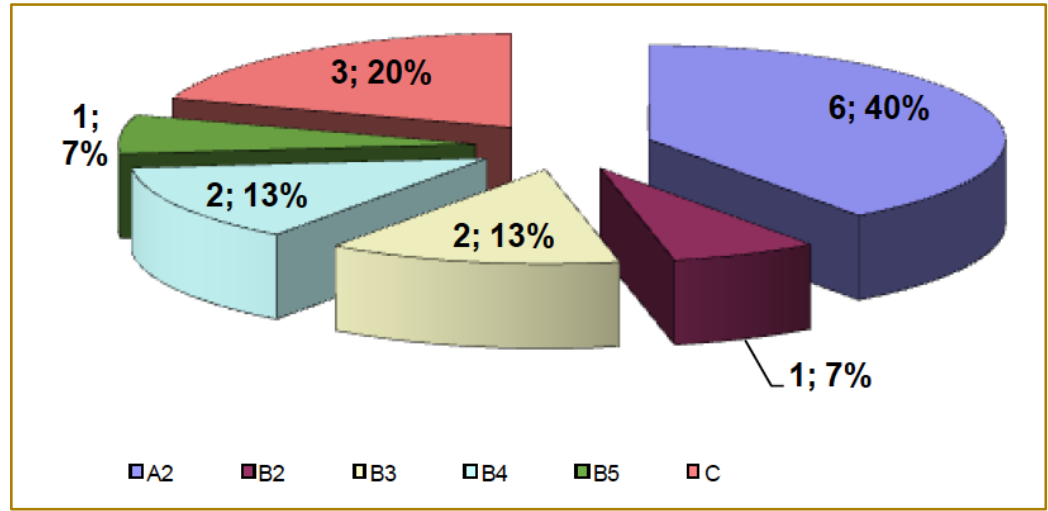

FONTE: Elaboração própria, 2017.

Os dados demonstram que não houve artigos versando sobre o tema publicados em periódicos A1. Adicionalmente verifica-se que o maior volume de trabalhos na base SPELL concentra-se nos dois outros extremos, nos periódicos A2 com $40 \%$ do total e em periódicos $\mathrm{C}$ com $20 \%$. As demais categorias acumulam 13\% (B3 e B4) e 7\% (B2 e B5). A Figura 3, apresenta ao leitor o detalhamento destas publicações, identificando-se seu quantitativo por periódico pertencente à base analisada.

Figura 3: Publicações base SPELL por Periódico e Qualis CAPES

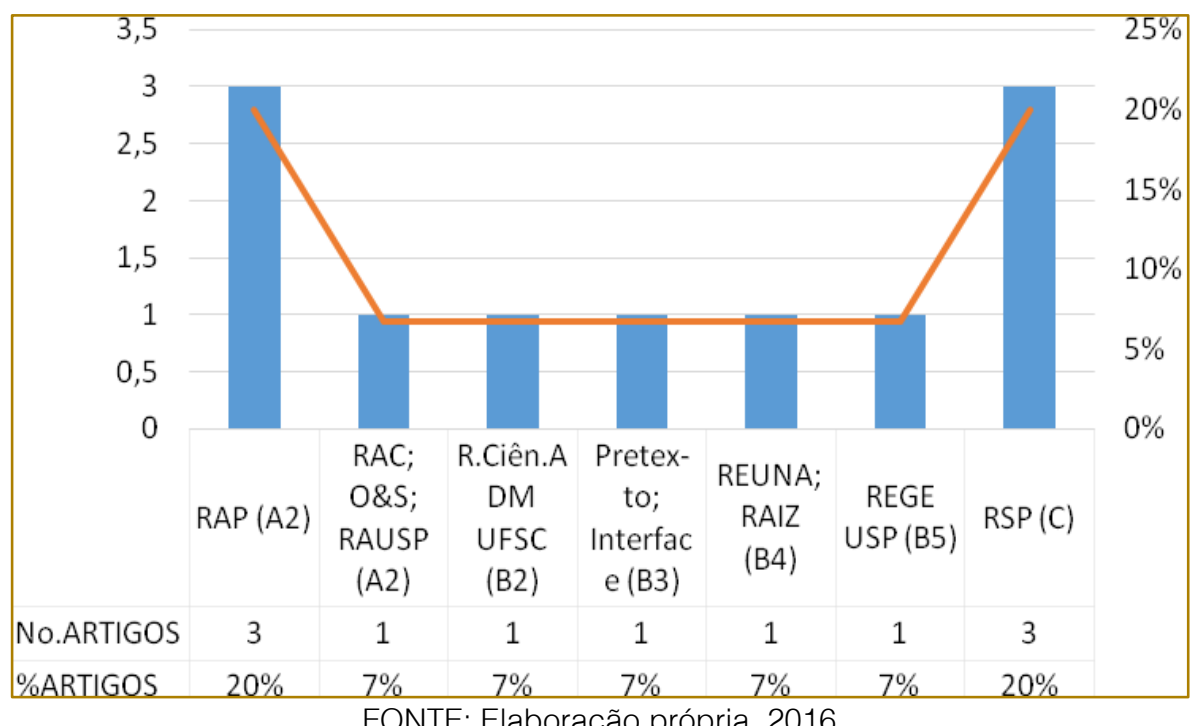

FONTE: Elaboração própria, 2016

Verifica-se a maior concentração de publicações em periódicos que discutem diferentes aspectos da administração pública: Revista de Administração Pública (RAP) da Fundação Getulio Vargas e Revista do Serviço Público (RSP) publicada pela Escola Nacional de Administração Pública (ENAP). Destaca-se ainda que a RSP, em que pese o seu reconhecimento na área, é classificada como B4 por ser uma revista tecnológica. As demais publicações, sendo 10 ao todo, possuem apenas um artigo cada, refletindo o pouco foco atribuído à administração pública em suas linhas editoriais.
Quanto as Instituições que desenvolveram essas pesquisas é possível verificar na Figura 4 que 14 instituições são federais e 7 IES privadas são responsáveis pela maior parte da produção aqui analisada. Adicionalmente, pode-se perceber que duas IES federais Universidade de Brasília (UNB) e Universidade Federal do Rio Grande do Sul (UFRGS) - têm a elas vinculados autores responsáveis pela produção de 15 artigos e que, no âmbito das IES privadas, a Escola Brasileira de Administração Pública e de Empresas (FGV-EBAPE) responde por 4 trabalhos. Tal observação é justificada, pois 
em consulta aos sites destas IES mais profícuas, identificou-se a presença, dentre suas linhas de pesquisa, no tocante à Pós-
Graduação (Mestrado e Doutorado), a área de administração pública como um, senão o principal, dos seus focos de estudo.

Figura 4: Número e percentual de artigos por IES

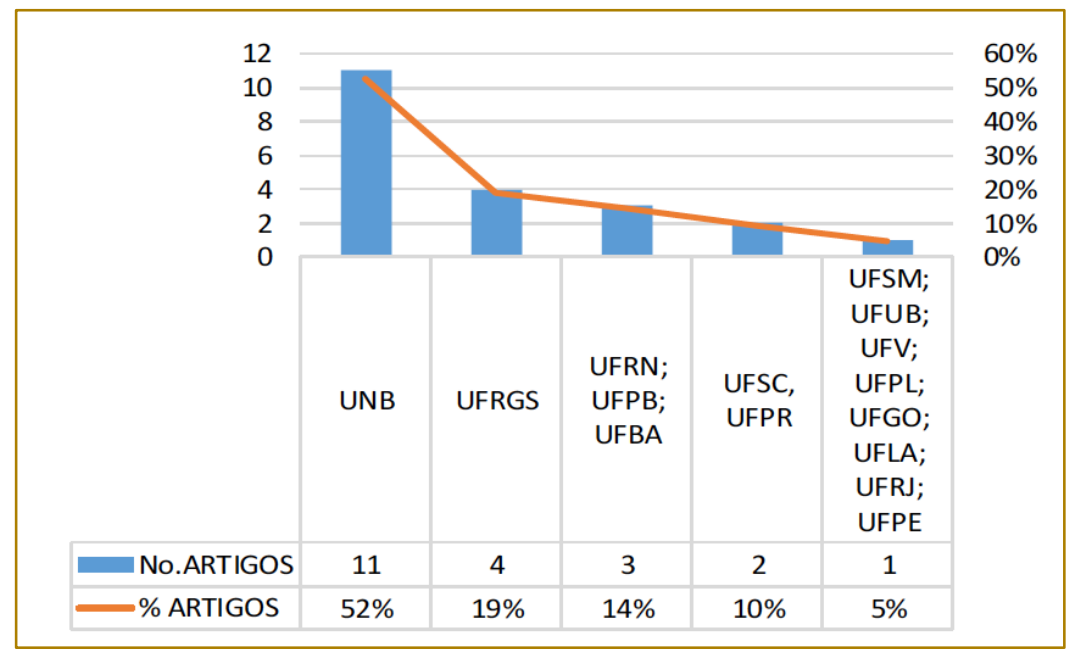

FONTE: Elaboração própria, 2017.

Quanto aos autores dessas pesquisas a Figura 5 demonstra algumas constatações interessantes. Inicialmente, identifica-se o grande uso de legislação nos artigos, representada aqui pela presença de "Brasil" enquanto autor em 22 trabalhos distintos. Pontua-se que se optou por reunir sob esta terminologia todas as referências elaboradas por algum órgão oficial federal.

Tem-se ainda a presença de dois autores nacionais na Figura 5, ambos da UNB -
Gardênia Abbad e Jairo Eduardo Borges Andrade - como principais autores que estudam capacitação no Brasil. No que se refere ao uso de referências internacionais, identifica-se a preferência por autores mais tradicionais, a exemplo de Mintzberg (9 trabalhos), Argyris e Bandura (com 7 trabalhos cada) e Hamel e Prahalad (5 trabalhos).

Figura 5: Autores mais citados nas duas bases (SPELL e ANPAD)

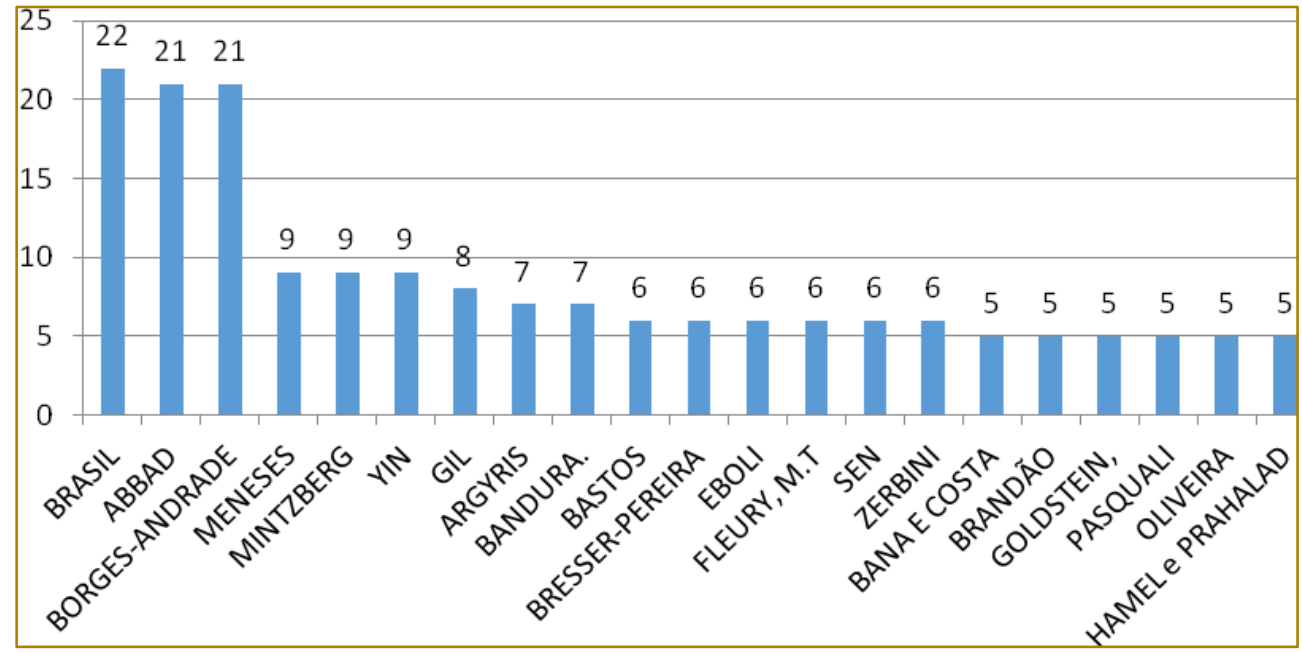

FONTE: Elaboração própria, 2017.

Estes achados parecem indicar a preferência dos pesquisadores nacionais em utilizar referenciais brasileiros, além de denotar relativa resistência ao uso de autores 
estrangeiros mais atuais. Destaca-se ainda a presença de autores que exploram conteúdos relativos à metodologia, tais como Yin (9 trabalhos) e Gil (8 trabalhos).

\subsection{EXPLORANDO A LITERATURA ALÉM DA BIBLIOMETRIA}

Para contribuir para a literatura de capacitação da gestão pública este artigo buscou explorar além da Bibliometria descritiva, sendo assim após a leitura dos referenciais dos trabalhos aqui analisados, os mesmos foram classificados como pertencentes a uma ou mais das três bases teóricas listadas: Treinamento e Aprendizagem; Desenvolvimento de Pessoas e Competências e Educação para o Trabalho conforme destaca a Figura 6.

Figura 6: Artigos por base conceitual

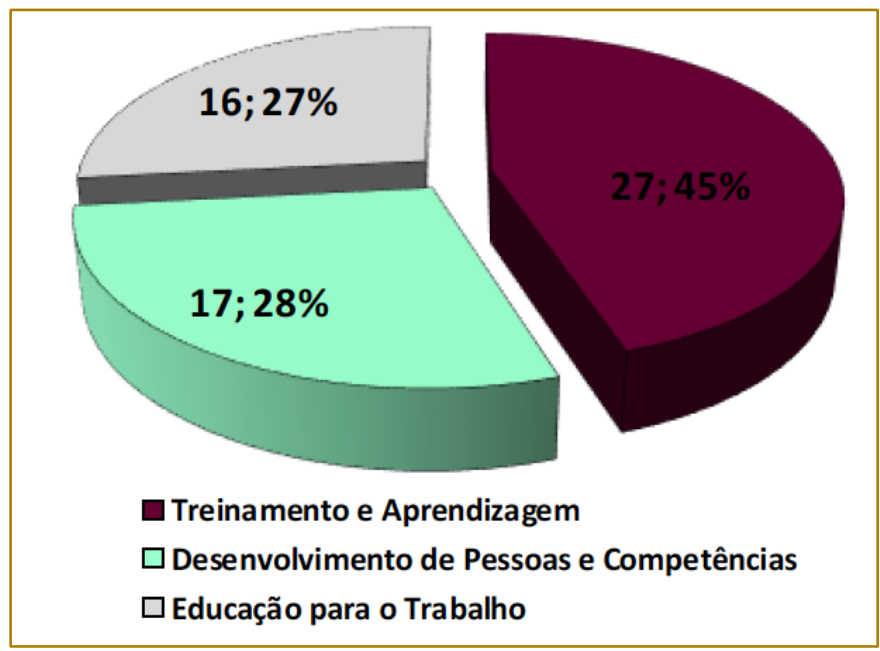

FONTE: Elaboração própria, 2016.

Antes da análise das informações trazidas acima, é oportuno destacar que há um número maior de observações (60) do que o número total dos artigos (42). Tal característica decorre do fato de que há artigos que se ancoram conceitualmente, para estudar o fenômeno da capacitação, em mais do que uma das categorias teóricas listadas no referencial e anteriormente explicitadas. Em outras palavras, fica claro que o conceito de capacitação é visto no mundo acadêmico sob uma ótica polissêmica.

Dos dados apresentados, é possível verificarse a predominância de estudos versando sobre Treinamento e Aprendizagem (45\%), reforçando-se assim, o que afirmam Hammel e Prahalad (1993), Pacheco, Scofano, Beckert e Souza (2005), Pantoja, Camões e Bergue (2010) e Noe, Clark e Klein (2014) sobre o foco em treinamento ainda muito presente na área de gestão de pessoas de organizações públicas e privadas. Ressalta-se ainda que os artigos mais recentes procuram fazer links mais formais dos processos de treinamento, foco mais tradicional da capacitação, com outras dimensões igualmente importantes, dentre elas a aprendizagem organizacional. Em linhas gerais, percebe-se que a dimensão "Treinamento" é aquela que mais se hibridiza com as demais bases teóricas.

No que se refere aos trabalhos que priorizam a base conceitual denominada "Desenvolvimento de Pessoas e Competências", constata-se em consonância com Fleury e Fleury (2001), Pacheco, Scofano, Beckert e Souza (2005), Pantoja, Camões e Bergue (2010), Brandão (2012) e Costa (2015) o interesse da realização de estudos sobre a temática das "Competências" em geral e, no que se refere à adoção de um modelo de gestão nelas baseado, em anos mais recentes do período analisado neste estudo. Em linhas gerais, os 17 trabalhos classificados nesta base conceitual são posteriores a 2006, ano no qual foi instituída a PNDP, através do Decreto 5707/2006, legislação essa que institui a obrigatoriedade da adoção da gestão por competências para a administração pública brasileira em todos os níveis (federal, estadual e municipal). 
Por fim, na última base conceitual aqui listada - Educação para o Trabalho - verificou-se, em que pese a importância do coaching nas organizações contemporâneas, como apontado por Pacheco et al. (2005) e Damasceno (2011), a inexistência de trabalhos que explorassem esta base conceitual. Na verdade, os 16 artigos que se utilizam desta base, fazem uso de conceitos relativos ao e-learning e à Universidade Corporativa, demonstrando a importância destes como sinalizado por Pacheco et al. (2005) para o contexto organizacional atual.

\section{CONSIDERAÇÕES FINAIS}

O artigo teve como objetivo explorar quais são as características da produção científica brasileira sobre capacitação na administração pública, nas bases SPELL e ANPAD, no período 2000-2015 com vistas a permitir, assim, a melhor sistematização da literatura acerca do tema.

Como uma primeira consideração a ser apresentada, entende-se que ao se levar em conta a relevância do tema Capacitação na Área Pública, assim como a sua polissemia, como observado em diversos autores a exemplo de Hamel e Prahalad (1993), Fleury e Fleury (2001), dentre outros, o número de artigos sobre esta temática ainda é consideravelmente reduzido no cenário nacional, como verificado pelo número de artigos encontrados pelo autor deste estudo nas bases SPELL e ANPAD no período 20002015, número este que totaliza 42 produções.

Adicionalmente, com base nos resultados decorrentes deste estudo verificou-se que a maior parte da produção acadêmica sobre o tema concentra-se na base ANPAD (67\%), sendo uma possível explicação para tal contexto o fato de a mesma englobar um leque diversificado de congressos, tanto com temáticas voltadas aos aspectos mais gerais do campo da gestão, quanto explorando temas específicos, dentre eles, a própria Administração Pública.

Além disso, foi ainda possível a observação de que a maior quantidade de publicações é da autoria de estudiosos que pertencem a instituições de ensino superior localizadas no Distrito Federal (23\%) e em estados pertencentes às regiões Sudeste (32\%) e Sul (22\%), reforçando assim, achados de pesquisas similares em relação à produção acadêmica nacional sobre outros temas, a exemplo de Caldas, Tonelli e Lacombe (2002), Loiola e Bastos (2003), Ribeiro (2009), dentre outros. Foi ainda identificada a presença de maior volume de produção no âmbito das Universidades Públicas, em especial as Instituições Federais de Ensino Superior (IFES), as quais responderam por $70 \%$ do total de artigos sobre o tema, com a participação destacada da UNB, que responde por $52 \%$ destes. Sinaliza-se que estes últimos dados também corroboram os resultados obtidos nas pesquisas bibliométricas anteriormente mencionadas.

Ao se fazer a análise do tema à luz da polissemia envolvida no conceito de Capacitação, detectou-se a presença predominante de artigos versando sobre o subtema Treinamento e Aprendizagem, os quais consistiram em $45 \%$ do total aqui analisado. No tocante aos referenciais mais citados nos estudos aqui analisados, fica clara a presença de grande número de referências aos aspectos contemplados na legislação, inclusive, confirmando-se assim o grande número de artigos que se valeram da análise documental como informações secundárias na sua elaboração.

Em termos citação de autores, há a forte presença dos professores brasileiros Gardênia Abbad e Jair Borges-Andrade, cada um deles com 21 citações. Aponta-se ainda, que ambos autores pertencem ao quadro docente da UNB. Dentre os autores internacionais, merecem destaque Henry Mintzberg (9 citações) e Chris Argirys (7 citações) como aqueles mais utilizados na elaboração dos trabalhos aqui analisados.

Com base neste conjunto de análises, é possível concluir-se que a pesquisa nacional sobre capacitação na Administração Pública brasileira é constante e com razoável grau de concentração em poucas instituições de ensino superior. Além disso, caracteriza-se pela utilização de pequena variedade de referenciais e metodológica, contexto este que possibilita a realização de diferentes pesquisas acerca do tema.

Como limitações deste estudo cita-se o fato de terem sido pesquisados apenas trabalhos publicados em duas bases de dados, sendo que nenhuma delas internacional, contexto este pode de alguma forma enviesar os resultados aqui discutidos acerca do tema; destaca-se ainda o fato de não terem sido pesquisados congressos da área da Psicologia, assim como, não ter sido feito 
qualquer tipo de análise em relação às redes de pesquisadores e universidades nacionais e internacionais.

Em sendo assim, como uma possível forma de se buscar a superação destas limitações, apresentam-se como sugestões para pesquisas futuras: a realização de estudos bibliométricos versando sobre a mesma temática, contudo, consultando-se outras

\section{REFERÊNCIAS}

[1] ABRUCIO, F. L. O impacto do modelo gerencial na Administração Pública. Cadernos ENAP, Brasília, n.10, 1997.

[2] ABRUCIO, F. L. Trajetória recente da Gestão Pública brasileira: um balanço crítico e a renovação da agenda de reformas. Rio de Janeiro, Revista de Administração Pública, Edição Especial Comemorativa, p. 67-86, 2007.

[3] ANPAD. Associação Nacional de PósGraduação e Pesquisa em Administração (Base de Dados). Disponível em: $<$ http://www.anpad.org.br/ anpad/pesquisa_result ado.php>. Acesso em 10 de fevereiro de 2017.

[4] BARROSO, L. R. Da falta de efetividade à judicialização excessiva: Direito à saúde, fornecimento gratuito de medicamentos e parâmetros para a atuação judicial. Jurisprudência Mineira, Belo Horizonte, v.60, n.188, p. 29-60, jan./mar. 2009.

[5] BRANDÃO. H. P. Mapeamento de competências: métodos, técnicas e aplicações em Gestão de Pessoas. São Paulo, Atlas, 2012.

[6] BRESSER-PEREIRA, L. C. Instituições, Bom Estado e Reforma da Gestão Pública. In: Ciro Biderman; Paulo Arvate. (Org.). Economia do Setor Público no Brasil. São Paulo: Editora Campus, v. 1, p. 03-15, 2004.

[7] BRESSER-PEREIRA, L. C. Reforma do Estado para a Cidadania. 1. ed. São Paulo: Editora 34, 368p, 1998.

[8] CALDAS, M.; TONELLI, M.; LACOMBE, B. Espelho, espelho meu: Meta-estudo da Produção científica em Recursos Humanos nos ANPADs da década de 90. In: XXVI Encontro Nacional de Programas de Pós-Graduação em Administração, 2002, Salvador. Anais ... Salvador, 2002.

[9] CAMARGOS, M. A.; COUTINHO, E. S.; AMARAL, H. F. O perfil da área de finanças do ANPAD: um levantamento da produção científica e de suas tendências entre 2000 - 2004. In: XXIX Encontro Nacional de Programas de PósGraduação em Administração, 2005, Brasília. Anais... XXIX EnANPAD, Brasília, 2005. bases acadêmicas de dados, principalmente internacionais, assim como congressos no campo da Psicologia; podem ainda ser feitos estudos que permitam tecer comparações em relação ao processo de capacitação nos setores público e privado; e também pesquisas que se debrucem sobre a produção das redes de pesquisadores e universidades nacionais e internacionais sobre o tema.

[10] CAMPOS, E. B. D.; ABBAD, G. S.; MACEDO, A. G. A. P. S; e SILVA, N. P. Necessidades de Treinamento: Uma Proposta de Avaliação Estratégica no Contexto de Empresas Juniores Brasileiras. Revista de Administração Mackenzie, São Paulo, v. 16, n. 6, p. 126-158, nov./dez. 2015

[11] COSTA, T. D. Gestão de Pessoas por Competências. Salvador: UFBA, 2015. DAMASCENO, B. A sociedade contemporânea e seus meios de competência: uma crítica ao coaching à luz da teoria psicanalítica. In: VI Congresso Nacional de Psicanálise e do XV Encontro de Psicanálise da UFC, Fortaleza, 2011. Anais ... Fortaleza, 2011.

[12] DUTRA, J. S.; HIPÓLITO, J. A. M.; e SILVA, C. M. Gestão de Pessoas por Competências: o Caso de uma Empresa do Setor de Telecomunicações. Revista de Administração Contemporânea, Curitiba, v. 4, n. 1, p. 161-176, jan./abr. 2000.

[13] ENAP. Escolas de governo de todo o Brasil reúnem-se na ENAP para debater capacitação dos servidores públicos. Revista do Serviço Público, Brasília, v. 62, n. 3, p. 242-249, abr./jun. 2012.

[14] FLEURY, A. Capacitação Tecnológica e Processo de Trabalho: Comparação Entre o Modelo Japonês e o Brasileiro. Revista de Administração de Empresas, São Paulo, v. 30, n. 4, p. 23-30, out./dez. 1990.

[15] FLEURY, M. T. L.; FLEURY, A. Construindo o conceito de competência. Revista de Administração Contemporânea, Edição Especial 2001, p.183-196.

[16] FREITAS, E. C. e BARTH, M. Profissionalização da gestão nas empresas familiares: estagnar ou inovar? Revista Brasileira de Gestão e Desenvolvimento Regional, Taubaté, v. 7, n. 3, p. 158-185, set./dez. 2011.

[17] GAETANI, Francisco. O Ensino da Administração Pública no Brasil em um Momento de Inflexão. Revista do Serviço Público, Brasília, v. 50, n. 4, p. 92-120, out./dez. 1999 
[18] HAMEL, G.; PRAHALAD, C. K. Strategy as stretch and leverage. Harvard Business Review, Cambridge, mar./abr. 1993.

[19] KING, A. W.; FOWLER, S. W.; e ZHEITAML, C. P. Competências Organizacionais e Vantagem Competitiva: o desafio da gerência intermediária. Revista de Administração de Empresas, São Paulo, v. 42, n. 1, p. 36-49, jan./mar. 2002.

[20] LACOMBE, B. M. B. e CHU, R. A. Políticas e Práticas de Gestão de Pessoas: as abordagens estratégica e institucional. Revista de Administração de Empresas, São Paulo, v. 48, n.1, p. 25-35, jan./mar. 2008.

[21] LOIOLA, E.; e BASTOS, A. V. B. A produção acadêmica sobre Aprendizagem Organizacional no Brasil. Revista de Administração Contemporânea, Curitiba, v. 7, n. 3, p. 181-201, jul./set. 2003.

[22] MELLO, M. L. B. D. de; e AMÂNCIO FILHO, A. A gestão de recursos humanos em uma instituição pública brasileira de ciência e tecnologia em saúde: o caso Fiocruz. Revista de Administração Pública, Rio de Janeiro, v. 44, n. 3, p. 613-636, mai./jun. 2010.

[23] MOURÃO, L; ABBAD, G. da S.; e ZERBINI, T. Avaliação da efetividade e dos preditores de um treinamento a distância em uma instituição bancária de grande porte. Revista de Administração, São Paulo, v.49, n.3, p.534-548, jul./ago./set. 2014.

[24] NOE, R. A.; CLARKE, A. D. M.; KLEIN, H. J. Learning in the Twenty-First-Century Workplace. Organizational Psychology and Organizational Behavior, Columbus, v.1, p. 245-275, mar. 2014.

[25] PACHECO, L.; SCOFANO, A. C.; BECKERT, M. e SOUZA, V. de. Capacitação e desenvolvimento de pessoas. Rio de Janeiro: FGV, 2005

[26] PANTOJA, M. J.; CAMÕES, M. R. de S.; BERGUE, S. T. (orgs.). Gestão de pessoas: bases teóricas e experiências no setor público. Brasília: ENAP, 2010.

[27] PANTOJA, M. J.; IGLESIAS, M.; BENEVENUTO, R.; PAULA, A. de. Política Nacional de Desenvolvimento de Pessoal na Administração
Pública Federal. Anais ... V Congresso CONSAD de Gestão Pública, Brasília, 2012. Anais eletrônicos, Brasília, 2012.

[28] RIBEIRO, D. Estruturas Organizacionais: Um Possível Delineamento da Produção Científica Nacional sobre o Tema, no Período 1998-2008. Gestão e Sociedade, Brasília, v.3, n.6, p. 204-229, jul./dez. 2009

[29] SCHWARTZMAN, S.; CASTRO, C.M. Ensino, formação profissional e a questão da mão de obra. Ensaio: aval. pol. públ. Educ., Rio de Janeiro, v. 21, n. 80, p. 563-624, jul./set. 2013.

[30] SHIROMA, E. O. Implicações da Política de Profissionalização sobre a Gestão e o Trabalho Docente. Trabalho \& Educação, Belo Horizonte, v. 13, n. 2, p. 113-125, ago./dez. 2004.

[31] SILVA, L. P. da; e FADUL, E. A produção científica na área de cultura organizacional dentro de organizações públicas no período de 1997 a 2007: um convite à reflexão. In: III Encontro de Administração Pública e Governança (EnAPG). Salvador, 2008. Anais eletrônicos ... Salvador, 2008

[32] SILVA NETO, J.M.; RIBEIRO, R. P. Gestão Estratégica de Recursos Públicos: Avaliação das Variáveis Restritivas à Efetividade na Execução do Programa de Saúde da Família. Revista Eletrônica de Administração, Porto Alegre, v.1, p. 191-210, jan./abr. 2012.

[33] SPELL. Scientific Periodicals Electronic Library. Disponível em: < http://www.spell.org.br/>. Acesso em: 08 de março de 2017.

[34] TEIXEIRA FILHO, A.; e ALMEIDA, D.R. Gestão por Competências: mapeamento de competências na Universidade Federal da Bahia. In: XIV Colóquio Internacional de Gestão Universitária, 2014, INPEAU-UFSC Florianópolis. Anais eletrônicos.... Florianópolis, 2014

[35] WANG, D. W. L. Escassez de recursos, custos dos direitos e reserva do possível na jurisprudência do STF. Revista Direito GV, São Paulo, v. 4, p. 539-568, jul./dez. 2008.

[36] ZUPIC, I; ČATER, T. Bibliometric Methods in Management and Organization. Organizational Research Methods, Ljubljana, v. 18, n. 3, p. 429472, jul. 2015. 


\section{Capítulo 9}

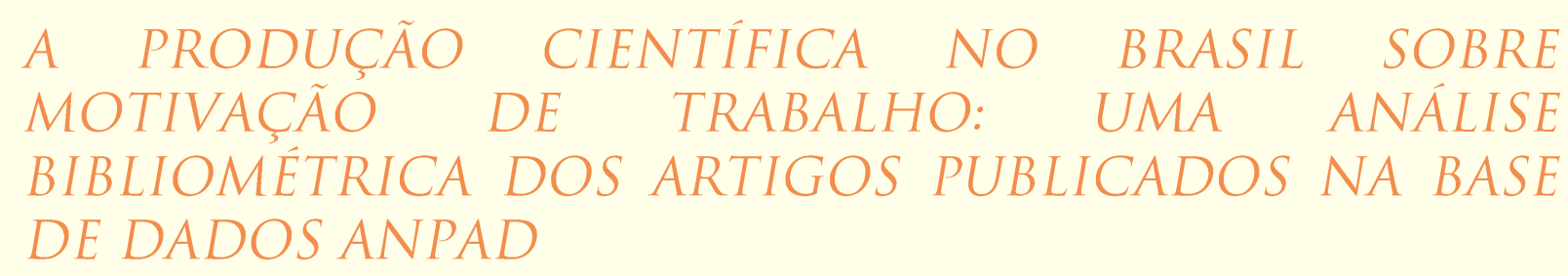

Fatinha Badjeta Mendonça

Marcus Brauer*

Marcelo Motta Veiga

Rossando Ramos

Resumo: Cada vez mais empregados encontra-se desmotivados em organizações públicas e privadas. O objetivo desta pesquisa foi mapear e analisar a recente produção científica no Brasil sobre Motivação no Trabalho, na base de dados ANPAD, para entender melhor tal fenômeno. Esta pesquisa teve abordagem qualitativa e o seu método foi da pesquisa documental com análise bibliométrica. Foram mapeados e analisados 24 artigos e os resultados apontam a distribuição geográfica irregular das pesquisas e predominância de certas estratégias de pesquisa. Conclui-se que o tema deve ser mais pesquisado e com diferentes estratégias, bem como os gestores devem conhecer mais do tema para aprimorar suas decisões sobre esse importante assunto. Desmotivados, os empregados entregam bem menos, e seus gestores são responsáveis pelas entregas de seus subordinados.

Palavras-chave: Motivação no Trabalho. Bibliometria. Gestão de Pessoas. Comportamento Organizacional. 


\section{INTRODUÇÃO}

Diversos autores, dentre eles, Bergamini (2003), Gondim e Silva (2004), Pinder (2008), Morim (2001), Pink (2010), Daft (2010), alertam que o desempenho humano pode ser influenciado por diversos fatores, sendo a motivação o fator mais importante para atingir o êxito. Fischer (2002) acrescenta que, sem a motivação, o resultado e o desempenho humano tendem a ser baixo, criando um ponto de preocupação nas empresas e organizações.

A motivação pode ser definida como "um conjunto de forças energéticas que se originam tanto dentro como fora do indivíduo, para iniciar o comportamento relacionado com o trabalho e determinar sua forma, direção, intensidade e duração" (PINDER, 2008, p. 34). Desta forma, faz com que a pessoa se sinta motivada e a leva a acreditar em realizar algo pela vontade própria. Tal fato é considerado relevante, uma vez que determina algo que pode fazer mover a conduta do ser humano.

Muito lideres ainda acreditam na possibilidade de motivar seus liderados usando fatores externos. Bergamini (2003) esclarece que, independentemente da necessidade humana, o potencial da motivação já nasce dentro de cada pessoa.

Morin (2001), outra corrente desse pensamento, acredita que um trabalho motivador é aquele que possui sentido para o indivíduo. Quando a pessoa se identifica com os valores da organização e do trabalho que realiza, inclina-se a ficar mais motivado. Segundo a autora, um trabalho que tem sentido é intrinsecamente satisfatório, executando as tarefas com prazer e sentimento. Também é um trabalho que tem sentido aquele moralmente aceitável, executado de maneira "socialmente responsável", uma atividade que "coloca as pessoas em relação umas com as outras, sendo fonte de experiências de relações humanas satisfatórias". É, portanto, um trabalho que tem sentido aquele que garante a segurança, a autonomia e a independência, estruturando e organizando a vida diária, mantendo o indivíduo ocupado.

Sintetizar os achados passados é uma das tarefas mais importantes no avanço do conhecimento em uma particular linha de pesquisa (ZUPIC; CATER, 2014) e isso geralmente é feito por meio da bibliometria. A bibliometria é o conjunto de leis e princípios empíricos que contribuem para estabelecer os fundamentos teóricos seja elas da ciência de informação, métodos estatísticos, para analisar as informações científicas de uma determinada área de estudo (PRITCHARD, 1969). Ela foi usada pela primeira vez para as necessidades em biblioteconomia. A motivação no trabalho tem sido tema de constante relevância na vida das organizações, sobretudo, matéria de estudo em inúmeras pesquisas nas áreas de ciências humanas e sociais, embora ainda pouco explorada. Apesar do crescente número de trabalhadores desmotivados e, considerando a forte relação entre motivação e desempenho, são poucos os estudos recentes no avanço do conhecimento científico sobre o tema no Brasil.

Diante desse tema tão discutido e ainda pouco explorado, o estudo irá analisar: se a produção de publicações no país sobre o tema "motivação no trabalho" está acompanhando a crescente mudança das organizações e o papel da gerência e do empregado no ambiente de trabalho.

Para alcançar o propósito em questão, o objetivo desta pesquisa foi mapear e analisar a recente produção científica no Brasil sobre Motivação no Trabalho, na base de dados ANPAD no período dos anos de 2006 a 2015, trazendo elencados os diversos assuntos explorados sobre o tema, traçando a estatística de uma análise bibliométrica.

O método utilizado para o estudo de caso é a pesquisa descritiva qualitativa, que busca compreender a variável, sem entrar no mérito do conteúdo. Também foi feito um levantamento bibliográfico acerca dos conceitos trabalhados para a construção do referencial teórico, alicerçado em autores renomados no assunto, como: Deci, Koestner e Ryan (2001), Gondim e Silva (2004), Motta e Vasconcelos (2010), Pink (2010), Daft (2010), Robbins, Judge e Sobral (2010), Bergamini (2013), Costa, Bento, Sá, e Ziviani (2013), Zupic e Cater (2014), entre outros.

O estudo justifica-se pela grande relevância que o assunto proporciona ao se pensar no que se tem pesquisado sobre a motivação na última década no Brasil, analisando um dos bancos de dados mais importantes e atualizados no país e que abrem espaço para publicações sobre o tema, a ANPAD. A escolha para analisar os artigos publicados na base de dados da ANPAD se deu pela 
importância que esta representa na produção acadêmica brasileira.

O texto está dividido em cinco seções, sendo a primeira esta introdução, situando o objeto da pesquisa e o problema, os objetivos, a justificativa e o método desenvolvido. $\mathrm{Na}$ segunda seção será apresentado o referencial teórico, contendo os principais conceitos e teorias sobre motivação no trabalho, bem como os fatores motivacionais e a recompensa do desempenho humano. A terceira seção apresenta a metodologia utilizada na elaboração da bibliometria. A quarta seção traz os dados sob a forma de gráficos, abordando as discussões a respeito dos resultados obtidos. A quinta e última seção apresenta alguns relatos sobre considerações finais, as limitações do estudo, e a importância de pesquisas futuras sobre o avanço do tema no Brasil.

\section{REFERENCIAL TEÓRICO}

Bergamini (2006) diz que o interesse pela motivação humana é observado nas obras dos primeiros pensadores da humanidade. Retrocedendo ao tempo, os filósofos tinham a preocupação de explicar o comportamento humano, levando a crer que já eram indícios de que a motivação humana já existia. $\mathrm{O}$ autor afirma que a preocupação com 0 comportamento humano no trabalho levou muito tempo até chegar às organizações:

Antes da Revolução Industrial, a principal maneira de motivar consistia no uso de punições, criando, dessa forma, um ambiente generalizado de medo. Tais punições não eram unicamente de natureza psicológica, podendo aparecer sob forma de restrições financeiras, chegando até a se tornar reais sob a forma de prejuízos de ordem física. Levando em conta que as organizações passaram a existir muito tempo antes da Revolução Industrial, é possível concluir que a preocupação com o aspecto motivacional do comportamento humano no trabalho represente um fato bastante recente (BERGAMINI, 2006).

O conceito de motivação é muito abrangente e possui uma sequência de sentidos diferentes propostos por diversos autores. Esta seção objetiva entender os diferentes sentidos que envolvem a motivação, como também apresentar as teorias criadas em torno do tema. Serão desenvolvidas algumas observações diferentes sobre motivação no trabalho, seguidos dos fatores motivacionais e por fim, situar o leitor sobre o desempenho humano e a recompensa.

\subsection{MOTIVAÇÃO NO TRABALHO}

Pink (2010) traz um histórico da motivação como sistemas operacionais de determinadas épocas. Classifica a motivação em 1.0, 2.0 e 3.0. Na Motivação 1.0 a motivação é um impulso biológico, como um instinto de sobrevivência. Na Motivação 2.0 o indivíduo busca recompensas e evita punições, chamada de motivação "cenoura e chicote", funcionando muito bem para atividades repetitivas. Já a Motivação 3.0 é construída em torno de motivadores intrínsecos, é a paixão em realizar, independente se vai ser recompensado ou punido pelo ato. Através de recompensas e punições as organizações delimitam $\mathrm{o}$ empenho no processo de conceder maior autonomia aos funcionários para seu crescimento profissional. Vale lembrar que este sistema, muitas vezes, não funciona como o desejado, apesar do desempenho humano ser influenciado pela motivação, o resultado nem sempre é possível de ser alcançado, mesmo aplicando o esquema "cenoura e chicote".

Vários autores afirmam que o tema motivação no trabalho teve um aumento significativo na última década no ambiente de gestão de pessoas nas organizações (DECl; KOESTNER; RYAN, 2001; GONDIM; SILVA, 2004; NASCIMENTO, 2007; MOTTA; VASCONCELOS 2010; PINK, 2010; DAFT, 2010; ROBBINS; JUDGE; SOBRAL, 2010; BERGAMINI, 2011 e KLEIN, 2016). Bergamini (1998) acrescenta que na maioria dos estudos, se esperava conseguir equilibrar o comportamento produtivo ao nível mais alto da motivação do indivíduo.

Apesar do interesse da gestão de pessoas nas organizações tenha um aumento significativo na última década sobre o tema motivação no trabalho, o que se esperava na maioria dos estudos era de conseguir equilibrar o comportamento produtivo a nível mais alto da motivação do indivíduo, segundo estudos da Bergamini, (1998).

Os estudos sobre motivação no trabalho tiveram início no século vinte após os testes realizados pelo Elton Mayo, no Western Electric Company, para entender a melhor forma de gerenciar os funcionários, em uma experiência denominada Warthorne. Nesta experiência, foram contidos alguns dos trabalhadores a um ambiente iluminado e 
diferenciado, porém, mais flexível em relação aos outros. O resultado da experiência foi positivo e a produtividade cresceu exponencialmente devido ao aumento da iluminação (MOTTA; VASCONCELOS, 2010).

Percebe-se que os trabalhadores motivados e movidos informalmente conhecem mais os objetivos do trabalho que estão realizando. A escolha de um modelo de gerência participativa nem sempre melhora absolutamente a produtividade dos grupos organizacionais, uma vez que dependem dos demais fatores, além do único aperfeiçoamento do clima social (MOTTA; VASCONCELOS, 2010).

Bergamini (1998) esclarece que nos estudos de Locke e Lhatan as metas são importantes fatores motivadores da conduta humana. Metas e objetivos influenciam na motivação, mas não são suficientes para mantê-la em nivel elevado. Para a autoria, ainda existem fatores moderadores envolvidos no processo, tais como: a clareza dos objetivos, as dificuldades da tarefa, a aceitação da meta pela pessoa, as características individuais e a presença da opinião gerencial. Portanto, não basta colocar ordem e estabelecer metas ao indivíduo para que dê o melhor de si, é preciso que ele valorize o trabalho e o veja como um desafio que não é fácil de ser atingido por qualquer um.

O conceito de motivação no trabalho é reforçado por Bergamini (2011), acreditando que o problema de autodesenvolvimento das atividades não está no indivíduo, e sim, na própria cultura organizacional. Isso porque, o indivíduo por si só é capaz de se comprometer com seu autodesenvolvimento no trabalho sem que haja coação externa. Com base nisso, o trabalho só passa a ser principal alvo quando o indivíduo busca sua autorealização, ou seja, quando ele se envolve com a organização aplicando sua máxima energia para atingir o êxito.

Certas organizações não levam a sério a questão da motivação dos funcionários no trabalho. Isso acaba afetando os liderados e, principalmente, afetando o crescimento da empresa. Em um estudo realizado por Gondim e Silva (2004), os autores afirmam que a satisfação diz respeito ao contentamento com as relações interpessoais no trabalho e com a atividade executada. Acrescentam que a motivação determina algo que pode fazer mover a conduta do ser humano, e a ação das pessoas na organização irá mudar significativamente o resultado final das atividades.

A teoria da hierarquia de necessidades, de Maslow (1943), mostra que o estudo sobre a motivação no trabalho não é recente. Segundo o autor, o ser humano tem necessidades complexas que podem ser hierarquizadas em cinco níveis para atingir a sua plena autorealização. Porém, as organizações devem oferecer os meios para que 0 trabalhador satisfaça essas necessidades, assim ele irá se sentir motivado e bem disposto a trabalhar.

Para Daft (2010), a motivação humana é considerada um desafio para gestores, acreditando que a mesma venha dos próprios funcionários, e de maneira diferente em cada um. Sendo assim, o administrador precisa canalizar a motivação para realização das metas organizacionais, recompensando o indivíduo e fazendo-o compreender que o comportamento usado foi correto.

Também é muito importante e fundamental para um bom desempenho o estabelecimento de metas, pois "aumenta a persistência, e o desenvolvimento de estratégia de motivação". A opinião é muito importante e deve ser levada em conta para melhoria do desempenho (LOCKE et. al., 1981).

Nas subseções seguintes serão abordadas as teorias criadas para entender 0 comportamento do indivíduo dentro das empresas.

\subsection{TEORIAS MOTIVACIONAIS}

Diversas teorias sobre a motivação surgiram na década de 1950 fundamentando as abordagens atuais, buscando entender as necessidades do ser humano. Essas teorias procuram explicar o comportamento do individuo dentro das organizações, em seu ambiente de trabalho, e nas suas atividades laborais. São elas: a Teoria das necessidades de Maslow (1943); a Teoria das necessidades de McClelland (1553); a Teoria dos dois fatores de Herzberg (1959); a Teoria X e Y de McGregor (1960); a Teoria da Expectativa de Vroom (1995); e a Teoria da Autodeterminação de Ryan e Deci (1987), abordadas a seguir. 


\subsubsection{TEORIA DAS NECESSIDADES DE MASLOW}

O conceito da hierarquia de necessidades de Maslow (1962) foi importante para os estudos da motivação do trabalho. O autor defende que as necessidades são satisfeitas de baixo para cima, da base para o topo, a saber. É necessário que um trabalhador satisfaça as necessidades básicas fisiológicas, assim ele se sente motivado e bem disposto a trabalhar.

Maslow (1943) formulou uma teoria da motivação baseado na hierarquia de necessidades que influenciam o comportamento humano, entendendo que a motivação é o resultado dos estímulos que agem com força sobre os indivíduos, levandoos a ação. Percorrem uma escala hierárquica para atingir sua plena autorealização, a seguir (MOTTA; VASCONCELOS, 2010):

- necessidades fisiológicas: ar, comida, repouso, etc.;

- necessidades de segurança: proteção contra o perigo, ordem, segurança;

- necessidades sociais: amizade, inclusão em grupos, família, etc.;

- necessidades de estima: reputação, reconhecimento, dignidade, prestígio, etc.;

- necessidades de auto-realização: realização do potencial, autonomia, independência, etc.

Maslow concebeu essa hierarquia pelo fato de o homem ser uma criatura que expande suas necessidades no decorrer de sua vida. À medida que o homem satisfaz suas necessidades básicas, outras mais elevadas tomam o predomínio do seu comportamento. Para que haja uma ação, é preciso um estímulo decorrente de coisa externa ou do próprio organismo, criando um ciclo motivacional (MOTTA; VASCONCELOS, 2010).

Para Gondim e Silva (2004) os motivos superiores na escala de Maslow aumentam a autonomia da pessoa, tendo mais oportunidade de criar coisas novas, uma vez que é motivado pela própria realização no trabalho, e não pelas condições extrínsecas.

Ao se falar das necessidades motivacionais, deve-se levar em consideração de como elas são vista em cada indivíduo, afinal o que traz motivação em uma pessoa, pode não trazer em outra. Nos estudos de Motta e
Vasconcelos (2010), a autorealização é considerada um elemento complexo, difícil de entender, com significados diferentes para diversos autores. Isso porque, cada indivíduo apresenta interesses específicos de cada um. Para o autor, ainda que essas necessidades tiverem significados na vida do ser humano, nem sempre é atingida, pois "elas variam e se alteram de acordo com as experiências dos indivíduos e as mudanças que eles enfrentam em suas vidas" (MOTTA; VASCONCELOS 2010, pag. 66). Acrescenta ainda que as necessidades de segurança elencadas na pirâmide de Maslow podem ser da própria família ou do trabalho. Em relação às necessidades sociais, estas são consideradas de amizade ou de relacionamento amoroso, e as realizações profissionais podem ser da pessoa e da autoestima, sendo atingidas quando as metas e as outras necessidades tenham sido atendidas ou cumpridas.

O estudo sobre motivação de Latham e Pinder (2005), tendo como base Gondin e Silva (2004), salienta que é necessário entender o motivo que explica a escolha das necessidades citadas pelo Maslow. Para os autores, as identidades pessoais e sociais podem de certa forma, alterar a hierarquia das necessidades. Isso se dá ao fato de que, quando a identidade pessoal é ativada, a orientação das necessidades se centraliza na pessoa e, principalmente, no favorecimento de sua autoestima. Quando a identificação social é ativada, as necessidades se deslocam para a conformidade com o grupo.

Embora os princípios de Maslow não tenham comprovadamente colaborado na pesquisa empírica, sua teoria teve absoluta aceitação devido a clareza da pirâmide hierárquica organizacional e a sequência das necessidades motivacionais, onde o processo de satisfação das necessidades é contínuo, ou seja, uma vai depender da outra, enquanto uma necessidade é satisfeita, surge logo outra em seu lugar (BERGAMINI, 2006).

\subsubsection{TEORIA X E TEORIA Y DE MCGREGOR}

As teorias X e Y de McGregor (1960) também chamaram a atenção sobre dois tipos de trabalhadores: a primeira teoria, denominada $X$, as pessoas não gostam de trabalhar, não se sentem motivados para tal atividade; a segunda teoria, intitulada $Y$, nela as pessoas são motivadas a trabalhar e buscam desafios no trabalho. 
As duas teorias de McGregor relacionam os conceitos de motivação e liderança, mostrando a visão negativa e positiva do homem em relação ao trabalho, chamando atenção para dois tipos de trabalhadores: na Teoria X, o indivíduo é motivado pelo menor esforço, uma pessoa indolente e preguiçosa, que não gosta de trabalhar e não se sente motivada, apenas demandada por seu líder, que comanda os processos de trabalho. Em contra partida, na Teoria Y, o gerente exerce um estilo democrático de gerenciamento, onde o indivíduo é motivado a trabalhar e buscar desafios no trabalho, com participação maior nas decisões e negociações de suas atividades na organização (ROBBINS; JUDGE; SOBRAL, 2010).

Para Motta e Vasconcelos (2010), a primeira teoria não passa de um estilo chamado gerência autoritária. Este tipo de gerencia traz um desperdício à organização, permitindo que gerente e administrador sejam os responsáveis pela logística dos fatores da produção, ignorando totalmente a opinião e conhecimento dos funcionários. Esse comportamento demonstra claramente que a insatisfação do indivíduo no trabalho não é por ser ele indolente e preguiçoso, como afirma a teoria, e sim, por não deparar com a motivação que precisa para se dedicar mais ao trabalho.

Na Teoria $Y$, as pessoas não são passivas e indolentes, e sim, motivadas, buscando desafios no trabalho. Aqui o foco é na técnica de gerência participativa que desempenha papel fundamental na empresa, ou seja, o líder comunica com seus funcionários, permitindo que suas ideias sejam acatadas, contribuindo para a tomada de decisões. A partir daí, os indivíduos conseguem realizar os seus objetivos pessoais de autodesenvolvimento. Por exemplo, a empresa japonesa "Toyota" cresceu muito nos anos de 1970 e 1980, usando este tipo de gerência participativa, respeitando a opinião e conhecimento de seus trabalhadores, tornando-os mais ligados a organização (MOTTA; VASCONCELOS, 2010).

\subsubsection{TEORIA DOS DOIS FATORES DE HERZBERG}

Segundo Herzberg (1997, p. 61), criador da Teoria dos dois fatores:

Os fatores envolvidos na produção da satisfação (e motivação) no trabalho são separados e distintos dos fatores que levam à insatisfação no trabalho. Já que é necessário considerar fatores separados, dependendo do fato de estarmos examinando a satisfação ou insatisfação no trabalho, segue-se que esses dois sentimentos não são antagônicos. O oposto de satisfação no trabalho não é insatisfação no trabalho, mas sim a ausência de satisfação; e, da mesma forma, o oposto de insatisfação no trabalho não é satisfação no trabalho, mas sim ausência de satisfação.

Esta teoria tem o objetivo de identificar os fatores que causam a insatisfação ou a satisfação do indivíduo no ambiente de trabalho. Herzberg dividiu os fatores em motivacionais, os que agradam aqueles de realização pessoal e profissional de automerecimento no trabalho, e fatores higiênicos, os que geram insatisfação no empregado, como a falta de equipamentos para trabalhar, um salário ruim, benefícios sociais, entre outros. A teoria foi fundamental para os estudos sobre a motivação no trabalho, dando grande contribuição para a escola comportamental (HERZBERG; MAUSNER; SNYDER, 1959).

Herzberg acredita em dois fatores fundamentais em que o indivíduo deve se relacionar ao trabalho, uma deles se relaciona com as necessidades básicas do homem, são os fatores higiênicos ou extrínsecos, que devem ser atendidas em um nível mínimo, como o da segurança e do reconhecimento social. A verdade é que essas necessidades, ao serem atingidas, não aumentam a produtividade, ou seja, o atendimento das necessidades básicas do indivíduo é fundamental, mas não o suficiente, para o aumento da produtividade no trabalho (MOTTA; VASCONCELOS, 2010).

Bergamini (2003) fala sobre os fatores motivacionais ou intrínsecos, que vão além das necessidades básicas. São as aspirações individuais e os significados atribuídos pelo indivíduo, fazendo perceber que a motivação não é condicionada pela organização, nem pela condição de trabalho oferecido, muito menos pelo ambiente social. A motivação nasce dentro do próprio indivíduo.

Hersey e Blanchard (1986) demonstram que os fatores higiênicos desempenham a função importante de prevenir o descontentamento no trabalho, e que precisam ser mantidos continuamente. Já os fatores motivacionais são eficazes na medida em que motivam as pessoas para um desempenho superior. 
Daft (2010) diz que com estes dois fatores o gerente tem o papel de eliminar a insatisfação do trabalhador, fornecendo a ele os fatores de higiene suficiente para satisfazer suas necessidades básicas. Para o autor, ainda existe outra maneira de satisfazer as necessidades motivacionais de nível mais elevado, contribuindo para que as pessoas alcancem recompensas intrínsecas.

Sob o mesmo prisma, esta teoria contribuiu em grande relevância para os estudos da motivação, permitindo perceber com melhor clareza a diferença entre fatores que não motivam (fatores higiênicos) e os que representam a satisfação motivacional (fatores motivacionais):

A importância desse tipo de pesquisa desenvolvida por Herzberg é permitir que se perceba a diferença entre os fatores chamados de higiene, que não motivam, mas tão somente neutralizam a insatisfação e aqueles que representam a verdadeira fonte de satisfação motivacional. Com isso, Herzberg conclui que o contrário de insatisfação não é satisfação, mas nenhuma insatisfação, assim como o contrário de satisfação não é insatisfação, mas nenhuma satisfação. Isso significa que aquilo que deixa as pessoas insatisfeitas quando está ausente, não as satisfaz quando presente. E aquilo que deixa as pessoas satisfeitas quando presente, não as deixa insatisfeitas quando ausente. Se, por exemplo, as políticas administrativas forem justas, ninguém estará mais motivado por causa disso, pois é considerado como obrigação da empresa, mas, se forem injustas, instala-se um clima de insatisfação geral (BERGAMINI, 1998, p. 13).

A Teoria dos dois fatores ainda desempenha importante papel na cultura organizacional no contexto da motivação do trabalho, embora tenha recebido algumas críticas. Porem não recebeu respaldo na literatura, sendo contestada por alguns autores. (Robbins, Judge e Sobral, 2010) aponta as seguintes críticas:

1) $O$ procedimento utilizado por Herzberg é limitado por sua metodologia. Quando as coisas vão bem, as pessoas tendem a tomar o crédito para si. Caso contrário, buscam culpar o ambiente externo pelo fracasso;

2) A confiabilidade da metodologia de Herzberg é questionável. Os pesquisadores precisam fazer interpretações e, dessa forma, podem contaminar os resultados interpretando uma resposta de determinada maneira, enquanto outra resposta semelhante é interpretada de modo diferente;

3) Não se utilizou uma medida geral para a satisfação. Uma pessoa pode não gostar de alguns aspectos de seu trabalho, mas ainda assim considera-lo aceitável de maneira geral;

4) Herzberg pressupõe uma relação entre satisfação e produtividade, mas a metodologia de pesquisa que usou enfoca apenas a satisfação, não a produtividade. Para tornar essa pesquisa relevante, é preciso considerar um forte relacionamento entre satisfação e produtividade.

As condições oferecidas ao fator intrínseco e fator extrínseco no trabalho não são suficiente para satisfazer ou motivar a pessoa em suas atividades, porém, deveriam de qualquer forma ser alvo de atenção e de responsabilidade dos dirigentes organizacionais para evitar insatisfação no trabalho, prejudicando o desempenho das funções laborais (GONDIM; SILVA, 2004).

Já Bergamini (2011) conclui que os fatores de motivação estão ligados ao próprio indivíduo ao trabalho que ele desempenha. Ao passo que, fatores de higiene formam o meio ambiente no qual se situa o indivíduo e sua atividade na organização.

\subsubsection{TEORIA DAS EXPECTATIVAS DE VROOM}

Uma das explicações sobre a motivação mais coerentes e aceitas na literatura é a Teoria das expectativas, desenvolvida por Victor Vroom, conforme Figura 1, explicando como são "combinados a habilidade e o conhecimento do empregado, o sistema de mensuração e de recompensa pelo desempenho da empresa e os valores pessoais do indivíduo para determinar a motivação individual" (CASEMIRO, 2014). 
Figura 1 - Modelo de motivação de Vroom

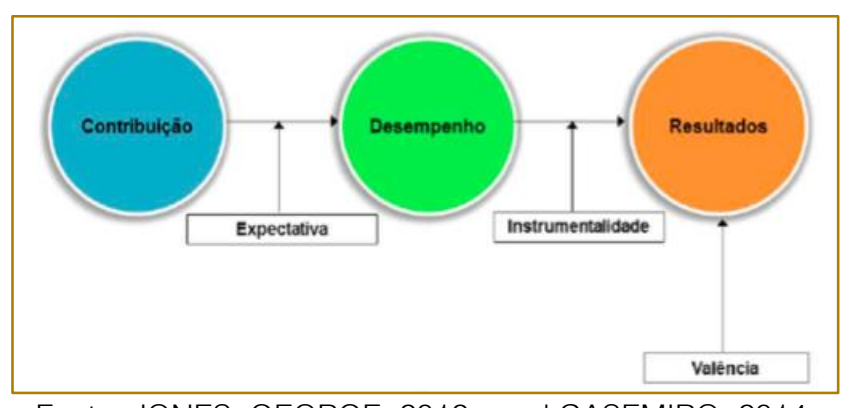

Fonte: JONES; GEORGE, 2012 apud CASEMIRO, 2014.

Em sua abordagem, a motivação é um processo de governar as escolhas entre diferentes possibilidades de comportamento do indivíduo que avaliem as consequências de cada alternativa. Para que a motivação ocorra, "é preciso que os resultados sejam desejados e que as expectativas e instrumentalidades sejam altas". Considera fatores motivacionais da seguinte forma: a relação entre o esforço e um bom desempenho (expectativa); entre 0 desempenho e a recompensa (valência); e a relação entre a recompensa e os objetivos (instrumentalidade). Nesse sentido, a Motivação (M) é um produto dos seguintes fatores: expectativa (E), valência $(V)$ e instrumentalidade (I), formando uma equação $(\mathrm{M}=\mathrm{E} \times \mathrm{V} \times \mathrm{I})$. Ambos se relacionam entre si, considerando a motivação inexistente caso algum deles faltar (VROOM, 1964).

Fiorelli (2006) entende que, dentro dessa interpretação do Vroom, os indivíduos fazem escolhas baseados em seus ideais de recompensa não obtidos ainda. Tais recompensas devem estar inseridas em período de tempo médio para que haja uma relação desempenho-recompensa justa.

Outra corrente de pensamento propõe que nesta teoria os conteúdos mentais mais relevantes são cúmplices do comportamento motivacional, isso porque são demonstrados pelos valores guardados na mente humana. Refere-se a um modelo que leva em consideração a dignidade humana, quando os indivíduos da organização passam a ser vistos como pessoas presentes. Desta feita, suas percepções e estimativas de perspectivas influenciam fortemente seus comportamentos (BERGAMINI, 2006).

$\mathrm{Na}$ prática, esta teoria sugere que um trabalhador se sente motivado para alcançar um alto grau de esforço, resultando em uma boa avaliação de desempenho; que por sua vez, vai resultar em recompensas organizacionais, tais como benefícios, aumento de salário ou promoção, atendendo as suas metas pessoais. Considera a Teoria das expectativas como um modelo contingente, situacional, em que não existe um conceito único para explicar as motivações de todos os indivíduos (ROBBINS, 2002).

Para Gondim e Silva (2004), a motivação para a ação de meta pessoal dependerá da valência que 0 indivíduo atribui para conseguir seu objetivo, realizada através de atividades como: entender a jornada diária do trabalho, a colaboração com os colegas de trabalho, entre outros.

A Teoria das expectativas possui efeitos indiretos na conduta, onde "os resultados, as valências, as expectativas e a instrumentalidade sofrem restrições ambientais, e, em função disso, ela é classificada como nível intermediário de ação". Isso porque a política da organização é restrita e não combina com o objetivo de dirigir as expectativas e as valências pessoais (KANFER, 1992 apud GONDIM; SILVA, 2004, p. 181).

\subsubsection{TEORIA DA AUTODETERMINAÇÃO}

A Teoria de autodeterminação, criada por Ryan e Deci (1987), tem o propósito de lidar com as ações benéficas da motivação intrínseca e com ações contrárias da motivação extrínseca. A teoria opera com quatro miniteorias desenvolvidas através de pesquisas de campo e de laboratório: a Teoria das necessidades básicas, abrangendo a necessidade de autonomia pessoal; a Teoria da integração organísmica, onde o processo de socialização ocupa papel principal desde o processo de internalização; a Teoria das orientações de causalidade, 
descrevendo os recursos internos utilizados pela pessoa na interação com o contexto social, considerando três aspectos: a autonomia, a regulação e o controle; e a Teoria da avaliação cognitiva, que estuda as motivações intrínsecas, quando o que move a pessoa para a ação são motivos internos, e extrínsecas, quando a pessoa é movida por condições externas a ela, e as diferenças individuais entre essas modificações (ROBBINS; JUDGE; SOBRAL, 2010).

A Teoria de avaliação cognitiva mostra que as recompensas extrínsecas reduzem a motivação intrínseca. Ela é vista como forma de controle da organização sobre o comportamento dos trabalhadores. Esta situação acontece quando a pessoa começa a ser remunerado mediante 0 trabalho voluntário, um trabalho que o indivíduo sente prazer em fazer. Na motivação intrínseca a pessoa sente prazer e interesse a realizar determinada tarefa, porém, a atividade passará a ser vista como um fim em si mesmo (ROBBINS; JUDGE; SOBRAL, 2010). Nesse sentido, Deci, Koestner e Ryan (2001) consideram que nesta teoria a atividade externa, o avanço de recompensas, volta a influenciar negativamente a motivação intrínseca.

Outro aspecto de destaque em relação à Teoria de autodeterminação diz respeito aos estudos feito pelos autores Leal, Miranda e Carmo (2013), que utilizaram o propósito da teoria para avaliar a motivação dos estudantes do curso de Ciências Contábeis de uma universidade pública brasileira. De acordo com os autores, a motivação extrínseca por regulação externa dos alunos do último período do curso, foi a maior média obtida na pesquisa.

Os novos ingressantes no curso são intrinsecamente motivados uma vez que suas atividades possuem um fim em si mesmo. Já os estudantes do último período realizam tarefas como se fossem pressionados a fazêla. Segundo os autores (2013 apud GUIMARÃES; BZUNECK, 2008), a realização da atividade escolar é sustentada pela importância que a mesma possui para as metas almejadas. Uma explicação para essa atitude é de que, os estudantes do último período do curso de Ciências Contábeis se preocupam mais com a obtenção do diploma e das possibilidades por ele proporcionadas, como conseguir um emprego com melhor remuneração, uma qualidade de vida melhor, dentre outros motivos adicionais.

\subsubsection{TEORIA DE NECESSIDADES DE MCCLELLAND}

Baseada na Teoria de Maslow já tratada anteriormente, McClelland e sua equipe desenvolveram a teoria com base em três necessidades (ROBBINS; JUDGE; SOBRAL, 2010):

- Necessidade de realização - se faz na busca da excelência e a realização pelo sucesso.

- Necessidade de poder - necessidade de influenciar o comportamento do outro.
- Necessidade de afiliação - relacionamentos interpessoais próximos e amigáveis.

Gondim e Silva (2004) esclarecem que a motivação no trabalho dependerá dessas três necessidades, isso porque, quando a necessidade de realização for atingida, a pessoa se sente motivada a dar continuidade ao trabalho, em busca de seu sucesso pessoal, lutando pelo sucesso. Quando a necessidade do poder for realizado, aquela necessidade de impactar, controlar as pessoas, influenciar, utilização da dominação ou carisma, a pessoa passa a sentir-se motivado pela vontade de competir, no interesse em manter seu prestígio e reputação, dirigindo e mudando algumas atitudes dentro da organização. Por fim, a necessidade de afiliação, o desejo de ser amado e aceito pelos outros, construir sólidas amizades, tornando o relacionamento mais estável, agindo de forma amigável e cooperando com a organização.

Considerando as duas necessidades de poder e de afiliação, a pessoa se sente profundamente motivada porque o trabalho passa a ser uma grande responsabilidade. Essa teoria tem grande influência para as pessoas que tem necessidade de poder e de autoridade, como os gestores, por exemplo, que aprendem a correr riscos moderados e a atingir as metas. Esta teoria é menos praticada em relação às outras, isto porque, sem saber, a pessoa pode se identificar com alto grau dessas três necessidades (MOTTA; VASCONCELOS, 2010).

\subsubsection{TEORIA DA EQUIDADE DE STACY ADAMS}


John Stacy Adams (1963) chamou atenção com sua contribuição para os estudos da motivação no trabalho com a Teoria da equidade, baseada na comparação social no trabalho. Esta teoria só é aplicada de forma correta em organizações que tenham uma política de recursos humanos bem definidos e uma estrutura salarial organizada. A teoria tem idealiza 0 individuo que compara as recompensas por ele recebidas, fruto de seu esforço, com a recompensa de outras pessoas com esforços semelhantes. Cria então uma questão de o que é considerado justo e injusto pelos funcionários, trazendo conseqüências desagradáveis à empresa. A equidade deve ser uma comparação entre desempenho e benefícios de indivíduos em situações parecidas, reconhecendo igualmente o direito de cada um.

De acordo com Robbins, Judge e Sobral (2010) existem quatro pontos que podem ser usados como comparação:

1) Próprio-interno: a experiência do funcionário em relação a outra posição dentro da mesma empresa;

2) Próprio-externo: a experiência do funcionário em relação a uma situação ou posição fora da empresa atual.

3) Outro-interno: outra pessoa ou grupo da mesma empresa.

4) Outro-externo: outra pessoa ou grupo fora da empresa atual.

Se um trabalhador perceber uma injustiça em relação a ele, poderá tomar algumas atitudes, fazendo uma escolha entre as seguintes opções:

1) Modificar seus insumos: fazer menos esforço (ou mais esforço) se sentirem que ganham menos (ou mais) do que deveriam;

2) Modificar suas recompensas: por exemplo, funcionários que recebem por unidade produzida tendem a produzir mais peças, mas com qualidade menor;

3) Rever sua autoimagem: algo do tipo "eu achava que trabalhava na média dos meus colegas, mas agora eu percebi que trabalho muito mais";

4) Rever a percepção que tem dos outros: por exemplo, "o trabalho do meu colega ao lado não é tão bom quanto eu imaginava que fosse";

5) Buscar outro ponto de referência: por exemplo, "não ganho tão bem quanto meu cunhado, mas certamente ganho mais do que meu pai ganhava quando ele tinha a mesma idade".

6) Desistir: buscar outro emprego (ROBBINS; JUDGE; SOBRAL, 2010).

A comparação interna ou externa pode ser favorável ou desfavorável entre ganhos e investimentos, levando o trabalhador a sair da zona de conforto, buscando mudanças no ambiente do trabalho ou até mesmo outra organização que se enquadre em sua satisfação.

\subsection{A RECOMPENSA DO DESEMPENHO HUMANO}

Algumas organizações oferecem incentivos para campanha de motivação aos seus trabalhadores. Para alcançar um bom desempenho, as organizações precisam levar em consideração vários fatores que motivam os funcionários. É necessário que haja um alto grau da dimensão essencial do trabalho, levando em conta os fatores de variedade, autonomia, identidade de tarefa, e opinião (COSTA, 2013).

O sistema operacional Motivação 2.0 abordado por Pink (2010), define que o melhor caminho para melhorar "o desempenho no trabalho", "aumentar a produtividade e estimular a excelência", é recompensar o bem e punir o mau. Esta seria a única forma de um ser humano se mobilizar na direção certa, caso contrário, empunha-lhe a um chicote. Este sistema encontrou, ao longo dos anos, algumas resistências e críticas por outros autores.

Para Daft (2010, p. 738) "o uso da punição nas organizações é controverso e com frequência criticada. Isso porque falha em indicador o comportamento correto". Mesmo assim, os gestores levam em consideração a aplicação de punições em situações determinadas necessárias. O autor acredita no reforço positivo, onde as pessoas levam em consideração outros fatores mais importantes na recompensa, como o elogio, a opinião, o reconhecimento, 0 apoio do gerente, e na participação.

Bergamini (1998) traz a forma para resolver a falta de motivação do desempenho humano, dando como solução o planejamento de uma estratégia administrativa de condicionamento aplicada ao trabalhador, como a distribuição de prêmios em compensação a um bom 
desempenho. Alerta que não é necessário permanecer a perspectiva do controle extrínseco "punição", quando se pensa em motivar pessoas no trabalho, a recompensa é uma boa resposta para a motivação.

Seguindo a mesma linha de raciocínio, Costa (2013) acrescenta que o trabalho remunerado, como qualquer outro tipo de benefícios, faz com que o trabalhador considere muito mais o lugar onde trabalha, agregando com mais precisão o valor à organização. Em uma avaliação do autor, os gerentes não estão sendo coerentes com seus colaboradores na participação de tomada de decisão, limitando suas opiniões e não dando oportunidades de serem reconhecidos pela empresa, isso porque seu nível de realimentação extrínseca é muito baixo.

Vale lembrar que a recompensa tem um impacto negativo para 0 trabalhador. Inicialmente, eles sentem satisfeitos porque algo a mais foi estabelecido pelo mesmo serviço prestado anteriormente. Com o passar de tempo, esse prêmio passará a ser algo recíproco por considerações menores do que esperavam, ou seja, os trabalhadores passam a levar desvantagem mesmo sendo remunerados.

Bergamini (1998) aponta os possíveis impactos que a recompensa causa no trabalhador, devendo o gestor tomar o devido cuidado ao atribuir prêmios, sendo necessária a transparência entre ambas as partes, procurando criar critérios "bem claramente estabelecidos para não provocarem uma sensação de injustiça ou iniquidade. As pessoas que podem ser agraciadas com prêmios precisam saber exatamente que atitude ou ação foi digna de retribuição por parte da empresa" (BERGAMINI, 1998, p. 12).

Alguns autores acreditam que o indivíduo perca sua motivação quando certo nível de necessidade foi atendido. Neste caso, a motivação passa a ter outra característica diferente daquele que já nasce dentro do indivíduo. Entretanto, percebe- se que o conceito da motivação é muito mais complexo e difícil de entender, por conta de vários fatores envolvidos a seu respeito. A motivação só nasce dentro do indivíduo quando ele realmente precisa traçar um objetivo específico, e neste caso, ela não pode ser considerada algo permanente dentro das pessoas, já que varia de acordo com as necessidades do momento, e não pelo fato de gostar do que faz, pelo fato de gostar do seu trabalho (MOTTA; VASCONCELOS, 2010).

O cenário organizacional contemporâneo ainda traz a perspectiva de controle extrínseco para motivar pessoas no trabalho. Com a complexidade do comportamento motivacional, fica difícil de achar uma teoria ideal para motivar as pessoas nos tempos atuais em que nada permanece estável. $\mathrm{Na}$ seção seguinte serão apontados os processos metodológicos aplicados na sua elaboração da pesquisa.

\section{PROCEDIMENTOS METODOLÓGICOS}

A pesquisa é classificada como qualitativa descritiva, porque busca descrever a produção cientifica sobre a motivação no trabalho. A pesquisa descritiva tem como objetivo primordial "a descrição das características como da população ou fenômeno ou então, o estabelecimento de relação entre variáveis" (GIL, 2002, p.42).

A abordagem qualitativa é importante, pois levam em consideração algumas variáveis que auxiliam no processo de compreensão e classificação. Seu objetivo é de apresentar apoio na criação ou formação de opiniões de determinado grupo, contribuindo para mudanças e participações mais efetivas nos resultados almejados (OLIVEIRA, 1997).

A bibliometria é o conjunto de leis e princípios empíricos que contribuem para estabelecer os fundamentos teóricos da Ciência de Informação, com métodos estatísticos para analisar as informações científicas de uma determinada área de estudo (PRITCHARD, 1969). A bibliometria foi usada pela primeira vez para as necessidades na área de Biblioteconomia

Não há estudos de bibliometria recentes no avanço do conhecimento cientifico sobre "motivação no trabalho no Brasil", mesmo com o grande número de trabalhadores desmotivados na atual situação do país. O recente estudo a considerar foi o de Pinder (2004), que acredita ser a motivação nada mais que a junção do homem e do ambiente em que se encontra, concluindo que, quanto mais favorável for o ambiente, mais motivado o homem ficará.

Este estudo trata de uma pesquisa bibliográfica, desenvolvida com base em material já elaborado, porém selecionando especificamente livros e artigos científicos. A 
abordagem qualitativa da pesquisa dá suporte às sugestões propostas para a construção de hipótese. Segundo Zupic e Cater (2015), a análise bibliométrica é importante para o avanço do conhecimento nessa linha de pesquisa, pois se desenvolve a partir de dados bibliográficos contidos em base de dados específica e reconhecida no mundo acadêmico.

A escolha da base de dados da Associação Nacional de Pós-Graduação e Pesquisa em Administração (ANPAD) enquanto fonte de pesquisa teve como justificativa por entender que a mesma reúne os trabalhos mais relevantes da produção acadêmica nacional da área de Administração, Administração Pública, Administração de Empresas, entre outros.

Os resultados do procedimento metodológico foram filtrados da seguinte forma, com artigos coletados durante os meses de maio e junho de 2016, no banco de dados da ANPAD:

a) delimitou-se o período de pesquisa para artigos publicados entre 2006 a 2015;

b) filtrados e selecionados artigos que tinham como principal título a palavra-chave "motivação";

c) preferidos e escolhidos os artigos que tratavam do assunto "motivação no trabalho";

d) análise bibliométrica realizada como importante atividade para o avanço do conhecimento nessa linha de pesquisa.

Após essa seleção, os 24 (vinte e quatro) artigos encontrados na pesquisa foram organizados em um quadro, anexo em seção posterior, destacando de cada publicação o título, ano da publicação, nome da revista em que foi publicado, nome do(s) autor(es) e instituição de origem, Estado de origem da instituição afiliada ao(s) autor(ES), a abordagem e o tipo da pesquisa. Em seguida, discriminou se o estudo era teórico ou empírico, como também qual o instrumento da coleta de dados, o nome da base de dados, neste caso todos eram da ANPAD, a quantidade e o sexo dos autores, por artigo.

\section{RESULTADOS E DISCUSSÕES}

As bases de dados eletrônicas são ferramentas que promovem o conhecimento e colaboram para o desenvolvimento científico. A bibliometria vem sendo utilizada em diversas áreas do conhecimento como avaliadora da produção científica, analisando a atividade pelo estudo quantitativo das publicações, apoiada em base de dados bibliográficos, resumos e indexadores. Para a relevância deste trabalho, a bibliometria ajudou para a identificação de características temáticas da literatura. Em síntese, a bibliometria é feita através de estudo dos aspectos quantitativos da produção, disseminação e uso da informação (VANTI, 2002 apud RAVELLI, 2009). O Quadro 1 (ANEXO) apresenta a relação de publicações encontradas da pesquisa feita na base de dados da ANPAD, com os principais artigos do estudo bibliométrico elaborado, dentre as diferentes perspectivas analisadas.

\subsection{CARACTERIZAÇÕES DA PRODUÇÃO}

A análise de resultado é uma das etapas mais importante da pesquisa. Sendo assim, na busca dos artigos disponíveis nos períodos acima descritos, os quais continham a palavra-chave "motivação", obteve-se um total de 24 artigos. Quanto à distribuição dos artigos sobre motivação na base de dados da ANPAD, percebe-se que a maioria dos textos foram publicados a partir do ano de 2015, conforme Quadro 2 abaixo: 
Quadro 2 - Quantidade de publicação dos artigos por ano

\begin{tabular}{|c|c|}
\hline Total de artigos & Ano de publicação \\
\hline 3 & 2006 \\
\hline 2 & 2007 \\
\hline 1 & 2008 \\
\hline 1 & 2009 \\
\hline 0 & 2010 \\
\hline 1 & 2011 \\
\hline 2 & 2012 \\
\hline 5 & 2013 \\
\hline 3 & 2014 \\
\hline 6 & 2015 \\
\hline
\end{tabular}

Gráfico 1: Estados de origem das instituições de afiliação dos autores dos artigos (\%)

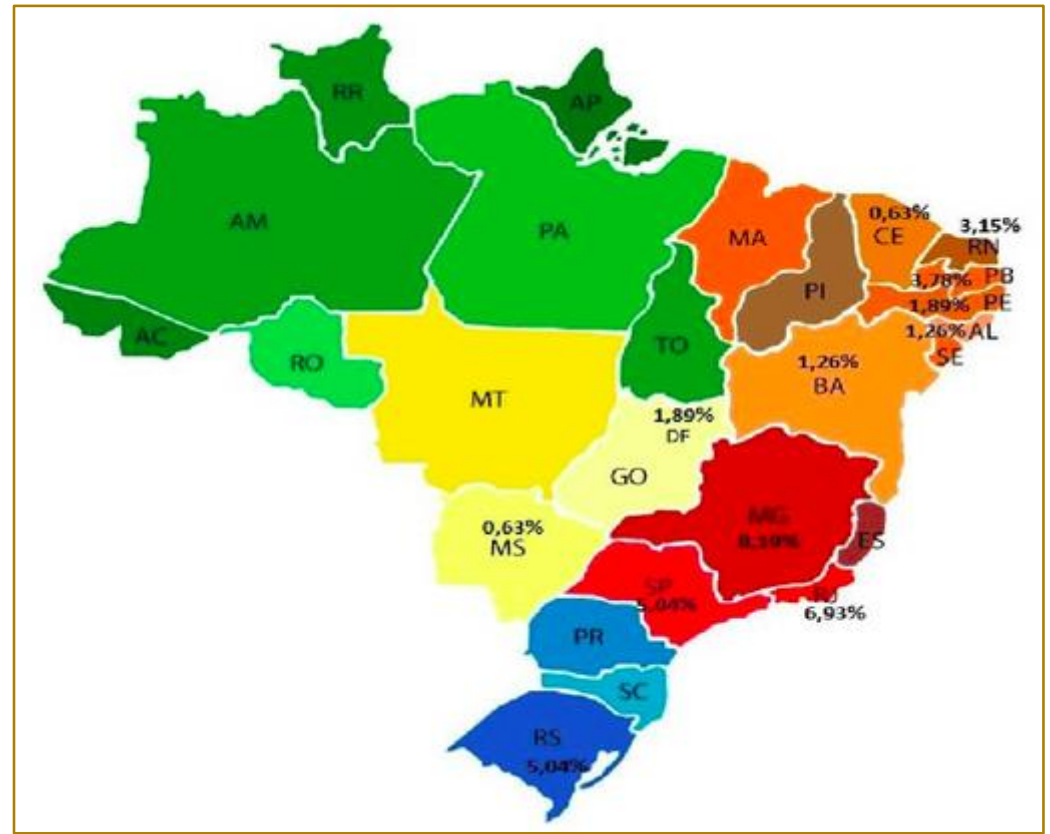

O Quadro 2 mostra que no ano de 2010 não teve nenhuma publicação de artigos com o tema, e no ano de 2015 a produção aumentou bastante, levando a crer que a o assunto será muito mais discutido nos dias atuais.

O Gráfico 1 ilustra a distribuição por estado das instituições de afiliação dos autores dos artigos publicados no período de 2006 a 2015 sobre o tema "motivação no trabalho". O estado de Minas Gerais teve uma escala de 13 instituições (8,19\%), e o estado do Rio de Janeiro um total de 11 instituições (6,93\%), sendo o estado com maior frequência de autorias, seguido dos estados de São Paulo e Rio Grande do Sul, empatados com 8 instituições cada um (5,04\%). Vale destacar que no estado de RS, o município de Santa Maria teve a maioria das instituições (6). Logo abaixo aparece Campina Grande (PA) com 6 instituições (3,78\%); em seguida, Rio Grande de Norte, com 5 instituições (3,15\%); depois Pernambuco e Distrito Federal, com três instituições cada (1,89\%); em seguida os estados de Alagoas e Bahia, com 2 instituições cada $(1,26 \%)$. Finalmente, os estados que tiveram a menor taxa são Mato 
Grosso do Sul e Ceará, com apenas 1 instituição cada (0,63\%).

Gráfico 2: Contagem de abordagem da pesquisa (quanti, quali ou quanti/quali)

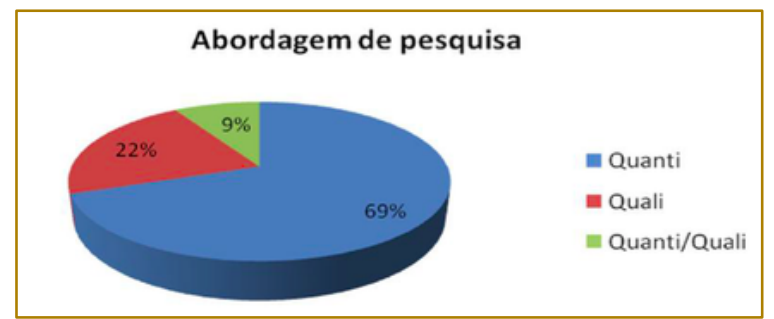

Em relação à abordagem da pesquisa no Gráfico 2, dos 24 artigos encontrados a maioria deles é exclusivamente quantitativa. Portanto, ao se limitar os artigos publicados na base de dados da ANPAD, pode-se observar que enfoque qualitativo é ainda mais representativo do que a abordagem quantitativa prevalecendo com $69 \%$. Outros $22 \%$ representam a abordagem qualitativa, estudos estes que, conforme afirma Oliveira (1997), apoiam na criação ou formação de opiniões de determinados grupos, contribuindo assim, para mudanças e participações mais efetivas nos resultados almejados. Bem menor que as outras, a abordagem quanti- qualitativa ocupa $9 \%$ do total de artigos da base de dados da ANPAD.

Gráfico 3: Contagem de tipo de pesquisa

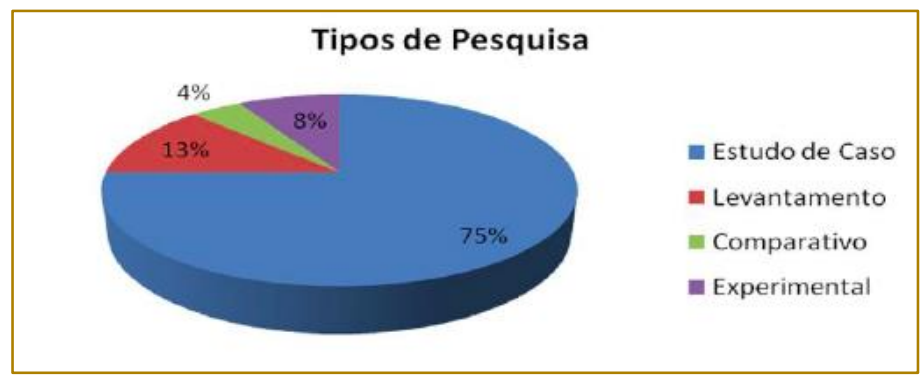

O Gráfico 3 apresenta os tipos de métodos e técnicas de pesquisa constatados nos artigos selecionados, entre eles: estudo de caso, levantamento, comparativo e experimental. Grande parte dos artigos tinha como pesquisa o estudo de caso, com 75\%. Segundo Severino (2007), na pesquisa do estudo de caso os dados devem ser coletados e registrados com 0 necessário rigor, apresentados em relatórios qualificados, seguindo todos os procedimentos da pesquisa do campo. Trata de uma pesquisa descritiva que visa estudar um caso ou um sistema. A pesquisa por levantamento ou survey teve $13 \%$ na contagem do total de artigos. É uma pesquisa que descreve a distribuição das características ou de fenômenos que ocorrem naturalmente em grupos da população. A pesquisa experimental teve $8 \%$ do total de artigos analisados, sendo uma pesquisa que visa identificar a manipulação de tratamentos na tentativa de estabelecer relações causa-efeito nas variáveis investigadas. Por fim, a pesquisa comparativa ficou com uma porcentagem bem abaixo, com $4 \%$ do total de publicações nesse período. Esta pesquisa é um método de investigação de fatos, coisas ou pessoas, que analisa suas diferenças e semelhanças. 
Gráfico 4: Tipos de estudo

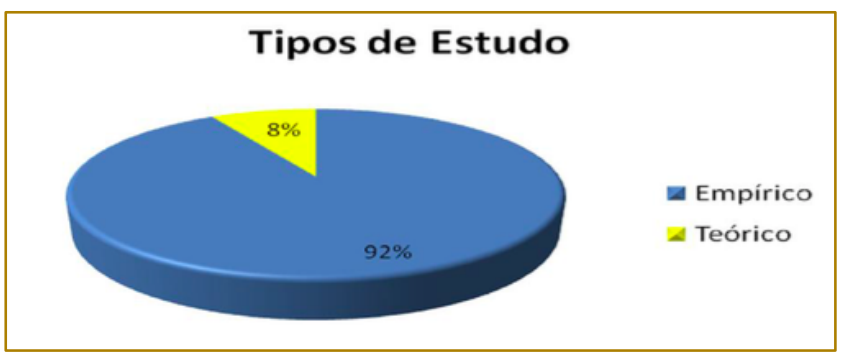

As aplicações dos artigos foram sobre em dois tipos de estudos, conforme Gráfico 4, o empírico e o teórico. O estudo empírico, aquele que visa a observação de experiências vividas, ficou com a maior parte da análise, $92 \%$ no total, enquanto somente $8 \%$ foram estudos teóricos, ou pesquisas que aprofundam conhecimentos e discussões.

Gráfico 5: Coleta de dados utilizada pelos autores

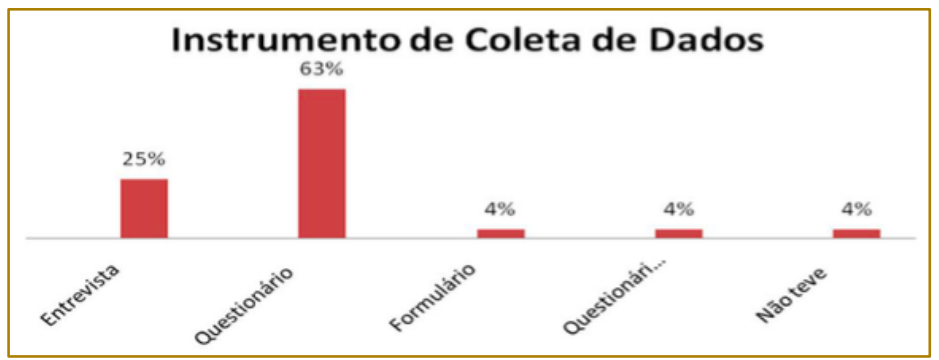

A coleta de dados é uma tarefa muito importante na pesquisa. Segundo Cervo, Berviam e da Silva (2007), a coleta de dados envolve diversas pessoas, analisando diversos fatores, como a determinação da população a ser estudada, a elaboração de instrumento de coleta, a programação da coleta e também o tipo de dados e de coleta. Portanto, o pesquisador tem que levar em conta o que oferece menos desvantagem, respeitando o objetivo da pesquisa. No
Gráfico 5 a distribuição da pesquisa ficou a maior parte, 63\%, com os autores que utilizaram o questionário, uma das formas mais seguras para coletar os dados porque possibilita ter um feedback maior do resultado esperado. Somente as entrevistas tiveram um percentual de $25 \%$ desse total. O uso de questionário e entrevista simultâneos, o uso de formulários, e nenhum instrumento utilizado para coleta de dados tiveram um percentual igual, ficando com $4 \%$ cada um destes. 
Gráfico 6: Quantidade de autores por artigo

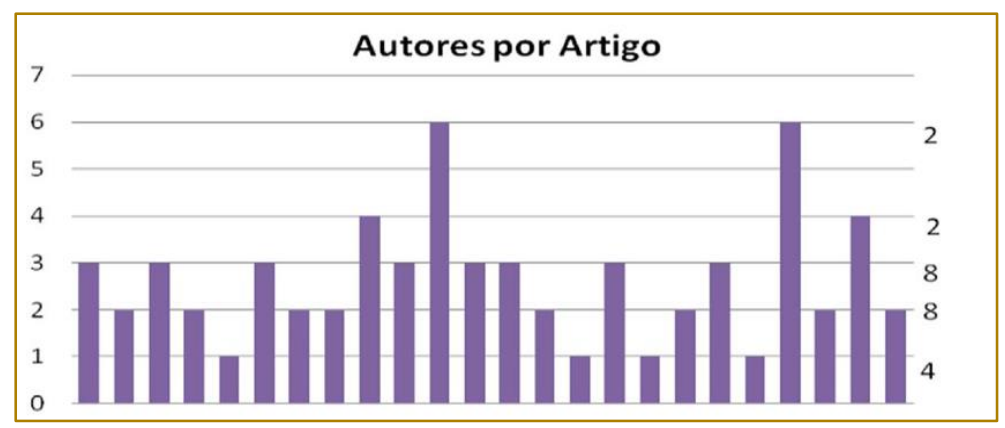

Com relação aos autores por artigo, o Gráfico 6 mostra que apenas quatro artigos foram escritos por um único autor. Os outros 20 artigos foram escritos por dois ou mais autores, atingindo um número máximo de seis autores por artigo, que aconteceu com dois artigos. Oito artigos foram escritos por dois e três autores juntos e, finalmente, dois artigos foram escritos por quatro autores, conforme mostra o gráfico. Percebe-se, portanto, que o estudo do tema "motivação no trabalho" foi pesquisado e escrito por autores em parceria, nesta última década.

Gráfico 7: Sexo dos autores

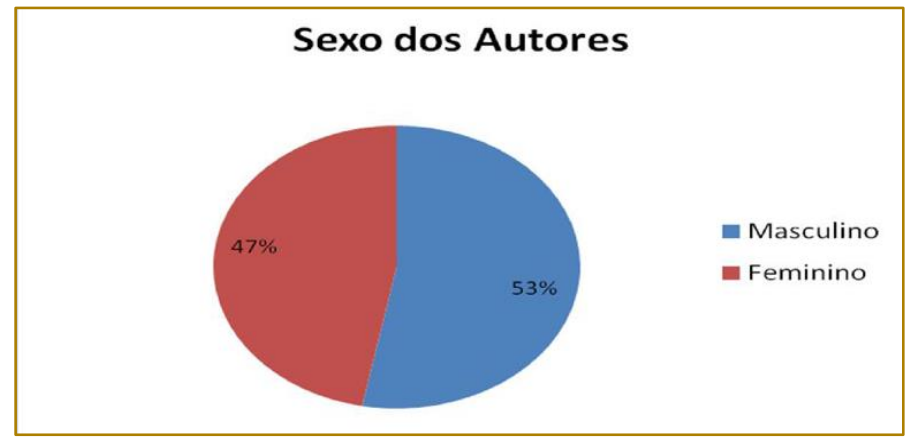

O Gráfico 7 apresenta cerca de $53 \%$ de autores do sexo masculino escrevendo sobre o estudo de motivação no trabalho nos últimos dez anos, e $47 \%$ de autores do sexo feminino. De acordo com Robbins, Judge e Sobral (2010), há uma diferença na motivação do sexo masculino e feminino. Os homens são relativamente mais motivados para se superarem no trabalho, $e$ as mulheres se sentem mais motivadas a manter relacionamento.

\footnotetext{
As pesquisas indicam que os homens são aparentemente mais definidos pelo que chamamos de "características agênticas", tais como: ativo, dedicado e competitivo. As mulheres costumam ser mais descritas pelo que chamamos de "características comunais", tais como: cuidadosa, emotiva e atenciosa. (ROBBINS; JUDGE; SOBRAL, 2010, pag. 199).
}

\section{CONSIDERAÇÕES FINAIS}

O objetivo desta pesquisa foi mapear e analisar a recente produção científica no Brasil sobre motivação no trabalho, na base de dados da Associação Nacional de PósGraduação e Pesquisa em Administração (ANPAD). Era esperado que este mapeamento contribuísse para o desenvolvimento da pesquisa, e colaborasse na aplicação dos entendimentos na rotina das organizações, aprimorando a gestão de pessoas, buscando uma motivação intrínseca de cada indivíduo, sobretudo colaborando para a tomada de decisões dos gestores.

A primeira consideração apresentada através da análise da bibliometria mostra o possível crescimento do estudo sobre motivação no trabalho no Brasil, levando em conta a 
quantidade de artigos publicados na base de dados da ANPAD no ano de 2015 em relação a quantidade publicada nos anos anteriores.. Entretanto, apesar do gráfico mostrar a crescente produção, ainda há muito pouco material elaborado sobre este assunto no país, formando uma lacuna na pesquisa nacional sobre o tema.

Com base nos artigos encontrados no estudo bibliométrico, apurou-se que a maior concentração dos estudos sobre o tema foi nos estados de Minas Gerais (8,19\%), Rio de Janeiro (6,93\%) e São Paulo (5,04\%). É possível perceber também o baixo número de instituições afiliadas aos estudos sobre a motivação no trabalho nas seguintes regiões: Norte, Nordeste, e Centro Oeste. Portanto, é sugerido $O$ estimulo a pesquisa nessas regiões.

A grande maioria dos artigos tem um enfoque metodológico e quantitativo (69\%). Vale ressaltar que 0 enfoque quantitativo se fundamenta em um esquema dedutivo e lógico, formulando questões de pesquisa para testar posteriormente, generalizando os resultados de seus estudos mediante amostras representativas. Outro dado interessante a concluir é que a maioria dos dados coletados nos artigos foi através de questionário (63\%), e pelo método da abordagem de investigação intitulada estudo

\section{REFERÊNCIAS}

[1] ADAMS, J. S. Towards an understanding of inequity. The Journal of Adnormal and Socioal Psychology, v. 67. n. 5, p. 422, 1963. BERGAMINI, C. W. A Difícil Administração das Motivações. Rev. Administração de Empresas, v. 38, n. 1, São Paulo, 1998.

[2] Motivação: Mitos, Crenças e MalEntendidos. Rev. Administração de Empresa. São Paulo, 1990.1 Disponível em: http://bibliotecadigital.fgv.br/ojs/index.php/rae/ article/viewFile/38667/37403. Acesso em: 24 mar. 2017.

[3] Motivação nas organizações. São Paulo: Atlas, 2006.

[4] Motivação: uma viagem ao centro do concerto. Harvard Business Review, v.1, n. 2, 2003. Disponível em: http://rae.fgv.br/gv-executivo/vol1num2-2002/motivacao-viagem-ao-centro-conceito. Acesso em: 24 mar. 2017.

[5] .Psicologia aplicada à administração de empresa: psicologia do comportamento de caso, que teve uma quantidade expressiva, com $75 \%$ da análise.

Em relação à autoria, o sexo feminino levou desvantagem em uma diferença de $47 \%$ em relação ao sexo masculino, com $53 \%$ do total de autores. Essa diferença afirma a análise de Robbins, Judge e Sobral (2010), dizendo que os homens são relativamente mais motivados para se superarem no trabalho, enquanto as mulheres se sentem mais motivados a manter um relacionamento.

É importante salientar que esta pesquisa limitou-se apenas a trabalhos publicados em uma base de dados da ANPAD, no período de 2006 a 2015. Destaca- se ainda o fato de não terem sido pesquisadas as sociometrias, e não ter expandido a pesquisa para as redes internacionais, ficando o alerta para novos estudos mais abrangentes.

A pesquisa suscitou novos estudos sobre o tema, apresentando como importantes sugestões o avanço na exploração sobre o assunto "motivação no trabalho"; a elaboração de um trabalho baseado em análise qualitativa; a elaboração de estudos bibliométricos em outras bases de dados, principalmente bases internacionais; e a colaboração entre pesquisadores de diferentes áreas de conhecimento, para o desenvolvimento do tema no Brasil, que ainda é muito carente.

organizacional. 4. ed. 7. reimpr. São Paulo: Atlas, 2011.

[6] CASEMIRO, I. P. Conteúdos sobre gestão da diversidade em projetos pedagógicos de cursos de graduação em Administração. 2014. Dissertação (Mestrado em Administração)Universidade Federal de Rondônia, Porto Velho, 2014. CERVO, A. L; BERVIAM, P. A; DA SILVA, R. Metodologia cientifica. 6. ed. São Paulo: Pearson Prentice Hall, 2007.

[7] COSTA, C. A. et. al. Qualidade de Vida no Trabalho, Satisfação e Motivação do Trabalhador no Setor de Varejo. Rev. Administração da UNIMED, v. 11, n. 1, 2013. DAFT L. R. Administração. 2. ed. São Paulo: Cengage Learning, 2010.

[8] DECI, E. L.; KOESTNER, R.; RYAN, R. M. Extrinsic Rewards and instrinsic motivationin education: reconsidered once again. In: Review of Education Research, Spring, v. 71, n. 1, p. 1-27, 2001. FISCHER, A. L. As pessoas na organização. 14. ed. São Paulo: Gente, 2002. 
[9] FIORELLI, J. Q. Psicologia para Administradores: integrando teoria e prática. 5. ed. São Paulo: Atlas, 2006.

[10] GIL, A. C. Como elaborar projetos de pesquisa. 4. ed. São Paulo: Atlas, 2002.

[11] GONDIM, S. M. G. ; SILVA, N. Motivação no trabalho. In: ZANELLI, J.J.; BORGES-

[12] ANDRADE, J.E.; BASTOS, A.V.B. Psicologia, organizações e trabalho no Brasil. Porto Alegre: Artmed, 2004.

[13] HERZBERG, F.; MAUSNER, B.; SNYDE, B. B. The motivation to work. 2. ed. New York: John Wiley \& Sons, Inc., 1959.

[14] HERZBERG, F. Novamente: como se faz para motivar funcionários? In: BERGAMINI, C., CODA; R. (Org.). Psicodinâmica da vida organizacional: motivação e liderança. 2. ed. São Paulo: Atlas, 1997.

[15] HERSEY, P. BLANCHARD, K. H. Psicologia para administradores: a teoria e técnicas da liderança situacional. São Paulo: EPU, 1986.

[16] JONES, G. R.; GEORGE, J. M. Fundamentos da administração contemporânea. Porto Alegre: McGrawHill - Bookman, 2012.

[17] KOHN, A.; BERGAMINI, C. W.; STEINER, M. H. Punidos pelas recompensas: os problemas causados por prêmios por produtividades.São Paulo: Atlas, 1998.

[18] LATHAM, G. P.; PINDER, C. C. Work motivation theory and research at the dawn of the twenty-first century. Annual Review of Psychology, v. 56, p. 485-516, 2005. LOCKE, E. A. et. al.. Goal Setting and Task Performance: 1969-1980. Psychological Bulletin, v. 90, n. 1, 1981.

[19] LEAL, E. A.; MIRANDA, G. J.; CARMO, C. R. S. Teoria da Autodeterminação: uma analise da motivação dos estudantes do curso de Ciências Contábeis. Rev. Contabilidade \& Finanças -USP, v. 24, n. 62. São Paulo, 2013.

[20] MASLOW, A. H. Introdução a Psicologia do Ser. Rio de Janeiro: Eldorado, 1962. MCGREGOR, D. The Human Side of Enterprise. New York: McGraw Hill Book Company Inc., 1960.
[21] MOTTA, F. C. P. Teoria das organizações: evolução e crítica. São Paulo: Pioneira, 1986.

[22] MOTTA, F. C. P, VASCONCELOS, I. G. Teoria Geral as Administração. 3. ed. São Paulo: Cengage Learning, 2010.

[23] MORIM, E. Os Sentidos do Trabalho. Rev. Administração de Empresas, v. 41, n. 3, p.8-19, 2001. Disponível em: http://www.scielo.br/pdf/rae/v41n3/v41n3a02.pdf. Acesso em: 15 abr. 2017.

[24] OLIVEIRA, S. L. Manual de metodologia da pesquisa cientifica. 2. ed. São Paulo: Pioneira, 1997.

[25] PINK, D. H. Motivação 3.0: os novos fatores motivacionais para a realização pessoal e profissional. 7. ed. Rio de Janeiro: Alta Books, 2010.

[26] PINDER, C. C. Work Motivation in Organizational Behavior. 2. ed. New York: Psychology Press, 2008.

[27] PRITCHARD, A. Statistical bibliography or bibliometrics? Journal of Documentation, v.25, n.4, p.348-349, 1969.

[28] RAVELLI, A. P. X. et.al. A produção do conhecimento em enfermagem e envelhecimento: estudo bibliométrico. Rev. Texto Contexto Enferm, Florianópolis, v. 18, n. 3, p. 506-12, jul-set. 2009,

[29] ROBBINS, S. P; JUDGE, T. A; SOBRAL, S. Comportamento Organizacional. 14. ed. São Paulo: Person Prentice Hall, 2010.

[30] SEVERINO, A. J. Metodologia do trabalho científico. 23. ed. Rev. e atual. São Paulo: Cortez, 2007.

[31] VROOM, V. H. (Org.). Gestão de pessoas, não de pessoal. 11. ed. Rio de Janeiro: Elsevier, 1997.

[32] .Trabalho e motivação. Nova lorque: Wiley, 1964.

[33] ZUPIC, I; CATER, T. Bibliometric Methods in Management and Organization. Organizational Research Methods. v. 18, n. 3, p. 429-472, jul. 20 


\section{ANEXO}

Quadro 1 - Relação de artigos analisados na base de dados da ANPAD

\begin{tabular}{|c|c|}
\hline Quant. & Referência dos artigos \\
\hline 1 & $\begin{array}{l}\text { FERREIRA, A.; FUERTH, L.; ESTEVES, R. C. P.; Fatores de Motivação no Trabalho: O Que Pensam os } \\
\text { Líderes. XXX Encontro da ANPAD. Salvador/BA } 23 \text { a } 27 \text { de setembro de } 2006\end{array}$ \\
\hline 2 & $\begin{array}{l}\text { NETO, M. T. A Remuneração Voluntária na Percepção dos Empregados e Suas Consequências na } \\
\text { Motivação e no Desempenho. XXX Encontro da ANPAD Salvador/AB - } 23 \text { a } 27 \text { de setembro de } 2006 \text {. } \\
\text { EnANPAD. }\end{array}$ \\
\hline 3 & $\begin{array}{l}\text { SOUZA, W. J; CARVALHO, V. D. Elementos do Comportamento Organizacional no Trabalho } \\
\text { Voluntário: Motivação na pastoral da Criança a Luz da Teoria da Expectânia. XXX Encontro da } \\
\text { ANPAD. Salvador/BA - } 23 \text { a } 27 \text { de setembro de 2006. EnANPAD. }\end{array}$ \\
\hline 4 & $\begin{array}{l}\text { TESTA, M. G.; FREITAS, H. M. R.; LUCIANO, E. M.; A Influência da Motivação no Contato Social dos } \\
\text { Estudantes na Efetividade da Educação a Distancia via Internet. XXXI Encontro da EnANPAD. Rio de } \\
\text { Janeiro/RJ. } 22 \text { a } 26 \text { de setembro de } 2007 .\end{array}$ \\
\hline 5 & $\begin{array}{l}\text { NASCIMENTO, S. B. Aspectos que Influenciam a Motivação em Treinamento a Distancia. XXXI } \\
\text { Encontro da ANPAD. Rio de Janeiro/RJ - } 22 \text { a } 26 \text { de setembro de } 2007 .\end{array}$ \\
\hline 6 & $\begin{array}{l}\text { SOUZA, C. P. S.; LIMA, L. L. B.; MARQUES, A. A. Fatores Condicionantes da Motivação de } \\
\text { Colaboradores Voluntários: Estudo de Caso de uma Empresa Júnior da Universidade Federal de } \\
\text { Alagoas. XXXII Encontro da ANPAD. Rio de Janeiro/ RJ - } 6 \text { a } 10 \text { de setembro de 2008. EnANPAD. }\end{array}$ \\
\hline 7 & $\begin{array}{l}\text { SOUZA, S. A.; REINERT, J. N. Motivação para entrada e permanência nos cursos de graduação em } \\
\text { Administração da Universidade Federal de Mato Grosso do Sul. XXXVII Encontro da ANPAD. São } \\
\text { Paulo/ SP - } 19 \text { a } 23 \text { de setembro de 2009. EnANPAD. }\end{array}$ \\
\hline 8 & $\begin{array}{l}\text { PROCÓPIO, M. L. Motivação e Organização: como uma ideia pode ajudar a entender a outra? XXXV } \\
\text { Encontro da ANPAD. Rio de Janeiro/RJ - } 4 \text { a } 7 \text { de setembro de 2011. EnANPAD. }\end{array}$ \\
\hline 9 & $\begin{array}{l}\text { GOMES, R. C.; ALFINITO, S.; BERMAN, E.; Ética, liderança e motivação no trabalho: } \\
\text { microcomportamentos organizacionais associados entre os servidores públicos. Encontro de } \\
\text { Administração Pública e Governo - EnAPG. } \\
\text { Salvador/ BA - } 18 \text { a } 10 \text { de novembro de } 2012 \text {. }\end{array}$ \\
\hline 10 & $\begin{array}{l}\text { SILVA, C. S; RIEGAL, V; LIMA, M. C. Os Fatores de Motivação na Definição de Estudantes } \\
\text { Estrangeiros em Mobilidade Acadêmica Internacional no Brasil. XXXVI Encontro da ANPAD. Rio de } \\
\text { Janeiro/RJ - } 22 \text { a } 26 \text { de setembro de 2012. EnANPAD. }\end{array}$ \\
\hline 11 & $\begin{array}{l}\text { PEDROSA, R. P. A; MATTOS, A. C. M; CUNHA, PB. P. F; GONÇALVES F. M; } \\
\text { JOSEPH, R. E; CARVALHO, J. G. Motivação: Diferença de Percepção Entre Funcionários e Gestores } \\
\text { uma Perspectiva de uma Empresa Brasileira. XXXVII Encontro da ANPAD. Rio de Janeiro/RJ - } 7 \text { a } 11 \\
\text { de setembro de 2013. EnANPAD. }\end{array}$ \\
\hline 12 & $\begin{array}{l}\text { PANOEIRO, P; MATTOSO, C. L. Q. O Consumidor Infantil de baixa renda, sua motivação para o } \\
\text { consumo e sua relação com as marcas. XXXVII Encontro da ANPAD. Rio de Janeiro/RJ - } 7 \text { a } 11 \text { de } \\
\text { setembro de 2013. EnANPAD. }\end{array}$ \\
\hline 13 & $\begin{array}{l}\text { FURTADO, L. M. G. P. Dar Dinheiro é prata, dar Suporte e Trabalho é ouro: um Estudo Empírico sobre } \\
\text { a Motivação no Trabalho de Serviços Públicos. XXVII Encontro da ANPAD. Rio de Janeiro/ RJ - } 7 \text { a11 } \\
\text { de setembro de 2013. EnANPAD. }\end{array}$ \\
\hline 14 & $\begin{array}{l}\text { ANTUNES, E. V.; STEFANO, S. R.; SANTOS, H. B.; A motivação para o } \\
\text { trabalho e sua importância estratégica: análise da perspectiva individual em uma empresa do ramo } \\
\text { de autopeças e serviços. IV Encontro de Gestão de Pessoas e Relações de Trabalho. EnGPR } \\
\text { Brasília/DF - } 3 \text { a } 5 \text { de novembro de } 2013 \text {. }\end{array}$ \\
\hline 15 & $\begin{array}{l}\text { GROHMANN, M. Z; CUNHA, L. V; SLINSKE, J. Relações entre motivação, satisfação, } \\
\text { comprometimento e desempenho no trabalho: estudo em um hospital público. IV Encontro de Gestão } \\
\text { de Pessoas e Relações de Trabalho. EnGPR Brasília/DF - } 3 \text { a } 5 \text { de novembro de } 2013 .\end{array}$ \\
\hline
\end{tabular}


Quadro 1 - Relação de artigos analisados na base de dados da ANPAD (Continuação)

\begin{tabular}{|c|c|}
\hline Quant. & Referência dos artigos \\
\hline 16 & $\begin{array}{l}\text { SANTOS, J. N.; BATISTA, C. S.; Motivação e Confiabilidade Humana: uma análise da percepção do } \\
\text { indivíduo. XXXVII Encontro da ANPAD. Rio de Janeiro/ RJ - } 13 \text { a } 17 \text { de setembro de 2014. EnANPAD. }\end{array}$ \\
\hline 17 & $\begin{array}{l}\text { SOL, A. S; NETO, M. T. R; ROQUE, L. M; GOMES, J. F. S. Influencia na Motivação de Vendedores: Um } \\
\text { Estudo envolvendo Remuneração, Indeterminação, Conflitos, Sistemas de Controle, Diferenciação e } \\
\text { Facilitadores. XXXVII Encontro da ANPAD. Rio de Janeiro/RJ - } 13 \text { a } 17 \text { de setembro de } 2014 \text {. } \\
\text { EnANPAD. }\end{array}$ \\
\hline 18 & $\begin{array}{l}\text { KLEIN, F. A; MASCARENHAS, A. O. Motivação no Serviço Público: Efeitos Sobre a Retenção e } \\
\text { Satisfação Profissional dos Gestores Governamentais. XXXVII Encontro da ANPAD. Rio de Janeiro/RJ } \\
13 \text { a } 17 \text { de setembro de 2014. EnANPAD. }\end{array}$ \\
\hline 19 & $\begin{array}{l}\text { KENDLER, V. THEOTÔNIO, K. S. - Valores, Motivação, Comprometimento, Desempenho e } \\
\text { Recompensas: a Validação de um Modelo com Profissionais de Baixa Renda. VEncontro de Gestão } \\
\text { de as Pessoas e Relações de Trabalho - EnGPR. Salvador/BA - } 15 \text { a } 17 \text { de novembro de } 2015 . \\
\text { ANPAD. }\end{array}$ \\
\hline 20 & $\begin{array}{l}\text { AVELINO, A. F. A; LOBLER, M. L; FLAVIANO, V. Sobrecarga de Informação no Processo Decisório: o } \\
\text { Papel da Motivação Epistêmica na Resposta Individual. XXXIX Encontro de ANPAD. Belo } \\
\text { Horizonte/MG - } 13 \text { a } 16 \text { de setembro de 2015. EnANPAD. }\end{array}$ \\
\hline 21 & $\begin{array}{l}\text { ALMEIDA, A. C; CANTON, A. W. P. Motivação Intrínseca e Participação em Processos de Inteligência } \\
\text { Competitiva. XXXIX Encontro da ANPAD. Belo Horizonte/MG } 13 \text { a } 16 \text { de setembro de 2015. EnANPAD. }\end{array}$ \\
\hline 22 & $\begin{array}{l}\text { COURA, E. A. A; BATISTA, F. F; ALBUQUERQUE, L. S; CIME, G. M. P; CARVALHO J. R. M; OLIVEIRA, } \\
\text { F. D. C. Analise da Motivação dos Discentes do Curso de Ciências Contábeis e Administração, sob a } \\
\text { Perspectiva da Teoria da Autodeterminação de das Metas e Realização. V Encontro de Ensino e } \\
\text { Pesquisa em Administração de Contabilidade. EnEPQ. Salvador/BA- } 15 \text { a } 17 \text { de novembro de } 2015 .\end{array}$ \\
\hline 23 & $\begin{array}{l}\text { D'ANJOUR, M. F; MEDEIROS, B. C; GALVÃO, M. F. S. M; CARVALHO, A. E. C. Motivação a Luz da } \\
\text { Teoria da Autodeterminação: uma Analise Comparativa do Processo Motivacional de Concluintes dos } \\
\text { Mestrados Acadêmica e Profissional na Administração. XXXIX Encontro da ANPAD. Belo } \\
\text { Horizonte/MG - } 13 \text { a } 16 \text { de 2015. EnANPAD. }\end{array}$ \\
\hline 24 & $\begin{array}{l}\text { PAULA, C. R. A; CKAGNAZAROFF, I. B. Gestão de Pessoas no Setor Público e o Desafio da } \\
\text { Motivação: Estudo de Caso com Empreendedores Públicos do Governo de Minas Gerais. XXXIX } \\
\text { Encontro da ANPAD. Belo Horizonte/MG } 13 \text { a } 16 \text { de setembro de 2015. EnANPAD. }\end{array}$ \\
\hline
\end{tabular}




\section{Capítulo 10}

\section{LIDER COACH: COACHING UMA NOVA CONCEPÇÃO DE LIDERANÇA}

\section{Priscila França Gonzaga Carneiro \\ Josiane Aparecida Cardoso de Souza}

Resumo: O presente artigo tem como finalidade mostrar sobre a contribuição das técnicas e ferramentas de Coaching no desenvolvimento de uma nova concepção de liderança. Hoje, visto que a mentalidade das pessoas mudaram e as característica da era industrial, não serve mais. Por esse motivo, é essencial que as empresas mudem o paradigma e inovem no intuito de atender os objetivos humanos, representados pelos desejos individuais de seus colaboradores. Para isso, é fundamental empregar uma visão sistêmica do ser humano, a qual propõe que as pessoas são dotadas de corpo, mente, coração e espírito, dimensões estas que devem estar estavél para o sucesso de qualquer projeto pessoal ou profissional. O estudo é realizado com base em pesquisa bibliográfica sobre liderança e coaching, em especial Lígia Dias Feitosa (2014), Vanessa Aparecida de Almeida (2011) e Denise Cristina Durello Banachi (2014). Finalmente, à conclusão do trabalho, compreendermos que ao abandonar a mentalidade ultrapassada e adotar os pressupostos do coaching como concepção de liderança, o líder transforma-se em um Líder Coach e faz a diferença na organização, pois ao despertar o melhor em seus liderados, conseguirá aquilo que todas as empresas desejam: concretizar as metas, atingir resultados extraordinários e alcançar o topo.

Palavras-chave: liderança, Coaching, Líder coach, Organização, Gestão de pessoas. 


\section{INTRODUÇÃO}

De acordo com Almeida (2011), as empresas já perceberam que o recurso mais importante e disputado nos dias atuais é o talento humano. O grande diferencial competitivo passou a ser determinado pela forma como as organizações selecionam, treinam e gerenciam seus colaboradores. Sendo que objetivo fundamental da área de Recursos Humanos de uma empresa é conduzir o processo pelo qual as organizações desenvolvem seu capital humano com o propósito de aumentar sua competitividade, garantindo uma perfeita interação dos profissionais com o sistema e os resultados do negócio

Segundo Almeida (2011), A Revolução Industrial foi muito importante para o desenvolvimento da indústria e o crescimento das cidades. O autor Almeida cita a famosa frase Henry Ford," Por que tenho que ter a pessoa inteira se preciso apenas de um par de mão ?" , ou seja, o homem era valorizado apenas por sua mão-de-obra, isto é, sua força de trabalho.

De acordo com Litas e Silva Jr. (2009), liderança pode ser entendida como a forma de inspirar e motivar os colaboradores no atingimento de metas. O líder deve servir de influência aos seus liderados, inspirando confiança e merecendo respeito de seus seguidores, criando estratégias e os melhores caminhos a serem trilhados pela equipe, contando com o acompanhamento de seus colaboradores.

Segundo Feitosa (2014), a era do conhecimento é marcada pela globalização, pela Internet, pelas inovações tecnológicas, pela quantidade de informações e a velocidade com que temos acesso a elas, pela alta competitividade e pela complexidade das relações interpessoais, impõe inúmeros desafios às pessoas e às organizações.

Assim, considerando a competitividade do mercado, a importância do líder na condução de uma equipe de alto desempenho e a necessidade de aprendizado contínuo, este artigo visa apresentar uma introdução à metodologia do Coaching, relacionando-a ao papel do líder no ambiente corporativo atualmente e a relação do Coaching no desenvolvimento de uma nova concepção de liderança de forma a contribuir para uma organização mais competitiva.

\section{MATERIAIS E MÉTODOS}

A abordagem da pesquisa é qualitativa por ser um método de investigação ciéntifica que se foca no carater subjetivo do objeto analisado estudando sua particularidades. A natureza do estudo é básica, ou seja, com o objetivo de gerar conhecimentos novos úteis para o avanço da ciência sem aplicação prática prevista.

\subsection{TIPO DE PESQUISA}

Quanto ao objetivo da pesquisa, ele é de caráter exploratório pois visa proporcionar maior familiaridade com o problema.

\section{2- PROCEDIMENTO TÉCNICO}

Esta pesquisa é caréter bibliográfica apresenta uma fundamentação teórica sobre o Coaching, relacionando-a ao papel do líder no ambiente corporativo atualmente e a relação do Coaching no desenvolvimento de uma nova concepção de liderança.

Sendo assim foi realizada uma pesquisa bibliográfica sobre liderança e coaching, em especial Lígia Dias Feitosa (2014), Vanessa Aparecida de Almeida (2011) e Denise Cristina Durello Banachi (2014) de maneira que esses estudos visam mostrar como a liderança e o coaching está interligado e sua importância nas empresas.

\section{FUNDAMENTAÇÃO TEÓRICA}

A revisão da literatura deste trabalho dispõe dos aspectos sobre liderança e coaching, em especial Lígia Dias Feitosa (2014), Vanessa Aparecida de Almeida (2011) e Denise Cristina Durello Banachi (2014).

\subsection{O PODER DA LIDERANÇA}

Conforme Megginson e Mosley (1998), a liderança é um processo de influenciar as atividades individuais e grupais no estabelecimento e atingimento das metas. Como um líder você trabalha para conseguir equilíbrio entre as metas da organização, as suas próprias e as do grupo.

Para Mussak (2010) existem pessoas que já nascem líderes natos e outras que podem ter 
suas habilidades desenvolvidas. Para a empresa não basta somente saber liderar, o líder precisa entender os valores defendidos pela organização para saber guiar seus liderados, e principalmente acreditar nas ideias que está propondo para que possa desenvolver seu papel na empresa.

Líder é responsável pelo crescimento profissional de cada um dos colaboradores que tem em sua equipe e ele deve desenvolver os pontos fortes e inativar os pontos fracos das pessoas sobre o seu comando, fazendo com que cada indivíduo se sinta parte do processo, comprometendo-se assim com o resultado. Quando os colaboradores se identificam com o líder, também se dedicam à causa, oferecendo assim esforços extraordinários e alcançando desempenhos significativos (MUSSAK, 2010).

De acordo Banachi e Bazoli (2014), o líder não introduz apenas uma forma de visualizar o futuro, mas ensina novas maneiras de agir, de abordar e de tratar os problemas. Isto traz à tona outra característica do líder carismático que é a quebra constante do convencionalismo. Tradições, valores e normas são desafiados para que mudanças possam ser implantadas a todo instante.

A liderança não deve ser confundida com direção nem com gerência. Um bom administrador deve ser necessariamente um bom líder. Por outro lado, nem sempre um líder é um administrador. Na verdade, os líderes devem estar presentes no nível institucional, intermediário e operacional das organizações. Todas as organizações precisam de líderes em todos os seus níveis e em todas as suas áreas de atuação.

A liderança é um fenômeno tipicamente social que ocorre exclusivamente em grupos sociais e nas organizações. Podemos definir liderança como uma influência interpessoal exercida numa dada situação e dirigida através do processo de comunicação humana para a consecução de um ou mais objetivos específicos. Os elementos que caracterizam a liderança são, portanto, quatro: a influência, a situação, o processo de comunicação e os objetivos a alcançar.

Segundo Mussak (2010), a liderança envolve o uso da influência e todas as relações interpessoais podem envolver liderança. Todas as relações dentro de uma organização envolvem líderes e liderados: as comissões, os grupos de trabalho, as relações entre linha e assessoria, supervisores e subordinados etc. Outro elemento importante no conceito de liderança é a comunicação. A clareza e a exatidão da comunicação afetam o comportamento e o desempenho dos liderados. A dificuldade de comunicar é uma deficiência que prejudica a liderança. 0 terceiro elemento é a consecução de metas. O líder eficaz terá de lidar com indivíduos, grupos e metas. A eficácia do líder é geralmente considerada em termos de grau de realização de uma meta ou combinação de metas. Mas, por outro lado, os indivíduos podem considerar o líder como eficaz ou ineficaz, em termos de satisfação decorrente da experiência total do trabalho. De fato, a aceitação das diretrizes e comandos de um líder apóia-se muito nas expectativas dos liderados de que suas respostas favoráveis os levarão a bons resultados. Nesse caso, o líder serve ao grupo como um instrumento para ajudar a alcançar objetivos.

De acordo com Banachi e Bazoli (2014), a liderança exige fazer com que as tarefas sejam desempenhadas. Os comportamentos de desempenho de tarefas são os esforços do líder para garantir que a unidade de trabalho ou a organização atinjam suas metas. Essa dimensão é às vezes mencionada como preocupação com produção, liderança diretiva, estrutura iniciadora ou proximidade de supervisão. Inclui o enfoque na velocidade, qualidade e precisão do trabalho, quantidade de produção e na obediência às regras.

Liderar não está ligado somente no mundo dos negócios, desde criança essa habilidade já se percebe em algumas pessoas, quando nos destacamos em algum grupo, exercemos o papel de liderança informal, isso pode ocorrer em grupo de amigos, no bairro onde moramos, na igreja e escola, mas quando somos escolhidos por uma organização para exercer cargos de chefia passamos a exercer a liderança formal, ou autoridade.

Viana (2011) O poder e a liderança são elementos interligados no processo de influenciar pessoas para a eficácia de uma equipe. Liderar não é uma tarefa fácil, pois o líder é o responsável direto pelo sucesso, mas também pelo fracasso. Transformar chefes de uma equipe desportiva em lideres é um dos árduos papeis do psicólogo do esporte, mas exige disciplina, respeito, compromisso e credibilidade pelo trabalho prestado por um profissional qualificado por parte dos dirigentes, técnicos e principalmente atletas, para que sua equipe seja eficaz e eficiente e 
atinja os objetivos propostos. Pois o ambiente mutável de uma equipe desportiva é desfavorável a transformação de chefes em lideres, mas não é impossível, pois qualquer pessoa que aspire a ser um gerente, técnico ou capitão eficaz deve também se conscientizar de praticar e desenvolver suas habilidades de liderança.

\subsection{O CONCEITO DE COACHING}

Segundo Conti (2010), o coaching é uma ferramenta de treinamento para o desenvolvimento pessoal e profissional composto por um líder que recebe o nome de Coach e por pessoas que participam desse Treinamento denominadas de Coachees.

O objeto do coaching é proporcionar o desenvolvimento de habilidades e competências de um indivíduo para a harmonia e eficiência do seu desempenho enquanto pessoa ou profissional (CONTI, 2010).

O termo coach tem origem no campo esportivo e tem sido utilizado para designar o papel do técnico, aquele profissional que treina times de futebol ou basquete. Nos últimos anos, entretanto, esse termo vem sendo utilizado nas empresas, não necessariamente para designar um cargo, mas um papel profissional: o da pessoa que se compromete a apoiar alguém com vista em melhorar seu desempenho e promover seu desenvolvimento profissional e pessoal (GIL, 2007).

Para Nunes (2007), o coaching pode ser tomado como um processo que tem como objetivo fomentar no colaborador o conhecimento de si próprio e ajudar a criar neste o desejo de melhorar ao longo do tempo. Trata-se, assim, de uma filosofia de liderança que assenta no pressuposto de que a aquisição e o desenvolvimento das competências são processos contínuos individualmente e de responsabilidade de todos, e não apenas impulsionados pelas chefias.

Rocha (2010), conta que coaching representa "um meio de trabalhar com pessoas que as torna mais competentes e mais realizadas, de modo que sejam mais capazes de contribuir para suas organizações e encontrar significado no que fazem". De modo bem similar, Chiavenato (2002), um dos poucos brasileiros que tem se aventurado a escrever sobre o tema, diz que ele é "um relacionamento que provoca novas competências" e que "agrega valor à organização e ao cliente".

Marshal Goldsmith (2010), no Prólogo do Livro Coaching executivo para resultados: guia definitivo para o desenvolvimento de líderes organizacionais, de Underhill, Mc Anally e Koriath, é elucidativo em sua colocação. Para ele, coaches executivos podem ajudar líderes a transpor o largo vão que existe entre entender o que fazer e realmente fazê-lo (GOLDSMITH, 2010, p. 15). Ele defende que o coaching pode ajudar líderes com alto potencial a se tornar grandes líderes.

Segundo Lopes (2016),embora seja muito complicado que uma pessoa seja coach de si mesma, ao submeterse a um encargo de coaching, o profissional aprende uma série de procedimentos que podem ser utilizados em outras situações profissionais que surgirem ao longo de sua trajetória. Isso significa que o líder terá condições de, a partir daquela experiência, replicar para outros desafios as soluções aprendidas, terá se tornado um multiplicador. Ele terá aprendido a aprender. A transferência de habilidades permite isso. No entanto, quando este processo não ocorre de forma eficiente, o líder permanece inseguro, precisando que o coach ratifique cada passo dado, cada decisão a ser tomada. O coach precisa preparar o coachee para a independência. Este é um dos principais desafios de todo processo

Para Pimenta (2011), o coaching não se confunde com terapia, embora exista alguma sobreposição entre as duas abordagens, como construções teóricas similares, confidencialidade, relacionamento praticantecliente etc. Enquanto na terapia o foco é tipicamente retrospectivo, relacionamentos anteriores, problemas e padrões de comportamento, no coaching as recordações não compõem o seu principal eixo, pois o processo se dá com foco no presente e no futuro, buscando a desvelar as possibilidades presentes e tendo em vista despertar a consciência para a ação. Durante as sessões de coaching, embora os afetos atravessem a linguagem do cliente, as dificuldades de ordem emocional, traumas, angústias e sofrimentos não são abordados, mas recomendados para um processo terapêutico com outro profissional.

Ou seja o para Pimenta (2011), Coach vai usar sua habilidade para fornecer um ambiente seguro e de confiança para que você possa 
explorar livremente o tema que você deseja discutir, fornecendo apoio, desafio, feedback e estímulo para o seu processo de pensamento. Coaching eficaz está fortemente associado com a identificação de objetivos claros, a construção de uma maior consciência de si mesmo e dos outros. O treinador também se concentra em aumentar a responsabilidade pessoal e, como resultado, requer autoridade final para a ação, transformação e mudança.

\subsection{O LÍDER COACHING}

O principal papel do coach é o de identificar, seja no trabalho ou na vida pessoal, quais são os potenciais não aproveitados e os riscos atuais que impedem a pessoa ou 0 profissional de sentir-se realizado e com isso gerar ganhos para si e para a empresa (MAMEDE, 2010). Assim eles passam a atuar de forma mais efetiva no alcance das metas propostas e na solução dos problemas encontrados durante o processo.

A liderança é a dom de guiar pessoas a alcançar com glória os resultados planejados. É uma habilidade das principais características onde leva um líder a destaque na vida pessoal e também profissional. Existem inúmeras teorias e modelos de lideranças que foram estudados com diversos pesquisadores, veja os três estilos destacado por BANOV, (2008).

Autocrática: É caracterizada pelo autoritarismo individual do líder, também chamada de liderança autoritária. O líder fixa normas e as impõem, sem necessidade de opinião de seus subordinados, sem deixar espaço para a criatividade e a participação do grupo liderado.

Democrática: O líder propõe a participação de todos os departamentos, em debates em prol de todos os que compõem a organização. Possibilita a integração, o desenvolvimento de providências e técnicas para atingir o objetivo esperado.

Liberal (laissez-faire): Nesse caso, a atuação do líder fica muito reduzida, há liberdade para grupos e indivíduos tomarem decisões independentes quer o líder saiba ou não. Não há imposição de regras, o líder não é respeitado

Para os líderes Coaches, saber delegar com assertividade, uma vez que identifica as capacidades individuais de cada um de seus liderados e as utiliza para potencializar seus resultados. Ele apresenta desafios e novidades motivadoras, que gera um ambiente mais agradável colaborativo e empreendedor, favorece uma evolução profissional e chega ao alcance das metas da empresa.

Para Mussak (2010), o líder coaching é um profissional que se compromete, no âmbito de uma organização, a apoiar as pessoas que visam alcançar determinado resultado. Ele pode ser encontrado dentro da própria empresa - coaching interno, ou ser contratado de fora somente para este fim coaching externo.

De acordo com Mussak (2010), o coaching interno pode ser desenvolvido por um profissional da própria empresa, que detenha um perfil de liderança e que possa auxiliar no desenvolvimento de outros profissionais, ajudando-os a fazer o melhor uso de seus recursos em busca de melhores resultados. Portanto nesse processo, o líder deverá atuar como um orientador de sua equipe, estabelecendo a inter-relação do indivíduo com a equipe. Nesse aspecto, irá funcionar principalmente como aquele elemento que acompanha e cria um clima de transferência de aprendizagens para o cotidiano do trabalho, facilitando a implementação dos conteúdos que deverão ser desenvolvidos pós-treinamento.

Entretanto, os resultados esperados póstreinamento só são alcançados quando há acompanhamento. Essa é uma tarefa que deveria ser exercida por um líder cujo perfil fosse semelhante ao do coach, que é um profissional preocupado com o desenvolvimento de sua equipe. Segundo Marinho (2005, p. 13), "o crescimento de um grupo de liderados resulta no crescimento de seu líder, produzindo um crescimento mais completo de ambos. É assim que o líder com a visão de servir cresce: fazendo os outros crescerem."

No estudo realizado por Corrêa e Soares (2008) percebe-se que oito entrevistados em uma Concessionária da Fiat em Belo Horizonte consideram que os valores e normas aprendidos nos treinamentos comportamentais podem ser fortalecidos por meio da liderança-coaching. É um dado importante para a concessionária, mostrando que o líder-coaching pode auxiliar no desafio de utilizar cada vez mais e melhor o conhecimento residente na concessionária 
estudada com o objetivo de manter a vantagem competitiva, considerando a criação e o compartilhamento do conhecimento com e entre as equipes de trabalho. Esse aspecto permitiu verificar que o compartilhamento do conhecimento sobre as normas e valores contribui favoravelmente o trabalho dos membros da equipe, aumentando o sentimento de time e, consequentemente, o compromisso com a organização.

De acordo com o estudo acima verificamos que os líderes da concessionária consolidam substancialmente a aprendizagem da equipe no ambiente de trabalho, aprendizagem esta que se desenvolve em treinamentos comportamentais promovidos pela empresa.

Segundo Silva (2016), as empresas buscam profissionais como esses e reconhecem, principalmente por conservarem a capacidade de transformar as pessoas e o mundo à sua volta, mostrando a mesmice da quais muitas empresas são reféns. Mais do que agente desta mudança, ao coach compete dispersá-la, preparando seus liderados para que desenvolvam suas competências e garantam a continuidade e também dispersação da criticidade e de uma cultura corporativa diferenciada e produtiva.

Para Chiavenato, (2004), a globalização sugere que se tenha uma visão global, para visualizar o posicionamento da organização com relação à concorrência e como estão sendo avaliados seus produtos ou serviços. É preciso vencer esses desafios: liderança de pessoas, a fidelidade e explanação da clientela, diferenciação dos produtos e serviços, ter conhecimentos e domínio no ramo de atividade e outros que estiverem ligados a ele, a melhoria da qualidade visando melhores resultados e a importância de extrair o máximo das tecnologias.

Silva (2016), o coach lidera,guia, treina, aconselha, estimula, desenvolve, impulsiona o aprendiz, enquanto este aprendiz aproveita o impulso e a direção para aumentar seus conhecimentos, aperfeiçoa o que já sabe aprende coisas novas e deslancha seu desempenho. Com a utilização do coaching as empresas agregam benefícios e desenvolvem performance em seus funcionários, podendo ser observado no estímulo à criatividade, desenvolvendo seu potencial. $\mathrm{O}$ aconselhado tem mais segurança e não é preciso utilizar de ações centralizadas, de controle extenso ou de autoritarismo enfraquecendo a criatividade dos integrantes da equipe; e nos aspectos culturais, que podem ser sensivelmente minimizado.

O Líder coach proporciona a partir daí o movimento sinérgico em torno da arte do co criar, ativando o potencial das pessoas para serem ainda melhores; auxiliando no desenvolvimento e no aprimoramento de suas competências.

A liderança não é algo que se desenvolve da noite para o dia e, a capacidade de liderar pode ser desenvolvida.Nesse momento a busca pelo autoconhecimento é uma premissa.Somente quando conseguirmos reconhecer nossos pontos fortes e os a desenvolver é que conseguiremos vencer os obstáculos que emperram nosso crescimento.

\section{RESULTADO E DISCUSSÕES}

De acordo com os argumentos apresentado no estudo Feitosa (2014), percebemos a confiança existente entre o líder coach com seus liderados, sendo que nos dias de hoje a relação de confiança é fundamental para o bom desempenho e obtenção bons resultados. Notamos então que é extrema importância que se tenha uma transparência na relação ao líder e seus liderados.

No estudo de Palmero (2009), identificamos também a relação de confiança entre líder coach com seus liderados. O líder-coach, por conhecer a si mesmo e também por conhecer as pessoas à sua volta, pode construir uma base sólida para obter resultados verdadeiros e sustentáveis ao longo do tempo.

Verificamos que este dois autores citados acima, revelam que a relação de confiança entre o líder e seus liderados contribui significativamente para o desempenho organizacional.

Já para Almeida (2011) o líder coach enfatiza o desempenho das pessoas através do poder pessoal, ou seja, o líder não introduz apenas uma forma de visualizar o futuro, mas ensina novas maneiras de agir, de abordar e de tratar os problemas.

Um líder de sucesso tem que trazer segurança para sua equipe, reconhecendo a capacidade de sua equipe e recompensando assim o bom desempenho, fornecendo o feedback para melhorias futuras. 
Tendo em vista os aspectos observado no estudo Almeida (2011), o autor Banachi (2014) também acredita que o líder coach precisa obter um melhor desempenho da equipe e ainda proporcionar a seu liderado constantes feedbacks para que assim possam manter juntos, o desenvolvimento pessoal e profissional. Já no estudo O'Neill (2000), o relacionamento entre o coach e o executivo é altamente produtivo e importante para a equipe de trabalho que o executivo comanda.

Portanto notamos que o líder coach adquire experiências de liderança que ele pode e deve passar para sua equipe, facilitando a interatividade entre estes e o recebimento de feedback.

Podemos verificar de acordo com os autores estudados que os lideres tem a capacidade de influenciar pessoas visando atingir os objetivos identificados como sendo para o bem comum.

\section{CONSIDERAÇÕES FINAIS}

Este presente artigo buscou refletir sobre as contribuições do coaching e a relação do Coaching no desenvolvimento de uma nova concepção de liderança de forma a contribuir para uma organização mais competitiva.

Em virtude do que foi mencionado pelos autores Feitosa (2014), Almeida (2011) e

\section{REFERÊNCIAS}

[1] ALMEIDA, Vanessa Aparecida de. Liderança: o desafio na gestão de Pessoas. Campo Grande, 2011.

[2] ARAUJO, Ane. Coach: um parceiro para seu sucesso. Rio de Janeiro: Elsevier, 1999.

[3] BANACHI,Denise Cristina Durello. BAZOLI, Thiago Nunes. coaching e a sua importância no aperfeiçoamento de lideres:um estudo exploratório realizado com a coach kátia marcos gomes. Paraná, 2014.

[4] BANOV, Márcia Regina. Psicologia no gerenciamento de pessoas. São Paulo, Atlas, 2008.

[5] CONTI, Vicente de Paula. Coaching - O Processo Mágico de Mudanças. Disponível em Site:

http://www.jornal100porcentovida.com.br/coaching. html. Acesso em 15 de outubro de 2018, ás 08h45.
Banachi (2014), conclui-se que a liderança é arte de influenciar pessoas, o líder coach deve ser digno de confiança e trabalhando sempre em equipe, buscando o melhor desempenho para a organização.

Como vistos no estudo de Banachi (2014), os funcionários eram vistos como ferramentas e recursos para a execução das metas da organização. Identificamos que o líder atual é um desenvolvedor de pessoas e construtor de relacionamento, ou seja, um coach.

Constatamos de acordo com os autores estudos neste presente artigo que o processo de coaching pode ser considerado como o aperfeiçoamento na arte de liderar, onde o coach instrui, informa, melhora e estimula os liderados, de maneira que este aproveita o incentivo e o caminho para expandir seus conhecimentos, lapidar seus potenciais, aprendendo coisas novas e aumentando seu desempenho.

Conclui-se, portanto que adotar o Coaching como uma nova concepção de liderança concede enxergar as relações no ambiente de trabalho de outra maneira, sendo que é a partir das experiências compartilhadas por colaboradores e do conhecimento que líderes e empresários, possibilitam o crescimento e inovação da organização transformando-a competitiva.

[6] CORRÊA, Maria Laetitia. SOARES, Maurília de Cássia Veloso. O LÍDER-COACH E SUA INFLUÊNCIA NO PROCESSO DE APRENDIZAGEM COMPORTAMENTAL: UM ESTUDO DE CASO. Salvador, 2008.

[7] CHIAVENATO, I. Construção de talentos: Coaching \& Mentoring. Rio de Janeiro, Editora Campus, 2002.

[8] FEITOSA, Ligia Dias. Líder Coach: Coaching como filosofia de liderança. São Paulo, 2014.

[9] FISCHER, A. L. A constituição de um modelo competitivo de gestão de pessoas no Brasil- um estudo sobre empresas consideradas exemplares. São Paulo, 1998.

[10] GIL, Antonio Carlos. Gestão de Pessoas: enfoque nos papéis profissionais. Ed. 7 . Reimpressão. São Paulo: Atlas, 2007. 
[11] GOLDSMITH, Marshal. Prólogo. In: UNDERHILL, Brian O.; MC ANALLY, Kimcee; KORIATH, John J. Coaching executivo para resultados: guia definitivo para o desenvolvimento de líderes organizacionais. Osasco: Novo Século, 2010 .

[12] GOLDSMITH, M. Coaching: o exercício da liderança. Rio de Janeiro: Campus,2003. O coaching no cerne da estratégia. In: Goldsmith, M. et. al. Coaching: o exercício da liderança. Rio de Janeiro: Campus, 2003.

[13] LYONS, L. O coaching no cerne da estratégia. In: Goldsmith, M. et. al. Coaching: o exercício da liderança. Rio de Janeiro: Campus, 2003.

[14] LLTAS, V e SILVA JR., W. Liderança Organizacional - Reflexões sobre Liderança Organizacional. Publicado em 07 de junho de 2009. Disponível em: $<$ http://www.administradores.com.br/informese/artigos/lideranca-organizacional/30579/> Acesso em 15 de outubro de 2018.

[15] LOPES, Vanessa Albertinence. Coaching: modismo ou uma ferramenta de gestão de pessoas que veio para ficar?.Rio Grande do sul, 2016.

[16] MAMEDE, W. Coaching - Uma nova forma de potencializar pessoas e alavancar resultados. Publicado em 16 de abril de 2016. Disponível em: $<$ http://www.administradores.com.br/informese/artigos/coaching-uma-nova-forma-depotencializar-pessoas-e-alavancarresultados/50887/ > Acesso em 15 de outubro de 2018

[17] MARINHO, M. R. Liderança em teoria e prática. São Paulo: Saraiva, 2005. In: OLIVEIRA, J. F.;
[18] MARINHO, M. R. Liderança uma questão de competência. São Paulo: Saraiva, 2005.

[19] MUSSAK, E. Gestão Humanista de Pessoas - O Fator Humano como Diferencial Competitivo. Rio de Janeiro: Elsevier, 2010.

[20] MEGGINSON, Leon C. MOSLEY, Donald C. Administração: conceitos e aplicações. 4a Edição. São Paulo: Harbra, 1998.

[21] NUNES, Paulo. O Conceito de Coaching. Criação em: 31 de Outubro de 2007. Disponível em:

http://www.knoow.net/cienceconempr/gestao/coac hing.htm. Acesso em 15 de outubro de 2018, às $22 \mathrm{~h} 46$.

[22] O`NEIL, Mary Beth. Coaching - treinando executivos: como colocar os líderes frente a frente com seus desafios. São Paulo: Futura, 2000.

[23] PALMERO, Barbara. Coaching e os desafios da liderança. Disponível em: http://www.cedet.com.br/index.php?/Artigos/Desen volvimento-Gerencial/coaching-e-os-desafios-dalideranca.html. Acesso em 15/10/2018, ás 14:10.

[24] PIMENTA, Fernando Fernandes. A transformação através do processo de coaching.ABRAPSO, 2011, pp. 157-168.

[25] ROCHA, Cláudio Miranda da. Princípios do coaching e sua aplicabilidade na verificação da efetividade de técnicos esportivos. Disponível em: http://www.efdeportes.com/efd88/coach.htm. Acesso em 15/10/2018, às $19 \mathrm{~h} 48$

[26] SILVA, José Aparecido da. Líder coaching: o papel da liderança na capacitação e influência de pessoas.

[27] VIANA,Mauro. Liderança, poder e comportamento.São Paulo, 2011. 


\section{Bapítulo 11}

\section{CULTURA ORGANIZACIONAL EDUCACIONAL: DIMENSÕES \\ PERCEPCCAOO DOS ATORES DE UMA ESCOLA DO PROGRAMA DE ENSINO INTEGRAL DO ESTADO DE SÃO PAULO}

\section{Marcelo Oda Yamazato}

Caio Marcelo Lourenço

Rita de Cássia Arruda Fajardo

Fernando César Almada Santos

Resumo: Este trabalho busca o entendimento da permeabilidade de políticas públicas educacionais, as diferenças entre a concepção e a prática. Compreendendo a escola como uma organização social, foram usados os conceitos de cultura organizacional, cultura de escola e cultura escolar para, num estudo de caso, aplicar um questionário estruturado para os atores de uma escola estadual do Programa de Ensino Integral do Estado de São Paulo. Analisou-se o alinhamento das percepções dos níveis de macro- (supervisores), meso- (direção) e micro-análise (professores) da escola, a partir das dimensões culturais de Hofstede. Os resultados apontam para um alinhamento geral das percepções. Porém, para questões mais operacionais, houve maior divergência entre os supervisores e os professores. Conclui-se que os atores encontram-se alinhados quanto aos valores e pressupostos do programa, mas que no cotidiano ainda existem pontos de atenção referentes à implantação e acompanhamento das práticas.

Palavras-chave: Cultura Organizacional; Educação; Escola; Políticas Públicas; Dimensões Culturais. 


\section{INTRODUÇÃO}

A gestão do conhecimento em uma sociedade baseia-se no modelo de educação apoiada pelo Estado, tal que nenhum país saiu de uma situação de terceiro mundo para um alto ou médio desenvolvimento sem investir em educação, sem um esforço compromissado com a educação pública.

É fato que o Brasil conseguiu um avanço expressivo no setor ao longo dos anos de 1990 e 2000, praticamente universalizando o acesso à educação pública. Porém, a qualidade de ensino está estagnada e os indicadores da educação, principalmente a partir dos anos finais do ensino fundamental, não são promissores. (OLIVEIRA, 2007).

Além disso, como explica Schneckenberg (2000),

Sabe-se que as reformas na estrutura educacional nem sempre são suficientes para responder às exigências do contexto social. Na verdade, a mudança pretendida no âmbito educacional apela ainda às condições coletivas da criatividade nas escolas, em vista do que a reforma se efetiva conforme entendimento e com- prometimento dos atores por ela envolvidos, pois cabe a estes a implementação da mudança. Neste contexto, surge, muitas vezes, a impotência dos responsáveis pela reforma, quando observam, na prática, o seu descumprimento.

O tema de políticas públicas educacionais é muito abrangente, podendo ser analisado de diversas formas, ângulos e níveis organizacionais. Dessa maneira, e partindo do entendimento da escola como o palco principal onde ocorre o aprendizado das novas gerações, essa passa a ser a unidade de análise central em uma pesquisa que deseja discutir a efetividade de políticas públicas educacionais e a recontextualização de uma política educacional para atingir objetivos estipulados.

Para isso, é necessário o entendimento da escola como uma organização. Como afirma Nóvoa (1995, p. 20), a escola é "uma instituição dotada de uma autonomia relativa [...] que não se limita a reproduzir as normas e valores do macrossistema, mas que também não pode ser exclusivamente investida como um microuniverso dependente do jogo dos atores sociais em presença". Assim, escolas devem ser entendidas como "espaços de autonomia pedagógica, curricular e profissional, o que implica um esforço de compreensão do papel dos estabelecimentos de ensino como organizações, funcionando numa tensão dinâmica entre a produção e a reprodução, entre a liberdade e a responsabilidade" (NÓVOA, 1995, p. 18).

Compreender a realidade social da escola é entender que sua estruturação se constrói como processo (TEIXEIRA, 1998). Para tanto, o referencial teórico da cultura organizacional pode dar uma importante contribuição.

A cultura organizacional, como definida por Schein (1984, p.3) é um

conjunto de pressupostos básicos compartilhados que um grupo aprendeu ao resolver seus problemas de adaptação externa e integração interna. Estes funcionaram bem o suficiente para serem considerados válidos e ensinados a novos membros como a forma correta de perceber, pensar e sentir em relação a esses problemas. Assim, o termo cultura organizacional é constituído pelas concepções básicas compartilhadas pelos membros da organização, operando sobre estes de forma inconsciente e mostrando a visão que a organização tem de si mesma e de seu ambiente.

Assim, o problema tratado nesta pesquisa é: como a cultura organizacional influencia na recontextualização de políticas públicas, no contexto endógeno de uma escola?

Para cumprir esse propósito, esta pesquisa buscou analisar o alinhamento organizacional em três níveis de trabalho de uma escola do Programa de Ensino Integral, a partir de uma fundamentação teórica na cultura organizacional.

\section{$\begin{array}{llll}2.1 & \text { CULTURA } & \mathrm{E} & \text { CULTURA }\end{array}$ ORGANIZACIONAL}

O tema da cultura organizacional surge em meio às diversas transformações na sociedade e mercado por volta da década de 1970. Com o declínio da produtividade norteamericana e o crescimento da japonesa, inicia-se uma mudança nos paradigmas de produção, de forma que a busca para entender os fatores de sucesso que causavam essas diferenças fica em ascensão.

De acordo com Vieira (2007), o entendimento de cultura organizacional, para os defensores da corrente funcionalista da administração (escola clássica, escola de relações 
humanas, escola neoclássica e escola estruturalista), é tido como um "cimento normativo", que permite à organização ter uma identidade coletiva, ao fornecer a seus membros as significações que eles precisam, contribuindo com a performance organizacional. Essa perspectiva sob a ótica da cultura fez surgir no discurso, bem como nas ações empresariais, a aceitação de que o domínio do simbólico é parte fundamental da realidade organizacional, tal qual os aspectos tecnológicos, operacionais e econômicos, ou seja, aquilo que é subjetivo e simbólico integra a vida da organização da mesma maneira que a realidade objetiva.

Os elementos da cultura organizacional podem ser resumidos por Freitas (1991) como os valores; crenças e pressupostos; ritos, rituais e cerimônias; histórias e mitos; tabus; heróis; normas; e o processo de comunicação.

Existem diversas abordagens culturais de organizações, tal que esta pesquisa focou em uma em específico, que são as dimensões culturais de Hofstede (2003). Na busca de determinar critérios diferenciadores de culturas nacionais, Hofstede (2003) agrupa valores em 5 dimensões que, em conjunto, representam características culturais, sendo estas: distância do poder, aversão à incerteza, individualismo versus coletivismo, masculinidade versus feminilidade e orientação de curto versus longo prazo.

A primeira dimensão de Hofstede (2003) Alta versus Baixa Distância do Poder refere-se ao quanto a distribuição desigual de poder e influência entre chefe e subordinado é aceito e esperado. Uma cultura com baixa distância do poder demonstra uma maior distribuição e compartilhamento do poder, mais horizontal; enquanto que no extremo oposto temos uma cultura mais hierárquica, onde as pessoas "entendem seu lugar".

A segunda dimensão Alta versus Baixa Aversão à Incerteza, se refere a quanto as pessoas que estão inseridas em determinada cultura toleram situações ambíguas, desestruturadas, imprevisíveis e que geram ansiedade. Culturas com alto grau de aversão à incerteza buscam minimizar a possibilidade de tais situações por meio de códigos de conduta, leis, regras, desaprovação de opiniões divergentes e credo numa verdade absoluta.

A dimensão de Individualismo versus Coletivismo descreve o tipo de relação entre o indivíduo e o coletivo que prevalece na sociedade. No individualismo, encontram-se culturas em que os laços entre os indivíduos são frouxos: espera-se que cada um cuide de si e de sua família mais próxima. No lado do coletivismo, encontram-se culturas nas quais as pessoas desde 0 nascimento são integradas em grupos fortes e coesos.

A dimensão Masculinidade versus feminilidade representa a extensão em que a agressividade, competição, recompensa material e sucesso são valorizados, em oposição à cooperação, preocupação com os relacionamentos e com a qualidade de vida.

A última dimensão é Orientação de curto versus longo prazo que é independente das quatro dimensões descritas anteriormente. Culturas com orientação de longo prazo estão relacionadas a recompensas futuras e valorizam a parcimônia e a perseverança. Culturas com orientação de curto prazo estão relacionadas ao passado e ao presente e valorizam o respeito às tradições e a satisfação dos compromissos sociais.

\subsection{A ESCOLA COMO UMA ORGANIZAÇÃO}

De forma objetiva, pode-se definir a escola como

Uma organização social constituída pela sociedade para cultivar e transmitir valores sociais elevados e contribuir para a formação de seus alunos, mediante experiências de aprendizagem e ambiente educacional condizentes com os fundamentos, princípios e objetivos da educação (LUCK, 2009, p.20).

Como aponta Teixeira (1998), a escola como promotora da educação, deve ser entendida além apenas de sua estrutura física, membros e atividades. Há de se ter em vista toda a dinâmica envolvida no processo educativo.

Em lugar da concepção da organização como realidade física, dá-se destaque à sua composição como realidade social; em substituição à visão unitária de um sistema de ensino regido por normas uniformes, abre-se espaço para a visão pluralista da partilha de valores e interesses. A abordagem da organização escolar como estrutura formal dá lugar à concepção de que sua estruturação se constrói como processo. A ênfase na separação entre a organização e os seus membros, característica das abordagens clássicas de administração, cede lugar a considerações que atribuem aos membros o 
papel de atores das realizações e mudanças da organização. Nessa perspectiva, a organização escolar é concebida como um processo em construção, fato que contesta os pressupostos da concepção burocrática da mesma, adotando uma linha de estudo com caráter sociocrítico (TEIXEIRA, 2000, p.20)

Teixeira (2000) diz que somente por meio de uma abordagem que leve em conta a cultura organizacional, torna-se possível elaborar um projeto político pedagógico capaz de contemplar a escola como uma organização social e dinâmica, cujo funcionamento é resultante das influências externas e das interrelações dos diversos atores que a compõem.

Ao enxergar a escola como uma organização permite-se que os processos educativos sejam analisados sob o prisma da cultura organizacional, tal que esse tipo de visão, de acordo com Nóvoa et al. (1992, p.28)

Estimula um olhar mais plural e dinâmico, obrigando a recorrer aos fatores políticos e ideológicos para compreensão do cotidiano e dos processos organizacionais; estimula também a passagem de uma racionalidade técnica, e mesmo de uma racionalidade organizacional, para uma racionalidade político-cultural.

A partir deste entendimento da escola como uma organização - uma realidade social composta e construída no processo do jogo de valores, interesses e crenças dos diversos atores - inicia-se a compreensão da utilidade da abordagem da cultura organizacional no contexto educacional.

Assim, entende-se que o estudo da cultura organizacional no contexto educacional diferencia-se de outros cenários uma vez que escola como uma organização possui diversas especificidades culturais, sendo palco de um processo constante de construção e reconstrução social. Este tópico de estudo torna-se ainda mais singular neste cenário ao observar que os processos e resultados se confundem; tal que o estudante é o operário que se constrói como o produto final, é agente e sujeito dos processos de aprendizagem. Assim, a cultura organizacional em contexto educacional surge como uma forma de coordenação da qualidade dos processos em um ambiente subjetivo e não linear.

Como bem ilustra Torres (2003, p.224):

Decorrente das especificidades do modelo organizativo da escola, o impacto das reformas educativas sobre os processos de mudança nas organizações escolares assume proporções mais expressivas, ao visibilizar uma descontinuidade entre o contexto heterónimo de concepção de orientações/medidas (administração central) e o contexto localizado e periférico de adopção e implementação pelos actores (escolas). A constatação de uma certa desregulação e, por vezes mesmo, de uma ruptura profunda entre as esferas da concepção (objetivos) e os espaços concretos de implementação (resultados), fomentou a necessidade de se compreender, por um lado, as especificidades culturais dos contextos onde decorre a acção educativa e, por outro lado, a reacção destes a um conjunto de factores, como, por exemplo, um pacote de programas de acção externamente produzidas. Esta dupla preocupação em olhar a cultura organizacional simultaneamente como processo e produto, parece estar presente em grande parte das investigações enquadradas no movimento crítico.

Para compreender melhor essas ideias, devese lembrar da organização escolar como se num nível meso- e micro- de análise, demonstrado anteriormente e caracterizado por seu processo social. Iremos, então, observar aqui o macro (HOFSTEDE, 1990).

A escola como instituição mantém-se praticamente inalterada desde sua concepção, possuindo características, crenças e ritos que legitimam sua ação funcional. Além disso, a escola, principalmente a pública, está sujeita a diversas legislações e normas externas ao seu domínio. Estas duas dimensões, sua construção histórica e funcional e a modelização de suas formas e estruturas, representam a questão macro do contexto de análise.

A partir das elucidações já apresentadas, nota-se a importância de entender como e em que níveis se constrói e se manifesta a cultura. Como se dão as ações e relações dos fatores externos e internos da escola, sua estrutura formal e informal. Assim, discute-se os conceitos de cultura escolar e cultura (organizacional) de escola, já bem fundamentados na literatura da área.

\subsubsection{CULTURA ESCOLAR}

A cultura escolar representa o nível macro da análise, uma dimensão política e social já 
prescrita e estabelecida. Como Viñao (2002, p.33), definem:

Conceito de cultura escolar como um conjunto de teorias, ideias, princípios, normas, diretrizes, rituais, inércias, hábitos e práticas formas de fazer e pensar, mentalidades e comportamentos - sedimentados ao longo do tempo na forma de tradições, regularidades e regras de jogos não postos em questão e que propiciam estratégias para integração nessas instituições, para interagir e realizar, sobretudo em sala de aula, as tarefas diárias que cada um espera, bem como para enfrentar as demandas e limitações que essas tarefas implicam ou envolvem. Seus traços característicos seriam a continuidade e a persistência ao longo do tempo, sua institucionalização e uma relativa autonomia que the permite gerar produtos específicos por exemplo, as disciplinas escolares - que o constituem como uma cultura independente.

Brito (1990 apud SEGURA, 2007) apresenta a cultura organizacional escolar como fonte de referências capaz de exprimir a identidade da organização construída ao longo do tempo e de contribuir para sua permanência e coerência, servindo de elo entre o passado e o presente, ao moldar as ações de seus membros segundo um mesmo sistema de referências. Numa mesma linha de pensamento, Julia (2001 apud SILVA, 2006, p.206) descreve a cultura escolar como um conjunto de normas que definem conhecimentos a ensinar e condutas a inculcar, e um conjunto de práticas que permitem a transmissão desses conhecimentos e a incorporação desses comportamentos; normas e práticas coordenadas a finalidades que podem variar segundo as épocas (finalidades religiosas, sociopolíticas ou simplesmente de socialização).

Barroso (2004, p.2) adota três abordagens diferentes para o tema da cultura escolar, tal que a abordagem "funcionalista" vai na mesma linha que os autores citados anteriormente. De acordo com o autor, a abordagem funcionalista da cultura escolar é

[...] cultura no sentido mais geral, que é veiculada através da escola. A instituição educativa é vista como um simples transmissor de uma cultura que é, definida e produzida exteriormente e que se traduz nos princípios, finalidades e normas que o poder político (social, econômico, religioso) determina como constituindo o substrato do processo educativo e da aculturação das crianças e dos jovens.

\subsubsection{CULTURA DE ESCOLA}

A cultura organizacional escolar, ou só cultura de escola, faz referência ao nível de meso- e micro-análise, ou seja, a escola como uma organização em si. Nesse ponto podemos observar características mais próximas das abordagens clássicas da cultura organizacional; um estudo dos jogos sociais dos atores, uma busca pela significação dos processos e elementos organizacionais que identificam e diferenciam uma escola, a construção dos ritos, valores, pressupostos e suposições.

António Nóvoa et al. (1992) sugere a sistematização dos elementos da cultura organizacional da escola em duas zonas: zona de invisibilidade, constituída pelas bases conceituais e pressupostos invisíveis (valores, crenças e ideologias); e a zona de visibilidade, composta pelas manifestações verbais e conceituais (fins, objetivos, currículo, linguagem, metáforas, histórias, heróis, estruturas), pelas manifestações visuais e simbólicas (arquitetura, equipamentos, artefatos, logotipos, lemas, divisas, uniformes, imagem exterior) e pelas manifestações comportamentais (rituais, cerimônias, ensino, aprendizagem, normas, regulamentos e procedimentos).

Além disso, Nóvoa et al. (1992, p.32) também ressalta a importância da cultura organizacional como um fator de diferenciação da escola:

A totalidade dos elementos da cultura organizacional tem de ser lida ad intra e ad extra às organizações escolares, isto é, estes elementos têm de ser equacionados na sua 'interioridade', mas também nas inter-relações com a comunidade envolvente. De facto, se a cultura organizacional desempenha um importante papel de integração, é também um factor de diferenciação externa. As modalidades de interacção com o meio social envolvente constituem, sem dúvida, um dos aspectos centrais na análise da cultura organizacional das escolas.

Por fim, Torres (2003, p.295) demonstra resumidamente a diferença entre os conceitos de cultura escolar e cultura de escola:

Enquanto o cenário sugerido pela cultura escolar, resulta da pressuposição básica de 
uma relação de continuidade e isomorfismo entre as orientações normativas e culturais e os contextos de acção concretos, o segundo cenário por nós aludido, a cultura organizacional escolar, pretende evocar a importância dos contextos endógenos de acção no processo de construção da cultura organizacional.

Finalizando o embasamento teórico com a cultura de escola, permite-se a integração das diversas ideias apresentadas. Compreendemos a noção de cultura organizacional, a escola como uma organização e os conceitos de cultura escolar e cultura (organizacional) de escola. Buscase, a partir da cultura da escola, compreender como se dá a recontextualização da cultura escolar pela cultura de escola.

\section{METODOLOGIA}

Para esta pesquisa, foi realizado um estudo de caso no qual foi tomado como objeto de investigação o Programa de Ensino Integral (PEI) do Estado de São Paulo implementado em uma escola estadual da cidade de São Carlos - SP.

Para este fim, foram escolhidos aspectos principais do PEI: suas diretrizes, Modelo de Gestão e duas ferramentas de gestão fundamentais do programa, o Plano de Ação e o Programa de Ação.

De forma a compreender a interface entre o que é concebido e planejado na lei e o que é encontrado na prática pelo prisma da cultura organizacional, os aspectos escolhidos do programa foram classificados pelas dimensões culturais de Hofstede (2003). Assim, foram tomadas as percepções dos atores envolvidos (professores, gestão da escola e supervisores da diretoria de ensino regional) em relação a esses pontos por meio de um questionário na Escala Likert.

Neste estudo são analisadas questões subjetivas - as percepções e expectativas pessoais - diante das dimensões culturais de Hofstede, no intuito de compreender as dimensões mais presentes e divergentes (em relação aos pressupostos do programa). Assim, de forma a traduzir questões subjetivas em dados quantitativos, é utilizado o questionário.

Para permitir maior compreensão do cenário como um todo, o questionário foi ministrado para três estratos: para o nível de micro (professores), para o nível meso (direção da escola) e para o nível macroanálise (supervisores do programa na escola estudada).

As questões foram desenvolvidas a partir da análise do documento de Diretrizes do Programa de Ensino Integral, 1a Edição (2012). Tomando os principais conceitos e pressupostos envolvendo as diretrizes do programa e o Modelo de Gestão apresentado, os tópicos foram agrupados nas cinco dimensões culturais de Hofstede.

\section{DISCUSSÕES}

Os resultados obtidos permitem observar que os atores nos três níveis de trabalho (os professores, direção da escola e os supervisores) estão bem alinhados nas cinco dimensões culturais de Hofstede. Da mesma forma, apresentam-se de acordo com os valores e pressupostos do Programa de Ensino Integral, uma vez que as afirmações se baseiam em suas diretrizes.

O modelo de gestão do PEI aborda questões mais abrangentes do programa, tal que possui suas afirmações associadas à valores e pressupostos do mesmo, situando-se num nível macro, buscando pintar o quadro completo. O Plano de Ação e o Programa de Ação são ferramentas do modelo de gestão, tal que a primeira busca guiar as ações dos atores da escola (direção, professores, comunidade e alunos) e está mais relacionado a um nível de estratégia de direção escolar, e a segunda é um documento individual que delineia todas ações que os educadores e a equipe gestora da escola irão tomar ao longo do semestre para cumprir o Plano de Ação. As questões relacionadas à estas ferramentas abordam pontos processuais e operacionais de uso e construção destes instrumentos, apresentando-se de forma mais tangível.

A primeira dimensão, Alta versus Baixa Distância do Poder das questões 1 a 8 apresenta-se alinhada na escola, porém com o maior ponto de divergência dentre todas as dimensões. Apesar da tendência à baixa distância do poder, como esperado pelas diretrizes do Programa de Ensino Integral, observa-se que o Plano de Ação não atende completamente sua função de tornar as estruturas de decisão mais transparentes e seu processo de construção não é percebido como colaborativo e democrático por todos os 
professores. A percepção do subordinado (professores) quanto à distribuição e influência do poder em relação aos pontos citados do Plano de Ação possui um valor menor do que a percepção da direção e supervisores.

$\mathrm{Na}$ segunda dimensão, Alta versus Baixa Aversão à Incerteza das questões 9 a 18, as respostas, assim como o $\mathrm{PEI}$, possuem características que vão para ambos os lados desta medida. As questões relacionadas ao modelo de gestão, que abordam valores como autonomia e iniciativa dos professores e alunos, estão alinhadas e tendendo à baixa aversão à incerteza. Paralelamente, as afirmações associadas ao Plano de Ação e Programa de Ação trabalham aspectos de controle do trabalho, também estão alinhadas, porém, tendendo à alta aversão à incerteza. Compreende-se que os profissionais do PEI entendem os objetivos do programa e seus pressupostos, mas que, na prática do cotidiano, sua concretização por meio das ferramentas utilizadas não reflete efetivamente os valores intencionados.

$\mathrm{Na}$ dimensão de Individualismo versus Coletivismo das questões 19 a 26, predomina o coletivo em todos os níveis, tal que é possível observar o sentimento de que todos são responsáveis pelo aprendizado dos alunos e que o PEl busca promover o engajamento dos diversos grupos relacionados tais quais a rede escolar, comunidade vizinha, professores e alunos. Além disso, a partir da premissa da replicabilidade, observa-se a preocupação do compartilhamento de boas práticas, buscando o melhoramento da rede escolar como um todo.
$\mathrm{Na}$ dimensão de Masculinidade versus Feminilidade das questões 27 a 33, todas as notas vão na direção da feminilidade, especialmente quanto ao modelo de gestão do PEl e o Plano de Ação. Nota-se pela discrepância das respostas entre professores e supervisores, porém, que quanto à elaboração e acompanhamento do Programa de Ação, temos um controle menos pautado pelo diálogo e confiança mútua entre coordenadores e professores do que o entendido pelos supervisores.

$\mathrm{Na}$ última dimensão, Orientação de Curto versus Longo Prazo das questões 34 a 37 , as respostas apresentam-se alinhadas em todas as afirmações, demonstrando que os atores percebem a visão do futuro do modelo de gestão do PEl que busca ser reconhecida internacionalmente em 2030, como uma rede de ensino integral pública de excelência. Além disso, e paralelamente, entendem que suas ferramentas possuem um foco nas ações cotidianas de forma a construir o aprendizado dos alunos e operacionalizar as diretrizes do Programa de Ensino Integral.

Foi possível observar que os três níveis estão alinhados em todas as dimensões culturais, especialmente quanto ao modelo de gestão do PEI, apontando que todos os atores escolares analisados entendem as diretrizes e os pressupostos do programa. Porém, destaca-se que, apesar de poucas, as maiores divergências ocorreram em afirmações relacionadas ao Plano de Ação ou Programa de ação, demonstrando uma discordância no nível de microanálise entre a percepção dos professores e dos supervisores. Os resultados das questões estão sintetizados no gráfico de radar abaixo. 
Gráfico 1- Respostas do questionário.

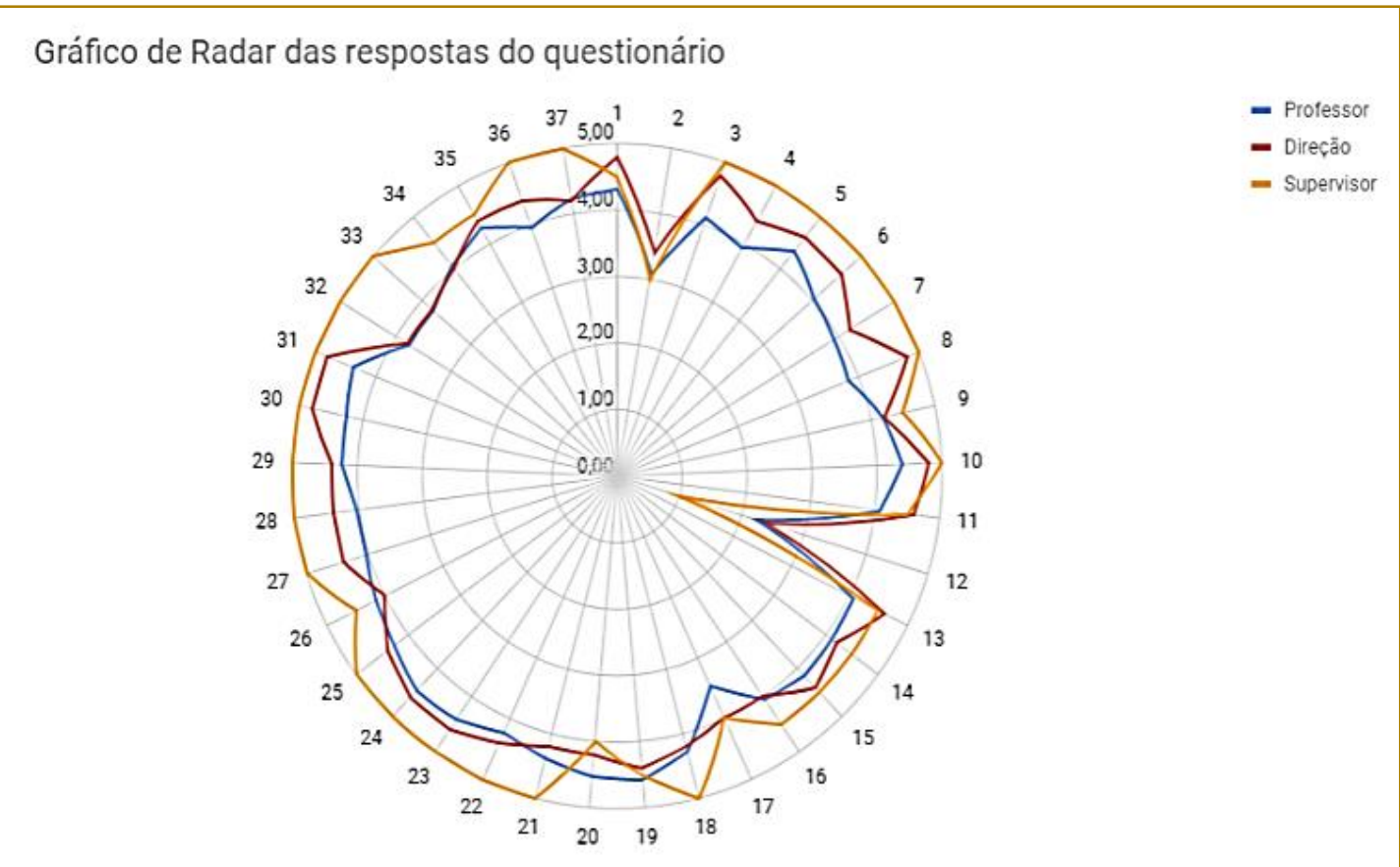

Fonte: Autoria própria.

\section{CONSIDERAÇÕES FINAIS}

A escola foi discutida como uma organização, tal que sua função e trabalho vai além de somente dar continuidade aos valores e conhecimentos da sociedade, deve-se formar um indivíduo crítico e autônomo. Tão logo o ambiente escolar torna-se um espaço de construção e reconstrução de significados próprios da organização e de seus membros, verifica-se que o externo passa a ser recontextualizado, a conjuntura de fatores extrínsecos passa a sofrer influências do âmago da organização. Observa-se que a cultura escolar interfere no funcionamento e pressupostos da escola, mas que, ao mesmo tempo, a cultura da escola proporciona as opções de aceitar tais ações como são ou buscar a ressignificação de tal dinâmica, servindo como um envoltório social para com interferências de fora.

Foi verificado parte da extensa bibliografia referente à cultura organizacional, tal que pôde-se observar sua função e importância na compreensão dos processos internos das organizações. Além disso, fica claro a diversidade de abordagens existentes para com a cultura de uma instituição, de forma que aqui foram citadas apenas algumas das mais referenciadas. Ao enxergar uma organização como um grupo de pessoas, percebe-se a necessidade de entender as relações sociais envolvidas entre os membros, de modo que se perpassa por valores, ritos, crenças, pressupostos, concepções básicas, entre outros aspectos.

Logo, buscou-se analisar as percepções dos principais atores envolvidos na orientação e manutenção do Programa de Ensino Integral (PEI) do Estado de São Paulo em uma escola estadual da cidade de São Carlos. A partir da maneira como tais agentes, divididos nos níveis de macro, meso e microanálise, compreendem o funcionamento do PEI foi estudado a convergência organizacional em torno das diretrizes do mesmo.

A idealização e implementação de uma estratégia ou política pública em um sistema educacional (plano macro) é recontextualizada pelas particularidades das organizações, adaptando os aspectos originais do plano para a realidade vivenciada. Neste sentido, foi possível observar que a análise de programas macros e planos (operacionais) de ação relacionados à educação podem ser tratados no âmbito da Engenharia de Produção, tal qual a discussão realizada neste estudo.

Pode-se, ao fim, tomar como entendimento das questões e elucidações que incitam este 
trabalho: a partir da compreensão da escola como uma organização, investigou-se o alinhamento organizacional a partir das dimensões culturais de Hofstede (2003), tal que se observou as divergências e convergências nas diretrizes e pressupostos do Programa de Ensino Integral do Estado de São Paulo, obtendo-se a explicitação de pontos de atenção. Dessa forma, pode ser possível decidir por melhores e mais eficientes caminhos na implementação e manutenção de programas públicos.

Algumas limitações e perspectivas de pesquisa são que a ferramenta de estudo foi um questionário na escala Likert de forma a

\section{REFERÊNCIAS}

[1] BARROSO, João. Cultura, cultura escolar, cultura de escola. Escolas, culturas e identidades. Coimbra: Ediliber, 2004. v. 1.

[2] FREITAS, Maria Ester de. Cultura organizacional grandes temas em debate. Revista de Administração de empresas, v. 31, n. 3, p. 7382, 1991.

[3] HOFSTEDE, Geert. Culture's consequences: Comparing values, behaviors, institutions and organizations across nations. Beverly Hills: Sage, 2003.

[4] HOFSTEDE, Geert et al. Measuring organizational cultures: a qualitative and quantitative study across twenty cases. Administrative Science Quarterly, v. 35, n. 2, p. 286-316, June 1990.

[5] LÜCK, Heloísa. Dimensões da gestão escolar e suas competências. Curitiba: Editora Positivo. 2009.

[6] NÓVOA, Antonio. As Organizações Escolares Em Análise, Temas de Educação 2. Lisboa: Publicações Dom Quixote de Inovações Educacionais:, 1995.

[7] NÓVOA, António et al. As Organizações escolares em análise. Lisboa: Dom Quixote, 1992. p. $13-43$

[8] PORTELA DE OLIVEIRA, Romualdo. Da universalização do ensino fundamental ao desafio da qualidade: uma análise histórica. Educação \& Sociedade, v. 28, n. 100, p.661-690, 2007.

[9] SCHEIN, Edgar H. Coming to a new awareness of organizational culture. Sloan management review, v. 25, n. 2, p. 3-16, 1984.

[10] SÃO PAULO (Estado). Secretaria de Educação. Diretrizes do programa ensino integral escola de tempo integral. Disponível em:<http://www.educacao.sp.gov.br/a2sitebox/arq transformar o subjetivo em quantitativo, porém, numa pesquisa mais extensa poderiam ser usadas questões abertas e entrevistas estruturadas com os atores, realizando uma análise de suas implicações. Além disso, o questionário também poderia ser incrementado para abranger as expectativas em relação ao programa, permitindo enxergar a discrepância entre a concepção das propostas, a expectativa dos atores e a percepção da prática. Ademais, foram analisados três níveis de trabalho (supervisores, direção e professores), mas os alunos também poderiam ser incluídos no estudo.

uivos/documentos/342.pdf>. Acessado em: 30 jan. 2018.

[11] SEGURA, Daiane Roberta Basso Fernandes et al. Clima organizacional escolar: implicações para o desenvolvimento profissional docente. 2007. 172p. Dissertação (Mestrado) Faculdade de Ciências e Letras, Universidade Estadual Paulista "Julio de Mesquita Filho", Araraquara, 2007.

[12] SILVA, Fabiany de Cássia Tavares. Cultura escolar: quadro conceitual e possibilidades de pesquisa. Educar em Revista, v. 22, n. 28, p. 201-216, 2006.

[13] SCHNECKENBERG, Marisa. A relação entre política pública de reforma educacional e a gestão do cotidiano escolar. Em aberto, v. 17, n. 72, p.113-124, 2000.

[14] TEIXEIRA, Lúcia Helena Gonçalves et al. Cultura organizacional e projeto de mudança em escolas públicas: um estudo de escolas da rede estadual de Minas Gerais. Campinas: Autores Associados, 1998.

[15] TEIXEIRA, Lúcia Helena Gonçalves. Cultura organizacional da escola: uma perspectiva de análise e conhecimento da unidade escolar. Revista Brasileira de Política e Administração da Educação - Periódico científico editado pela ANPAE, v. 16, n. 1, $2000 . \quad$ Doi: http://dx.doi.org/10.21573/vol16n12000.25758.

[16] TORRES, Leonor Lima. Cultura organizacional em contexto educativo: sedimentos culturais e processos de construção do simbólico numa escola secundária. 2003. Tese (Doutorado) - Instituto de Educação e Psicologia, Universidade do Minho, Braga, 2003.

[17] VIEIRA, Almir Martins. Cultura organizacional em instituições de ensino: mapeamento e análise descritivo-interpretativa da produção acadêmica (1990-2005). 2007. Tese 
(Doutorado) - Faculdade de Filosofia e Ciências, Universidade Estadual Paulista "Julio de Mesquita Filho", Marília, 2007.
[18] VIÑAO, Antonio. Sistemas educativos, culturas escolares y reformas: continuidades y cambios. Madrid: Morata, 2002. 


\section{Capítulo 12}

\section{ESTUDO DO MODELO DE COMPORTAMENTOS ÉTICOS ORGANIZACIONAIS}

\section{Eric David Cohen}

Resumo: Nos dias atuais, é normal nos deparamos com a palavra ética inserida nos meios corporativos, bem como podemos relacioná-la com as atitudes comportamentais e tomadas de decisões feitas pelo trabalhador dentro da empresa, seja ela privada ou pública. O presente estudo busca compreender as origens da ética e sua influência no comportamento organizacional dentro das empresas. Assim, o principal objetivo é mensurar o comportamento ético utilizando a Escala de Percepção de Comportamento Éticos Organizacionais criada por Gomide Jr. em 2003.

Palavras Chave: Ética organizacional; Gestão de Pessoas; Validação da Escala. 


\section{INTRODUÇÃO}

A população hoje vem desenvolvendo uma maior consciência do seu papel social, impulsionada pelo acesso rápido e imediato à informação. Com isso, há uma influência crescente frente às ações das empresas, em resposta aos escândalos financeiros e à necessidade de respeito aos direitos dos cidadãos.

Neste sentido, a discussão da ética passa a exigir uma vivência prática nos setores público e privado, produzindo efeito nas ações dos trabalhadores. Não obstante, ainda há organizações que não desenvolvem esforços voltados à ética organizacional. Algumas nem reconhecem existir problemas relacionados à falta de ética, como o enfrentamento ao comportamento discriminatório, o preconceito racial e social, e o favorecimento pessoal (HOYOS VASQUEZ, 2006).

Desta forma, coloca-se como objeto de estudo a questão da ética organizacional, que visa facilitar a tomada de decisão dos colaboradores da empresa à luz de um código de conduta, de forma a estimular os comportamentos desejados no ambiente de trabalho.

Neste contexto, a ética empresarial está fortemente relacionada às questões morais e ao enfretamento das ações que levam à obtenção de benefício particular, favorecendo o indivíduo em detrimento do benefício coletivo. Assim, vale indagar como as empresas no Brasil mensuram o comportamento ético de seus colaboradores, ou ainda verificar a imagem que os colaboradores possuem da organização onde trabalham.

Apoiados na escala EPCEO de Gomide Jr (2003) e no trabalho de Srour (2000), objetivase analisar se - na percepção dos colaboradores - a empresa pratica: valores de: qualidade no trabalho e respeito interpessoal; igualdade de oportunidade e tratamento não discriminatório; importância do cliente; respeito aos prazos; confiabilidade, credibilidade e estabilidade de normas e objetivos; capacitação e autodesenvolvimento e comprometimento com normas sociais e integração em comunidade.

Neste sentido, coloca-se como questão de pesquisa a seguinte indagação: qual a percepção dos colabores em relação à ética da empresa, utilizando o instrumento EPCEO de Gomide Jr. et al. (2003)?

Justifica-se a realização desta pesquisa frente ao desenvolvimento das empresas, bem como à necessidade de seguir comportamentos no relacionamento com stakeholders e com a sociedade em geral.

\section{FUNDAMENTAÇÃO TEÓRICA}

O termo Ética Empresarial depende das diferentes formas de conceituação por diversos autores ao longo de sua evolução e consolidação. O termo vem do grego "éthos", e pode significar os costumes e o modo de pensar e sentir. Assim, seu conceito encontrase ancorado na conduta social, pois a partir do momento em que o homem passou a conviver em sociedade, ele passou a desenhar normas de comportamento e convívio (VASQUEZ, 1993).

A ética se desenvolve para buscar respostas a problemas para os conflitos do homem frente ao seu comportamento moral. Nestes parâmetros, a conduta das ações humanas sofre influência da ética normativa e a moral, que designam o que é certo ou errado (MASSARUTTI, 2003, p.29).

Ainda, a ética está relacionada à reflexão de um grupo social, para designação de princípios que possam dar legitimidade a ação humana. Neste conceito, a ética influencia a tomada de decisão do ser humano, alicerçada pelo convívio social. Cenci (2001, p.46) corrobora este entendimento, ao postular que a ética é determinada pela teoria, e, portanto, não é um julgamento variável ou sujeito às circunstâncias.

A moral se manifesta no ambiente de trabalho, evidenciando o uso da ética e da moral na tomada de decisões tanto (SROUR, 2000). Para este autor, nas ações corriqueiras, a ética e a moral tem poder de influenciar as decisões dos colaboradores (HOYOS VASQUEZ, 2006).

Weber contextualiza duas teorias sobre ética e a responsabilidade: a convicção e a responsabilidade, baseadas na necessidade de avaliar o resultado da ação (ou seja, no mapeamento das suas consequências). Para Srour (2000), deve-se analisar o resultado para o coletivo, avaliando as opções para decidir pela exclusão das opções que produzem piores resultados. Assim, esta 
abordagem preconiza duas vertentes: a utilitarista, que utiliza a crítica da eficácia, e a finalidade, cuja máxima é "alcance os objetivos, custe o que custar"

A responsabilidade e a convicção são, para Massarutti (2003), a melhor forma de tomada de decisão, visto que as empresas nos dias atuais buscam a ética para tomada de valores, e consequentemente utilizam princípios e valores internos para influenciar a conduta de seus colaboradores.

No âmbito acadêmico, os primeiros pesquisadores eram da área de filosofia e sociologia. Devido ao caráter inovador, a academia adotou uma abordagem deontológica, através da qual direitos, justiça e deveres não poderiam ser corrompidos por interesses utilitários, enquanto outros cursos possuíam um enfoque maior no aspecto utilitário. Já no contexto brasileiro, o desenvolvimento do tema ganha impulso nos anos 90. Apesar do início tardio, os pesquisadores vêm diminuindo as lacunas.

A ética empresarial visa criar sistemas e estruturas que incentivem seus funcionários a agirem de maneira ética, incentivando este tipo de comportamento, através de programas de treinamento, códigos de ética, canais de denúncia anônimos e a criação de um ombudsman. Embora algumas empresas sempre tenham embasado suas ações na ética (como a Johnson \& Johnson e o Banco Itaú), muitas empresas ainda não haviam desenvolvido estas estruturas. Mais recentemente, houve a criação de departamentos de Compliance dentro de empresas como a Petrobrás e a Odebrecht, condenadas na operação Lava-Jato.

A ética dentro das empresas recebeu grande destaque nos últimos anos, porquanto diversas empresas tiveram envolvimentos com a ausência de qualidade dos produtos, bem como de questões ambientais. Outrossim, a necessidade de transparência da empresa encadeia a responsabilidade de seus funcionários nas decisões que envolvem os seus valores, levando ao comportamento ético nos relacionamentos envolvendo clientes, fornecedores, competidores, empregados e governo (SROUR, 2000, p.17).

A ética possui grande impacto quando conscientiza as pessoas a pensar nos seus valores e obrigações como cidadãos, além de fomentar nos funcionários a criação de debates sobre a práticas das empresas. Três elementos norteiam este comportamento: os papéis, as normas e os valores; as normas são uma representação das ações e comportamentos esperados e os valores são as justificativas para tais ações (ANTONIK, p167,2016).

Imposta a estratégia ética dos negócios, a empresa terá o poder de exigir, influenciar e fiscalizar a conduta de seus colaboradores, porquanto instaurada a ética, a empresa consegue lealdade e dedicação, à medida que os procedimentos éticos facilitam e solidificam os laços de parceria empresarial com clientes, fornecedores e sócios efetivos ou potenciais. Segundo Antonik (2016, p162), a utilização da ética confere outras vantagens, tais como: aproximar os profissionais da organização; solidarizar o profissional com a categoria; ser um instrumento que soluciona conflitos e problemas de transparência; fortalecer a imagem da instituição; e deixar clara a conduta moral da empresa para os colaboradores.

Diante disto, Siqueira (2008) aborda a distinção entre Ética Empresarial e Responsabilidade Social, argumentando que - embora os temas estejam altamente entrelaçados - existem distinções importantes entre elas. Citando Ferrel, Friederich e Ferrel (2003), a autora postula que a responsabilidade social é o dever inerente da empresa de promover o impacto positivo na dimensão legal, ética, econômica e filantrópica. Por sua vez, a ética consiste da associação entre responsabilidade e o processo de tomada de decisão. Para a autora, há uma forte relação entre a ética e o bom desempenho empresarial.

Srour (2000) define como ação moral como sendo a que é praticada de forma sistemática pela organização, nas seguintes vertentes:

a.) Qualidade no trabalho e respeito interpessoal: São ações práticas, na qual a organização tem o dever de conferir com transparência das responsabilidades que seus trabalhadores devem possuir quando relacionadas a decisões à serem tomadas (SROUR, 2000, p.191).

b.) Igualdade de oportunidade e tratamento não discriminatório: Moral ética que nega a existência dentro das organizações de qualquer tipo de favoritismos, especialmente quando está atrelado ao detrimento de outros funcionários. Além disso, a empresa não deve tolerar qualquer tipo de ação que possa causar constrangimento e até mesmo 
desqualificação ou redução de algum colaborador.

c.) Importância do cliente: A transparência entre a relação da empresa e do cliente é de extrema relevância, à medida que a instituição de capital deve fornecer produtos ou serviços com qualidade e no prazo prometido ao cliente, bem como a mesma deve manter os preços competitivos. A empresa deve manter informações precisas e objetivas sobre seu produto ou serviço facilmente para seus consumidores, oferecer a prestação de serviços pós-vendas, assegurar o monitoramento das transações, servir seu consumidor com qualidade e profissionalismo.

d.) Respeito pelos prazos: Prática relaciona a necessidade da empresa em inspecionar, tal qual oferecer ao cliente, seja interno ou externo, o acompanhamento sobre a sua demanda, isto é o histórico desde a solicitação até a entrega de sua encomenda. Vale ressaltar, que esse conceito implica que a empresa mitigue seus processos internos, porquanto cabe à mesma realizar estudos para definir o tempo hábil da sua própria produção interna, mas também ao período da entrega de seus produtos ou serviços para estabelecer um padrão a ser divulgado.

e.) Credibilidade e Confiabilidade, e estabilidade de normas e objetivos: O valor de credibilidade para uma empresa está fortemente relacionado à sua transparência de objetivo, valores e conteúdos pragmáticos estabelecidos tanto para seus colaboradores tanto para seus consumidores, em vista que a organização não deve mudar suas regras, objetivos e estratégias sem consultar aqueles possuem relação de interesse.

f.) Capacitação e autodesenvolvimento: Valor ligado à responsabilidade da empresa em promover a capacitação profissional de seus colaboradores, tal qual superar a obsolescência dentro do seu quadro de funcionários, à medida que incentiva as práticas de ações e estudos relacionados a inovações tecnológicas e saber.

g.) Comprometimento com normas sociais: A essência deste ponto é a necessidade da organização em promover ações que os colaboradores aprendam através das atividades profissionais, ou até mesmo em seus treinamentos a lidarem com projetos e tomadas de decisões em grupo.
Ora atentando-nos às consequências do comportamento antiético, Ferrel, Friederich e Ferrel (2001) postulam que existem quatro vertentes que são impactadas positivamente por comportamentos éticos: Engajamento dos Funcionários, Lealdade de Investidores, Satisfação do Consumidor e Lucro. O primeiro está diretamente correlacionado à existência de uma visão de longo prazo do mesmo (JAWORSKI; KOHLI, 1993).

No âmbito dos investidores, os autores afirmam que eles hoje estão cada vez mais preocupados com a reputação das empresas. Sabendo que existe uma correlação positiva entre comportamentos éticos, engajamento dos funcionários e eficiência dentro da companhia, os fundos de investimentos associam comportamentos éticos com crescimento da empresa e aumento do preço das ações, fazendo com que essas empresas sejam investimentos atrativos.

\subsection{ESCALA EPCEO}

A Escala de Percepção de Comportamento Éticos Organizacionais foi criada por Gomide Jr. et al. (2003), com o intuito de conseguir mensurar o clima organizacional e a ética percebida por funcionários dentro das instituições públicas e privadas. O instrumento original é composto de um modelo com 25 itens que correspondem às sete vertentes do comportamento ético organizacional de Srour (2000), quais sejam:

a) qualidade no trabalho e respeito no trato interpessoal;

b) valores de igualdade de oportunidades e tratamento não-discriminatório;

c) importância do cliente;

d) respeito pelos prazos;

e) confiabilidade, credibilidade e estabilidade de normas e objetivos;

f) capacitação e autodesenvolvimento e

g) comprometimento com normas sociais e integração com a comunidade.

A aplicação do EPCEO pode ser de forma individual ou coletiva, tomando cuidado para que os entrevistados entendam como assinalar as respostas corretamente, e que o ambiente estimule as respostas livremente. Os respondentes são solicitados a indicar dentre quatro possibilidades: $1=$ Discordo 
totalmente, 2 = Apenas discordo, 3 = Apenas concordo e 4 = Concordo totalmente.

Gomide Jr e colaboradores coletaram dados em 243 instituições da região do Triângulo Mineiro, sendo $35 \%$ públicas e $65 \%$ privadas. A amostra era composta d e36,5\% de homens, e 43,1\% dos indivíduos tinham ensino médio completo e idade média de 29,73 anos (SIQUEIRA, 2008).

\section{PROCEDIMENTOS METODOLÓGICOS}

A presente pesquisa foi realizada com 150 trabalhadores de diversas empresas, instituições e fundações da região da grande São Paulo, durante o mês de abril de 2018. O questionário foi administrado de forma anônima, a fim de garantir a veracidade de nossas informações e para preservar as opiniões e o sigilo dos entrevistados.

Foram acrescentadas quatro perguntas para capturar dados sociodemográficos como idade, setor de atividade, escolaridade e nível hierárquico e para possibilitar análises relacionadas ao perfil dos participantes frente à percepção de ética no ambiente de trabalho.

Inicialmente, foi realizado um pré-teste do questionário com 10 pessoas, com o fito de avaliar se havia problemas de interpretação e, se necessário, possibilitar correções que fossem necessárias antes de executar a pesquisa. Uma vez vencida esta etapa, a pesquisa foi aberta ao público em geral, visando angariar o maior número de respostas possíveis com a maior diversidade possível. Foram obtidas 131 respostas efetivas, sobre quais os resultados discorreremos sobre na próxima seção do trabalho.

\section{ANÁLISE DOS RESULTADOS}

O questionário EPCEO possui 20 itens que dizem respeito ao comportamento ético nas empresas, divididos em "gestão do sistema" e "orientação para o cliente". Na discussão que segue, serão apresentados os dados colhidos com a aplicação do questionário.

Em relação à faixa etária dos respondentes, observou-se que a maioria dos respondentes está na faixa etária de 20 a 25 anos (61 respostas), seguida dos respondentes que tinham entre 31 e 40 anos (35 respostas). $37,4 \%$ são casados e $51 \%$ solteiros. A formação dos respondentes se concentra principalmente na área das ciências aplicadas, que englobam as carreiras de Administração, Administração Pública, Engenharia, Economia e Contabilidade (aproximadamente 78\% dos respondentes).

Ora analisando a faixa etária dos respondentes com níveis hierárquicos, verifica-se que $50 \%$ dos respondentes entre 20 a 30 anos e que 53\% estão das primeiras etapas da carreira profissional. Assim, a parcela mais representativa se concentra nos níveis hierárquicos mais baixos, isto é: analista (20\% dos respondentes) e estagiários $(17 \%)$.

Mais da metade dos entrevistados (51\%) concorda e $15 \%$ concordam totalmente que a empresa onde trabalham oferece a oportunidade de corrigir seus próprios erros situação relacionada ao item "Qualidade no trabalho e respeito interpessoal" de Srour (2003). A maior parte dos respondentes (63\%) trabalham em empresas que possuem código de ética e promovem o desenvolvimento dos colaboradores, dando subsídios aos projetos para melhoria contínua e qualificando os funcionários.

Em relação ao oferecimento de produtos a preços competitivos (ou seja, à orientação ao cliente, $73 \%$ dos colaboradores entrevistados acreditam que a empresa busca oferece preços competitivos para seus clientes, à luz de um cenário com concorrência acirrada, mercado extremamente globalizado e clientes mais exigentes.

Em relação ao cumprimento dos prazos prometidos, 47\% concordam e 14, \% concordam muito. Este item apresenta relação com o anterior, na linha da orientação para o cliente, com cerca de $81 \%$ dos respondentes que trabalham em empresas comprometidas com o prazo. Apenas $13,7 \%$ dos respondentes possuem uma percepção negativa, ou não estão aptos a responder o item acima.

Em relação às informações precisas e objetivas ao cliente, 82,7\% manifestam concordância de uma relação transparente com o cliente - segundo Srour (2003), isto implica que com os objetivos, valores e conteúdos pragmáticos para o cliente, a empresa alcança credibilidade e confiabilidade.

Em relação ao respeito e valorização dos clientes, na atual pesquisa, $80 \%$ concordam que a empresa mantém informações precisas, 
transparentes e objetivas sobre os produtos e serviços, e manifestam a importância do pósvenda, da qualidade e do profissionalismo.

Dentro da categoria "Gestão de Sistema", o tratamento igualitário a todos os empregados apresenta dispersão dos resultados: apenas $22,9 \%$ discordam que a empresa não trata com igualdade seus funcionários. Este resultado demonstra um questionamento da moral ética da organização, que leva ao constrangimento, à desqualificação e 0 favoritismo, com uma consequente redução da produtividade e a desmotivação.

A questão relacionada com o tratamento dado aos empregados, em relação aos direitos e deveres, mostra que $87 \%$ dos respondentes concordam, e apenas $11,5 \%$ discordam frente aos comportamentos estipulados no código de ética da empresa.

Quando questionados em relação ao reconhecimento publicamente, dentro ou fora da empresa, pelos trabalhos bem-feitos, 10\% dos respondentes declararam discordar; a falta de reconhecimento do trabalho pode desmotivar o funcionário.

Em relação às políticas que impeçam os empregados de ser humilhados ou discriminados na empresa, $86 \%$ dos entrevistados concordam que a empresa tem mecanismos para impedir atos discriminatórios. Além da prevenção desses atos, a empresa impede atos externos que tais ações geram - como o comportamento antiético como forma de retaliação na forma de sabotagem, espionagem, entre outros.

Em relação ao estabelecimento de prazos compatíveis com as tarefas a serem executadas, $33 \%$ dos entrevistados discordam; eles ou elas acham que o tempo alocado para a realização de atividades não é compatível com a necessidade real de tempo para a sua realização. Note-se que um dos maiores direcionadores de comportamento antiético é a necessidade de pegar "atalhos" para realizar tarefas dentro do tempo que é dado.

Em relação ao quesito do conhecimento dos objetivos por todos, $67 \%$ dos entrevistados disseram que há objetivos bem definidos. A boa definição de objetivos, de forma clara e concisa, leva à eficiência e faz com que o colaborador tenha noção do que é preciso fazer para atingir a performance satisfatória. Quando há clareza, o trabalhador pode planejar suas atitudes e não precisa recorrer a comportamentos antiéticos, podendo sempre estar em conformidade com as regulações locais.

Em relação às políticas justas de avaliação de seus empregados, $57 \%$ dos entrevistados manifestaram concordância. 39\% dos colaboradores não acreditam haver clareza nos critérios de avaliação da performance, o que pode favorecer o florescer de comportamentos antiéticos ao criar o sentimento de injustiça, podendo ser traduzida em rancor contra o avaliador e possíveis comportamentos antiéticos.

Em relação à participação de todos os envolvidos na tomada de decisão, 49\% dos entrevistados discordaram. A faltam de políticas que garantam o envolvimento de todos na tomada de decisão estimula o comportamento antiético em duas vertentes: o funcionário pode não se sentir representado e frustrado, levando-o a buscar melhorar artificialmente sua performance para conseguir um "lugar na mesa"; por parte dos chefes, a cúpula decisória enxuta pode levar ao chamado "viés de confirmação" sentimento que a cúpula é intocável.

Em relação às políticas que permitem aos gerentes permanente renovação de seus conhecimentos, $69 \%$ dos entrevistados concordaram. A constante renovação de conhecimento é importante para a mudança de normas regulatórias e atualização do conhecimento. Além disso, novos aprendizados podem conferir vantagem competitiva em relação aos concorrentes.

Em relação ao conhecimento das políticas por todos, $79 \%$ dos entrevistados concordaram. A existência de políticas claras e bem difundidas dentro da empresa faz com que as regras do jogo sejam conhecidas por todos, definindo bem claramente o que é autorizado e o que agride as regulações.

Em relação às regras e normas definidas a partir da consulta a todos os envolvidos, $48 \%$ dos entrevistados discordam que as regras e normas corporativas do ambiente onde trabalham sejam fruto de um processo participativo. Tal situação gera um sentimento de não-pertencimento por parte do funcionário, que deixa de seguir as regras por não acreditar na veracidade e validade das regras, abrindo caminho para as transgressões éticas.

Em relação às respostas, de maneira precisa, às demandas de sua clientela, 69\% 
concordaram; atender às demandas da clientela é um dos indicadores que a empresa não está agindo de maneira antiética.

Quanto às políticas que permitem aos empregados uma contínua revisão de seus conhecimentos, $69 \%$ dos entrevistados afirmaram que a empresa permite esta constante revisão de conhecimentos. Ela é necessária para identificar possíveis mudanças de regulação e conseguir vantagens competitivas legais.

Em relação à modificação das regras e normas sem prévia consulta aos envolvidos, $45 \%$ dos envolvidos afirmaram que a empresa consulta os envolvidos antes das mudanças. Essa consulta é importante para que o empregado perceba que participou do processo decisório da empresa.

\section{CONCLUSÃO}

A Ética organizacional no mundo corporativo é uma vertente de estudo relativamente emergente, o que se confirma pela produção crescente de trabalhos acadêmicos referentes ao tema. Além disso, a discussão em relação à ética é subjetiva, visto não ser uma ciência exata, abrindo margem para diferentes interpretações e vereditos sob os acontecimentos contemporâneos.

À luz dos acontecimentos recentes do Brasil, a discussão em todos os âmbitos de atuação frente a este tema que ainda se encontra em evolução abre espaço para diversas práticas e ações voltadas a ética empresarial.

A Escala de Percepção de Comportamentos Ético Organizacionais é um instrumento eficiente para avaliar a existência e manutenção de comportamentos éticos da organização. Analisando o perfil das

\section{REFERÊNCIAS}

[1] ANTONIK, R. Compliance, Ética, responsabilidade social e empresarial: uma visão prática. Rio de Janeiro. Alta Books,2016.

[2] ARISTOTLE Politics; Nicomachean Ethics, ed. Roger Crisp, Cambridge: Cambridge University Press, 2000.

[3] CENCl, A. O que é ética. 2. ed. Passo Fundo: Batistel, 2001.

[4] FERREL; FRIEDRICH; FERREL, Ethics in Business, 2002. respostas obtidas, podemos concluir que as empresas dispõem de bons mecanismos de controle para evitar comportamentos antiéticos, bem como estimular a revisão de procedimentos em todas as áreas de conhecimento e de atuação.

Como sugestões de desenvolvimento e pesquisas futuras, sugere-se replicar a pesquisa com uma amostra maior para avaliar empiricamente, através das técnicas analíticas confirmatórias, a eficiência da escala EPCEO.

O processo de criação e de revisão de normas e regulação deve prever a participação de todos os colaboradores, para enraizar na cultura o sentimento de pertencimento. Segundo a literatura da área, este sentimento é fundamentalmente relacionado à diminuição do comportamento antiético.

Desta forma, propõe-se que as ações mais efetivas para a promoção do comportamento ético é fomentar a participação do colaborador em todos os processos, tratandoos como stakeholders. Quando o colaborador se sente parte integrante, ele passa a agir como se fosse o seu dono, mantendo a empresa lucrativa e aderindo aos bons princípios de conduta, sem incorrer riscos que ameacem a sustentabilidade a longo prazo da empresa.

\section{AGRADECIMENTOS}

O autor agradece o apoio da FUNADESP Fundação Nacional para o Desenvolvimento de Pesquisa, que viabilizou o desenvolvimento desta pesquisa

[5] FLEURY, M. (Org.). As pessoas na organização. São Paulo: Gente, 2002.

[6] GOMIDE JR., S. FREITAS, C.; SCHUCHT, L. CARVALHO, L. MACHADO, M.; SANTOS, M. Construção e validação de um instrumento de medida de percepção de comportamentos éticos organizacionais. In: XXXIII Reunião anual da Sociedade de Psicologia, 33, Resumos de Comunicação Científica, Belo Horizonte: Sociedade Brasileira de Psicologia, 2003, p. 280. 
[7] JAWORSKI, B. e KOHLI, A., Market Orientation: Antecedents and Consequences, Journal of Marketing, v. 57, 1993.

[8] LOE, T. The Role of Ethical Culture in Developing Trust, Market Orientation and Commitment to Quality (Dissertação de Doutorado, University of Memphis, 1996.

[9] MASSARUTTI, N. Ética Empresarial: valores e normas que delineiam a identidade organizacional. Dissertação (Mestrado em Administração) - Universidade Estadual de Maringá / Universidade Estadual de Londrina, 2003.

[10] MOREIRA, J. A ética empresarial no Brasil. Revisão Jance Yunes. São Paulo. Pioneira, 1999.

[11] SIQUEIRA, M. Medidas do comportamento organizacional: Ferramentas de diagnóstico e de gestão. Mirlene Maria Matias Siqueira (org.). Porto Alegre: Artmed, 2008
[12] SROUR, R. Poder, cultura e ética nas organizações. Rio de Janeiro: Campus, 1998.

[13] Ética empresarial: posturas responsáveis nos negócios, na política e nas relações pessoais. Rio de Janeiro: Campus, 2000.

[14] VÁSQUEZ, A. Ética. 14.ed. Rio de Janeiro: Civilização Brasileira, 1993.

[15] HOYOS VASQUEZ, G. Ciencia y ética desde una perspectiva discursiva. Convergencia, Toluca, v. 13, n. 42, p. 117-131, dezembro de 2006.

$<$ http://www.scielo.org.mx/scielo.php?script=sci_art text\&pid=S1405

$14352006000300007 \& \operatorname{lng}=e s \& n r m=i s o>$. Acesso em 17 de julho de 2018.

[16] WEBER, M. Max Weber: textos selecionados. 2.ed. São Paulo: Abril Cultural, 1980. 


\section{Gapítulo 13}

\section{COMPLIANCE - A TRANSICÃO MORAL NO UNIVERSO CORPORATIVO BRASILEIRO}

\section{Célia de Lima Pizolato \\ Fleuri Cândido Queiroz \\ Michele Abib Pernice \\ Gicélia Lima Santos do Nascimento}

Resumo: Nos últimos anos, inúmeros escândalos vêm ocorrendo no mundo corporativo no Brasil, os quais acabam por afetar a ordem e a ética, configurado numa urgência em elencar o tema Compliance como ponto crucial de estudos. Conhecer as leis, regras, normas, responsabilidades das organizações e seguir os procedimentos recomendados se faz perceber a responsabilidade de ser ético como ponto de relevância para o desenvolvimento das organizações. Ser adequado e conveniente, em todas as atitudes seja como: empresário, gestor e os colaboradores é ser Compliance. A necessidade de tornar urgente algumas posturas tornou esse assunto uma estruturação do alicerce legal, criminal e regulatório para evitar crimes da natureza ética. Foi em 2013 que se promulgou a Lei 12.846/2013 Anticorrupção, assunto de grande relevância. Neste artigo será tratada a cultura brasileira e seus valores como ponto motivador para subsidiar a atuação dos profissionais competentes e atualizados com os preceitos dentro das necessidades e legalidades, imbuídos nesta nova transição moral brasileira. O Compliance na Governança Corporativa previne os riscos, orientam a evitar os impactos que podem ser causados pela falta de transparência no trabalho aos gestores, funcionários, fornecedores, clientes e comunidades inter-relacionarem-se com a organização de forma ética, estar associada as melhores formas de comunicação e convivência organizacional na prática da legislação. A governança corporativa será tratada como um estudo base para uma tecnologia avançada, concernente a sua relevância e associada aos valores profissionais, socioambientais e tecnológicos. Este tema vem a priorizar o bem-estar e o engajamento de boas práticas internas e externas na administração que contribuam para a evolução tecnológica dentro da cultura brasileira neste novo milênio.

Palavras chave: Ética; Cultura Brasileira; Globalização; Governança Corporativa. 


\section{INTRODUÇÃO}

No intuito de discorrer sobre o papel da governança corporativa junto ao Compliance em um Brasil globalizado, este será apresentado como alternativa dentro da organização, onde ser é ético e transparente impera com o objetivo de motivar o ambiente organizacional com todos os colaboradores, como uma forma de administração mais participativa na qual se permite buscar melhorias e inovação com transparência ao seguir as normas da legislação vigente e atualizada.

Esse estudo tem o intuito de esclarecer que a ética profissional e socioambiental embasada no avanço da tecnologia, torna-se uma visão futura para a administração dentro da governança corporativa, com o foco principal na cultura brasileira para estabelecer os princípios norteadores nas responsabilidades sociais corporativas.

Consoante ao pensamento de Barros (2010) o qual agrega que a Ética Profissional pode ser definida como um conjunto de normas e valores que direcionam as condutas dos colaboradores para que estes mantenham uma reputação positiva no ambiente de trabalho.

No Brasil, algumas organizações buscam grande desenvolvimento com práticas sociais e corporativas estendidas por todo o mundo, o zelo com o meio ambiente, a vida humana e a valorização da boa conduta empresarial.

As mudanças dentro das organizações estão avançando cada vez mais no mundo globalizado, haja vista as inovações no mercado como a robótica da internet das coisas possibilitando colaboradores especializados. Cada vez mais o número de máquinas tem se integrado ao processo de reengenharia e avanços tecnológicos nas organizações.

O Brasil possui inúmeras riquezas naturais e ambientais, o que propõe as organizações em dar especial atenção ao tema da sustentabilidade para garantir a preservação socioambiental.

As inovações tecnológicas tem sido a mão propulsora de novas culturas, provocando as organizações engajar-se nos trabalhos socioambientais, sem apenas envolver-se com os resultados financeiros. É necessário que a ética prevaleça e faça-se presente no cotidiano das organizações, aumentando a competitividade da governança corporativa.
O mundo globalizado requer avanço tecnológico saudável que não prejudique a vida humana e o meio ambiente, conduzindo boas práticas da governabilidade e transparência no Brasil, conciliada às mudanças surgidas neste milênio.

\section{OBJETIVOS}

\subsection{OBJETIVO GERAL}

O presente artigo tem como papel primordial destacar a importância do termo Compliance e suas variáveis como fator de integração da governança corporativa dada a participação explícita de gestores e colaboradores das organizações no Brasil.

Outro ponto a ser salientado nesta exordial é identificar como o Brasil tem a grande preocupação em estabelecer princípios de responsabilidades sociais dentro e fora das organizações. Embora algumas dessas empresas brasileiras já encontram-se em um patamar de eficiência quanto os padrões ético e de sustentabilidade. Ainda é necessário expandir a qualidade e manter a essência das empresas, praticando as boas condutas da ética profissional da administração moderna. O incentivo deste processo é o de prevalecer uma maior quantidade de procedimentos e ações práticas que garantam a cidadania das populações e das organizações nos preceitos ambientais.

A ética profissional tem como objetivo alcançar os procedimentos organizacionais.

Segundo Vasquez, a "Ética é a teoria ou ciência do comportamento moral dos homens em sociedade". Para tanto, o comportamento ético sempre deve prevalecer nas decisões empresariais.

A transparência nas atividades e o total engajamento do Compliance na governança corporativa e sua participação no socioambiental fazem a grande diferença entre os colaboradores internos, resultando em profissionais reconhecidos eticamente por seus potenciais junto a sociedade.

$\mathrm{Na}$ atual conjuntura a existência do conhecimento das responsabilidades sociais e organizacionais para com a natureza e seus benefícios, traz para o bem-estar da sociedade possíveis necessidades que muita das vezes não há uma conscientização da sua relevância e de seus benefícios que fazem os diferencias das organizações. 


\subsection{OBJETIVO ESPECÍFICO}

Uma das vertentes é demonstrar como a governança corporativa somada a ética e o socioambiental faz um grande diferencial em uma administração moderna, tecnológica e inovadora. A qual beneficia todos aqueles que estão engajados em um único ideal: o de trazer as melhorias contínuas para as organizações aproveitando os anseios culturais brasileiros.

\section{METODOLOGIA}

Conforme Gil (2007), "Pode se definir pesquisa como o procedimento racional sistemático que tem como objetivo proporcionar respostas aos problemas que são propostos".

Para tanto, a pesquisa elaborada neste trabalho é de ordem exploratória e explicativa, de acordo com classificação de Gil (2007), e tem objetivo proporcionar maior familiaridade com o problema, com vistas a torná-lo mais explícito ou a construir hipóteses.

Ao apresentar o termo Compliance e suas aplicações, benefícios e desafios para os gestores e colaboradores no Brasil, percebese a significância desses fatores que determinam ou que contribuem para a ocorrência dos fenômenos ou seja, dos elementos que permeiam a governança corporativa a qual atinge objetivos e valores como fator vital aos resultados perante a sociedade e mercado.

Para abordagem metodológica desta investigação exploratória qualitativa e descritiva utilizamos uma literatura especializada em fontes bibliográficas e leis específicas.

Buscando trazer esclarecimento e evidenciar acontecimentos surgidos no Brasil em modalidades do socioambiental em diferentes pilares da tecnologia e da globalização, interligando as culturas brasileiras e trazendo a importância do Compliance na governança corporativa.

O termo Compliance tem origem no idioma inglês e vem do verbo to comply, que significa agir de acordo com regras internas de uma organização, seja ela uma empresa publica ou privada em órgãos estatais ou federais. Portanto, é estar em conformidade com padrões e regulamentos internos e externos.
É uma obrigação dada a gestores e empresários para orientar seus colaboradores a seguir e fazer cumprir as leis, regras, manuais e processos administrativos.

\section{DESENVOLVIMENTO}

A literatura tem enfatizado a necessidade de um estudo especializado para atendimento das demandas atuais e futuras quanto ao termo Compliance nas empresas.

Conceitualmente Compliance é agir em sintonia com as regras no controle interno e externo do negócio. Mas no decorrer da investigação observa-se que ele é muito além do que atender as regras, mas as mudanças de atitude comportamento, na forma de agir que fará toda diferença nos resultados financeiros, econômicos e socioambiental de acordo com a ética.

O estudo esclarece inovações que reacendem a preocupação de sustentabilidade dentro das organizações.

O desenvolvimento que satisfaz as necessidades do presente sem comprometer a capacidade das gerações futuras de satisfazerem suas próprias necessidades, está na definição de Sustentabilidade (BRUNTLAND, 1987).

Para Cavalcanti (2003) o tema trata-se como a possibilidade de se obterem continuamente condições iguais ou superiores de vida para um grupo de pessoas e seus sucessores em dado ecossistema. Tal conceito equivale à ideia de manutenção de nosso sistema de apoio da vida. Considerando o reconhecimento daquilo que biofísico possível em uma perspectiva de longo prazo.

As práticas administrativas do novo milênio encontram-se modernizadas, porém nas prerrogativas legais acaba por contradizer sua intenção, visto que as empresas mudam, mas as leis muitas das vezes não.

A administração contemporânea corrobora cada vez mais com o processo de modernização, mas, são de difícil implementação no Brasil, devido as divergências culturais do país.

Conceitua o pensamento de Silveira (2010) ao lembrar que existem dois potenciais benefícios principais que a boa governança pode acarretar às empresas: os benefícios externos, associando a maior facilidade de captação de recursos e a redução do custo 
de capital; e os benefícios internos, vinculados ao aprimoramento do processo decisório na alta gestão.

Dada à importância do estudo Compliance, a figura(1) demonstra subjetivamente as transparências em percentuais da importância de se preservar e manter o meio ambiente salutar a existência de futuras vidas humanas.

Figura 1.

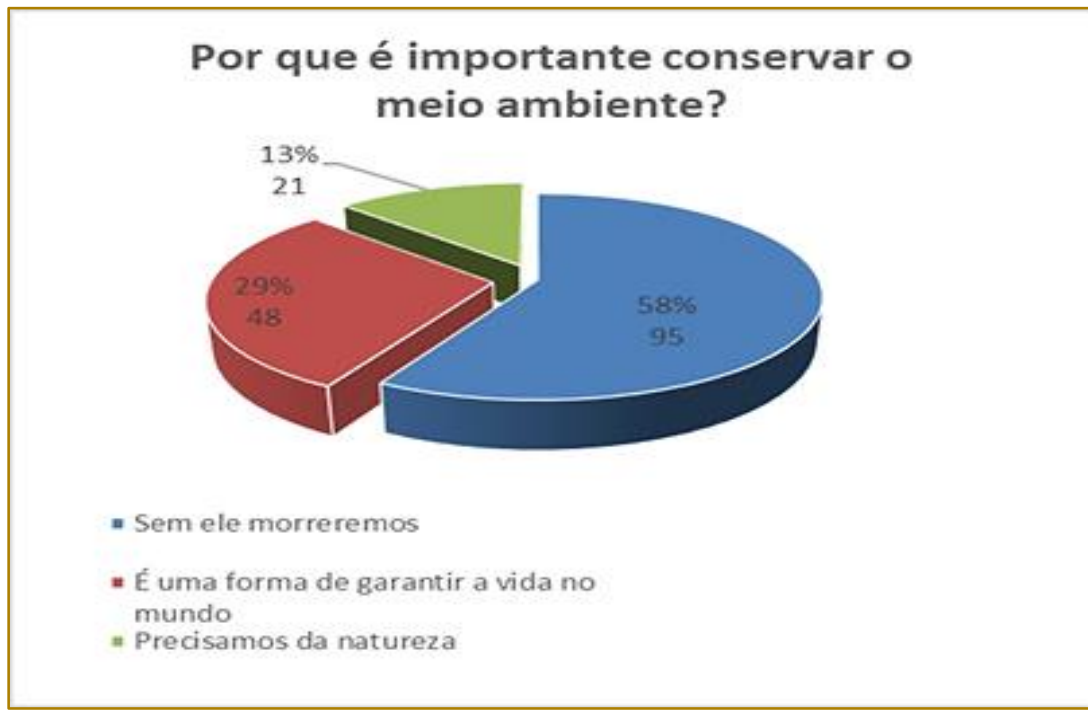

Fonte: Disponivel em:

(http://revistaea.org/pf.php?idartigo=2580)

Acesso em 28/11/2018

No Brasil, o Compliance começou a ser discutido e implantado nas empresas a partir da Lei Anticorrupção, no 12.846/2013, que pune empresas por atos de corrupção contra a administração pública.

As empresas seriam responsabilizadas por práticas ilícitas e poderia pagar multa de até $20 \%$ de seu faturamento, que é considerado um valor muito alto. Entretanto apesar de ter sido aprovada em agosto de 2013, muitas empresas brasileiras, sequer conhecem a Lei Anticorrupção, o que pode trazer graves problemas institucionais.
Pode-se evidenciar que o Compliance pode garantir para as organizações um resultado positivo e elevado nas transparências em um engajamento de participação de todos.

Segundo Lethebridge (1997), a governança corporativa deverá se transformar numa preocupação importante no Brasil na medida em que as mudanças em curso dos seus sistemas de propriedade estatal e familiar acelerem e atraem novos investidores, especialmente estrangeiros.

Figura 2

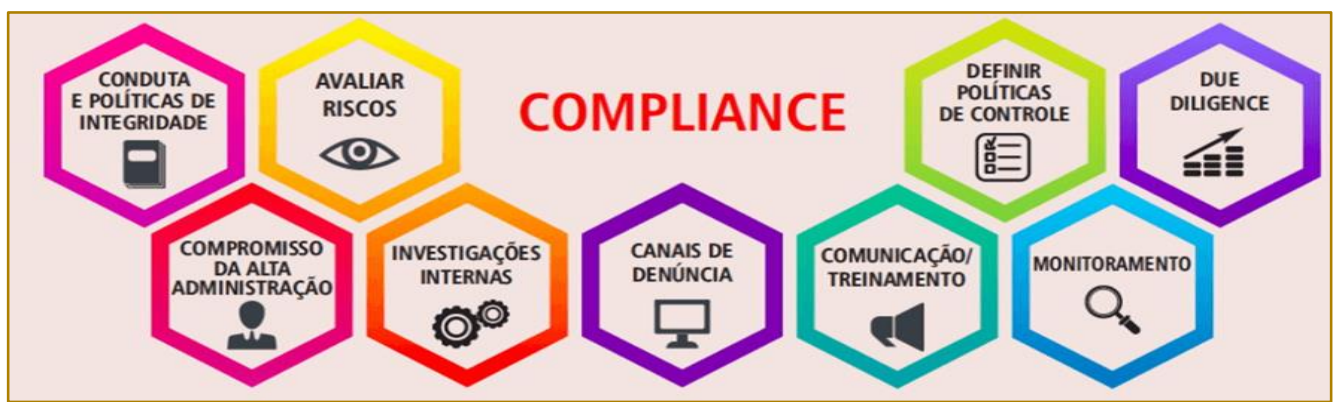

Fonte: www.studioestrategia.com.br Acesso em 30/11/2018 
Para a organização ter o Compliance, se faz necessário englobar na cultura organizacional e aplicar as normas das disciplinas interna, na gestão de alertar os riscos e na transparência geral entre os participantes.

\section{RESULTADOS}

A governança corporativa tem impacto com as empresas e seus colaboradores em uma administração ampla, inovadora que busca zelar a gestão das empresas com transparência. Surgiu através das necessidades do perfil de investidores e demais parceiros sociais, visando à empresa como um todo e trazendo melhorias que ganhou forças no Brasil no ano de 1998.

Em conjunto com o Compliance a governança corporativa é reconhecida por manter e conduzir as boas aplicações profissionais dentro das organizações. A cultura empresarial não deve somente visar valores em moedas correntes, deve ter o compromisso com a ética profissional e a sustentabilidade engajada nas tecnologias.

Desta forma, alcançará o sucesso com efetividade e o reconhecimento da sociedade pelo exemplo da empresa, mostrando o desenvolvimento e objetivo para todos os participantes, repercutindo naturalmente de forma positiva e comprometida no aumento de clientes e resultados financeiros.

O tema conecta a organização com a tecnologia e favorece a natureza que traz o ar puro e a beleza do nosso país, se adaptando e preparando para o novo processo de perspectivas da "Revolução Tecnológica".

A prática da cultura associada a ética é essência para o sucesso da empresa. Ser ético é essencial pra ser Compliance.

O Compliance no engajamento com governança corporativa tem 0 intuito de melhorias continuas, trazendo transparência e trabalhando dentro da legislação vigente.

O Brasil encontra-se em difícil implantação as novas mudanças da empresa com o socioambiental, por outro lado, torna-se de grande importância a preocupação brasileira, pois depende desse zelo para com o meio ambiente e as reservas naturais.

Os gestores e empresários das organizações precisam conscientizar-se que 0 meio ambiente, a tecnologia e a empresa tem que estar associado um a o outro, trazendo transparência e praticada a implementação do sistema no Brasil.

\section{CONSIDERAÇÕES FINAIS}

Através do estudo percebeu-se que o Brasil é um país que possui vários gestores e empresários, onde cada um tem suas formas diferenciadas de administrar uma empresa. Porém em comum, todos os gestores que administram ou governam uma empresa, tem a visão de obter crescimento no mercado e lucrar recursos financeiros.

O Compliance junto à governança corporativa veio ao Brasil para trazer uma gestão de transparência, resiliência e responsabilidade na governabilidade de uma nova modalidade de administração moderna, tendo como resultado Onde a busca do aperfeiçoamento profissional e ético no foco a melhorias continuas no Brasil.

Destarte, que a ética tem seu valor nas governanças corporativas e deve ser a principal meta nas práticas cotidianas que tem trazido benefícios e engajamento profissional dentro das legalidades e transparências com os colaboradores.

A administração corporativa aponta os fatores de uma organização de sucesso associada a tecnologia sem prejudicar o meio ambiente, permeando o engajamento das pessoas com socioambiental e uma tecnologia inovadora e arrojada. Tudo dentro da ética, da cultura brasileira com suas inúmeras atuações no sistema de preservação e cuidados socioambientais.

O Compliance age em constante reciprocidade com as regras e normas estabelecidas pela legislação, trabalha com diretrizes, regulamentações, assegurando a ao cumprimento das normas.

A sinergia do Compliance na governança corporativa, socioambiental e tecnológica avança para o novo futuro, traz para o Brasil o caminho do equilíbrio, da ética, da responsabilidade e da justiça, em uma administração esclarecedora com sua missão e visão que valoriza e respeita o maior capital de uma organização, o "capital humano".

Concluiu-se que ao utilizar o Compliance como base deste estudo, colaborou para uma maior reflexão sobre o tema e a importância 
de analisar o assunto sustentabilidade e ética como melhorias para o desenvolvimento tecnológico.

Insuflado por um espírito pátrio, espera-se, já tardia, a nova transição moral brasileira

\section{REFERÊNCIAS}

[1] ALENCASTRO, M. S. C.. Ética empresarial na prática: liderança, gestão e responsabilidade corporativa. Curitiba: Ibpex, 2010.

[2] ANDRADE, Adriana: ROSSETTI, José Paschoal. Governança Corporativa: fundamentos, desenvolvimento e tendências. São Paulo: Atlas ,2014.

[3] ANDRADE, R. O. B. Tecnologias da informação aplicadas ás instituições de ensino e ás universidades corporativas. São Paulo: Atlas, 2003

[4] BARROS, M. F. R. A ética no exercício da profissão contábil. 2010. Monografia (Bacharelado em Ciências Contábeis) - Instituto de Ciências Econômicas e Gerenciais, Pontifícia Universidade Católica de Minas Gerais, Belo horizonte, 2010.

[5] BORGES, L.; SERRÃO, C. Aspectos da Governança Corporativa no Brasil. Revista do BNDES, v. 12, n.24, Rio de Janeiro, dez. 2005.

[6] BRUNDTLAND, comissão. Comissão Mundial sobre o Meio Ambiente e Desenvolvimento: o nosso futuro comum . Universidade de Oxford. Nova Iorque.1987.

[7] CAVALCANTI, C. Desenvolvimento e natureza: estudos para uma sociedade sustentável. São Paulo: Cortez, 2003. p.29-40. apegada no crescimento sustentável, valorizando a ética, a boa gestão dos patrimônios humanos, tecnológicos e ambientais.
[8] ÉTICA e responsabilidade social nos negócios. 2. ed. São Paulo: Saraiva, 2008.

[9] EXAME. Guia exame de sustentabilidade, São Paulo. Disponível em: portalexame. abril.com.br

[10] GESTÃO AMBIENTAL. Revista Brasileira de Administração, Brasília: Conselho Federal de Administração, ano 11, n 32, abr. 2001.

[11] GIL, A. C. Como elaborar projetos de pesquisa. 4. ed. São Paulo: Atlas, 2007.

[12] INSTITUTO BRASILEIRO DE GOVERNANÇA CORPORATIVA (IBGC). Código das Melhores Práticas de Governança Corporativa. 3a edição, São Paulo, 2004.

[13] LETHBRIDGE, E. Governança corporativa Revista BNDS, Rio de Janeiro, n.8, dez.1997

[14] SILVEIRA, Alexandre Di Miceli da. Governança Corporativa no Brasil e no Mundo: teoria e pratica . Rio de Janeiro: Elsevier , 2010.

[15] VASQUEZ, Adolfo Sánchez.Ética. 16 ed.Rio de Janeiro: Civilização Brasileira, 2007.

\section{SITE VISITADO:}

LEl Anticorrupção: https://www.pontodosconcursos.com.br/artigo/10944/marcelo-alexandrino/lei-12846-2013-responsabilizacao-de-pessoas-juridicas-poratos?gclid=CjwKCAiA9K3gBRA4EiwACEhFe5yy849xYmBt9wPqJRAgnbQIrx2UiGwX2BILiqDTkcWtTqkWkrUPBoCa-UQAvD_BwE, Acesso em 08/12/2018. 


\section{Gapítulo 14}

\section{A INFLUENCIA DO TREINAMENTO NA MELHORIA DE PRODUTIVIDADE: UM ESTUDO DE CASO EM UMA EMPRESA DO SEGMENTO EMPIRICO DE PERFUMARIA.}

\section{Maissa Rufino Theodoro}

\section{Thiago Bragança Nogueira}

Maria de Lara Moutta Calado de Oliveira

Eduardo de Moraes Xavier de Abreu

Resumo: A produtividade se apresenta como a meta de qualquer organização, porém, isso se torna um desafio quando falamos de pessoas, seus métodos, a capacidade de serem independentes e de se desenvolverem. Mas, diante de qualquer equipamento enconttra-se um ser humano, ele é racional e consegue criar soluções que os equipamentos não podem oferecer para a organização. Neste contexto, este trabalho tem como objetivo identificar a associação entre treinamento e produtividade, partindo do pressuposto de que quanto maior a preparação e capacitação dos colaboradores, melhor é a produtividade da empresa. O percurso metodológico escolhido foi a pesquisa qualitativa, aplicada e exploratória, a partir do estudo de caso em uma empresa de perfumaria e cosmético. Os resultados apontam a existência de uma forte influência dos treinamentos no desenvolvimento da produtividade, ratificando assim a importância da continuidade das políticas de treinamentos e qualificação pessoal, com foco em atendimento a produtividade estabelecida.

Palavras-chaves: treinamento; produtividade; capital humano. 


\section{INTRODUÇÃO}

Diante da concorrência no mercado, as empresas encontram-se em busca de obter um melhor desempenho em seus processos empregando o uso de estratégias, ampliando habilidades e competências. O capitalismo está levando as empresas a revisarem sua gestão, gerando diversas reestruturações visando a tão sonhada competitividade. No universo empresarial é notável que os processos sofrem mudança contínua, o que demanda o aumento do conhecimento administrativo pela procura por inovação e versatilidade no âmbito empresarial. Compete ao capital humano, a construção de planos de ação nos mais variados setores, sendo esse, um elemento de competitividade empresarial. Dessa forma, as empresas devem desenvolver o seu capital humano de maneira que seja habilitado para atingir os objetivos empresariais (SANTOS, 2012).

O capital humano constitui-se pelo conhecimento, habilidade e experiência dos colaboradores na realização de seus deveres diários, os princípios da empresa e outros ativos não monetários. Ele pode ser visto como um alto referencial de resultado no âmbito organizacional uma vez que, apesar de ser intangível, proporciona um notável retorno financeiro (SANTOS, 2012).

Dessa forma, faz-se necessário que o setor produtivo passe por mudanças e adaptações. Para isso, as empresas vêm encontrando dentro de sua própria organização, meios para se manterem a frente da concorrência e garantir a eficiência na produtividade, fornecendo aos seus colaboradores um preparo profissional a partir da capacitação da mão de obra por meio de treinamentos desenvolvidos pela própria organização. Investir na capacitação pode ser um fator diferencial nas organizações. Mas quais os ganhos que os treinamentos efetivamente podem trazer?

Neste contexto, este trabalho tem como objetivo identificar a associação entre treinamento e produtividade, partindo do pressuposto de que quanto maior a preparação e capacitação dos colaboradores, melhor é a produtividade da empresa.

O artigo está dividido em cinco seções. A primeira seção apresentou uma breve introdução e o objetivo do trabalho. $\mathrm{Na}$ segunda seção, serão apresentados os pressupostos teóricos, envolvendo treinamento, produtividade e capital humano.
$\mathrm{Na}$ terceira seção será apresentado o percurso metodológico. A quarta seção apresentará o estudo de caso propriamente dito. A quinta e última seção será composta pelas considerações finais e limitações do estudo.

\section{REFERENCIAL TEÓRICO}

\subsection{TREINAMENTO}

O treinamento é um instrumento administrativo de vital importância para o aumento da produtividade do trabalho. O treinamento é um método pedagógico de prazo não longo, posto de forma estruturada, por onde os indivíduos absorvem conhecimentos e habilidades sob determinados objetivos dentro de uma organização, com a finalidade de obter um aumento produtivo de maneira que não afete seus procedimentos (VOLPE, 2009).

Treinamento é uma palavra muito usada no campo de desenvolvimento humano, e significa estar apto, capaz de realizar determinada tarefa e de ter habilidades. 0 objetivo do treinamento consiste na aprendizagem, na melhoria de conhecimentos específicos e aptidão para executar em seguida, tarefas estabelecidas. Sendo assim, o treinamento está diretamente ligado a habilidade (TEIXEIRA, 2005).

O treinamento, proporciona experiências, aumentando o desempenho e consequentemente a produtividade, fazendo com que ao longo do tempo, o custo unitário de produção seja reduzido (BETHLEM, 1999).

Além de aperfeiçoar os colaboradores em sua função, o treinamento objetiva o desenvolvimento de habilidade, fazendo com que as pessoas sejam mais produtivas, e em consequência contribuí para a conquista das metas organizacionais. Toda e qualquer organização consegue incluir em seu plano o processo de treinar, para isso se faz necessário que a empresa veja o processo como sendo um investimento, e que é possível ser realizado por uma pessoa da própria organização ou por alguma empresa de treinamento e desenvolvimento (FLEURY, 2002).

Por transformação nos referimos ao uso dos recursos para mudar o estado ou condição de algo para produzir outputs. A produção envolve um conjunto de recursos de entrada, que pode ser subdividido em recursos 
transformados (matéria-prima e informações) e recursos de transformação (mão-de-obra e equipamentos), usados para se obter outputs de bens e/ou serviços, convergente com os conceitos de treinamento (SLACK, 2007).

FIGURA 2 - Modelo de transformação, adaptado.

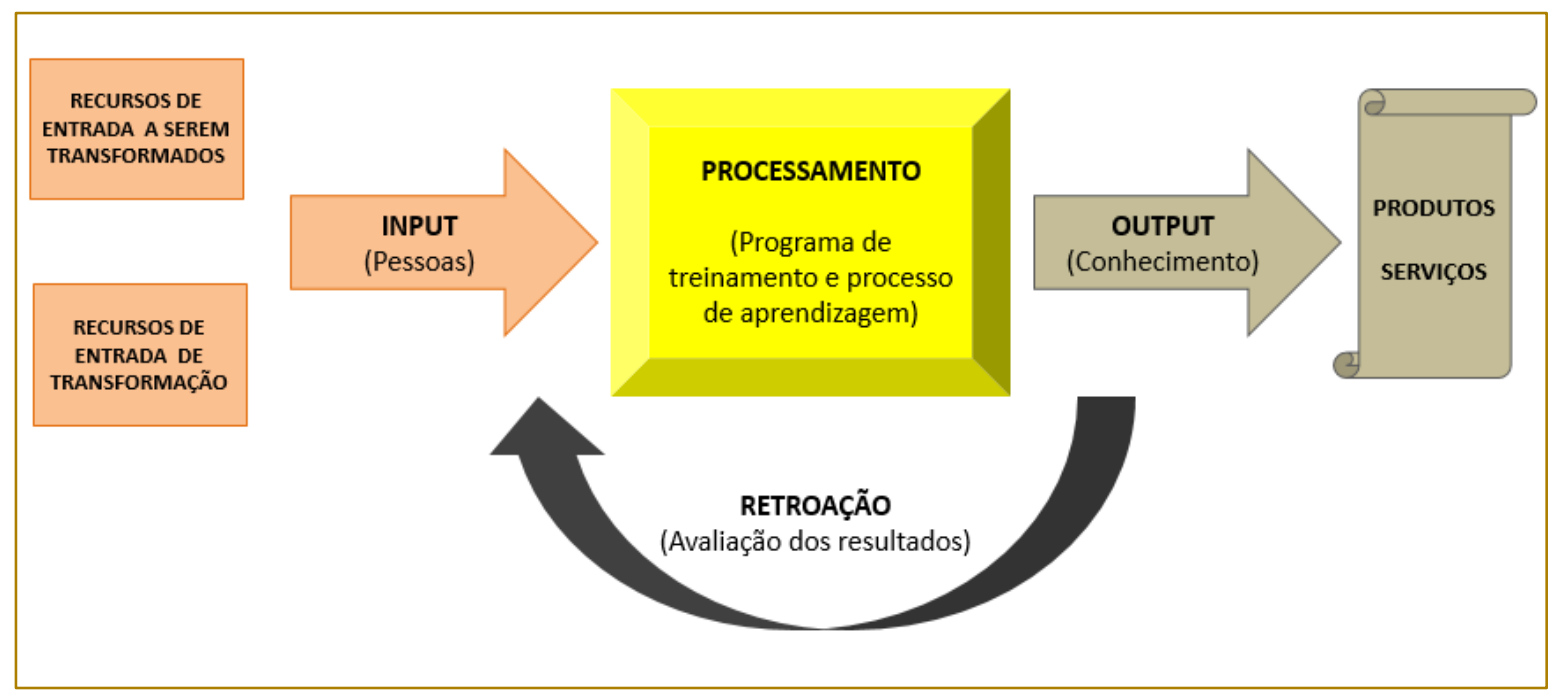

Fonte: Slack (2002)

Existe uma crescente evidência de que os investimentos em treinamento estão associados ao aumento da lucratividade no longo prazo, e que as empresas que reorganizam suas operações com base em programas como trabalho em equipes e círculos de qualidade conseguem maior produtividade, se esses programas estiverem em sintonia com a educação do trabalhador (MILKOVITCH; BOUDREAU, 2010).

\subsection{PRODUTIVIDADE}

A produtividade pode ser definida como a eficiência com a qual os insumos são transformados em produção, onde os fatores de produção definem-se como sendo pessoas, máquinas, matérias e outros. Entende-se por produção, um composto de atividade que levam a confecção, criação ou ganho de um bem ou serviço. A partir da produtividade, pode-se mensurar a competência de um sistema para desenvolver os produtos/ serviços e o nível em que são empregados os recursos. A melhor produtividade concebe maior rentabilidade para uma empresa (RITZMAN; KRAJEWSKI, 2004).

A verificação do grau de produtividade não está relacionada apenas a associação de quantidade de produzida por hora trabalhada, têm relação também com o entendimento da função, o propósito, as técnicas, renovação e adequação. Diante separação do trabalho sugerido pelo fordismo, que possibilitou tamanho aproveitamento de tempo em linha de produção, surgiu a preocupação com fatores até então não notados, como o gerenciamento da força de trabalho (MELLO, 2009).

Podemos medir a produtividade por meio de diversos agrupamentos, como a quantidade de chamadas atendidas por um colaborador de um call center, as metas diárias alcançadas por um promotor de vendas, a quantidade de automóveis fabricadas por um colaborador dentro de um mês ou a quantidade em peso de tecido fabricado por um equipamento de tecedura. No contexto empresarial, a produtividade pode depender de elementos extrínsecos tais como o quadro econômico do país, concorrência, fornecedores, e elementos intrínsecos como nível de emprego do estoque à disposição, conhecimento, habilidades, competências e o ânimo dos indivíduos envolvidos nos processos de trabalho (CORREA; CORREA, 2004).

Ela pode ser medida também de duas maneiras: global e parcial. A global é medida por meio do resultado total da empresa, onde pode ser identificada em indicadores parciais que permitem uma melhor leitura a respeito do desempenho de cada setor. Já a 
produtividade parcial, pode ser mensurada por meio de trabalho humano, máquinas ou um dos insumos (WAINER, 2002).

Existem dois motivos que colocam a produtividade como uma grandeza consideravelmente importante. O primeiro é que na economia clássica, o aumento de produtividade se apresenta como um divisor do desenvolvimento real da economia. Com ideia de que a economia de um estado está restrito, a sua capacidade produtiva, aquele que tem uma maior produção, possui uma economia superior. Logo, o crescimento econômico está ligado a dois motivos: Ou acrescenta-se colaboradores ao sistema de produção e esses produzem mais ou a produtividade dos colaboradores aumentou e com isso produzem mais (WAINER, 2002).

Existem diversos elementos que visam aumentar a produtividade, entre eles, o emprego de novas técnicas de planejamento e o planejamento dos procedimentos. A frequência com a qual se executa um trabalho, a prática, o conhecimento e o treinamento, também acarretam o aumento da produtividade (HEINECK, 1991).

Para um engenheiro de produção de tradição taylorista, produtividade é simplesmente a quantidade produzida por unidade de tempo. Para um economista neoclássico, é a relação entre a quantidade de produção e a quantidade de um dos fatores de produção utilizados. Para um administrador de empresas, produtividade é a relação entre lucro bruto o investimento total (COSTA, 1983).

\subsection{CAPITAL HUMANO}

A teoria do capital humano foi agregada na economia contemporânea por Jcob Mincer e divulgada por Schultz e Becker nos anos 50 e 60. O conceito substancial da teoria é que o conjunto de atividades produtivas ou criativas exercidas pelo homem, mais do que um agente de produção, é uma espécie de capital, o chamado capital humano. Este, torna-se mais produtivo quando elevado seu nível de qualidade, onde a qualidade se dá por meio do nível de treinamento que cada funcionário obtém durante sua vivência. Essa qualidade, além de aprimorar o rendimento pessoal do funcionário, o que o deixa mais produtivo, é também um agente relevante para propiciar riqueza, desenvolvimento econômico do país e equilíbrio social (MOTTA, 2008).

O conceito de capital humano surgiu nos Estados Unidos em 1950, a partir de uma disciplina criada por Theodore W. Schultz, naquela época, um professor do setor de economia da universidade de Chicago, com intuito de especificar os ganhos produtivos oriundos do fator humano na produção. Para Schultz o conhecimento é uma maneira de gerar recursos financeiros e o investimento sobre a capacitação pode ser unilateral ou de ambas as partes envolvidas (PONCHIROLLI, 2009).

O capital humano é um conjunto de capacidades produtivas que uma pessoa pode adquirir, devido à acumulação de conhecimentos gerais ou específicos, que podem ser utilizados na produção de riqueza. A atividade humana, quando preparada por meios de conhecimento, se tornava um dos meios mais relevantes para o aumento da produtividade (BECKER, 1993).

Em um estudo bibliográfico sobre o impacto do fator motivação na produtividade, notou que para obter as metas almejadas se faz necessário que a organização rentabilize seus recursos. Valorizando o capital humano, a produtividade garantirá lucratividade (SATT, 2009).

Em 2016, foi feito uma pesquisa a respeito de produtividade que apresentou onde pode-se observar casos de varejistas que conseguiram aumentar sua produtividade no ano de 2015 a partir do investimento sobre o capital humano, onde o desenvolvimento e o treinamento dos funcionários dessas empresas é considerado a principal prioridade para $89,7 \%$ das 300 maiores empresas varejistas do Brasil. 
FIGURA 3 - Prioridades das 300 maiores empresas varejistas.

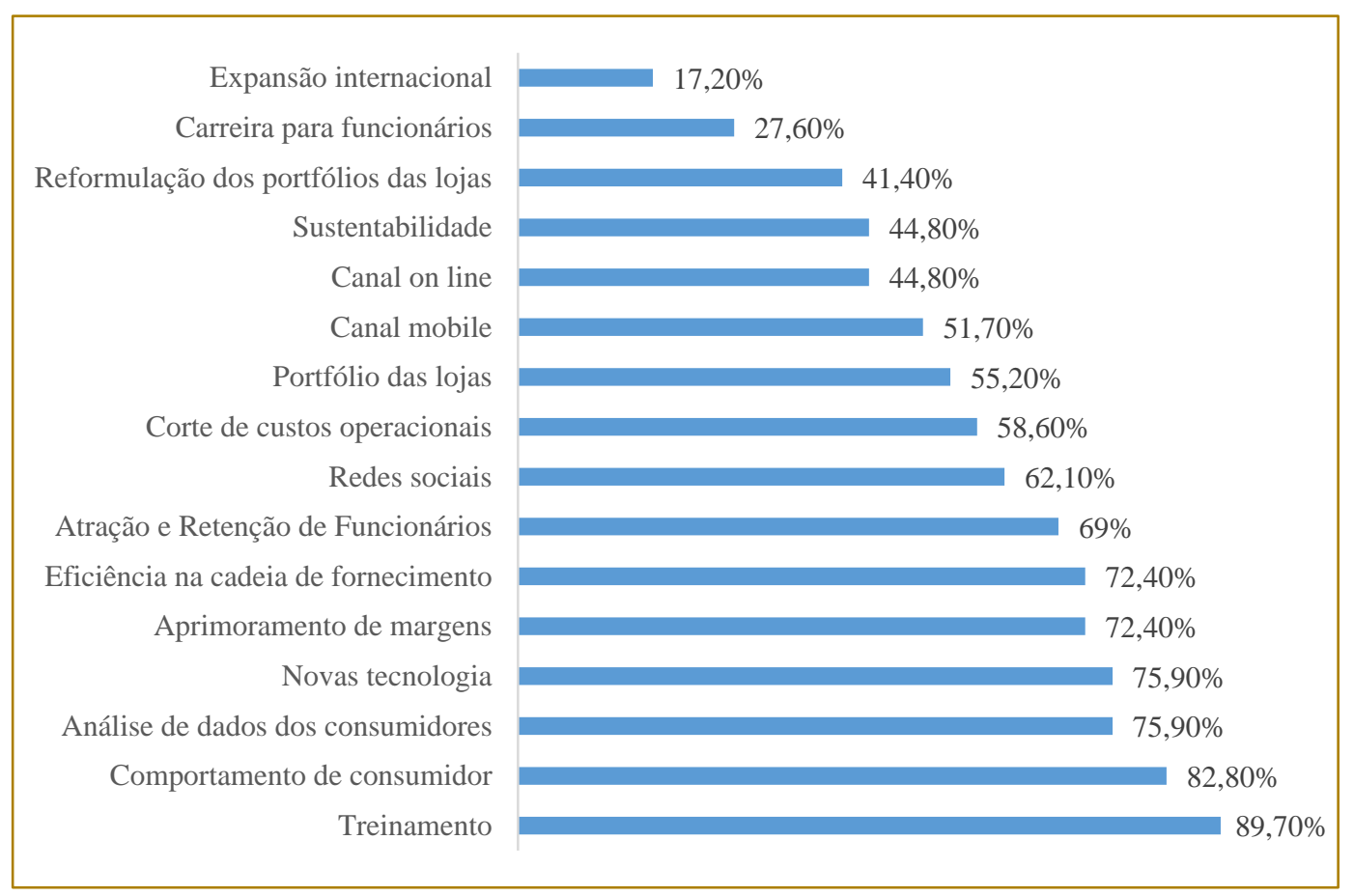

Fonte: Adaptado de (NOVAREJO, 2016).

Os dados apresentam que a principal prioridade para o crescimento futuro dessas empresas é o desenvolvimento e o treinamento dos funcionários. Segundo a fonte, as empresas vêm investido em média cerca de $1 \%$ de seu faturamento em capacitação de mão de obra, e a empresa que assumiu o topo da pesquisa faz parte do segmento de perfumaria e cosméticos, apresentando o maior crescimento da produtividade por funcionário com 0 percentual de 100,7\% (NOVAREJO 2016).

\section{METODOLOGIA}

A pesquisa desenvolvida ao longo desse trabalho foi caracterizada como aplicada e exploratória. Aplicada em virtude da utilização, na prática, de conhecimentos disponíveis de treinamento, capital humano e produtividade para responder às demandas da sociedade em contínua transformação; e exploratória, por proporcionar uma maior familiaridade com o problema de pesquisa (CERVO, BERVIAN, 2007).

Neste trabalho, a pesquisa de campo foi desenvolvida por meio da observação de fatos. A partir dos relatos dos entrevistados, dos dados observados e dos documentos secundários descrevemos detalhadamente os fatos e dados, agregando informações ao conhecimento acadêmico e evidenciando a característica descritiva da pesquisa qualitativa com respaldo do meio acadêmico (MERRIAM, 1998; YIN, 1999).

O trabalho é um estudo de caso em uma empresa do segmento empírico de perfumaria e cosméticos que está no mercado pernambucano há mais de quinze anos. Utilizaremos o nome fictício Perfumaria do Brasil para apresentar a empresa pesquisada, destacamos que os dados são reais, porém a empresa não autorizou a divulgação do seu nome. A empresa é líder de mercado no ramo de perfumaria e cosméticos. A coleta de dados foi realizada com uma promotora de vendas, a partir de uma entrevista semiestruturada, que faz parte do quadro de quatorze funcionários de uma das lojas da dessa Perfumaria do Brasil, além da observação participativa em campo, conforme figura a seguir. 
FIGURA 4 - Entrevista. Fonte: Elaborada pelos autores.

\begin{tabular}{l} 
Você já participou de algum treinamento? Quais? \\
\hline Que temas abordaram? Como é a metodologia do treinamento? \\
\hline Qual a importância do treinamento na sua produtividade? E em geral o que treinamento agrega? \\
\hline Qual a frequência de treinamento?
\end{tabular}

\section{ESTUDO DE CASO}

A entrevista foi aplicada à uma colaboradora de vinte e sete anos, promotora de vendas da Perfumaria do Brasil há quatro anos e um mês. A partir da aplicação da entrevista, identificamos que a promotora já participou e participa de treinamentos que são frequentemente aplicados para a equipe de trabalho.

O primeiro treinamento recebido pelos funcionários é o treinamento de integração, toda equipe recém contratada passa por esse momento, este treinamento possui aproximadamente 3 dias de duração e é aplicado por etapas. Na primeira etapa todos os colaboradores independentemente de suas funções recebem conhecimento greal sobre a Perfumaria do Basil, nessa estapa é abordado a história, o surgimento e o propósito da marca.

A segunda etapa é aplicada por um responsável de cada setor, nesta os colaboradores tomam conhecimento a respeito de como opera e qual a responsabilidade de cada setor, para que saibam a quem recorrer em determinada situação, esse conhecimento é necessário porquê em vários casos, a gerente da loja supervisiona duas ou três unidades, sendo assim, os funcionários conseguem identifcar o ocorrido e sabem a qual setor deve solicitar a solução.

$\mathrm{Na}$ terceira etapa os colaboradores são sepeparados por funcões, neste cada grupo recebe a capacitação para o desenvolvimento de seu trabalho. Os estoquistas aprendem sobre armazenamento e recebimento de mercadorias, controle de entradas e saídas de produtos dentro do sistema de gerenciamento Primeiro que Entra, Primeiro que Sai (PEPS) e Último que Entra, Primeiro que Sai (UEPS) que visam evitar a perda de mercadoria por vencimento.

As operadoras de caixa aprendem a movimentar todo fluxo de caixa e suas operações onde recebem senha individuais de maneira a controlar a movimentação de recebimentos e cancelamentos de compra. A embaladoras são instruidas a fazer as embalagens de maneira ágil, dentro do padrão da franquia com $\mathrm{o}$ controle da quantidade de material usado $e$ as promotoras tomam conhecimento sobre os tipos de cliente, como sondar e entender a necessidade dos consumidores, como contornar objeções e agregar produtos na compra.

Todos, independentemente de suas funções, aprendem sobre postura, higiene comportamento e apresentação pessoal. As mulheres apredem a automaquigem que é um item fundamental na apresentação pessoal de lojas do setor de cosméticos. Ao final de cada etapa é aplicado uma avaliação de conhecimento de maneira a verificar o nível de conhecimento adquirido após o treinamento e uma avaliação de reação, nesta é possível avaliar o grau de satisfação do treinando em relação ao treinamento recebido.

Então, após devidamente capacitados e aptos a desenvolverem suas funções os novos funcionários são direcionados a seus locais de trabalho onde receberão o apoio e o suporte da gerente e da equipe de loja que, experientes poderão ajudar caso o novo integrante apresente qualquer dúvida ao desenvolver o trabalho. Visando a apliacação prática, a perfumaria também dispõe o treinamento on the job, que é aplicado no local de trabalho sob situações reais.

Normalmente os treinamentos podem ser aplicados de três maneiras: presencial, on the job e online. No presencial os colaboradores das lojas se deslocam para um local onde tem uma sala específica para realização de treinamentos, que fica em um ponto central na cidade de maneira com que todos consigam acesso, no on the job os funcionários recebem treinamentos dentro de seu local de trabalho, este pode ser aplicado pela gerente 
de loja que anteriormete recebeu o treinamento ou via extranet, onde é disponibilazado o treinamento online e em seguida é feito uma avaliação de conhecimento.

Quanto à frequência, aproximadamente a cada quinze dias a equipe recebe um treinamento via extranet onde o mesmo é relacionado a composição e características dos produtos à serem lançados nos próximos ciclos, e em seguida recebem uma avalição sobre o conteúdo. Ao menos uma vez ao ano acontece a convenção anual com o objetivo de repassar aos colaboradores os resultados alcançados ao longo do ano e planos estratégicos para o próximo ano.

Além disso, nas datas sazonais, aquelas que aquecem o mercado, toda equipe de loja recebe treinamento de energização, neste, é trabalhado o tema motivação, técnicas em vendas, como contornar objeções, como sondar e entender a necessidade do cliente, como dar atenção para vários clientes ao mesmo tempo. Estes podem ser aplicados por um instrutora própria, pela gerente de loja ou por alguma empresa contratada.

A promotora acredita que o treinamento contribui com seu trabalho por que a partir dele, ela adquire conhecimentos específicos sobre os produtos fazendo com que ela tenha os argumentos necessário para comparar o produto dela ao produto da concorrência e assim conquistar o cliente. Além disso ela consegue ter uma boa postura profissional, reconhecimento dos clientes pelo atendimento e da empresa pelos resultados obtidos a partir do conhecimento adquirido e como consequência tem benefícios pessoais.

Quando se tem conhecimento sobre os produtos, tipos de cliente, é possível entender a necessidade dele e assim, saber indicar, dentro de tantas opções, aquilo que mais se encaixa com o que ele busca, assim eu ganho tempo e alcanço meu objetivo. O tempo todo faço uso de conhecimento que aprendi nos treinamentos pois ele é voltado para o desenvolvimento do meu trabalho (ENTREVISTA, 2018).

O acompanhamento da produtividade é feito por meio do boleto médio e dos itens por boleto. Para medir o boleto médio é feito uma divisão de todo valor vendido pela quantidade de boletos tirados naquele dia, esse medida e individual de cada promotor e a soma total mostra a produtividade da loja naquele dia. Os itens por boleto é a divisão da quantidade de itens vendidos naquele dia pela quantidade de boletos tirados também no dia. No final com a soma do boleto médio e dos itens por boleto de cada promotor, temos a produtividade total das vendas.

Uma promotora que vendeu $R \$ 300,00$ para o primeiro cliente e $\mathrm{R} \$ 150,00$ para o segundo cliente, teve o boleto medio de $\mathrm{R} \$ 225,00$ que é a soma de todos o valores vendidos dividivos pela quantidade de boletos tirados. Para o primeiro cliente ela vendeu quatro itens e para o segundo ela vendeu um, isso significa que a média de itens por boleto dela foi de 2,5 que é a divisão da soma de todos os itens vendidos pelo total de boletos tirados. Nesse caso, a produtividade foi baixa por que a média esperada pela Perfumaria é de 3,0 no que diz respeito a itens por boleto, já no boleto médio a produtividade foi boa porque a média esperada pela Perfumaria é de $R \$ 200,00$

Assim, todos os promotores conseguem fazer o acompanhamento de sua produtividade diária, sabendo ele que a produtividade não alcançada em um dia pode ser compensada pelo dia seguinte caso ele supere a produtividade deste dia. Esse acompanhamento faz com que o promotor consiga entender onde ele precisa traballar melhor e então buscar ações para que no final do mês consiga o resultado estipulado pela Perfumaria.

Caso ela perceba que precisa trabalhar os índices, ela irá se esforçar para aumentar o valor ou os itens de compra de cada cliente que entra na loja, então colocará em prática os argumentos de vendas e o conhecimento sobre os benefícios dos produtos para despertar uma necessidade de compra no cliente fazendo com que ele adquira mais itens que dependendo do valor unitário pode elevar o boleto médio e dependendo da quantidade de itens elevar os itens por boleto. Sugerimos também a partir dessas entrevistas o controle individual por gráficos, o que permite o acompanhamento individual de cada promotora, gerando inclusive um histórico individual e coletivo dos resultados alcançados. 
FIGURA 5 - Proposta de acompanhamento individual.

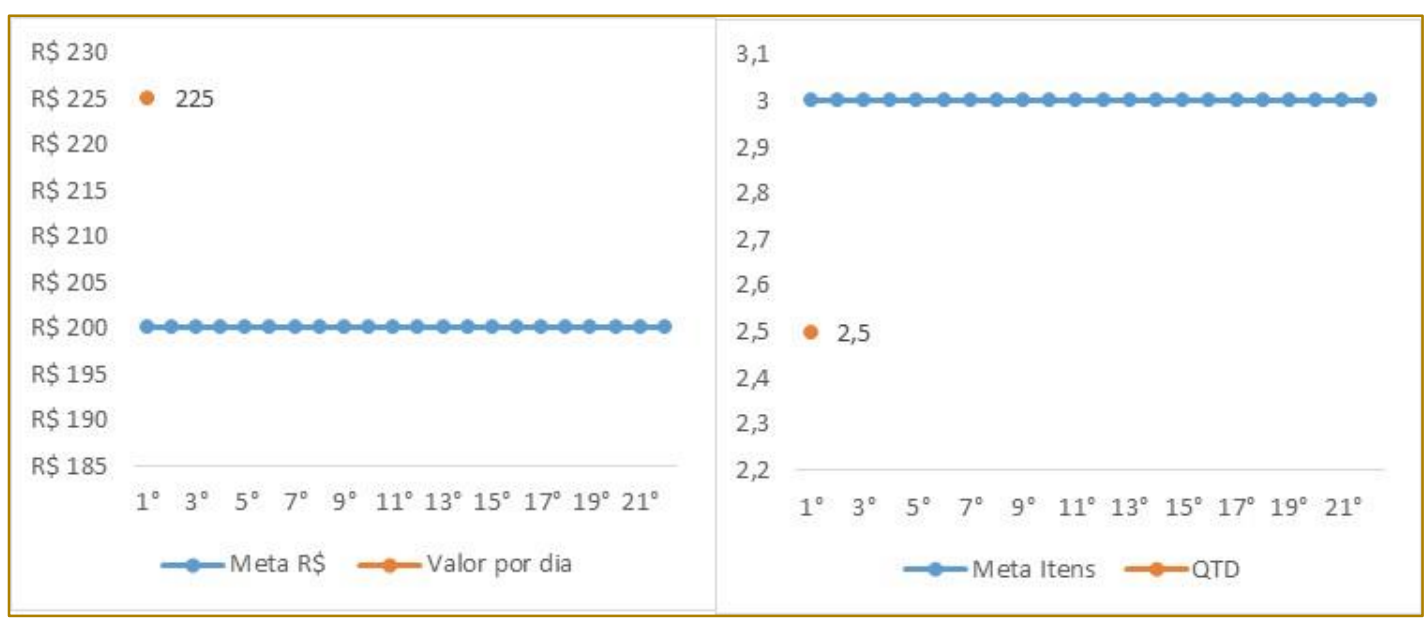

Fonte: Elaborada pelos autores.

Pelo acompanhamento dos níveis de produtividade individual, a promotora diz perceber diferença nos resultados entre um ciclo com produtos que ela domina 0 conhecimento sobre os itens e um ciclo que por algun motivo ela não pôde participar dos treinamentos, porque neste, ela não tem o conhecimento teórico para agumentar os beneficios dos produtos e associar a necessidade do cliente com 0 item. A entrevistada disse que somente não recebe os treinamentos quando está em férias que por direitos trabalhistas, ela deve se afastar de suas atividades laborais.

No fluxo apresentado no anexo, é possível observar os principais momentos em que a promotora coloca em prática todo o aprendizado absorvido durante os treinamento e assim, alcançar maior de produtividade nos indicacores de intens por boleto e boleto médio.

Os colaboradores da Perfumaria admiram o empenho e investimento sobre a capacitação e o desenvolvimento deles em um momento que o mercado e os clientes estão cada vez mais exigente de conhecimento. A promotora diz que os clientes têm cada vez mais o domínio das informações e já entram na loja sabendo exatamente o que procuram e se ela não domina as informações de seus produtos no mesmo nível ou maior que o domínio do cliente, ela tem a possibilidade muito grande de perder a venda, por que as informações repassadas em treinamento são informações corretas e as vezes a informação que o cliente trás de fora é apenas especulação.

\section{CONSIDERAÇÕES FINAIS}

Tamanha concorrência no mercado, têm feito com que as organizações encontrem formas de se manterem de maneira competitiva no mercado. Com a grande concorrência e a busca de um diferencial, o treinamento de pessoas é uma forma eficiente de adicionar valor, conhecimentos técnicos e específicos aos colaboradores, e desenvolver o capital humano.

Este artigo teve por objetivo falar sobre a influência do treinamento na melhoria de produtividade, a partir da multiplicação de conhecimentos dentro de uma organização, de maneira teórica ou prática com assuntos pontuais voltados para a necessidade do trabalhador com o objetivo de atingir as necessidades da empresa.

É fundamental que o treinamento seja um instrumento de grande influência nas organizações pois a patir desse metódo é possivel desenvolver as habilidades dos colaboradores de qualquer ambiente organizacional. O treinamento se tornou uma estratégia das organizações que vizam aumentar sua produtividade e alcançarem suas metas a partir da preparação e do desenvolvimento de capital humano.

Podemos observar no estudo de caso, que a empresa se empenha em viabilizar mecanismos e técnicas de treinamento como meio tático para a evolução dos colaboradores e por consequência obter maior produtividade. Assim, as operações realizadas têm em vista o desenvolvimento dos colaboradores oferecendo discernimento e capacitação, em consequência, a 
organização obtém crecimento produtivo, boa performance, atenuação de desperdícios e gastos, tudo isso por meio do emprego de treinamento para a força de trabalho.

A partir da curva de experiência proposta por Bethlem, 1999, verificamos a importância do treinamento para o desenvolvimento da produtividade. Apesar do trabalho ser qualitativo, o fluxograma (anexo), faz a associação entre no treinamento e a produtividade, ratificando a curva proposta por Bethlem, 1999, apresentando assim mais uma contribuição nesse contexto.

\section{REFERÊNCIAS}

[1] BECKER, G. S. Human capital a theoretical and empirical analysis, with special reference to education. New York: Columbia University Press, 1964.

\section{[2] BETHLEM,A. Estratégia}

Empresarial: Conceitos, Processo e Administração Estratégica. 2. ed. São Paulo: Atlas, 1999

[3] CERVO, A. L; BERVIAN, P. A; SILVA, R. Metodologia Científica. 6a Ed. São Paulo: Prentice Hall, 2007.

[4] CORREA, Henrique; CORREA, Carlos. Administração de Produções e Operações Manufatura e Serviços: Uma Abordagem Estrategica. 1aㅡ ed. São Paulo: Editora Atlas, 2004.

[5] COSTA, ANTÔNIO L. M. C. - A questão da produtividade. et. al. FLEURY, AFONSO C. C. \&

[6] HEINECK, Luiz F. M; Efeito Aprendizagem, Efeito Continuidade e Efeito Concentração no Aumento de Produtividade nas Alvenarias, 1991.

[7] MELLO, L. Uma avaliação do impacto do treinamento na produtividade do trabalho, 2009

[8] MERRIAM, S. B. Qualitative research and case study applications in education: revised and expanded from case study research in education. 2.ed. São Francisco-CA: Jossey-Bass Education Series and The Josey-Bass Higher Education Series, 1998.

[9] MILKOVICH, George T.; BOUDREAU, John W. Administração de Recursos Humanos. São Paulo: Atlas, 2010.

[10] MOTTA, V. Ideologias do capital humano e do capital social: da integração à inserção e ao conformismo, 2008
Logo, com todo o esboço, percebemos que o treinamento é um elemento que influência a produtividade, uma vez que para o colaborador, quanto maior for sua aptidão, capacidade e habilidades ao realizar determinada tarefa, maior é a sua eficiência e consequentemente sua produtividade.

Apesar do trabalho ter limitações quanto a abrangência, em virtude de ser um estudo de caso, de forma exploratória ele contribuiu para apresentar a importância do treinamento, seja comportamental, seja no sentido de produtividade.

[11] NOVAREJO, foco nos resultados ago. 2016. www.portalnovarejo.com.br, acesso em 01/06/2018.

[12] PONCHIROLLI, Osmar. O capital humano como elemento estratégico na economia da sociedade do conhecimento sob a perspectiva da teoria do agir comunicativo. 2000

[13] RITZMAN, L. P.; KRAJEWSKI, L. J. Administração da Produção e Operações. São Paulo: Prentice Hall, 2004.

[14] SANTOS, Évani Larisse. Ganhos de produtividade e qualidade na UFAM: Um estudo sobre a capacitação dos servidores. 2012

[15] SATT, Gabriella P. Motivação versus produtividade: O impacto do fator motivação na produtividade das organizações. 2012

[16] SLACK, N. et al. Administração da produção. São Paulo: Atlas, 2007

[17] TAYLOR, Frederick Winslow. Princípios de administração científica / Frederick Winslow Taylor: tradução de Arlindo Vieira Ramos. - 8. ed. - São Paulo: Atlas, 1990

[18] TEIXEIRA, Enise Barth. Educação continuada corporativa: aprendizagem e desenvolvimento humano no serto metal-mecânico. 2005

[19] VOLPE, Renata Araújo \& Lorusso, Carla Bittencourt. A importância do treinamento para o desenvolvimento do trabalho. Disponível em: www.psicologia.com.pt. Acesso em 06 /12/ 2016.

[20] WAINER, Jacques. O paradoxo da produtividade. 2002

[21] YIN, R. K. Estudo de caso: planejamento e métodos. Porto Alegre: Bookman, 2001. 
ANEXO A - INSTRUÇÕES COMPLEMENTARES

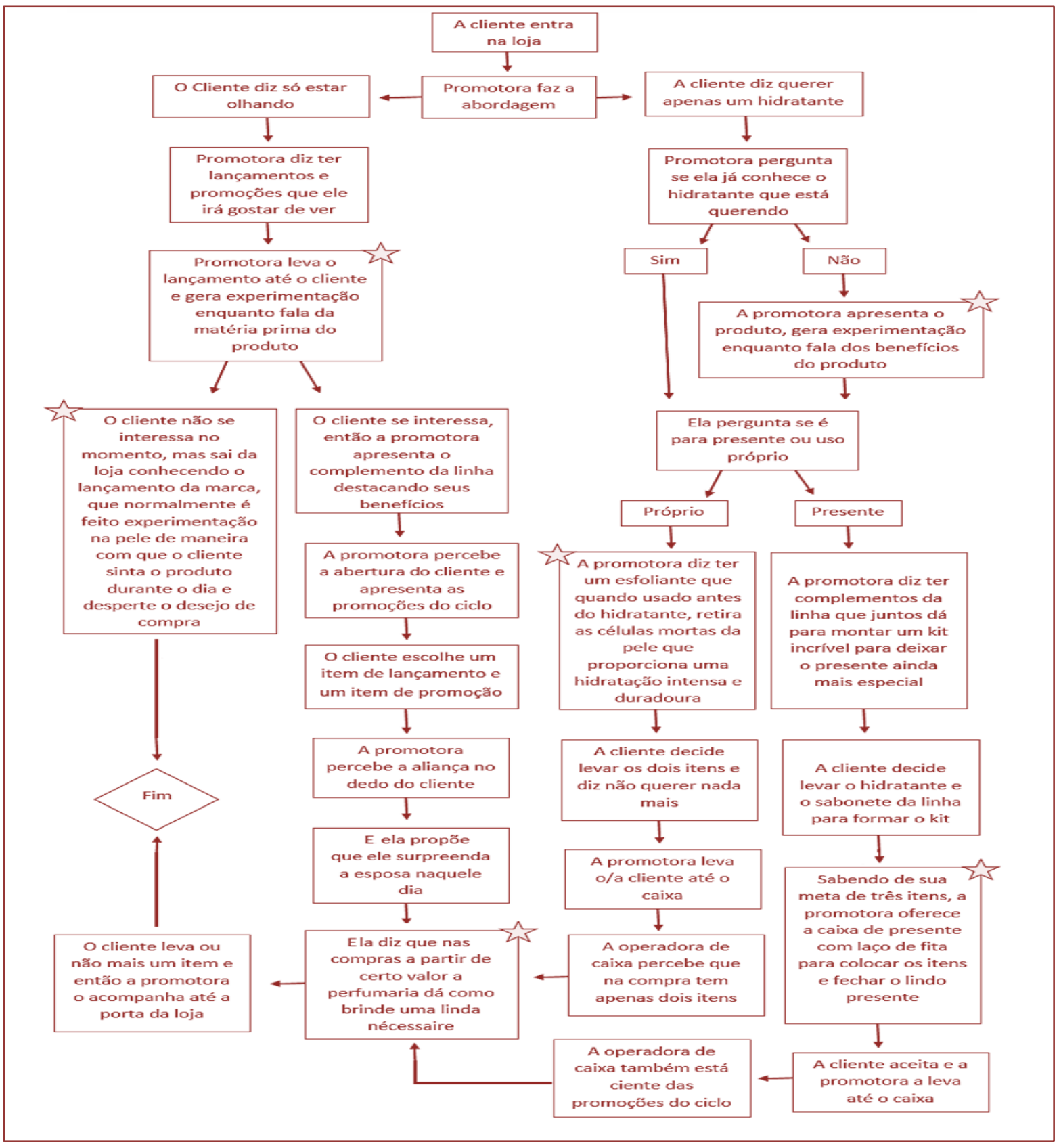




\title{
Gapítulo 15
}

\section{PROTOCOLO DE IDENTIFICACÃO DO PACIENTE: UMA PROPOSTA DE IMPLANTACẼO EM UMA MATERNIDADE PÚBLICA}

\author{
Hercules Guimarães Honorato
}

Maria Aparecida Campos de Azevedo

Resumo: O objetivo central deste estudo foi elaborar um Protocolo Operacional Padrão (POP) para identificação dos pacientes de um hospital de portas abertas genérico, que no caso em questão optou-se por ser do tipo "maternidade", em consonância com o Programa Nacional de Segurança do Paciente (PNSP). Este estudo é de caráter bibliográfico exploratório, com revisão documental das portarias, Resoluções da Direoria Colegiada (RDC) da Agência Nacional de Vigilância Sanitária (Anvisa). Na construção desse POP, apropriamo-nos de um protocolo em vigor de um grande hospital da rede particular da cidade do Rio de Janeiro. Minimizar ao máximo os eventos adversos em nossa atividade de assistência à saúde é de suma importância para a segurança do paciente. Eliminar a culpa e os erros com aumento da qualidade dos serviços é o caminho que se está procurando. O início desse processo de cultura da segurança foi em 2013 no Brasil com as portarias e resoluções do Ministério da Saúde com a instituição do PNSP. A estratégia de sua implantação estabeleceu, além dos seis protocolos básicos de Segurança do Paciente, a necessidade de formação do pessoal que comporá os Núcleos de Segurança do Paciente nas unidades hospitalares e estabelecimentos de saúde. O presente estudo procurou espelhar a importância do tema e em especial mostrar que a identificação do paciente é um dos principais fatores para agir como minimizador dos efeitos adversos em procedimentos que envolvem todos os profissionais, tanto da área da saude quando da administração. O paciente corretamente identificado é fator de qualidade em nossas práticas - assistências, ambulatoriais ou cirúrgicas - que deve ser uma prática indispensável para a garantia da segurança do paciente e seu acompanhante, em qualquer ambiente de cuidado à saúde. Na elaboração do POP a ser sugerido, alguns pontos importantes devem ser destacados para a excelência da identificação do paciente: (i) ser uma política do hospital; (ii) participação efetiva de todos os profissionais da instituição; (iii) formação continuada e divulgação da cultura de segurança e qualidade em saúde; (iv) gestão do risco pela análise dos indicadores estatístico da identificção; (v) ser uma voz única no trato do paciente e seu acompanhante; (vi) inclusão do paciente e seu acompanhante no verificação correta da sua identificação; e (vii) tratamento diferenciado aos diversos setores do hospital e necessidade de atendimento do paciente; (viii) preocupação necessária com a Unidade neonatal.

Palavras-chave: Hospital Maternidade. Identificação do paciente. Programa Nacional de Segurança do Paciente. Protocolo Operacional Padrão. 


\section{INTRODUÇÃO}

"Deixaram a janela aberta, e pela manhã todo o céu entrou por ela." (Federico Garcia Lorca).

O século XXI está marcado pela complexidade e ambivalência de toda a ordem e natureza, onde o imponderável é habitado na liquidez da globalização. Em todos os momentos de nossas vidas estamos à procura da qualidade, em especial a de vida. Numa sociedade que se deseja a excelência nos serviços e produtos de todas as modalidades, tipos e naturezas, o serviço público de saúde não pode ficar maculado por incidentes ou danos a clientes que poderão ocorrer em uma ou mais etapas da cadeia terapêutica.

Fato é que a questão da qualidade de vida associa-se quase de forma imediata à saúde, sendo um passo primordial para o planejamento e gestão dos serviços de saúde. Assim, "a procura pela equidade na saúde tem serviço de motor para o reforço da necessidade de medidas eficazes em nível global (com aplicação local) no sentido de amenizar o efeito que os determinantes da saúde podem ter nas populações" (CARRAPATO; CORREIA; GARCIA, 2017, p. 689).

Para termos de políticas públicas efetivas no nosso campo de atuação, se faz mister termos indicadores de desempenho que busquem identificar, obter informações e monitorar a ocorrência dos eventos adversos; que se ocorressem, induziriam a população ao descrédito no sistema de saúde, bem como no aumento dos custos da assistência hospitalar.

A segurança do paciente é um tema que vem ganhando uma amplitude mundial em sua discussão e em ações mais efetivas, mas que nem sempre foram acompanhadas por mudanças na forma como prestar esse atendimento pelos profissionais e gestores de saúde. "O cuidado à saúde, que antes era simples, menos efetivo e relativamente seguro, passou a ser mais complexo, mais efetivo, porém potencialmente perigoso" (CHANTLER 1999 apud BRASIL, 2014, p.6).

Assim exposto, o objetivo central deste estudo foi a elaboração de um Protocolo Operacional Padrão (POP) para identificação de clientes de um hospital maternidade de portas abertas genérico, em consonância com o Programa Nacional de Segurança do Paciente (PNSP). Foram também estipulados os seguintes objetivos específicos: verificar quais itens identificadores devem ser registrados nas pulseiras/crachás; identificar a frequência da utilização da identificação do cliente nos diversos setores da unidade hospitalar; e fomentar práticas de capacitação dos profissionais envolvidos na questão da segurança do paciente e em especial na verificação correta dos dados nas pulseiras de identificação.

Este estudo é de caráter bibliográfico exploratório, com revisão documental das portarias, Resoluções da Direoria Colegiada (RDC) da Agência Nacional de Vigilância Sanitária (Anvisa) e documentos internos da unidade hospitalar, tipo maternidade. A abrangência é de cunho qualitativo, por se tratar de um campo de investigação que atravessa temas, com uma ampla variedade de práticas interpretativas interligadas, com o escopo de compreender melhor o assunto que está sendo estudado (DENZIN; LINCOLN, 2010).

Acreditamos ser relevante em diversos aspectos ligados a minimização dos eventos adversos, bem como à construção do conhecimento e formação continuada dos profissionais envolvidos nos serviços de assistência direta ao cliente, e na qualidade, avaliação e segurança dos serviços de saúde.

\section{PRINCIPAIS CONCEITOS ENVOLVIDOS \\ 2.1 QUALIDADE EM SAÚDE}

Palavra polissêmica e de conceituação ampla, a "qualidade" se funde ao ideário de conhecimento, que já não se verifica pela simples manipulação do homem e da natureza como forças opostas. Segundo Bittar (2000, p.1), qualidade "é o grau no qual os serviços prestados ao cliente aumentam a probabilidade de resultados favoráveis que, em consequência, reduzem os desfavoráveis dado o presente estado da arte". Esse autor ainda afirma que a qualidade tem dois componentes básicos: o operacional, que o processo desenvolvido propriamente dito; e o de percepção, como os clientes e os prestadores de serviços em saúde se sentem na oferta do que fazem.

Quadrado e Tonchin (2012) citam Donabedian (1988) ao ratificarem que qualidade em saúde é um conjunto de atributos, como a excelência do profissional, do uso dos recursos com eficiência e com um mínimo de risco para o cliente, que culmina com um alto 
grau de satisfação por parte do usuário do sistema de saúde e sem esquecer os valores sociais existentes. Martins (2014, p.27) argumenta que a ideia de qualidade está "presente em todos os tipos de avaliação em saúde, cuja característica nuclear é fazer um juízo de valores, que, quando positivo, significa ter qualidade".

\subsection{SEGURANÇA DO CLIENTE}

O sujeito em questão, o cliente, é a "pessoa que recebe cuidado de saúde", sendo este conceituado como "serviços recebidos por indivíduos ou comunidades para promover, manter, monitorar ou restaurar a saúde" (REDE, 2010, p.9). Os clientes são referidos como clientes, preferencialmente a consumidores ou clientes. A segurança dele é um ponto crítico e um grande desafio da qualidade do cuidado em saúde. Vincent (2009 apud QUADRADO; TONCHIN, 2012, p. 2) a conceituam como

[...] o ato de evitar, prevenir e melhorar os resultados adversos, oriundos dos processos de assistência à saúde; a segurança reside nos sistemas e nas pessoas e, por isso, precisa ser ativamente procurada e estimulada, visando a redução de todos os tipos de erros, procurando a alta confiabilidade, como componente essencial de assistência em saúde.

Hoffmester e Moura (2015) afirmam que a segurança do cliente tem a finalidade precípua de reduzir ou minimizar os erros advindos da prática em saúde e ampliar o número de práticas seguras, buscando a difusão de uma cultura de segurança dos clientes com qualidade assistencial. O que poderíamos resumir o seu conceito para a redução, a um mínimo aceitável, do risco de dano desnecessário associado ao cuidado de saúde.

\subsection{IDENTIFICAÇÃO DO CLIENTE}

A identificação do cliente é uma prática indispensável para garantir a sua segurança em qualquer ambiente de cuidado à saúde (CONSELHO, 2010). Há necessidade de assegurar que todos os clientes tenham sua identificação adequada em todos os momentos de atendimento ou procedimento em uma unidade hospitalar, como garantia de minimizar os eventos adversos, em especial o de maior ocorrência relacionado à medicação (PORTO et al., 2011).

Segundo ainda Porto e outros (2011, p.68), para que o sistema seja eficaz na identificação do cliente, existem três funções primordiais que devem ser seguidas: fornecer a identificação desde o momento de sua admissão na unidade hospitalar; possuir um método visual e automatizado de vincular o cliente à sua documentação médica e terapêutica; e evitar que os dados de identificação de um cliente sejam transferidos para outro. Além do exposto, um planejamento adequado e cuidadoso para os processos de cuidado irão garantir a identificação de qualquer intervenção de saúde.

\subsection{EVENTOS ADVERSOS}

Eventos adversos (EA) são conceituados como complicações indesejadas decorrentes do cuidado prestado aos clientes, não atribuídas à evolução natural da doença de base. Gallotti (2004) afirma que o EA é um dos maiores desafios para o aprimoramento da qualidade na área da saúde, pois afeta, em média, 10\% das admissões hospitalares. "Incidente que resulta em dano à saúde" (BRASIL, 2013a, p.2).

Alguns fatores favorecem sobremaneira a ocorrência de EA, destacando-se, entre outros citados por Galloti (2014, grifo nosso): gravidade do quadro clínico inicial, a existência de comorbidades, a duração e a intensidade do cuidado prestado, a fragmentação da atenção à saúde, a inexperiência de jovens profissionais envolvidos no atendimento, a sobrecarga de trabalho e as falhas de comunicação. "O reconhecimento da real dimensão destes problemas representa uma oportunidade ímpar para o aprimoramento da segurança dos clientes" (GALLOTTI, 2004, p.114).

\subsection{A UNIDADE HOSPITALAR IDEALIZADA PARA ESTE ESTUDO}

A maternidade idealizada é uma instituição de médio porte que presta assistência a gestantes de riscos habitual, médio e alto gestacional e a recém-nascidos de médio e alto riscos. Com capacidade instalada de 100 leitos obstétricos e 50 leitos neonatais, conta ainda com serviço de admissão/emergência que realiza em média sugerida de 1500 
atendimentos/mês, resultando em aproximadamente 400 partos/mês e cerca de 200 outros procedimentos obstétricos em Centro Cirúrgico Obstétrico. A demanda ambulatorial atinge em média 2000 consultas /mês.

Em sua estrutura completa, a maternidade em estudo está dividida em cinco grandes setores: Ambulatório, Emergência, Internação, Centro Cirúrgico Obstétrico (CCO) e Unidade Neonatal (UNEO). Contando, claro, para seu pleno funcionamento com a Administração e os demais serviços de apoio, como: Farmácia, Serviço Social, Laboratório, Hemoterapia, Anatomia Patológica, Nutrição e Diagnósticos por Imagem (Raios X e Ultrassonografia). Tais setores apresentam, dentro de suas especificidades, diferentes graus de complexidade e riscos para eventos adversos.

\section{REFERENCIAL TEÓRICO}

A Aliança Mundial pela Segurança do Cliente, criada em 2004 pela Organização Mundial da Saúde (OMS), tem a missão de coordenar, disseminar e acelerar melhorias para a segurança do cliente em termos mundiais. São previstas, atualmente, quatorze áreas prioritárias para a segurança do cliente, onde podemos verificar a necessidade de uma correta e eficiente atenção devido àquele que procura uma unidade de saúde, em especial e com certeza, pública. Podemos apresentar algumas áreas ligadas ao escopo deste estudo:

- Promover comunicação adequada durante a transferência de responsabilidade do cliente;

- Realizar o procedimento correto na parte correta do corpo;

- Garantir a adequação da medicação em todo o processo de cuidado:

- Usar uma única vez dispositivo para injeção;

- Melhorar a higiene das mãos para prevenir infecções associadas ao cuidado de saúde;

- Prevenir queda do cliente;

- Prevenir úlcera de pressão;

No Brasil foi instituído, em 01 de abril de 2013, pela Portaria MS/GM no 529 do Ministério da Saúde e com o apoio da Agência Nacional de
Vigilância Sanitária (Anvisa) o Programa Nacional de Segurança do Cliente (PNSP) (BRASIL, 2013a), que tem como objetivo o de prevenir e reduzir a incidência de eventos adversos nos serviços de saúde públicos e privados. A ação em questão prevê a utilização de seis protocolos que funcionam como guias e normas que devem ser utilizados nos hospitais e também as práticas mais recomendadas para manter a segurança ao cliente.

Segundo o seu Documento de Referência (BRASIL, 2014, p.15), o PNSP tem quatro eixos: "O estímulo a uma prática assistencial segura; o envolvimento do cidadão na sua seguranca; a inclusão do tema no ensino; e o incremento de pesquisa sobre o tema". Assim, neste trabalho de conclusão de curso, podemos verificar os eixos da pesquisa e ensino sendo amplificados na temática de segurança do cliente. Um ponto importante deve ser bem realçado e é de extrema importância em relação a esse programa, que a cultura de segurança do cliente é elemento que perpassa todos os eixos citados anteriormente.

A Portaria MS/GM no 529/2013 estabelece que um conjunto de protocolos básicos, definidos pela Organização Mundial de Saúde (OMS), que devem ser elaborados e implantados nos estabelecimentos de saúde, como: a prática de higiene das mãos; cirurgia segura; segurança na prescric,ão, uso e administrac,ão de medicamentos; identificacâão de clientes; melhorar a comunicação entre os profissionais de saúde; prevencão de quedas; úlceras por pressão; transferência de clientes entre pontos de cuidado; e uso seguro de equipamentos e materiais (BRASIL, 2013a, grifo nosso). Foi destacado o protocolo grifado, pois foi o desenvolvido neste estudo.

A Portaria em questão e a RDC no 36/2013 da Anvisa (BRASIL, 2013c) determinaram a criação dos Núcleos de Segurança do Cliente (NSP) nas unidades hospitalares e estabelecimentos de saúde para promoverem e apoiarem a implementac,ão de iniciativas voltadas à segurança do cliente. Os núcleos hospitalares devem ser vinculados "organicamente à direc,ão e ter uma agenda permanente e periódica com a direc,ão geral, a direcão técnica/médica e a coordenac,ão de Enfermagem, e participar de reuniões com as demais instancias que gerenciam aspectos da qualidade" (BRASIL, 2014, p.22). 
A RDC citada, em seu art. 8o, estabelece o Plano de Segurança do Cliente em Serviços de Saúde (PSP), que deverá ser elaborado pelo NSP. O plano deve estabelecer estratégias e ações de gestão de risco. Foram estipuladas atividades que deverão ser desenvolvidas pelo serviço de saúde, entre as dezesete elencadas está a quarta, que trata da identificação do cliente.

No caso deste estudo, o protocolo de Identificação do Cliente foi aprovado pela Portaria no 2095, de 24 de setembro de 2013 (BRASIL, 2013b). O parágrafo único do art. 10 determina que os protocolos "visam instituir ações para a segurança do cliente em serviços de saúde e a melhoria da qualidade em caráter nacional. Devem ser utilizados em todas as unidades de saúde do Brasil, podendo ser ajustados a cada realidade."

\section{RESULTADO E DISCUSSÕES}

O objetivo deste estudo foi a elaboração de um POP para identificação dos clientes de um hospital maternidade de portas abertas tipo, em consonância com o Programa Nacional de Segurança do Paciente (PNSP). A base estruturante do presente trabalho foi $O$ Protocolo de Identificação do Paciente, que consta do Apêndice A do PNSP, e que tem por finalidade "garantir a correta identificação do paciente, a fim de reduzir a ocorrência de incidentes. O processo de identificação do paciente deve assegurar que o cuidado seja prestado à pessoa para a qual se destina" (BRASIL, 2013b, p.1).

Antes da apresentação deste POP, a OMS em seu documento que trata da Identificação do paciente, estabelece três estratégicas básicas para a sua elaboração (WHO, 2007, grifos nossos), que em suma denotam o uso de sistemas de identificação, a incorporação de treinamento do pessoal envolvido na atividade, e apresentar ao cliente a necessidade de também participar desse processo. A seguir estão listadas essas estratégicas em tradução livre do autor:

1. Assegurar que as organizações de cuidado de saúde tenham sistemas que:

a) Enfatizam a responsabilidade primária dos trabalhadores de cuidado a saude para checarem a identificação dos pacientes e conectarem os pacientes ao seu correto cuidado médico (ex. resultados laboratoriais, procedimentos médicos, espécimes) antes que esse cuidado seja administrado. b) Encorajem o uso de pelo menos dois identificadores (ex. Nome e data de nascimento) para verificar a identidade do paciente antes de sua admissão e transferência para outro hospital ou ala de cuidado e antes da administração dos cuidados médicos. Nenhum desses identificadores deve ser o número do quarto do paciente.

c) Padronizar a abordagem de identificação do paciente entre as diferentes alas médicas de um sistema de cuidado de saúde. Por exemplo, uso de identificadores brancos nos quais existe um padrão em que podem ser escritas informações específicas (ex. nome e data de nascimento), ou implementação de tecnologia biométrica.

d) Providenciar protocolos claros para identificação dos pacientes que não tenham identidade e para distinguir pacientes com o mesmo nome. Abordagens não-verbais para identificação de pacientes inconscientes ou confusos deve ser desenvolvida e utilizada.

e) Encorajar os pacientes a participarem em todas as etapas do processo.

f) Encorajar a marcação dos recipentes utilizados para sangue e outros espécimes na presença do paciente.

g) Providenciar protocolos claros para manter a identificação das amostras dos pacientes durante o processo pré-analítico, analítico e pós-analítico.

h) Providenciar protocolos claros para questionamento dos resultados laboratoriais e outros achados quando eles não são consistentes com o histórico clínico do paciente.

i) Providenciar a conferência repetitiva e revisão em vias de prevenir uma multiplicação automática de um erro de entrada em computador.

2. Incorporar treinamento nos procedimentos de checagem/verificação da identidade do paciente na orientação e desenvolvimento contínuo profissional dos trabalhadores dos sistemas de saúde.

3. Educar pacientes na importância e relevância da correta identificação do paciente de maneira positiva e que também respeite os intereses de privacidade.

\subsection{O POP DE UM HOSPITAL AVALIADO}


O Protocolo Operacional Padrão do hospital, cujo título é "Identificação correta e segura dos pacientes no Hospital", e está em vigor desde 2009, em sua segunda revisão de setembro de 2013, com vigência de três anos. A equipe que elaborou, revisou e aprovou este POP era composta por profissionais, integrantes da coordenação médica e de enfermagem, da seção de Qualidade da instituição.

Objetiva definir e normatizar a identificação dos pacientes atendidos no Setor de Emergência do hospital e dos pacientes admitidos como internados na Instituição. Consta os setores da unidade que estão envolvidos com a identificação do paciente, ou seja: as unidades assistenciais, o setor de internação, a própria recepção, o laboratório e a radiologia. Um ponto importante a destacar são os serviços que estão envolvidos para a correta identificação do paciente, como os serviços assistenciais e administrativos, principalmente no suporte logístico tanto do material de identificação como na instrução dos setores.

A partir deste ponto a norma estabelece a política da unidade em relação a correta identificação do paciente, como uma forma única de conhecimento para que todos os interessados e usuários possam comprrender os procedimentos a serem utilizados. Ao começar o documento é bem claro e não deixa dúvidas: "Todo paciente que receber cuidado na Emergência ou ao ser admitido na Instituição receberá identificação através de pulseira ou crachá". Assim exposto, qualquer um indivíduo não identificado deve ser questionado sobre sua situação de trânsito interno no hospital.

A identificação deverá constar dos seguintes dados: nome completo, data de nascimento e registro hospitalar. No caso de uma unidade maternidade com Unidade Neonatal, onde existe uma possibilidade maior de eventos adversos resultantes de nomes semelhantes e número de registros hospitalares. Segundo Quadrado e Tonchin (2012), existe a necessidade de três pulseiras identificadoras no recém-nascido, todas com o nome da mãe, duas seriam colocadas nos membros superiores e uma no membro inferior.

A partir desse momento são discriminados os tipos de pacientes e a modalidade para sua identificação. Por exemplo: pacientes admitidos no hospital: pulseira azul no punho direito. Em situações específicas também são categorizados por cores, como o paciente que usa de medicamento de alto risco, como anticoagulantes ou com propriedades anticoagulantes, o uso será de pulseira amarela no punho esquerdo. Existe também prevista a situação em que o paciente recusa a identificação, neste caso o chefe do setor ou o próprio diretor do hospital decidirá, pois implica em grave falha de segurança.

A última parte do POP estudado trata dos procedimentos administrativos e funcionais para os setores envolvidos, como a elaboração do crachá ou pulseira de identificação; reposição de pulseira ou crachá; solicitações de exames de imagem e laboratoriais; tranfusões sanguíneas; centro cirúrgico; e administração de medicamentos. Neste último caso, que tem a maior probabilidade dos eventos adversos, é deixado claro no documento que antes da adminsitração do medicamento, o técnico de enfermagem ou enfermeiro perguntará NOME COMPLETO e DATA DE NASCIMENTO ao cliente, familiar ou responsável legal e confirmará na pulseira.

Importante ressaltar que em contato com a responsável pelo setor de qualidade do hospital em questão, foi-nos passado também a existência de aula, que é disponibilizada por rede interna de computadores sobre o tema de segurança do cliente e mais espcificamente do protocolo de identificação correta da cliente. 
Figura 1 - Locais destinados as pulseiras

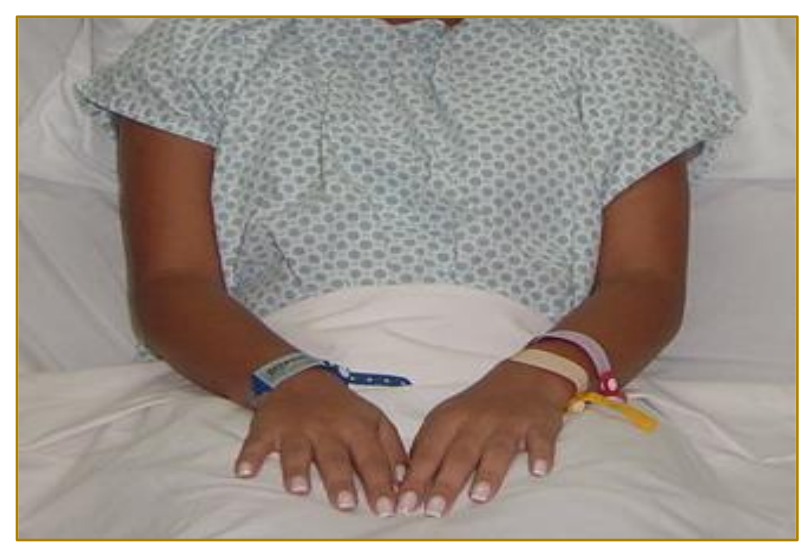

Fonte: Apresentação de aula.

\subsection{O PROTOCOLO DE IDENTIFICAÇÃO DO PACIENTE DO PNSP}

O documento do MS/anvisa é bem extenso e completo, abarcando todos os aspectos importantes no trâmite da identificação correta do cliente em uma unidade hospitalar ou estabelecimento de saúde de qualquer porte ou atuação específica. A sua justificativa é clara e direta: "A identificação correta do paciente é o processo pelo qual se assegura ao paciente que a ele é destinado determinado tipo de procedimento ou tratamento, prevenindo a ocorrência de erros e enganos que o possam lesar" (BRASIL, 2013a, p.1).

Ao iniciarmos o processo de implantação do PSP do nossa unidade, tínhamos a noção da importância dos protocolos. No caso em estudo, a identificação do cliente tem sua abrangência na aplicação em todos os ambientes de prestação do cuidado de saúde (por exemplo, unidades de internação, ambulatório, salas de emergência, centro cirúrgico) em que sejam realizados procedimentos, quer terapêuticos, quer diagnósticos. O que ratifica a importância da escolha por iniciarmos por este protocolo, visto que na maternidade-tipo existiria uma internação, um ambulatório, uma UNEO e um centro cirúrgico, que receberiam diversos interessados no trânsito interno, desde clientes a acompanhantes.

O item quatro do protocolo básico prevê as diversas intervenções necessárias a qualidade da identificação do paciente. Logo no início determina que para a correta identificação, pelo menos dois identificadores em pulseira branca padronizada, cuja
Figura 2 - Exemplo da pulseira identificadores

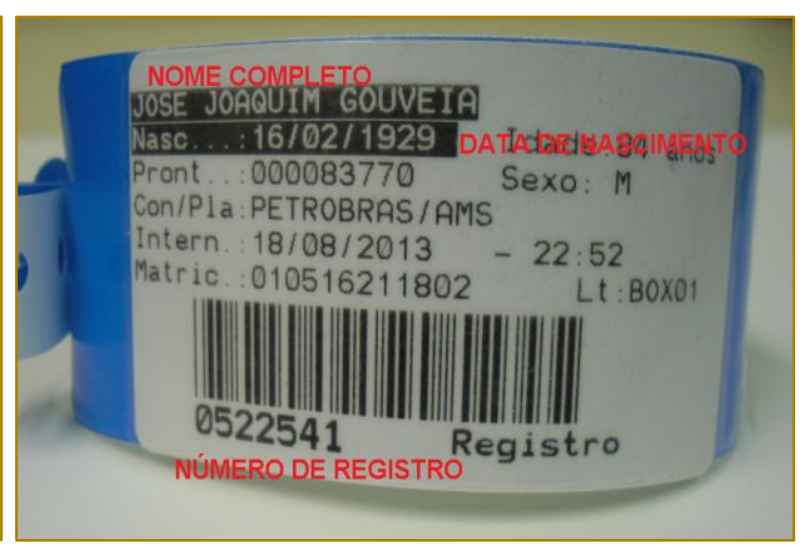

Fonte: Apresentação de aula.

especificação consta do Apêndice a este protocolo. Em geral, o local escolhido para o adulto é "o punho, mas, para recém-nascidos, a pulseira deve ser colocada preferencialmente no tornozelo. Nos casos em que não haverá possibilidade do uso em adultos em membros superiores, indicar o uso em membros inferiores" (BRASIL, 2013a, p.2).

Um ponto importante e que não fez parte do POP do hospital analisado, mas consta do protocolo padrão e das estratégias da OMS descritas anteriormente, é educar o paciente/acompanhante/familiar/cuidador,

para que se envolvam no processo de identificação correta. Para que isso ocorra com eficácia, é necessário que sejam explicados os propósitos dos dois identificadores da pulseira e que a conferência da identificação seja obrigatória antes do cuidado a realizar.

O último item da intervenção é a confirmação da identificação do cliente antes do cuidado. Como destacado também no POP estudado, reitera-se a orientação principalmente na administração de medicamentos, do sangue e de hemoderivados, da coleta de material para exame, da entrega da dieta e da realização de procedimentos invasivos.

O item cinco do protocolo base do MS trata dos procedimentos operacionais, onde são destaque a identificação do paciente e a confirmação de sua identificação, esta já comentada no parágrafo anterior. Nas definicões institucionais a unidade deve definir pelo menos um funcionário preferencial para a colocação de pulseiras como dispositivo de identificação, visto que poderia 
haver um rodízio funcional daqueles que trabalham com essa função.

$\mathrm{Na}$ escolha de no mínimo dois indicadores, utilizar o nome completo do cliente, da mãe, a data de nascimento ou o número de prontuário. No hospital estudado, são necessários três identificadores obrigatórios, sem escolha dos mesmos. Independente do custo de máquina que emita as etiquetas, é previsto que o registro possa ser manuscrito, com boa caligrafia, que não cause dúvidas para a correta identificação do cliente, sem abreviação.

Um fator de evento adverso na identificação pode ocorrer na transferência do cliente para outro serviço de saúde. No caso, um identificador adicional pode ser incluído, constando seu endereço, "para refinar a exatidão da identificação, devido a não transferência do número do prontuário entre os serviços de saúde. O mesmo deve ocorrer quando a transferência for entre o serviço de ambulância e um serviço de saúde" (BRASIL, 2013a, p.4).

É determinado e encarado como importante que o número do quarto/enfermaria/leito do cliente não pode ser usado como um identificador, em função do risco de trocas no decorrer da estada no serviço.

\subsection{O POP ELABORADO PARA O HOSPITAL MATERNIDADE TIPO}

A elaboração do protocolo para identificação correta e segura dos clientes do hospital estudado teve como base o protocolo de identificação do paciente do Programa Nacional de Segurança do Paciente, anexo 02 da Portaria no 2095/2013 (BRASIL, 2013a). Foram utilizadas também a análise realizada no documento recebido de um hospital de grande porte da cidade do Rio de Janeiro, que significou uma verificação do que está sendo aplicado com eficiência na área de saúde.

Importante destacar que o referencial teórico levantado para o estudo em tela foi significativo para a melhoria da qualidade do que foi construído como POP para identificação correta. Assim, contamos ainda com o artigo de Quadrado e Tronchin (2012) cujo título é "Avaliação do protocolo de identificação de um hospital privado", e o documento da Organização Mundial de Saúde sobre identificação do paciente, que possibilitou, em certa medida, customizar o protocolo criado com as características de uma hospital maternidade com Unidade de Tratamento Intensivo Neonatal.

Os seguintes itens foram constituídos no protocolo proposto: objetivo, justificativa, abrangência, setores envolvidos, serviços envolvidos, política, procedimento operacional, indicadores, referências bibliográficas e vigência e validade. O POP que foi proposto consta do Apêndice A com seus itens e o que cada um significa na relação cliente versus hospital, para o início do procedimento com qualidade e segurança.

Para responder com qualidade e presteza em realção ao controle das pessoas que não são funcionárias, a ideia foi utilizarmos dois tipos de identificação em função dos custos envolvidos: a etiqueta autoadesiva para clientes externos e todos os acompanhentes e a pulseira identificadora para as que forem internar para o procedimento cirúrgico e no caso do neonatal as três pulseiras, customizaçào necessária e imprescindível para evitarmos os efeitos adversos de uma unidade tão específica. 
Figura 3 - Pulseira de identificação para recémnascido com código de barras

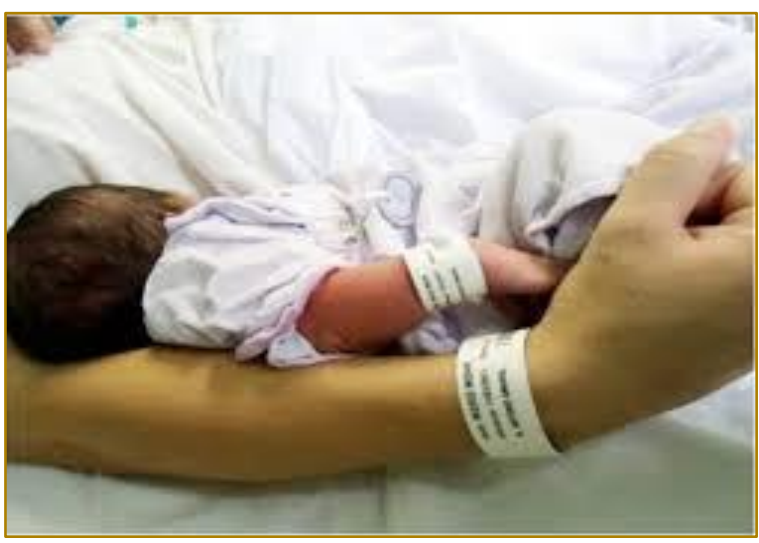

Fonte: Disponível em:

http://www.revistahospitaisbrasil.com.br. Acesso em: 04 ago. 2017.

O Apêndice ao protocolo padrão do MS especifica a cor, o tamanho, o conforto, as facilidades de uso e o registro dos identificadores do paciente. Em relação a cor, a pulseira deve ser branca, contra-indicando as pulseiras coloridas de alerta ou etiquetas "não devem ser utilizadas como identificadoras do paciente, devido ao aumento dos riscos de erros de identificação" (BRASIL, 2013a, p.7). No caso da alergia opta-se pela cor vermelha e para usuárias de medicamento de alto risco a amarela. Esperase que com essa diferenciação, possam ser minimizados os eventos adversos.

\section{CONSIDERAÇÕES FINAIS}

Minimizar ao máximo os eventos adversos na atividade de assistência à saúde é de suma importância para a segurança do cliente. Eliminar a culpa e os erros com aumento a qualidade dos nossos serviços é o caminho que se está procurando. Tudo isso, porém, exigem encarar desafios e enfrentar barreiras nas unidades hospitalares e estabelecimentos de saúde, por intermédios de medidas que tenham como elos os profissionais engajados diretamente ou não no atendimento/procedimento ao cliente.

O início desse processo de cultura da segurança foi em 2013 no Brasil com as portarias e resoluções do Ministério da Saúde com a instituição do Programa Nacional de Segurança do Paciente. A estratégia de sua implantação estabeleceu, além dos seis protocolos básicos de Segurança do Paciente, a necessidade de formação do
Figura 4 - Pulseira de identificação para recémnascido escrita

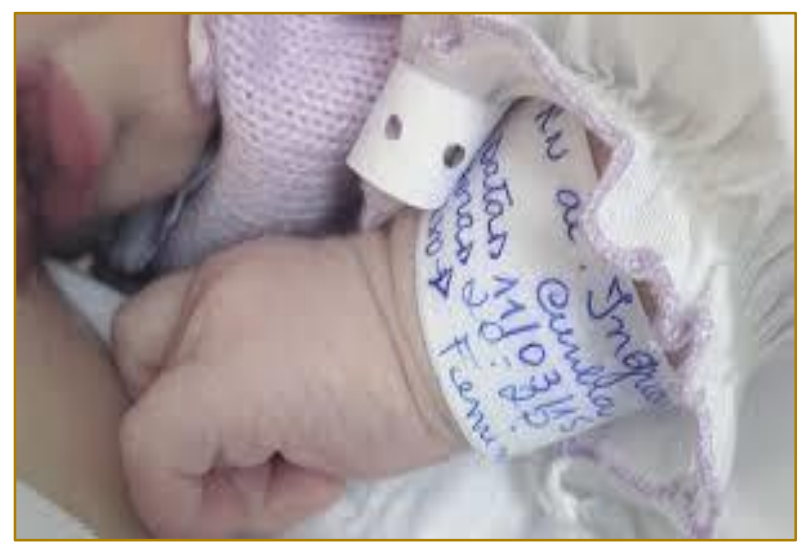

Fonte: Disponível em:

$<$ http://sesentindomae.blogspot.com.br>. Acesso em: 04 ago. 2017.

pessoal para compor os Núcleos de Segurança do Paciente nas unidades hospitalares e estabelecimentos de saúde. E, assim, chegamos ao Curso Internacional de Qualidade em Saúde e Segurança do Paciente como futuros multiplicadores do que nos foi ensinado no trato da excelência do serviço público em relação aos clientes.

O presente estudo procurou espelhar a importância do tema e em especial mostrar que a identificação do cliente é um dos principais fatores para agir como minimizador dos efeitos adversos em procedimentos que envolvem todos os profissionais, tanto da área da saúde quando da administração. O cliente corretamente identificado é fator de qualidade em nossas práticas - assistências, ambulatoriais ou cirúrgicas - que deve ser uma prática indispensável para a garantia da segurança do cliente e seu acompanhante, em qualquer ambiente de cuidado à saúde.

$\mathrm{Na}$ elaboração do Protocolo Operacional Padrão a ser sugerido ao Núcleo de Segurança do Paciente do hospital maternidade tipo, alguns pontos importantes devem ser destacados para a excelência da identificação: (i) ser uma política do hospital; (ii) participação efetiva de todos os profissionais da instituição; (iii) formação continuada e divulgação da cultura de segurança e qualidade em saúde; (iv) gestão do risco pela análise dos indicadores estatístico da identificação; (v) ser uma voz única no trato do cliente e seu acompanhante; (vi) inclusão do cliente e seu acompanhante no verificação correta da sua identificação; e (vii) tratamento diferenciado aos diversos 
setores do hospital e necessidade de atendimento do cliente; (viii) preocupação necessária com a Unidade neonatal.

Este POP é o primeiro. Estamos também no início dos nossos trabalhos. O desafio é grande, mas precisamos de forma urgente multiplicar na instituição a qualidade em saúde e segurança do cliente, aspectos que levamos a sério no nosso dia a dia de trabalho

\section{REFERÊNCIAS}

[1] BITTAR, O. J. N. V. Gestão de processos e certificação para qualidade em saúde. Rev da Associação Médica Brasileira.; v.1, n.1, p.1-10, jan./mar. 2000. Disponível em: <http://www.scielo.br/scielo.php?script=sci_arttext \&pid $=$ S010442302000000100011 >. Acesso em: 29 ago. 2017.

[2] BRASIL. Ministério da Saúde. Documento de Referência para o Programa Nacional de Segurança do Cliente. Brasília, DF: Ministério da Saúde; 2014. Sistema de legislação da Saúde. Disponível em: <http://bvsms.saude.gov.br/bvs/publicacoes/docu mento_referencia_programa_nacional_seguranca.p df>. Acesso em: 29 ago. 2017.

[3] BRASIL. Ministério da Saúde. Portaria $n^{\circ}$ 529, de 10 de abril de 2013, institui o Programa Nacional de Segurança do Cliente (PNSP). Brasília, DF: Ministério da Saúde; 2013a. Sistema de legislação da Saúde. Disponível em: <http://bvsms.saude.gov.br/bvs/saudelegis/gm/201 3/prt0529_01_04_2013.html>. Acesso em: 12 ago. 2017

[4] Portaria no 2.095 , de 24 de setembro de 2013. Aprova os Protocolos Básicos de Segurança do Cliente. Brasília, DF: Ministério da Saúde; 2013b. Sistema de legislação da Saúde. Disponível em: <http://bvsms.saude.gov.br/bvs/saudelegis/gm/201 3/prt0529_01_04_2013.html>. Acesso em: 12 ago. 2017.

[5] Agência Nacional de Vigilância Sanitária. RDC oㅡ. 36, de 25 de julho de 2013. Institui ações para a segurança do cliente em serviços de saúde e dá outras providências. Brasília, DF: Anvisa; 2013c. Sistema de legislação da Saúde. Disponível em: <http://bvsms.saude.gov.br/bvs/saudelegis/anvisa/ 2013/rdc0036_25_07_2013.html>. Acesso em: 25 ago. 2017

[6] CARRAPATO, P.; CORREIA, P.; GARCIA, B. Determinante da saúde no Brasil: a procura da equidade na saúde. Saude soc., São Paulo, v. 26, n. 3, p. 676-689, set. 2017. Disponível em <http://www.scielo.br/scielo.php?script=sci_arttext \&pid=S010412902017000300676\&lng=pt\&nrm=iso em prol de uma sociedade que procura cada vez mais o melhor em saúde pública. A autora, médica há 30 anos, expressando sua vocação, retrata parte do seu juramento, que muito significa no tratamento e segurança dos seus clientes: "[...] Exercerei a minha arte com consciência e dignidade. A Saúde do meu Doente será a minha primeira preocupação $[\ldots] "$.

$>$.

Acesso

em: 18 maio 2018. http://dx.doi.org/10.1590/s010 4-12902017170304.

[7] CONSELHO Regional de Enfermagem do Estado de São Paulo (COREN-SP). 10 passos para a segurança do cliente. Rede Brasileira de enfermagem do Cliente (Polo São Paulo). São Paulo: Coren-SP, 2010. Disponível em: <http://www.corensp.gov.br/sites/default/files/10_p assos_seguranca_cliente_0.pdf>. Acesso em: 21 abril 2017

[8] DENZIN, N. K.; LINCOLN, Y. S. O planejamento da pesquisa qualitativa: teorias e abordagens. 2. ed. Tradução Sandra Regina Netz. Porto Alegre: Artmed, 2006.

[9] GALLOTTI, R. M. D. Eventos adversos: o que são? Rev Assoc Med Bras, v.50, n.2, p.114, 2004.

[10] HOFFMEISTER, L.V.; MOURA, G. M. S. S. Uso de pulseiras de identificação em clientes internados em hospital universitário. Rev LatinoAmericana de Enfermagem; v.23, n.1, p.1-6, 2015. Disponível

em:<http://www.scielo.br/scielo.php?pid=S010411692015000100036\&script=sci_arttext\&tlng=pt $>$. Acesso em: 29 ago. 2017.

[11] MARTINS, M. Qualidade do cuidado em saúde. In: SOUSA, P.; MENDES, W (Org.). Segurança do cliente: conhecendo os riscos nas organizações de saúde. Rio de Janeiro: EAD/ENSP, 2014.

[12] PORTO, T. P. et al. Identificação do cliente em unidade pediátrica: uma questão de segurança. Rev Soc Bras Enferm Ped., v.11, n.2, p.67-74, 2011. Disponível em: <ponent/zine/article/142-identificao-do-cliente-emunidade-peditrica-uma-questo-de-segurana.html> . Acesso em: 29 ago. 2017.

[13] QUADRADO, E. R. S.; TRONCHIN, D. M. R. Avaliação do protocolo de identificação do neonato de um hospital privado. Rev LatinoAmericana de Enfermagem, v.20, n.4, p.18,jul./ago,2012. Disponível em: <http://www.scielo.br/scielo.php?pid=S0104- 
$11692012000400005 \&$ script $=$ sci_arttext $\&$ tlng $=$ pt $>$. Acesso em: 29 ago. 2017.

[14] REDE Brasileira de Enfermagem e Segurança do Cliente (REBRAENS). Estratégias para a segurança do cliente: manual para profissionais da saúde / Rede Brasileira de
Enfermagem e Segurança do Cliente. Porto Alegre: EDIPUCRS, 2013.

[15] WORLD Health Organization (WHO). Patient Identification. Patient Safety Solutions,v.1, n.2, 2007.Disponível em: $<$ http://www.who.int/patientsafety/solutions/patients afety/PS-Solution2.pdf>.Acesso em: 27 ago. 2015. 
APÊNDICE A

Protocolo Operacional Padrão

POP-HMXYZ-001/2015 Identificação correta e segura dos clientes no Hospital Maternidade XYZ

\section{OBJETIVO}

Definir e normatizara correta identificação dos clientes atendidos e dos que são admitidos como internados na Instituição, como pré-requisito para assegurar que o cuidado seja prestado à pessoa para a qual se destina.

\section{JUSTIFICATIVA}

A correta identificação do cliente é o processo pelo qual se assegura ao cliente que a ele, e somente a ele, é destinado determinado procedimento ou tratamento, prevenindo a ocorrências de erros e enganos que possam gerar danos, garantindo assim a qualidade e segurança da assistência.

\section{ABRANGÊNCIA}

O POP deverá ser aplicado em todos os ambientes de prestação do cuidado de saúde em que sejam realizados procedimentos terapêuticos, ambulatoriais, cirúrgicos, diagnósticos ou internação.

\section{SETORES ENVOLVIDOS}

Unidades assistenciais/ambulatoriais, setor de internação, recepção, laboratório, centro cirúrgico obstétrico, Unidade Neonatal (UNEO), farmácia e radiologia.

\section{SERVIÇOS ENVOLVIDOS}

Serviços assistenciais/ambulatorias, cirúrgico, anestesiológicos e administrativos.

\section{POLÍTICA}

Todo cliente que receber cuidado na Emergência ou ao ser admitido na Instituição deve receber à identificação através de pulseira ou crachá adesivo de identificação. Tal identificação constará, obrigatoriamente, dos seguintes identificadores:

1. Nome completo;

2. Data de nascimento; e

3. Registro hospitalar.

O recém-nascido deverá possuir, obrigatoriamente, três pulseiras, todas com os seguintes indicadores:

1. Nome completo da mãe;

2. Data de nascimento; e

3. Registro hospitalar.

Como medida de segurança e controle da entrada e saída da pessoa que for acompanhar o cliente, esta deverá ser identificada por intermédio de um crachá adesivo que constará, obrigatoriamente, os seguintes indicadores:

1. Nomecompleto;

2. Nome completo do cliente que está acompanhando; e 
3. Setor do HMCD que acompanhará o cliente.

Clientes atendidos no ambulatório/consultas de pré-natal: crachá de identificação adesivo (fixado no peito).

Clientes atendidos na Emergência: ao serem encaminhados para o repouso ou ao serem atendidos na sala de trauma, receberão pulseira que conterá os identificadores acima descritos. Esta pulseira terá a cor branca recebida durante o procedimento de admissão e será colocada no membro superior direito ou tornozelo direito. O crachá adesivo de identificação será utilizado pelo responsável/acompanhante que estiver acompanhando a cliente.

Recém-Natos da UNEO: três pulseiras brancas com os indicadores obrigatórios, colocadas nos membros superiores e no tornozelo. Casos especiais: o serviço de saúde deve definir como identificar clientes que não possam utilizar a pulseira, como uma má formação congênica.

Clientes portadoras de deficiência física (por exemplo, amputados): colocar a pulseira azul de identificação, no membro contralateral, ou, se necessário, nos membros inferiores. No caso raro de uma cliente não possuir condições adequadas para a permanência da identificação nos membros, optar-se-á por colocar um crachá adesivo.

No caso de manifestação de alergias às pulseiras de identificação por parte do cliente internado: optar-se-á pelo crachá adesivo.

Clientes admitidos em coma ou com diminuição do nível da consciência e sem documentos ou acompanhantes que o identifiquem nominalmente, serão cadastrados no setor de Emergência como:

Para homens de qualquer idade ou raça: JOÃO 1

Para mulheres de qualquer idade ou raça: MARIA 1

Caso sejam admitidos mais de um cliente inconsciente na mesma data, serão registrados como JOÃO 2 ou MARIA 2, e assim sucessivamente, por ordem de chegada no setor.

Caso o cliente seja identificado ao longo do seu atendimento, com dados oficiais, será corrigido o cadastro realizado anteriormente.

Situações de recusa da identificação pelo cliente: o caso será decidido pela Chefia do setor, onde encontra-se o cliente ou pelo Diretor do Hospital, pois implica em grave falha de segurança.

Identificações em situações específicas:

Alergia - pulseira vermelha no punho esquerdo - Será escrito na pulseira o material ou o medicamento que o cliente é alérgico. Nos casos de clientes portadores de necessidades especiais, segue o padrão descrito acima.

Para os casos em que o cliente seja alérgico a várias substâncias, medicamentos ou materiais, estes deverão estar listados e anexados ao prontuário médico. Na pulseira constará a palavra: "Diversos"

Medicamento de alto risco - medicamentos anticoagulantes ou com propriedades anticoagulantes pulseira amarela no punho esquerdo.

\section{PROCEDIMENTO OPERACIONAL}

Informação de caráter geral:

Ao receber o cliente, o profissional do setor envolvido deverá: saudar o cliente, informando o seu nome e a sua função; orientar e, se for o caso, tranquilizar o cliente, familiar, responsável legal ou acompanhante; perguntar ao cliente, NOME, DATA DE NASCIMENTO e confirmar na pulseira ou adesivo de identificação; por último conferir a identificação no prontuário ou na ficha registro, comparando-os. Em caso de discrepância, deverá ser reportado ao setor de análise de risco do hospital e registrado no livro ou sistema informatizado pertinente, a fim de compor a estatística de eventos adversos na identificação do cliente.

Elaboração do crachá adesivo de identificação ou pulseira de identificação: 
Ao ser preparada a ficha de atendimento ou o formulário de internação para a Admissão, é gerada a etiqueta de identificação do cliente que será colada ao crachá ou pulseira, passa a servir de identificação do cliente e será colocado no corpo (crachá) ou punho (pulseira) do cliente.

Reposição de pulseira ou crachá:

Nas situações de uso prolongado (ou não) que se observar dificuldade de leitura dos dados da pulseira ou crachá, o mesmo será trocado/reposto, quantas vezes forem necessárias.

Solicitações de exames de imagem e laboratoriais:

A etiqueta-padrão de identificação do Hospital será colocada no local padronizado do formulário de solicitação do exame solicitado.

Antes da realização do exame, a enfermeira confirmará o pedido junto ao médico. Imediatamente antes do exame, o técnico da radiologia e/ou o colhedor do laboratório perguntará ao cliente, familiar ou responsável legal NOME, DATA DE NASCIMENTO e confirmará na pulseira de identificação. Somente após esta confirmação, o exame será colhido e/ou realizado. Caso não haja acompanhante ou cliente com alterações cognitivas ou em coma, terá sua identificação checada diretamente na pulseira de identificação e com outro cuidador.

Transfusões sanguíneas:

Segue-se o mesmo padrão descrito para Imagem e Laboratório. A enfermeira da Unidade Transfusional perguntará NOME COMPLETO, DATA DE NASCIMENTO ao cliente, familiar ou responsável legal e confirmará na pulseira (concomitantemente, fará termo de consentimento, conforme política estabelecida). Esta confirmação será feita sob dupla-checagem com a enfermagem diretamente relacionada ao cuidado do cliente que será hemotransfundido. Caso não haja acompanhante ou cliente com alterações cognitivas ou em coma, sua identificação será checada diretamente na pulseira de identificação também sob o procedimento de dupla- checagem com a enfermagem do setor.

\section{Centro Cirúrgico Obstétrico:}

Seguirá o Protocolo Universal de Cirurgia Segura (BRASIL, 2013b).

Administração de medicamentos:

Antes da administração do medicamento, o técnico de enfermagem ou enfermeiro perguntará NOME COMPLETO e DATA DE NASCIMENTO ao cliente, familiar ou responsável legal e confirmará na pulseira. Caso não haja acompanhante ou o cliente apresente alterações cognitivas ou esteja em coma, sua identificação será checada diretamente na pulseira de identificação e com outro cuidador. Após esta confirmação, em posse do medicamento, o técnico de enfermagem ou enfermeiro, deverá também confrontar os dados da etiqueta do medicamento (NOME COMPLETO e NÚMERO DE REGISTRO), previamente a administração do mesmo.

\section{INDICADORES}

Como medida de eficácia deste protocolo, ao final de cada mês, deverão ser levantados indicadores do seu cumprimento, como: constatações de clientes ou acompanhante sem identificação e fora do local determinado do seu procedimento ou atendimento; e erros ou eventos adversos por falhas na elaboração das etiquetas/pulseiras.

Outros indicadores poderão ser sugeridos e, se for o caso, aprovados pelo Comitê de Segurança e Qualidade do HMXYZ.

\section{REFERÊNCIAS}

BRASIL. Ministério da Saúde. Anexo 02 - Protocolo de Identificação do Cliente. Portaria no 2095, de 24 de setembro de 2013, aprova os Protocolos Básicos de Segurança do Cliente, Programa nacional de Segurança do Cliente, 2013a. 
BRASIL. Ministério da Saúde. Anexo 03 - Protocolo de Cirurgia Segura. Portaria no 1377, de 09 de julho de 2013, aprova os Protocolos Básicos de Segurança do Cliente, Programa nacional de Segurança do Cliente, 2013b.

10. VIGÊNCIA E VALIDADE

Vigência a partir da data de publicação.

Válido por 4 (quatro) anos. 


\section{Gapítulo 16}

\section{ANÁLISE E PROPOSIÇÕES PARA A HUMANIZAÇÃO NO HOSPITAL UNIVERSITÁRIO PEDRO ERNESTO COM BASE NO DESIGN THINKING}

\section{Andrea Santos Cabral}

Diego Cesar Cavalcanti de Andrade

Ricardo Miyashita

Thais Spiegel

Resumo: Este estudo busca aplicar o Design Thinking para sugerir ações de humanização que sigam as diretrizes do SUS e abrangendo os três grupos de usuários envolvidos (pacientes, equipe de saúde e acompanhantes) especificamente no setor de acolhimento do ambulatório do Hospital Universitário Pedro Ernesto da Universidade do Estado do Rio de Janeiro (HUPE/UERJ). A metodologia utilizada, Design Thinking, envolveu quatro fases: descoberta dos problemas, definição do que seria realizado, e desenvolvimento e entrega de propostas e melhorias, como também a utilização de diversas ferramentas como: shadowing, brainstorming, Desdobramento da Função Qualidade (QFD), personas e outras. Sendo assim, foi possível encontrar soluções que atendessem as políticas de humanização. Desta maneira, conseguiu-se apresentar quatorze sugestões para aplicação no hospital, buscando a melhoria do serviço de saúde e procurando atingir o objetivo de humanizar a assistência da saúde. 


\section{INTRODUÇÃO}

A humanização é um tema que vem sendo discutido em vários setores da sociedade e está sendo vista como um meio importante de discutir as relações interpessoais, principalmente nas áreas onde o humano é o próprio objeto de estudo, como no setor de saúde. O termo "humanizar" refere-se à valorização e ao respeito do humano de acordo com princípios éticos e morais, e constitui um meio de transformação cultural através de ações coletivas que visam o bemestar e a integridade da pessoa (RIOS, 2009).

No sistema brasileiro de saúde, é frequente a ausência de procedimentos que atuam na questão social e psicológica do paciente, além da falta de tratamento humanizado aos mesmos, seus acompanhantes e aos funcionários de um hospital público.

O Sistema Unificado de Saúde (SUS), entendendo a necessidade de explorar o tema, criou o Programa Nacional de Humanização da Assistência Hospitalar (PNAH) com a finalidade de determinar diretrizes aos hospitais públicos para "ofertar atendimento de qualidade, articulando os avanços tecnológicos com acolhimento, melhoria dos cuidados e das condições de trabalho dos profissionais" (RIOS, 2009).

É importante que as ações humanizadas na saúdesejam percebidasnão apenas como atitudes éticas, mas sim como objetivo a ser proporcionado pela melhoria dos aspectos organizacionais do sistema e serviços de saúde. Portanto, "como a abordagem do tema de humanização pode contribuir para a melhoria no tratamento de pacientes?"e "de que forma esse estudo pode ser transformado em ações práticas que contribuam para uma melhor organização do sistema de saúde e para o atingimento de seus objetivos?" foram perguntas que nortearam o projeto ao longo de seu desenvolvimento.

Foi necessário restringir o âmbito de atuação ao setor ambulatorial do Hospital Universitário Pedro Ernesto (HUPE), fazendo com que o objetivo central do projeto fosse asugestão de ações de humanização da saúde seguindo as diretrizes do SUS e enfocando os três grupos de usuários envolvidos (pacientes, equipe de saúde e acompanhantes) especificamente no setor de acolhimento dos pacientes ambulatoriais do HUPE.

O método Design Thinking, utilizada no projeto, contribuiu para que houvesse aproximação efetiva de todos os envolvidos no processo, e buscou "estabelecer correspondências entre as necessidades humanas com recursos técnicos disponíveis, considerando as restrições práticas dos negócios" (BROWN, 2010, p.3).

\section{HUMANIZAÇÃO}

$\mathrm{Na}$ literatura associada ao conceito de Humanização, encontra-se a derivação do termo pela palavra "humanismo", que pode ser definida como uma doutrina filosófica cuja visão é centrada na importância do humano e de seus valores (DESLANDES, 2006). Já na área da saúde, o "humanismo" surgiu como uma proposta de humanização do ambiente em busca da valorização da pessoa humana e das relações das partes envolvidas. O assunto é frequente nas discussões atuais nos ambientes hospitalares, já que busca a recuperação desses valores e das relações mais pessoais entre médicos, pacientes e funcionários (RIOS, 2009)

A humanizar em relação à saúde pode ser considerado como uma forma de "entender cada pessoa em sua singularidade, tendo necessidades específicas, e, assim, criando condições para que tenha maiores possibilidades para exercer sua vontade de forma autônoma" (FORTES, 2004).

Práticas humanizadas estiveram presentes durante a evolução e a construção do sistema de saúde brasileiro, mas foi somente em 2000, que o Ministério da Saúde criou o Programa Nacional de Humanização da Assistência Hospitalar (PNAH), após a observação de situações alarmantes e desumanas nos hospitais: desrespeito aos direitos dos usuários, falta de atendimento das necessidades dos pacientes, desvalorização dos trabalhadores área da saúde etc. A PNAH surgiu como forma de promover uma cultura que auxiliasse a qualidade e a eficácia dos serviços prestados, focando nas relações entre os trabalhadores de saúde, usuários e profissionais, e hospitais e comunidades (RIOS, 2009).

Em 2003, a política sofreu uma mudança no nome, passando para Política Nacional de Humanização (PNH), e definiu diretrizes com o objetivo de "construir processos coletivos de enfrentamento de relações de poder, trabalho e afeto que muitas vezes produzem 
atitudes e práticas desumanizadoras" (BRASIL, 2004).

$\mathrm{Na}$ diretriz de Acolhimento, ponto de atuação deste projeto, a cartilha do SUS (BRASIL, 2010) define acolher com sentido de "estar com" ou "próximo de", expressando a metodologia de inclusão do indivíduo na gestão do sistema de saúde proposto pelo programa.

O acolhimento deve ser utilizado como "ferramenta relacional de intervenção na escuta, na construção de vínculo, na garantia do acesso com responsabilização e na resolutividade dos serviços" (BRASIL, 2010). Portanto, não deve ser visto como um local e horário determinados, mas sim como uma atitude de toda a equipe em todos os locais e a todos os pacientes, desde o momento que o mesmo chega para ser atendido até sua saída.

Para atingir um bom acolhimento, é necessário analisar, segundo a cartilha do PNH (BRASIL, 2010): o caminho percorrido pelo paciente durante sua visita ao hospital; qual o ponto de acesso do mesmo e suas condições; por quem o usuário é recebido e quem o atende; as informações dadas aos pacientes (seja pelos funcionários ou por sinalizações); a percepção das necessidades dos usuários; e a participação de todos os funcionários.

\section{DESIGN THINKING}

O Design Thinking é uma metodologia que leva em consideração as pessoas em primeiro lugar, fazendo uso de uma profunda empatia para obter um entendimento das necessidades e motivações das pessoas. Para isso é necessário observar detalhadamente o mundo e perceber coisas que as outras pessoas não percebem facilitando assim, o surgimento de insights e inspiração para a inovação (BROWN, 2008).

Uma das formas de aplicação do Design Thinking é através da abordagem denominada de Double Diamond, trazida pelo British Design Council. O modelo mapeia desde processos de design que passam por pontos onde $O$ pensamento $e$ as possibilidades são mais amplas possíveis (divergência) a situações onde os processos são estreitados e focados em determinados objetivos (convergência) Para atingir o propósito de cada etapa, inúmeras ferramentas e processos são utilizados, o que possibilita melhores resultados (DESIGN COUNCIL, 2015).

O Double Diamond propõe a abordagem de quatro processos conforme é mostrado na figura abaixo. A fase de Descobertas, onde são identificados problemas, oportunidades e necessidades e busca criar inspirações de atuação.

\section{FIGURA 1: Double Diamond}

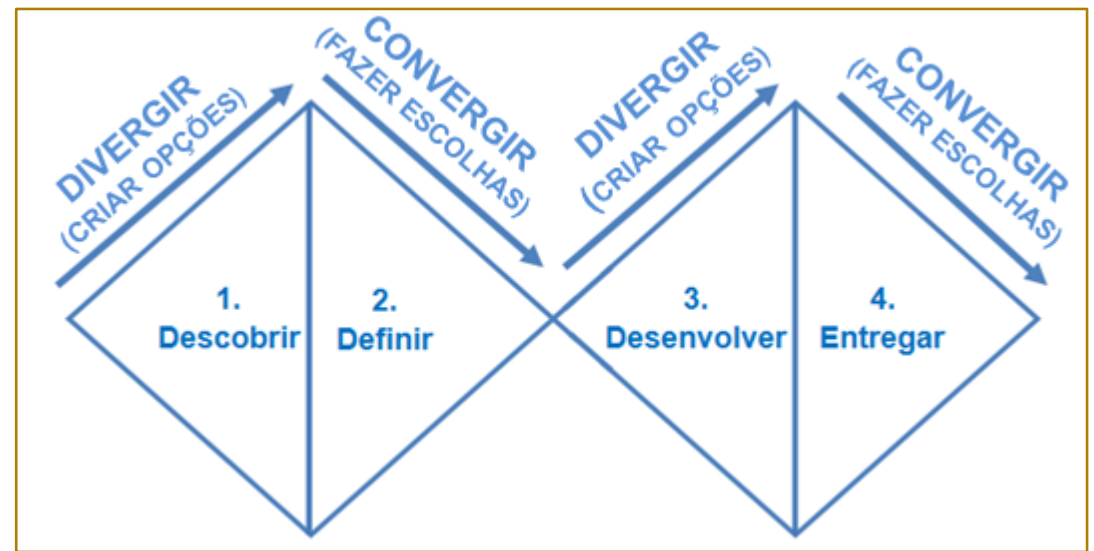

Fonte: Adaptado de Design Council (2015)

A fase de Definição, com o objetivo de analisar os dados descobertos na etapa anterior, sintetizar as descobertas e definir claramente o problema. A fase de Desenvolvimento, que busca desenvolver as instruções definidas anteriormente em testes e experimentos de produtos ou serviços; e, por fim, a fase de Entrega, ou seja, o momento em que o produto ou serviço já foi desenvolvido e será implementado. É nessa etapa que os 
detalhes finais são ajustados e finalizados. (BRITISH DESIGN COUNCIL, 2011).

Desta forma, pode-se perceber que a relevância do Design Thinking com o projeto ao focar no atendimento das necessidades reais do usuário, considerando todo o sistema em questão e envolvendo todos os indivíduos. Esta percepção se alia à ideia do método da Tríplice Inclusão, proposto pelo Ministério da Saúde no programa de humanização, em que se integram todos os funcionários, médicos e pacientes envolvidos à gestão do hospital.

\section{METODOLOGIA}

A etapa de definição do escopo do projeto é o passo inicial para a determinação e a delimitação das fases do trabalho. Portanto, foi necessário definir qual seria o tema do projeto e, a partir daí, perceber a relevância e a importância do assunto, o contexto do trabalho, o objetivo do mesmo, as limitações do tema e como o estudo seria desenvolvido.

Para desenvolver o estudo e dar suporte às pesquisas realizadas pelo Design Thinking, foi importante fazer uma revisão sistemática da literatura para se aprofundar e entender melhor o tema.

A metodologia Design Thinking escolhida é um conjunto de métodos e processos, que utiliza uma série de ferramentas para criar novas soluções centradas nos seres humanos (IDEO, 2011). O processo inicia no design, a partir da necessidade da pessoa, examinando seus desejos e comportamentos, e buscando ouvir e entender suas carências, visando à resolução dos problemas. A nomenclatura utilizada no projeto foi da abordagem Double Diamond, contemplando as seguintes fases: Descobertas, Definição, Desenvolvimento e Entrega.

Na fase de Descobertas, foram utilizadas as técnicas de shadowing e brainstorming. A proposta do shadowing é que o pesquisador entre na vida do consumidor e faça uma "sombra" sobre as ações e comportamentos das pessoas sem que ocorram interferências por parte do mesmo (BRITISH DESIGN COUNCIL, 2011). Já o brainstorming estimula a criação de ideias em grupos e pretende inspirar pessoas a partir da discussão e análise do projeto em conjunto.

FIGURA 2: Fluxograma das etapas do projeto

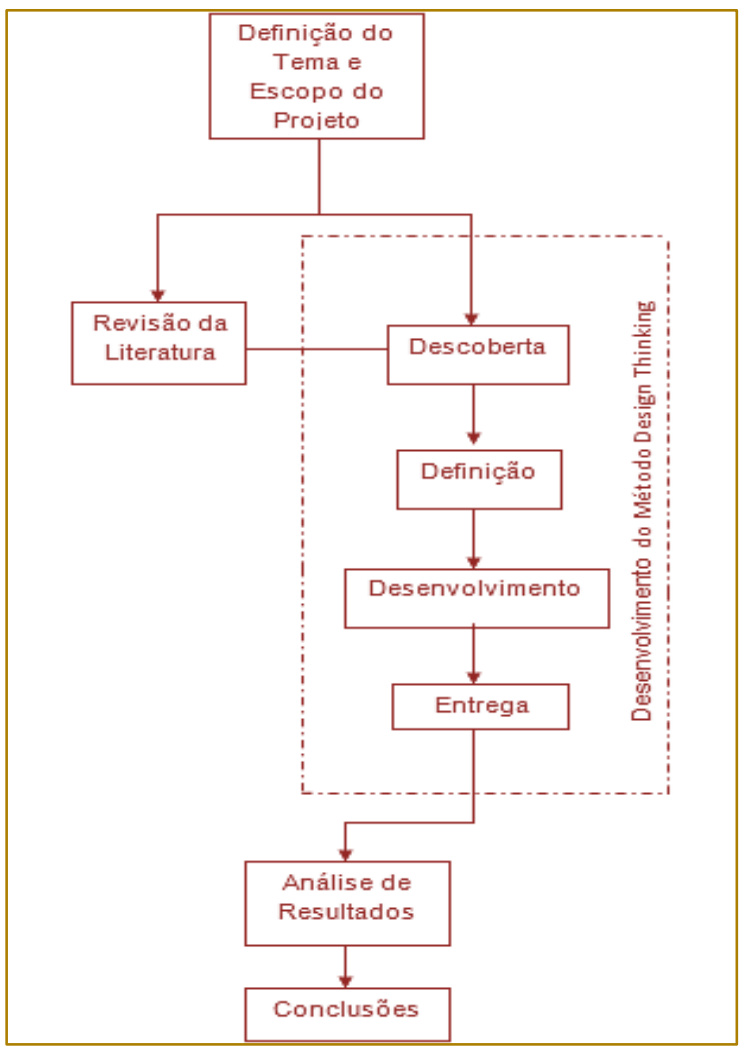


Na fase de Definição, foram criadas personas, que são personagens fictícios que representam os comportamentos dos usuários, trazendo uma síntese de como geralmente as pessoas reagem ao seu serviço ou como reagiriam mediante mudanças (BRITISH DESIGN COUNCIL, 2011) e definido o design briefing do projeto, ou seja, foi definida de forma objetiva, as informações e instruções sobre a tarefa a ser executada.

Por fim, foram utilizadas técnicas de Quadro de Valor dos pacientes, na fase de Desenvolvimento, demonstrando os serviços e produtos pensados para gerar ganhos e diminuir as dores de cada persona, e o Quality function deployment (QFD) utilizado na fase de entrega. Esta técnica utiliza das abordagens da voz do cliente (o que eles necessitam ou querem), dos requisitos criados pela engenharia para atender essas necessidades (como serão resolvidos os problemas e anseios), da análise de concorrência com outras empresas (no caso deste trabalho foi trabalhado concorrência entre as próprias propostas), e de comparação técnica (em relação aos recursos utilizados pelos concorrentes).

Além disso, pode-se dizer que o método de Design Thinking apresenta suas limitações. A técnica não fornece uma solução determinística e certa, porém tem se mostrado um bom meio para a criação de soluções e melhoria do serviço ao usuário.

Portanto, uma etapa de análise de resultados, após a finalização das fases propostas pelo Double Diamond fez necessária. Pretende-se observar se as respostas encontradas através do desenvolvimento da técnica condizem com o escopo de humanização. Ao final, será realizada uma reflexão sobre o trabalho como um todo, através da conclusão deste estudo.

\section{APLICAÇÃO DO MÉTODO}

\subsection{FASE DAS DESCOBERTAS}

O Hospital Universitário Pedro Ernesto (HUPE) está localizado no bairro de Vila Isabel no Rio de Janeiro e caracteriza-se como um hospital geral, terciário e de grande porte. Ou seja, a instituição é responsável por doenças e tratamentos de alta complexidade (serviços ambulatoriais e hospitalares de alto custo ou risco, como quimioterapia, radioterapia, tomografia, cirurgias cardíacas, transplantes etc.) e não apresenta setor de emergência.
No entanto, o hospital engloba também algumas funções de nível secundário, contendo consultas médicas especializadas e serviços de diagnose e terapia. Apresenta atendimento ambulatorial, internações em enfermarias, centro cirúrgico e unidades de terapia intensiva, além das atividades de ensino e pesquisa. Desta forma, o paciente pode ser encaminhado por uma unidade básica de saúde (de nível primário) a partir de uma avaliação de um médico de família, ou ser encaminhado por um especialista para realização de ações de nível terciário.

O ambulatório do hospital está localizado em uma construção auxiliar, onde atende-se 21 especialidades diferentes. O paciente, ao chegar ao ambulatório, deve se direcionar a um posto de atendimento para registro no sistema e, então, ser encaminhado ao consultório de sua especialidade. Os agendamentos são realizados em apenas dois horários: 8 horas da manhã e 13 horas da tarde.

A organização das filas é realizada pelos auxiliares das salas e não há um padrão ou procedimentos para a mesma. A maioria das salas organiza a filas por chegada dos pacientes.

Através de observações, entrevistas com pacientes, acompanhantes e especialistas, e o processo de shadowing foi possível mapear as dificuldades e necessidades que os usuários do hospital apresentaram. Ao todo foram realizadas entrevistas com 28 pacientes e acompanhantes e 5 especialistas (pessoas ligadas ao Hospital Pedro Ernesto, incluindo outros alunos que realizaram trabalhos e projetos no local e funcionários com funções de coordenação). Como o foco das entrevistas era o percebimento de problemas pela visão do usuário, não se fez necessário o agrupamento destes a partir de suas características físicas, psicológicas ou demográficas.

O processo de shadowing foi utilizado para observar os procedimentos e caminhos percorridos pelo usuário até chegar a uma consulta no ambulatório do HUPE. Foram acompanhadas uma senhora e sua filha, que estavam indo a uma consulta com um Gastroenterologista pela primeira vez ao hospital.

Dito isso, foram descritas as reivindicações e percepções das necessidades de acolhimento no hospital. 
Uma das maiores dificuldades encontradas foi a falta de informação. É importante perceber a dificuldade de encontrar o ambulatório no espaço do hospital, que se encontra "escondido", faltando orientações para o paciente chegar até ele. No processo de shadowing, essa dificuldade ficou evidente. As pacientes precisaram pedir informações para outros pacientes durante todo o percurso até chegar à consulta, devido à falta de placas de direcionamento e pessoas para recebê-las.

Ao chegar ao ambulatório, tampouco existe uma estrutura de acolhimento para os usuários. É difícil identificar o balcão de informações e é possível perceber pessoas perdidas na entrada e na região do balcão de atendimento. Foi comum ouvir dos pacientes durante as entrevistas sobre a falta de informação no hospital em geral e no ambulatório. A maioria foi direcionada à falta de uma pessoa que pudesse orientar tanto sobre procedimentos, quanto sobre o local.

Além disso, a maior parte dos usuários do HUPE não se habituou ao novo sistema implementado pelo Estado (o SISREG). Como a maioria dos pacientes são antigos e estão acostumados com o processo anterior, reclamam do novo modelo, em que é necessário marcar uma consulta em outra unidade de atendimento - a Clínica da Família.

Reclamações sobre atraso no atendimento da consulta também foram constantes. Pacientes queixaram de esperar até quatro horas por um atendimento, sem nenhuma distração. Inclusive, nas entrevistas com especialistas, foi enfatizada a importância de mudar o tipo de agendamento atual, que gera grandes esperas por parte do paciente e uma sobrecarga das funções dos auxiliares.

Outra dificuldade comum comentada pelos usuários é a maneira como são organizadas as filas do ambulatório, onde, muitas vezes, não se faz controle de chegada do paciente no consultório e a organização é feita por sobreposição de cartões de identificação, tornando o processo confuso e desorganizado. É importante citar também o momento de convocação do paciente ao consultório. Os usuários mencionaram que não se consegue ouvir o nome o paciente quando o auxiliar ou médico o chama, por conta da movimentação do local.

Por fim, especialistas lembraram da alta taxa de absenteísmo por parte dos pacientes encaminhados por unidades externas ao hospital e o erro de diagnóstico realizado também em outras unidades e, poucos pacientes reivindicaram a falta de remédios no hospital, falta de vagas para internação e problema de transporte para edifícios auxiliares.

Com as informações coletadas foi possível desenhar uma jornada geral do usuário do ambulatório do HUPE, desde sua chegada ao hospital até seu atendimento.

FIGURA 3: Jornada do Usuário

\begin{tabular}{|c|c|c|c|c|c|c|c|c|c|c|}
\hline EVIDÊNCIA FÍ́ICA & $\begin{array}{l}\text { Edificio do } \\
\text { Hospital }\end{array}$ & Não há & $\begin{array}{l}\text { Edificio do } \\
\text { Ambulatório }\end{array}$ & Balcão & Balconista & Não há & $\begin{array}{l}\text { Portas com } \\
\text { numeraçẫo }\end{array}$ & $\begin{array}{l}\text { Caixinha } \\
\text { de Cartão }\end{array}$ & $\begin{array}{l}\text { Sala de } \\
\text { espera } \\
\text { (assentos) }\end{array}$ & $\begin{array}{l}\text { Secretária } \\
\text { ou Médica } \\
\text { chama }\end{array}$ \\
\hline $\begin{array}{l}\text { AÇÕES DO } \\
\text { USUÁRIO }\end{array}$ & $\begin{array}{c}\text { Chegar ao } \\
\text { Hospital }\end{array}$ & $\begin{array}{l}\text { Dirigir-se ao } \\
\text { ambulatório }\end{array}$ & $\begin{array}{l}\text { Chegar ao } \\
\text { Ambulatóri } \\
\text { - }\end{array}$ & $\begin{array}{l}\text { Dirigir-se à } \\
\text { secretaria } \\
\text { de }\end{array}$ & $\left\{\begin{array}{l}\text { Realizar } \\
\text { registro de } \\
\text { consulta }\end{array}\right.$ & $\begin{array}{l}\text { Dirigir-se } \\
\text { ao } \\
\text { consultório }\end{array}$ & $\begin{array}{l}\text { Chegar ao } \\
\text { local de } \\
\text { consulta }\end{array}$ & $\begin{array}{l}\text { Entrar na fila } \\
\text { de } \\
\text { atendimento }\end{array}$ & $\begin{array}{l}\text { Esperar } \\
\text { consulta }\end{array}$ & Ser atendido \\
\hline $\begin{array}{l}\text { NECESSIDADES } \\
\text { DO USUÁRIO }\end{array}$ & $\begin{array}{l}\text { TER } \\
\text { ACESSOE } \\
\text { IDENTIFI- } \\
\text { CARO } \\
\text { HOSPITAL } \\
\text { COM } \\
\text { FACILIDA- } \\
\text { DE }\end{array}$ & $\begin{array}{l}\text { RECEBER } \\
\text { DIRECIO- } \\
\text { NAMEN- } \\
\text { TOS AO } \\
\text { AMBULA- } \\
\text { TÓRIO }\end{array}$ & $\begin{array}{l}\text { IDENTIF- } \\
\text { CARO } \\
\text { AMBULA- } \\
\text { TÓRIO }\end{array}$ & $\begin{array}{l}\text { RECEBER } \\
\text { DIRECIO- } \\
\text { NAMEN- } \\
\text { TOS AO } \\
\text { BALCÃO } \\
\text { DE } \\
\text { ATENDI } \\
\text { MENTO }\end{array}$ & $\begin{array}{l}\text { RECEBER } \\
\text { NÃOSÓ } \\
\text { INSTRU- } \\
\text { çÕES, } \\
\text { MAS } \\
\text { TAMBÉM } \\
\text { ACOLHI- } \\
\text { MENTO }\end{array}$ & $\begin{array}{l}\text { RECER } \\
\text { DIRECIO } \\
\text { NAMENT } \\
\text { OS AO } \\
\text { CONSULT } \\
\text { ÓRIO }\end{array}$ & $\begin{array}{l}\text { IDENTIFI- } \\
\text { CARO } \\
\text { LOCAL } \\
\text { DE } \\
\text { CONSUL- } \\
\text { TA }\end{array}$ & $\begin{array}{l}\text { RECEBER } \\
\text { INSTRU- } \\
\text { ÇÕES } \\
\text { SOBRE O } \\
\text { QUE } \\
\text { FAZER }\end{array}$ & $\begin{array}{l}\text { TER } \\
\text { LOCAL } \\
\text { ACON- } \\
\text { CHEGAN- } \\
\text { TE, } \\
\text { DISTRA- } \\
\text { ÇÕESE } \\
\text { ESPERA } \\
\text { CURTA }\end{array}$ & $\begin{array}{l}\text { CONSE- } \\
\text { GUIR } \\
\text { IDENTIFI- } \\
\text { CARO } \\
\text { SEU } \\
\text { NOME } \\
\text { AOSER } \\
\text { CHAMA- } \\
\text { DO }\end{array}$ \\
\hline $\begin{array}{l}\text { OQUEELE } \\
\text { SENTE? }\end{array}$ & $\begin{array}{l}\text { FACILIDA } \\
\text { DEEM } \\
\text { IDENTIFI- } \\
\text { CAR QUE } \\
\text { CHEGOU } \\
\text { AO } \\
\text { HOSPITAL }\end{array}$ & $\begin{array}{l}\text { PERDIDO } \\
\text { ONDEÉ? } \\
\text { COMO } \\
\text { FAÇO } \\
\text { PARA } \\
\text { CHEGAR } \\
\text { LÁ? }\end{array}$ & $\begin{array}{l}\text { PERDIDO } \\
\text { CONFUSO } \\
\text { CHEGUEl? }\end{array}$ & $\begin{array}{l}\text { PERDIDO } \\
\text { CONFUSO } \\
\text { OQUE } \\
\text { FAZER? } \\
\text { AONDE } \\
\text { DEVOIR? }\end{array}$ & $\begin{array}{l}\text { BEM } \\
\text { INSTRUI- } \\
\text { DO } \\
\text { SENSAC̃Ã } \\
\text { ODE NÃO } \\
\text { ESTAR } \\
\text { SENDO } \\
\text { ACOLHI- } \\
\text { DO }\end{array}$ & $\begin{array}{l}\text { PERDIDO } \\
\text { CONFUSO }\end{array}$ & $\begin{array}{l}\text { PERDIDO } \\
\text { CONFUSO }\end{array}$ & $\begin{array}{l}\text { PERDIDO } \\
\text { CONFUSO } \\
\\
\text { OQUE } \\
\text { DEVO } \\
\text { FAZER? }\end{array}$ & $\begin{array}{l}\text { TEDIOSO } \\
\text { CANSADO } \\
\text { COM } \\
\text { SONO }\end{array}$ & $\begin{array}{l}\text { NÃO } \\
\text { ESCUTA }\end{array}$ \\
\hline
\end{tabular}


A partir da jornada do usuário e do entendimento do funcionamento do ambulatório do hospital, foi possível desenvolver ainda um diagrama associando cada etapa do paciente com o processo interno associado. É importante observar que cada processo, representado pelo círculo cinza, deve ser pensado de forma que atenda o paciente e, por isto, ele foi representado no centro do desenho.

FIGURA 4: Processos Internos ligados à Jornada do Usuário

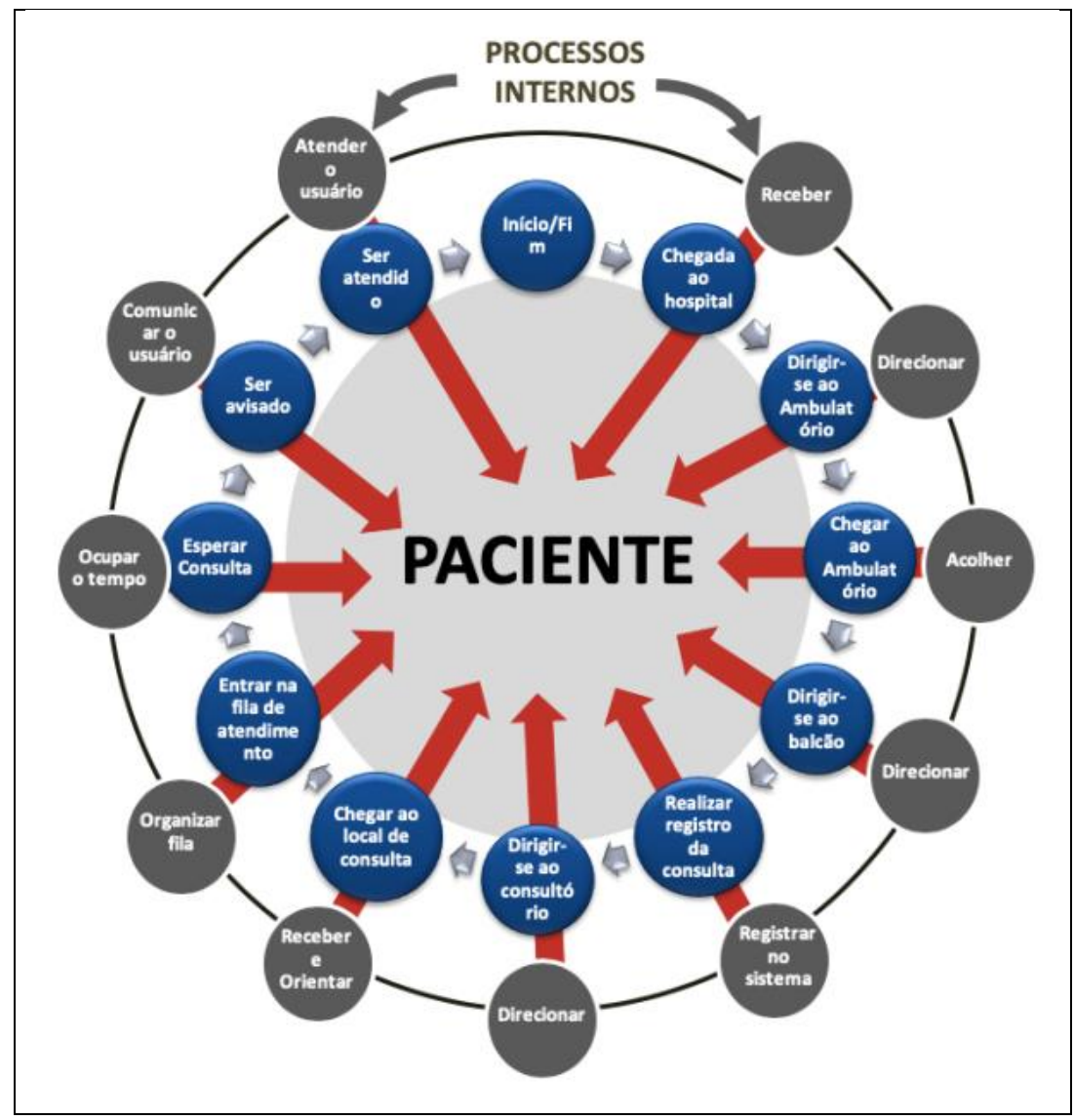

\subsection{FASE DE DEFINIÇÃO}

A partir das descobertas realizadas na etapa anterior, fez-se necessário analisar os diferentes perfis de pacientes que existem no hospital e definir o design brief do projeto, ou seja, a proposta deste trabalho.

Desta forma, foi realizada uma etapa de criação de personas, baseada nas características percebidas dos pacientes através das entrevistas, e uma etapa de reflexão de suas necessidades pensando em três pontos: nas tarefas de cada um (quais são as necessidades a serem satisfeitas?); nos ganhos que poderão obter com os serviços (quais benefícios cada perfil espera?); e nas dores que poderão existir (o que pode incomodá-los?). As personas e as reflexões estão detalhadas abaixo: 
QUADRO 1 - Definição das Personas e Descrição de seus Ganhos e Dores.

\begin{tabular}{|c|c|c|}
\hline Perfil & Ganhos & Dores \\
\hline $\begin{array}{l}\text { Sr. Pedro: } 67 \text { anos, morador do bairro de Santa } \\
\text { Cruz- RJ, não possui escolaridade e é analfabeto. } \\
\text { Aposentado há } 10 \text { anos, procura um } \\
\text { oftalmologista. Já realiza tratamento na } \\
\text { oftalmologia do HUPE há cinco anos. }\end{array}$ & $\begin{array}{l}\text { Fica satisfeito em } \\
\text { simplesmente ser atendido } \\
\text { (não é crítico quanto à } \\
\text { espera); não tem outras } \\
\text { referências de hospital (não } \\
\text { é exigente). }\end{array}$ & $\begin{array}{l}\text { Tem dificuldade de ler } \\
\text { informações; tem } \\
\text { dificuldade de } \\
\text { entender o novo } \\
\text { sistema (SISREG) }\end{array}$ \\
\hline $\begin{array}{l}\text { Ivan: } 32 \text { anos, morador de Vila Isabel, possui } \\
\text { Ensino Médio completo, sabendo ler e escrever. } \\
\text { Atualmente está desempregado. Foi encaminhado } \\
\text { pela Clínica da Família para consulta na } \\
\text { especialidade de urologia do ambulatório. }\end{array}$ & $\begin{array}{l}\text { Atendimento rápido é um } \\
\text { ganho (é crítico quanto à } \\
\text { espera); espera ser bem } \\
\text { atendido e conseguir } \\
\text { realizar o tratamento. }\end{array}$ & $\begin{array}{l}\text { Por ser a primeira } \\
\text { consulta, pode se } \\
\text { perder nos } \\
\text { direcionamentos do } \\
\text { hospital. }\end{array}$ \\
\hline $\begin{array}{l}\text { Lucia: } 42 \text { anos, moradora de Laranjeiras, exerce } \\
\text { cargo de gerente de uma revista. Acompanha sua } \\
\text { mãe, de } 74 \text { anos, ao consultório de Neurologia. } \\
\text { Um médico conhecido indicou o tratamento de sua } \\
\text { mãe no Hospital Pedro Ernesto }\end{array}$ & $\begin{array}{l}\text { Ter atendimento de } \\
\text { qualidade; obter } \\
\text { informações detalhadas } \\
\text { sobre os tratamentos e } \\
\text { procedimentos. }\end{array}$ & $\begin{array}{l}\text { Não fica satisfeita em } \\
\text { apenas ser atendida: } \\
\text { um atendimento ruim } \\
\text { é uma dor; é exigente } \\
\text { em relação ao } \\
\text { ambiente, barulho, } \\
\text { local etc. }\end{array}$ \\
\hline
\end{tabular}

Por fim, o design brief do projeto foi definido: propor iniciativas e soluções que visam à melhoria do recebimento no Hospital Pedro Ernesto, de modo que os pacientes se sintam acolhidos, com maior facilidade de orientação e direcionamento, com melhor obtenção de informação, evitando perdas de tempo e deslocamentos desnecessários, pretendendo também diminuir o tempo de fila e melhorar o conforto dos usuários.

\subsection{FASE DE DESENVOLVIMENTO}

A fase de desenvolvimento tem como objetivo desenvolver o que foi definido pelo Design Briefdo projeto. Portanto, a partir das etapas anteriores, foi realizada uma atividade com a finalidade de identificar as dificuldades encontradas pelos usuários e propor ideias de soluções e iniciativas que visam à melhoria do acolhimento do ambulatório.

Primeiramente, com a organização de todas as necessidades do usuário (levantadas na etapa de descoberta), foi necessário identificar os problemas raízes do sistema, sistematizadas no quadro a seguir:

QUADRO 2 - Definição das Personas e Descrição de seus Ganhos e Dores.

\begin{tabular}{|c|c|}
\hline Causas Raízes & Qual aspecto de Humanização não foi atendido? \\
\hline Sinalização Falha & $\begin{array}{l}\text { Falta de um pensamento do paciente em sua integralidade: o paciente com } \\
\text { suas condições sociais e fisiológicas (analfabetos, deficientes visuais etc.) } \\
\text { precisam de sinalizações e direcionamentos que o atenda. }\end{array}$ \\
\hline $\begin{array}{l}\text { Falta de Posto para dar } \\
\text { Informações }\end{array}$ & Não identificação das necessidades do usuário. \\
\hline $\begin{array}{l}\text { Falta de Organização das } \\
\text { Filas }\end{array}$ & $\begin{array}{l}\text { Falta de reconhecimento do paciente em sua integralidade e falta de empatia } \\
\text { (ninguém deveria ficar mais de } 3 \text { horas em uma fila). }\end{array}$ \\
\hline $\begin{array}{l}\text { Funcionários treinados } \\
\text { apenas para processos } \\
\text { operacionais }\end{array}$ & $\begin{array}{l}\text { Falta de reconhecimento do paciente como um ser insubstituível (que precisa } \\
\text { ser escutado, que merece atenção). }\end{array}$ \\
\hline $\begin{array}{l}\text { Falta de um ambiente } \\
\text { agradável }\end{array}$ & Falta de reconhecimento do paciente em sua integralidade e falta de empatia. \\
\hline
\end{tabular}

Em um segundo momento, foi possível gerar ideias que solucionassem os problemas levantados anteriormente e refletir se cada ideia gerada agregaria valor para as personas criadas na etapa de Definição. As soluções foram pensadas de forma com que atendessem, ou ao menos, fossem direcionados pelos conceitos de Humanização e Acolhimento. Algumas ideias geradas, considerando os perfis dos personagens, estão descritas a seguir: 
QUADRO 3 - Propostas para as personas.

\begin{tabular}{|l|l|l|}
\multicolumn{2}{|c|}{ Sr. Pedro } & \multicolumn{1}{c|}{ Lucia } \\
\hline $\begin{array}{l}\text { Pessoa para acolher e conversar } \\
\text { sobre seus problemas }\end{array}$ & $\begin{array}{l}\text { Pessoa para acolher e conversar } \\
\text { sobre seus problemas }\end{array}$ & Ambiente com distrações \\
\hline $\begin{array}{l}\text { TV e Alto-Falante para } \\
\text { organização das filas }\end{array}$ & $\begin{array}{l}\text { Ligação para o paciente para } \\
\text { confirmar consulta }\end{array}$ & Ambiente aconchegante \\
\hline Sinalização Visual & Sinalização Escrita & Funcionários treinados \\
\hline $\begin{array}{l}\text { Cores diferentes nas portas de } \\
\text { cada sala }\end{array}$ & Funcionários treinados & $\begin{array}{l}\text { Balcão de informação mais } \\
\text { pessoal }\end{array}$ \\
\hline $\begin{array}{l}\text { Explicação sobre o sistema } \\
\text { (SISREG) do SUS }\end{array}$ & $\begin{array}{l}\text { Balcão de informação mais } \\
\text { pessoal }\end{array}$ & \\
\hline $\begin{array}{l}\text { Balcão de informação mais } \\
\text { pessoal }\end{array}$ & & \\
\hline
\end{tabular}

\subsection{FASE DE ENTREGA}

$\mathrm{Na}$ etapa de entrega, foi necessário estruturar as ideias geradas na fase anterior e avaliá-las com funcionários e especialistas a fim de analisar se a proposta atenderia as necessidades dos usuários e se seria aplicável à realidade do Hospital.

\section{QUADRO 4 - Descrição das Propostas}

\begin{tabular}{|c|c|}
\hline Propostas & Descrição \\
\hline Placa de Direcionamento & $\begin{array}{l}\text { Placas visuais (com desenhos e pictogramas) nos pontos onde os } \\
\text { pacientes apresentam dúvidas para onde seguir. }\end{array}$ \\
\hline Marcações Visuais & $\begin{array}{l}\text { Marcação dos caminhos que o paciente pode realizar, através de fitas } \\
\text { adesivas coloridas }\end{array}$ \\
\hline Balcão de Acolhimento & $\begin{array}{l}\text { Tornar o Balcão de Informação mais próximo dos usuários e transformá-lo } \\
\text { em um local onde os pacientes teriam o primeiro contato com o Ambulatório }\end{array}$ \\
\hline O Voluntário Bom Ouvinte & $\begin{array}{l}\text { Voluntário que pudesse percorrer pelos corredores do ambulatório, } \\
\text { tentando conversar e captar os problemas dos usuários. }\end{array}$ \\
\hline $\begin{array}{l}\text { Treinamento Pessoal de } \\
\text { Funcionários }\end{array}$ & $\begin{array}{l}\text { Demonstrar e definir a função de cada funcionário e setor do ambulatório, } \\
\text { entendendo não só cada função, mas os processos do hospital em geral. }\end{array}$ \\
\hline Mural Informativo & $\begin{array}{l}\text { Utilizar o mural presente no ambulatório para oferecer informações que } \\
\text { frequentemente são negligenciadas pelos funcionários, como por exemplo, } \\
\text { como funciona a organização da fila. }\end{array}$ \\
\hline Secretarias Unificadas & $\begin{array}{l}\text { Unificar as secretarias de todos os consultórios, existindo um único ponto } \\
\text { de contato ao paciente que chega ao local de atendimento. }\end{array}$ \\
\hline Nova Agenda & $\begin{array}{l}\text { Mudar os horários de agendamento do hospital, a partir de um estudo } \\
\text { realizado em cada especialidade para observar os diferentes tempos de } \\
\text { atendimento. }\end{array}$ \\
\hline Painel Visual & $\begin{array}{l}\text { Painel onde os pacientes poderiam visualizar seu nome na hora do } \\
\text { atendimento }\end{array}$ \\
\hline Alto-falante & Anunciação do nome e consultório do paciente em um alto-falante \\
\hline Criação de Distrações & Atrativos e detalhes para distrair a espera (revistas, jogos). \\
\hline Ambiente Feliz & $\begin{array}{l}\text { Criar um ambiente mais aconchegante e alegre ao ambulatório, pintando } \\
\text { seus corredores e trazendo recursos visuais às pessoas. }\end{array}$ \\
\hline Central de Telefonia & $\begin{array}{l}\text { Central de ligações para a confirmação das consultas agendadas em } \\
\text { unidades externas. }\end{array}$ \\
\hline Investigação SUS & $\begin{array}{l}\text { Investigação entre os pontos de ligação com unidades externas e com o } \\
\text { Sistema único de Saúde (SUS). }\end{array}$ \\
\hline
\end{tabular}


Depois disso, foi pensando em uma forma de tentar priorizar essas ideias, utilizado o método de Desdobramento da Função Qualidade (QFD) para projetar a qualidade do serviço proposto.Primeiramente, foi necessário realizar uma Relação entre necessidades dos usuários e as Propostas. Foi criada uma priorização das necessidades dos usuários, de acordo com a quantidade de vezes que os usuários demandavam àquela necessidade e das observações realizadas pelos especialistas e pelo projeto. Os pesos foram definidos em uma escala de 1 a 5 , sendo que 0 índice 5 contemplava as necessidades mais importantes. Além disso, foi feita uma escala que correlacionasse proposta e necessidade, sendo: 0 - Relação inexistente; 1 - Relação Fraca; 3 - Relação Média; 5 - Relação Forte. Por fim, a pontuação dessa relação foi calculada através da soma das multiplicações entre o peso das necessidades dos usuários pelo índice de relação entre demanda e proposta.

FIGURA 5: Matriz QFD das Propostas de Humanização

\begin{tabular}{|c|c|c|c|c|c|c|c|c|c|c|c|c|c|c|c|c|}
\hline & & & & & & & & & & & & & & & & DIFICULDADES \\
\hline & & 5 & 5 & 3 & 0 & 3 & 3 & 3 & 0 & 5 & 5 & 0 & 1 & 1 & 0 & Recursos Tecnológicos \\
\hline & & 3 & 3 & 3 & 5 & 5 & 5 & 5 & 5 & 5 & 5 & 5 & 1 & 0 & 5 & Recursos Humanos \\
\hline & & 1 & 0 & 1 & 5 & 3 & 3 & 3 & 3 & 0 & 1 & 5 & 3 & 1 & 1 & $\begin{array}{l}\text { Tempo para } \\
\text { Implementação }\end{array}$ \\
\hline & & 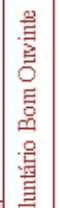 & 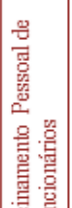 & 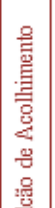 & 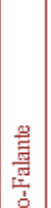 & 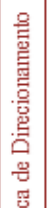 & 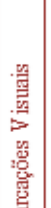 & 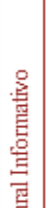 & 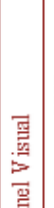 & 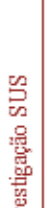 & 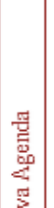 & 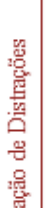 & 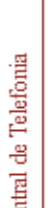 & 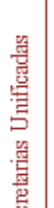 & 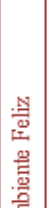 & \\
\hline NECESSIDADES DO USUARIO & PESO & $\frac{7}{0}$ & 总豪 & 焉 & 象 & 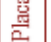 & $\frac{5}{2}$ & $\frac{5}{2}$ & 产 & 常 & z & & & & है & \\
\hline $\mathrm{O}$ usuário entende com facilidade a informação & 5 & 5 & 5 & 5 & 5 & 5 & 5 & 5 & 5 & 1 & $=0$ & 0 & 1 & $\frac{3}{3}$ & 0 & \\
\hline O usuário sente atenção individualizada e prestativa & 5 & 5 & 5 & 5 & 1 & 3 & 3 & 3 & 1 & 1 & 0 & 0 & 3 & 5 & 0 & \\
\hline $\begin{array}{l}\text { O usuário sente que suas necessidades são } \\
\text { compreendidas pelos funcionários }\end{array}$ & 5 & 5 & 5 & 5 & 3 & 0 & 0 & 0 & 3 & 3 & 0 & 1 & 3 & 5 & 0 & \\
\hline O tempo de espera é reduzido & 5 & 1 & 0 & 0 & 0 & 0 & 0 & 0 & 0 & 3 & 5 & 1 & 0 & 0 & 0 & \\
\hline $\mathrm{O}$ usuário consegue se direcionar e se orientar & 4 & 3 & 3 & 3 & 0 & 5 & 5 & 0 & 0 & 0 & 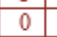 & 0 & 0 & 0 & 0 & \\
\hline $\mathrm{O}$ usuário recebe informações com facilidade & 4 & 5 & 5 & 5 & 3 & 3 & 3 & 5 & 3 & 1 & 0 & 0 & 1 & 3 & 0 & \\
\hline O usuário consegue compreender a organização da fila & 3 & 3 & 3 & 3 & 3 & 0 & 0 & 5 & 3 & 0 & 1 & 0 & 0 & 5 & 0 & \\
\hline $\mathrm{O}$ usuário consegue perceber quando será sua consulta & 3 & 0 & 1 & 0 & 5 & 0 & 0 & 0 & 5 & 0 & 5 & 0 & 0 & 5 & 0 & \\
\hline O usuário sente que o ambiente é aconchegante & 2 & 3 & 3 & 3 & 0 & 1 & 1 & 0 & 0 & 0 & 0 & 5 & 0 & 1 & 5 & \\
\hline O tempo de espera é preenchido com distraçōes & 2 & 5 & 0 & 1 & 0 & 0 & 0 & 0 & 0 & 0 & 0 & 5 & 0 & 0 & 0 & \\
\hline O usuário entende as mudanças no sistema de saúde & 1 & 5 & 1 & 3 & 0 & 0 & 0 & 0 & 0 & 5 & 0 & 0 & 3 & 0 & 0 & \\
\hline A taxa de absenteísmo dos pacientes é reduzida & 1 & 1 & 1 & 1 & 3 & 1 & 1 & 0 & 3 & 5 & 1 & 0 & 5 & 0 & 0 & \\
\hline Pontuação (Necessidades x Propostas) & & 143 & 127 & 128 & 84 & 75 & 75 & 75 & \begin{tabular}{|l|l|}
84 & -1 \\
\end{tabular} & 54 & 44 & 30 & 47 & 109 & 10 & \\
\hline Pontuação (Dificuldades X Propostas) & & 9 & 8 & 7 & 10 & 11 & II & 11 & 8 & 10 & II & 10 & 5 & 2 & 6 & \\
\hline Pontuação Total & & 129 & 102 & 90 & 84 & 83 & 83 & 83 & 67 & 54 & 48 & 30 & 24 & 22 & 6 & \\
\hline
\end{tabular}

A relação entre dificuldades e as propostas também se fez importante. Foram analisadas três dificuldades técnicas, com as respectivas escalas: Recursos Tecnológicos $(0$ - Alto Custo, 1 - Médio Custo, 3 - Baixo Custo, 5 Sem Custo); Recursos Humanos (0 Necessidade de muitos funcionários realocados ou contratados, 1 - Necessidade de alguns funcionários; 3 - Necessidade de poucos funcionários, 5 - Não há necessidade de contratação ou alocação); e Tempo de Implementação (0 - Muito Tempo, 1 - Médio Tempo, 3 - Pouco Tempo, 5 - Imediato). A pontuação dessa relação foi dada a partir das somas desses fatores para cada proposta. Por fim, foi calculada a pontuação total, através da multiplicação da pontuação de cada relação descrita anteriormente, divida por 10. A divisão foi realizada apenas para os valores não serem tão altos.

\section{ANÁLISE DOS RESULTADOS}

É importante observar que o método de Design Thinking se mostrou extremamente adequado e significativo para a obtenção de propostas de soluções sobre o tema de Humanização abordado. A concepção de colocar o cliente como foco do projeto e o objetivo de resolver e ajudar as necessidades das pessoas desempenhou corretamente a função que a humanização propõe de realizar práticas seguindo quatro dimensões: 0 reconhecimento da vida humana, a afirmação do ser humano como insubstituível, a identificação das pessoas em sua integralidade e a empatia e o afeto pelas partes envolvidas.

Além disso, pôde-se perceber que durante a aplicação do método e de suas ferramentas, diversos aspectos sugeridos pela cartilha do 
Ministério da Saúde sobre a Política de Humanização Nacional (PNH) foram analisados: as técnicas de shadowing ajudaram a perceber o caminho percorrido pelo paciente durante a visita ao hospital, os pontos de acesso do paciente e suas condições; e por quem e quais informações eram dadas a esses usuários. As entrevistas com pacientes e com funcionários e a criação de personas também foram necessárias principalmente para a percepção das necessidades dos pacientes e para 0 entendimento da participação de todos os funcionários nos processos internos e na trajetória percorrida pelos usuários.
Desta forma, a partir de um método humanizado, as ideias e propostas geradas também seguiram as dimensões estabelecidas pelo conceito e os aspectos sugeridos pelo Sistema Único de Saúde (SUS). E foram além: tiveram como objetivo atender os princípios, o método, a inclusão de dispositivos estabelecidos no $\mathrm{PNH}$, inclusive tentando atingir as metas estabelecidas. Do mesmo modo, foi considerado durante a proposição de soluções os conceitos de acolhimento e os direcionamentos dados pelo Ministério da Saúde a essa diretriz.

QUADRO 5 - Relação entre propostas e teoria

\begin{tabular}{|c|c|c|c|}
\hline \multicolumn{2}{|r|}{ HUMANIZAÇÃO } & $\begin{array}{l}\text { POLÍTICA NACIONAL DE } \\
\text { HUMANIZAÇÃO (PNH) }\end{array}$ & ACOLHIMENTO \\
\hline $\begin{array}{l}\text { Voluntário } \\
\text { Bom } \\
\text { Ouvinte }\end{array}$ & $\begin{array}{l}\text { A proposta atinge os problemas } \\
\text { relevantes da vida dos usuários que } \\
\text { podem influenciar em sua saúde (que } \\
\text { também inclui as condições } \\
\text { psicológicas e sociais); desenvolve } \\
\text { afeto e empatia pelos pacientes, além } \\
\text { de reconhecer o ser humano como } \\
\text { insubstituível (ao ouvir os problemas e } \\
\text { vivências de cada pessoa) }\end{array}$ & $\begin{array}{l}\text { Além de atender a diretriz de } \\
\text { acolhimento, inclui o usuário } \\
\text { do hospital ao permitir que } \\
\text { deem opiniões e sejam } \\
\text { escutados seus problemas e } \\
\text { demandas }\end{array}$ & $\begin{array}{l}\text { Atinge diretamente o } \\
\text { conceito de acolher } \\
\text { como uma ferramenta } \\
\text { de escuta para a } \\
\text { construção de um } \\
\text { vínculo, escutando } \\
\text { suas queixas e } \\
\text { expectativas }\end{array}$ \\
\hline $\begin{array}{l}\text { Balcão de } \\
\text { Acolhimento }\end{array}$ & $\begin{array}{l}\text { A proposta se propõe a desenvolver } \\
\text { empatia e afeto pelos usuários do } \\
\text { hospital, ao identificar a necessidade } \\
\text { de um ponto de primeiro contato com } \\
\text { o ambulatório }\end{array}$ & $\begin{array}{l}\text { Desenvolve a diretriz de } \\
\text { acolhimento do PNH e } \\
\text { permite a conquista da meta } \\
\text { de garantir informações e o } \\
\text { conhecimento das pessoas } \\
\text { que os atende }\end{array}$ & $\begin{array}{l}\text { Atinge o conceito ao } \\
\text { se propor a ser um } \\
\text { primeiro contato com } \\
\text { o usuário, acolhendo } \\
\text { essas pessoas e } \\
\text { respondendo suas } \\
\text { demandas }\end{array}$ \\
\hline $\begin{array}{l}\text { Treinamento } \\
\text { Pessoal de } \\
\text { Funcionário } \\
\text { s }\end{array}$ & $\begin{array}{l}\text { Atinge todas as dimensões da } \\
\text { humanização: faz os funcionários } \\
\text { perceberem a importância da empatia } \\
\text { e do reconhecimento dos pacientes } \\
\text { como seres únicos e com experiências } \\
\text { própria e faz os próprios funcionários } \\
\text { serem reconhecidos desta maneira }\end{array}$ & $\begin{array}{l}\text { Agrega diversos conceitos e } \\
\text { diretrizes do PNH: o } \\
\text { reconhecimento } \\
\text { funcionários, o método da } \\
\text { Tríplice Inclusão, o } \\
\text { conhecimento dos usuários } \\
\text { de quem são os funcionários } \\
\text { que os atendem }\end{array}$ & $\begin{array}{l}\text { A proposta propõe a } \\
\text { percepção por parte } \\
\text { dos funcionários de } \\
\text { que todos são } \\
\text { responsáveis por } \\
\text { acolher os usuários }\end{array}$ \\
\hline $\begin{array}{l}\text { Placas de } \\
\text { Direcioname } \\
\text { nto }\end{array}$ & $\begin{array}{l}\text { Percebe que as necessidades de cada } \\
\text { paciente podem ser diferentes (cada } \\
\text { ser é único) ao tentar agregar recursos } \\
\text { escritos e visuais para direcionar os } \\
\text { pacientes e acompanhantes }\end{array}$ & $\begin{array}{l}\text { Atinge uma das metas: } \\
\text { garantia de informações }\end{array}$ & $\begin{array}{l}\text { Acolhem as pessoas } \\
\text { ao conseguirem } \\
\text { direcioná-las }\end{array}$ \\
\hline $\begin{array}{l}\text { Marcações } \\
\text { Visuais }\end{array}$ & $\begin{array}{l}\text { Percebe que as necessidades de cada } \\
\text { paciente podem ser diferentes (cada } \\
\text { ser é único), tentando propor recursos } \\
\text { visuais para pessoas com menor nível } \\
\text { de escolaridade }\end{array}$ & $\begin{array}{l}\text { Atinge uma das metas: } \\
\text { garantia de informações }\end{array}$ & $\begin{array}{l}\text { Acolhem as pessoas } \\
\text { ao conseguirem } \\
\text { direcioná-las }\end{array}$ \\
\hline $\begin{array}{l}\text { Mural } \\
\text { Informativo } \\
\text { da Fila }\end{array}$ & $\begin{array}{l}\text { Percebe as necessidades dos } \\
\text { pacientes }\end{array}$ & $\begin{array}{l}\text { Atinge uma das metas: } \\
\text { garantia de informações }\end{array}$ & $\begin{array}{l}\text { Acolhem as pessoas } \\
\text { ao conseguirem } \\
\text { orientá-las }\end{array}$ \\
\hline Painel Visual & $\begin{array}{l}\text { Reconhece o ser como insubstituível, } \\
\text { percebendo a dificuldade que os } \\
\text { pacientes encontram o não escutarem } \\
\text { seu nome e se propondo a resolver a } \\
\text { questão }\end{array}$ & $\begin{array}{l}\text { Atinge uma das metas: } \\
\text { garantia de informações }\end{array}$ & $\begin{array}{l}\text { Acolhem as pessoas } \\
\text { ao conseguirem } \\
\text { orientá-las }\end{array}$ \\
\hline
\end{tabular}


QUADRO 5 - Relação entre propostas e teoria

(continuação...)

\begin{tabular}{|c|c|c|c|}
\hline \multicolumn{2}{|r|}{ HUMANIZAÇÃO } & $\begin{array}{l}\text { POLITICA NACIONAL DE } \\
\text { HUMANIZAÇÃO (PNH) }\end{array}$ & ACOLHIMENTO \\
\hline Alto-Falante & $\begin{array}{l}\text { Reconhece o ser como insubstituível, } \\
\text { percebendo a dificuldade que os } \\
\text { pacientes encontram o não escutarem } \\
\text { seu nome e se propondo a resolver a } \\
\text { questão }\end{array}$ & $\begin{array}{l}\text { Atinge uma das metas: } \\
\text { garantia de informações }\end{array}$ & $\begin{array}{l}\text { Acolhem as pessoas } \\
\text { ao conseguirem } \\
\text { orientá-las }\end{array}$ \\
\hline $\begin{array}{l}\text { Secretarias } \\
\text { Unificadas }\end{array}$ & $\begin{array}{l}\text { Reconhece a necessidade dos pacientes } \\
\text { ao propor uma opção de contato com o } \\
\text { consultório }\end{array}$ & $\begin{array}{l}\text { Atinge a meta de garantia } \\
\text { de informações e segue a } \\
\text { diretriz de acolhimento }\end{array}$ & $\begin{array}{l}\text { A proposta se propõe } \\
\text { a ser um primeiro } \\
\text { contato com o } \\
\text { consultório r e, } \\
\text { portanto, tem função } \\
\text { de acolher os } \\
\text { pacientes }\end{array}$ \\
\hline $\begin{array}{l}\text { Nova } \\
\text { Agenda }\end{array}$ & $\begin{array}{l}\text { Ao tentar diminuir o tempo de fila dos } \\
\text { pacientes, estabelece empatia e afeto, ao } \\
\text { reconhecer a desumanização de uma } \\
\text { espera longa }\end{array}$ & $\begin{array}{l}\text { Propõe a atingir uma das } \\
\text { metas: a diminuição das } \\
\text { filas e do tempo de } \\
\text { espera }\end{array}$ & $\begin{array}{lr}\text { Reconhece } & \text { que } \\
\text { acolhimento } & \text { deve } \\
\text { responder } & \text { as } \\
\text { necessidades dos } \\
\text { usuários, tentando } \\
\text { diminuir o tempo de } \\
\text { fila }\end{array}$ \\
\hline $\begin{array}{l}\text { Investigação } \\
\text { SUS }\end{array}$ & $\begin{array}{l}\text { Propõe uma investigação que atinge } \\
\text { todas as dimensões de humanização: cria } \\
\text { afeto, reconhece a vida humana, percebe } \\
\text { o humano como ser insubstituível e } \\
\text { identifica as pessoas em sua } \\
\text { integralidade }\end{array}$ & $\begin{array}{l}\text { A investigação seria ideal } \\
\text { para atingir todas as } \\
\text { diretrizes, princípio e } \\
\text { metas do PNH, a fim de } \\
\text { integrar todo o sistema } \\
\text { SUS em uma única } \\
\text { direção }\end{array}$ & $\begin{array}{lr}\text { Propõe } & \text { uma } \\
\text { investigação que } \\
\text { pode melhor o } \\
\text { acolhimento dos } \\
\text { usuários em todas as } \\
\text { vertentes do SUS }\end{array}$ \\
\hline $\begin{array}{l}\text { Central de } \\
\text { Telefonia }\end{array}$ & $\begin{array}{l}\text { Percebe as necessidades dos pacientes } \\
\text { e propõe a criação de ouvidoria para } \\
\text { receber problemas de cada pessoa e } \\
\text { demonstrar empatia pelos usuários }\end{array}$ & $\begin{array}{l}\text { Pode ser considerada um } \\
\text { dos dispositivos } \\
\text { propostos: um sistema de } \\
\text { escuta especializada }\end{array}$ & $\begin{array}{l}\text { Pode ser considerado } \\
\text { o primeiro contato } \\
\text { com o hospital com } \\
\text { pacientes de primeira } \\
\text { vez e, portanto, } \\
\text { devem ser acolhidos, } \\
\text { escutado, } \\
\text { identificando suas } \\
\text { queixas e demandas }\end{array}$ \\
\hline $\begin{array}{l}\text { Criação de } \\
\text { Distrações }\end{array}$ & $\begin{array}{l}\text { Propõe a diminuição da sensação do } \\
\text { tempo de espera: reconhece o ser com } \\
\text { suas dificuldades (utilização da televisão } \\
\text { para quem não sabe ler) e como pessoas } \\
\text { únicas }\end{array}$ & $\begin{array}{l}\text { Segue a diretriz de } \\
\text { acolhimento e permite } \\
\text { uma menor sensação do } \\
\text { tempo de fila }\end{array}$ & $\begin{array}{l}\text { As distrações também } \\
\text { acolhem os usuários } \\
\text { ao perceberem suas } \\
\text { necessidades durante } \\
\text { a fila de espera }\end{array}$ \\
\hline $\begin{array}{l}\text { Ambiente } \\
\text { Feliz }\end{array}$ & $\begin{array}{l}\text { Percebe as necessidades dos usuários } \\
\text { de estar em um ambiente aconchegante e } \\
\text { não mais em um local cinza e sem vida }\end{array}$ & $\begin{array}{l}\text { Segue a diretriz de } \\
\text { acolhimento ao permitir } \\
\text { que os usuários se sintam } \\
\text { confortáveis }\end{array}$ & $\begin{array}{lrr}\text { Uma organização do } & \text { lr } \\
\text { ambiente, com } & \text { a } \\
\text { utilização de } & \text { cores, } \\
\text { iluminação e } & \text { móveis } \\
\text { estabelece } & & \text { uma } \\
\text { percepção } & \text { de } \\
\text { acolhimento } & \text { do } \\
\text { usuário } & \end{array}$ \\
\hline
\end{tabular}

O quadro anterior relaciona cada proposta gerada com os conceitos de humanização, com o PNH e com o conceito de acolhimento. É importante destacar ainda que as propostas com maior pontuação (voluntário bom ouvinte, treinamento humanizado de funcionários e balcão de acolhimento) foram aquelas em que os conceitos de humanização e acolhimento estavam diretamente incluídos e as diretrizes do $\mathrm{PNH}$ eram mais bem abordadas. 


\section{CONCLUSÃO}

Quando se pensa na palavra Humanização, características relacionadas à ética e ao reconhecimento da pessoa humana são lembradas. No entanto, não se percebe como o tema deveria ser abordado em todas as ações da sociedade e como humanizar deveria ser uma prática comum. Este projeto tentou, portanto, efetivar os ideais de humanização e as diretrizes do SUS em ações. Pode-se dizer que o objetivo de utilizar - Design Thinking para sugerir ações de humanização da saúde seguindo as diretrizes do SUS foi atingida, de forma que cada proposta também apresentou abordagem em acolhimento.

É importante ressaltar que o Design Thinking por possuir foco em atender as necessidades do usuário possui grande sinergia com o tema de Humanização, pois ambos buscam colocar as pessoas como foco e se beneficiam do uso da empatia.

É necessário observar, no entanto, que, apesar das propostas estarem interligadas com as diretrizes e conceitos desenvolvidos

\section{REFERÊNCIAS}

[1] BRASIL. Ministério da Saúde. SecretariaExecutiva. Núcleo Técnico da Política Nacional de Humanização. HumanizaSUS: Política Nacional de Humanização: A humanização como eixo norteador das práticas de atenção e gestão em todas as instâncias do SUS, 2004

[2] BRASIL; Ministério da Saúde. Secretaria de Atenção à Saúde. Política Nacional de Humanização: Acolhimento e Classificação de Risco nos Serviços de Urgência, HumanizaSUS 1a Ed., Brasília, 2010

[3] British Design Council, Design methods for developing services; 2011

[4] BROWN, T. Design Thinking. Harvard Business Review, 2008.

[5] BROWN, T. Design Thinking: Uma Metodologia Poderosa para decretar o fim das velhas ideias. Rio de Janeiro: Elsevier, 2010 pela teoria do projeto, a maioria das ideias não contemplaram diretamente e profundamente a proposta de integrar gestão, funcionários e pacientes; a ampliação da autonomia das pessoas envolvidas no sistema e a diminuição de diferenças e hierarquizações.

A realização de um estudo futuro que visa integrar a gestão dos funcionários, médicos e pacientes mais profundamente seria interessante e atingiria as diretrizes de humanização do SUS. Pesquisas e investigações sobre o tema no hospital Pedro Ernesto como um todo e no sistema de saúde do Estado e em âmbito nacional, seriam outras propostas de trabalho.

Por fim, é importante concluir com a percepção de que o projeto pretendeu acrescentar ao Hospital Pedro Ernesto medidas concretizadas e humanizadas que pudessem atender as demandas dos usuários, pensando nos recursos que o hospital pudesse fornecer.

[6] DESIGN COUNCIL; The Design Process: What is the Double Diamond?. 2015

[7] DESLANDES, S.F. Humanização dos cuidados em saúde: conceitos, dilemas e práticas. Rio de Janeiro: Editora Fiocruz; 2006.

[8] FORTES, P.A. Ética, direitos dos usuários e políticas de humanização da atenção à saúde. Saúde e Sociedade v.13, n.3, p.30-35, set-dez 2004.

[9] IDEO, Human Centered Design, Toolkit, 2nd Edition, 2011

[10] MORAES, Alexandre de. Direito Constitucional, 2000, 7 ed. Editora Atlas

[11] RIOS, I. Caminhos da Humanização na saúde: Prática e Reflexão. São Paulo: Editora Áurea, 2009. 


\section{Gapítulo 17}

\section{CONDICÕES DE TRABALHO DOS TATUADORES: UMA ANÁLISE ERGONÓMICA A PARTIR DO MÉTODO RULA}

\section{Anderson Vinicius Knoedler Farias}

Humberto da Silva Gonçalves

Ettore de Lacerda Arpini

Fernando Gonçalves Amaral

Resumo: Embora culturalmente aceitas em sociedades da antiguidade, tatuagens historicamente possuem caráter controverso no mundo ocidental. O crescimento vertiginoso de adeptos desta prática nos últimos anos despertou interesse acadêmico quanto aos seus impactos sociais, culturais e de saúde. Porém, os artistas que a promovem são recorrentemente negligenciados, de modo que existem poucos estudos versando sobre as condições de trabalho de tatuadores. Estes profissionais trabalham várias horas ininterruptamente em posturas desfavoráveis, expostos à vibração manubraquial e, ainda, a produtos químicos e fluidos corporais, capazes de transmitir infecções. Dado este contexto, o presente estudo visa analisar as condições ergonômicas relativas à postura dos profissionais tatuadores de um estúdio de tatuagem. A metodologia utilizada empregou entrevistas e checklists, associados à aplicação do método RULA em três sessões de tatuagem. Os resultados indicaram que as partes do corpo sujeitas a maior risco são o pescoço e o punho, cuja postura, aliada à carga estática prolongada, torna o trabalho dos tatuadores penoso.

Palavras-chave: Ergonomia. RULA. Posturas estáticas. Tatuador. Tatuagem. 


\section{INTRODUÇÃO}

A crescente profissionalização da prática da tatuagem, assim como sua tendência de estabelecer-se em locais especializados não foi homogênea no mundo ocidental. Até bem entrados os anos sessenta, esta atividade permaneceu itinerante e manual, centrada na figura dos tatuadores, que se deslocavam por diferentes ambientes à procura de clientes, e, em numerosas ocasiões, percorrendo grandes trajetos em caminhões ou veículos que eram acondicionados como ateliês (PIERRAT, 2000, p. 210).

Nos anos 1980, a tatuagem passa por uma nova fase: especialmente na Europa e nos Estados Unidos, esta atividade ingressa no mundo do mercado profissionalizado, com o estabelecimento de estúdios de caráter comercial, com equipamentos importados, materiais descartáveis, e diversos catálogos e revistas de desenhos disponíveis para a clientela fazer suas escolhas (MARQUES, 1997, p. 198). Tal transição aconteceu durante os anos oitenta e começo dos noventa no Brasil, e era um período que se caracterizava pela abertura de várias lojas modernas no meio urbano e uma simultânea proliferação de ateliês improvisados dentro do círculo doméstico (MARQUES, 1997, p. 198). A partir dos anos 2000, a Internet e as revistas especializadas se tornaram meios importantes de difusão, onde se pode encontrar a informação essencial e especialmente en vogue no momento, assim como os procedimentos e cuidados para realização e manutenção da tatuagem, os novos desenhos e estilos, dados históricos e curiosidades. O resultado desta mudança cultural foi a criação de um universo de apreciação e valoração desta nova expressão estética (LE BRETON, 2002, p. 178).

Devido a crescente apreciação da tatuagem como arte e da expansão deste ofício, existe um movimento por parte dos estúdios de tatuagem para oferecerem condições ergonômicas adequadas aos seus clientes, aprimorando aspectos de higiene, segurança e conforto do procedimento. O emprego de luvas, máscaras e agulhas descartáveis visa mitigar a transmissão de doenças infecciosas através de bactérias, como Staphylococcus aureus e Streptococcus pyogenes, ou de vírus como das hepatites B e C (HANDRICK et al., 2003). No que concerne ao conforto, o uso de macas com design ergonômico buscam reduzir o desconforto e a dor referida pelo cliente. Contudo, aos tatuadores Ihe é, em geral, negligenciado o cuidado com a ergonomia: quotidianamente expostos a fluidos corporais, tintas de tatuagens e diversos produtos solventes, desinfetantes, potencialmente irritantes ou alergênicos (KLUGER, 2014), estes profissionais estão quotidianamente expostos a posturas estáticas mantidas em longa duração e a vibrações manubraquiais de até $150 \mathrm{~Hz}$. Tais vibrações de forma profissional estão relacionadas com problemas vasculares nas mãos de trabalhadores (AARHUS et al., 2018).

Em particular, o estudo compreensivo $\mathrm{La}$ santé dans l'industrie du tatouage: une étude observationnelle de 448 tatoueurs français realizado na França (KLUGER, 2004), aponta que a maior parte das reclamações relacionadas a saúde ocupacional por parte dos tatuadores são relacionadas a problemas musculoesqueléticos. Como agravante, há poucos estudos acadêmicos acerca do tema - um dos poucos existentes, no entanto, conduzido por Keester e Sommerich (2017), no qual se mediu o esforço muscular de 10 tatuadores da cidade de Ohio (EUA) durante sessões de tatuagem, apontou que todos estes profissionais excederam o valor máximo de esforço recomendado para impedir danos à saúde, especialmente nos músculos das costas e do pescoço.

Não obstante, embora a Norma Regulamentadora NR $\neg 17 \quad$ estabeleça parâmetros que visam proporcionar o máximo de conforto, segurança e eficiência ao trabalhador, a profissão do tatuador sequer é regulamentada no Brasil, existindo um projeto de lei - ainda não aprovado - o Projeto de Lei 199 de 2015, proposto pela Deputada Cristiane Brasil, que dispõe sobre o exercício da profissão de Tatuador e do aplicador de Piercing. Todavia, nos 17 artigos contidos no Projeto de Lei, nenhum discorre sobre condições ergonômicas do trabalhador.

Evidencia-se, assim, a presença de um gap teórico-prático neste quesito. Dado o contexto, o presente estudo se propõe a analisar o posto de trabalho e a postura de tatuadores de um estúdio de tatuagem através da aplicação do Método RULA, objetivando analisar o risco das posturas assumidas por estes profissionais e os fatores que o agravam, bem como avaliar o grau de urgência de ações mitigadoras, oferecer sugestões de melhorias e embasar estudos futuros que queiram explorar este assunto. Além disso, o artigo visa explicitar melhor a aplicação do método, podendo ser utilizado 
como guia para análises em outros postos de trabalho com posturas predominantemente estáticas.

\section{PROCEDIMENTOS METODOLOGICOS}

O método RULA (MCATEMNEY e CORLETT, 1993), é uma adaptação do método OWAS, acrescido de outras variáveis como: força, repetição e amplitude de movimento articular, sendo recomendado para analisar a sobrecarga concentrada no pescoço e membros superiores durante o trabalho, e para tanto utiliza diagramas para simplificar a identificação das amplitudes de movimentos nas articulações, bem como avalia o trabalho muscular estático e as forças exercidas pelos segmentos em análise. Desta forma, o método RULA mostrou-se o mais adequado, visto que principalmente os membros superiores são utilizados nas tarefas e a postura estática grande fonte de riscos à categoria - é mantida por longos períodos. Decidido o instrumento de análise, foi feita uma visita ao local, onde se entrevistou os colaboradores e o dono do estabelecimento. Com a permissão para uso de imagens, foi então acompanhado o trabalho de três tatuadores do local, analisando e fotografando as posturas de cada um deles.

A aplicação do método ocorreu com o acompanhamento de uma cópia física em papel de um worksheet como guia de aplicação do método. Este foi preenchido manualmente, com o auxílio de uma caneta esferográfica, in loco, durante a inspeção da postura do trabalhador enquanto exercia o seu ofício. Com a permissão do tatuador, foi possível se posicionar em qualquer local das salas de tatuagem sem que houvesse interrupções ao profissional em nenhum momento durante as observações.

Note-se, ainda, que um tatuador pode assumir diferentes posturas na realização do seu trabalho, dependendo das dimensões da tatuagem a se realizar e, em especial, na localização da tatuagem no corpo do cliente.
Não obstante, é ainda evidente o fato de cada tatuador adotar posturas diferentes para uma mesma tarefa, em função da sua percepção pessoal de conforto. Deste modo, cientes destes empecilhos e limitações, foi decidido acompanhar três sessões distintas de tatuagem, realizadas na mesma empresa, porém por tatuadores diferentes, a fim de compreender os problemas relacionadas à postura dos profissionais de tatuagem.

\section{RESULTADOS}

O presente estudo foi realizado em um estúdio com mais de 21 anos de atuação no ramo de piercings e tatuagens contando com duas sedes. Os tatuadores do local enfrentam longas jornadas de trabalho estático, muitas vezes passando de 8 horas diárias, com poucos minutos de descanso, conforme mencionado pelos próprios profissionais, pois o ganho depende de sua própria produtividade.

Antes de aplicar o método RULA, uma conversa informal com os tatuadores da empresa abordada revelou que estes já possuíam ciência das condições ergonômicas precárias do ofício, mas as tomam como intrínsecas ao trabalho. É importante mencionar que na percepção dos tatuadores, a prevalência de casos graves de lombalgia e de problemas musculoesqueléticos severos no punho é alta.

Para a ratificação destas hipóteses, foram denominadas as três sessões de tatuagem: (i) Sessão A, (ii) Sessão B e (iii) Sessão C. Esta seção do trabalho apresenta os resultados do método RULA para cada uma das sessões acompanhadas.

\subsection{SESSÃO DE TATUAGEM A}

A Sessão A refere-se à primeira sessão de tatuagem estudada, cuja tatuagem foi realizada na parte inferior do antebraço do cliente, como mostra a Figura 1. 
FIGURA 1: posição do tronco, do punho e das pernas do tatuador da sessão A.
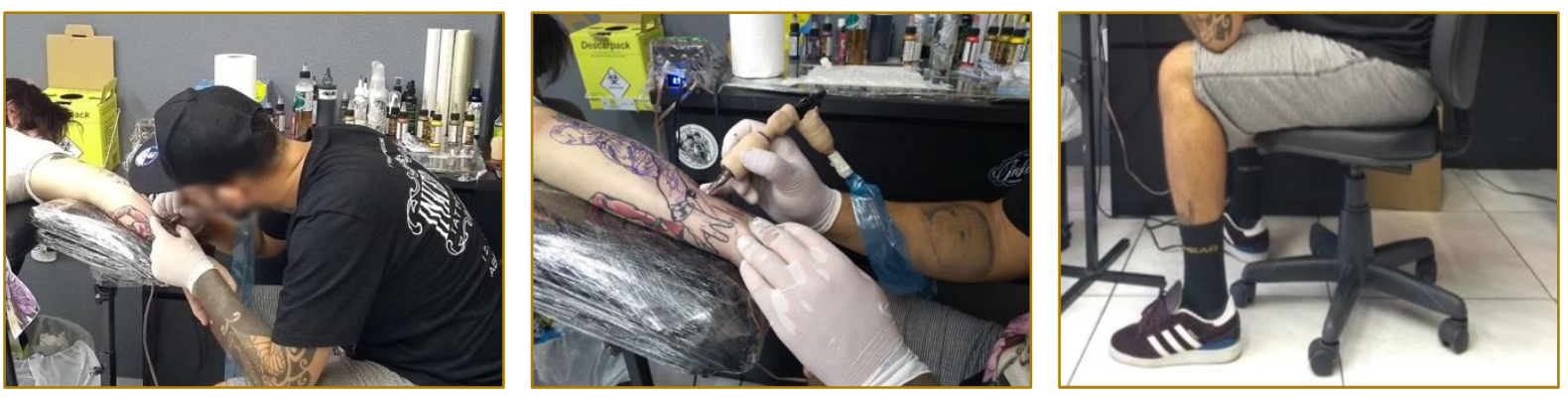

Fonte: Autor (2018)

A primeira etapa de aplicação do método RULA consistiu na análise dos braços e punhos do trabalhador. O escore oriundo da posição do braço foi 4 (soma de +3 , pois braço está entre $45^{\circ}$ e $90^{\circ}$ em relação ao tronco, +1 pois os ombros estão encolhidos, +1 pela abdução dos braços e -1 , porque há apoio dos cotovelos e o trabalhador está inclinado). Quanto ao escore advindo da posição do antebraço, levou-se em consideração o fato de estes se encontrarem a mais de $90^{\circ}$ em relação ao braço, sem nenhum outro desconto, o que resultou em 2 pontos. Resta ainda, como parte da primeira etapa, avaliar a posição do punho: evidenciase, ainda pela Figura 1, a seguir, que no pior caso, do punho direito, este está levemente flexionado ( +2 pontos) e possui um desvio da linha neutra (+1 ponto), resultando em um escore de 3 pontos.

Pela Tabela A do método RULA, chegou-se a um escore de postura de 4 pontos. A esta pontuação foram adicionados 1 ponto de uso muscular, pois a posição é estática ou se repete mais de quatro vezes por minuto, e 3 pontos de carga, pois, apesar de a máquina de tatuagem ser leve, ela gera vibração constante em uma posição estática ao trabalhador. Os resultados da análise de braços e punhos da Sessão A estão consolidados na Tabela 1.

TABELA 1: consolidação da análise de braço, antebraço e punho durante a Sessão A

\begin{tabular}{|l|c|c|c|}
\multicolumn{1}{|c|}{ Análise } & Escore & Ajuste & Total \\
\hline Posição do Braço & 3 & 1 & 4 \\
\hline Posição do Antebraço & 2 & 0 & 2 \\
\hline Posição do Punho & 2 & 1 & 3 \\
\hline Resultado na Tabela A & 4 & - & 4 \\
\hline Uso muscular & 1 & - & 1 \\
\hline Força ou Carga & 3 & - & 3 \\
\hline \multicolumn{2}{|c|}{ Escore Total de Braços, Antebraços e Punhos na } & 8 \\
\hline
\end{tabular}

Fonte: Pesquisa de campo (2018)

A segunda etapa do método RULA constituise pelo estudo da posição do pescoço, do tronco e da extremidade inferior do trabalhador. No que tange ao pescoço do tatuador, evidencia-se que esse está em extensão em relação ao tronco (vide Figura 1) e que eventualmente ocorre desvio ou torção, o que gera um escore de 4 pontos com ajuste de 2 pontos por torção e desvio do pescoço.
Analisando a posição do tronco, percebe-se que tal está em um ângulo acima de $20^{\circ} \mathrm{com}$ a normal, porém sem qualquer giro ou desvio. Assim, o escore que se the atribuiu foi 3 pontos. Relativamente à posição da extremidade inferior, nota-se que tais estão retas e apoiadas, gerando assim uma pontuação de 1 ponto. 
Aplicando-se estes valores na Tabela B, chegou-se a uma pontuação de 8 pontos. Em consonância com o método, adicionou-se 1 ponto de uso muscular, em função de esta posição do tronco ser mantida por sessões de tatuagem que podem durar horas. Como não há carga externa suportada pelo pescoço, tronco ou pernas, não houve ajuste quanto a este aspecto. Deste modo, a pontuação resultante deste trecho da análise é 9 pontos, como mostra a Tabela 2.

TABELA 2: consolidação dos resultados da análise de pescoço, tronco e pernas durante a Sessão A

\begin{tabular}{|l|c|c|c|}
\multicolumn{1}{|c|}{ Análise } & Escore & Ajuste & Total \\
\hline Posição do Pescoço & 4 & 2 & 6 \\
\hline Posição do Tronco & 3 & 0 & 3 \\
\hline Posição das Pernas & 1 & 0 & 1 \\
\hline Resultado na Tabela B & 8 & - & 8 \\
\hline Uso muscular & 1 & - & 1 \\
\hline Força ou Carga & 0 & - & 0 \\
\hline Escore Total de Pescoço, Tronco e Pernas na Sessão & 9 \\
\hline \multicolumn{2}{|c|}{ A } \\
\hline
\end{tabular}

Fonte: Pesquisa de campo (2018)

De posse das pontuações resultantes da análise de braços, punhos, de pescoço, tronco e pernas, pôde-se aplicar na Tabela C, o que resultou em um escore final de 7 pontos. Assim, a postura adotada pelo tatuador durante a Sessão A possui classificação alto risco, cujos fatores predominantes foram, em particular, a posição do pescoço, a posição dos braços e o fato de a carga da máquina de tatuagem ser constante e vibratória. Medidas para que as condições de trabalho do tatuador sejam melhoradas devem ser tomadas imediatamente dado a situação exposta neste estudo.

\subsection{SESSÃO DE TATUAGEM B}

A Sessão B concerne à segunda sessão de tatuagem estudada, cujo desenho foi realizado na parte inferior do braço do cliente, vide Figura 2.

FIGURA 2: posição do tronco, do punho e das pernas do tatuador da sessão A.

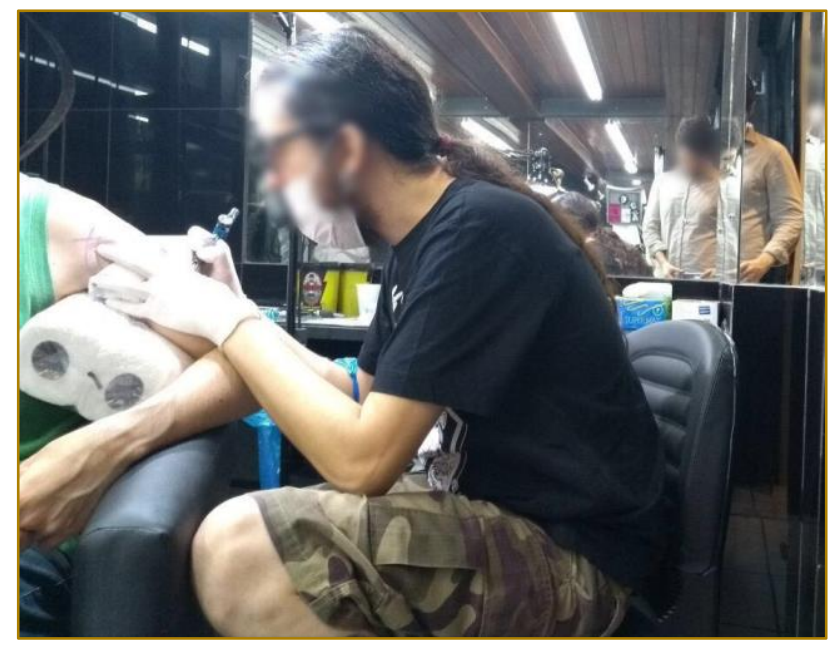

Fonte: autor (2018) 
Sob o aspecto postural dos braços e punhos do método RULA, observou-se que os braços do tatuador estavam em posicionados entre $20^{\circ}$ e $45^{\circ}$ em relação ao tronco, sem abdução perceptível. Adicionalmente, além de os ombros não estarem levantados, há suporte para dos braços durante o exercício do ofício sobre as pernas, de modo que o escore de risco desta posição para os braços resulte em apenas 1 ponto. Quanto ao antebraço, é visível que a angulação formada entre este e o braço é superior a $100^{\circ}$, o que gera um escore de risco de 2 pontos. Neste escore, ainda, não há ajustes na pontuação, pois os ombros não estão encolhidos e não ocorre abdução do antebraço. Quanto à posição do punho, a Figura 2 ilustra a presença de uma pequena flexão com ângulo inferior a 15으, a qual, considerando o desvio lateral em relação à linha neutra, gera um risco de 3 pontos para esta parte do corpo, considerando giro do pulso médio.

Utilizando a Tabela A do método RULA com base nos valores obtidos, chega-se a um escore de postura de 3 pontos. Semelhantemente à análise da Sessão A, somam-se a tal pontuação 1 ponto de uso muscular, em função de a posição ser estática ou se repetir mais de quatro vezes por minuto, e 3 pontos de carga, em decorrência da vibração constante da máquina de tatuagem. O escore final de risco sobre braços e punhos obtidos por análise por Método RULA da Sessão B foi, assim, 7 pontos. Os resultados da análise se encontram consolidados na Tabela 3.

TABELA 3: consolidação dos resultados obtidos na análise de braço e punho durante a Sessão B

\begin{tabular}{|l|c|c|c|}
\multicolumn{1}{|c|}{ Análise } & Escore & Ajuste & Total \\
\hline Posição do Braço & 2 & -1 & 1 \\
\hline Posição do Antebraço & 2 & 0 & 2 \\
\hline Posição do Punho & 2 & 1 & 3 \\
\hline Resultado na Tabela A & 3 & - & 3 \\
\hline Uso muscular & 1 & - & 1 \\
\hline Força ou Carga & 3 & - & 3 \\
\hline \multicolumn{2}{|c|}{ Escore Total de Braços e Punhos na Sessão B } & 7 \\
\hline \multicolumn{2}{|r|}{ Fonte: Pesquisa de campo (2018) } \\
\hline
\end{tabular}

Procedendo-se para a segunda etapa do método, a análise da posição do pescoço, do tronco e da extremidade inferior, evidenciouse que o pescoço do tatuador da Sessão B estava, assim como aquele do tatuador da Sessão A, com leve extensão (mascarada pela flexão do tronco), como se vê ainda na Figura 2. Na ausência de desvios e giros, seu escore de risco foi averiguado, portanto, em 4 pontos.

No que toca ao tronco, a mesma imagem revela uma leve inclinação frontal, estimada inferior a 20 , sem presença de giro ou desvio, o que gera um escore de risco de 2 pontos.
Quanto à extremidade inferior, as pernas se encontram firmes no chão, com escore de 1 ponto de risco. Assim, a pontuação resultante da busca por estes valores na Tabela B do Método RULA é de 5 pontos, aos quais foram adicionados 1 ponto por uso muscular, assim como na análise da Sessão $A$, em função da necessidade de a atividade ser estática. Analogamente a análise da seção anterior, não existindo carga suportada pelos membros analisados nesta etapa do método, não foram adicionados pontos de risco sob o aspecto de carga. Assim, a pontuação resultante deste trecho da análise é 6 pontos, como mostra a Tabela 4. 
TABELA 4: consolidação dos resultados da análise de pescoço, tronco e extremidade inferior durante a Sessão B

\begin{tabular}{|l|c|c|c|}
\multicolumn{1}{|c|}{ Análise } & Escore & Ajuste & Total \\
\hline Posição do Pescoço & 4 & 0 & 4 \\
\hline Posição do Tronco & 2 & 0 & 3 \\
\hline Posição das Pernas & 1 & 0 & 1 \\
\hline Resultado na Tabela B & 5 & - & 5 \\
\hline Uso muscular & 1 & - & 1 \\
\hline Força ou Carga & 0 & - & 0 \\
\hline Escore Total de Pescoço, Tronco e Pernas na Sessão & 6 \\
\hline
\end{tabular}

Fonte: Autor (2018)

Aplicando os valores obtidos na Tabela C do Método empregado, obtém-se um escore de risco da postura do tatuador da Sessão B equivalente a 7 pontos. É notável que, assim como na Sessão A de tatuagem, análise da postura do trabalhador foi classificada como de risco máximo. De modo similar ao observado no RULA da Sessão de tatuagem A, listaram-se entre os fatores preeminentes para o risco da postura a sua manutenção prolongada, agravada pela constante exposição do trabalhador à vibração manubraquial, e a posição do pescoço, a qual apresentou em leve extensão. O risco da postura se deixa converter, assim, em um nível máximo de urgência para tomada de ações de melhoria. Ações mitigadoras de risco são de caráter imediato.

\subsection{SESSÃO DE TATUAGEM C}

A Sessão $C$ diz respeito à terceira sessão de tatuagem estudada, cujo desenho foi realizado na região do ombro do cliente, como evidencia a Figura 3.

FIGURA 3: tatuador da Sessão C.

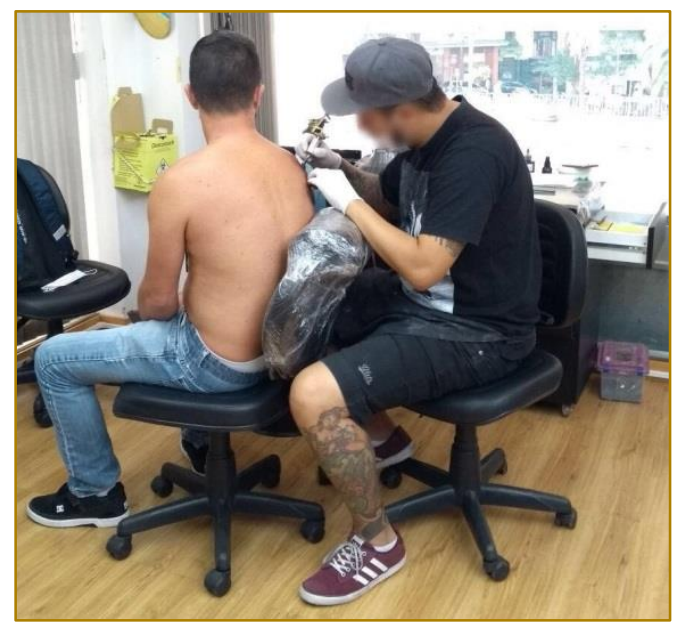

Fonte: Autor (2018)

Observando-se a posição dos braços do tatuador da Sessão C, constata-se que estes encontram-se entre $20^{\circ}$ e $45^{\circ}$ em relação ao tronco, com leve abdução. Cabe ressaltar que, ao contrário do verificado nas outras sessões, em função de a tatuagem ser realizada em outra região do corpo do cliente, o tatuador é incapaz de usar as próprias pernas como suporte para os braços. Há, ainda, a elevação dos ombros, de modo que o risco avaliado desta postura em relação aos braços seja de 4 pontos. Prosseguindo-se para a análise da posição do antebraço, é visível a repetição do ocorrido nas outras 
sessões de tatuagem: o ângulo formado pelo antebraço e o braço é superior a 100, o que gera um escore de risco de 2 pontos. Embora a adução do antebraço não incorra em incremento do risco, o fato de os ombros estarem elevados gera um ajuste de um ponto adicional ao escore do antebraço, totalizando 3 pontos de risco para este membro. $\mathrm{Na}$ análise do punho, foi considerado o pior caso observado durante a sessão: flexão com ângulo inferior a $15^{\circ}$ e desvio lateral em relação à linha neutra, o que, considerando giro do pulso médio, gera um escore de risco de 4 pontos.
Empregando a Tabela $A$ do método RULA, chega-se a um escore de risco postural para braços e punhos de 5 pontos. Analogamente às sessões analisadas nas seções anteriores, somaram-se 4 pontos à esta pontuação, devido a manutenção prolongada da postura e da constante vibração manubraquial advinda da máquina de tatuar. O escore final de risco sobre braços e punhos obtidos por análise por Método RULA da Sessão de tatuagem $\mathrm{C}$ foi, portanto, 9 pontos. A consolidação destes resultados é observável na Tabela 5

TABELA 5: consolidação dos resultados obtidos na análise de braço e punho durante a Sessão C

\begin{tabular}{|l|c|c|c|}
\hline \multicolumn{1}{|c|}{ Análise } & Escore & Ajuste & Total \\
\hline Posição do Braço & 2 & 2 & 4 \\
\hline Posição do Antebraço & 2 & 0 & 2 \\
\hline Posição do Punho & 3 & 1 & 4 \\
\hline Resultado na Tabela A & 5 & - & 5 \\
\hline Uso muscular & 1 & - & 1 \\
\hline Força ou Carga & 3 & - & 3 \\
\hline \multicolumn{2}{|c|}{ Escore Total de Braços e Punhos na Sessão C } & 9 \\
\hline
\end{tabular}

Fonte: Autor (2018)

No que tange à análise da posição do pescoço do tatuador da Sessão C estava, verificou-se que, ao contrário das outras sessões, nas quais o tatuador se encontrava na pior posição possível, com o pescoço levemente estendido, aqui esta parte do corpo do profissional está flexionada em um ângulo superior a 20․ Contudo, apesar disso, evidencia-se, ainda, a ocorrência dos agravantes giro e desvio do pescoço (vide Figura 3). Deste modo, o escore de risco atribuído nesta etapa para este membro foi de 5 pontos.

O fato de a posição da tatuagem ser mais elevada faz com que o tronco do tatuador esteja em uma posição próxima ao seu eixo zenital, em contraste com o registrado nas outras sessões, o que the confere um escore de risco de apenas 1 ponto, pois não há giro ou desvio. É interessante ressaltar que se, de certa forma, o tronco estava em uma posição adequada, o tatuador busca melhor visibilidade da tatuagem em execução e acaba compensando com a posição precária do pescoço. Em relação às pernas, estas se encontravam bem apoiadas no chão, com escore de 1 ponto de risco. Assim, o output da Tabela B do Método RULA ao se Ihe entrar os dados obtidos acerca das posições do pescoço, tronco e pernas é de 7 pontos, aos quais foram adicionados 1 ponto por uso muscular, assim como nas análises das sessões $A$ e B. A pontuação resultante deste trecho da análise é, portanto, 6 pontos, como mostra a Tabela 6. 
TABELA 6: consolidação dos resultados obtidos na análise de pescoço, tronco e pernas durante a Sessão C

\begin{tabular}{|l|c|c|c|}
\hline \multicolumn{1}{|c|}{ Análise } & Escore & Ajuste & Total \\
\hline Posição do Pescoço & 3 & 2 & 5 \\
\hline Posição do Tronco & 1 & 0 & 1 \\
\hline Posição das Pernas & 1 & 0 & 1 \\
\hline Resultado na Tabela B & 7 & - & 7 \\
\hline Uso muscular & 1 & - & 1 \\
\hline Força ou Carga & 0 & - & 0 \\
\hline Escore Total de Pescoço, Tronco e Pernas na Sessão & 8 \\
\hline
\end{tabular}

Fonte: Autor (2018)

Assim como nas outras sessões de tatuagem estudadas, o resultado obtido da Tabela C do Método RULA sugere que a postura adotada pelo trabalhador possui risco máximo, equivalente a 7 pontos e, portanto, demanda ação imediata, enquadrando-se no nível 4 da classificação de urgência. Contribuíram hegemonicamente para o risco alto da postura do tatuador na Sessão C fatores já identificados nas outras sessões, como evidenciado no gráfico de colunas da Figura 8: a ruim posição dos braços, do punho e dos pescoço, agravados pela longa duração da manutenção da postura e da presença de vibração manubraquial.

FIGURA 8: comparação entre os escores de risco obtidos da aplicação do método RULA nas sessões de tatuagem analisadas A, B e C.

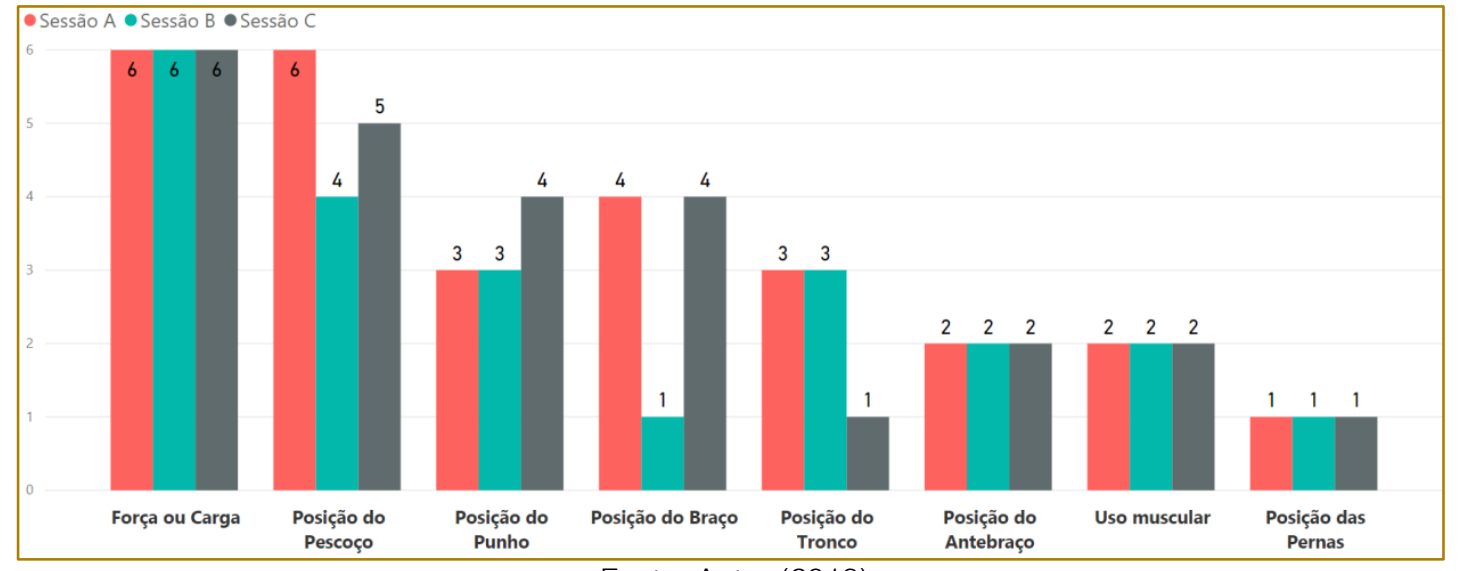

Fonte: Autor (2018)

Realizando-se uma análise comparativa entre as sessões, é perceptível que o elemento que mais contribuiu negativamente para a avaliação dos riscos das posturas de todas as sessões de tatuagem analisadas foi a posição do pescoço do trabalhador, como ilustra o gráfico de colunas das médias dos escores obtidos para cada membro analisado (Figura 9). 
FIGURA 9 - médias dos escores de risco obtidos da aplicação do método RULA nas sessões de tatuagem analisadas $\mathrm{A}, \mathrm{B}$ e $\mathrm{C}$.

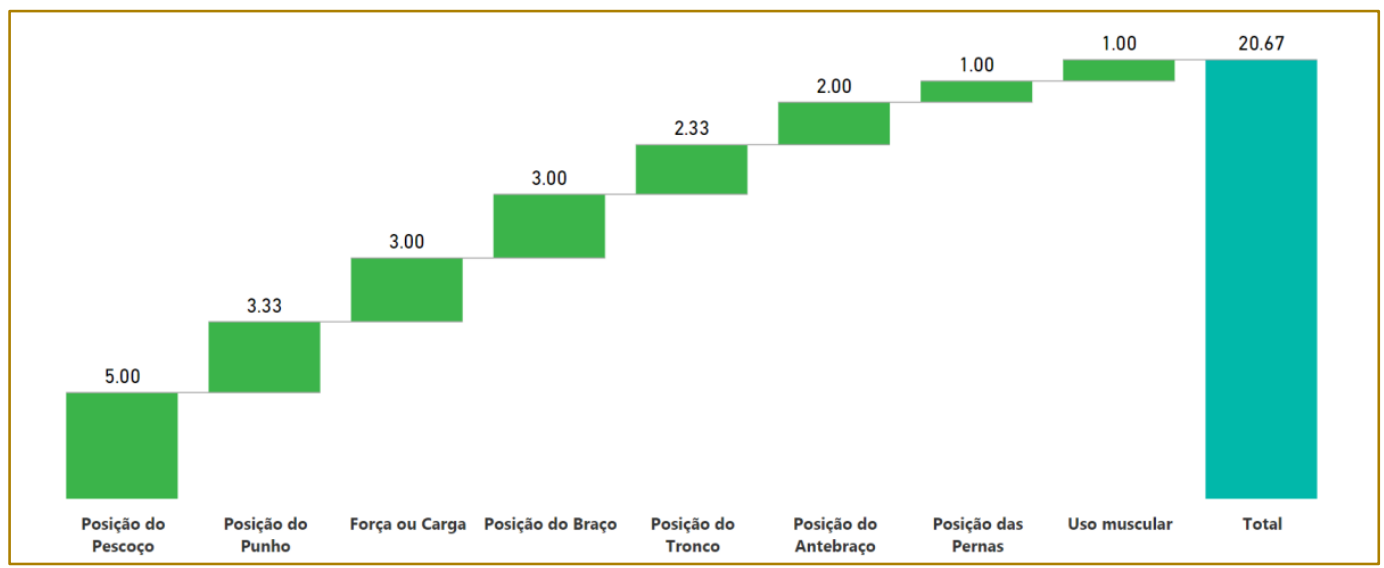

Fonte: Autor (2018)

Isto é particularmente interessante, pois esta região não foi mencionada pelos próprios tatuadores, durante diálogos informais, como uma zona particularmente suscetível a dores ou desconfortos. Outra particularidade deve ser mencionada é o fato de os escores de risco relacionados com a posição do tronco não serem, de acordo com os resultados do Método RULA, o principal membro afetado pela postura de trabalho; apesar de os trabalhadores comentarem possuir alta prevalência de lombalgia. Não obstante, a alta pontuação de risco por força ou carga sugere que não é a postura do tronco que é necessariamente ruim, senão o fato da sua manutenção prolongada, por vezes chegando a 15 horas seguidas, dependendo do tamanho e complexidade da tatuagem realizada.

Tendo em vista os resultados obtidos nas análises, entende-se que estes profissionais correm sérios riscos durante o exercício de sua profissão. O dono do estabelecimento afirmou estar trabalhando neste ramo há cerca de 20 anos e já passou por cirurgias devido a problemas relacionados com a coluna vertebral. As consequências que estes profissionais podem enfrentar devido a fatores como o trabalho estático e repetitivo, se não forem tomadas medidas para melhorar as suas condições de trabalho, são sérias e podem comprometer as capacidades de desempenho de suas tarefas no futuro.

\section{CONSIDERAÇÕES FINAIS}

Todos os profissionais analisados apresentaram resultados preocupantes advindos das análises ergonômicas realizadas pelo método RULA, exigindo mudanças de caráter imediato nos postos de trabalho. Uma das mudanças seria na cadeira utilizada pelos tatuadores: o encosto da cadeira somente oferece suporte às costas do indivíduo, sendo que no momento do seu trabalho é necessário também suporte na parte frontal do seu corpo. Se a cadeira desse suporte para a parte frontal do corpo do tatuador, bem como aos seus cotovelos, evitaria que o encosto fosse as próprias pernas do profissional, os resultados das análises poderiam ser diferentes $e$ as condições de trabalhos poderiam ser consideravelmente melhores, dado que esta mudança melhoraria a carga no tronco e pescoço do trabalhador.

Não foram presenciados momentos de pausa na execução das tatuagens durante as sessões observadas. Em conversas informais, alguns tatuadores afirmaram alongar-se antes de iniciar o trabalho, sendo a única vez que realizavam esta prática durante o dia. Desta forma, é altamente recomendado que sejam estudados intervalos durante as sessões de tatuagem, assim como deveriam alongar-se com mais frequência para aliviar as tensões causadas pela má postura que exercem durante o trabalho.

Este artigo evidenciou o passo a passo da aplicação do método RULA. Tal procedimento procurou contribuir para aplicações futuras de um método capaz de gerar resultados satisfatórios para mitigar problemas relacionados com as posturas estáticas e gerar rapidamente indicadores de gestão para problemas ergonômicos. 
Outrossim, as máquinas utilizadas pelos tatuadores costumam apresentar vibrações que variam entre $80 \mathrm{~Hz}$ a $150 \mathrm{~Hz}$. Conforme a literatura indica as vibrações nestas frequências podem provocar consequências na saúde dos trabalhadores, principalmente

\section{REFERÊNCIAS}

[1] AARHUS, L;STRANDEN, E; NORDBY, K C; EINARSDOTTIR, E; OLSEN, R; RUUD, B; BASTPETTERSEN, R. Vascular component of hand-arm vibration syndrome: a 22-year follow-up study. Occupational Medicine. 2018. Disponivel em: https://doi.org/10.1093/occmed/kqy085

[2] BONATO, F.; HARA, M.M.; PENTEADO, A.C.B.; CATAI, R.E. Ergonomics analysis of tattoo artists. FIEP Bulletin, v.87, n. 1., 2017.

[3] BUSSMAN, A.P. Estação de trabalho móvel para tatuadores e esteticistas. 2007. $89 \mathrm{f}$. Trabalho de Conclusão de curso - Universidade Tuiuti do Paraná, Curitiba.

[4] CARDOSO, M.M. Avaliação ergonômica: Revisão dos métodos para avaliação postural. Revista Produção Online. v.6, n.3., 2006.

[5] FONSECA, A.L.P. Tatuar e ser tatuado: "etnografia da prática contemporânea da tatuagem". 2003. 151 f. Tese (Mestrado em Antropologia Social) - Programa de PósGraduação em Antropologia Social, Universidade Federal de Santa Catarina, Florianópolis.

[6] MARQUES, Toni. O Brasil Tatuado e Outros Mundos. Rio De Janeiro: Rocco, Janeiro, 1997.

[7] LE BRETON, David. Antropología del cuerpo y modernidad. Buenos Aires: Nueva Visión, 1995. problemas vasculares. Desta forma, pesquisas futuras abordando o efeito das máquinas de tatuagem nos tatuadores seriam importantes para melhor compreensão dos riscos que este profissional se expõe durante o exercício da sua profissão.

[8] PAIM, C.; PERAÇA, D.; SAPPER, F.; MOREIRA, I.; MOREIRA, T. Análise Ergonômica: Método RULA e OWAS aplicados em uma instituição de ensino superior. Revista Espacios, v. 38, n. 11., 2017.

[9] PIERRAT, JÉRÔNNE. Les hommes illustrés. Le tatouage des origines a nos jours. Paris: Larivière, 2000.

[10] SOMMERICH, C.; KEESTER, D. Being a tattoo artist is a pain in the neck, studies find. Disponível em https://news.osu.edu/news/2017/02/15/tattooartists/ > Acesso em: 09 Jun. 2018.

[11] KLUGER, N. La santé dans l'industrie du tatouage: une étude observationnelle de 448 tatoueurs français. In: Annales de Dermatologie et de Vénéréologie. Elsevier Masson, 2014. S. S365S366.

[12] HANDRICK, W., NENOFF, P., MÜLLER, $\mathrm{H}$. et al. Infektionen durch Piercing und Tattoos - eine Übersicht. WMW, n. 153, p. 194, 2003.

[13] Aarhus, L;Stranden, E; Nordby, K C; Einarsdottir, E; Olsen, R; Ruud, B; BastPettersen, R. Vascular component of hand-arm vibration syndrome: a 22-year follow-up study. Occupational Medicine. 2018. Disponivel em: https://doi.org/10.1093/occmed/kqy085 


\section{Gapítulo 18}

\section{SATISFAÇÃO NO TRABALHO: UMA ANÁLISE DOS SERVIDORES TECNICOS ADMINISTRATIVOS DA FACULDADE DE ADMINISTRAÇÃO E FINANÇAS DA UERJ}

Milena Neves Gradim Ramos

Nátalie Gonçalves Silva

Marcus Brauer*

Fábio Braun

Resumo: O objetivo desta pesquisa foi verificar as principais razões que influenciam na satisfação dos servidores da Faculdade de Administração e Finanças da UERJ. Metodologicamente, foi realizada uma abordagem qualitativa por meio de entrevistas semiestruturadas com servidores administrativos concursados de níveis médio da universidade entre outubro e novembro de 2017, e as perguntas foram adaptadas a partir de um estudo que utilizou uma escala validada com questões sobre satisfação no trabalho. Após análise de conteúdo, os principais resultados indicaram que a dimensão que obteve o maior nível de satisfação foi a relação com os colegas de trabalho e o menor nível de satisfação foi a promoção. Concluímos que devem ser fixadas melhores políticas relacionadas à promoção do servidor, bem como uma progressão que seja efetivamente válida, e devem ser feitos investimentos na capacitação dos servidores para o aperfeiçoamento do seu desempenho. Uma contribuição teórica desta pesquisa foi a adequação de uma escala quantativa para uma pesquisa qualitativa.

Palavras-chave: Satisfação no trabalho. Servidores públicos. UERJ. Servidores técnicos administrativos. 


\section{INTRODUÇÃO}

Para o ser humano o trabalho é primordial, pois é por ele que o ser se relaciona com o mundo, natureza e sociedade. Por proporcionar essas ligações, o trabalho manifesta-se como ininterrupta fonte de criação de subjetividade, acarretando um sentido à vida (ROHM e LOPES, 2015). Por essa razão é relevante que as organizações se preocupem com a valorização, bem-estar e satisfação dos colaboradores.

A satisfação no trabalho está relacionada a uma ciência não exata que pode modificar conforme o ambiente e as particularidades de cada indivíduo (WEYMER et al,2014). Ela está diretamente ligada ao comportamento do funcionário no ambiente de trabalho, pois suas atitudes levam ao bom desempenho empresarial e impacta diretamente na produtividade (PAIVA, et al. 2017). A satisfação ou insatisfação no trabalho pode interferir na saúde do indivíduo, e impactar diretamente na vida pessoal e no ambiente de trabalho do mesmo. (MARQUEZE e MORENO, 2009). Os indivíduos possuem valores diferentes uns dos outros e satisfazer tais valores se torna uma tarefa difícil. Entretanto, quando o gestor aprende a identificar as necessidades e os valores individuais, consegue ter uma melhor percepção a cerca da satisfação (BRANDÃO et al., 2014). Os gestores devem estar cientes de que cada indivíduo tem uma percepção sobre os principais fatores de satisfação e estes estão presentes nos mais variados tipos de organizações, inclusive nas públicas (AGAPITO et al., 2014).

Um dos obstáculos da Administração Pública contemporânea compõe-se do aperfeiçoamento do seu desempenho. Este obstáculo engloba o desempenho dos servidores públicos (GAVAZINI e DUTRA, 2016), que concilia a Administração Pública e a sociedade (AQUINO et al., 2015). O ambiente de trabalho do servidor público está sujeito a críticas e questionamentos em relação à sua produtividade e eficiência do serviço (LIMA e SILVA, 2015). Por esse motivo, considera-se valoroso que os gestores pensem cada vez mais em como tornar o serviço mais eficaz e melhorar a sua qualidade (LIMA e SILVA, 2015). Essa relação de trabalho também se aplica aos servidores de uma universidade pública, que não lidam somente com outros servidores e com problemas internos, mas também com os alunos e a comunidade. Um exemplo de universidade pública é a UERJ.

A UERJ teve origem em 1950, denominada na época como Universidade do Distrito Federal (UDF), somente em 1975 a instituição foi rebatizada mudando o nome para Universidade do Estado do Rio de Janeiro. Atualmente, é referência em ensino superior, pesquisa e extensão. Nela, encontram-se 30 unidades acadêmicas de diversos cursos, dentre elas a Faculdade de Administração e Finanças - FAF. Essa unidade foi criada há 52 anos para formação de bacharéis em Administração e Ciências Contábeis. Hoje, além da formação dos bacharéis, existe o acadêmico e vários cursos de especialização em nível de pós-graduação. Atualmente, a FAF ela conta com um quadro de servidores composto por 47 docentes e 12 técnicos administrativos.

O que influenciou a escolha da UERJ como campo de pesquisa, foi o fato de que os autores pesquisadores são compostos por professores e alunos da instituição, gerando assim um interesse em verificar as principais razões que influenciam na satisfação ou até mesmo na insatisfação dos servidores em relação ao trabalho, pois é possível que o fenômeno que ocorra na FAF pode ocorrer em outras instituições. A frequência no campo de estudo e facilidade de acesso, possibilitou uma melhor obtenção dos dados da pesquisa.

Embora a satisfação das pessoas no trabalho seja considerando um assunto relevante, poucas pesquisas nacionais verificam as razões que influenciam essa satisfação, e nessa perspectiva o estudo sobre esse tema torna-se expressivo. Durante a busca em revistas cientificas e bancos de dados como Spell e Anpad por outros estudos nacionais que tivessem como tema a satisfação no trabalho, para obtenção de conhecimento e para embasar a pesquisa, verificou-se a escassez de estudos voltados a esse objetivo, principalmente no campo da Administração Pública.

O objetivo desta pesquisa foi verificar as principais razões que influenciam na satisfação dos servidores técnicos administrativos da Faculdade de Administração e Finanças da Universidade do Estado do Rio de Janeiro. Com os resultados obtidos, pode-se identificar os pontos que precisam melhorar e o que precisam de manutenção e isso pode ser considerado 
como conhecimento de valor para a tomada de decisão dos gestores. Tais decisões, podem influenciar na motivação, no comprometimento e no ambiente de trabalho. E como consequência, os serviços prestados por esses profissionais tendem a ter um aumento significativo de qualidade, gerando um beneficio para a sociedade.

Após esta introdução, são discutidas pesquisas anteriores sobre a satisfação do trabalho e a exposição das proposições. Posteriormente, serão detalhados os aspectos metodológicos do estudo, que serão feitos a partir de entrevistadas semiestruturadas onde as perguntas foram adaptadas de um estudo que utilizou uma escala validada, bem como a análise dos dados por meio do método de análise de conteúdo. Por fim, serão discutidos os resultados, seguidos das considerações finais, onde serão apresentadas as conclusões, as limitações do estudo e as sugestões para pesquisas futuras.

\section{REVISÃO DA LITERATURA}

\subsection{MOTIVAÇÃO E SATISFAÇÃO NO TRABALHO}

Quando os indivíduos trabalham em algo que consideram importante são mais felizes (MASLOW, 2000), e por esse motivo considera-se relevante o estudo de maneiras para torná-los cada vez mais satisfeitos e motivados. Abraham Maslow criou a Teoria da Hierarquia das Necessidades em 1943 e, mesmo após décadas de sua criação, é uma das teorias mais conhecidas e utilizadas como base para estudos sobre motivação e satisfação no trabalho por sua relevância no tema (BOHRER, 1981; FERREIRA, et. al. 2010). A teoria consiste que as necessidades humanas estão organizadas em níveis hierárquicos, as necessidades de nível mais baixo levam o nome de necessidades fisiológicas e as de nível mais alto, são chamadas de necessidades de auto realização (BOHRER, 1981). Apesar do consenso da importância da contribuição dessa teoria, autores afirmam que não foi Maslow que criou tal pirâmide (BRIDGMAN et al., 2018).

Outra teoria importante é a Teoria dos Dois Fatores de Frederick Herzberg, que deixa claro que o oposto da satisfação não é a insatisfação, mas sim a não satisfação. E seguindo o mesmo pensamento o oposto da insatisfação não é a satisfação, mas sim nenhuma insatisfação (HERZBERG, 1987). Além disso, Herzberg considera que o salário não é um fator motivacional.

\subsection{SATISFAÇÃO COM O SALÁRIO}

O salário possibilita satisfazer as necessidades e não produzir motivação (PILATTI, 2012; HERZBERG, 1987). O indivíduo baseia a sua satisfação com o salário comparado ao que ele pode produzir profissionalmente, com o seu custo de vida e sua dedicação para a realização do trabalho (SIQUEIRA, 2008).

Diferente da iniciativa privada, o setor público obedece a procedimentos e normas burocráticas, tornando difíceis melhorias relativas aos salários. A possibilidade do aumento do salário do servidor geralmente ocorre com uma troca de cargo ou quando ele assume outra função que tenha um adicional.

Em um estudo realizado na Secretaria de Administração da Prefeitura de Serra Talhada, foi identificada uma considerável insatisfação em relação aos valores dos salários dos seus servidores (QUEVEDO et. al, 2012). Essa informação também se confirma no estudo feito na Superintendência Regional do Trabalho e Emprego do Ceará, onde foi comprovado que os servidores administrativos se encontram insatisfeitos com seus salários (BRANDÃO et. al, 2014). Baseado nessas informações foi construído a seguinte proposição:

\section{P1: O salário gera uma insatisfação aos servidores.}

\subsection{SATISFAÇÃO COM A NATUREZA DO TRABALHO}

Para obter uma satisfação com a natureza do trabalho, as tarefas devem envolver totalmente o indivíduo (SIQUEIRA, 2008). Ele pode gostar tanto do que faz ao ponto de seu tempo no trabalho passar sem ser muito notado. Considerando um estudo sobre a Qualidade de Vida no Trabalho de Pilatti (2012), quando as tarefas se tornam mais rotineiras ocorre uma diminuição no nível de satisfação do empregado. Baseado nessas informações foi construído a seguinte proposição: 
P2: Quando a tarefa é rotineira, gera uma insatisfação em relação à natureza do trabalho.

\subsection{SATISFAÇÃO COM A CHEFIA E COM OS COLEGAS DE TRABALHO}

A satisfação com a chefia envolve questões relacionadas ao quanto de profissionalismo o chefe possui, a forma como ele passa as informações e tarefas para os seus subordinados (SIQUEIRA, 2008). Quando os chefes conseguem transparecer $O$ que realmente desejam em relação ao serviço que será executado, e quando essa informação é compreendida de forma clara por seus funcionários, há um aumento na possibilidade de satisfação entre as partes (PILATTI, 2012).

Já a satisfação com os colegas de trabalho está relacionada ao inter- relacionamento no ambiente de trabalho, que envolve a confiança e companheirismo entre o pessoal (SIQUEIRA, 2008). No estudo feito com servidores técnicos administrativos da Universidade do Estado do Rio Grande do Norte, foi constatado que existe um grau elevado de satisfação em relação aos relacionamentos interpessoais entre os servidores e também relacionada com a surpevisão (LEAL et al 2015). Essa informação também se confirma no estudo feito na Superintendência Regional do Trabalho e Emprego do Ceará, onde foi comprovado que os servidores estão satisfeitos com a supervisão e com os relacionamentos pessoais (BRANDÃO et. al, 2014). Baseado nessas informações foi construído as seguintes proposições:

P3: Quanto maior o nível de objetividade da chefia, maior o nível de satisfação do trabalho.

P4: Uma boa relação interpessoal com os colegas de trabalho interfere aumentando o nível de satisfação do trabalho.

\subsection{SATISFAÇÃO COM A PROMOÇÃO}

A satisfação com a promoção envolve o tempo de espera, a quantidade de vezes que ocorreu, e a visão que a empressa passa sobre a promoção (SIQUEIRA, 2008). Na instituição escolhida para o presente estudo, as possibilidades de promoção só ocorrem quando os servidores atendem aos itens especificados na Lei $n^{\circ}$ 6701/2014, que informa sobre o plano de cargos, carreiras e remuneração do quadro de pessoal dos servidores técnico-administrativos da UERJ. Nessa lei um dos itens diz respeito à capacitação dos servidores como exigência para a progressão na carreira.

Em um estudo realizado na Superintendência Regional do Trabalho e Emprego do Ceará, foi identificada que um dos fatores ao qual os servidores estão insatisfeitos é a progressão da carreira, pelo fato da dificuldade de promoção para os servidores públicos. (BRANDÃO et. al, 2014). Baseado nessas informações foi construído a seguinte proposição:

P5: A dificuldade de promoção afeta na satisfação dos servidores.

\subsection{ADMINISTRAÇÃO PÚBLICA}

Baseado no artigo 37 da Constituição Federal de 1988 existem cinco princípios da Administração Pública, que são: legalidade, impessoalidade, moralidade, publicidade e eficiência. Como toda a entidade pública tem o dever de obedecer a esses princípios, a gestão de pessoas pode se tornar mais engessada e ao invés de se preocuparem com melhorias em relação aos aspectos motivacionais dos servidores, os gestores tendem a focar os serviços operacionais, como por exemplo: registro, admissão e advertência dos servidores públicos (VIEIRA et al. 2011; BRANDÃO e BASTOS, 1993). Por esses motivos, "a grande maioria das entidades públicas brasileiras enfrentam problemas crônicos em termos estruturais e conjunturais, o que leva a um clima organizacional de desmotivação, insatisfação, desânimo" (VIEIRA et. al. 2011, p 7).

Nesses ambientes, por mais complicado que pareça, é possível estimular o servidor, pois a motivação ao contrário do que muitos pensam é algo plausível, que deve ser levado em consideração por todos, principalmente pelos gestores, para a busca de melhorias continuas e assim melhorar a imagem da Administração Pública e dos próprios (VIEIRA et.al. 2011). Os servidores não devem ser vistos como recursos operacionais, mas sim como recursos estratégicos da organização, para torná-la mais eficiente e eficaz (VIEIRA et.al. 2011).

\section{MÉTODO DE PESQUISA}


Foi realizada uma abordagem qualitativa nesta pesquisa. A estratégia selecionada para a coleta de dados foi o estudo de caso a partir de entrevistas semiestruturadas, tendo como amostra desta entrevista quatro servidores técnicos administrativos. Os entrevistados em questão têm como perfil as seguintes características: são todos ligados diretamente a UERJ através de concurso público, prestam o serviço na Faculdade de Administração e Finanças e são do sexo masculino. Tendo como diferenças os setores onde atuam e o tempo de serviço, conforme demostra $\quad 0 \quad$ quadro 01.

Quadro 01: Sujeitos da Pesquisa

\begin{tabular}{|c|c|c|}
\hline Código & \multicolumn{2}{|c|}{ Setor } \\
\hline E1 & Financeiro & 16 anos de UERJ e 06 anos de FAF \\
\hline E2 & Financeiro & 07 anos de FAF e UERJ \\
\hline E3 & Secretaria & 04 anos de FAF e UERJ \\
\hline E4 & Secretaria & 05 anos de FAF e UERJ \\
\hline
\end{tabular}

Fonte: próprios autores

Esse levantamento de dados foi realizado nos dias 24 de outubro e 21 de novembro de 2017, na UERJ, no Campus Maracanã. O instrumento de coleta de dados escolhido foi a entrevista semiestruturada, que foi gravada e posteriormente transcrita e analisada. Ela foi estruturada em duas partes: a primeira, composta de 03 perguntas de "quebra-gelo" e a segunda, composta de 05 perguntas relacionadas à satisfação do trabalho, onde os participantes podiam dar notas de 0 a 10 ao nível de satisfação que tinham em relação a cada item. As perguntas da segunda parte foram adaptadas baseadas no modelo da Escala de Satisfação no Trabalho (EST), que é uma escala que tem uma visão multidimensional de satisfação no trabalho e que foi construída e validada no Brasil (SIQUEIRA, 2008).

O método utilizado para a análise dos dados foi a análise de conteúdo, que é uma análise que tem um agrupamento de técnicas o qual tem por objetivo a busca do sentido do documento (CAMPOS, 2004).

\section{RESULTADOS E DISCUSSÃO}

Para o estudo desse artigo foram elaboradas 05 proposições conforme visto anteriormente. A partir das entrevistas coletadas foi realizada a análise de cada proposição.

\section{Proposição 1: O salário gera uma insatisfação aos servidores.}

No período das entrevistas, os servidores estavam há 03 meses com os salários em atraso. Caso esse atraso fosse levado em consideração para avaliar a satisfação com o salário, a nota dos servidores seria 0 .

"Porque se ele não está em dia é zero. Pois zero não dá pra pagar nada, então a satisfação é zero". (E4)

Então, foi solicitado que os servidores dessem a nota baseada em uma comparação entre o valor do seu salário, às suas tarefas e custo de vida. A relação salário/tarefa é satisfatória, todos disseram que o valor recebido é compatível com as tarefas desempenhadas. Porém, a relação salário/custo de vida tem uma baixa satisfação, pois o custo de vida no Rio de Janeiro é considerado alto, fazendo com que o salário ao olhar do servidor não seja suficiente.

"Eu não posso ser injusto, acho que se a gente for comparar o salário com a função. Eu acho que poderia dar uns 7. Mas eu não acho que essa é minha nota definitiva. Porque comparado com o custo de vida que a gente tem no Rio, e isso tem que ser levado em conta. Eu cairia essa nota para 4". (E3)

Também existe a questão levantada pelo entrevistado E2, que possui mais tempo de serviço na UERJ em relação aos outros entrevistados, que é a falta dos rejustes salariais, contribuindo para que sua nota seja muito baixa.

"A nota que eu dou é exatamente essa, 3. É triste, porque você pega o contracheque de tempos atrás e você fica assim: caramba não está diferente!" (E2)

Conforme demonstrado, as notas obtidas em relação ao item satisfação com o salário foram 
baixas, confirmando a proposição de que o salário gera uma insatisfação ao servidor. Verificou-se que essa informação vai de acordo com o que foi verificado nos estudos realizados por Quevedo et. al (2012) e Brandão et. al (2014), onde foi identificado que os servidores tinham uma insatisfação com relação aos valores dos seus salários.

Proposição 2: Quando a tarefa é rotineira, gera uma insatisfação em relação à natureza do trabalho.

$\mathrm{Na}$ amostra selecionada, existem entrevistados de dois setores dentro da FAF: o setor financeiro e o setor da secretária do curso. Essa diferença de setor influenciou claramente as notas obtidas. Um dos entrevistados trabalhou na graduação (secretaria do curso) e atualmente é do setor financeiro. Na fala dele ficou evidente a discrepância de notas em relação às tarefas de cada setor.

"Quando eu trabalhava na graduação eu gostava de lá (...). Era só fazer declaração, fazer outras coisas, e cansava um pouco, depois que eu passei pra pós-graduação e financeiro junto com o E2 é um trabalho que cria mais, a gente pode empreender mais assim. É um pouco menos, vamos colocar assim, um pouco menos com a caixinha fechada. Antes era 05 (graduação/secretária), mas agora pode botar 08". (E1).

O entrevistado E3 que sempre trabalhou na secretária, deu uma nota muito baixa devido à falta de evolução nas tarefas.

"O trabalho que a gente exerce quando entra é o que a gente exerce quando sai. Não há muita coisa que a gente possa melhor. A gente tenta mais esbarrar na burocracia. Por isso que eu daria 3". (E3)

Conforme demonstrado pelas falas acima dos entrevistados E1 e E3, a proposição de que a tarefa rotineira gera insatisfação foi confirmada, corroborando com o estudo de Pilatti (2012) citado na revisão da literatura, onde concluiu que quando as tarefas se tornam mais rotineiras ocorre uma diminuição no nível de satisfação do empregado.

Proposição 3: Quanto maior o nível de objetividade da chefia, maior o nível de satisfação do trabalho.

Os entrevistados da secretária possuem dois chefes, o chefe da secretária e o Diretor da FAF, devido a esse fato eles deram duas notas.
"Têm duas chefias aqui né? Tem a chefia imediata que é o chefe da secretária. E tem o nosso chefe supra, que é o diretor. Da minha chefia imediata nos temos uma relação muito boa. Mas... eu acho que de 0 a 10 acho que ninguém é perfeito. Então não daria 10 porque a gente tem sempre alguma coisa que melhorar, mas eu daria uns $8,5 \ldots 8,5$ a 9 . E... o no nosso diretor, eu não tenho... tenho algum contato com ele. Mas por conta da greve, a gente não esta com as relações muito estreitas... porque não se ver tanto. Mas comparados com os outros... Eu acho que também daria... daria uns... 7,5, 8". (E3).

$\mathrm{Na}$ fala do entrevistado E2, observa-se que o Diretor se envolve nas tarefas.

"Atualmente também, muito satisfatório, 10 Porque é exatamente o que acontece, ele trás a gente pro compromisso e ele participa, entendeu. Então ele não joga assim. Ele tá sempre preocupado em como vai ser feita a coisa, como é que ela funciona. Tá sempre ali no dia-a-dia fazendo com que flua, e isso é importante né". (E2)

As respostas obtidas não conseguiram confirmar nem rejeitar a proposição proposta nesse trabalho em relação à chefia.

Proposição 4: Uma boa relação interpessoal com os colegas de trabalho interfere aumentando o nível de satisfação do trabalho.

Essa dimensão foi a que obteve o maior nível positivo em relação à satisfação do trabalho. Mesmo os entrevistados trabalhando em diferentes setores, foi constatado que a relação com os colegas de trabalho é muito boa e que há bastante cooperação entre as equipes. Este resultado está em conformidade com o os estudos de Leal et. al. (2015) e Brandão et. al. (2014) mencionados na revisão da literatura, ao qual identificaram que existe um bom nível de satisfação em relação aos relacionamentos interpessoais entre os servidores. Todos os quatro entrevistados deram notas entre 09 e 10, confirmando a proposição acima levantada.

"Os funcionários daqui se ajudam, colaboram, são bons uns com os outros, não tem mesquinharia, todo mundo faz tudo, ajuda sempre quando precisa. Então em relação aos colegas, satisfeito, bota 09". (E1)

"Eu aqui 10, graças a Deus a toda a equipe é show de bola". (E2)

"Atualmente eu digo para você que é 10. A gente teve até uns probleminhas anteriores... 
(RISOS) (...) E aí se resolveu e hoje posso dizer que daria 10 mesmo. Não tem nada que tirar nem que por". (E3)

"Aqui na secretária o ambiente de trabalho é maravilhoso. Eu só não vou dar 10, porque 10 é uma coisa muito perfeita né? 9". (E4)

E assim verifica-se que, de todas as dimensões, a relação com os colegas de trabalho é a que, para eles, mais contribui para o aumento da satisfação no trabalho.

"Vale apena acordar na segunda-feira pra vir trabalhar, pelo menos em relação aos colegas". (E2)

Proposição 5: A dificuldade de promoção afeta na satisfação dos servidores.

Mediante as entrevistas, podemos constatar que para os cargos dos servidores entrevistados não é oferecido nenhum tipo de promoção relacionada ao seu desempenho. Existe apenas uma gratificação relacionada ao nível acadêmico.

"Se tiver nível superior você ganha cem reais a mais, pós- graduação duzentos reais a mais...". (E1)

Relacionada ao crescimento, existe uma progressão de equiparação salarial referente ao tempo de serviço. Conforme aumenta o nível do cargo há um aumento de salário, porém essa progressão não está sendo realizada.

"E em relação a crescimento, por exemplo, de cargos, existe alguma progressão? (entrevistador)

Existe só pra dizer que existe né, a cada dois anos que você trabalha você sobe uma casinha na progressão, aí aumenta 60 reais o salário". (E1)

"De dois em dois anos teria que ter promoção. Tá? Eu to a cinco, e nunca fui promovido. A promoção na verdade, não é de mudança de cargo e sim de nível no cargo. São dez níveis que a cada nível você tem um aumento salarial, pouco, mas tem. E ... a cada vez que ia ter uma mudança, tem um problema. la ter uma mudança, aí vem esse problema da crise no Rio. Eu já ouvi falar de servidores que já estão a dez anos e sempre que ia ter promoção surgiu um problema e ele não teve. (...) Então pra mim no caso promoção é 0 , porque eu já teria que tá numa promoção três. $\mathrm{E}$... indo pra três e até agora to no nível um do meu cargo". (E4)
Neste cenário, as notas relativas à promoção foram extremamente baixas, chegando perto de 0 . Isso reforça a proposição apresentada. Ainda pode se acrescentar que a dificuldade de promoção afeta de forma negativa a satisfação do trabalho. Do mesmo modo, podemos identificar essa dificuldade de promoção que produz uma insatisfação no servidor no estudo de Brandão et. al. (2014), citado na revisão da literatura.

\section{CONCLUSÃO}

Para alcançar o objetivo de verificar as principais razões que influenciam na satisfação dos servidores técnicos administrativos da Faculdade de Administração e Finanças da UERJ, foi realizado nos dias 24 de outubro e 21 de novembro entrevistas semiestruturadas com quatro servidores, tais entrevistadas formaram a base de dados para esse estudo. Para uma melhor compreensão, a revisão da literatura foi subdivida entre os seguintes tópicos: teorias relacionadas à satistação no trabalho, onde foram alencada as principais teorias, e dentre elas a Hierarquia das Necessidades de Abraham Maslow; administração pública, onde foram apresentadas principalmente as dificuldades que o servidor enfrenta por ser dirigido pela administração pública; e em sequência as dimensões, satisfação com o salário; satisfação com a natureza do trabalho; satisfação com a chefia e com os colegas de trabalho; e satisfação com a promoção.

A metodologia selecionada para a análise dos dados foi a análise de conteúdo. Os resultados encontrados em sua maioria acompanham o que foi citado em outros artigos da revisão da literatura. Cabe destacar que dentro dos itens que foram propostos neste estudo para verificar a satisfação, a dimensão que obteve as maiores notas foi a satisfação com os colegas de trabalho, alcançando notas 09 e 10. E o que se mostrou como um influenciador de baixa satisfação foi a dimensão satisfação com o salário que chegou a obter nota 0 . Os resultados obtidos sobre a dimensão satisfação com a chefia, não conseguiram confirmar nem demolir a proposição apresentada.

Como contribuição prática dessa pesquisa, temos um melhor entendimento da satisfação dos servidores técnicos administrativos que possibilita os gestores a buscarem uma melhoria nas dimensões que foram 
constatados como influenciadores de diminuição da satisfação. Como contribuição teórica, testamos a escala de satisfação no trabalho de Siqueira (2008) e temos um crescimento de conhecimento sobre satisfação no trabalho na esfera pública.

Quanto às principais limitações deste estudo, existem os fatos de ter sido utilizado como instrumento de coleta de dados apenas as entrevistas semiestruturadas, de ter uma amostra reduzida - provavelmente devido às greves - e de ter sido realizado somente em uma unidade acadêmica da UERJ.

\section{REFERÊNCIAS}

[1] AGAPITO P.R.; SANTOS C.B.; ALVES C.H.; SÁ C.R.C.B.; SANTOS H.R. Análise da Satisfação no Trabalho e do Cumprimento dos Contratos Psicológicos dos Profissionais da Região do ABC Paulista. Revista Eletrônica Gestão e Serviços v.5, n.1, p. 766- 786, 2014.

[2] AQUINO J.M.C.; TEIXEIRA L.A.A.; ANDRADE D.F. Imagem do servidor público: um estudo com os usuários do Tribunal de Justiça do Estado de Minas Gerais. Revista do Serviço Público, Brasília, v. 66, nº 4, p. 585-604, 2015.

[3] ARRUDA, S.M.; ALVES, B.M.; Como Fazer Referências: bibliográficas, eletrônicas e demais formas de documentos. Disponível em: <http://www.bu.ufsc.br/home982.html>. Acessado em: 19/06/2017.

[4] BOHRER, R.S. Motivação abordagem crítica da teoria de Maslow pela propaganda. Revista de Administração de Empresas, v. 21, n. 4, p. 43-47, 1981.

[5] BRANDÃO I.F.; LIMA L.C.; CABRAL A.C.A.; SANTOS S.M.; PESSOA M.N.M. Satisfação no serviço público: um estudo na superintendência regional do trabalho e emprego no Ceará. Revista Eletrônica de Administração, v. 77, n. 1, p. 90-113, 2014.

[6] BRANDÃO, M.G.A; BASTOS, A.V.B. Comprometimento organizaciobal em uma instituição universitária. Revista de Administração, v. 28, n. 3, p. 50-61, 1993.

[7] BRASIL. Constituição (1988). Constituição da República Federativa do Brasil. Brasília, DF: Senado Federal: Centro Gráfico, 1988.

[8] BRIDGMAN, T., CUMMINGS, S., BALLARD, J. Who Built Maslow's Pyramid? A History of the Creation of Management Studies' Most Famous Symbol and Its Implications for Management Education. Academy of Management Learning \& Education (In-Press). Disponível em: < https://journals.aom.org/doi/abs/10.5465/amle.2017 .0351>. Acessado em: 18/07/2018.
Concluímos também que devem ser fixadas melhores políticas relacionadas à promoção do servidor, bem como uma progressão que seja efetivamente válida, e também devem ser feitos mais investimentos na capacitação dos servidores para o aperfeiçoamento do seu desempenho. Para futuros estudos sugere-se a realização de pesquisas quantitativas e qualitativas em outras unidades acadêmicas da UERJ, bem como com servidores docentes e funcionários terceirizados.

[9] CAMPOS, C.J.G. Método de análise de conteúdo: ferramenta para a análise de dados qualitativos no campo da saúde. Revista Brasileira de Enfermagem, v. 57 n. 5, p. 611- 614, 2004.

[10] FERREIRA, A.; DEMUTTI, C.M.; GIMENEZ, P.E.O. A Teoria das Necessidades de Maslow: A Influência do Nível Educacional Sobre a sua Percepção no Ambiente de Trabalho. In: XIII SEMEAD Seminários Em Administração, São Paulo, 2010.

[11] GAVAZINI A.A.; DUTRA A. Avaliação multicritério de desempenho do servidor público: 0 caso do poder judiciário. Revista de Carreiras e Pessoa - ReCaPe, v. 6, . 2, p.158- 174, 2016.

[12] HERZBERG, F; One More Time: How do you motivate employees. Harvard Business Review, p. 5-16, set/out 1987.

[13] LEAL, P.H.; COSTA, B.M.N; CABRAL, A.C.A.; SANTOS, S.M.; PESSOA, M.N.M. Satisfação no trabalho: um estudo na Universidade do Estado do Rio Grande do Norte. Revista Raunp, v.7, n.2, p. 106-120, Fev./Maio 2015

[14] LIMA, J.O.; SILVA, A.B. Determinantes do desenvolvimento de competências coletivas na gestão de pessoas. Rev. Adm. Mackenzie - RAM, v. 16, n. 5 , p. 41-67, 2015

[15] MARQUEZE, E.C.; MORENO, C.R.C. Satisfação o trabalho e capacidade para o trabalho entre docentes universitários. Psicologia em Estudo, v. 14, n. 1, p. 75-82, 2009.

[16] MASLOW, Abraham Harold. The Maslow Business Reader. 1. ed. United States: Stephens, 2000.

[17] PAIVA L.E.B.; LIMA T.C.B.; OLIVEIRA T.S.; PITOMBEIRA S.S.R. Percepção da influência das políticas e práticas de recursos humanos na satisfação com o trabalho. Revista Pensamento Contemporâneo em Administração, v. 11, n. 1, p. 55-69, 2017.

[18] PILATTI, L.A. Qualidade de vida no trabalho e teoria dos dois fatores de Herzberg: 
possibilidades-limite das organizações. Revista Brasileira de Qualidade de Vida, v. 04, n. 01, p. 1824, 2012.

[19] QUEVEDO, A.P.F.; SOUZA, V.N.; LIMA, M.V.S. Motivação no serviço público: um estudo de caso com a Secretaria de Administração da Prefeitura Municipal de Serra Talhada. In: $9^{\circ}$ Convibra - Administração, 2012.

[20] RIO DE JANEIRO. Lei no 6701 de 11 de março de 2014. Reestrutura o plano de cargos, carreiras e remuneração do quadro de pessoal dos servidores técnico- administrativos da Universidade do Estado Do Rio de Janeiro - UERJ e dá outras providências, Rio de Janeiro, p. 13, mar 2014

[21] ROHM R.H.D.; LOPES N.F. O novo sentido do trabalho para o sujeito pós-moderno: uma abordagem crítica. CADERNOS EBAPE.BR, v. 13, n. 2, p. $332-345,2015$.
[22] SIQUEIRA, M. M. M. et al. Medidas do comportamento organizacional: ferramentas de diagnóstico e de gestão. Porto Alegre: Artmed, 2008. Universidade do Estado do Rio de Janeiro. Informações. Disponível em: <http://www.uerj.br/institucional/> Acessado em: $18 / 10 / 2017$

[23] VIEIRA, C.B.; BOAS, A.A.V; ANDRADE, R.O.B; OLIVEIRA, E.R. Motivação na Administração Pública: considerações teóricas sobre a aplicabilidade dos pressupostos das teorias motivacionais na esfera pública. Revista ADMpg Gestão Estratégica, v. 4, n. 1, 2011.

[24] WEYMER A.S.Q.; MACIEL C.O. ; CASTOR B.V.J. A influência da Sobrequalificação e da Aprendizagem sobre a Satisfação do Indivíduo no Trabalho. Revista Brasileira Gestão Negócio, v. 16, n. 50, p. 96-109, jan./mar. 2014. 


$$
\text { Alutary }
$$




\section{ALEXANDRE DE OLIVEIRA SIQUEIRA}

Doutorando em Administração pela Universidade Federal de Pernambuco (UFPE), Mestre em Administração pela Faculdade Boa Viagem / DeVry Brasil (2015), especialista em Marketing pela Fundação Getúlio Vargas (2007) e graduado em Comunicação pela Universidade Federal de Pernambuco (2004). Profissional de Marketing com experiência executiva em plataformas diversas como planejamento estratégico, atendimento e relacionamento com clientes, eventos, ações promocionais, endomarketing, gestão de equipes e de projetos, social media marketing e comunicação organizacional. Atua como docente nas áreas de Gestão Empresarial, Administração e Marketing, assim como docência em pós-graduação (MBA), pesquisador do Grupo de Pesquisa MOS/FBV (Marketing e Operações de Serviços) e palestrante convidado nas áreas citadas. Os interesses acadêmicos incluem: Administração e operações de Serviços, Marketing e Comportamento do Consumidor, Estratégia Empresarial, Processos Decisórios e Gestão da Qualidade.

\section{ANDERSON VINICIUS KNOEDLER FARIAS}

Graduando em Engenharia de Produção pela Universidade Federal do Rio Grande do Sul (UFRGS).

\section{ANDREA SANTOS CABRAL}

Trainee de Gestão Pública, atuando como Analista de Projetos nos programa Formar, em uma parceria entre Fundação Lemann e Vetor Brasil. É graduada em Engenharia de Produção pela Universidade do Estado do Rio de Janeiro. Possui experiência na área de turismo ecológico, saúde e educação pública, tendo como principal interesse as linhas de implementação e monitoramento de políticas públicas.

\section{CAIO MARCELO LOURENÇO}

Possui graduação em Engenharia de Produção Mecânica e mestrado em Engenharia de Produção pela Escola de Engenharia de São Carlos da Universidade de São Paulo (EESC/USP). Atualmente é doutorando do programa de pós-graduação na mesma instituição. Faz parte do grupo de pesquisa Integração das Estratégias de Recursos Humanos e de Produção. Atua principalmente nos seguintes temas: cultura organizacional, dimensões culturais, organização do trabalho e sistemas nacionais de inovação.

\section{CÉLIA DE LIMA PIZOLATO}

Doutoranda em EPISTEMOLOGIA E HISTÓRIA DA CIÊNCIA na Argentina - BUENOS AIRES UNTREF/ 2015 Mestrado em Controladoria e Contabilidade Estratégica ata de defesa aprovada 2003, área de concentração o Ensino da Contabilidade pelo Centro Universitário Alvares Penteado UNIFECAP. Especialização em Didática do Ensino Superior pela Universidade Mackenzie. Especialização em Controladoria pela Univesidade Mackenzie ,Especialização gestão Financeira e Contabilidade Avançada pela Universidade São Judas. Didática do ensino Técnico Esquema I pela Faculdade Campos Salles. Graduação em Ciências Contábeis pelo Centro Universitário das Faculdades Metropolitanas Unidas. Área de conhecimento e atuação Contabilidade como fonte de informações Logísticas. Instituições , Contribuições Acadêmicas , Coordenação e Administrativas: Ensino Técnico desde 1977. Ensino Superior desde 1987 nos cursos: Tecnológicos, Graduação e Pós graduação : Faculdade Peruíbe- UNISepe-Fatec São Bernardo do Campo ; Faculdade Brasília de São Paulo, Estácio unidades da Moóca e Vila Formosa, Álvares Penteado. Ensino Técnico Público na CEETEPS em 1985 e coordenação mais de 10 anos nos cursos de Contabilidade, Administração e diretora substituta na ETEC 
Professor Camargo Aranha; contribuição grupo de trabalho nas alterações efetivas 1996 na adequação LDB no programa de ensino Técnico e Tecnológico CEETEPS do estado de SP.Atuei como diretora de Serviços na ETEC Rocha Mendes. Na Fatec Guarulhos Participação da Comissão de Implantação e membro da Congregação em, 2012 Regime de Jornada Integral e Coordenadora do Curso de Logística Aeroportuária, atuação na Reestruturação Curriculares das Competências e Renovação do Reconhecimento por 5 anos do curso de Logística Aeroportuária. As disciplinas as quais dedico-me : Contabilidade Social, Contabilidade Avançada Aplicada, Contabilidade geral, Administração Financeira Orçamentária, Custos e Tarifas Logísticas e Gestão de Custos e Planejamento Tributária. Participação e Orientadora de bancas de trabalhos de pesquisa científica .Participação de bancas de seleção de professores, Atuação como Pareceristas: IFLOGSUZANO, SEMANA DO CONHECIMENTO; FATECLOG; SEMTEC; 1 FÓRUM DE METODOLOGIAS ATIVAS DO CEETEPS; REVISTA DA FATEC GUARULHOS e Organização de Congressos FatecLog ; Semcitec; Semana Tecnológica da Fatec Guarulhos e Ciclos de debates Fatec Guarulhos; Artigos publicados e apresentados USA- TEXAS; e Europa. Participação como suplente do Conselho Municipal de Desenvolvimento Econômico da prefeitura de Guarulhos. e como Titular na secretaria do meio Ambiente. Participação em Congressos, Feiras, CONIC-SEMESP Visitas Técnicas FATECLOG- Membro do Comitê de Coordenadores das Fatecs. Presidente da Implantação da CPA Fatec Guarulhos e membro do NDE curso de EaD Gestão Empresarial e NDE NÚCLEO DOCENTE ESTRUTURANTE do curso de Administração da FASUPI E CNPQ.(Texto informado pelo autor)

\section{CLAUDELINO MARTINS DIAS JUNIOR}

Graduado em Administração de Empresas pela Universidade da Região da Campanha URCAMP (1994), Mestre em Engenharia de Produção pela Universidade Federal de Santa Catarina - UFSC (2003) e Doutor em Engenharia de Produção pela UFSC em Regime de Cotutela com a Universidade Nova de Lisboa - UNL (2008). Tem experiência em Engenharia de Produção, foco em Engenharia do Produto, atualmente tem como linha de pesquisa: ativos intangíveis, simulação empresarial, cadeia de suprimentos e valor.

\section{DIEGO CESAR CAVALCANTI DE ANDRADE}

Professor da Faculdade Miguel Ângelo da Silva Santos e Pesquisador da Universidade do Estado do Rio de Janeiro. É graduado em Engenharia de Produção pela Universidade Federal Fluminense e mestre em Engenharia Civil pela Universidade do Estado do Rio de Janeiro. Tem como principais linhas de pesquisa Simulação, Jogos de Empresa e Design Thinking,

\section{EDUARDO DE MORAES XAVIER DE ABREU}

Possui graduação em Engenharia de Materiais pela Universidade Federal de Campina Grande (1998) e mestrado em Engenharia Mecânica pela Universidade Federal de Pernambuco (2005). Tem experiência na área de Engenharia de Materiais e Metalúrgica e Ensino Superior. Atualmente é coordenador da escola de engenharia da Faculdade Metropolitana da Grande Recife.

\section{ERCULES COSTA}

Mestre em Engenharia da Produção na linha de pesquisa em Gestão Econômica e da Inovação Tecnológica. Possui graduação em Ciências Econômicas pela Universidade Estadual de Ponta Grossa (2005) e Pós-graduação Lato sensu em Gestão de Empresas pela UNICESUMAR. 
Atualmente é Professor de Economia, Estatística, Administração Financeira e Orçamentária, Metodologia de Pesquisa em CESCAGE e UNICESUMAR (PR).

\section{ERIC DAVID COHEN}

Graduado em Engenharia Elétrica pela Universidade S. Judas Tadeu (1982), com Mestrado em Administração pela Clemson University (1997) e Master of Computer Science pela Arizona State University (1993). Doutor em Administração de Empresas pela Fundação Getúlio Vargas (2004) e Pós doutorado em Administração pela Universidade Mackenzie. Professor do curso de Mestrado em Administração do Centro Universitário Alves Faria. Foi pesquisador bolsista do governo americano (Fulbright Scholar). Possui larga experiência acadêmica e administrativa nas áreas de Mercadologia, Métodos Quantitativos aplicados à Administração, Pesquisa de Marketing e Gestão de Serviços.

\section{ETTORE DE LACERDA ARPINI}

Graduando em Engenharia de Produção pela Universidade Federal do Rio Grande do Sul (UFRGS), Ettore trabalha no setor de operações do World Resources Institute em Washington D.C., um think e do-tank que transforma grandes ideias em ações tangíevis através de pesquisa nas áreas de florestas, clima, alimentação, água e cidades sustentáveis. Ettore possui cursos em operações e gestão de projetos pela Deflt University of Technology e pela University of Adelaide da Austrália e se comunica em português, inglês, espanhol, alemão, italiano, francês e mandarim.

\section{FÁBIO BRAUN}

Doutorando Engenharia de Transportes - COPPE / UFRJ, Mestre em Administração UNIGRANRIO, Especialista em Engenharia de Produção - UFF, Especialista em Planejamento e Gestão - UFF. Professor da graduação e pós-graduação na UERJ e UFRRJ. Coordenador da pósgraduação em Gestão Logística no NPG / UERJ. Mais de 15 anos de experiência como gestor de empresas de pequeno, médio e grande porte nas áreas de finanças, administrativa, compras, comercial e tributária. Bolsista Pesquisa Produtividade da UNESA.

\section{FATINHA BADJETA MENDONÇA}

Bacharel em Administração Pública pela Universidade Federal do Estado do Rio de Janeiro UNIRIO

\section{FERNANDO CÉSAR ALMADA SANTOS}

Doutorado em Administração de Empresas pela Fundação Getúlio Vargas de São Paulo (1998). Atualmente é Professor Associado da Escola de Engenharia de São Carlos da Universidade de São Paulo. Atua na interface entre Engenharia de Produção, Organização do Trabalho e Gestão de Pessoas.

\section{FERNANDO GONÇALVES AMARAL}

Fernando Gonçalves Amaral, engenheiro civil, especialista em ergonomia pela Université Catholique de Louvain (UCL) Bélgica (1991), mestre em ergonomia pela UCL (1992), mestre em ergonomia pela École Pratique de Hautes Études Sorbonne França (1995), doutor em ergonomia pela Université Catholique de Louvain (UCL) Bélgica em 1999. Atualmente é Professor Associado 3 da Universidade Federal do Rio Grande do Sul e orientador de mestrado 
e doutorado no Programa de Pós-graduação em Engenharia de Produção. Publicou diversos artigos em periódicos especializados e trabalhos em anais de eventos. Orientou mais de 60 dissertações de mestrado concluídas, 11 teses de doutorado concluídas, além de ter orientado diversos trabalhos de conclusão de curso nas áreas de Engenharia de Produção, Segurança do Trabalho, Saúde Coletiva e Administração. Atua na área de Engenharia de Produção, com ênfase em Ergonomia, realizando trabalhos de pesquisa em diversas empresas na região sul do Brasil.

\section{FERNANDO JOSÉ MACHADO BARBOSA DE MELO}

Possui graduação em Filosofia pela Universidade Católica de Pernambuco (2001). Pós graduação, lato sensu, Especializações em Economia, Gestão de Negócios e Logística, e Pós graduação, stricto sensu, Mestrado em Gestão Empresarial, ênfase em Operações de Serviços. Atualmente é Professor Mestre da Faculdade de Ciências Humanas e Sociais de Igarassu e Profissional da Petrobras Petróleo Brasileiro S.A. Tem experiência nas áreas de engenharia, administração e logística.

\section{FLEURI CÂNDIDO QUEIROZ}

Pós-graduado em Administração de Marketing e Recursos Humanos pela FAAP - Fundação Armando Alvares Penteado (1997), Mestrando em Ciência da Educação pela Unigrendal Santos-SP, Bacharel em Ciências Contábeis pela FATI, com diploma reconhecido pela Universidade de São Paulo - USP (1991). Licenciatura em Finanças e Contabilidade pela FATEC - Santos (2012). Adquiri prêmios como melhor Gestão Administrativo Comercial na Instituição financeira Santander Banespa. Tenho experiências profissionais nas áreas de Administração e Finanças. Atualmente sou Coordenador dos Cursos de Administração e Ciências Contábeis, Palestrante, trabalho como Professor na UNISEPE nos Módulos Presenciais e Professor Conteúdista / Tutor nos Módulos; EAD\&quot;. Alocado no Campus da Faculdade de Peruíbe nos cursos de Administração, Contábeis e Direito. No Campus Itanhaém nos cursos de Administração e Gestão. No Campus Registro nos cursos de Pós Graduação na área de Finanças e Controladoria, Na UNIP - Universidade Paulista nos cursos de Pós Graduação na área de Finanças e Banking e atuo como Coach e consultor de empresas nas áreas de Recursos Humanos, Administração, Marketing e Finanças.

\section{GICÉLIA PESSOA DO NASCIMENTO}

Graduação em andamento em Administração. União das Instituições de Serviço, Ensino e Pesquisa, UNISEPE, Brasil.

\section{GUEIBE PERES SOUZA}

Possui graduação em Ciências Econômicas (Bacharelado) pela Fundação Universidade Federal do Rio Grande (2002), mestrado (2005) e doutorado (2008) em Engenharia de Produção pela Universidade Federal de Santa Catarina (UFSC), Pós-Doutorado em Economia pela Universidad Atónoma de Madrid (2016-2017). Professor Adjunto de Economia e Relações Internacionais da UFSC. Temas de interesse: métodos e metodologias (quantitativas e qualitativas) de previsão e controle estatístico de qualidade. 


\section{HERCULES GUIMARÃES HONORATO}

Chefe da Divisão de Assuntos Psicossociais da Escola Superior de Guerra (ESG), Rio de Janeiro, Brasil; Doutor em Política e Estratégia Marítimas pela Escola de Guerra Naval (2007); Curso de Altos Estudos de Política e Estratégia pela Escola Superior de Guerra (2010); Mestre em Educação pela Universidade Estácio de Sá (2012); Especialista em Gestão Internacional (2007) e MBA Logística pelo Instituto COPPEAD de Administração da Universidade Federal do Rio de Janeiro (2009); Docência do Ensino Superior pelo Instituto "A Vez do Mestre" da Universidade Cândido Mendes (2008); e Bacharel em Ciências Navais com habilitação em Administração pela Escola Naval (1982).

\section{HUMBERTO CAETANO CARDOSO DA SILVA}

Possui graduação em Engenharia Civil pela Universidade Federal de Pernambuco (1999), Especialização em Computação com ênfase em Banco de Dados (2011), Mestrado em Gestão Empresarial pela Faculdade Boa Viagem - FBV/DeVry, aluno de Doutorado em Administração pelo PROPAD/UFPE. Atualmente é Diretor Técnico da Alliance3. Tem experiência na área de Ciência da Computação, com ênfase em segurança e governança de TI.

\section{HUMBERTO DA SILVA GONCALVES}

Graduando em Engenharia de Produção pela Universidade Federal do Rio Grande do Sul (UFRGS), Humberto Gonçalves atualmente trabalha no mercado financeiro, mais especificamente com Corporate \& Investment Banking, sendo que já trabalhou em Bancos comerciais e Serviços. Além disso, possui Diploma em Business Management e em Project Management pela British Columbia Institute of Technology (Vancouver, Canadá), é certificado CAPM pelo PMI e se comunica fluentemente em Português, Inglês e Espanhol. Vale lembrar que já liderou times de desenvolvimento de $\mathrm{TI}$, serviços e vendas, tanto no Brasil quanto no Canadá.

\section{JOÃO GABRIEL MORENO DE LACERDA}

Estudante do curso de Engenharia de Produçao pela UFPI

\section{JOICE REGINA DA COSTA SANTANA DA LAPA}

Possui graduação em Serviço Social (2000), Especialização (Pós-graduação "lato sensu") em Gestão Universitária (2003) e Mestrado em Administração Universitária (2015) pela Universidade Federal de Santa Catarina. Desde dezembro de 2004 exerce a função de Coordenadora de Apoio Administrativo do Centro de Comunicação e Expressão da Universidade Federal de Santa Catarina.

\section{JOSIANE APARECIDA CARDOSO DE SOUZA}

Graduação em Engenharia de Produção (2009 - 2013), Especialização em Gestão Estratégica e Inteligência em Negócios (2014 - 2016).Mestrado em andamento em Engenharia de Produção( 2018),Curso técnico/profissionalizante em Técnico em Logística (2011 - 2012),Curso técnico/profissionalizante em Técnico em Meio Ambiente (2010 - 2011). Curso técnico/profissionalizante em Técnico em Segurança do Trabalho (2010 - 2011). 


\section{LEONARDO RIBEIRO DE ALMEIDA}

Possui graduação em Administração Pública pela Universidade Federal do Estado do Rio de Janeiro (2016). Experiência na área de Administração, com ênfase em Administração Pública. Autor de artigos acadêmicos e livro versando sobre temáticas diversas da Administração Pública disponível em: http://lattes.cnpq.br/1916924790721602

\section{LETÍCIA CUNICO}

Professora e coordenadora de extensão e eventos no Instituto Federal de Santa Catarina (IFSC), desenvolve trabalhos a oito anos no Segmento de Confecção para marcas nacionais em diferentes segmentos. Formada pela Universidade do Estado de Santa Catarina - UDESC no curso de Bacharelado em Moda, possui MBA em Gestão Empresarial pela Fundação Getúlio Vargas - FGV e Mestre em Administração pela Universidade Federal de Santa Catarina - UFSC.

\section{LUIZ PINHEIRO JR}

Professor na Positivo Business School (UP). Atua como Coordenador de Qualidade Acadêmica (AQUA) vinculado a Pró-Reitoria Acadêmica (CSA) na mesma Instituição (UP). Avaliador do INEP. Bacharel (2012), Mestre (2015-UFPR) e Doutorando (2016-FGV-EAESP) em Administração de Empresas. Possui expertise nas áreas de Sistemas (SI) e Tecnologia (TI) [ERP, BI \& Cloud]. Acesse meu Website: www.luizpinheirojunior.com

\section{MAÍRA DOS SANTOS LIARTH}

Formada em Administração de Empresas pela Universidade Estadual do Piauí (UESPI), PósGraduada em Logística pela Universidade Federal do Piauí(UFPI) e cursando o 6 período do curso Engenharia de Produção na UFPI.

\section{MAISSA RUFINO THEODORO}

Aluno do curso de Engenharia de Produção da FMGR, atua no segmento de capacitação e treinamento em uma empresa do segmento industrial.

\section{MARCELO MOTTA VEIGA}

Possui graduação em Direito pela Universidade Federal do Rio de Janeiro(2006), graduação em Ciências Econômicas pela Universidade do Estado do Rio de Janeiro(1996), graduação em Administração pela Universidade Federal do Rio de Janeiro(1994), graduação em Engenharia Mecânica pela Pontifícia Universidade Católica do Rio de Janeiro(1987), especialização em Direito Sanitário pelo Fundação Oswaldo Cruz(2008), mestrado em Engenharia de Produção pela Universidade Federal do Rio de Janeiro(1997), doutorado em Engineering Management (Engenharia de Produção) pela George Washington University(2000), pós-doutorado pela University of Alberta(2009), pós-doutorado pela Swedish Royal Institute of Technology(2008), pós-doutorado pela Universidade Federal do Rio de Janeiro(2007) e aperfeicoamento em Chemical Management Policy pela National Institute Of Technology Evaluation(2005). Atualmente é Professor-Pequisador do Fundação Oswaldo Cruz, pesquisador da Universidade Federal do Rio de Janeiro, Professor Adjunto da Universidade Federal do Estado do Rio de Janeiro. Bolsista Pesquisa Produtividade da UNESA. 


\section{MARCELO ODA YAMAZATO}

Graduado em Engenharia de Produção Mecânica pela Escola de Engenharia de São Carlos da Universidade de São Paulo (EESC - USP). Atualmente mestrando em Educação pela Universidade Federal de São Carlos (UFSCAR).

\section{MARCUS AUGUSTO VASCONCELOS ARAÚJO}

Possui Doutorado em Administração pela Universidade Federal de Pernambuco (2012), mestrado em Administração pela mesma instituição (2006) e graduação em Engenharia Elétrica Eletrônica pela Universidade de Pernambuco (2004). Possui larga experiência gerencial em empresas multinacionais e no serviço público nas áreas de Marketing, Gestão de Serviços, CRM, Gestão de Operações e de Riscos. Na área acadêmica, é Professor Adjunto da UPE e do Mestrado Profissional em Gestão Empresarial da Wyden/UniFBV (MPGE/UniFBV), onde também atua como Coordenador do Grupo de Pesquisa MSC (Marketing, Serviços e Consumo). Atua como pesquisador no núcleo de pesquisa GIRO/UFPE (Gestão de Inovação em Redes de Operações) e como Professor convidado em diversos cursos de Pós-Graduação Lato Sensu. Tem atuado, ainda, como avaliador ad hoc e publicado trabalhos em diversas revistas e eventos científicos, cujas áreas de interesse se concentram em temas como Marketing, Gestão de Serviços, Marketing de Relacionamento, Comportamento do Consumidor, Customer Experience, Gestão Estratégica, Gestão de Riscos e Cultura Organizacional.

\section{MARCUS BRAUER}

Pós-doutorado e doutorado em Administração de Empresas na FGV-EAESP, mestrado em Administração Pública pela FGV-EBAPE e graduação em Administração Industrial pelo CEFETRJ. Professor adjunto do Mestrado em Administração e Desenvolvimento Empresarial da Universidade Estácio de Sá (MADE/UNESA), professor adjunto da UERJ e da UNIRIO. Membro da Academy of Management, da Associação Nacional de Pós-Graduação e Pesquisa em Administração (ANPAD) e do Clube da Ciência. Ex-professor da UFF, do IBMEC, do SENAI CETIQT, da FGV Online e da Universidade Católica de Petrópolis. Ex coordenador de curso de pós graduação a distância do PNAP - Programa Nacional de Formação em Administração Pública. Avaliador de congressos e revistas científicas na área de Administração. Exsuperintendente de Recursos Humanos da FINEP - Financiadora de Inovação e Pesquisa, Exanalista executivo de RH do INMETRO - Instituto Nacional de Metrologia, Qualidade e Tecnologia, tendo trabalhado também na Eletrobrás e na Petrobras Distribuidora S. A.. Fundador e ex-presidente da empresa júnior Cefet Jr Consultoria. Estágio na Lufthansa (Munique, Alemanha). Vencedor do II Prêmio Docência Dedicada ao Ensino Anísio Teixeira UERJ. Site: marcusbrauer.com

\section{MARIA APARECIDA CAMPOS DE AZEVEDO}

Especialização Internacional de Qualidade em Saúde e Segurança do Paciente - Escola Nacional de Saúde Pública Sérgio Arouca - Fundação Oswaldo Cruz, Rio de janeiro, RJ, Brasil (2016). Residência Médica e Especialização em Anestesiologia no Centro de Ensino e Treinamento do Serviço do Hospital do Andaraí - Rio de Janeiro, RJ, Brasil. (1985 - 1987). Internato no Centro Médico Naval do RJ - Hospital Naval Marcílio Dias - Rio de Janeiro, RJ, Brasil (1984). Graduação Médica na Fundação Técnico-Educacional Souza Marques - Rio de Janeiro, RJ, Brasil. (1979 - 1984). 


\section{MARIA DE LARA MOUTTA CALADO DE OLIVEIRA}

Possui graduação em Engenharia Mecânica pela Universidade de Pernambuco (1995) e mestrado em Engenharia de Produção pela Universidade Federal de Pernambuco (1999). Especialização da área de qualidade e produtividade (1997) pela Universidade de Pernambuco e Especialização em Psicopedagogia Institucional (2007) pela Faculdade Metropolitana da Grande Recife. Possui doutorado em Administração (2016). Possui MBA em Gerenciamento de Projetos(2017). Servidora pública concursada do Ministério de Planejamento Orçamento e gestão. Desenvolve suas atividades no Ministério dos Transportes, Portos e Aviação, especificamente no Departamento da Marinha Mercante, atuando na análise de projetos, custos navais, composição e avaliação de custos navais, acompanhamento da construção de navios e estaleiros, bem como a liberação de recursos para essas obras. Desenvolve, em paralelo, atividades acadêmicas em docência na Faculdade Metropolitana da Grande Recife e no Programa de Pós graduação em Qualidade e Produtividade da Universidade de Pernambuco. Atua em pesquisas na área de capacidade e produtividade operacional, bem como na Construção Naval.

\section{MATEUS ANDRADE}

Estudante do Curso de Engenharia de Produçao pela UFPI. Fez intercâmbio no Mexico pelo InstitutoTecnologico de Chihuahuall. Possui curso em Educaçao Ambiental no SENAl, organizado, comunicativo e responsável.

\section{MICHELE ABIB PERNICE}

Mestranda do curso de Ciências em Educação pela Universidade Unigrendal (2017 - em curso). Pós-graduanda em Administração de Cidades e Gestão Pública pelo Centro Universitário Uninter de Curitiba. (2017). Possui graduação em Pedagogia pelo Centro Universitário Internacional (2013), Direito pela Universidade Paulista (2005). Pós graduada em Gestão de Recursos Humanos pelo Centro Universitário Internacional (2009). Pós graduada em Pedagogia Empresarial e Educação Corporativa pelo Centro Universitário Internacional (2016). Pós graduanda no curso de Administração de Cidades e Gestão Pública pelo Centro Universitário Internacional de Curitiba (2017-em curso). Empreendedora de Cursos de Formação Profissional e Consultoria Empresarial pela Empresa Renovação Educação Profissional -ME (FUNDAÇÃO CASA de Peruibe/Itanhaém 2014-2017). Atualmente nos cursos de capacitação no municipio de Peruibe, no Recanto Vida (2018). Professora da Faculdades Integradas do Ribeira, nos cursos de Tecnologia e Administração. Professora da Unisepe de Peruibe nos cursos de Administração e Ciências Contábeis. Tem experiência na área de Administração pública e privada, com ênfase em Administração de Recursos Humanos e financeiro. Atualmente é Coordenadora de Serviços na Empresa Associação de Apoio a Pessoa Com Deficiência de Peruibe.

\section{MILENA NEVES GRADIM}

Bacharel em Administração pela Universidade do Estado do Rio de Janeiro - UERJ

\section{NÁTALIE GONÇALVES SILVA}

Bacharel em Administração pela Universidade do Estado do Rio de Janeiro - UERJ

\section{NÍVEA MARIA PIRES SILVA}

Estudante do curso de Engenharia de Produçao pela UFPI 


\section{PATRICIA CARNEIRO LINS DE NOVAES}

Mestrado empresarial em Gestão Empresarial, com ênfase em Marketing de Serviço na Faculdade Boa Viagem. Possui MBA em Gestão empresarial pela faculdade Boa Viagem e graduação em Ciências Econômicas pela Universidade Católica de Pernambuco (2003). Tem experiência na área de Economia, com ênfase em Microeconomia. Experiência no varejo, tendo trabalhado como Gerente de produtos (categorias) em grandes empresas como, Bompreço, Wal-mart, Carrefour e Polishop.

\section{PATRÍCIA CARNEIRO LINS DE NOVAES}

Mestrado empresarial em Gestão Empresarial, com ênfase em Marketing de Serviço na Faculdade Boa Viagem. Possui MBA em Gestão empresarial pela faculdade Boa Viagem e graduação em Ciências Econômicas pela Universidade Católica de Pernambuco (2003). Tem experiência na área de Economia, com ênfase em Microeconomia. Experiência no varejo, tendo trabalhado como Gerente de produtos (categorias) em grandes empresas como, Bompreço, Wal-mart, Carrefour e Polishop.

\section{PEDRO FILIPE DA CONCEICÃO PEREIRA}

Possui graduação em Engenharia de Produção pela Universidade Federal do Piauí - UFPI (2015) e especialização em Engenharia de Segurança no Trabalho pelo Centro Universitário UNINOVAFAPI (2018) e atualmente encontra-se cursando mestrado em Engenharia de Produção pela Universidade Tecnológica Federal do Paraná - UTFPR. Tem experiência na área de Engenharia de Produção com ênfase em Gestão da Produção e Ergonomia e Segurança do Trabalho. É professor na EaD na Faculdade Maurício de Nassau - Unidade Aliança e Professor Substituto no curso de Engenharia de Produção da Universidade Federal do Piauí - UFPI.

\section{PRISCILA FRANÇA GONZAGA CARNEIRO}

Graduação em Engenharia de Produção (2009 - 2014),Graduação em Programa Especial de Formação Pedagógica de Docentes - Física (2016 - 2017), Graduação em andamento em Formação Pedagógica em Matemática (2018), Especialização em Pós Graduação em Gestão de Pessoas (2015 - 2016). Curso técnico/profissionalizante em Eletrotécnica (2017 - 2018).

\section{RICARDO MIYASHITA}

Professor Associado da Faculdade de Engenharia da Universidade do Estado do Rio de Janeiro. É graduado em Engenharia de Produção pela Escola Politécnica da USP, mestre em Administração de Empresas pelo Coppead/UFRJ e doutor em Engenharia de Produção pela Coppe/UFRJ. Tem como principais linhas de pesquisa Design Thinking, Gestão da Inovação, Projeto de Produtos e Serviços, Simulação, Gestão da Saúde e Jogos de Empresa.

\section{RITA DE CÁSSIA ARRUDA FAJARDO}

Graduada em Engenharia de Produção Mecânica pela Universidade de São Paulo- USP (1995). Possui Especialização em Engenharia de Segurança do Trabalho (1997) pela Universidade Federal de São Carlos - UFSCar. É mestre (2005) e doutora (2014) em Engenharia de Produção pelo Programa de Pós-Graduação em Engenharia de Produção (PPGEP) do Departamento de Engenharia de Produção da UFSCar. Atualmente é docente no Instituto Federal de São Paulo campus São Carlos, na área de Gestão. 


\section{RODRIGO SPECKHANN SOARES DA SILVA}

Graduação em Física pela Universidade Federal de Santa Catarina (2009), especialização em Gestão Pública Universidade do Sul de Santa Catarina (2015), mestrado em Administração pela UFSC (2018). Tem experiência na área de Física Aplicada, com ênfase em Física de Plasmas e Descargas Elétricas; na avaliação de desempenho no setor público e na construção de medidas baseadas em itens utilizando a Teoria da Resposta ao Item (TRI).

\section{ROGÉRIO DA SILVA NUNES}

Possui Graduação em Administração Pública e Administração de Empresas pela Universidade Federal do Rio Grande do Sul (UFRGS), Mestrado em Administração pela Universidade Federal do Rio Grande do Sul (UFRGS) e Doutorado em Administração pela Universidade de São Paulo (USP). Atuou como docente, pesquisador e em cargos administrativos na Universidade Federal de Santa Maria (UFSM), Centro Universitário Álvares Penteado (FECAP), Centro Universitário das Faculdades Metropolitanas Unidas (UNIFMU) e Universidade Nove de Julho (UNINOVE). Atualmente, é Professor Associado da Universidade Federal de Santa Catarina (UFSC) e leciona no Programa de Mestrado Profissional em Administração Universitária (PPGAU).

\section{ROSSANDO RAMOS}

Possui graduação em Engenharia de Produção pela Universidade do Estado do Rio de Janeiro (2003) e mestrado em Ciências Econômicas pela Universidade do Estado do Rio de Janeiro (2005). É doutorando do Programa de Pós Graduação em Políticas Públicas e Formação Humana na UERJ (2013). Atualmente é analista - Financiadora de Estudos e Projetos e Professor Assistente II da Universidade Federal do Estado do Rio de Janeiro, lotado do Departamento de Gestão da Estratégia, na Escola de Administração Pública. Tem experiência na área de Engenharia de Produção, com ênfase em Avaliação de Projetos, atuando principalmente nos seguintes temas: Tecnologia para o Desenvolvimento Social, Capital Social, Tecnologia Social, Políticas Públicas de C,T\&I na perspectiva CTS e desenvolvimento local.

\section{THAÍS SPIEGEL}

Doutora e Mestre em Engenharia de Produção pela COPPE/UFRJ. Graduada em Engenheira de Produção pela Escola Politécnica da UFRJ. Professora Adjunta da Faculdade de Engenharia da UERJ. Pesquisadora e coordenadora do Laboratório de Engenharia e Gestão em Saúde (LEGOS/UERJ). Tem experiência na área de Engenharia de Produção, com ênfase em Projeto Organizacional, Modelos de Gestão e Referência, Tomada de decisão, Engenharia de Processos de Negócio e Logística e Gestão da Cadeia de Suprimentos.

\section{THIAGO BRAGANÇA NOGUEIRA}

Aluno do Curso de Engenharia de produção da FMGR, experiência na área de siderurgia e segurança do trabalho.

\section{VIVIANE CAU AMARAL}

Mestre em Gestão Empresarial pela DeVry Brasil, com MBA em Gerenciamento de projetos e Pós Graduação em Controladoria e Finanças, Bacharel em Administração de Empresas pela rede Laureate International Universities; Professora nas disciplinas: Planejamento estratégico, Gestão estratégica, Negociação, Planejamento de Marketing, Comportamento do consumidor, Marketing de Produtos e Serviços e Teoria Geral da Administração; Experiência em desenvolvimento de Estratégias Comerciais envolvendo desde a análise, dimensionamento e 
segmentação de mercado, até o acompanhamento de tendências, posicionamento de marca, estudos de nichos e projeções de vendas. Vivência em análises competitivas de desempenho, visando alavancar oportunidades de negócios; Sólidos conhecimentos em lançamento e gestão de campanhas de vendas, incluindo a definição de mix de ofertas (produtos e serviços), orçamentos, política de preços, mecânica operacional e plano comercial; 


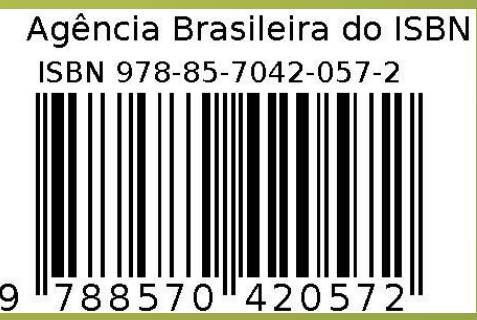

